
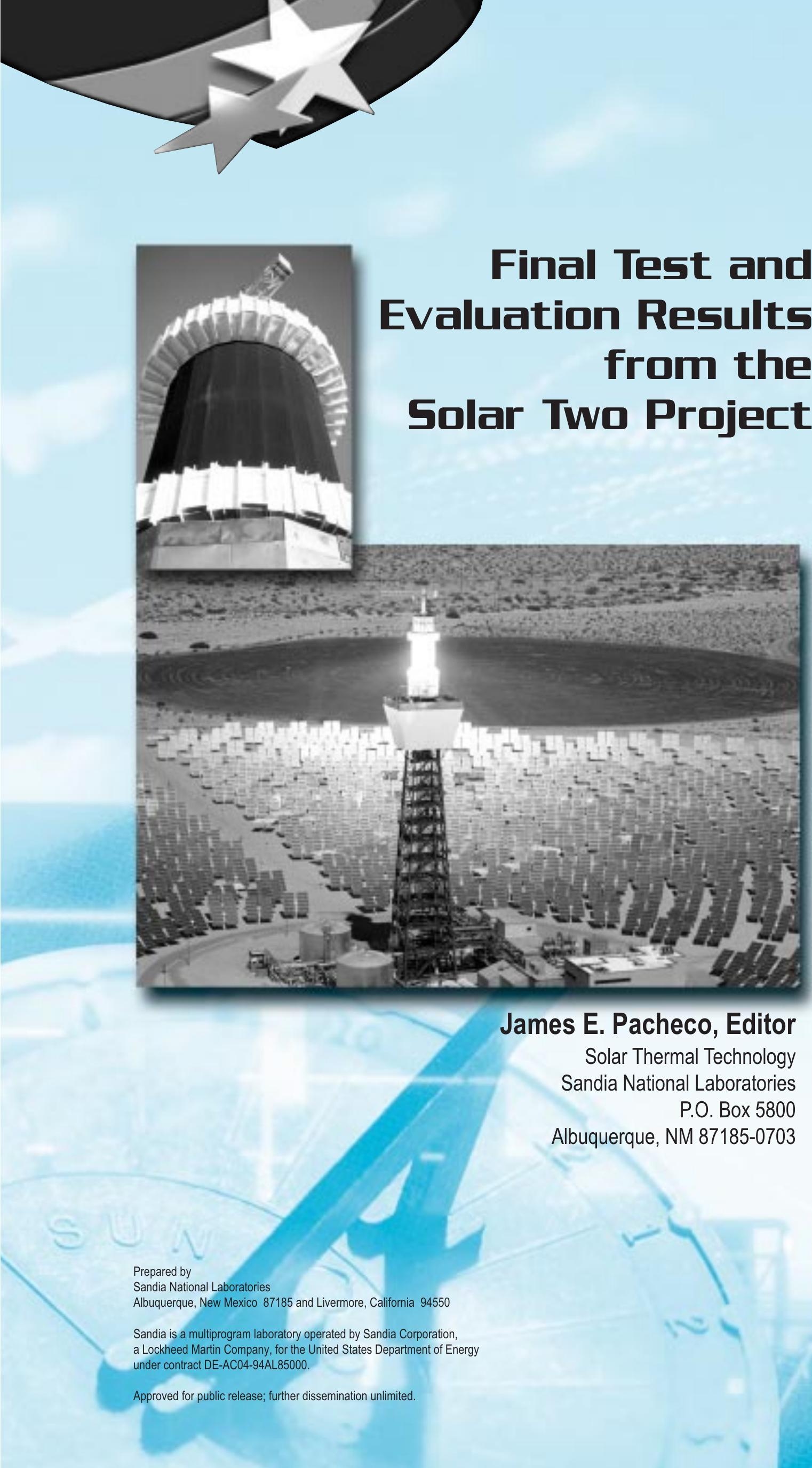

SAND2002-0120 Unlimited Release Printed January 2002 
Issued by Sandia National Laboratories, operated for the United States Department of Energy by Sandia Corporation.

NOTICE: This report was prepared as an account of work sponsored by an agency of the United States Government. Neither the United States Government, nor any agency thereof, nor any of their employees, nor any of their contractors, subcontractors, or their employees, make any warranty, express or implied, or assume any legal liability or responsibility for the accuracy, completeness, or usefulness of any information, apparatus, product, or process disclosed, or represent that its use would not infringe privately owned rights. Reference herein to any specific commercial product, process, or service by trade name, trademark, manufacturer, or otherwise, does not necessarily constitute or imply its endorsement, recommendation, or favoring by the United States Government, any agency thereof, or any of their contractors or subcontractors. The views and opinions expressed herein do not necessarily state or reflect those of the United States Government, any agency thereof, or any of their contractors.

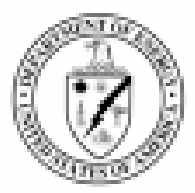


SAND2002-0120

Unlimited Release

Printed January 2002

\title{
Final Test and Evaluation Results from the Solar Two Project
}

\author{
James E. Pacheco, Editor \\ Solar Thermal Technology \\ Sandia National Laboratories \\ P. O. Box 5800 \\ Albuquerque, NM 87185-0703 \\ Contributing Authors \\ Robert W. Bradshaw1, Daniel B. Dawson ${ }^{1}$, Wilfredo De la Rosa ${ }^{2}$, \\ Rockwell Gilbert ${ }^{3}$, Steven H. Goods ${ }^{1}$, \\ Mary Jane Hale ${ }^{4}$, Peter Jacobs ${ }^{5}$, Scott A. Jones ${ }^{6}$, \\ Gregory J. Kolb 6 , James E. Pacheco ${ }^{6}$, Michael R. Prairie 6 , \\ Hugh E. Reilly ${ }^{6}$, Steven K. Showalter ${ }^{6}$, and Lorin L. Vant-Hull ${ }^{7}$
}

\begin{abstract}
Solar Two was a collaborative, cost-shared project between $11 \mathrm{U}$. S. industry and utility partners and the U. S. Department of Energy to validate molten-salt power tower technology. The Solar Two plant, located east of Barstow, CA, comprised 1926 heliostats, a receiver, a thermal storage system, a steam generation system, and steam-turbine power block. Molten nitrate salt was used as the heat transfer fluid and storage media. The steam generator powered a 10-MWe (megawatt electric), conventional Rankine cycle turbine. Solar Two operated from June 1996 to April 1999. The major objective of the test and evaluation phase of the project was to validate the technical characteristics of a molten salt power tower. This report describes the significant results from the test and evaluation activities, the operating experience of each major system, and overall plant performance. Tests were conducted to measure the power output (MW) of the each major system, the efficiencies of the heliostat, receiver, thermal storage, and electric power generation systems and the daily energy collected, daily thermal-to-electric conversion, and daily parasitic energy consumption. Also included are detailed test and evaluation reports.
\end{abstract}

\footnotetext{
1 Sandia National Laboratories, Livermore, CA

2 Southern California Edison, San Dimas, CA

3 Consultant to Sandia National Laboratories, Albuquerque, NM

${ }^{4}$ National Renewable Energy Laboratory, Golden, CO

5 Consultant to National Renewable Energy Laboratory, Golden, CO

6 Sandia National Laboratories, Albuquerque, NM

${ }^{7}$ University of Houston, TX
} 


\section{ACKNOWLEDGEMENT}

Solar Two was funded by a consortium consisting of the following partners:

Participants: Arizona Public Service, Bechtel Corp., California Energy Commission, Electric Power Research Institute, Idaho Power Co., Los Angeles Dept. of Water and Power, PacifiCorp, Sacramento Municipal Utility District, Salt River Project, Southern California Edison Co.

Contributors: Chilean Nitrate (of New York), Nevada Power Co., South Coast Air Quality Management District.

Government Partners: U.S. Department of Energy. Sandia National Laboratories and the National Renewable Energy Laboratory provided technical support to the project.

Sandia is a multiprogram laboratory operated by Sandia Corporation, a Lockheed Martin Company, for the United States Department of Energy under Contract DE-AC04-94AL85000. 


\section{Table of Contents}

Executive Summary ......................................................................................................................................11

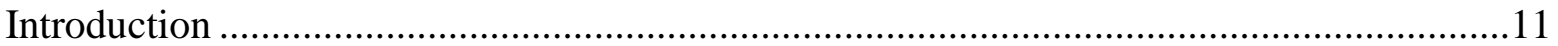

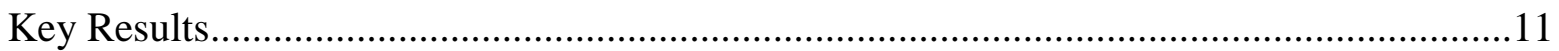

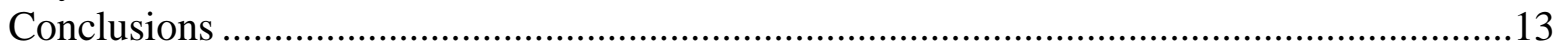

Issues that Require Further Development .......................................................................

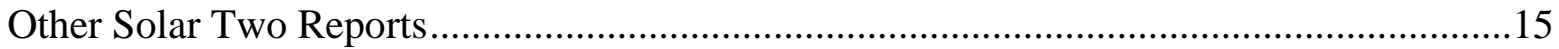

1. Introduction ..........................................................................................................................................17

1.1. Project Background and System Description ...............................................................17

1.2. Goals and Objectives of the Solar Two Test and Evaluation Program ..........................19

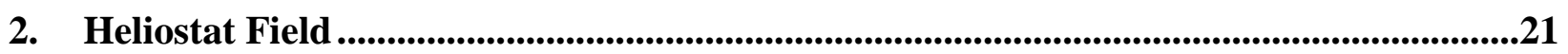

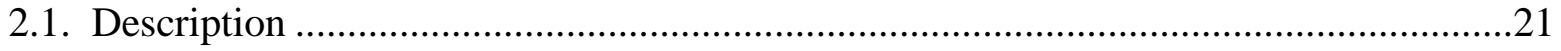

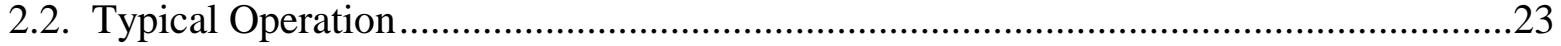

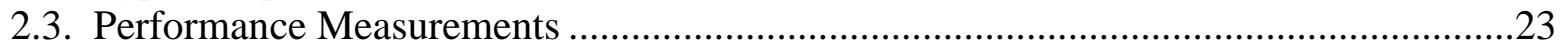

2.3.1 Field Efficiency and Power Incident on Receiver ..............................................23

2.3.2 Heliostat Tracking Accuracy ……………………........................................24

2.3.3 Heliostat Beam Quality ..............................................................................2

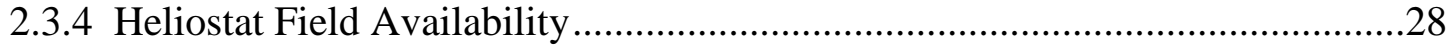

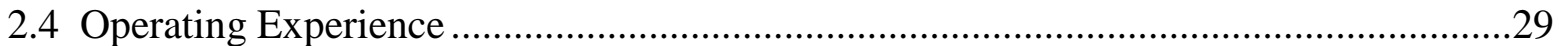

2.4.1 Beam Characterization System Experiences ........................................................30

2.4.2 Heliostat Spillage on Receiver Oven Covers......................................................31

2.4.3 Heliostat Field Flux Management Systems ……………………………….......32

2.4.4 Heliostat Field Maintenance ……………………………..................................37

2.4.5 Heliostat Field Washing and Cleanliness ...........................................................37

2.4.6 Measurements of Mirror Corrosion ……………………………....................40

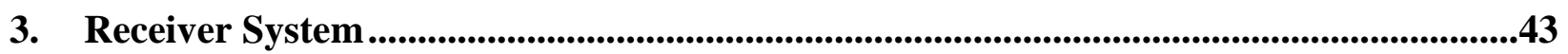

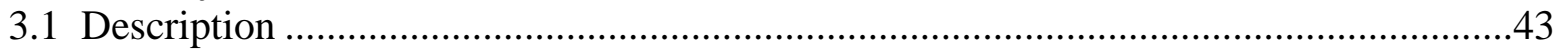

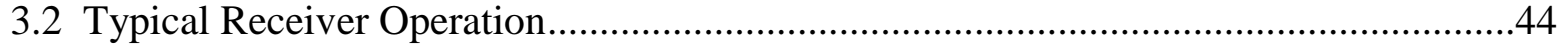

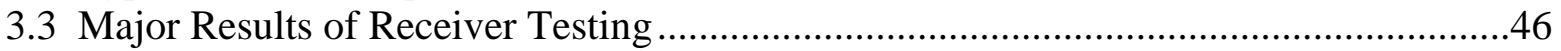

3.3.1 Receiver Efficiency...................................................................................46

3.3.2 Testing of Receiver Control Algorithm ..........................................................48

3.4 Receiver Operating Experience …………………........................................................48

3.4.1 Salt Freezing in Receiver Tubes on Startup....................................................49

3.4.2 Measuring Level in the Receiver Inlet Vessel ...................................................51

3.4.3 Receiver Tube and Panel Thawing ...................................................................51

3.4.4 Metallurgical Analysis of Receiver Tubes...........................................................53

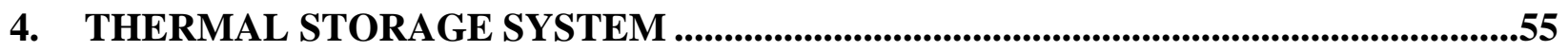

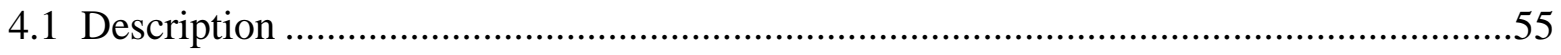

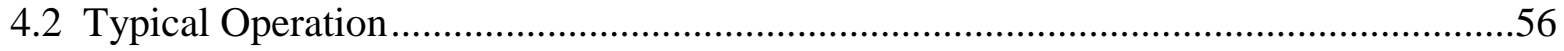

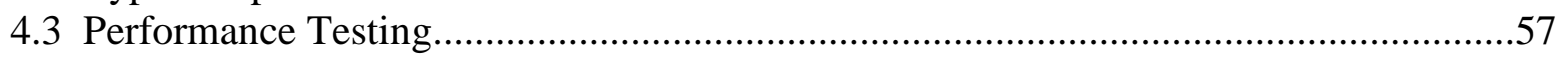

4.3.1 Thermal Growth During Initial Heatup and Melting ..........................................57

4.3.2 Heat Loss and Efficiency Test .........................................................................58

4.3.3 Actual Thermal Capacity of the Storage System ................................................58

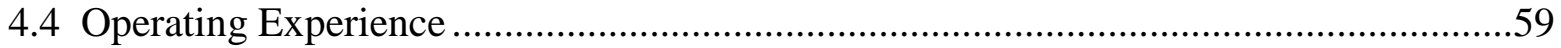




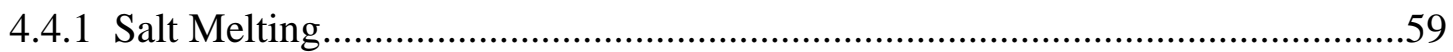

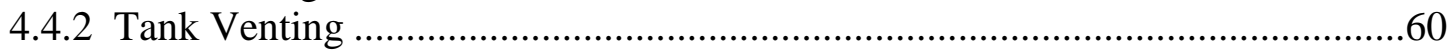

4.4.3 Recycling Spilled Salt...................................................................................60

4.4.4 Restart After Long Outage ..........................................................................61

4.4.5 Changes in Salt Over Time .........................................................................61

4.4.6 Removing the Salt Inventory from Site for Recycle..........................................62

4.4.7 Postmortem Metallurgical Analysis of Tank Alloys .........................................62

5. STEAM GENERATOR/ELECTRIC POWER GENERATION SYSTEM .....................65

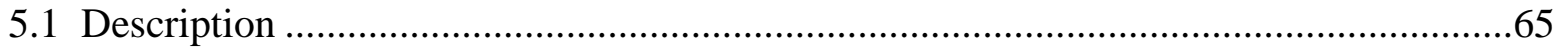

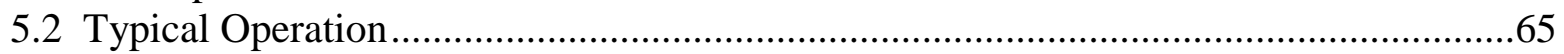

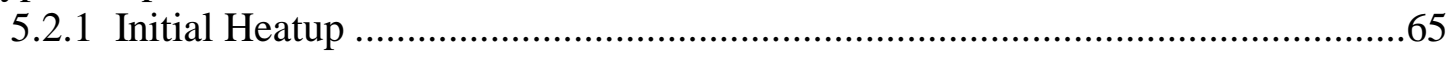

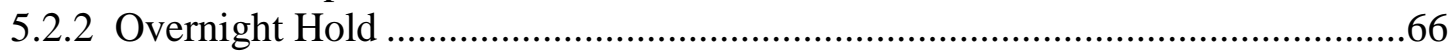

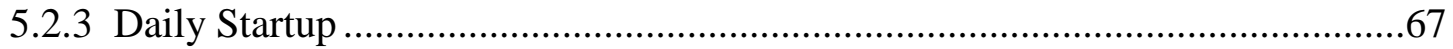

5.2.4 Shutdown and Return to Overnight Hold .......................................................68

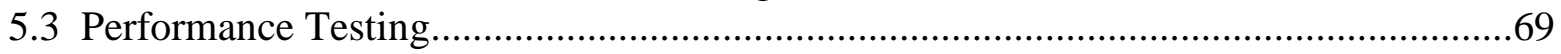

5.3.1 Performance over a Range of Loads ...............................................................69

5.3.2 Steady-State Conversion Efficiency ……………….........................................69

5.3.3 Startup Energy Requirement .....................................................................69

5.4 Operating Experience ……………………………....................................................

5.4.1 Addition of a Startup Feedwater Heater after Steam Generator Tube

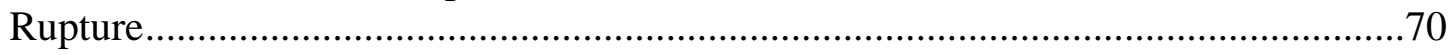

5.4.2 Fouling in Steam Generator System ……………….....................................70

6. OVERALL PLANT PERFORMANCE ......................................................................................73

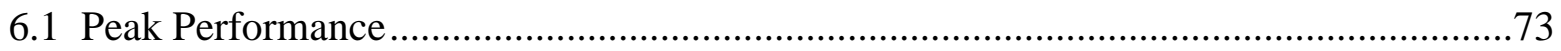

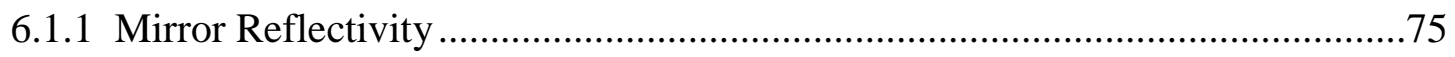

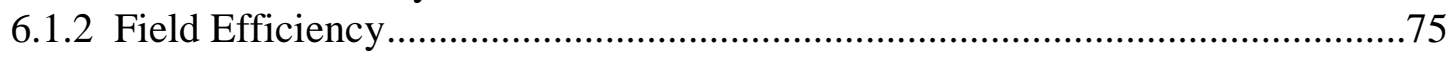

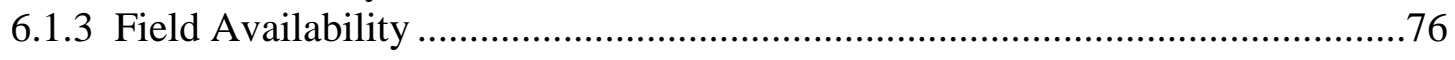

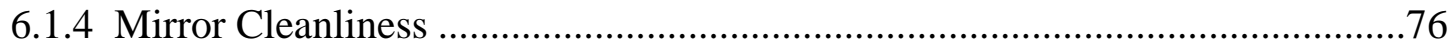

6.1.5 Receiver Efficiency …………………………………………………....76

6.1.6 Storage Efficiency.......................................................................................76

6.1.7 Electric Power Generation System .................................................................77

6.1.8 Parasitics .................................................................................................

6.1.9 Overall Peak Efficiency …………………………………………………......77

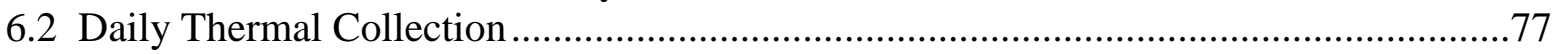

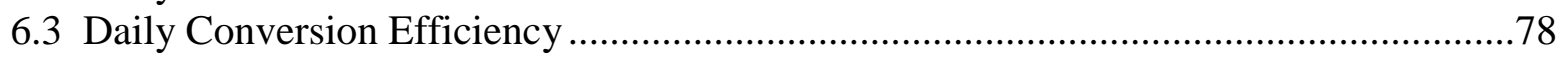

6.4 Parasitic Power Consumption .......................................................................................

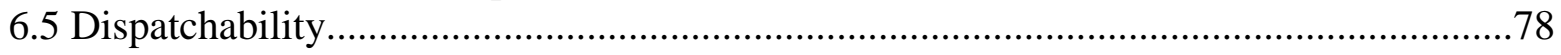

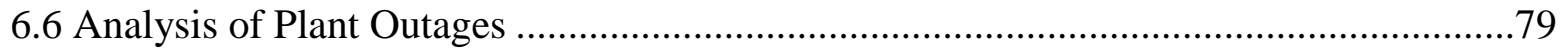

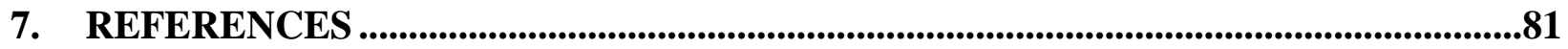

\section{APPENDICES}

A. Evaluation of Heliostat Walk-On and Walk-Off at Solar Two (J. E. Pacheco)................89

B. Receiver Efficiency Test (J. E. Pacheco) 
C. Solar Resource Measurement Quality Assessment at Solar Two (S. A. Jones)............119

D. Development and Test of Solar Two Receiver Control Algorithm (G. J. Kolb)...........127

E. Nuclear Level Sensor (H. E. Reilly) ..............................................................................135

F. Procedure for Thawing Receiver Panels That Have Become Frozen With Nitrate

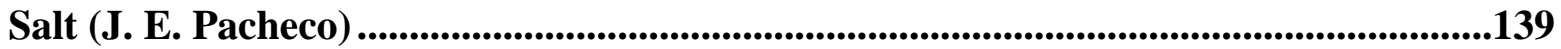

G. Analysis of Thawing Frozen Salt in the Solar Two Evaporator and Damage Mitigation (J. E. Pacheco)

H. Coupon Corrosion Tests, Salt Chemistry and Post Mortem Analysis (D. Dawson, B. Bradshaw, S. Goods) ............................................................................................153

I. Receiver Flush (S. Showalter) ..................................................................................195

J. Storage Tank Thermal Stresses Test (J. E. Pacheco) .......................................................197

K. Thermal Losses Throughout the Plant (J. E. Pacheco and R. Gilbert)........................203

L. Solar Two Nitrate Salt - Lessons Learned (S. Showalter) ..............................................207

M. Steam Generator/Electric Power Generation System Characterization Test (J. E. Pacheco).

N. Inspection of Preheater After Using Phosphate Injection System (Wilfredo de la

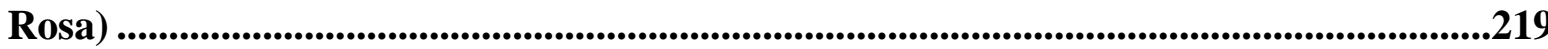

O. Solar Two Performance Evaluation (M. J. Hale) ...............................................................221

P. Evaluation of Plant Operations November 1, 1997 to April 8, 1999 (G. Kolb) ............235

Q. Test and Evaluation of Solar Two Heat Trace System (G. J. Kolb) ...............................245

R. Energy Conservation at Solar 2 (P. C. Jacobs) ................................................................255

S. Dispatchability Test (H. E. Reilly and R. Gilbert)...........................................................283 


\section{List of Figures}

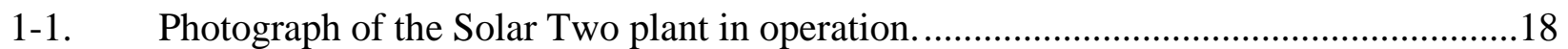

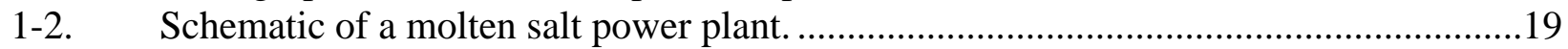

2-1. Martin Marietta heliostats......................................................................................22

2-2. Lugo heliostats at Solar Two. ...........................................................................22

2-3. Solar Two heliostat beam tracking the BCS target.............................................27

2-4. The daily maximum heliostat availability at Solar Two was consistently below

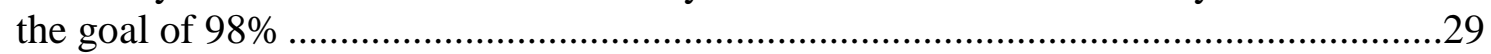

2-5. Instantaneous heliostat availability over six days near the end of Solar Two ................30

2-6. The Solar Two wash truck (a) and close-up of spray bar (b).......................................38

2-7. Average heliostat field cleanliness measurements...................................................39

2-8. By the summer of 1996, 2.8\% of the MM Field had been lost due to corrosion and $11 \%$ of the facets had lost their curvature (delaminated) .....................................41

3-1. Close-up of Solar Two receiver. .....................................................................4

3-2. Schematic of one flow circuit of the receiver flow circuit........................................45

3-3. $\quad$ Modeled and measured receiver efficiency as a function of wind speed. ....................47

3-4. Direct normal insolation and receiver outlet temperature during a partly-cloudy

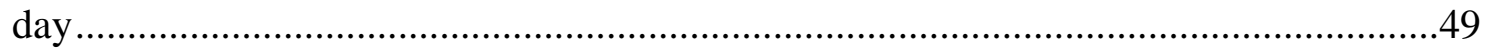

3-5. Frequency and location of tube freeze-ups in receiver during the period from July to November 1998, as observed by the operators ...........................................50

3-6. $\quad$ Modified oven covers with baffles and new oven seals. ...........................................50

3-7. Infrared image of the receiver containing a blocked tube on the edge of a panel ..........52

3-8. Aiming of heliostats to thaw a panel frozen with salt................................................53

4-1. Cold (left) and hot (right) nitrate salt storage tanks...........................................55

4-2. Tank wall temperature during preheat, soak, salt melting, and heating

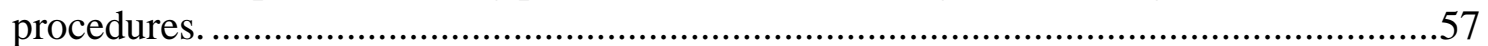

4-3. $\quad 1380$ tonnes of nitrate salt awaiting melting at Solar Two. ........................................59

4-4. Conveyor belt feeding crushed salt from the hammer mill into the salt hopper.............60

4-5. Salt recycler used to return spilled salt to the thermal storage system. .......................61

4-6. Chute on one side of the tower in which the nitrate salt was prilled for removal

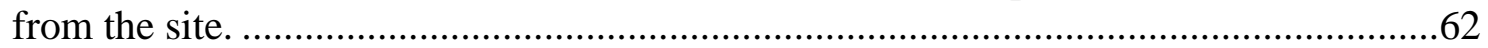

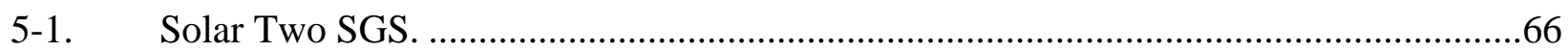

5-2. Schematic of the revised steam generator system..............................................67

5-3. Steady-state gross-turbine output as a function of heat input to the steam generator.

6-1. Daily thermal energy collected by heliostat/receiver system as a function of

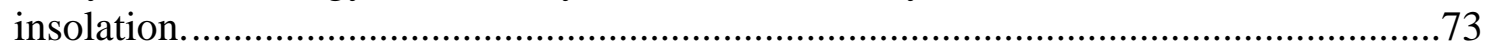

6-2. Measured daily gross electrical output versus daily energy sent to the SGS................74

6-3. Parasitic-energy consumption as a function of gross-generation for July through November, 1998. 


\section{List of Tables}

2-1. Technical characteristics of the heliostats...........................................................22

2-2. Heliostat field efficiency and incident power measurements .....................................24

2-3. Solar Two heliostat field tracking accuracy results collected from BCS Data of

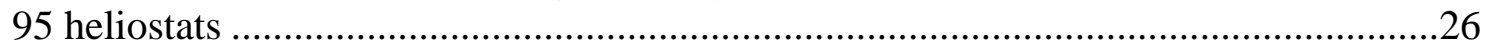

2-4. Solar Two heliostat field flux management systems ..............................................33

3-1. Technical characteristics of the Solar Two receiver ...............................................44

3-2. Summary of receiver efficiency measurements ....................................................4 47

4-1. Technical characteristics of thermal storage system............................................56

4-2. $\quad$ Measured and calculated thermal losses of tanks and sumps ....................................58

5-1. Technical characteristics of the steam generator/electric power generation

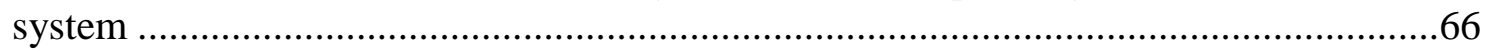

6-1. Solar Two peak efficiencies (goal and achieved) along with those expected for a commercial plant................................................................................................. 75

6-2 Outages at Solar Two from November 1, 1997 to April 8, 1999................................80 
Final Test and Evaluation Results from the Solar Two Project 


\section{Executive Summary}

\section{Introduction}

This report contains the final test and evaluation (T\&E) results of the Solar Two project. The objectives of the Solar Two Test and Evaluation program were to collect data, gather information, and perform analyses in order to:

1. Validate the technical characteristics of the nitrate salt receiver, storage system, and steam generator technologies.

2. Improve the accuracy of economic projections for commercial projects by increasing the database of capital, operating, and maintenance costs.

3. Distribute information to U.S. utilities and the solar industry to foster wider interest in commercial plants.

Originally, the T\&E program was scheduled to run for a period of one year after final plant acceptance. During this period, the entire plant and operations and maintenance (O\&M) personnel were to be devoted exclusively to $T \& E$ with no emphasis on power production goals. This was to be followed by a power production phase lasting approximately two additional years. The performance goals for the Solar Two Project were not expected to be met until the latter portion of the power production phase. However, because of the lengthy startup phase - due to design and construction issues, the $T \& E$ phase was scaled back and conducted concurrently with a limited power production phase both compressed into a 14-month operating schedule-the startup phase lasted nearly $2 \frac{1}{2}$ years before the plant was turned over to the O\&M company, instead of six months, as originally planned. Two major reasons for the lengthy startup were improper heat trace installation and the rupture of a tube in the evaporator. Many of the less critical T\&Es were eliminated or combined with other T\&Es.

Key performance and operating characteristics of the molten salt receiver, thermal storage, and steam generator systems (SGS) were measured in terms of peak (short time scales) and daily performance. However, longer-term (monthly and annual) performance measurements were not meaningful because of the prototypical nature of the plant and the compressed T\&E schedule.

\section{Key Results}

Despite the problems encountered during startup, the Solar Two project met most of its major goals. Some of the key results and experiences for each major system discussed below.

Receiver System: The receiver efficiency (absorbed power divided by incident power) measured $88 \%$ in calm winds and $86 \%$ in windy conditions $(>6 \mathrm{~m} / \mathrm{s})$, agreeing well with modeled results. The receiver controls maintained constant outlet temperatures during mild cloud transients. During severe cloud transients, the control system safeguarded the receiver by ramping up the flow to prevent overheating of the receiver after the cloud passed. Daily startup 
of the receiver was often delayed (reducing daily energy collection) because one or more tubes had frozen salt plugs, particularly on the windward side, which required careful thawing to prevent a tube rupture. New oven seals to prevent air infiltration, baffles between panels, and heat tracing all helped reduced the frequency of tube freezing.

Midway through the project, stress corrosion cracking was found in receiver tubes on the east side of the receiver, possibly due to an aqueous flush done early in the project, over-fluxing on the east side of the receiver due to a software glitch in the dynamic aim processing system, or exposure to humidity from the ambient during nightly shutdown. Purging the inside of the receiver with dry air at night and fixing the software glitch appeared to prevent further stress corrosion cracking. Post-mortem metallurgical analyses showed very acceptable amounts of oxide scale due to salt-induced corrosion, even in the highest flux regions.

Thermal Storage System: The thermal losses from the hot and cold storage tanks and the receiver and steam generator sumps measured $184 \mathrm{~kW}$. The hot storage tank could store useful thermal energy for weeks, while losing only $4^{\circ} \mathrm{C}$ per day. The instantaneous thermal efficiency (1 - heat loss/steam generator thermal demand) was greater than 99\%. Daily thermal efficiencies were greater than $98 \%$. The actual capacity of thermal storage was $107 \mathrm{MWh}_{\mathrm{t}}$, enough to run the turbine at full output for three hours.

Initial melting of 1400 tonnes ( 3 million pounds) of nitrate salt during the startup phase of Solar Two was conceptually straightforward, but required more auxiliary equipment than originally planned and took 16 days to complete. However, an impurity was discovered - magnesium nitrate - which added complexity to the melting process. The impurity decomposed rapidly when the salt was heated above $480^{\circ} \mathrm{C}$. After the initial melt, the salt inventory was heated to $540^{\circ} \mathrm{C}$ and held at that temperature for 20 days to reduce the levels of impurity. Over the course of the project, the melting point of the salt gradually lowered from 207 to $202^{\circ} \mathrm{C}$.

Post-mortem analysis of the tank alloys after continuous exposure to nitrate salts for over 30,000 hours at or near their operating temperatures showed that corrosion was minimal. Salt-induced corrosion of the tank alloys poses no practical limitation on the useful life of these structures.

Steam Generator/Electric Power Generation System (EPGS): Characterization of the steam generator/electric power generation system over a range of loads showed that its steady-state thermal-to-gross electric conversion efficiency was $34.1 \%$ at full load and $23.3 \%$ at $22 \%$ load, matching the values predicted by Bechtel Group, Inc. The amount of thermal energy required to start the SGS/EPGS each day was reduced from over $20 \mathrm{MWh}$ to $6.6 \mathrm{MWh}$ as operating experience was gained.

During the startup phase of the project, the evaporator suffered a tube rupture as a result of freeze/thaw cycles caused by cold water contacting the tube bundle during daily startup. The evaporator was retubed and the design modified by altering the feedwater flow path and adding a startup feedwater heater to prevent the problem from recurring. The tube rupture cause a oneyear outage of the plant.

Heliostat Field: Although characterization of the heliostat field was not an objective of the T\&E program, the field's output and efficiency were measured to better understand the overall 
performance of the plant. The power output of the heliostat field onto the receiver absorber surface was typically below $40 \mathrm{MW}-$ less than the design value of $48 \mathrm{MW}$. The field efficiency was measured to be between 62 and $66 \%$, which is 5 to 10 efficiency points below that predicted by computer models. Many factors contributed to the lower-than-design output and efficiency of the field: corrosion of mirror facets, poor mirror alignment, poor optical quality of the replacement facets, poor tracking accuracy, low heliostat availability, and underperformance of the Lugo heliostats. The majority of these effects can be partially attributed to reusing a heliostat field that had not been maintained for six years between Solar One shutdown and Solar Two startup. Even though the field underperformed, it rarely caused plant outages. Field availability (percent of heliostat available to track the receiver) was usually between 88 and $94 \%$. Maintenance of the aging field proved to be a major effort, requiring much more manpower than originally anticipated. Mirror washing was put at lower priority as a result, causing the mirror cleanliness to suffer.

Overall Plant Performance: The daily plant performance was characterized by three input/output metrics and compared to the performance predicted by the computer program SOLERGY. Three daily input/output metrics used were: energy collected by the working fluid as a function of solar insolation, gross-electrical output as a function of thermal energy input, and parasitic electricity consumption as a function of gross generation. The measured energy collection met the predicted value for the given solar insolation on several occasions, showing that the design level of performance could be met if actual heliostat availability, performance, and mirror cleanliness were taken into account in the prediction. The majority of the time, however, the energy collection fell short of prediction. The major reasons were attributed to receiver startup delays caused by time spent thawing salt plugs in receiver tubes, test preparations, operator discretion, and other miscellaneous receiver or plant outages.

Daily conversion of thermal-to-gross-electrical energy matched predicted values when the turbine was operated at full load. On days when the turbine was operated at partial load (1 to 8 $\mathrm{MWe}$ ), the gross generation fell slightly below the predicted values because the predicted values were based on conversion efficiencies with the turbine operating at full load (9 to $12 \mathrm{MWe}$ ).

The daily parasitic electricity consumption was initially much higher than predicted by SOLERGY because the operators ran the plant conservatively, not turning off auxiliary loads such as tank heaters, heat trace, recirculation pumps, and lights when the plant was offline. After implementing a parasitic reduction procedure, parasitic energy was reduced by $50 \%$ and essentially met the predicted values. The parasitic reduction tests showed how important operating strategies could be to improve the performance of a solar plant.

\section{Conclusions}

The most significant feature demonstrated at Solar Two was its ability to dispatch solargenerated, grid-connected electrical power independent of solar collection. This feature enables solar power tower plants to compete with dispatchable technologies without fossil-fuel backup. Results showed that thermal energy could be stored effectively in the molten-salt thermal storage system to generate electricity during cloudy weather, after sunset, or through the night with daily 
thermal efficiencies greater than 98\%. In one demonstration of dispatchability, Solar Two produced grid-connected power continuously for 154 hours.

Tests successfully demonstrated that the receiver system, thermal storage system, steam generator/electric power generation systems, and auxiliary loads met their peak efficiencies goals. The daily performance metrics of Solar Two were quantified. When accounting for deficiencies in the heliostat field, the plant met it daily performance goals only on days when the plant operated reliably. But, as previously mentioned, the plant did not operate long enough to gather meaningful monthly- or annual-performance data. Long-term performance data is lacking and represents a risk for the first commercial plant of this type. When Solar Two shut down, the plant was not optimized because the improvements were still being identified at the end of the 14-month operation.

Reliability was a major issue with this first-of-a-kind, prototype plant. Many factors contributed to the low plant availability, some of which were unavoidable with a demonstration project that used refurbished hardware (e.g., heliostat field, turbine generator control electronics, and instrumentation). Other reliability issues could be contributed to the inexperience of O\&M staff handling the complexity of molten salt hardware (its high freezing point, tendency to leak from valves, subtlety of installing and handle heat trace, etc.). There were numerous startup issues with components, including heat trace, piping, and the steam generator, that delayed routine operation of the plant for more than a year. In the end, essentially all of the major issues at Solar Two were overcome with some combination of redesign and rework, improved operating procedures, or workarounds for fixes that could not be fully implemented at Solar Two. Only an issue with receiver startup in high winds could not be fully overcome during Solar Two operation, and that problem could be resolved with a minor design change in the next receiver.

Despite the limitations encountered during the project, Solar Two successfully proved that solar energy could be collected efficiently over a broad range of operating conditions and that the lowcost energy storage system operated reliably and efficiently. This unique storage capability allowed solar energy to be collected when the sun was shining and high-value, dispatchable electric power to be generated at night or whenever demanded by the utility, even when the sun was not shining.

\section{Issues that Require Further Development}

The Solar Two project identified a number of issues that must be resolved to improve the reliability, cost, and performance of a commercial plant. A complete list of all the development activities is beyond the scope of this report. A few significant areas are called out here.

- Resolution of receiver tube freezing during daily startup. To improve the startup and reduce delays caused by freezing salt, new header oven covers must be designed to ensure wind does not infiltrate the oven box. There should not be any heat sinks at the interface of the oven cover and absorber surface. Ideally, the region where the oven insulation meets the absorber surface should have heat trace. 
- Improving the reliability of all molten salt systems by eliminating valves. Valves for molten salt service required excessive maintenance. Some problems with valves were leaking packing and bonnet gaskets, failed heat trace on bonnets and bodies, and warping of valve bodies. Ball valves were found to be unacceptable for molten salt because they failed to provide positive shutoff. In the design of future molten salt power towers, as many valves as practical should be eliminated to improve the system reliability. Valves should be developed that do not require packing material.

- Instrumentation. Reliable instrumentation, such as high-temperature pressure transducers and level sensors for the pressure vessel, needs to be qualified for molten salt service.

- Long-shafted pumps. Full-sized long-shafted pumps that can be mounted above the storage tanks should be qualified so they can be confidently integrated into commercial plants. These pumps will simplify the molten-salt system by eliminating the pump sumps, interconnecting piping, valves, heat trace, and instrumentation.

\section{Other Solar Two Reports}

This report is one of a series of reports on the Solar Two project. Brief descriptions of other Solar Two reports follow.

An Evaluation of Molten-Salt Power Towers Including Results of the Solar Two Project, Sandia National Laboratories Report, H. E. Reilly and G. J. Kolb, Sandia National Laboratories Report, SAND2001-3674, November 2001. This report presents an update of the technical and economic status of molten-salt power towers, including an overview of the progression from Solar One to Solar Two. Also included are the likely configurations of a commercial plant and the expected performance and cost goals of the next power tower plant compared to actual performances at Solar One and Solar Two.

Solar Power Tower Design Basis Document, Revision 0, A. B. Zavoico, Sandia National Laboratories Report, SAND2001-2100, July 2001. This report provides the design basis and set of criteria for the next generation of molten-salt solar power towers. The report contains detailed criteria for each major system: The Collector System, Receiver System, Thermal Storage System, Steam Generator System, Master Control System, and Electric Heat Tracing System. The report is based on extensive experience gained from the Solar Two project and includes potential design innovations that will improve reliability and lower technical risk.

Receiver System: Lessons Learned from Solar Two, R. Z. Litwin, Sandia National Laboratories Report, SAND2002-0084, in press. This report identifies the most significant Solar Two receiver system lessons learned from the mechanical design, instrumentation and control, panel fabrication, site construction, receiver system operation, and management. The lessons learned described consist of two parts: the problem and one or more identified solutions. Also included are the results of inspecting an advanced nickel alloy panel installed at Solar Two.

Lesson Learned, Project History, and Operating Experience of the Solar Two Project, B. D. Kelly, Sandia National Laboratories Report, SAND2000-2598, November 2000 (Specified 
Dissemination only). This report summarizes the lessons learned from the Engineering, Construction, and Startup Engineering firm, Bechtel Group, Inc. These lessons cover a broad range of topics learned throughout the life of the Solar Two project, including the evolution of major systems, experience handling molten salt, final system operating procedures, project organization, equipment procurement, construction experiences, system designs, and economic analysis of commercial plants. 


\section{Introduction}

The Solar Two Plant was conceived in 1992 to demonstrate the potential of molten-salt power tower technology on a commercial scale. Construction began in 1995. After a lengthy startup between January 1996 and January 1998, the operations and maintenance (O\&M) company, Energy Services, Incorporated (ESI), accepted the plant on February 18, 1998. The plant operated until April 8, 1999. During the 14-month period, ESI operated the plant to conduct test and evaluations (T\&Es) and gain experience with the unique characteristics of this power plant.

This chapter begins with a background of power tower technology and the Solar Two project, followed by a summary of the goals and objectives of the T\&E program. The key performance measurements of the each major system are discussed in addition to the overall plant performance. Finally, detailed T\&E summaries are provided.

\subsection{Project Background and System Description}

The 10-MWe Solar One Pilot Plant, which operated from 1982 to 1988 in Barstow, California, was the largest demonstration of first-generation power-tower technology (Radosevich, 1988). During the operation of Solar One and after its shutdown, significant progress was made in the U.S. on more advanced second-generation power-tower designs. The primary difference between first and second-generation systems was the choice of receiver heat-transfer fluid. Solar One used water/steam, and the second-generation designs in the U.S. used molten salt. The molten-salt power tower design decouples the solar collection from electricity generation better than water/steam systems and allows the incorporation of a cost-effective energy storage system. Energy storage allows the solar electricity to be dispatched to the utility grid when the power is needed most, which increases the economic value of solar energy. In 1992, a team composed of utilities, private industries, and government agencies collaborated to demonstrate molten-salt power towers at the 10-MWe Solar Two plant, which was constructed by retrofitting Solar One with molten salt technology. The Solar One heliostat field, the tower, and the turbine/generator required only minimal modifications. Converting Solar One to Solar Two required a new molten salt heat transfer system (including the receiver, thermal storage, piping, and a steam generator) and a new control system. The major Solar Two systems and equipment are described below.

The original heliostats were reused from the Solar One project, but the facets of the inner rows of heliostats were recanted for the smaller Solar Two receiver. The Solar One heliostat field was modified at the boundary by moving north-side heliostats (which produced excessive flux on the north side of the receiver) to the sides of the field, and adding large area heliostats on the south boundary of the field. In conjunction with a carefully developed aiming-strategy, this allowed a significant reduction in receiver dimensions without exceeding its design limits. Figure 1-1 shows a photograph of the Solar Two plant. 


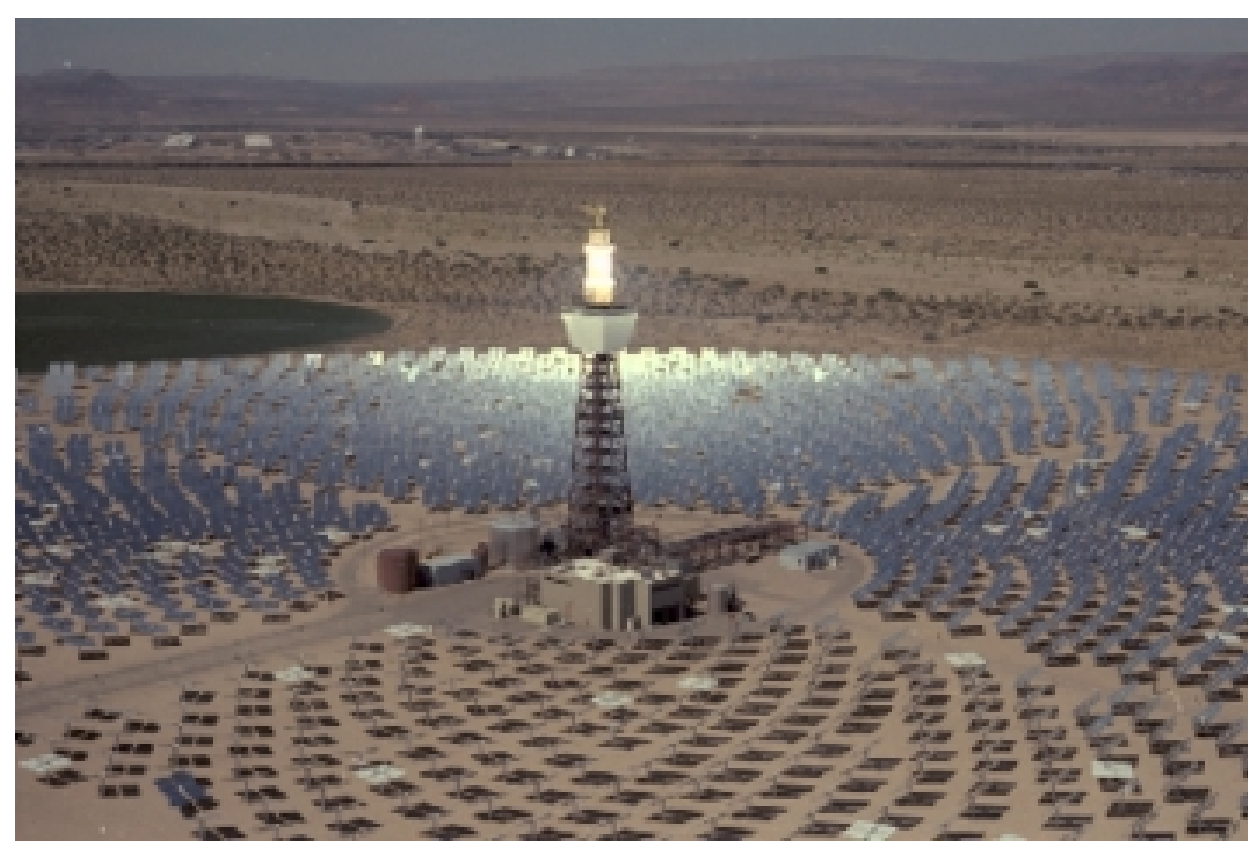

Figure 1-1. Photograph of the Solar Two plant in operation.

In a molten-salt power tower system, cold salt at $290^{\circ} \mathrm{C}$ is pumped from a cold tank through a heat exchanger, called the receiver, located at the top of a tower. Sunlight is reflected from a field of tracking heliostats and concentrated onto the receiver, which heats up the molten salt to $565^{\circ} \mathrm{C}$, flows back down to grade level, and is stored in a hot tank. To make electricity, hot salt is pumped from the hot tank through a steam generator to make high-pressure superheated steam, then returns to the cold tank. The steam powers a conventional Rankine turbine-generator. The molten salt storage system enables electricity to be produced during the day, through clouds, and at night, independent of solar collection. A schematic of the plant is shown in Figure 1-2.

The Bechtel Group, Inc. designed and constructed the new salt system; they developed the plant layout, sized much of the salt handling equipment, and developed specifications for the receiver, storage tanks, steam generation system, and the master control system. The design was based on experience gained from molten-salt receiver and system experiments conducted at the National Solar Thermal Test Facility (Smith and Chavez, 1992; Smith, et al., 1992). Bechtel also installed all of the salt piping (except piping in the receiver system), pumps, sumps, instrumentation, and controls. In addition, Bechtel was responsible for plant startup and acceptance testing.

The Solar Two receiver was designed and built by The Boeing Company. The new receiver was smaller than the Solar One receiver, consisting of panels arranged in a cylindrical shell around internal piping, instrumentation, and salt holding vessels. It was rated to absorb $42 \mathrm{MW}$ of thermal energy at an average solar flux density of $430 \mathrm{~kW} / \mathrm{m}^{2}$. 


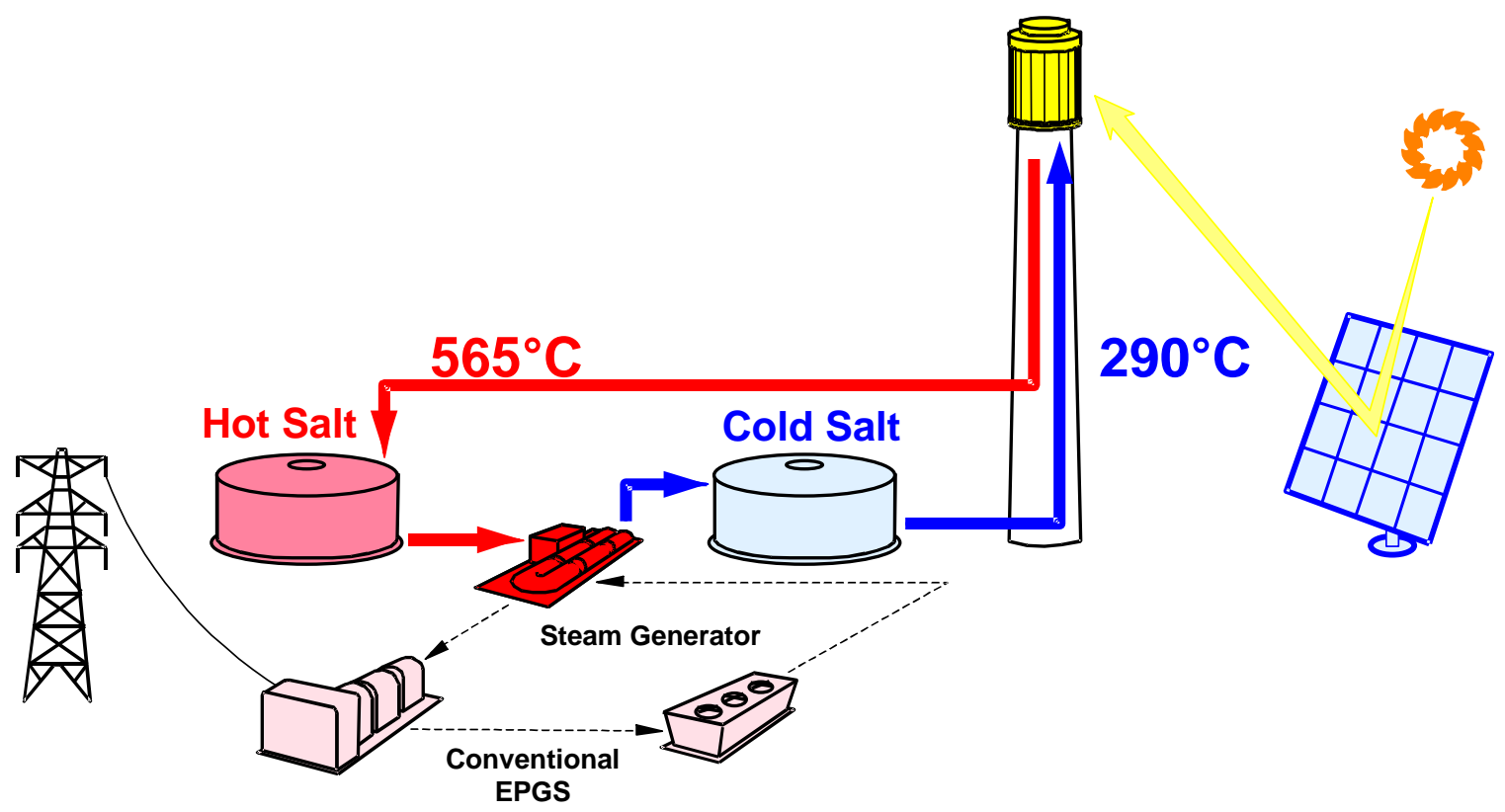

Figure 1-2. Schematic of a molten salt power plant.

The thermal storage tanks, which held the salt, were fabricated at the Solar Two site by Pitt-Des Moines. All pipes, valves, and vessels for hot salt were constructed from stainless steel because of its corrosion resistance to molten salt at $565^{\circ} \mathrm{C}$. Lower-cost carbon steel was used for cold salt containment because of the salt's lower corrosivity at $290^{\circ} \mathrm{C}$. Solar Two was designed with a minimum number of gasketed flanges and most instrument transducers, valves, and fittings were welded in place to minimize salt leaks.

The thermal storage medium consisted of approximately 1300 tonnes of nitrate salt nominally consisting of $60 \mathrm{wt} \% \mathrm{NaNO}_{3}$ and $40 \mathrm{wt} \% \mathrm{KNO}_{3}$. The nitrate salt was provided by Chilean Nitrate Corporation of New York. This salt melts at 205 to $220^{\circ} \mathrm{C}$ and is thermally stable to approximately $600^{\circ} \mathrm{C}$.

The steam generator system (SGS) was designed by ABB Lummus. It consists of a shell, tube superheater, preheaters, and a kettle evaporator. Stainless-steel cantilever pumps transported salt from the hot sump through the SGS to the cold tank. Salt in the cold tank flowed to the cold sump and was pumped with multistage centrifugal pumps up the tower to the receiver.

The power block was refurbished from the Solar One project. It was rated at $12.8 \mathrm{MWe}$ gross generation. It accepted steam from the steam generator at 100 bar and $510^{\circ} \mathrm{C}$.

\subsection{Goals and Objectives of the Solar Two Test and Evaluation Program}

The objectives of the Solar Two T\&E program were to collect data, gather information, and perform analyses in order to: 
1. Validate the technical characteristics of the nitrate salt receiver, storage system, and steam generator technologies.

2. Improve the accuracy of economic projections for commercial projects by increasing the database of capital, operating, and maintenance costs.

3. Distribute information to U.S. utilities and the solar industry to foster wider interest in the first commercial plants.

Originally, the T\&E program was scheduled to run for a period of one year after final plant acceptance. During this period, the entire plant and O\&M personnel would be devoted exclusively to $\mathrm{T} \& \mathrm{E}$ with no emphasis on power production goals. This would be followed by a power production phase lasting approximately two additional years. The performance goals for the Solar Two Project were not expected to be met until the latter portion of the power production phase. However, because of the lengthy startup phase - due to design and construction issues, the T\&E phase was scaled back and conducted concurrently with a limited power production phase - both were compressed into a 14-month operating schedule. 


\section{Heliostat Field}

\subsection{Description}

The heliostat field consisted of 1818 Martin Marietta (MM) heliostats from the original Solar One project and 108 large-area Lugo heliostats (so named because many of their parts were salvaged from the defunct Lugo photovoltaic plant) added so the Solar Two project could better match the desired balance of heat flux between the north and the south side of the molten-salt receiver. Thirty-two of the MM heliostats were also relocated for this purpose. The technical characteristics of the heliostat field are listed in Table 2-1. The MM heliostats, shown in Figure 2-1, were each $39.1 \mathrm{~m}^{2}$. The MM field had a mixture of low- and high-iron glass, with an average clean reflectivity of 0.903 . Each MM heliostat used 12 mirror modules mounted to a roof-truss and torque-tube assembly. An azimuth-elevation drive unit moved the assembly to the desired position. Many of the MM mirror module's reflective silver surface started to corrode, but this problem was greatly slowed by venting the modules. Some of the corroded mirror modules fell off in the early 1990s during an earthquake. Many damaged, missing, and corroded mirror modules on these heliostats were replaced with flat mirrors, cut down to size from another defunct photovoltaic power plant called Carrissa Plains. The Lugo heliostats, shown in Figure 22, were built with 16 Carrisa Plains flat mirror modules and had a total reflective area of $95 \mathrm{~m}^{2}$. These mirror modules consist of 1-mm thick glass mirrors laminated on 3-mm thick glass and have a clean reflectivity of 0.94 . This design is more durable than the mirror module design used on the MM heliostats. The low-cost, salvaged mirror modules were judged to be acceptable for the project despite their undesirable, flat curvature. The Lugo heliostats also have a roof-truss and torque-tube structure and an azimuth-elevation drive unit.

The Solar Two heliostat field was developed by modifying the existing Solar One field in response to a new receiver design with $1 / 3$ the surface area of the Solar One receiver. The objective of the modified heliostat layout was to emulate the performance of an optimized plant by trading off $100 \mathrm{MWe}$ commercial receiver performance and dimensions with heliostat field performance (Vant-Hull, et al., 1993; Vant-Hull and Pittman, 1988; Walzel, et al., 1977). All heliostats at Solar One had their mirror modules focused at a distance of $400 \mathrm{~m}$. To improve heliostat beam quality and system performance at Solar Two, the inner 17 circles (about 2/3 of the heliostats) were "recanted" to focus their mirror modules at their specific slant range from the Solar Two receiver (at 105 to $235 \mathrm{~m}$ distance). However, the poor quality of the recanting work reduced the benefit of this exercise and likely reduced field performance further by increasing heliostat tracking errors due to geometrical misalignment. 


\section{Table 2-1. Technical characteristics of the heliostats}

\begin{tabular}{ll}
\hline \hline Martin Marietta Heliostats & \\
Number & 1818 \\
Reflective Area & $39.13 \mathrm{~m}^{2}$ \\
Number of Mirror Modules & 12 \\
Type of Glass & Mixture of Low- and High Iron \\
Clean Reflectivity & 0.903 \\
Total MM Heliostat Field Area & $71140 \mathrm{~m}^{2}$ \\
Lugo Heliostats & 108 \\
Number & $95 \mathrm{~m}^{2}$ \\
Reflective Area & 16 \\
Number of Mirror Modules & Thin-glass laminated on thick glass \\
Type of Glass & 0.94 \\
Clean Reflectivity & $10260 \mathrm{~m}^{2}$ \\
Total Lugo Heliostat Field Area &
\end{tabular}

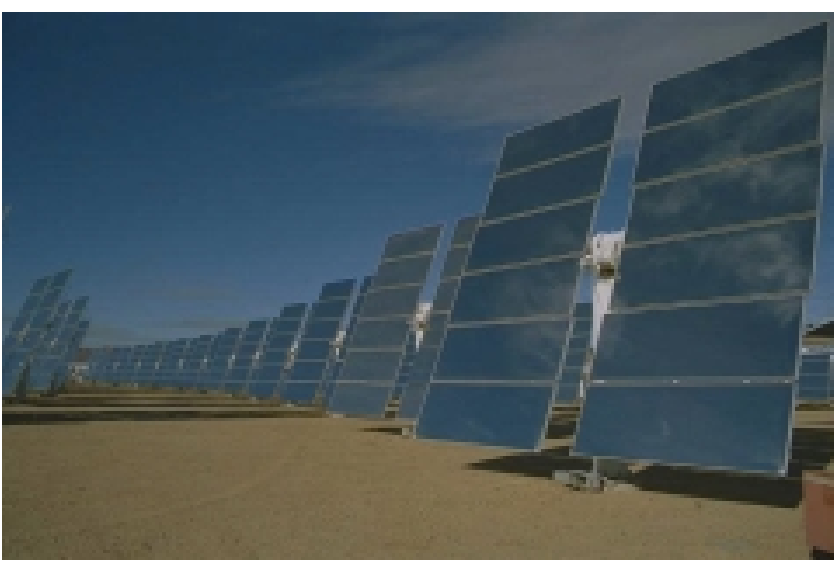

Figure 2-1. Martin Marietta heliostats.

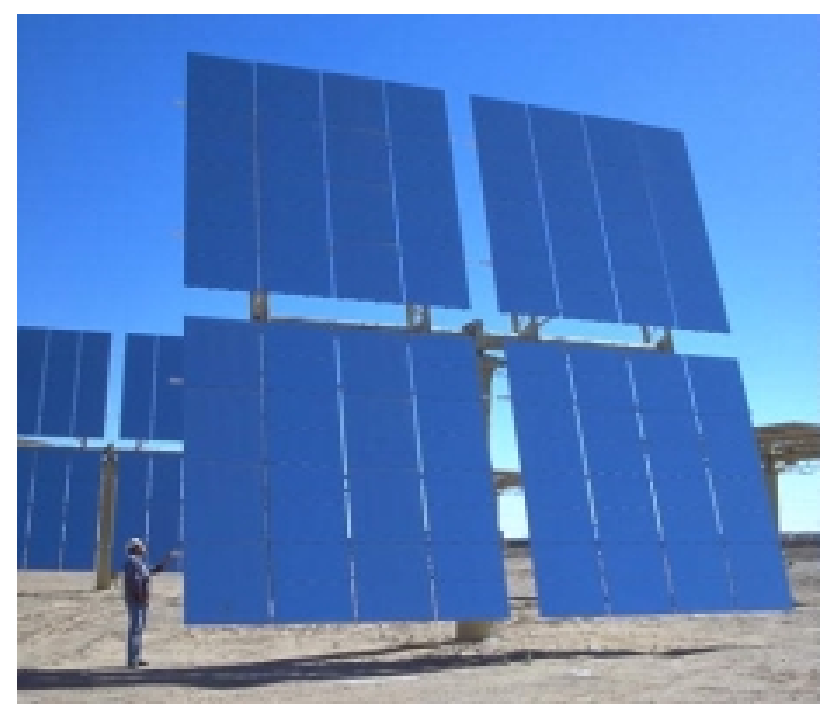

Figure 2-2. Lugo heliostats at Solar Two. 


\subsection{Typical Operation}

On a typical clear-weather operating day, the heliostat field was stowed until sunrise, at which time the heliostats were commanded to one of four standby aim points - points at an elevation of the centerline of the receiver, but offset from the receiver by several receiver diameters. The heliostat beams followed a specific "wire walk" between ground level and the standby aim point to prevent them from concentrating on site personnel, building or plant equipment, or on objects outside the plant boundaries. When the sun reached an elevation of approximately 10 degrees above the horizon, $20 \%$ of the heliostat field (preheated heliostats) focused on the receiver to preheat the tubes prior to filling the receiver with salt. Solar Two used sophisticated computer algorithms to control the aiming and selection of heliostats used during startup and operation. Once all the receiver tubes were heated above $260^{\circ} \mathrm{C}$, the receiver was filled with salt. After assuring the receiver had properly filled, the operators ramped up the power on the receiver over a period of approximately 5 minutes by commanding more heliostats to focus on the receiver. At the end of the day or when clouds rolled in, the heliostats were commanded to standby, except a subset (approximately 20\%) that provided heat to the receiver during draining. Once the receiver outlet temperature had diminished to its inlet temperature, the receiver pump was shut off and the receiver drained. The heliostats were stowed for the night. The Martin Marietta heliostats were stowed face-down, while the non-inverting Lugo heliostats were stowed face-up.

Three software-based systems at Solar Two managed the flux distribution incident on the receiver to: 1) heat the receiver while filling or draining, 2) update the aim points during normal operating conditions due to changes in daily and seasonal heliostat-field performance, and 3) protect the receiver against overflux conditions to ensure it has a long life. These systems are discussed in more detail in Section 3.4.2.

\subsection{Performance Measurements}

The primary purpose of the Solar Two project was to validate the molten salt technology. Since the heliostat technology was successfully demonstrated at Solar One and through other heliostatdevelopment activities, no specific T\&Es on the heliostat field were called out in the original test and evaluation plan. However, data was collected and analyzed on the heliostat system to assist in the characterization of the overall plant performance.

Less effort was spent on the heliostat field refurbishment and maintenance relative to other systems because a limited budget was allocated for the field. As an unforeseen consequence, the field performed below expectations, but the poorly-performing field rarely limited operation or testing of other plant systems.

\subsubsection{Field Efficiency and Power Incident on Receiver}

The performance of the heliostat field was measured in terms of its output and its efficiency averaged over short time-scales. The heliostat field efficiency was measured during receiver efficiency tests (discussed in the receiver system section). The efficiency is a measurement of how well the heliostat field transfers power to the absorber area of the receiver. The heliostat 
field efficiency is defined as the ratio of the power incident on the receiver absorber surface to the power incident on the heliostats tracking the receiver after being multiplied by the mirror reflectivity and mirror cleanliness. The mirror reflectivity, mirror cleanliness, and field availability are not included in this definition of field efficiency so that results from different days can be compared to each other more easily. The heliostat field efficiency includes losses due to: projected reflection area being lower than total reflective area (cosine losses); blocking of incident sunlight by adjacent heliostats; shading of reflected sunlight by adjacent heliostats; atmospheric attenuation of reflected sunlight; and reflected light that misses the receiver (spillage) due to heliostat errors and aiming strategies. Heliostat field efficiency varies with sun position. Measured heliostat field efficiency results for an approximately constant sun position near solar equinox and noontime are shown in Table 2-2. The first three tests in the table were conducted in September and October of 1997. No large-area Lugo heliostats tracked the receiver during these tests. The remainder of the tests were performed near the end of the Solar Two project in March, 1999, when the availability of the MM heliostats was lower.

The results showed that the field efficiency was lower than predicted in the RCELL computer model by $10-15 \%$ (5-10 efficiency points). The lower efficiency was due mostly to poor heliostat tracking, but lower-than-expected heliostat beam quality was also a contributor. Both will be discussed later in more detail. When the larger tracking and beam quality errors found at Solar Two were put into optical performance computer models used by Sandia and the University of Houston, the resulting predictions matched the field performance measurements.

Table 2-2. Heliostat field efficiency and incident power measurements

\begin{tabular}{cccccccc}
\hline \hline $\begin{array}{c}\text { Direct } \\
\text { Normal } \\
\text { Insolation, } \\
\text { W/m } \mathbf{m}^{2}\end{array}$ & $\begin{array}{c}\text { Heliostat } \\
\text { Area } \\
\text { Tracking } \\
\text { Receiver, } \\
\mathbf{m}^{2}\end{array}$ & $\begin{array}{c}\text { Power } \\
\text { on to } \\
\text { Heliostat } \\
\text { Field, } \\
\text { MW }\end{array}$ & $\begin{array}{c}\text { Clean } \\
\text { Reflectivity, } \\
\text { (area } \\
\text { weighted) } \\
\%\end{array}$ & $\begin{array}{c}\text { Clean- } \\
\text { liness, \% }\end{array}$ & $\begin{array}{c}\text { Power } \\
\text { Incident } \\
\text { on } \\
\text { Receiver, } \\
\text { MW }\end{array}$ & $\begin{array}{c}\text { Heliostat } \\
\text { Field } \\
\text { Efficiency, } \\
\%\end{array}$ & $\begin{array}{c}\text { Wind } \\
\text { Speed, } \\
\text { m/s at 10 } \\
\text { m }\end{array}$ \\
\hline $909 \pm 27$ & $69143 \pm 196$ & $62.8 \pm 1.9$ & $90.3 \pm 0.45$ & $96.7 \pm 1.9$ & $36.5 \pm 1.6$ & $66.5^{*} \pm 4.0$ & $0.5 \pm 10 \%$ \\
975 & 68908 & 67.2 & 90.3 & 96.7 & 38.8 & $66.2^{*}$ & 0.8 \\
944 & 70473 & 66.5 & 90.3 & 96.7 & 38.5 & $66.3^{*}$ & 0.5 \\
989 & 67407 & 66.6 & 90.5 & 91.7 & 36.4 & 65.8 & 2.5 \\
890 & 69689 & 62.0 & 90.6 & 90.7 & 31.4 & 61.6 & 1.5 \\
964 & 70146 & 67.6 & 90.7 & 92.9 & 36.1 & 63.4 & 1.2 \\
870 & 70032 & 60.9 & 90.6 & 92.7 & 31.8 & 62.1 & 0.8 \\
867 & 63606 & 55.1 & 90.3 & 93.8 & 29.2 & $62.5^{*}$ & 6.4 \\
893 & 71265 & 63.7 & 90.6 & 92.5 & 33.2 & 62.2 & 1.1 \\
\hline \hline
\end{tabular}

${ }^{*}$ In these tests, no large-area Lugo heliostats tracked the receiver.

\subsubsection{Heliostat Tracking Accuracy}

Heliostat tracking errors have many sources, but the MM heliostat controls have the capability to correct only encoder reference position errors. Consequently, great care was taken in the building and installation of the MM heliostats to minimize other error sources. The Lugo heliostat controls have more built-in capability, but still don't have the full error correction capability envisioned for modern heliostats. Further explanations of heliostat error sources, the 
limitations of the MM heliostat control systems, and strategies to improve the situation are documented elsewhere (Stone and Jones, 1999 and Jones and Stone, 1999).

Another potential source of heliostat tracking errors is inaccuracy in the calculation of sun position. Errors in the Solar Two sun position calculations were discovered in June-July, 1996. Much of the Solar One heliostat control software was reused at Solar Two, but was converted by a consulting company from FORTRAN to the $\mathrm{C}$ language using an automated conversion utility followed by testing. The sun model coefficients in the software were outdated for use at Solar Two and the sun coordinates were not properly converted to the plant coordinate system. Additionally, an erroneous Solar One sun position subroutine was incorrectly selected for conversion (likely some erroneous but unused subroutines had not been deleted from the Solar One control system) and had a leap year mistake so that the sun position calculations back to the beginning of 1996 were off by one day. These errors were not immediately apparent in the initial software testing because they were small.

Poor heliostat tracking was both measured with the Beam Characterization System (BCS) and qualitatively apparent by observing reflected heliostat beams striking objects other than the receiver. The BCS measures individual heliostat tracking accuracy and provides an intensity distribution (flux map) of the reflected beam that can be used to assess beam quality. For example, the metal plates covering the upper and lower receiver header ovens were subjected to higher flux levels than designed. Their white paint was burned and the oven covers warped by misaimed heliostats. The BCS records from Solar Two provided a quantitative indication of increased heliostat tracking errors.

Problems with the BCS software algorithm that performed coordinate conversions and use of improper operating procedures will be discussed further in Section 3.4.1, but are mentioned here because the resolution of these issues resulted in improved BCS accuracy later in the life of the Solar Two project. Consequently, the BCS results presented here were taken from the latest BCS measurement available for each heliostat in the field. The vast majority of these measurements were taken in the last six months of plant operation. Nonetheless, there were some issues with BCS data, including duplicate entries, erroneous measurements, and a problem with dates due to a two-year revolving timeframe limitation inherent in the database software, so an effort was made to exclude erroneous data from the results presented here.

Heliostat tracking accuracy can be described in many ways, using different coordinate systems and figures of merit. In an attempt to avoid misunderstanding by making comparisons on an unequal basis, the results shown in Table 2-3 are presented in different forms so that readers may use the basis they prefer.

Measurements of $95 \mathrm{MM}$ heliostats tracking accuracy at Solar One indicated they met the design requirements of less than $1.5 \mathrm{mrad}$ standard deviation beam error in both the $\mathrm{X}$ - and $\mathrm{Y}$-axis (Mavis, 1987). However, some mysterious tracking problems were documented in the same Solar One report and were fixed by replacing encoders that measure heliostat motion in each axis. Within the accuracy of the measurement system, both the Solar One and Solar Two BCS tracking data populations have a zero mean (note that for a zero-mean distribution of many values, the standard deviation and the root-mean-square (RMS) are essentially equal). 
When comparing the Solar Two heliostat tracking accuracy to the $1.5 \mathrm{mrad}$ accuracy requirement at Solar One, the $4.14 \mathrm{mrad}$ RMS 1-dimensional figure of merit (FOM) value in beam coordinates should be used. It shows nearly three times the tracking error. This poorer performance at Solar Two was due to problems with the degrading heliostat controller hardware that was left unused for many years, the introduction of additional tracking error sources ${ }^{8}$ due to poorly realigned heliostats, and miscellaneous software and communications problems. These problems will be discussed later in more detail.

\section{Table 2-3. Solar Two heliostat field tracking accuracy results collected from BCS Data of 95 heliostats}

\begin{tabular}{|c|c|c|c|c|c|c|c|c|}
\hline \multirow[b]{2}{*}{ Heliostats } & \multicolumn{4}{|c|}{ Reflected Beam Coordinate System } & \multicolumn{4}{|c|}{ Mirror-Normal Coordinate System } \\
\hline & $\begin{array}{l}\text { X-dir } \\
\text { RMS } \\
\text { (mrad) }\end{array}$ & $\begin{array}{l}\text { Y-dir } \\
\text { RMS } \\
\text { (mrad) }\end{array}$ & $\begin{array}{l}\text { Total } \\
\text { RMS } \\
\text { (mrad) }\end{array}$ & $\begin{array}{l}\text { 1-D FOM } \\
\text { RMS } \\
\text { (mrad) }\end{array}$ & $\begin{array}{l}\text { Azimuth } \\
\text { RMS } \\
\text { (mrad) }\end{array}$ & $\begin{array}{l}\text { Elevation } \\
\text { RMS } \\
\text { (mrad) }\end{array}$ & $\begin{array}{l}\text { Total } \\
\text { RMS } \\
\text { (mrad) }\end{array}$ & $\begin{array}{c}\text { 1-D FOM } \\
\text { RMS } \\
\text { (mrad) }\end{array}$ \\
\hline All & 4.11 & 4.17 & 5.86 & 4.14 & 3.17 & 2.18 & 3.85 & 2.72 \\
\hline MM & 4.08 & 4.18 & 5.84 & 4.13 & 3.13 & 2.16 & 3.80 & 2.68 \\
\hline Lugo & 4.67 & 3.87 & 6.07 & 4.29 & 3.89 & 2.51 & 4.63 & 3.27 \\
\hline
\end{tabular}

Since heliostat tracking errors actually occur in the azimuth and elevation axes, not in the reflected beam coordinates used by the BCS, coordinate conversions were performed to generate the values listed in the right half of the table as mirror-normal coordinates. This provides additional insight into the errors not available in the reflected beam coordinates. Specifically, the azimuth tracking errors were found to be larger than the elevation tracking errors. Both types of heliostats have a gravity moment when the mirror modules are offset from the axis of rotation. This tends to prevent the heliostat from experiencing tracking errors due to drive backlash in the elevation direction. The heliostats are more susceptible to tracking errors due to drive backlash in the azimuth direction, and the results reflect this fact.

It should be noted that the individual BCS tracking error measurements for each heliostat that were used to compute the RMS values in Table 2-3 are actually the average tracking error measured over a short (e.g. 30-second) time period. This averaging was done to avoid measuring tracking errors due to the control system dead-end, as well as those due to wind ${ }^{9}$, both of which tend to have a zero mean effect. Consequently, the heliostat RMS tracking errors seen by the receiver were slightly higher than indicated by the BCS measurements, since the slight tracking variability (which would increase the RMS error) seen over the approximately 30-second periods were excluded from Table 2-3.

Near the end of the project, heliostat tracking accuracy was investigated using the flux management systems described later. In these software systems, heliostat beam quality and tracking errors are combined into a single error metric. This error metric was adjusted and the

8 Aligning the mirror modules to focus on a point that is not orthogonal to the axes of rotation introduces a tracking error (Stone and Jones, 1999).

9 BCS measurements were supposed to be taken under low wind conditions, but requiring no wind would have been too restrictive. 
difference between the software predictions of incident receiver power and measurements of absorbed receiver power was monitored. Both the predictions and measurements have uncertainties, so it was not possible to draw definitive conclusions about the appropriate error metric. However, results appeared to support the heliostat tracking accuracy measurements listed in Table 2-3.

\subsubsection{Heliostat Beam Quality}

Lower beam quality was expected at Solar Two because of the delamination (loss of curvature) of MM heliostat mirror modules from water intrusion and the use of inexpensive, flat mirror modules from the defunct Carrissa Plains photovoltaic site to replace missing MM modules. The Lugo heliostats were also larger than was optimal for the size of the Solar Two receiver, but the use of salvaged trackers saved considerable money. However, BCS measurements showed that the beam quality was below expectations. For example, the heliostat beam shown in Figure 2-3 is non-symmetric and of poorer quality than was expected. One reason for this was difficulty in accurately aligning (canting) both replacement mirror modules and existing mirror modules in the inner 17 circles of heliostats (2/3 of the field) - a project undertaken because computer models showed it would improve field performance. At first a video-camera-based "lookback" canting approach was used, but it proved too cumbersome for the workers. Instead, guidelines for an "on-sun" approach were provided. For example, parts of the field were to be canted only during certain times. The guidelines were not followed carefully. Accurate mirror alignment is best done in a controlled environment by well-trained technicians with good equipment as part of the installation process. As mentioned previously, the poor results from recanting led to increased heliostat tracking errors and reduced beam quality.

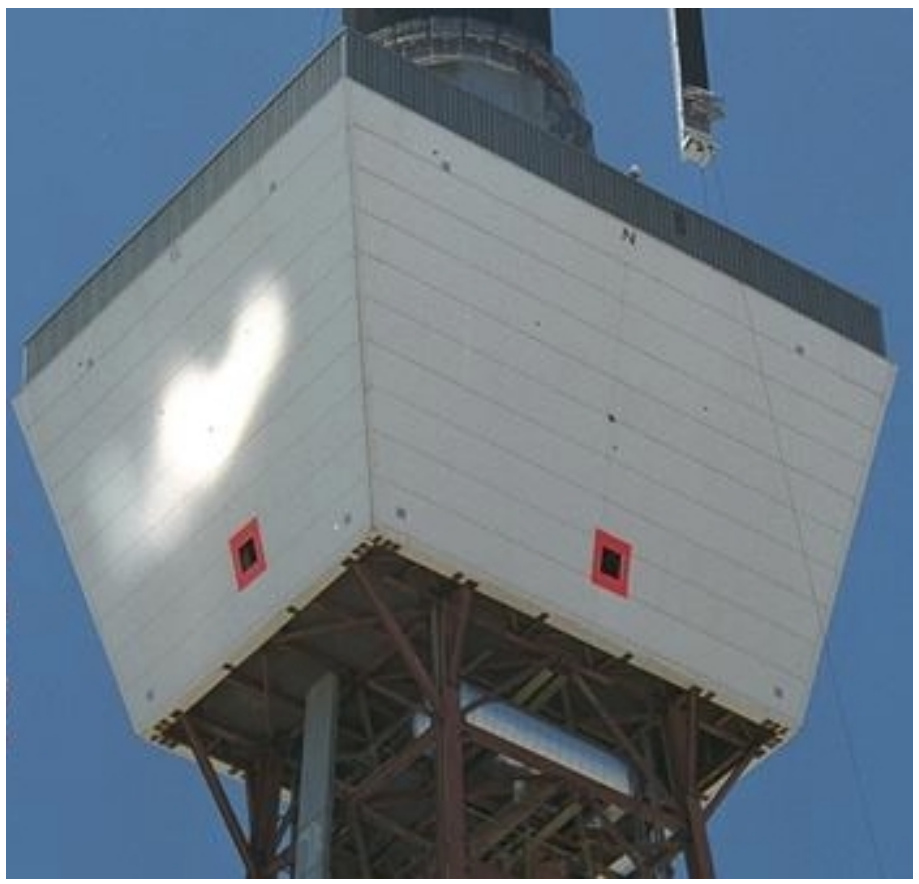

Figure 2-3. Solar Two heliostat beam tracking the BCS target. 
Other contributors to reduced beam quality were related to the hardware used in installing the replacement mirror modules. The replacement modules were larger than the originals and had to be installed further from the supporting structure, particularly when two replacement modules were installed adjacent to each other. Flexing of the bolts used for installation added to alignment errors. Additionally, welding the supports for the replacement modules caused the reflective surface to become convex, reducing their effectiveness. Improvements to installation hardware and procedures were implemented to address these issues when they were discovered.

\subsubsection{Heliostat Field Availability}

Heliostat availability is the fraction of the heliostat field able to track the receiver, and is another measure of field performance. At Solar One, annual heliostat availabilities of $96.7 \%, 98.2 \%$, and 98.8\% were recorded for the first, second, and third years of power production. Additionally, little maintenance was required to achieve these availabilities; one 3/4-time person was required for field maintenance in the third year of power production (Kolb and Lopez, 1988). Based on Solar One and the similar Solar Electric Generating System (SEGS) trough plant experiences (Cohen et al., 1999), the heliostat availability goal for Solar Two was set at 98\%. Figure 2-4 shows this goal line and the much lower measured daily maximum availabilities at Solar Two. The main reason for this decrease in availability compared with Solar One was the use of old heliostats that had been left unused and unmaintained between Solar One and Solar Two. Examples of degredation occurred in wiring cable harnesses exposed to the environment, incandescent encoder light bulbs with a projected lifetime of only 5000 hours, and the microprocessor-based control boards in each heliostat. Sometimes the use of more modern hardware, such as light-emitting diodes for encoders, wiring harnesses more resistant to ultraviolet light, and more robust electronics could have improved heliostat reliability. In other cases, reliable technology was available, but the knowledge base to select that hardware did not yet exist. For example, there were extensive problems with the DC motors used on the MM heliostats, whereas the DC motors used on the Lugo heliostats were trouble-free after a similar period of use. Even small, systematic problems can be very expensive with a field of thousands of heliostats, so component reliability is very important.

There was a severe lightning strike on July 22, 1998 that caused availability to drop from $92 \%$ to $70 \%$. Physical damage to the field was limited, but lightning caused communication problems for the MM heliostats that required the tedious cycling of power supplies in each pedestal to fix the problem, a process that can take several days. Following the lightning strike was a concerted effort between August and November, 1998 to improve heliostat availability. The fruit of this effort can be seen in Figure 2-4 by the steadily rising availability. There were similar periods of extra effort exerted at other times to improve heliostat availability that are largely responsible for the upswings in availability seen elsewhere in the figure. 


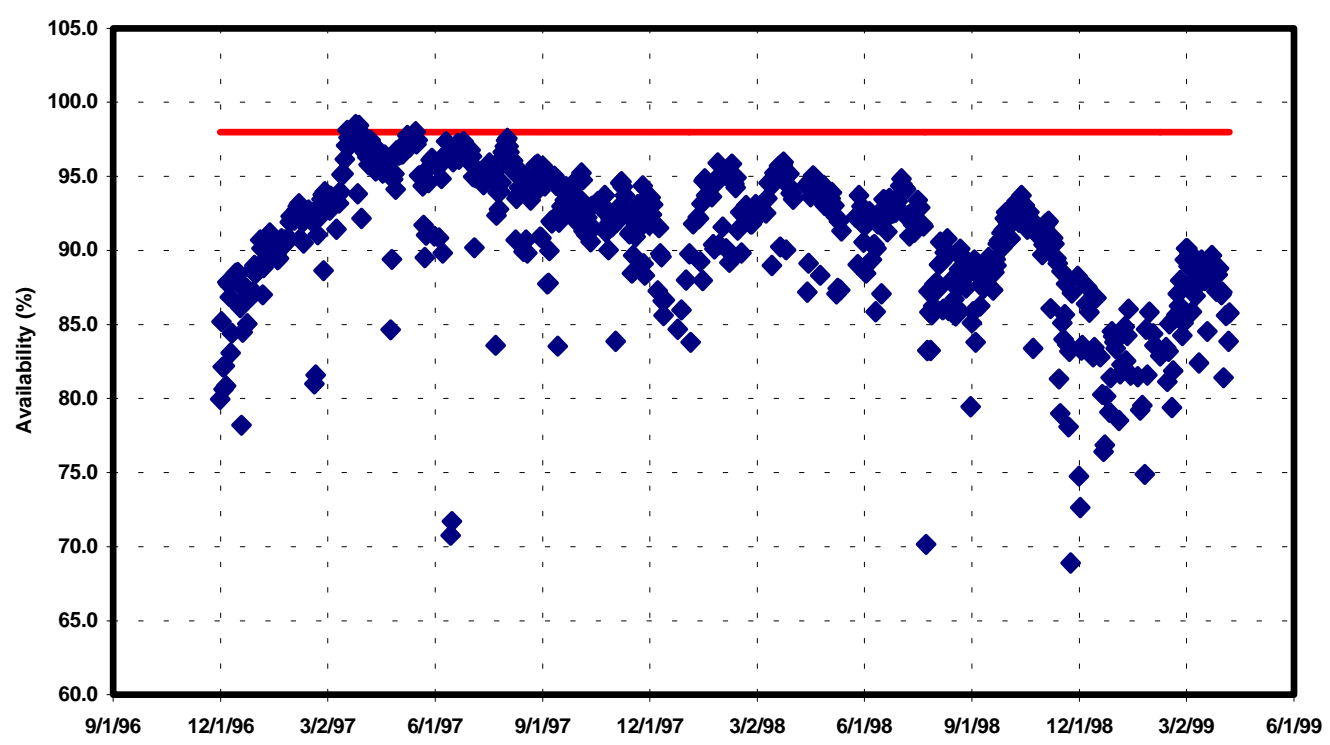

Figure 2-4. The daily maximum heliostat availability at Solar Two was consistently below the goal of $98 \%$. Years without use or maintenance is thought to be a major cause.

The daily maximum heliostat availability does not tell the whole story. Figure 2-5 shows the instantaneous heliostat availability over six days near the end of the project. There is a clear trend indicating a few percent $(<5 \%)$ drop in availability over each day. This was due in part to control software improvements added in July, 1998 to shut down heliostats that stopped operating properly. There was very limited information available from the heliostat control system to implement software diagnostics that test for proper heliostat operation. However, it is highly likely that the heliostats removed from operation were not tracking properly. Furthermore, some of the heliostats probably had problems that prevented their proper tracking, but were not severe enough to trigger the software that removed them from operation.

Normally, peak heliostat availability was restored the next day and many of the same heliostats were again removed from available status. Some of the problems were intermittent in nature and efforts to diagnose the root cause were not very successful. Additionally, no clear trends were seen in the heliostats that did require fixes.

\subsection{Operating Experience}

The experiences from the heliostat field, including the BCS, the heliostat flux management system, field maintenance, washing, cleanliness measurements, and measurement of mirror corrosion are discussed below. 


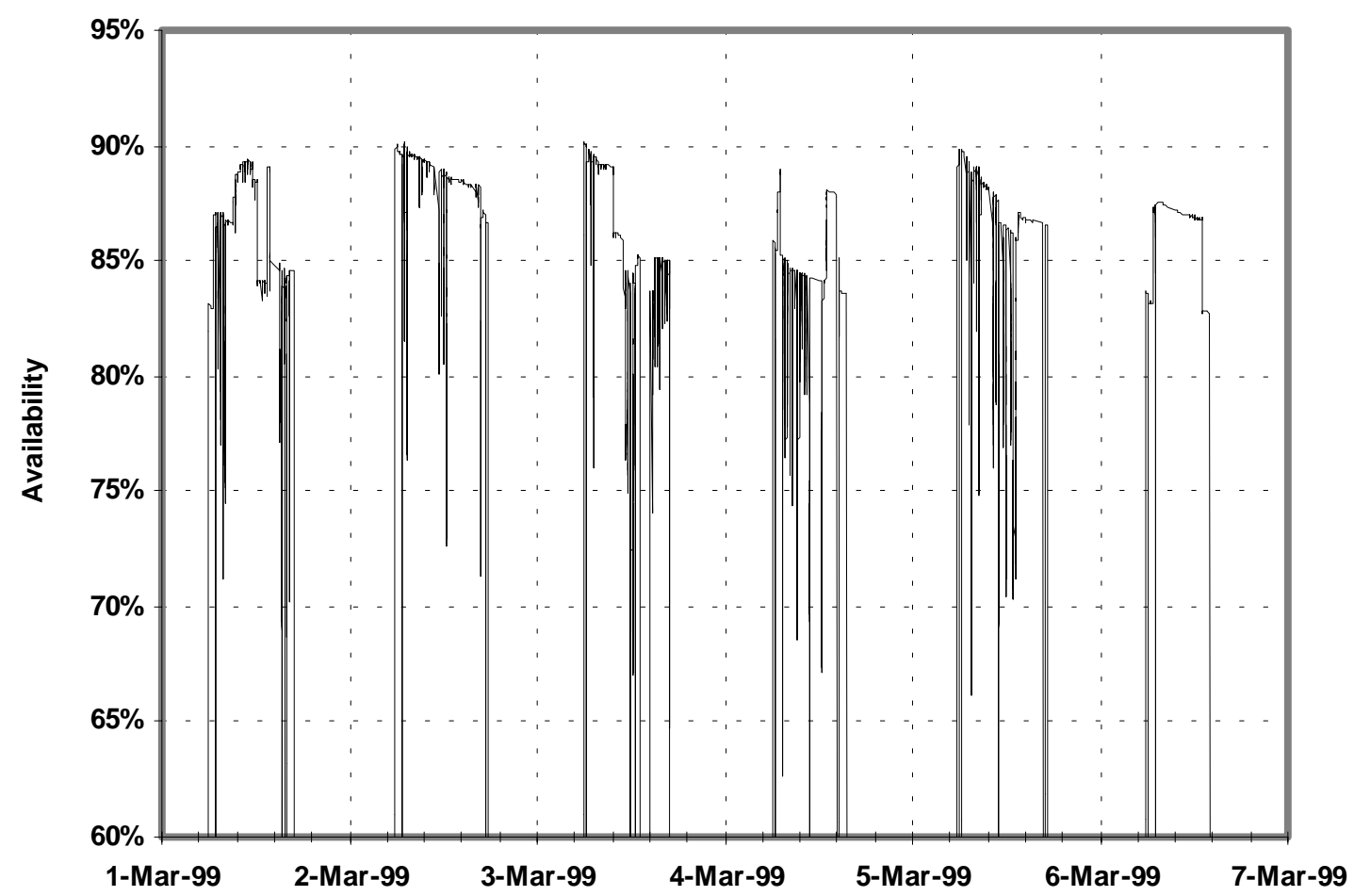

Figure 2-5. Instantaneous heliostat availability over six days near the end of Solar Two. The gradual drop over a day is from heliostats being removed when software found operational errors. The large, brief drops in availability are typically caused by heliostats transitioning between modes and do not indicate a true reduction in availability.

\subsubsection{Beam Characterization System Experiences}

The Solar Two BCS used many components from the system present at Solar One, including four large white targets below the receiver onto which individual heliostat beams could be aimed. In the field, four cameras fed signals back to the control room. An individual heliostat was commanded to focus its beam at the center of the BCS target and software digitized the image from the camera, calculating the beam's centroid relative to the target center. Figure 2-3 shows a heliostat beam on the BCS target at Solar Two.

At Solar One, it took years and much expense to get the highly automated BCS system operating. Operating the Solar One BCS system initially caused the main heliostat control computer to crash. Many BCS quality assurance tasks performed easily by a human operator are complex to computer-automate. For a time, operators had to stand in the field and draw pictures of the heliostat beams on graph paper, then estimate their tracking error. The heliostat control systems at Solar Two were unable to fully utilize extensive BCS data to correct the many possible heliostat tracking error sources, as is envisioned for modern heliostats. A BCS measurement of heliostat tracking done every three months provided the greatest benefit permitted by the 
heliostat control system, so limited BCS automation, and its associated expense, was selected for Solar Two.

Most of the hardware and software from the Solar One BCS system were upgraded for Solar Two. The old cameras located in the field were replaced with newer, charge-coupled-device (CCD) models, but the wiring from the control room was reused. A commercial software package running on a stand-alone personal computer was used to measure and analyze heliostat beam images, replacing the custom software running on the main heliostat control computer at Solar One.

However, much of the heliostat control software from Solar One was recycled for use at Solar Two. The old Solar One heliostat control computers were replaced with modern hardware and the software was converted from FORTRAN to the $\mathrm{C}$ language using an automated conversion utility followed by human checking and validation. A consulting company with expertise in this area and with the old Solar One hardware oversaw the process. In some cases, extensive programming was required to complete the system for Solar Two.

\subsubsection{Heliostat Spillage on Receiver Oven Covers}

The vertical aim point offsets calculated for each heliostat caused their edges to graze the rim of the receiver, resulting in minimal additional spillage and reducing the peak flux density to an acceptable level. The level of spillage onto the protective oven covers-the insulated housing located above and below the receiver absorber surfaces that insulate the headers at each end of the receiver panels-was held to below $50 \mathrm{~kW} / \mathrm{m}^{2}$ by the heliostat flux management system.

During the start-up phase of Solar Two operations, there was substantial flux falling on the oven covers and numerous heliostats were not tracking properly, showing substantial drift with time, etc. The continual improvement of the field performance with time did not seem to help the oven covers, so "clamps" were applied to the aim point shifts, limiting the shift to $85 \%$ of the calculated value for all shifts greater than $1 \mathrm{~m}$. This did help somewhat, but it necessarily increased the peak flux generated on the receiver. The results of extensive beam-characterization measurements, the observation of less power on the receiver than calculated by the Dynamic Aim Processing System (DAPS), and the excess spillage onto the oven covers were all consistent with substantially larger beam and pointing errors.

It was discovered that a simplified but erroneous algorithm was implemented at Solar Two to perform coordinate conversions on BCS data. This reduced the effectiveness of the BCS and increased heliostat tracking errors. Eventually, the correct algorithm was implemented in October, 1997. In early April, 1998, it was discovered that the east BCS camera was aimed about 3' higher than originally aimed, probably due to an accidental bump of sufficient force, but the BCS software had not been recalibrated to correct for this change. It was unknown how long the error existed. The error changed the aiming of heliostats calibrated with the BCS by a similar amount. The BCS camera aiming problem was masked by a flux management system software bug (see section 3.4.3). The software bug, poor heliostat tracking accuracy, and an increase in spillage due to the BCS camera missalignment were the root causes of the excessive spillage on 
the oven covers. As a result, several small sections of the oven covers melted at the top of the east side of the receiver.

Guidelines for BCS measurements at Solar Two were developed to maximize the benefits to heliostat tracking accuracy and minimize the labor required. For example, different regions of the field were to be measured at different times of the day. There were also detailed guidelines regarding the operation of BCS software and hardware to ensure the quality of measurements. The work was somewhat tedious, and unfortunately the guidelines were infrequently followed adequately.

The next commercial plant would be best served with a control system capable of correcting for many heliostat tracking error sources using numerous BCS measurements. A highly-automated BCS system would resolve these error sources.

\subsubsection{Heliostat Field Flux Management Systems}

At Solar Two, three software-based systems managed the heliostat field-reflected light intensity (flux) incident on the receiver. Table 2-4 lists these systems and their main purpose. Heliostat images change size and shape with changes in sun position, so the Static Aim Processing System (SAPS) adjusted heliostat aimpoints on approximately 10-minute intervals to minimize spillage (light that misses the receiver) and provide the approximate receiver flux pattern desired. The DAPS was designed to protect the receiver from overflux conditions by checking predicted flux patterns every few seconds and removing the offending heliostats. The preheat processor handled the difficult task of preheating the empty receiver before it was filled with molten salt, as well as providing heat during receiver draining. Heliostats were always aimed at the vertical centerline of the receiver, but at different elevations, to spread the flux over the full receiver area. More details about these systems and experiences with them appear in the following sections.

Computer simulations (predictions) were used instead of direct measurements of flux on the receiver because the latter is very difficult for a cylindrical receiver. Measurement of light reflected off the receiver has great uncertainty because a small change in receiver absorptivity (e.g. 0.95 to 0.94 is a $1 \%$ change) is likely and has a large relative impact on receiver reflectivity ( 0.05 to 0.06 is a $20 \%$ change). Highly reflective, sometimes moving Lambertian targets have been used successfully to measure flux incident on cavity receivers, but the geometry of the cylindrical receiver at Solar Two makes a system like this expensive, complex, and probably difficult to maintain (Pacheco, et. al., 1994). Receiver temperatures were also of interest to plant personnel and were used as inputs to some of the flux management systems. Temperatures were measured with numerous thermocouples located on the (non-illuminated) inside of the cylinder and at receiver panel header inlets and outlets. 
Table 2-4. Solar Two heliostat field flux management systems

\begin{tabular}{ll}
\hline \hline \multicolumn{1}{c}{ Name } & \multicolumn{1}{c}{ Function } \\
\hline SAPS & $\begin{array}{l}\text { Adjusts heliostat aimpoints every } \sim 10 \text { minutes during normal } \\
\text { operation to compensate for heliostat field performance } \\
\text { variations with changing sun position. }\end{array}$ \\
DAPS & $\begin{array}{l}\text { Protects the receiver from overflux conditions by comparing the } \\
\text { predicted receiver flux pattern against allowable flux limits } \\
\text { intended to ensure a long receiver life. It operates at } ~ \\
\text { intervals and removes heliostats from track to stay within limits. }\end{array}$ \\
Preheat Processor & $\begin{array}{l}\text { Heats the empty receiver prior to filling and again while } \\
\text { draining. }\end{array}$
\end{tabular}

\subsubsection{The Static Aim Processing System}

The Solar Two receiver had a flux limit of about $850 \mathrm{~kW} / \mathrm{m}^{2}$ while the field was capable of producing many times that flux density, so it was necessary to spread the heliostat aim points over the receiver surface. Heliostat aim points should change periodically because the size and intensity distribution of a heliostat beam can change substantially with sun position. The SAPS provided this type of "smart" aiming by computing heliostat aimpoints at approximately 10minute intervals during normal operating conditions. Aim points were changed to provide the approximate receiver flux distribution desired and to minimize spillage.

At high angles of incidence and reflection, optical aberrations enlarge a heliostat's beam. The focal length of mirror modules also typically varies with temperature, changing beam size, so this effect was modeled in SAPS. Heliostat structural deflections due to gravity can also make beam size a function of elevation angle, but this effect was minimal for MM heliostats and was not modeled at Solar Two.

Heliostat tracking errors change the location of the beam, not its size, and should also be considered when choosing aimpoints for the field. SAPS treated heliostat tracking errors as if they changed beam size. Because thousands of heliostats are aimed at the receiver, this assumption generally provides a reasonable approximation of the total incident flux distribution. Another approach could have been to guess the magnitude (typically following a normal distribution) and direction (roughly equal probability in all directions) of each heliostat tracking error and alter the aimpoint to compensate. This later approach was not used because mistaking the direction of tracking error could greatly increase spillage. The heliostat tracking errors at Solar Two were larger on average than the beam quality errors, so the assumption that they acted as a beam quality error and changed beam size was less appropriate than it would be for a new field. 


\subsubsection{The Preheat Processor}

The Solar Two receiver was drained each night to reduce thermal losses and refilled prior to startup with molten salt, which freezes at about $205^{\circ} \mathrm{C}$. Thus, the receiver must be preheated to prevent plugging during the fill process, but this must be done without overheating and damaging the receiver. The objective was to heat the receiver surface to a temperature between 260 and $380^{\circ} \mathrm{C}$ over the entire receiver area in a reasonable amount of time (15-30 minutes). The heliostat field was designated for this sensitive function, and provided a vertically uniform flux density that could vary azimuthally between 12 and $36 \mathrm{~kW} / \mathrm{m}^{2}$ (depending on local convective losses due to wind) without overheating the dry receiver tubes. Several algorithms, collectively called the Preheat Processor (Vant-Hull, et al., 1996b), were developed to carry out this important function. The process of preheating a cylindrical, molten-salt receiver with the heliostat field was proven and refined at Solar Two. Future plants will likely use a similar system.

The Preheat Processor software must update the aim points at least every 30 seconds to prevent damage to the receiver. Near sunrise, when the sun elevation angle is low, the flux from the field increases rapidly due to changes in insolation, shading, and cosine efficiency of the heliostats. In fact, the fractional change in available power to the receiver is approximately proportional to the fractional increase in elevation angle. So long as the sunward horizon is free of clouds or haze, preheat can be safely initiated. At 8 degrees solar elevation, the full heliostat field produces two to 12 times the allowed flux density on the receiver (on the sunward and anti-sunward sides, respectively.) Initially, $50 \%$ of the heliostats on the sunward (east) side are required for preheat, but in a short time, the number has to be reduced to $20 \%$ of the heliostats. The preheat program at Solar Two operated much faster than required, taking only a few seconds.

Depending on the sun position (summer, winter, morning, midday), a predetermined subset of the heliostats comprising about $15-30 \%$ of the field was made available to preheat the receiver. To assure a uniform vertical flux distribution, even at the ends of the receiver, a set of 11 aim points, uniformly distributed over 1.5 receiver heights, were assigned to those heliostats. A predicted flux density map (a $17 \times 24$ array) was generated for the current conditions of insolation, sun position, ambient temperature ${ }^{10}$, etc, on each heliostat. The total flux striking the receiver from all tracking heliostats was also computed and compared to the desired flux. When the predicted flux exceeded the desired flux, the node showing the largest excess was identified. The set of heliostat flux maps was scanned to find the heliostat producing the most flux at that node, and its flux contribution was subtracted from the total receiver flux map. These computations were repeated until no excess flux existed and then the responsible heliostats were directed to stop tracking the receiver.

\subsubsection{Preheat Under Windy Conditions}

Upon initiating receiver preheat, the desired flux level was set at $20 \mathrm{~kW} / \mathrm{m}^{2}$. The desired flux was then adjusted to achieve a reasonable rate of heating to the upper receiver temperature limit of $380^{\circ} \mathrm{C}$. Under ideal weather (midday and low wind conditions), preheat conditions were easy

10 The variation of mirror module focal length with ambient temperature was modeled. 
to achieve in under 15 minutes. However, during preheat operation with $9 \mathrm{~m} / \mathrm{s}$ winds, a wide range of flux densities was required due to the large azimuthal variation of convective losses from the receiver. The local Nussult number varies by a factor of about three around the receiver for the high Reynolds numbers encountered with the 5.1-m-diameter cylindrical receiver of Solar Two. The maximum Nussult number occurs at 90-110 degrees relative to the windward stagnation point (Giedt, 1949). To overcome this problem, significantly higher preheat flux density was assigned to panels that were heated slowly after 5 minutes. The flux density required on individual panels to match thermal losses varied from 12 to $36 \mathrm{~kW} / \mathrm{m}^{2}$, depending on wind speed and panel orientation relative to the wind direction. Operators carefully monitored the preheat process, and often manually aimed additional heliostats at the top and bottom of the receiver to meet the temperatures required for filling.

Once the receiver temperatures rose above the minimum required level of $232^{\circ} \mathrm{C}$, it was filled with molten salt. An infrared camera provided spatially-detailed, relative temperature maps of the receiver and was used to ensure the filling process was successful. The receiver fill and drain processes and infrared camera system are described further in Section 4 of this report. The combination of the preheat software, the infrared camera, and operator oversight worked very well and should be duplicated at future plants.

\subsubsection{Dynamic Aim Processing System}

The DAPS used the same methodology (and many of the same software subroutines) as the preheat system, but had the goal of protecting the receiver from overflux conditions during normal operation to help ensure the 30-year design life (Vant-Hull et al., 1996a). A protective system was desired because it was thought that off-design conditions could lead to excess flux. Examples of off-design conditions include: very sunny days, sun positions other than the several investigated, cloud transients, etc. Receiver strain and corrosion were quantified as functions of the allowable flux and temperature. The predicted incident flux was calculated using aim points from SAPS, ambient temperature, and estimated heliostat errors. The reflected flux and reradiated flux (a function of receiver temperature) were then subtracted to compute the receiver surface and film temperatures and to identify the locations of excess flux. The heliostat predicted to provide the greatest flux at an excess flux location was removed from the virtual flux map and the process iterated until no flux limits were exceeded. All heliostats removed from the virtual flux map were also removed from tracking the receiver. It was anticipated that a few heliostats would occasionally need to be removed from receiver tracking to meet the requirements, reducing annual energy absorbed by less than $0.25 \%$. However, the system also protected against the unlikely event of a catastrophic overflux situation due to substantial errors in selecting aim points, possibly by a failure of SAPS. In fact, DAPS helped identify the software bugs in SAPS, described previously.

While DAPS nominally appeared to function correctly, its behavior was mysterious and its benefits of questionable value to operators, so it was sometimes disabled by plant personnel. Although it may have been functioning correctly, an unstable situation that sometimes resulted from DAPS operation in particular was perceived as obstructing the efforts to maximize power collection and plant performance. The unstable situations occurred when DAPS removed some heliostats to meet allowable flux limits. The receiver control system responded by decreasing 
salt flow rate to the receiver to maintain the set point outlet temperature. This changed the receiver temperature profile from flow entrance to exit, the allowable flux limits, and the thermal losses, causing a new location on the receiver to suddenly suffer from an excess flux condition. In response, DAPS removed more and more heliostats as the unstable situation propagated. It is possible that the instability arose due to improper aimpoints selected by SAPS and/or issues with DAPS. In either case, the problem was not due to inherent instabilities in the plant design. The inability of DAPS to return to receiver tracking those heliostats that were removed contributed to the dissatisfaction of operating personnel because it meant that a slight overflux condition encountered in the morning reduced absorbed power for the remainder of the day. To overcome this, operators had to repeatedly return those heliostats to service manually until DAPS finally determined they were not causing an overflux condition. This tedious process was often neglected by more urgent or important tasks.

One problem with DAPS is related to a basic assumption used by the system. Like SAPS, DAPS assumes heliostat tracking errors act as beam quality errors and changes the size of the beam rather than its location. This assumption leads to acceptable errors in the total field flux predictions made by SAPS for many heliostats, but can have significant spatial errors in the flux predictions of a single heliostat. Since DAPS deals with individual heliostat flux patterns, this assumption causes errors-a trend intensified by the unexpectedly poor heliostat tracking accuracy at Solar Two. Heliostats removed from tracking at Solar Two may not have actually caused an overflux condition, while other heliostats that did cause an overflux condition were left tracking.

The qualification at Solar Two of a receiver alloy may make receiver lifetime less sensitive to fluxes levels, reducing the need for such protection. On the other hand, the development of a cost-effective system that directly measures incident receiver flux would make a receiver protection system more effective and desirable, but this is not an easy task. It appears at this time that the molten-salt power tower industry would not use a system like DAPS at future plants.

\subsubsection{Problems with the Heliostat Flux-Management System}

In general, SAPS worked well at Solar Two and a similar system would likely be used at future plants. However, there were two noteworthy software bugs discovered by observations of flux spillage and the burning of white, metal oven covers at the top and bottom of the receiver. First, from March, 1996 to December, 1997, the updated aim points calculated by SAPS were not normally sent to the heliostats in the field. Aim points were updated only when the plant operating state transitioned from standby to normal, full-power operation. Typically, this happened only once per day in the morning, but weather or plant outages sometimes caused this to happen in the afternoon or more than once per day. From December 21, 1997 to March 18, 1998, a similar problem existed. The overflow of a software version counter led to the aimpoints calculated at about 8 am on December $21^{\text {st }}$ to be fixed from that time forward. Both problems were fixed in March, 1998.

The impact of the aforementioned problems was typically the same in both cases, since aim points were stuck at their winter morning settings. In the morning, the beam size of east field 
heliostats is larger than west field heliostats because their greater angles of incidence and reflection lead to larger aberrations. Consequently, the aim points for east field heliostats are set closer to the midpoint of the receiver centerline, whereas aim points for the west field are shifted further from the midpoint. The reverse situation should be implemented in the afternoon, but was not due to the software problems. The expected impact of this problem would be excessive oven cover burning on the west side of the receiver, and overflux conditions on the east side of the receiver. There was slight qualitative evidence of greater overflux and oven cover burning on the east side of the receiver. The oven cover burning on the west side of the receiver was likely due to the large heliostat tracking errors whose effect, unlike the SAPS aim point errors, were evenly distributed between east and west field. The problem with the east BCS camera alignment discussed previously probably contributed to worse oven cover burning on that side of the receiver.

\subsubsection{Heliostat Field Maintenance}

The heliostat field was the most equipment-intensive system in the power plant and required significant maintenance to achieve the availabilities described previously. Common problems were associated with failures of the encoder, motors, and heliostat control boxes. These components were either replaced or repaired in the shop, but required a significant amount of time to diagnose. There were also problems with communications between the heliostat field controllers and the heliostat controllers. Some of these problems were traced to the field wiring (improper grounding and terminations) and others were due to noise in the line caused the heliostat motors. Lightning also caused a number of problems with communications and electronics in the field, which sometimes brought down entire strings (groups of 32 heliostats).

Different systems were used to track heliostat field maintenance over the life of the project. Initially, paper-based work requests were used. Later in the project, the O\&M contractor supplemented the previous system with a commercially-available software maintenance tracking system. At the end of the project, staff tried to extract relevant statistics on field maintenance, such as mean time between failures, and mean time to repair. Unfortunately, the software repeatedly crashed after many hours of processing and no results were obtained. Apparently, it was not designed for the large number of repetitive entries of the same type (heliostats). This was not viewed as a terrible loss for two reasons: 1) the quality of the Solar Two heliostat maintenance records was inconsistent (this was not a major goal of the project), and 2) the Solar Two heliostat maintenance experiences are not representative of future plants, because the field was a conglomeration of used parts that went years without use or maintenance. Similar field maintenance experiences at Solar One (Radosevich, 1988; Kolb and Lopez, 1988) or the SEGS trough plants (Cohen et al., 1999) should be representative of what is expected at future power tower plants.

\subsubsection{Heliostat Field Washing and Cleanliness}

The effective heliostat field mirror reflectivity is reduced when the mirrors are soiled from environmental exposure. This reduces plant output, so it is economically advantageous to wash 
heliostat mirrors to restore lost reflectivity. The optimal frequency and timing of heliostat field washing varies with local weather and plant economics.

Mirror cleanliness, the current reflectivity divided by the clean reflectivity, was used as a metric at Solar Two so results could easily be compared for mirrors with different clean reflectivities. While some reflectors degrade with time, the glass mirrors at Solar Two could be restored to their original reflectivity (100\% cleanliness) with contact cleaning.

The experiences at Solar One (Radosevich, 1988) and the Kramer Junction SEGS trough plants (Cohen et al., 1999) helped set the cleanliness goal of 95\% adopted at Solar Two. It was expected that the full field would have to be washed about every two weeks to achieve this goal, with some heliostats being washed every day weather permitted and during times the plant was not operating (e.g. nighttime). The O\&M contractor adapted a large truck, shown in Figure 2-6, for heliostat washing. Normally, this truck was used, but experiments were also performed with other approaches, including the Kramer Junction "Mr. Twister" device (Cohen et al., 1999). The truck sprayed deionized water (to prevent spotting) upwards at about 65 bars pressure while driving under the face-down, stowed MM heliostats.

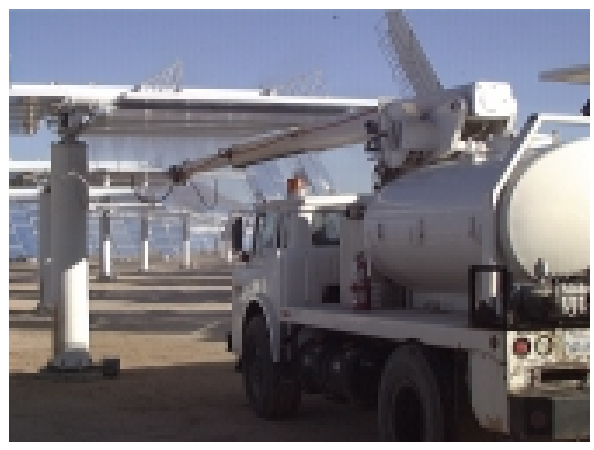

(a)

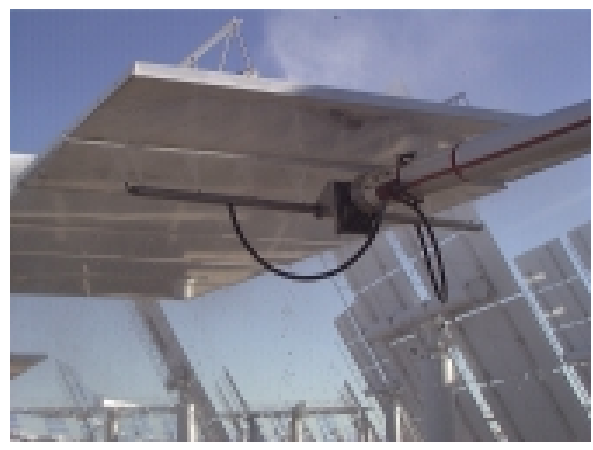

(b)

Figure 2-6. The Solar Two wash truck (a) and close-up of spray bar (b).

Heliostat field cleanliness was typically measured every two weeks from February 1998 to the end of the project using the same handheld device proven at Kramer Junction ${ }^{11}$ combined with correlations developed by Sandia for the heliostats at Solar Two. The field cleanliness measurement procedure required 752 measurements on heliostats distributed throughout the field. The MM mirror modules soil more near the edges, so the procedures called for the proper number of measurements in this region to provide the appropriate area weighting. The cleanliness of MM field quadrants, plus two Lugo regions, were calculated followed by a weighted average field cleanliness. Figure 2-7 shows the field cleanliness results with an average of $93 \%$, slightly below the goal of $95 \%$. Environmental soiling and rain washing can quickly change the field cleanliness between measurements, an effect that adds uncertainty to the 93\% average. Additionally, a review of the heliostat washing and cleanliness measurements completed in December, 1998 found the cleanliness readings could have been biased high due to human errors. At future plants, it would be beneficial to have a computer model of field

11 SMS Micro-Scan made by Schmitt Industries (http://www.schmitt-ind.com/products/micro.htm). 
cleanliness that includes data regarding the area and timing of heliostat washing and the ability to account for variable soiling and cleaning due to weather. More frequent cleanliness measurements would also improve accuracy, but this approach would require additional operations staff time. These types of refinements are more important for a commercial power plant.

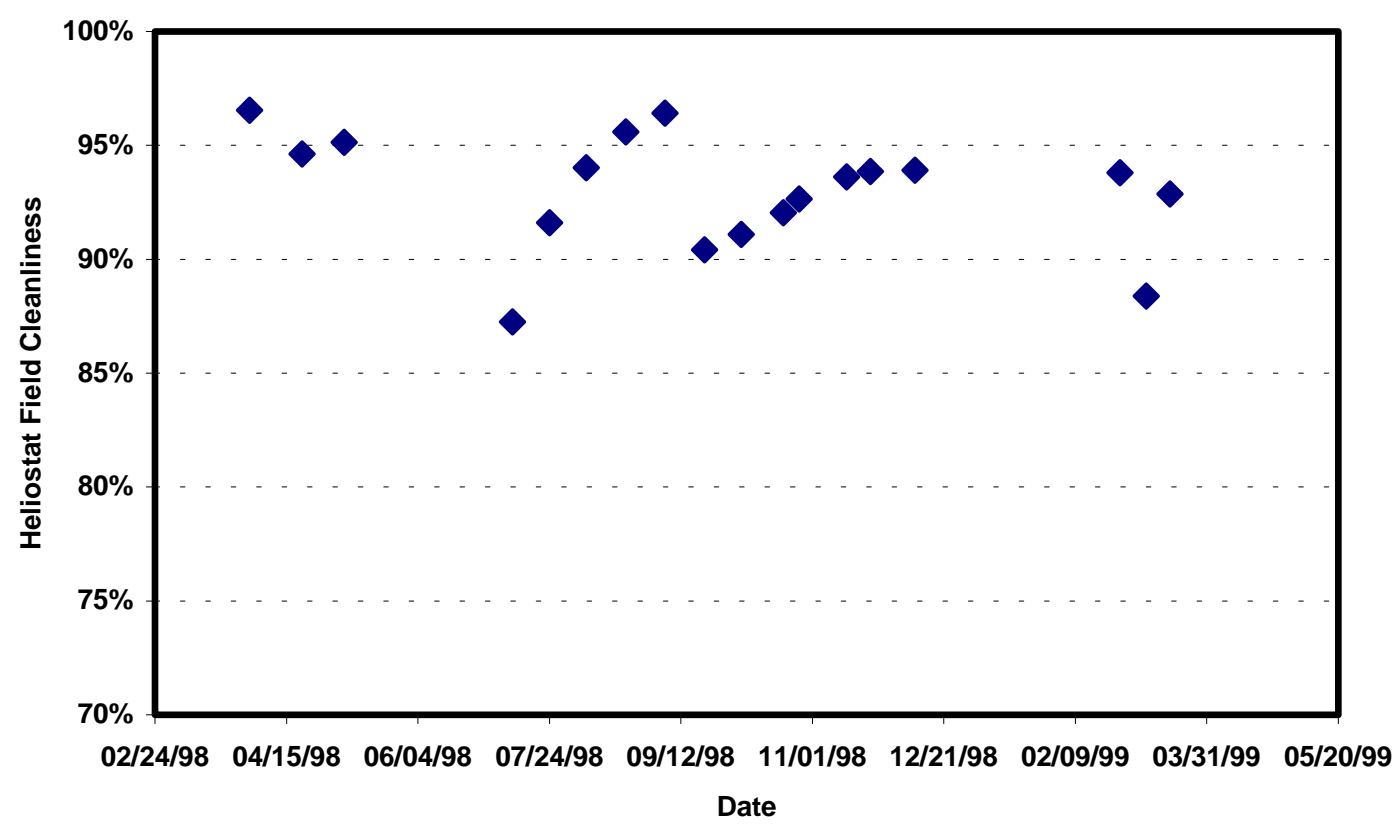

Figure 2-7. Average heliostat field cleanliness measurements.

There were also problems identified with the heliostat washing effectiveness, including insufficient water pressure and agitation to return the mirrors to new reflectivity, and spotting of the MM mirrors because the water droplets did not flow off the face-down mirrors. Instead, the water droplets collected dust from the air while they evaporated. The Lugo heliostat washing was also less effective because the equipment was ill-adapted to their size and lack of inverted stow capability. The Lugo heliostats were normally stowed face-up, rather than pointing at the horizon in low wind conditions, as is expected at commercial plants with noninverting heliostats. This led to noticeably higher soiling rates for the Lugo heliostats than for the MM heliostats. Higher pressure, rotating-water spray has proven effective at the SEGS trough plants and would be easy to implement at the next power tower plant. Contact cleaning, for example, with a rotating brush used like those used at automated car wash facilities, could be even more effective than spray washing and is certainly feasible to implement on the nominally flat surface of heliostats.

The minor problems with heliostat field washing and cleanliness measurements had little impact on achieving the goals of the Solar Two project. These problems could also be easily resolved at future commercial plants, as proven by the experiences at similar SEGS trough plants. 


\subsubsection{Measurements of Mirror Corrosion}

During the summer of 1996, a corrosion survey was conducted by students from the University of Riverside under the supervision of the Solar Two T\&E group. The students were asked to quantify the amount of mirror area that was lost due to corrosion and to identify mirrors that had lost their focus by becoming detached from their backing support (i.e., delaminated). Delamination is caused by degredation at the surface between the mirror and the support backing. Corrosion of the reflective silver layer is caused by moisture intrusion into the facet pan, as described below.

Corrosion of many of the MM heliostat facets was a problem since shortly after their installation in 1982 for the Solar One project. Corrosion is attributed to moisture intrusion into the metal pan on the back of a mirror facet. Facets that were manufactured before the problem was identified are subject to the worst corrosion. These are located predominantly in the south heliostat field. In the mid 1980s, the facet pans on one side of the heliostats in the south field were vented, as well as some in the NE, to see if venting would dry out the moisture trapped in the pan and slow the rate of corrosion. This strategy was found to be effective. Solar One shut down in September 1988 and the field corrosion continued to accelerate in the unvented facets. In 1990, funds from the Department of Energy (DOE) program were used to vent the remaining facets, but significant damage had already occurred. This is why most corrosion is in the south heliostat field and why it is mostly on one side of the heliostat (the side that was not vented until 1990).

The results of the corrosion survey for the MM heliostats are summarized in Figure 2-8. As discussed above, most of the degraded facets were found in the south field. The corrosion problem was specific to the MM mirror module design, which should not be replicated at future plants. The Carrissa Plains mirror modules used on Lugo heliostats and as replacements on MM heliostats showed no signs of mirror corrosion at the end of Solar Two after about 16 years of outdoor exposure $^{12}$. Greater than 1 million square meters of mirrors at the SEGS plants also show no significant corrosion after a similar outdoor exposure period.

12 Similar mirror modules located at Sandia showed no signs of corrosion at the time of this report after 18 years of outdoor exposure. 


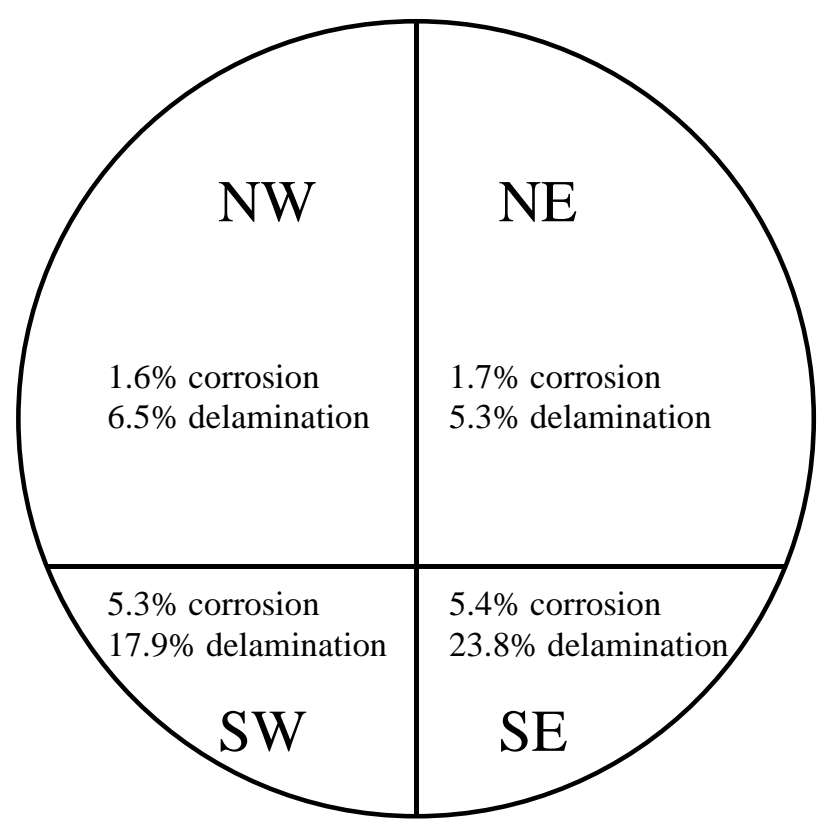

Figure 2-8. By the summer of 1996, 2.8\% of the MM Field had been lost due to corrosion and $11 \%$ of the facets had lost their curvature (delaminated). 
Final Test and Evaluation Results from the Solar Two Project 


\section{Receiver System}

\subsection{Description}

The Solar Two receiver was arranged in an external cylinder. It was rated for $42.2 \mathrm{MWt}$ absorbed power with a design average flux capability of $430 \mathrm{~kW} / \mathrm{m}^{2}$. The flux distribution was designed to heat salt from $290^{\circ} \mathrm{C}$ to $565^{\circ} \mathrm{C}$ while keeping the strain and corrosion in the receiver tubes within allowable limits (Vant-Hull, 1993). The receiver was designed, fabricated, and erected by the Rockwell Division of The Boeing Company. It consisted of 24 panels arranged in a cylinder. Each panel incorporated 32 thin-walled tubes with end-bends connected to manifolds on each end of the panel. Each tube was $2.1 \mathrm{~cm}$ in diameter, with a $1.2-\mathrm{mm}$ wall thickness constructed of 316 stainless steel. The external surfaces of the tubes were coated with a black Pyromark $^{\circledR}$ paint that was robust, resistant to high temperatures and thermal cycling, and absorbed $95 \%$ of the incident sunlight. The manifolds and end-bends were enclosed in insulated, electrically-heated oven covers. Figure 3-1 shows the receiver. The technical characteristics of the receiver system are listed in Table 3-1.

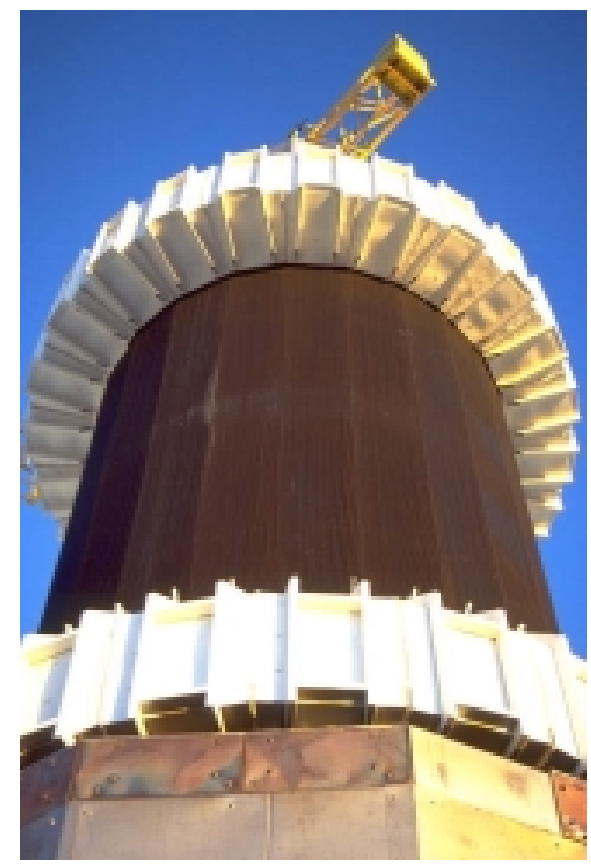

Figure 3-1. Close-up of Solar Two receiver. 
Table 3-1. Technical characteristics of the Solar Two receiver

\begin{tabular}{ll}
\hline \hline Configuration & External Cylindrical Receiver \\
Receiver Thermal Rating & $42.2 \mathrm{MW}$ \\
Heat Transfer Fluid & Molten Nitrate Salt $\left(60 \% \mathrm{NaNO}_{3}\right.$ and $\left.40 \% \mathrm{KNO}_{3}\right)$ \\
Inlet Temperatures & $290^{\circ} \mathrm{C}$ \\
Outlet Temperature & $565^{\circ} \mathrm{C}$ \\
Peak Flux & $800 \mathrm{~kW} / \mathrm{m}^{2}$ \\
Average Flux & $430 \mathrm{~kW} / \mathrm{m}^{2}$ \\
Material & $316 \mathrm{H}$ Stainless Steel \\
Panels & 24 \\
Flow Circuits & $2(12$ panels each) \\
Tubes/panel & 32 \\
Tube OD & $2.1 \mathrm{~cm}$ \\
Wall Thickness & $1.2 \mathrm{~mm}$ \\
Absorber Height & $6.2 \mathrm{~m}$ \\
Absorber Diameter & $5.1 \mathrm{~m}$ \\
Absorber Area & $99.3 \mathrm{~m}$ \\
Absorber Material & Black Pyromark® Paint \\
Elevation Above Ground & $76.2 \mathrm{~m}$ to receiver centerline \\
Manufacturer & Boeing North American \\
Dates Operated & Feb 28,1996 to April 8,1999 \\
Hours of Operation (approximate) & 1800 hours \\
Receiver Pump Type & Two $50 \%$ capacity, six-stage, vertical turbines \\
Receiver Pump Head & $244 \mathrm{~m}$ at 1.64 mmin \\
Receiver Pump Manufacturer & BW/ (IP) International, Inc. \\
\hline \hline
\end{tabular}

The receiver was designed to rapidly change temperature without being damaged. For example, during a cloud passage, the receiver could safely change from $565^{\circ} \mathrm{C}$ to $290^{\circ} \mathrm{C}$ in less than one minute (Kolb, 1992). A schematic of one side of the receiver flow path is shown in Figure 3-2. The salt fed to the receiver was split into two flow paths. One circuit entered the northern-most panel on the west side and flowed west in a serpentine fashion from panel to panel. The other stream entered the northern-most panel on the east side and flowed east. After flowing through six panels, both streams crossed over to balance energy collection variations that occurred from east to west as a function of the time of day, as shown by the crossover line in Figure 3-2.

\subsection{Typical Receiver Operation}

During typical operation, the electric heat trace (electrically-resistive, mineral-insulated heaters) on the piping, valves, inlet vessel, and outlet vessel of the receiver system were energized to prevent salt from freezing in these areas and reduce thermal shock. A few hours prior to daily startup, the receiver oven heaters were energized. After sunrise, the heliostat field was commanded to the standby aim points in preparation of preheat. After the sun was approximately 10 degrees above the horizon, if there wasn't significant cloud cover, a select group of up to 400 "preheat" heliostats were directed to the receiver to distribute a uniform heat flux on the surface of the receiver (partially spilling onto the oven covers). The receiver surface had to be preheated above $230^{\circ} \mathrm{C}$ to prevent salt from freezing in the receiver tubes during receiver fill. The initial preheat pattern established a uniform flux density of approximately 20 
$\mathrm{kW} / \mathrm{m}^{2}$. Back-wall thermocouples provided feedback control to the DAPS, which controlled the number and aiming of heliostats focused on the receiver. If winds were high enough that the initial pattern of heliostat beams were ineffective in bringing some of the receiver panel surfaces up to $300^{\circ} \mathrm{C}$, DAPS would sequentially add more heliostats, exposing cool panels to flux densities up to about $36 \mathrm{~kW} / \mathrm{m}^{2}$. Likewise, if the receiver panels became too hot, heliostats were pulled off, reducing the flux density to about $12 \mathrm{~kW} / \mathrm{m}^{2}$. Prior to filling the receiver, cold salt flow was established from the receiver sump, through the riser, into the receiver inlet vessel, through a bypass valve, down the downcomer, and back into the cold tank. Once the receiver surface was at an acceptable temperature (above $230^{\circ} \mathrm{C}$ to prevent salt from freezing in the receive tubes), all the drain and vent valves were opened to flood-fill the receiver panels. The receiver used six drain valves, but only one vent valve per flow circuit. Vent orifices allowed air to escape the receiver panel during filling, but limited the amount of salt to a few percent, which bypassed panels during operation. When salt level was detected in the outlet vessel (located higher in elevation than the receiver panels), the bypass valve, drain, and vent valves were shut to force the flow through the receiver in a serpentine flow pattern. As a safety feature, the inlet vessel was pressurized to force salt through the receiver for 60 seconds in case the pump tripped. The 60-second flow margin was enough time to defocus the heliostat field or, in the case of power loss, to start the diesel generator. Analyses were done to evaluate the paths the heliostat beam would take in the event of a power failure. These are described in Appendix A.

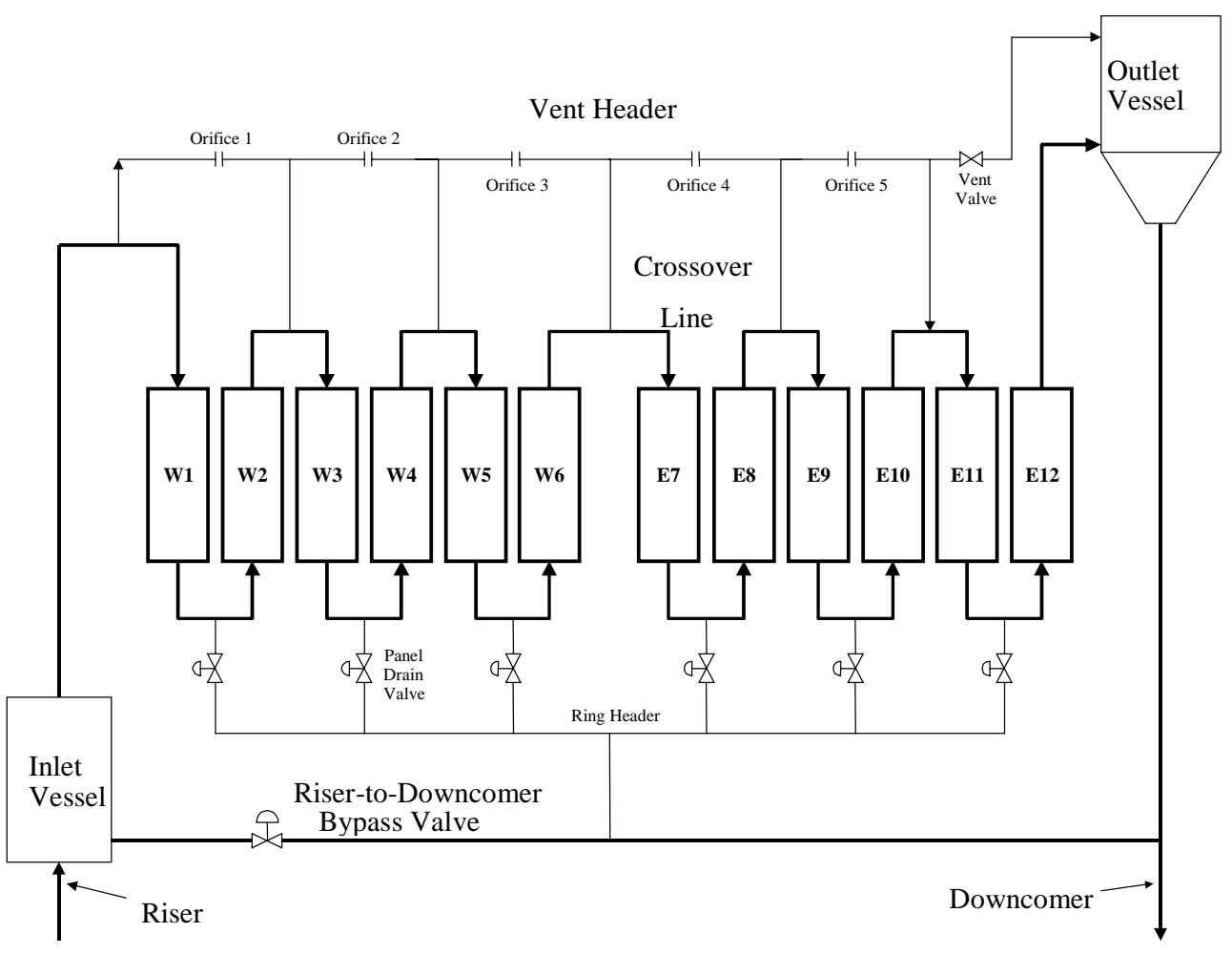

Figure 3-2. Schematic of one flow circuit of the receiver flow circuit.

If the flow was not restricted in any tubes due to frozen salt plugs (as detected by an infrared camera on the upwind side of the receiver), more heliostats were added to ramp up the incident 
power on the receiver. After all the available heliostats were focused on the receiver, the outlet temperature was set to the desired receiver outlet temperature, typically $565^{\circ} \mathrm{C}$. Flow control valves automatically modulated the flow rate to maintain the desired outlet temperature. Eight photometers, mounted around the periphery of the receiver, detected changes in the incident power due to cloud passages; those signals were input to the receiver control algorithm, which modulated the control valves. If heavy clouds passed over the field of heliostats, the control algorithm opened the flow control valves to match the clear-sky flow for protection against overflux when the clouds departed.

During receiver shutdown, either at the end of the day or after heavy cloud cover, the heliostats were defocused from the receiver and directed to the standby aim points. The receiver outlet temperature rapidly dropped to the inlet temperature. A fraction of the heliostats selected by DAPS were aimed at the receiver to maintain the panel-surface temperatures above $260^{\circ} \mathrm{C}$ while they drained. The inlet vessel was depressurized, drain and vent valves were opened, and the receiver pumps were shut off, allowing the receiver to drain. After a few minutes, the remaining heliostats were defocused from the receiver and the field was stowed.

During operation, the peak power absorbed by the receiver was less than the design level of $42 \mathrm{MWt}$, primarily due to lower heliostat availability than the design value of $98 \%$ and under performance of the heliostat field, as discussed previously. Measured peak absorbed power was typically between 35 and $38 \mathrm{MWt}$ when the heliostat availability was between 91 and $95 \%$.

\subsection{Major Results of Receiver Testing}

The major objectives of tests associated with the receiver were to evaluate the efficiency of the receiver as a function wind speed and incident power and to evaluate the receiver control algorithm under transient conditions, including cloud-induced turndown of the receiver flow.

\subsubsection{Receiver Efficiency}

The receiver thermal efficiency is defined as the ratio of the rate of energy absorbed by the working fluid (molten salt) to the rate of energy incident on the receiver surface. The receiver efficiency was measured as a function of wind speed using the power-on method, where the heliostat field was divided into two groups. The first group contained half the heliostats by selecting every other heliostat. The second group contained the other half. Random and systematic uncertainties, such as mirror cleanliness, heliostat availability, and cosine effects, were minimized from the energy balance equation because the incident power on the receiver could be cut precisely in half, since every other heliostat was selected for each group and the tests were conducted symmetrically at solar noon. This method contains an important assumption: under steady-state conditions with constant inlet and outlet salt temperatures and wind velocities, the temperature distributions on the receiver surface and throughout the receiver are independent of incident power level. Therefore, the thermal losses are also independent of the incident power. The assumption is reasonable, because both the radiative and convective thermal losses are functions on the surface temperatures on the receiver. The receiver surface temperatures do not vary significantly with incident power, as long as the inlet and outlet 
temperatures and wind velocities are constant. As a result, the thermal loss could be calculated accurately from measured data. Several receiver efficiency tests conducted over a range of wind speeds and at full power are summarized in Table 3-2. Combined radiative, convective, and conductive thermal losses were measured between 2.7 and 3.0 MWt.

Table 3-2. Summary of receiver efficiency measurements

\begin{tabular}{cccc}
\hline \hline $\begin{array}{c}\text { Average Wind } \\
\text { Speed at 10 } \mathbf{~ m ,} \\
\mathbf{m} / \mathbf{s}\end{array}$ & $\begin{array}{c}\text { Thermal Efficiency } \\
\text { at Full Power }\end{array}$ & $\begin{array}{c}\text { Power } \\
\text { Level, } \\
\mathbf{M W t}\end{array}$ & Notes \\
\hline $0.5 \pm 10 \%$ & $0.888+0.012 /-0.022$ & $32.4 \pm 1.4$ & No large-area (Lugo) heliostats were tracking \\
0.5 & 0.880 & 34.3 & No large-area (Lugo) heliostats were tracking \\
0.8 & 0.884 & 34.6 & No large-area (Lugo) heliostats were tracking \\
0.8 & 0.870 & 27.7 & \\
1.1 & 0.871 & 28.9 & \\
1.2 & 0.874 & 31.5 & \\
1.5 & 0.881 & 27.7 & \\
2.5 & 0.866 & 31.5 & No large-area (Lugo) heliostats were tracking \\
6.4 & 0.856 & 25.0 &
\end{tabular}

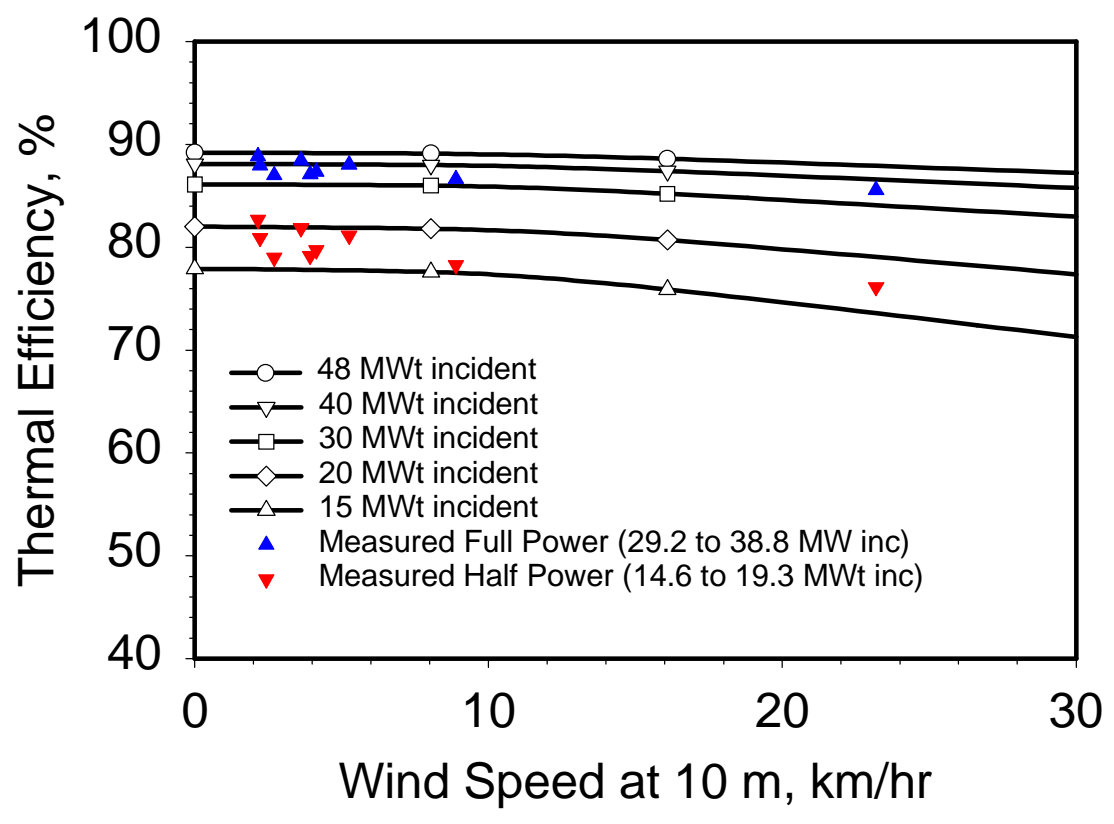

Figure 3-3. Modeled and measured receiver efficiency as a function of wind speed.

The receiver thermal performance was compared to the measured results. Figure 3-3 is a comparison of measured data to the model as a function of wind speed. In general, the model predicts the thermal efficiency of the receiver within $2 \%$-which is within the experimental errors. Details on the receiver efficiency test are described in Appendix B. Details on the quality assurance of the direct insolation measurements are in Appendix C. 


\subsubsection{Testing of Receiver Control Algorithm}

The receiver control algorithm allowed automatic operation of the receiver. With variations in the incident power on the receiver, primarily due to cloud passages, the algorithm was designed to 1) maintain salt temperature at $565^{\circ} \mathrm{C}$ at the exit of the receiver and 2) limit the thermal fatigue damage to the receiver tubes, ensuring a 20- to 30-year life. The algorithm accomplished this by regulating the salt flow to match the solar heat input to the receiver. The initial Solar Two control algorithm used three independent control signals to regulate the salt flow (in order of their authority):

1) a feed-forward signal from eight photometers (four for each circuit) that sensed incident power,

2) a feedback signal from the average-back-tube temperature thermocouples, and

3) a feedback signal from salt-outlet temperature thermocouples.

The three signals were summed to provide a total flow setpoint on a proportional-plus-integral (PI) controller that regulates the flow control valve to achieve the flow setpoint.

After implementation of the cloud standby feature, which ramped the flow up to maintain the desired outlet-salt temperature setpoint under clear-sky conditions, the design team decided that the control algorithm could be simplified. The Cloud Standby setting reduced the risk to the receiver in the event the cloud cleared and full power was returned to the receiver. Because of this feature, the control algorithm could be simplified by eliminating the feedback signal from the tube back-wall temperatures. The final receiver control algorithm used only the feedforward signal from the photometers and feedback from the outlet salt temperature.

The control algorithm successfully controlled the receiver outlet temperature throughout the project. An example of its performance is shown in Figure 3-4. As shown, the salt-outlet temperature is nearly constant between about 11:50 and 13:25. Between 13:25 and 13:40, the receiver went into cloud standby - ramping up the flow and decreasing the receiver outlet temperature, then returning to automatic control at about 13:40, maintaining the receiver outlet temperature at $565^{\circ} \mathrm{C}$. During this time, the direct normal insolation, measured on the roof of the control room, varied between about 550 and $900 \mathrm{~W} / \mathrm{m}^{2}$, as clouds obscured portions of the field. Details on the testing of the receiver control algorithm are found in Appendix D.

\subsection{Receiver Operating Experience}

The Solar Two receiver operated for over 1800 hours. Through the course of the project there were several issues with the receiver, most of which were addressed through changes to the operating procedures or modifications to the hardware. The major issues encountered were: 1) salt freezing in receiver tubes during startup, particularly in windy conditions, 2) measurement of salt level in the receiver inlet vessel, and 3) receiver tube and panel thawing after freezing. These issues are described in more detail below. 


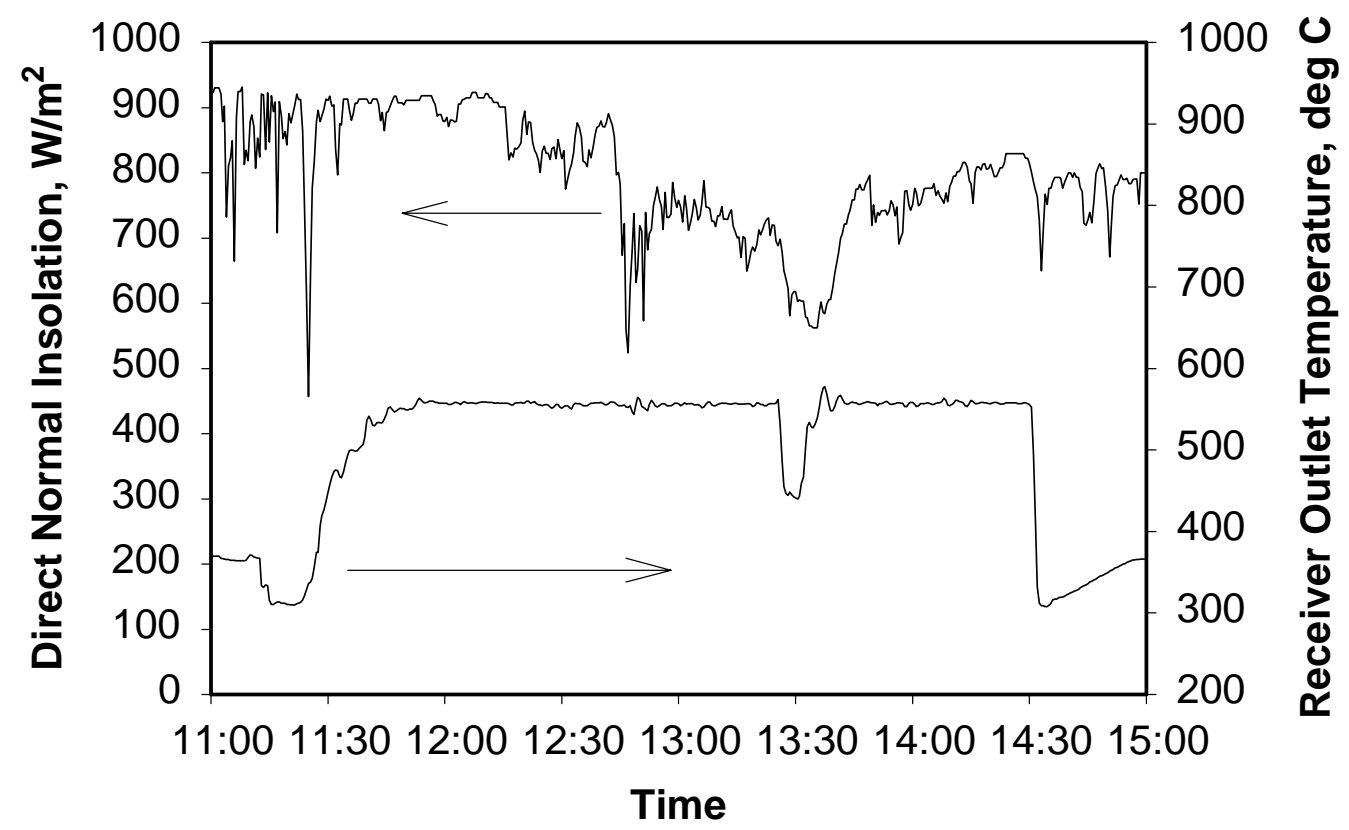

Figure 3-4. Direct normal insolation and receiver outlet temperature during a partly-cloudy day. At approximately 13:25, the receiver went briefly into cloud standby.

\subsubsection{Salt Freezing in Receiver Tubes on Startup}

The nitrate salt has a freezing point above $200^{\circ} \mathrm{C}$ and if any portion of the receiver was not above that temperature, the risk is significant that salt would freeze. On windy days, receiver tubes on the windward side of the receiver were susceptible to freezing. Typically, only one or two tubes in the receiver developed a frozen plug of salt. The plugged tubes were usually located on the west side of the receiver (at the location of the predominant wind direction), as illustrated in Figure 3-5 during the period of July to November 1998. In most cases, carefully heating the affected area and allowing the heat to penetrate caused the plug to melt without damaging the receiver tube. A particular problem area was the interface between the oven cover and the receiver absorber surface. This area did not receive adequate heat from sunlight or from the oven heaters, and was a primary path for cold ambient air entering the ovens. Furthermore, tube clips, which guided the tubes as they expanded or contracted, were located at this interface and acted as heat sinks, further cooling the tubes. When a panel that contained a frozen plug was replaced, it was verified that salt plugs had originated at these locations. Several theories were offered as the reason for freezing salt at the interface: 1) during receiver filling, the salt velocity was slow enough that when the salt came in contact with a cold spot, a frozen plug formed; 2) during preheat, residual salt on the surface of the tubes melted, ran down the tube wall, and froze when it contacted a cold spot forming a plug; and 3) when draining the receiver the previous night, a plug formed. Although the mechanism responsible for the freezing phenomenon was not identified, the freezing issue could be resolved with a new receiver by 1) modifying the design of the oven cover to prevent air infiltration, 2) relocating the tube clips to remove this heat sink, and 3) providing adequate heat trace at the interface. 
Late in the project, the oven covers were modified to address the freezing issue. Baffles were installed between oven covers W4 and W5 and between W6 and W7 to break up airflow between adjacent oven covers. The insulating oven seals on the covers, called bumpers, were relocated to the inner lip of the cover to reduce the size of the interface area and reduce direct exposure to concentrated sunlight, as shown in Figure 3-6. These modifications significantly improved the startup capability of the receiver, but did not fully resolve the freeze issue.

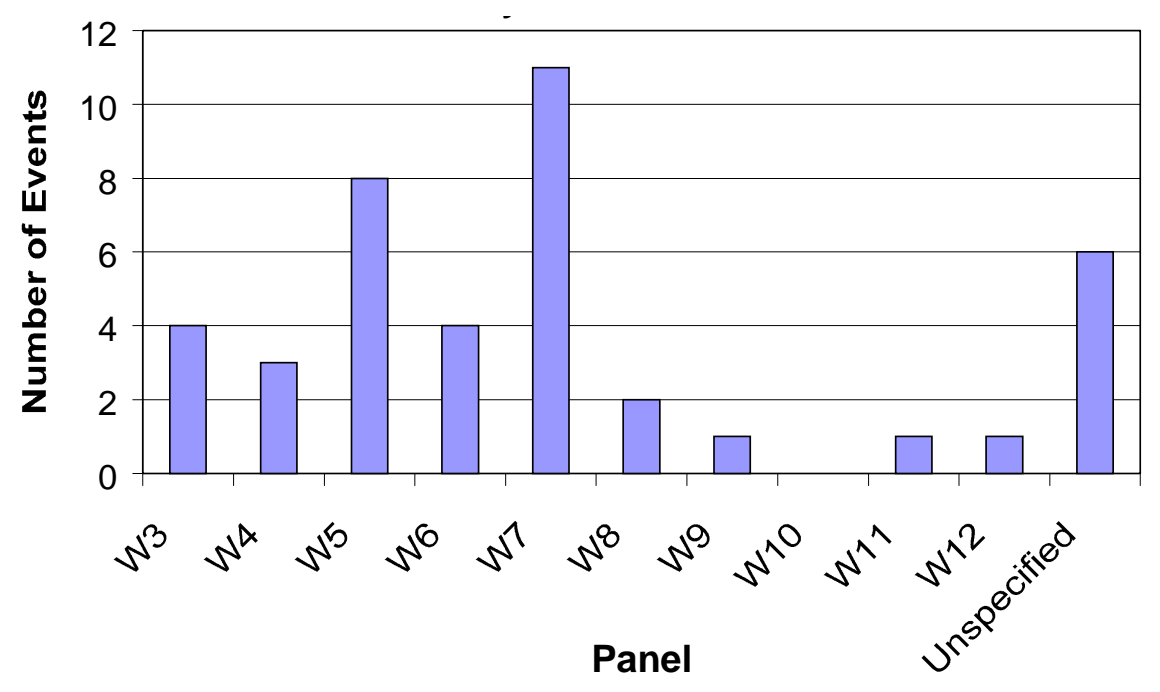

Figure 3-5. Frequency and location of tube freeze-ups in receiver during the period from July to November 1998, as observed by the operators. The panels were on the west side of the receiver. W1 was the northern-most panel; W12 the southern-most panel.

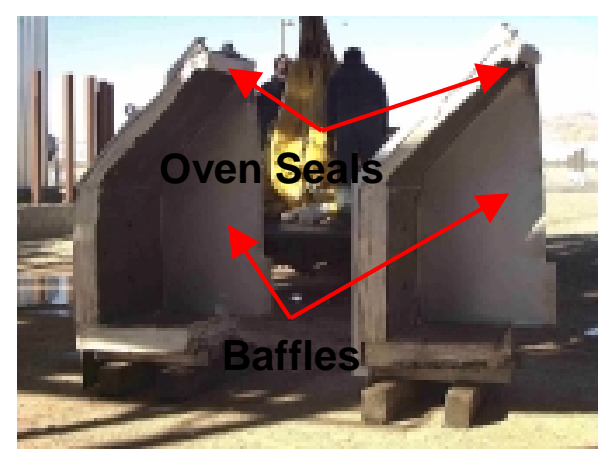

Figure 3-6. Modified oven covers with baffles and new oven seals. 


\subsubsection{Measuring Level in the Receiver Inlet Vessel}

The design of the Solar Two receiver required that the receiver inlet vessel provide 60 seconds of salt flow to the receiver following a failure of the cold salt pump; a free surface for establishing a level during normal operation; and an ullage volume above the salt inventory for compressed air. The speed of the cold salt pumps was adjusted to maintain a set point for the salt level in the receiver inlet vessel. Two independent air bubblers were used to monitor the level and provided feedback to the salt pumps. The ullage pressure was adjusted throughout the day to provide the energy required to drive the salt through the receiver for 60 seconds following a cold pump trip that resulted from a loss of power.

The bubblers worked adequately under steady-state conditions. However, during transients, such as receiver startup or transition to cloud standby mode when the inlet vessel pressure changed significantly, the bubblers gave erroneous level readings, causing the receiver pumps to change speed or the inlet vessel air supply to compensate for the erroneous readings. To overcome these problems, two solutions were tested: 1) fixing the cold salt pump speed during receiver startup, essentially removing the pump speed from the control loop, and 2) installing a nonintrusive nuclear level sensor that measured level with two cesium-137 gamma radiation sources and a detector. The first solution worked well and enabled the receiver control to operate stably with the bubblers.

The first nuclear level sensor tested did not respond quickly enough to provide the required accuracy and control because the two 50-millicurie $(\mathrm{mCi})$ radiation sources were too weak. In addition, the detector was susceptible to drift with ambient temperature due to an internal heater intended to maintain the detector at approximately $60^{\circ} \mathrm{C}$, which failed. Late in the project, the two $50 \mathrm{mCi}$ sources were changed out with two $100-\mathrm{mCi}$ sources and the detector was replaced with one containing a working internal heater. After the sensor was calibrated, its output correlated well with the two bubblers and did not drift with ambient temperature. Details on the testing of the nuclear level sensor can be found in Appendix E.

It should be noted that in atmospheric tanks, such as the receiver outlet vessel and the hot and cold salt storage tanks, the bubblers worked exceedingly well without incident.

\subsubsection{Receiver Tube and Panel Thawing}

At startup under windy conditions, one or two receiver tubes would sometimes fail to fill because a frozen plug of salt had formed in the unheated, unilluminated section of the receiver, i.e., at the oven cover interface. These tubes were starved of flow and appeared hotter than adjacent tubes in the illuminated area of the receiver, as shown in Figure 3-7. If too much heat was applied, the tube would plastically yield beyond its rupture strength and fail. However, the operators were trained to check the image from an infrared camera-usually set up to view the upwind side of the receiver-during the receiver startup, and if a blocked tube was detected, they would hold the receiver in the preheat mode until the blocked tube cleared.

Several techniques were used to enhance the thawing of tube plugs after the receiver was filled (see Appendix F). First, the oven temperature set point was increased well above the 
temperature of the salt flowing through the receiver, e.g., set to $400^{\circ} \mathrm{C}$. Next, additional heliostats were aimed at the interface between the lower oven cover and the absorber surface where the plug was located. Finally, heliostats were applied to upstream receiver panels and the salt flow rate was decreased so hotter salt flowed through the panel containing the frozen plug. The combination of these techniques improved the rate at which the receiver could recover from a tube plug.

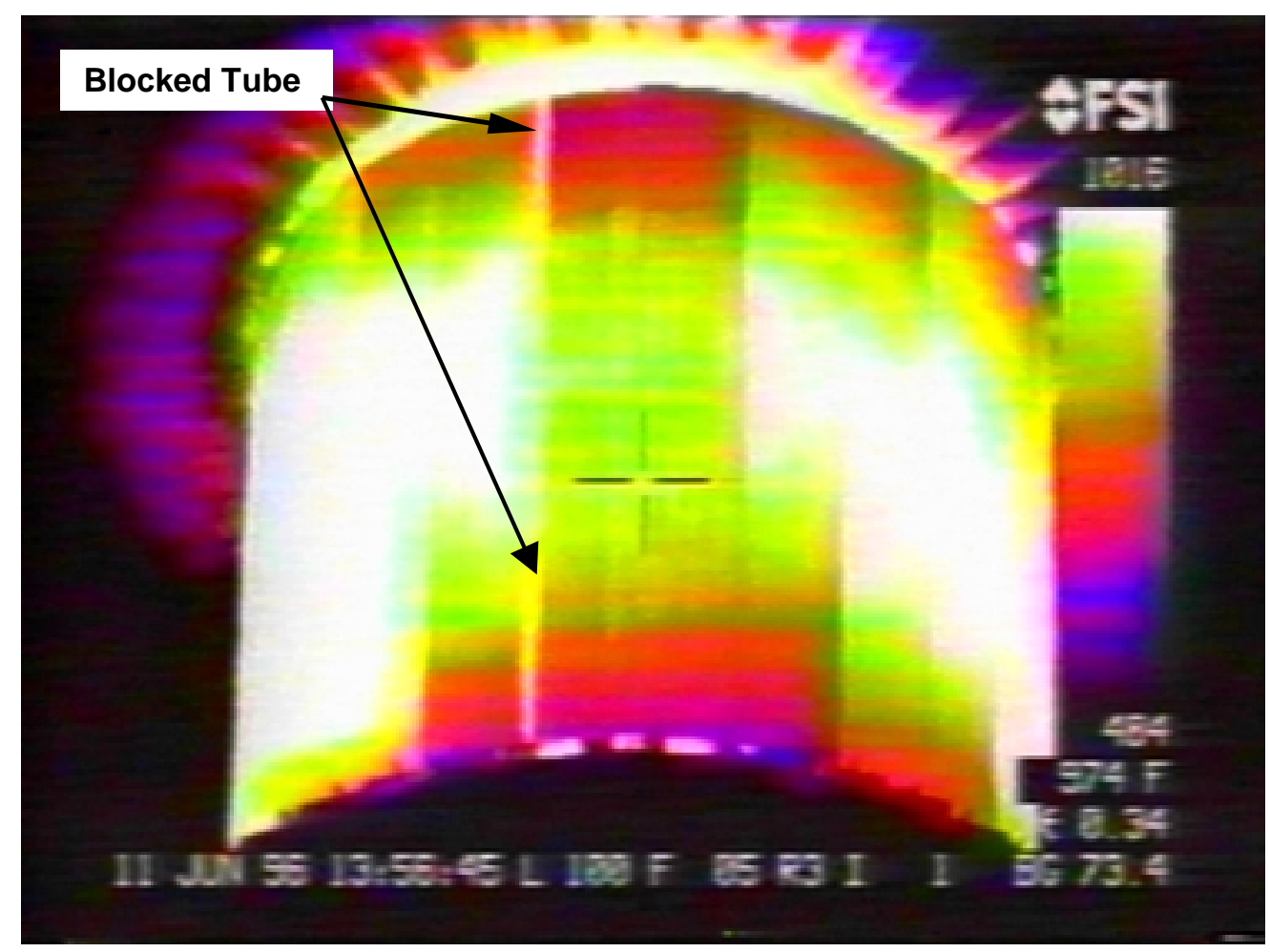

Figure 3-7. Infrared image of the receiver containing a blocked tube on the edge of a panel. The blocked tube appears as a bright vertical line.

Rarely, during nightly shutdown and drain of the receiver, a drain line plugged due to poor heat trace control (improper placement of the controlling thermocouple) or a frozen drain valve. In this situation, the two adjoining panels could not drain and would freeze full of salt. The frozen line or valve was generally fixed the next day or two, sometimes only requiring an increase in the heat-trace set point. Thawing the panels required careful heating to ensure the tubes did not experience excessive freezing and thawing cycles, which has been shown to rupture tubes (Pacheco and Dunkin, 1996).

The procedure to melt the salt from frozen receiver panels was developed from tests conducted at Sandia National Laboratories on a small panel (Pacheco, et al., 1995). It involved raising the drain line, drain valve, and the lower oven temperatures to well above $290^{\circ} \mathrm{C}$ to melt and drain salt out of these components before starting to melt salt in the panel. Once these areas were free of salt, panel thawing began by melting salt from the bottom upward, concentrating heliostats at the interface between the oven cover and absorber surface, as shown in Figure 3-8. As the salt melted in that region, it drained. More heliostat beams were added above the previous beams to 
continue melting salt. Eventually, the entire panel would be free of frozen salt. A procedure to thaw salt in panels that were frozen with nitrate salt is described in Appendix F.

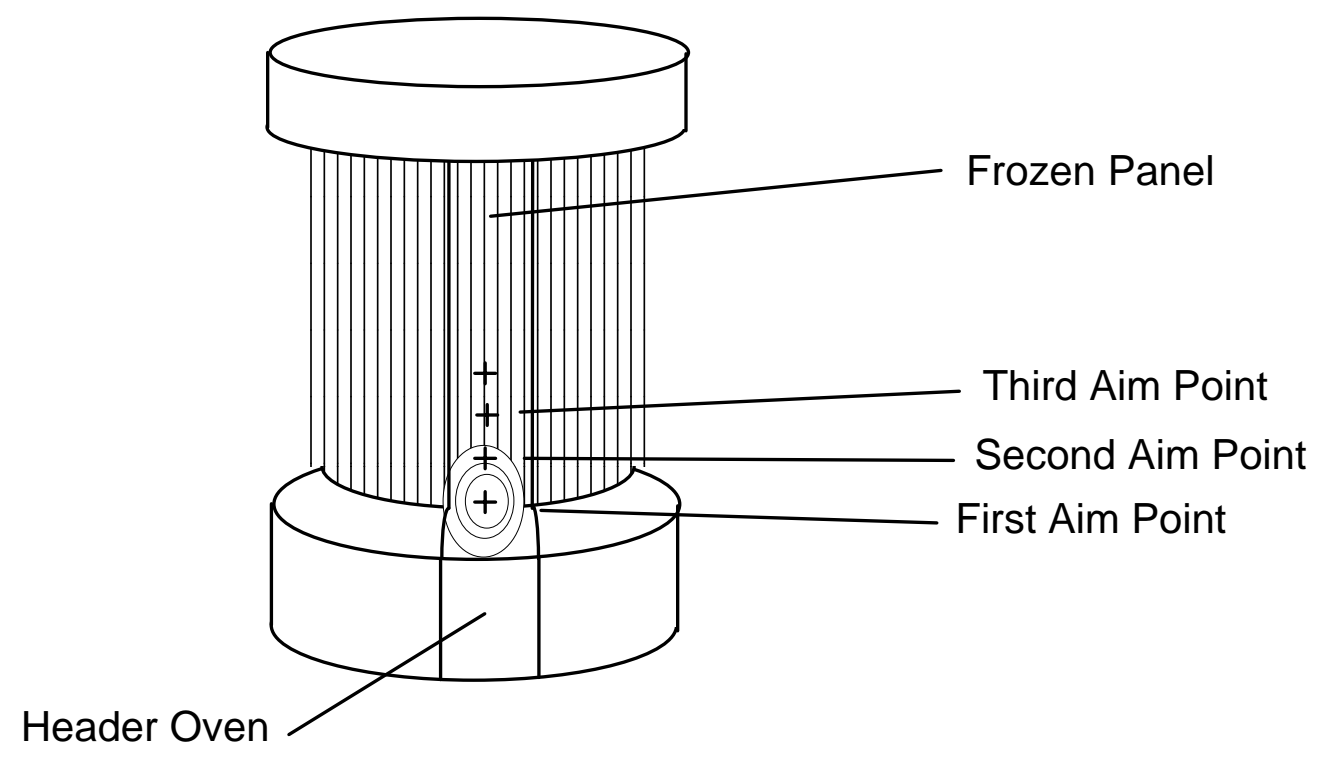

Figure 3-8. Aiming of heliostats to thaw a panel frozen with salt.

\subsubsection{Metallurgical Analysis of Receiver Tubes}

Sections of the stainless-steel tubing were removed from four panels (W1, W3, W12, and E3) at the conclusion of the project. Specimens were extracted from tubes located at or near the edge of these four panels. These sections were taken from either the mid-region of a tube, where the incident flux would be greatest, or from the top of the tube, where they were shielded from direct insolation. Total time on sun was approximately 1500 hours over the course of the demonstration (December 1995 to April 1999).

Salt-induced corrosion of the 316 stainless-steel (SS) receiver tubing resulted in the formation of very thin oxide films over the $\approx 1500$ hours of operation of the receiver. Even in the case of the highest bulk salt and salt film temperatures, oxide scales were never greater than approximately $10 \mu \mathrm{m}$. For tubes experiencing intermediate and lower temperatures, the oxide structures on the tube identifications (IDs) were typically less than $3 \mu \mathrm{m}$. Corrosion occurred via a process of uniform surface oxidation, as has been well-documented for austenitic stainless steels (Bradshaw and Goods, 2001, Goods, et. al. 1994). The thermomechanical environment of the receiver structure did not affect this mode of oxidation or the rate of oxide film formation. Details on metallurgical analysis of receiver tubes are described in Appendix $\mathrm{H}$.

During the post-mortem metallurgical analysis, evidence of Ca3(PO4)2 within the Solar Two receiver tubes raised questions about the chemicals used in the flush of the receiver in 1996 to remove debris. The debris originated from carbon steel piping that overheated due to improper installation of heat trace. The debris was entrained in the salt as it flowed to the receiver and was 
Final Test and Evaluation Results from the Solar Two Project

trapped in the headers of the receiver panels. An aqueous flush was used to dissolve the debris in the system. A discussion of the aqueous flush is included in Appendix I: Receiver Flush. 


\section{THERMAL STORAGE SYSTEM}

\subsection{Description}

The thermal storage system consisted of cold and hot storage tanks, a receiver pump sump, a steam generator pump sump, interconnecting piping, and the nitrate salt. The cold and hot tanks, built to the American Petroleum Institute standards, were flat-bottom, domed-roof, cylindrical, atmospheric tanks. A picture of the tanks is given in Figure 4-1. The cold and hot tanks were fabricated from carbon steel and stainless steel, respectively. Each tank was sized to hold the entire inventory of nitrate salt. Technical characteristics of the thermal storage system are listed in Table 4-1.

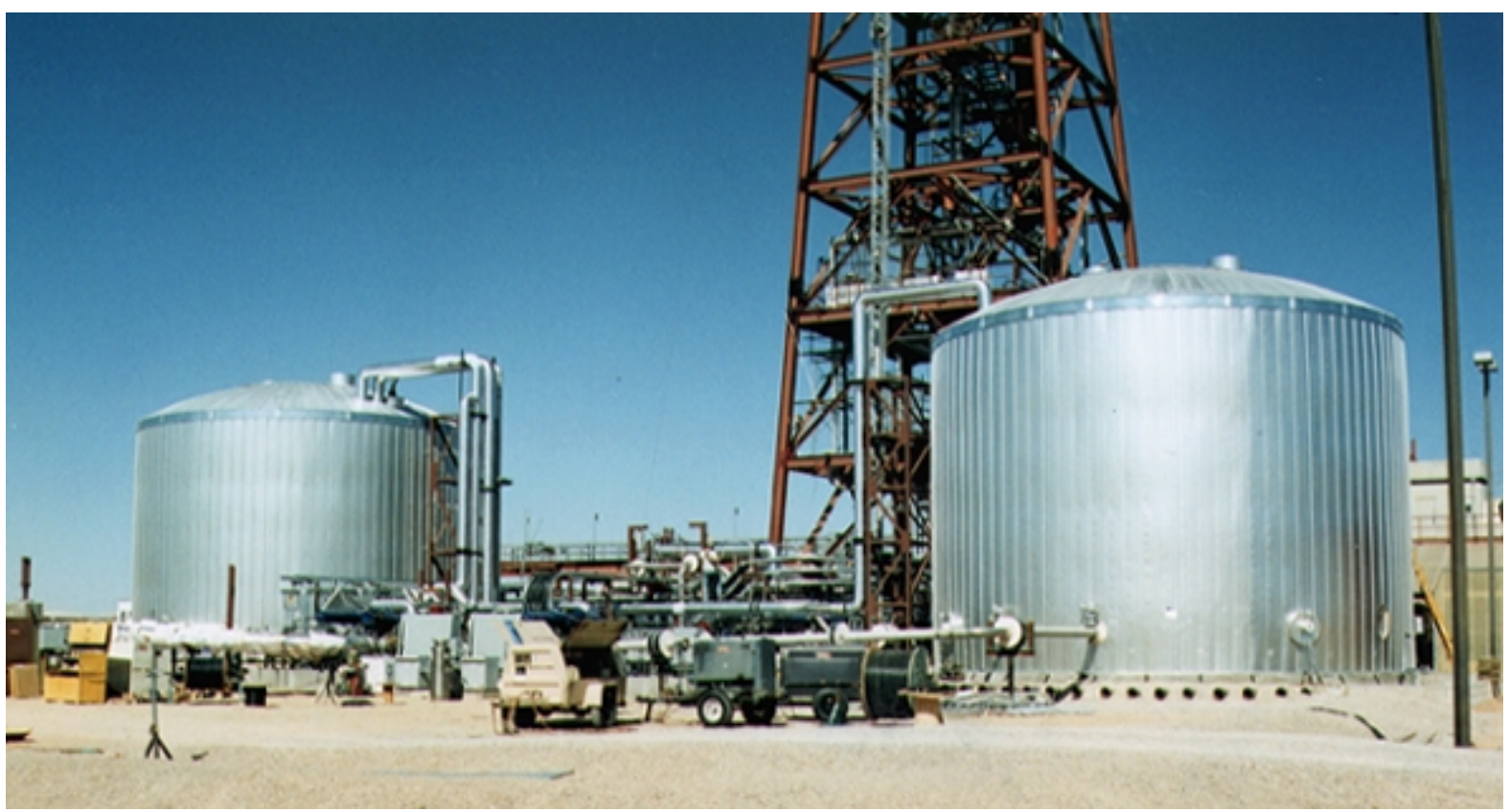

Figure 4-1. Cold (left) and hot (right) nitrate salt storage tanks.

The storage media was a mixture of molten sodium nitrate and potassium nitrate. The tanks gravity-fed salt to the sumps where the pumps were located. The salt level in each sump was monitored with a bubbler level detector, which modulated a control valve at the outlet of that tank to maintain the prescribed level. Each tank was also equipped with bubbler level detectors.

The cold tank contained two active $25-\mathrm{kWe}$ immersion heaters and one spare that maintained the tank at $290^{\circ} \mathrm{C}$. The sides and roof of the cold tank were insulated with $23 \mathrm{~cm}$ and $15 \mathrm{~cm}$ of mineral wool blankets overlaid with $5 \mathrm{~cm}$ of fiberglass boards. The exteriors of the tanks were covered with aluminum jackets for weather protection. The bottom of the cold tank was insulated with $41 \mathrm{~cm}$ of foamglass insulation under $10.2 \mathrm{~m}$ of the $11.4 \mathrm{~m}$-diameter tank. The outer ring of the tank bottom was insulated with $11 \mathrm{~cm}$ of hard firebrick on top of $30 \mathrm{~cm}$ of insulating firebrick. 
Table 4-1. Technical characteristics of thermal storage system

\begin{tabular}{ll}
\hline \hline Thermal Capacity & $110 \mathrm{MWh}$ \\
Molten Salt Inventory & 1400 tonnes \\
Tank Design Standard & American Petroleum Institute 650 \\
Tank Type & Field-erected, insulated, vertical, cylindrical tank with domed roof \\
Nominal Operating Temperatures & \\
Cold Tank & $290^{\circ} \mathrm{C}$ \\
Hot Tank & $565^{\circ} \mathrm{C}$ \\
Diameters and Heights & \\
Cold Tank & $11.6 \mathrm{~m}$ diameter, $7.8 \mathrm{~m}$ high \\
Hot Tank & $11.6 \mathrm{~m}$ diameter, $8.4 \mathrm{~m}$ high \\
Receiver Sump & $4.3 \mathrm{~m}$ diameter, $3.4 \mathrm{~m}$ high \\
Steam Generator System & $4.3 \mathrm{~m}$ diameter, $2.4 \mathrm{~m}$ high \\
Cold Tank & \\
Haterials Tank & ASTM A516-70 carbon steel \\
Tank Manufacturer & 304 stainless steel \\
\hline
\end{tabular}

The hot tank contained three active $25 \mathrm{kWe}$ immersion heaters and one spare that maintained the tank at $565^{\circ} \mathrm{C}$. The sides and roof of the hot tank were insulated with $46 \mathrm{~cm}$ and $30 \mathrm{~cm}$, respectively, of mineral wool blankets overlaid with $5 \mathrm{~cm}$ of fiberglass boards. The exterior was covered with an aluminum jacket for weather protection. The bottom of the hot tank was insulated with $15 \mathrm{~cm}$ of insulating firebrick on top of $30 \mathrm{~cm}$ of foamglass insulation under 10.2 $\mathrm{m}$ of the 11.4-m diameter tank. The outer ring of the tank bottom was insulated with $11 \mathrm{~cm}$ of hard firebrick on top of $38 \mathrm{~cm}$ of insulating firebrick.

In an effort to reduce heat losses as the tanks were charged or discharged, piping was connected to the vents of the two tanks so that air in the ullage space would not exchange with ambient air. This interconnected piping was heat traced and insulated to prevent salt (coming from mist entrained with the air or from wicking) from freezing and blocking the flow of air.

\subsection{Typical Operation}

At the start of a typical operating day, the hot tank had a minimum inventory of salt with a level of $0.9 \mathrm{~m}$. The remaining molten-salt inventory (minus salt in the pump sumps) was held in the cold tank, typically having a level of $5.8 \mathrm{~m}$. As the receiver was started and brought to full power, molten salt was pumped from the receiver sump through the receiver and back to the cold storage tank. Once the receiver had filled, the incident power was ramped up within 15 minutes, bringing the salt outlet temperature to $565^{\circ} \mathrm{C}$. As the receiver outlet temperature increased above $510^{\circ} \mathrm{C}$, the salt flow from the receiver was directed to begin filling the hot tank and storing energy. As the hot tank filled, air in the ullage space was pushed out the vent, through the interconnecting piping, and into the cold tank.

Once the molten-salt level in the hot tank exceeded $2.5 \mathrm{~m}$, the steam generator/turbine was brought online. The steam generator ran until the level in the hot tank dropped to $0.9 \mathrm{~m}$, at which time it was shut down. The tank heaters were designed to maintain the inventory of 
molten salt at its nominal operating temperature. However, the main purpose of the heaters was to prevent the salt from freezing during a long outage. The preferred set point of these heaters was less than $290^{\circ} \mathrm{C}$ to prevent them from activating during normal operation, thus reducing parasitic power consumption.

\subsection{Performance Testing}

Major tests associated with the thermal storage system measured the thermal growth of the hot tank during initial heatup, the heat loss from each tank and sump to estimate their thermal efficiencies, and the actual thermal capacitance of the thermal storage system.

\subsubsection{Thermal Growth During Initial Heatup and Melting}

The start-up team began heating the hot tank with a propane-fired convective heater on October 9, 1995. The tank was initially preheated from ambient temperature to approximately $315^{\circ} \mathrm{C}$ with propane and allowed to soak at this temperature for about 9.5 days to allow the foundation to reach equilibrium before introducing the first batch of melted salt. Once the tank was above $315^{\circ} \mathrm{C}$, molten salt was pumped into the hot tank as it melted. The melting procedure required 16 days. The entire salt inventory was then thermally conditioned above $540^{\circ} \mathrm{C}$ for 30 days using an external salt-recirculation loop containing a propane-fired heater. The salt inventory was thermally conditioned to reduce an impurity, described under Section 5.4.1. During the heating process, the tank temperatures, tank growth, and salt level were monitored. Figure 4-2 shows the temperature of the tank wall during preheat, soak, salt melting, and thermal conditioning.

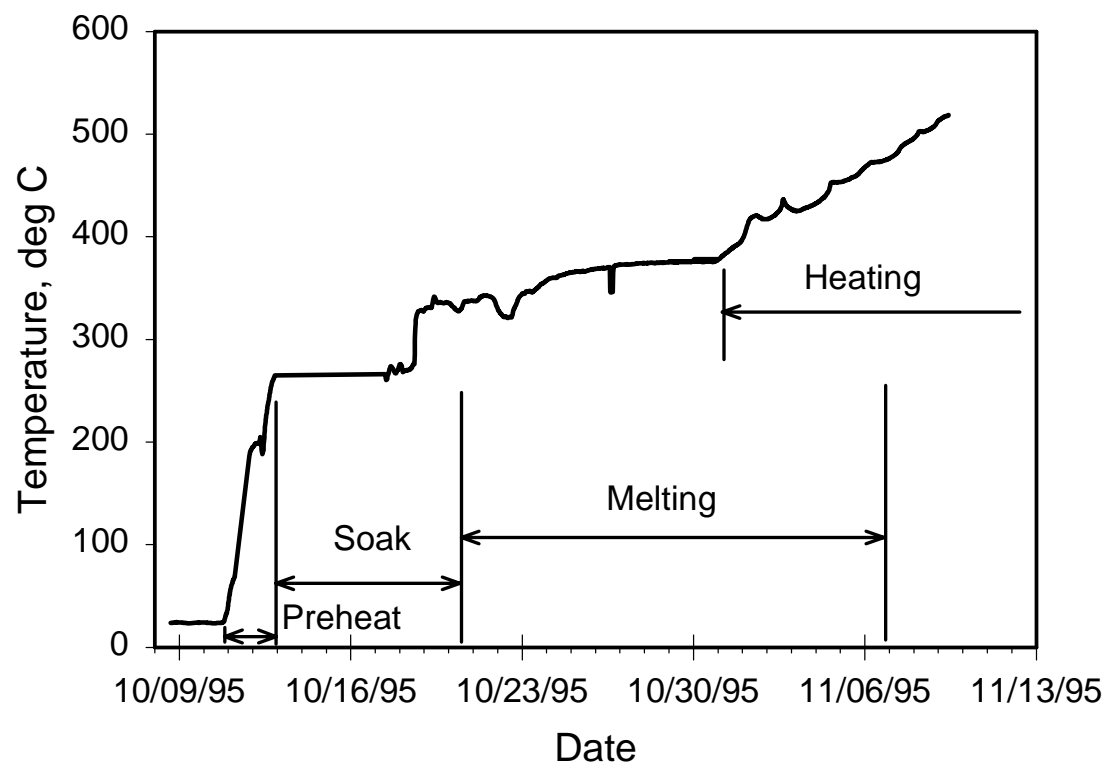

Figure 4-2. Tank wall temperature during preheat, soak, salt melting, and heating procedures. 
The expansion of the hot tank diameter was measured using plumb-bobs mounted to a threaded rod bolted to the flanged heater mounts. The plumb-bobs were suspended above rulers fixed next to the tank foundation. In addition, a laser measurement device was used as a secondary measurement. Attempts to measure strains of the tank walls were unsuccessful because the instrumentation installed was unstable. Based on the growth measurements and the tank temperatures, the tank expanded unrestrained and matched modeled results of the tank expansion. Details of this test can be found in Appendix $\mathbf{J}$.

\subsubsection{Heat Loss and Efficiency Test}

The thermal losses from the storage system were measured to compare with modeled results and to estimate the efficiency of the thermal storage system. Two methods were employed to acquire the data necessary to determine heat losses: the isothermal method and the cool-down method. The isothermal method involved measuring the power consumption of the heat trace and immersion heaters over a long, steady-state period (several days) as the vessels and components were maintained at a constant temperature. In the cool-down method, rate of change of the mean tank temperature was measured to estimate the thermal losses. This test required all the heat tracing and immersion heaters to be turned off so the decay of the tank temperature could be tracked over several days. The cool-down method was only used to measure the heat loss from the hot tank because the electric heaters had insufficient capacity to maintain the tank at $565^{\circ} \mathrm{C}$.

The results of the thermal losses for the sumps and tanks are presented in Table 4-2. All of the losses are essentially as predicted within experimental error, except for the steam generator system. The higher-than-expected steam generator system losses are likely from damaged insulation. During the startup phase, a salt leak saturated the sump's insulation and reduced its effectiveness. Details on the thermal losses test can be found in Appendix K.

Table 4-2. Measured and calculated thermal losses of tanks and sumps

\begin{tabular}{lcc}
\hline \hline Major Equipment & $\begin{array}{c}\text { Calculated Thermal } \\
\text { Loss, } \mathbf{k W}_{\mathbf{t}}\end{array}$ & $\begin{array}{c}\text { Measured Thermal } \\
\text { Loss, } \mathbf{k W}_{\mathbf{t}}\end{array}$ \\
\hline Hot Salt Tank at $565^{\circ} \mathrm{C}$ & 98 & $102 \pm 21$ \\
Cold Salt Tank at $290^{\circ} \mathrm{C}$ & 45 & $44 \pm 6.6$ \\
Steam Generator System at $565^{\circ} \mathrm{C}$ & 14 & $29 \pm 3.5$ \\
Receiver Sump at $290^{\circ} \mathrm{C}$ & 13 & $9.5 \pm 1.0$ \\
\hline \hline
\end{tabular}

The heat loss associated with the Solar Two thermal storage system is very low, as predicted. This allows for efficient storage of thermal energy. Based on these results, it is expected the annual efficiency of the thermal storage system in a commercial plant should be about $99 \%$.

\subsubsection{Actual Thermal Capacity of the Storage System}

The actual thermal capacity of the thermal storage system was estimated to be $107 \mathrm{MWh}$ based on the amount of salt in the storage system, accounting for the mass of salt in the heels of the tanks and the pump sumps, as well as for the actual attainable salt temperatures delivered to and 
from the SGS. The thermal storage system was designed to deliver thermal energy at full-rated duty of the steam generator for three hours at the rated hot and cold salt temperatures of $565^{\circ} \mathrm{C}$ and $290^{\circ} \mathrm{C}$. The amount of salt in the system was estimated to be 1380 tonnes based on the levels of salt in the tanks and sumps, which was somewhat less than design-specified 1490 tonnes. In addition, the maximum attainable hot salt temperature from thermal storage delivered to the SGS was typically $554^{\circ} \mathrm{C}$ due to attemperation of the hot salt by cold salt leaking through isolation valves. Despite the slightly lower-than-specified salt inventory and decreased hot-salt temperature, the storage system still had the capacity to deliver the full-rated steam generator duty for three hours $(35.5 \mathrm{MW} \times 3 \mathrm{~h}=106.5 \mathrm{MWh})$.

\subsection{Operating Experience}

\subsubsection{Salt Melting}

Figure 4-3 shows the salt in bags awaiting melting. The supersacks were loaded into a hammermill and crushed into small pieces that were then sent along a conveyor belt to a feed hopper, shown in Figure 4-4. The feed hopper had a screw auger to push the salt into the melting chest. The melted salt was then fed directly into the hot tank. The salt in the hot tank was continuously circulated through a $3 \mathrm{MW}$ propane heater to bring the salt temperature to $370^{\circ} \mathrm{C}$. It took 16 days to add the complete inventory of salt to the hot tank. Once the inventory of salt was in the hot tank, it was slowly heated to $540^{\circ} \mathrm{C}$ and soaked at that temperature for 20 days to reduce the magnesium nitrate impurity. The magnesium nitrate thermally decomposed, forming gaseous nitrous oxide byproducts that, if not reduced, could have caused flow stability problems in the receiver the first time the receiver was operated.

After 20 days at that temperature, the concentration of dissolved magnesium in the salt reached a level around $0.001 \mathrm{wt} \%$. Details on lessons learned associated with salt melting can be found in Appendix L.

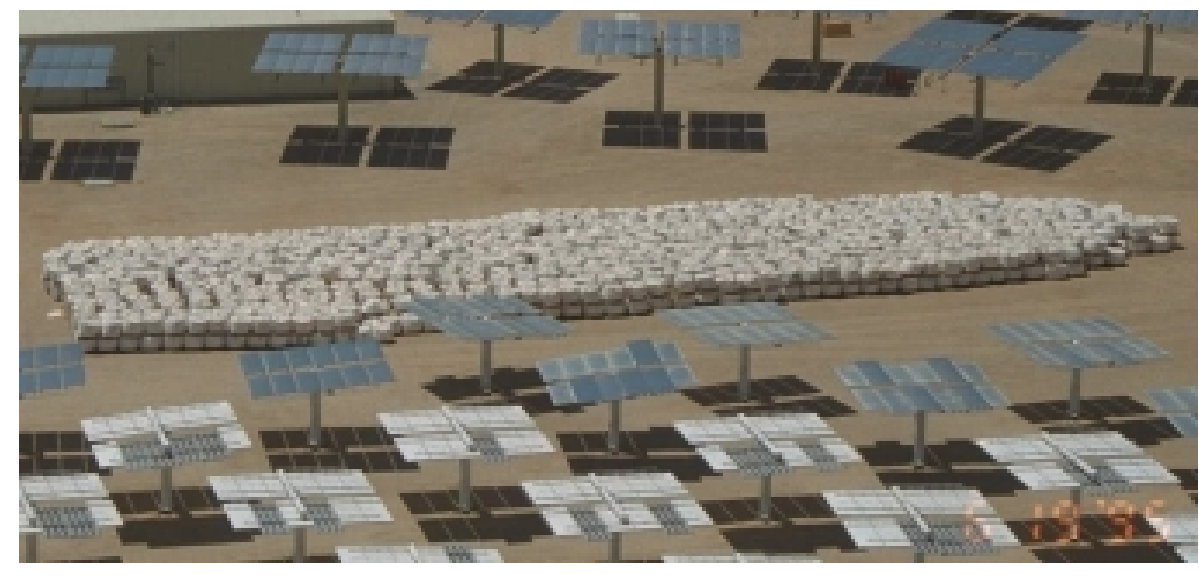

Figure 4-3. 1380 tonnes of nitrate salt awaiting melting at Solar Two. 


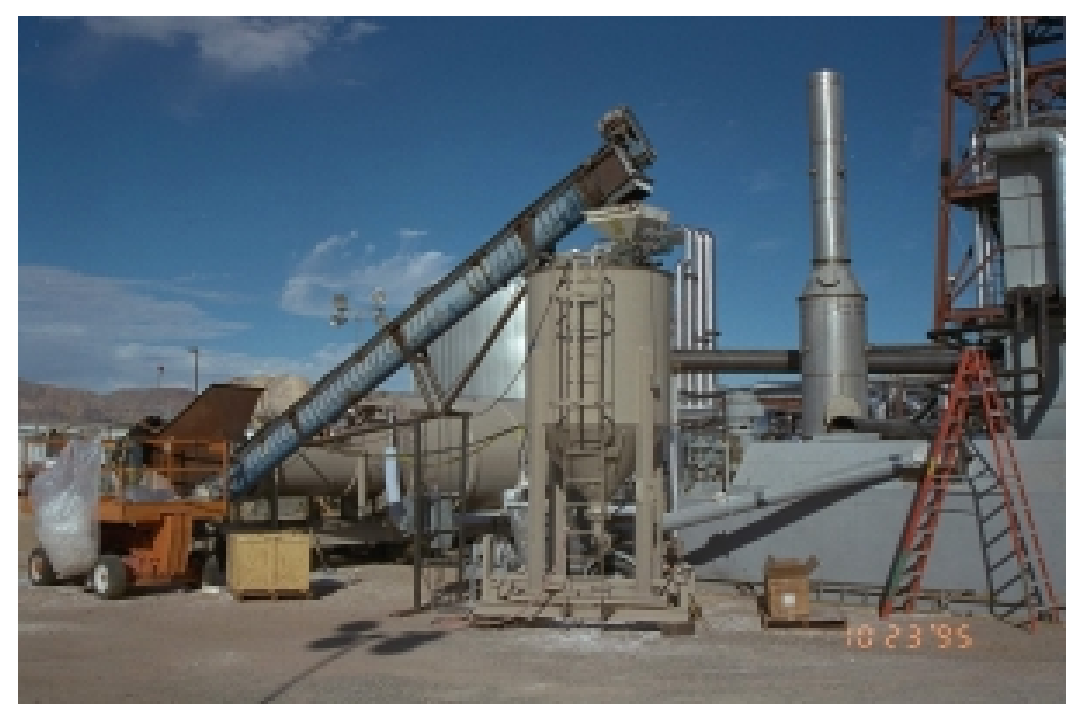

Figure 4-4. Conveyor belt feeding crushed salt from the hammer mill into the salt hopper. The screw auger can be seen as the pipe feeding into the wall next to the ladder.

\subsubsection{Tank Venting}

The cold and hot tank vents were connected together with an insulated, heat-traced pipe so that as one was filled and the other emptied, the air in the ullage space shuttled between the two tanks. The benefit of the intertank venting system was that the air in the ullage spaces would not exchange with outside air, which would increase the thermal heat losses.

Although the salt has a very low vapor pressure, the salt wicks and can be entrained in moving air. The salt will freeze if it comes in contact with a cold spot. Therefore, the vent-line heattrace zones had to be energized continuously to prevent salt buildup, which could eventually block the vent line. The electric energy consumed by the vent line heat trace exceeded the thermal energy saved by shuttling the air between the tanks. A new thermal storage system should not use an intertank venting system; instead, each tank should exchange air with the ambient.

\subsubsection{Recycling Spilled Salt}

On several occasions, salt slowly leaked from valve stem packing, from pressure relief valves, through flanges, or due to other events. After the salt froze and became solid, it could readily be cleaned up. It was desirable to recycle the salt back into the system, rather than disposing of it as hazardous waste, but sometimes there were foreign materials in the frozen salt. It was not uncommon to have insulation, rocks, dirt, and metal lagging encased in salt. Near the end of the project, a salt recycler was built at Sandia and sent to Solar Two to determine if the spilled salt could be decanted and recycled. The salt recycler was simply a heat-traced and insulated curvedbottom tank mounted on a small work platform that could accommodate several barrels of salt. Figure 4-5 shows a picture of the recycler. A pipe with a valve was tapped into the side about $15 \mathrm{~cm}$ from the bottom to decant the melted salt after allowing the material to settle on the 
bottom and skimming off any floating material. This pipe drained into a pump sump. Another pipe with a valve was tapped directly on the bottom of the tank to flush out accumulated sludge and other material from the bottom of the tank. The salt recycler was successful in separating foreign materials from spilled salt and returning the salt back to the system.

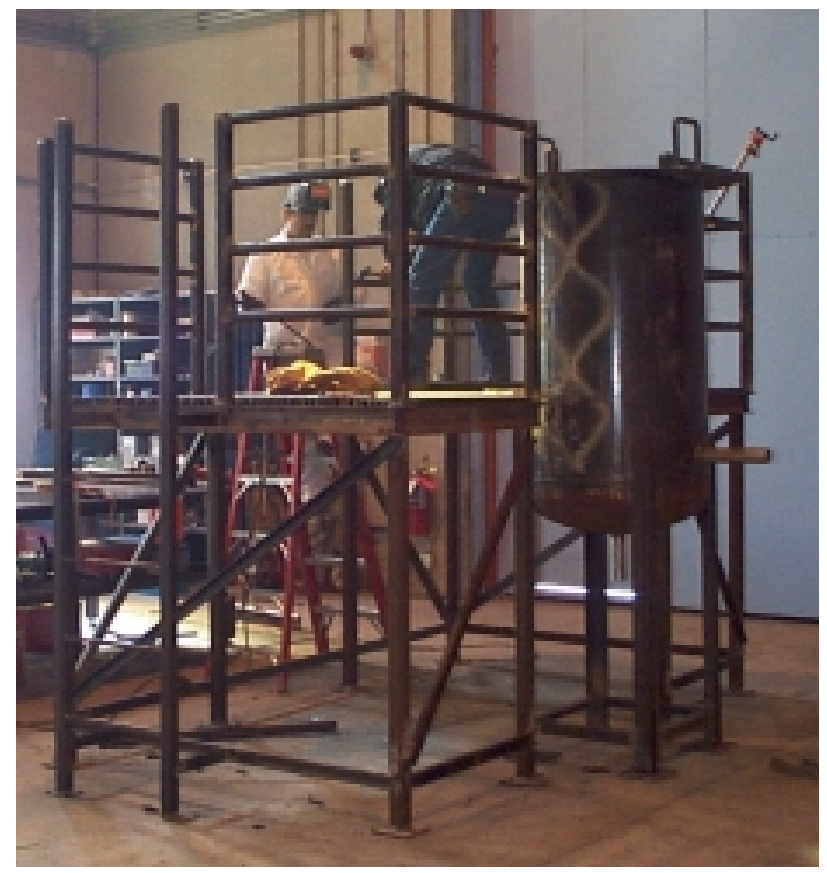

Figure 4-5. Salt recycler used to return spilled salt to the thermal storage system.

\subsubsection{Restart After Long Outage}

On one occasion during the three year operation, the molten-salt inventory in the hot tank had to be cooled down to $290^{\circ} \mathrm{C}$ to conduct an inspection of the tank. To reduce the thermal stresses in the tank upon restart, the receiver outlet temperature setpoint was derated to about $400^{\circ} \mathrm{C}$ by defocusing part of the field and increasing the salt flow rate through the receiver. This enabled the hot tank inventory to gradually increase in temperature, preventing the tank from experiencing a thermal shock. The receiver outlet temperature was gradually increased over several days of operation to thermally condition the hot tank to its normal operating temperature of $565^{\circ} \mathrm{C}$. This conservative restart method prevented the tank from undergoing severe temperature changes.

\subsubsection{Changes in Salt Over Time}

The composition of the salt changed throughout the project. After the initial melting and thermal conditioning of the salt (which decomposed the impurity $\mathrm{MgO}$ ), perchlorate decreased, magnesium stayed low, and nitrite formed within the bounds of equilibrium expectations. No problems were observed with these changes. For an unknown reason, the salt melting point 
gradually lowered throughout the project from $207^{\circ} \mathrm{C}$ initially to approximately $202^{\circ} \mathrm{C}$ at the end of the project. Although unexplained, this change appeared to have no effect, positive or negative, on the performance of Solar Two. Details on the salt chemistry can be found in Appendix $\mathrm{H}$.

\subsubsection{Removing the Salt Inventory from Site for Recycle}

At the end of the project, the entire 1380 tonnes of nitrate salt were removed from the site. Since the nitrate salt was to be recycled for use as fertilizer, the salt had to be frozen into small pellets (called prills), put into 1000-kg supersacks, and shipped offsite. A piping loop, which contained a prilling head (several plates with small holes to allow the salt to form droplets), was tapped into the downcomer at the top of the tower. The droplets sprayed down a $3 \mathrm{~m} \times 3 \mathrm{~m}$ chute erected with scaffolding on the side of the tower, shown in Figure 4-6. At the bottom of the chute, a hopper fed the salt prills into a fluidized bed cooler. A conveyor carried the salt prills through another fluidized bed cooler and then to a hopper fitted with a supersack.

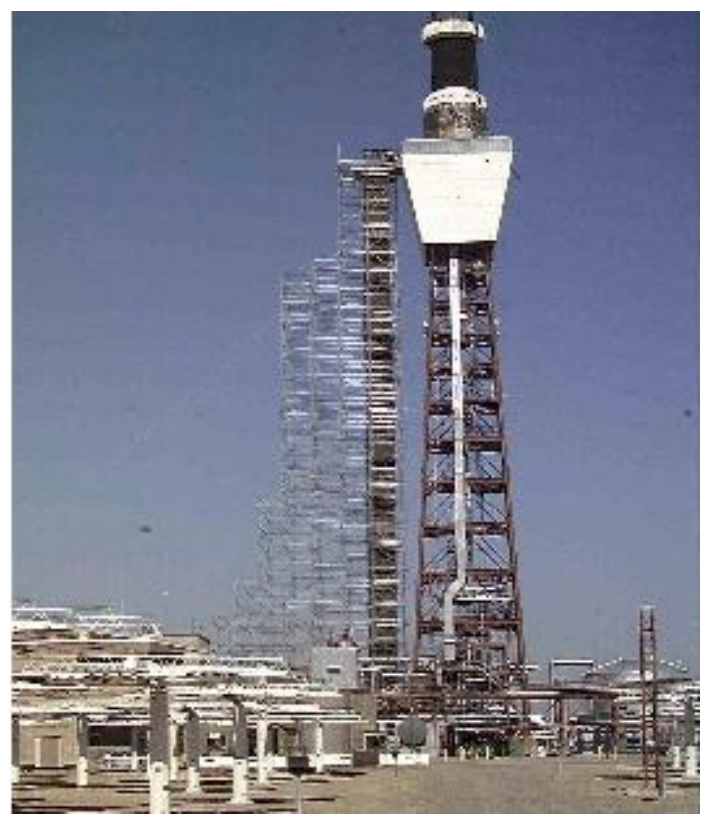

Figure 4-6. Chute on one side of the tower in which the nitrate salt was prilled for removal from the site.

\subsubsection{Postmortem Metallurgical Analysis of Tank Alloys}

Samples of the hot and cold tank alloys were removed at the conclusion of the project. The surface of the tanks were exposed to the nitrate salts continuously at or near their operating temperatures for over 30,000 hours. Samples were removed from areas of the tank walls that were continuously submerged in salt (approximately 0.5 meters from the bottom of the and tank) and areas that were never submerged by salt (e.g. approximately $6.7 \mathrm{~m}$ above the bottom). These samples were examined for corrosion penetration, surface contamination, and oxide growth. Analyses showed that corrosion occurred at an acceptably low rate (Goods, et. al, 1997). 
Notwithstanding the $>30,000$ hour exposure time of the storage tanks, corrosion was minimal. There were no unusual features with respect to oxide structure or oxidation products on the carbon steel used for the cold tank. For the hot tank, the singularly noteworthy observation was the presence of oxide films of only minimal thickness. Salt-induced corrosion of the receiver and salt storage tank alloys poses no practical limitation on the useful life of these structures. Detail on the metallurgy of the tank alloys can be found in Appendix $\mathrm{H}$. 
Final Test and Evaluation Results from the Solar Two Project 


\section{STEAM GENERATOR/ELECTRIC POWER GENERATION SYSTEM}

\subsection{Description}

The steam generator consisted of three major components: a preheater, an evaporator, and a superheater, shown in Figure 5-1. The U-tube, straight-shelled preheater brought 100 bar feedwater initially at approximately $260^{\circ} \mathrm{C}$ to near its saturation point of $310^{\circ} \mathrm{C}$. The kettle evaporator vaporized the saturated feedwater to produce high-quality saturated steam. The Utube, straight-shelled superheater produced superheated steam at approximately $535^{\circ} \mathrm{C}$ and 100 bars. Hot salt provided the thermal power to the steam generator. It was pumped with a cantilevered, single-stage, vertical hot pump from the hot-salt sump (at $565^{\circ} \mathrm{C}$ ) through the shell side of the superheater, through the tube bundle in the kettle evaporator, and finally through the shell side of the preheater, where it returned to the cold salt storage tank at $290^{\circ} \mathrm{C}$. A schematic of the SGS is shown in Figure 5-2.

Superheated steam from the steam generator was attemperated with feedwater to limit the temperature of steam to $510^{\circ} \mathrm{C}$ at the turbine inlet. The steam generator was designed to supply steam at $535^{\circ} \mathrm{C}$ to demonstrate the capability of a molten-salt steam generator as needed by modern Rankine turbines, even though the turbine used at Solar Two was limited to an inlet steam temperature of $510^{\circ} \mathrm{C}$. The turbine was the non-reheat turbine refurbished from Solar One. It was rated for $12.8 \mathrm{MWe}$-gross output. The technical characteristics of the steam generator/electric power generation system are shown in Table 5-1.

\subsection{Typical Operation}

\subsubsection{Initial Heatup}

From ambient temperature, the steam generator was heated by first establishing a water level in the evaporator, filling the preheater, then energizing a $232 \mathrm{~kW}$ electric water heater. The water recirculated through the preheater, evaporator, and electric heater to bring the inventory to $100^{\circ} \mathrm{C}$. Steam from the evaporator would condense in the superheater, slowly raise its temperature, then drained to the blowdown line. Once the superheater had heated to near $100^{\circ} \mathrm{C}$, the water side of the system was "bottled up" to build pressure. The temperature of the water increased to $200^{\circ} \mathrm{C}$ and held there until the temperature of the heat traced channel of the evaporator (in which the salt passes) was above the salt melting temperature $\left(220^{\circ} \mathrm{C}\right)$. This allowed salt in the channel and tube sheet to melt. 


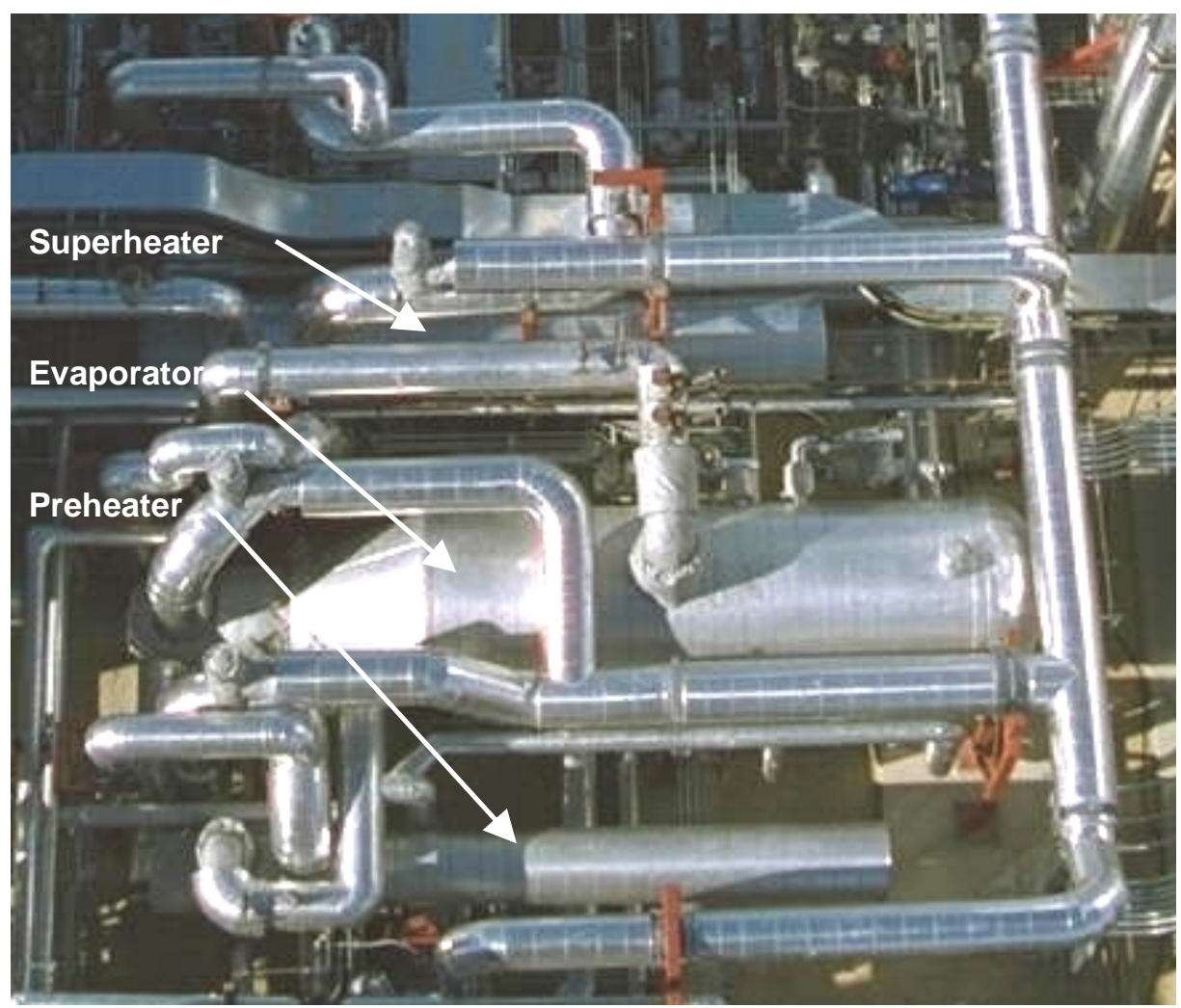

Figure 5-1. Solar Two SGS.

The water temperature was ramped from $200^{\circ} \mathrm{C}$ to $290^{\circ} \mathrm{C}$. Several immersion thermocouples in the shell of the evaporator monitored the thermal stratification across its length and vertically in the kettle boiler. To assure the evaporator tubes did not experience permanent strain due to freezing and thawing of residual salt in the tubes, the stratification was limited to approximately $4^{\circ} \mathrm{C}$. The superheater was heated using steam from the evaporator. The SGS was typically heated to $290^{\circ} \mathrm{C}$ in 16 hours. At that point, molten salt at $290^{\circ} \mathrm{C}$ could be introduced into the steam generator vessels by turning on the cold salt mixer pump, a four-stage vertical turbine pump.

\subsubsection{Overnight Hold}

During overnight hold, cold salt circulation was maintained through the steam generator vessels with the cold salt mixer pump to make up for heat loss though the insulation and to heat feedwater to maintain the water level in the evaporator. Although heat loss from the vessels through the insulation was estimated to be only $19 \mathrm{kWt}$, significantly more power was required to heat make-up feedwater as steam leaked past isolation and pressure relief valves and as a result of blowdown. For example, the heat rate required to replace 2 liters per minute of feedwater lost to blowdown is $38 \mathrm{kWt}$. 


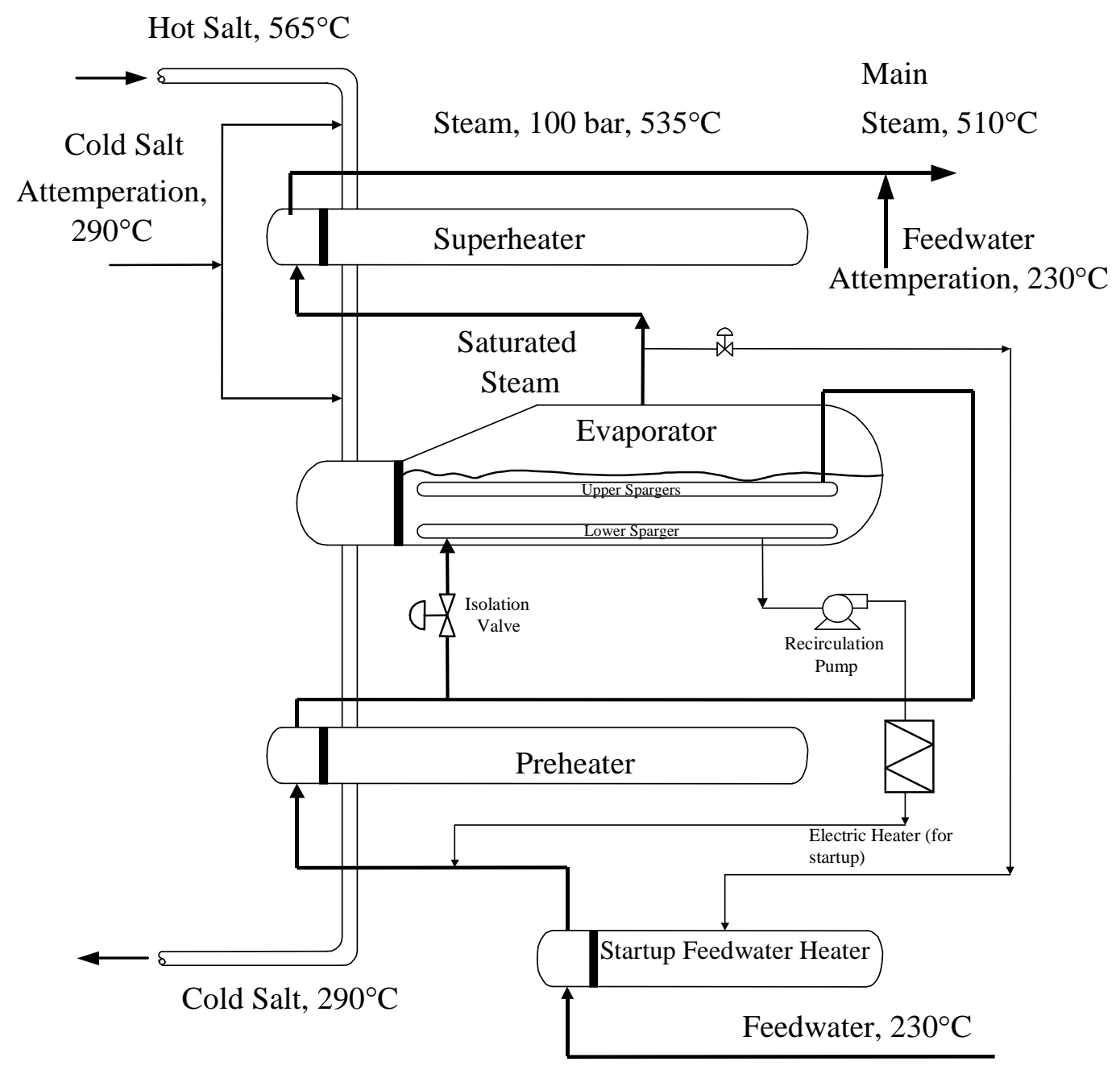

Figure 5-2. Schematic of the revised steam generator system.

\subsubsection{Daily Startup}

At the beginning of a typical day, the SGS had cold salt flowing through the vessels at $290^{\circ} \mathrm{C}$. The hot salt pump was started at $1 / 3$ full pump speed, and then the temperature controller at the inlet to the superheater increased the pump speed to ramp the mixed salt temperature (hot and cold salt) at a rate of $280^{\circ} \mathrm{C} /$ hour to a maximum temperature of $355^{\circ} \mathrm{C}$ by attemperating the hot salt with cold salt. This provided enough power to produce auxiliary steam so condenser vacuum could be established. The temperature set point of the salt to the inlet of the superheater was increased again at a rate of $280^{\circ} \mathrm{C} /$ hour to a temperature of $480^{\circ} \mathrm{C}$. The combined salt flow rate provided enough thermal power to heat the superheater, warm the main steam line, heat the turbine control-valve steam chest, and synchronize the turbine. The turbine was synchronized to the grid. The turbine was placed in inlet pressure control, which controlled the position of the turbine control valves and the load on the generator to maintain a set pressure in the steam generator. The extraction feedwater heaters were placed in service. The feedwater bypassed the 
startup feedwater heater. Adjusting the hot-salt pump speed controlled the turbine output set point.

Table 5-1. Technical characteristics of the steam generator/electric power generation system

\begin{tabular}{ll}
\hline \hline Steam Generator Components & Preheater, Kettle Evaporation, Superheater \\
Steam Generator Thermal Duty & $35.5 \mathrm{MW}$ \\
Heat Transfer Fluid & Molten Nitrate Salt $\left(60 \% \mathrm{NaNO}_{3}\right.$ and $\left.40 \% \mathrm{KNO}_{3}\right)$ \\
Salt Inlet Temperature & $565^{\circ} \mathrm{C}$ \\
Salt Outlet Temperature & $290^{\circ} \mathrm{C}$ \\
Feedwater Inlet Temperature & $260^{\circ} \mathrm{C}$ \\
Superheated Steam Temperature & $535^{\circ} \mathrm{C}$ \\
Operating Steam Pressure & $100 \mathrm{bar}$ \\
Hours of Operation (approximate) & 1700 hours \\
Preheater & U-tube, straight shell, salt on shell side \\
Configuration & Carbon steel \\
Material & $76.2 \mathrm{~m}^{2}$ \\
Surface Area & $1940 \mathrm{~W} / \mathrm{m}^{2} \mathrm{~K}$ \\
Overall Heat Transfer Coeff. & \\
Kettle Evaporator & Kettle boiler with salt-in-tubes \\
Configuration & $9 \mathrm{Cr}-1 \mathrm{Mo}$ ferritic steel tubes (originally), replaced with \\
Material & $21 / 4 \mathrm{Cr}-1 \mathrm{Mo}$ ferritic steel, carbon steel shell \\
Surface Area & $158.4 \mathrm{~m}^{2}$ \\
Overall Heat Transfer Coeff. & $1392 \mathrm{~W} / \mathrm{m}^{2} \mathrm{~K}$ \\
Configuration & $\mathrm{U}$-tube, straight-shelled, salt on shell side \\
Material & $300 \mathrm{series} \mathrm{stainless} \mathrm{steel}$ \\
Surface Area & $152.4 \mathrm{~m}^{2}$ \\
Overall Heat Transfer Coeff. & $911 \mathrm{~W} / \mathrm{m}^{2} \mathrm{~K}$ \\
Superheater & Struthers \\
Manufacturer & $100 \%$ capacity, single-stage, stainless steel cantilever \\
Steam Generator Hot Pump Type & $64 \mathrm{~m}$ at $2.9 \mathrm{~m} / \mathrm{min}$ \\
Steam Generator Hot Pump Head & Lawrence Pumps, Inc \\
Steam Generator Hot Pump Manufacturer & $12.8 \mathrm{MWe}$ \\
Turbine Gross Rating & $100 \mathrm{bars}$ \\
Turbine Inlet Pressure & $510 \circ \mathrm{C}$ \\
Turbine Inlet Steam Temperature & General Electric \\
Turbine Manufacturer &
\end{tabular}

\subsubsection{Shutdown and Return to Overnight Hold}

To shut down the steam generator, the supply of salt to the hot sump was terminated, causing the sump to be pumped down and finally tripping the hot salt pump. The SGS would then trip, which stopped the cold mixer pump, the feedwater pump, and closed the feedwater control valve to the evaporator. The turbine disengaged from the grid and its speed dropped below $1000 \mathrm{rev} / \mathrm{min}$. When the superheater had cooled to about $315^{\circ} \mathrm{C}$, cold salt was pumped through all three steamgenerator vessels. 


\subsection{Performance Testing}

Testing the steam generator/electric power generation system (EPGS) meant characterizing the steam generator over a range of operating conditions, including evaluating the amount of thermal energy consumed during startup. Details on testing the steam generator/electric power generation system can be found in Appendix M.

\subsubsection{Performance over a Range of Loads}

The test was intended to measure the SGS and electric power generation system performances over a range of power loads (between 1300 and 10,800 kWe-gross) and two inlet salt temperatures $\left(540^{\circ} \mathrm{C}\right.$ and $\left.555^{\circ} \mathrm{C}\right)$. There was a baseline test at normal operating condition and several tests that deviated from normal plant operation. Testing was performed under steadystate conditions where the unit was held at that state for a minimum of two hours, but typically three to eight hours. These results, along with the design performances, are shown in Figure 5-3. As shown, the measured gross turbine output correlates with the design performances for a given heat input from the salt. The design performance is based on performance data provided by the turbine vendor and thermodynamic analysis conducted by Bechtel.

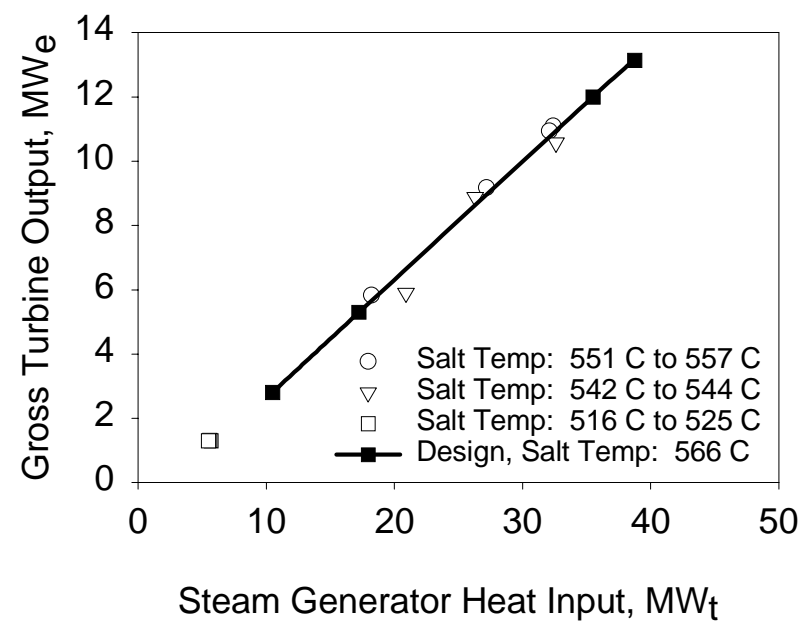

Figure 5-3. Steady-state gross-turbine output as a function of heat input to the steam generator.

\subsubsection{Steady-State Conversion Efficiency}

For the steady-state operation test, the steam generator and the electric power generation system were operated to measure the gross thermal-to-electric conversion efficiency at various loads. The steady-state gross conversion efficiency (gross electricity produced to thermal power input) was measured to be $34.1 \%$ at full load, $33.8 \%$ at $84 \%$ load, $32.0 \%$ at $57 \%$ load, and $23.3 \%$ at $22 \%$ load. The conversion efficiencies matched the design values within the uncertainty of the measurements. Since the Rankine turbine was not a reheat design, its efficiency was limited to about $34 \%$. Newer turbine designs that incorporate reheat have gross efficiencies greater than $41 \%$. 


\subsubsection{Startup Energy Requirement}

The steam generator and turbine/generator startup were characterized to measure and optimize thermal energy usage. The startup energy required over $20 \mathrm{MWh}$ of thermal energy to heat the steam generator components from overnight hold conditions $\left(290^{\circ} \mathrm{C}\right)$ to operating conditions, heat the main steam line, heat the turbine control valve steam chest, and synchronize the turbine. The daily startup energy was reduced to as low $6.6 \mathrm{MWh}$ by reducing the steam generator hold temperature while the main steam line and steam chest heated up and shortened the synchronization time. This thermal energy represented 2 to $3 \%$ of the thermal energy sent to the SGS.

\subsection{Operating Experience}

\subsubsection{Addition of a Startup Feedwater Heater after Steam Generator Tube Rupture}

A startup feedwater heater was added after a tube failure in the kettle evaporator in November 1996. The tube rupture was caused by freezing and thawing of salt in the evaporator when cold feedwater contacted the tube bundle. An analysis of the thawing of salt in the evaporator can be found in Appendix G. The startup feedwater heater used steam from the kettle boiler to ensure the feedwater was never below $230^{\circ} \mathrm{C}$ at the preheater. The feedwater circulation loop was also rerouted. This loop took saturated water from the bottom of the evaporator and recirculated it through the preheater (tying in to the main feedwater line) and back to the evaporator. The recirculation flow rate was such that $230^{\circ} \mathrm{C}$ feedwater coming from the startup feedwater heater could be mixed with $310^{\circ} \mathrm{C}$ water from the evaporator; thus, $260^{\circ} \mathrm{C}$ feedwater always entered the preheater during startup to prevent the freezing of salt. Once the extraction-steam feedwater heaters were put in service, the feedwater was hot enough that feedwater could be diverted around the startup feedwater heater.

\subsubsection{Fouling in Steam Generator System}

Although the relationship between heat supplied to the steam generator and steady-state power production is well characterized, a more useful measure of the performance of the steam generator components is the heat transfer effectiveness. The effectiveness of the preheater, evaporator, and superheater is a measure of how well each heat exchanger actually transferred heat relative to the maximum possible for the particular flow rates and inlet and outlet temperatures of the nitrate salt and water/steam. It indicates whether there was significant fouling. The results of actual performance measurements showed that the preheater had a low effectiveness, around 0.43, whereas the evaporator and the superheater were 0.75 and 0.97 , respectively. The preheater was found to have some fouling when the head of the preheater was removed in August 1998. The partition plate in the preheater leaked, causing bypass around the tube sheet. The tubes were cleaned and a new gasket was installed, which significantly improved the performance of the whole SGS/Electric Power Generator System, yielding a maximum turbine output. 
A phosphate injection system was installed in March 1999 to stop further scaling and possibly reduce the amount of scale already laid down on the tubes of the preheater. In addition, the phosphate treatment was expected to provide passivation of the tube surfaces. The head of the preheater was removed after the plant had shut down so it could be inspected. Although the phosphate treatment system was in service for only a few weeks, it appeared it had started to reduce the scale buildup already existing on the tubes. Details of this inspection can be found in Appendix N. 
Final Test and Evaluation Results from the Solar Two Project 


\section{OVERALL PLANT PERFORMANCE}

As stated before, the plant was turned over to the O\&M company for a period of 14 months before the plant shut down. During that time, O\&M procedures were under revision and the plant was operated in a conservative manner. In addition, there were some operating deficiencies of the plant. Despite the conservative operation and plant deficiencies, the peak and daily performances of the plant were characterized. Longer performance measurements (e.g., monthly and annual) were not meaningful because of the prototypical nature of the project. The peak performance tells how well the plant converted sunlight into electricity on a short time scale (<hour). The daily performance integrates the plant output over the day and is represented by three input-output plots: daily thermal collection, gross thermal-to-electric conversion, and parasitic energy consumption, shown in Figures 6-1 through 6-3 for the period July through mid November 1998. The daily thermal collection of a solar power plant tells how well the plant collected energy relative to what was predicted. The daily thermal collection is a function not only of the incident solar energy, but also of several factors, including the plant availability, heliostat field availability, mirror cleanliness, heliostat optical performance, receiver efficiency, and startup and shutdown losses. The daily gross thermal-to-electric conversion tells how well the plant converts thermal energy to gross electrical energy. The daily parasitic consumption plot shows the electrical energy consumed as a function of gross generation. More in-depth analysis of the Solar Two plant performance and comparisons to a commercial plant are described in $A n$ Evaluation of Molten-Salt Power Towers Including Results of the Solar Two Project (Reilly and Kolb, 2001). A lost energy evaluation can be found in Appendix O.

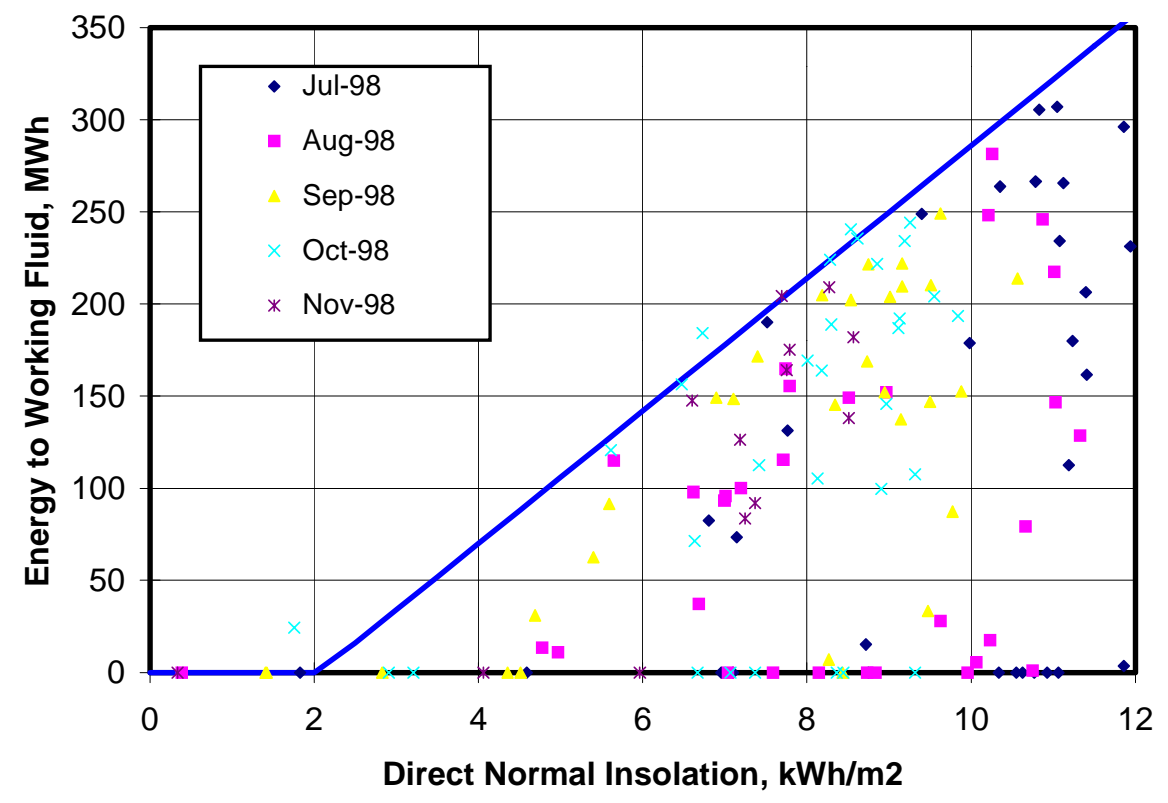

Figure 6-1. Daily thermal energy collected by heliostat/receiver system as a function of insolation. 


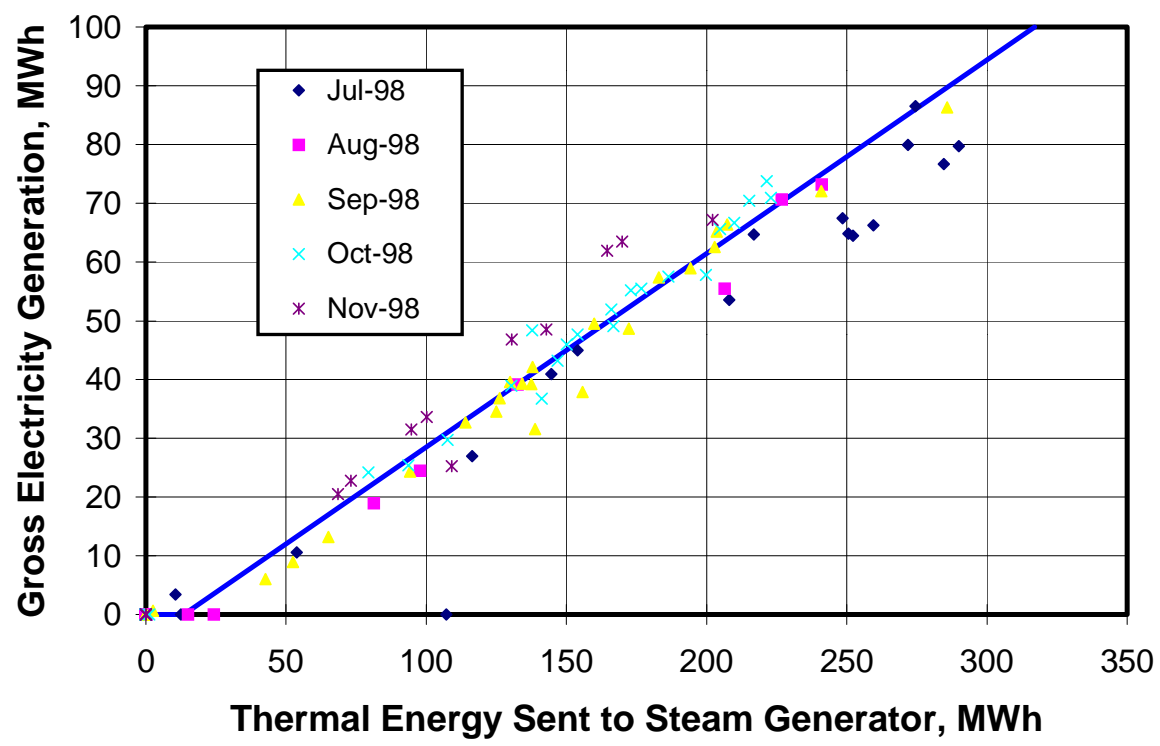

Figure 6-2. Measured daily gross electrical output versus daily energy sent to the SGS.

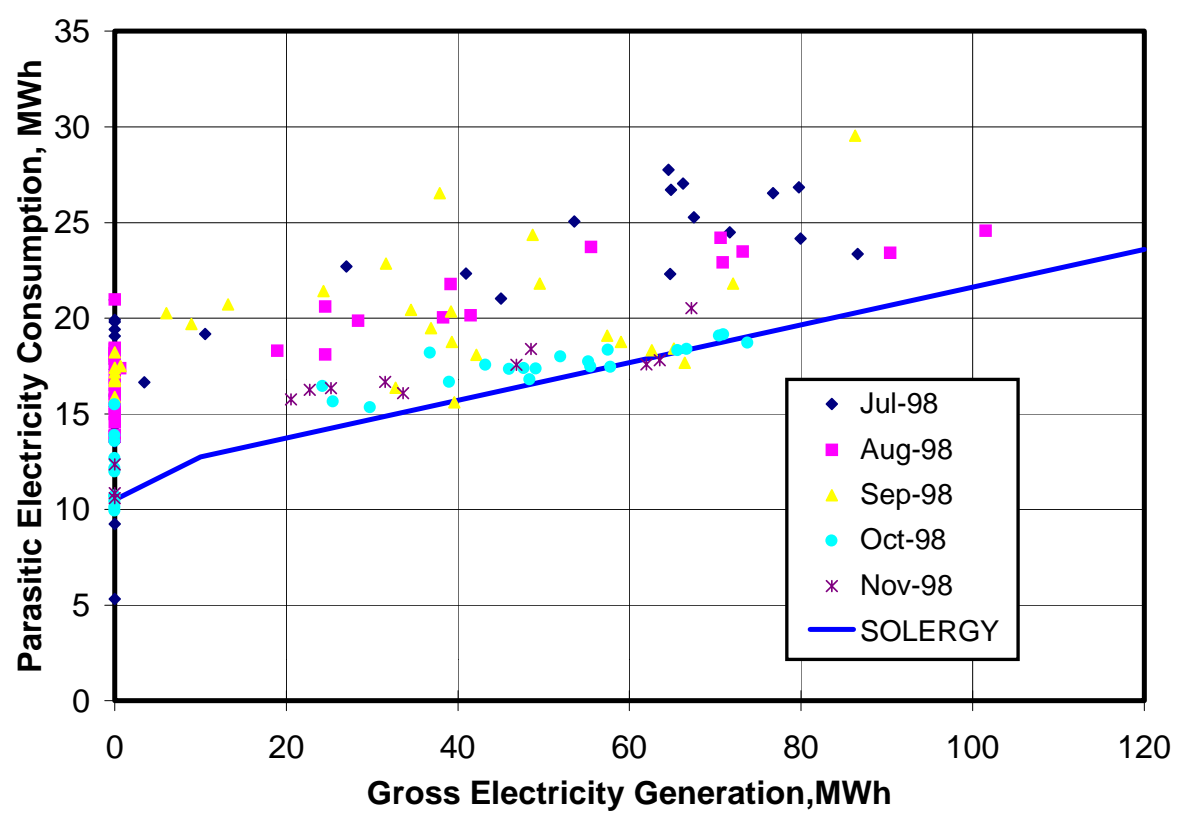

Figure 6-3. Parasitic-energy consumption as a function of gross-generation for July through November, 1998. The SOLERGY goal is also shown in the plot. 


\subsection{Peak Performance}

One of the performance goals of Solar Two was to demonstrate a $15 \%$ overall peak efficiency. The overall peak efficiency, measured over a short timeframe (a few hours), can be broken down into the efficiencies of each major step in the conversion from sunlight to grid-connected electricity, as shown in Table 6-1. The table shows the project goals, along with what was achieved at Solar Two and what would be expected in a commercial plant with design improvements. The project efficiency goals were meant to be achieved in the third year of operation, after the two-year T\&E phase, where the optimum operating conditions would be determined. As stated earlier, project delays severely compressed the testing schedule. Consequently, Solar Two was not fully optimized. The shortfalls in the actual peak performance can be attributed primarily to the under performance of the heliostat field. The old Solar One heliostat technology exhibited low availability, excessive corrosion, poor beam quality, and high tracking errors relative to performance attained 10 years earlier with Solar One. A discussion of each efficiency parameter follows.

Table 6-1. Solar Two peak efficiencies (goal and achieved) along with those expected for a commercial plant

\begin{tabular}{lccc}
\hline \hline Parameter & $\begin{array}{c}\text { Solar Two } \\
\text { Goal }\end{array}$ & Solar Two Achieved & $\begin{array}{c}\text { Commercial Plant } \\
\text { Predictions }\end{array}$ \\
\hline A. Mirror Reflectivity & $90 \%$ & $90 \pm 0.45 \%$ & $94 \%$ \\
B. Field Efficiency & $69 \%$ & $63 \pm 3.8 \%$ & $71 \%$ \\
C. Field Availability & $98 \%$ & $94 \pm 0.3 \%$ & $99 \%$ \\
D. Mirror Cleanliness & $95 \%$ & $93 \pm 2 \%$ & $95 \%$ \\
E. Receiver & $87 \%$ & $88 \pm 1.8 \%$ & $88 \%$ \\
F. Storage & $99 \%$ & $99 \pm 0.5 \%$ & $>99 \%$ \\
G. Overall Collection (Product of Above) & $50 \%$ & $43 \pm 2.3 \%$ & $55 \%$ \\
H. EPGS & $34 \%$ & $34 \pm 0.3 \%$ & $42 \%$ \\
I. Parasitics (Net Power / Gross Power) & $88 \%$ & $87 \pm 0.4 \%$ & $93 \%$ \\
J. Overall Peak Efficiency (G* $\left.\mathrm{G}^{*} \mathrm{l}\right)$ & $15 \%$ & $13 \pm 0.4 \%$ & $22 \%$ \\
\hline \hline
\end{tabular}

\subsubsection{Mirror Reflectivity}

The reflectivity of the Solar Two mirrors was area-weighted between the reflectivity of the MM heliostats (90.3\%) and the Lugo heliostats (93.9\%). Depending on the number of Lugo heliostat tracking the receiver, the area-weighted reflectivity was between 90.3 and $90.7 \%$. In a new commercial plant, it is reasonable to expect mirrors with $94 \%$ reflectivity would be used.

\subsubsection{Field Efficiency}

The Solar Two heliostat field efficiency was lower than the goal for several possible reasons. First, corrosion caused a loss of reflective area and contributed to the poor focus of the facets. This effect could account for a 3\% reduction in heliostat area. Second, poor canting of the original inner 17 rows of heliostats at the start of Solar Two construction may have worsened the performance of these heliostats. The inner 17 rows of heliostats were canted to their slant range 
to improve their focus; however, the canting procedures were not consistently followed. It is difficult to quantify the drop in efficiency due to the poor canting. Third, infrequent bias correction contributed to poor aiming of the heliostats. The effect of inadequate biasing could easily make up the difference between the goal and measured performance. Fourth, the 10895 -

$\mathrm{m}^{2}$ Lugo heliostats added to the south side of the heliostat field were much larger than optimum for the small Solar Two receiver. Between 20 and 30\% of the beams missed the receiver, reducing heliostat field performance. Although the Lugo heliostats provided needed power to south side of the receiver, their efficiency was very low. A commercial plant would have heliostats optimized for the receiver, both in terms of size and canting. In addition, properly designed heliostat will not have mirror corrosion problems. It is also likely a commercial plant would have an automated BCS that runs without operator intervention.

\subsubsection{Field Availability}

The availability goal of $98 \%$ for Solar Two was based on the high availability (>99\%) achieved for several years during the Solar One project. However, restarting the heliostat field at Solar Two after it had sat idle for six years introduced major maintenance and reliability issues. The heliostat field rarely experience higher than $94 \%$ availability. A new plant that is maintained continuously will likely have availability similar to Solar One.

\subsubsection{Mirror Cleanliness}

The goal for mirror cleanliness at Solar Two was 95\%. This value was based on years of mirror washing experience at the Kramer Junction SEGS plants (Cohen, et. al, 1999). However, because of the extra man-power required to maintain the aging heliostat field, washing was a low priority. The cleanliness goal of 95\% was achieved during short periods, but not at the same time the field availability was at $94 \%$. Typically, the mirror cleanliness was in the low 90s. In a commercial plant, it is expected that heliostat maintenance will not be such a burden that heliostat washing suffers.

\subsubsection{Receiver Efficiency}

Solar Two met the receiver efficiency goal. A new plant is expected to have a similar efficiency to the Solar Two receiver. It should be noted that the Solar Two receiver had 1/3 the surface area of the Solar One receiver. The smaller Solar Two receiver had much lower heat losses than Solar One's receiver, resulting in better efficiency (88\% versus 78\% (Radosevich, 1988)). With advanced metal alloys, higher fluxes are feasible, allowing even more compact, efficient receivers. However, an optimization study must be done to trade off heliostat field performance with receiver efficiency to yield the lowest levelized energy cost.

\subsubsection{Storage Efficiency}

The goal for thermal storage efficiency was met. The efficiency was nearly unity (99.5\%) because the rate of heat loss from the thermal storage system was small relative to the rate heat 
demanded by the steam generator (184 $\mathrm{kW}$ versus $35000 \mathrm{~kW})$. In a commercial plant, the heat loss should be an even smaller fraction of the heat demanded by the steam generator.

\subsubsection{Electric Power Generation System}

The gross thermal-to-electric conversion efficiency goal was met. The Solar Two turbine did not have reheat capability. It efficiency was limited to $34 \%$. Larger steam turbines that have reheat will be more efficient, e.g., will reach $42 \%$.

\subsubsection{Parasitics}

Solar Two essentially met the peak parasitic goals. The commercial goal is expected to be higher than Solar Two because the parasitic loads in a commercial plant will be a smaller fraction of the electrical power output. Some loads do not scale linearly with plant output. For example, a commercial plant generating 10 times the energy of Solar Two will have only one control room and one administration building. Also, power required by heat trace will scale less than linearly with the plant electrical rating.

\subsubsection{Overall Peak Efficiency}

The overall peak efficiency is the combined effect of the aforementioned parameters. Solar Two performance fell short of the peak efficiency goal primarily because of the poor field performance. A commercial plant will have a heliostat field with advanced electronics, glass mirrors, and a reheat turbine, and will be larger as well. The commercial plant efficiency values are reasonable extrapolations.

\subsection{Daily Thermal Collection}

Plant performance over longer periods was also of interest. Figure 6-1 shows the daily thermal energy collected as a function of daily incident insolation between July and mid-November 1998. The figure also includes a curve fit of SOLERGY predictions for $90 \%$ heliostat field availability and $90 \%$ cleanliness when the receiver was operated for a full day. SOLERGY is a code that predicts the performance of central receiver power plants (Stoddard et al., 1987). With typical heliostat availability between 88 and $94 \%$ and the known mirror degradation, the daily performance approached the predicted SOLERGY curve for 90\% field availability/90\% cleanliness on many days when the receiver operated for the full day. As the figure shows, many data points fall below the predicted curve. On those days, the plant failed to collect the expected amount of energy due to issues with receiver start-up, partial operation during testing, system debugging, test preparation, equipment failure, or lack of operator experience. These plant outages were not unusual for a first-of-the-kind prototype of a new technology. As more experience was gained with this technology and issues were worked through, more points would approach the design performance goal. A detailed evaluation of the plant outages during the period November 1, 1997 to April 8, 1999 can be found in Appendix P. 


\subsection{Daily Conversion Efficiency}

Another measure of the daily plant performance was how much of the daily energy sent to the steam generator was converted into electrical energy. This data is shown in Figure 6-2. As shown, a certain amount of energy was required to start up the SGS and keep the system warm at night and on cloudy days, indicated by the non-zero intercept. The data agreed well with the SOLERGY predictions. For several days in the month of July, when the energy sent to the SGS was $250 \mathrm{MWh}$ or greater, the performance was below the predicted line. The lower performance occurred when the turbine operated at a partial load (between 1 to $5 \mathrm{MW}$ ) to conduct a dispatchability test. At partial load, the cycle efficiency was lower.

\subsection{Parasitic Power Consumption}

The final measure of daily plant performance was how well Solar Two met its parasitic power consumption goal. In Figure 6-3, the daily plant parasitics are compared with the SOLERGY goals. It shows that the daily goals for parasitic power consumption were met after parasitic reduction methods were implemented in September-November of 1998. The goal was accomplished by turning off unnecessary cooling water pumps, plant lights, and altering the setpoints and operating procedures of the heat-trace circuits within the plant. Heat-trace consumption was $\sim 3 \mathrm{MWh}$ /day after implementing the parasitic reduction methods (Kolb, 2000). Details of evaluations of the Solar Two heat trace system can be found in Appendix Q. An evaluation of energy conservation at Solar Two is in Appendix R.

It should be noted that parasitics were generally high at Solar Two, even after achieving the goal (e.g. shown as $25 \%$ on an $80 \mathrm{MWh}$ day in Figure 6-3). The parasitic energy consumption was a fraction of the gross production because, as a non-commercial plant, Solar Two had a low annual capacity factor (only 20\%). In commercial plants designed to have high annual capacity factors (40 to 70\%), parasitic consumption is predicted to be about $10 \%$ of gross output. A commercial plant would also use a more efficient turbine. Thus, online parasitics in a commercial plant for similar categories of auxiliary equipment would be a smaller fraction of the gross turbine output. In addition, high-capacity-factor commercial plants will operate for longer periods of time each day. Offline parasitic consumption will be a smaller fraction of the total gross generation. Newer technology will also enable the heliostat-field electronics to be turned off, saving electricity consumed during offline periods.

\subsection{Dispatchability}

The dispatchability tests demonstrated the capability of Solar Two to satisfy a wide range of load-shifting requirements. The tests were run at various power levels and during periods when solar energy collection was not possible.

Producing electricity continuously for nearly one week underscored both the power-dispatch flexibility of a molten salt power tower plant, as well as the continuous improvements in operation of Solar Two. In July 1998, the plant produced electricity continuously for 154 hours, clearly showing the dispatchability potential of this technology. 
Demonstrating the ability to operate continuously affords some interesting options for plant design, operation, and maintenance. Continuous operation avoided the energy penalties associated with daily startup of the SGS and EPGS. Continuous operation also improved plant water chemistry. In addition, continuous operation quickly established maintenance priorities, both in terms of overnight maintenance (for example, on the receiver system) and for the next non-operational period for the steam generation and EPGS. These considerations will become increasingly important as plants are built with higher capacity factors, larger storage systems, and longer operating days. Details of the dispatchability test are included in Appendix S.

\subsection{Analysis of Plant Outages}

A detailed analysis of the plant operations during November 1, 1998 to April 8, 1999 was conducted to determine the major causes and resolution of the plant outages. These outages, the number of days they affected the plant operations, and the number of events are shown in Table 6-2. The outage that affected the plant the longest (the downcomer pipe failure) was caused by the pipe binding in the expanded position. Upon cooling, it was unable to contract, leading to a rupture. The piping expansion system was faulty due to an ill-defined design interface between the receiver supplier, who provided the piping on top of the tower, and the architect engineer, who provided the piping within the tower itself. The repair took longer than it should have because the project was almost out of funding and there was considerable debate over whether or not to fix it. The piping system was modified to accept the anticipated amount of expansion. The second and third major outages that affected plant operation were issues related to the Solar Two project, not the plant. The details of these plant outages can be found in Appendix P. 
Table 6-2 Outages at Solar Two from November 1, 1997 to April 8, 1999

\begin{tabular}{|c|c|c|}
\hline $\begin{array}{l}\text { Number of } \\
\text { Days } \\
\text { Problem } \\
\text { Affected } \\
\text { Plant }\end{array}$ & $\begin{array}{l}\text { Number of } \\
\text { Events }\end{array}$ & Problem Description \\
\hline 60 & 1 & Downcomer pipe ruptured \\
\hline 42 & -- & Plant shut down for weekend \\
\hline 32 & -- & Special testing performed \\
\hline 31 & 31 & Receiver tube plugging delayed startup \\
\hline 24 & 24 & Operators did not operate plant \\
\hline 21 & 1 & Warped partition plate in steam generator superheater \\
\hline 20 & 20 & High winds hampered operation of plant \\
\hline 19 & 7 & Heliostat aiming problems caused burning of receiver ovens \\
\hline 18 & 18 & Master control system/interlock logic system trips \\
\hline 17 & 17 & Receiver valve malfunctioned \\
\hline 12 & 4 & Receiver tube leaked \\
\hline 11 & 1 & Receiver panel replacement \\
\hline 7 & 1 & Hot Tank inspection \\
\hline 6 & 6 & Interruptions in power supply to heliostat field \\
\hline 6 & 1 & Poor water chemistry in steam generator \\
\hline 6 & 5 & Heat trace failure \\
\hline 5 & 4 & Heatup of steam generator after plant outage \\
\hline 4 & 4 & Malfunction of steam dump to condenser \\
\hline 4 & 4 & Operator error during startup of steam generator \\
\hline 3 & 1 & Electronics failures due to rain intrusion \\
\hline 3 & 3 & Malfunction of heliostat DAPS \\
\hline 3 & 3 & Steam-turbine generator trip \\
\hline 3 & 3 & Steam-generator trip \\
\hline 3 & 2 & Heliostat bias problems \\
\hline 3 & 3 & Receiver flow control cycled during cloudy weather \\
\hline 2 & 2 & Salt-flow meter failure \\
\hline 2 & 2 & Air conditioner failure in remote control buildings \\
\hline 2 & 2 & Maintenance error \\
\hline 2 & 2 & Condenser vacuum problem \\
\hline 2 & 2 & External grid restriction limited power production \\
\hline
\end{tabular}




\section{REFERENCES}

Bradshaw. R. W. and S. H. Goods (2001) Corrosion Resistance of Stainless Steels During Thermal Cycling in Alkali Nitrate Molten Salts, Sandia National Laboratories, Livermore, CA, SAND2001-8518, September 2001.

Cohen, G. E., D. W. Kearney and G. J. Kolb (1999) Final Report on the Operation and Maintenance Improvement Program for Concentrating Solar Power Plants, Sandia National Laboratories, SAND99-1290, June 1999.

Giedt, W. H. (1949) "Investigation of Variation of Point Unit-Heat-Transfer Coefficient around a Cylinder Normal to an Air Stream,” Trans. ASME, vol. 71, pp. 375-381.

Goods, S. H., R. W. Bradshaw, M. R. Prairie, and J. M. Chavez (1994) Corrosion of Stainless and Carbon Steels in Molten Mixtures of Industrial Nitrates, Sandia National Laboratories, SAND94-8211, March 1994.

Goods, S. H., R. W. Bradshaw, M. Clift, and D. R. Boehme (1997) The Effect of Silicon on the Corrosion Characteristics of $2^{1 / 4} \mathrm{Cr}-1 \mathrm{Mo}$ Steel in Molten Nitrate Salt, Sandia National Laboratories, SAND97-8269.

Kistler, B. L. (1987) A Users Manual for Delsol 3, Sandia National Laboratories, Livermore, CA, SAND86-8018.

Kolb, G. J. (1993) "Development of a Control Algorithm for a Molten-Salt Solar Central Receiver in a Cylindrical Configuration" Solar Engineering 1992, Proceedings of the 1992 ASME JSES KSES International Solar Energy Conference, April 1992, Maui, HI.

Kolb, G. J. (2000) "Methods for Reducing Parasitic Consumption Associated with the Use of Molten Salt at the Solar Two Power Tower," ASME proceeding of Solar 2000, the joint ASME/ASES/AIA Solar Energy Conference, June 16-22, 2000, Madison, Wisconsin.

Jones, S. A., and K. Stone (1999) "Analysis of Strategies to Improve Heliostat Tracking at Solar Two," SAND99-0092C, Proceedings of the Renewable and Advanced Energy Systems for the 21st Century, a joint ASME/JSME/JSES/KSME International Conference April 11-15, 1999, Maui, Hawaii.

Mavis, C.L. (1988) 10 MWe Solar Thermal Central Receiver Pilot Plant Heliostat and Beam Characterization System Evaluation, Nov. 1981-Dec. 1986, Sandia National Laboratories, SAND87-8003, May 1988.

Pacheco, J. E., R. M. Houser, and A. Neumann (1994) "Concepts to Measure Flux and Temperature for External Central Receivers," Solar Engineering 1994, Proceedings of the 1994 ASME, JSME, JSES International Solar Energy Conference, March 27-30, 1994, San Francisco, CA. 
Pacheco, J. E. and Dunkin, S. R. (1996) “Assessment of Molten-Salt Solar Central- Receiver Freeze-up and Recovery Events" Proceedings of the 1996 ASME International Solar Energy Conference, San Antonio, TX.

Pacheco, J. E., Ralph, M. E., Chavez, J. M., Dunkin, S. R., Rush, E. E., Ghanbari, C. M., and Matthews, M. W. (1995) Results of Molten Salt Panel and Component Experiments for Solar Central Receivers: Cold Fill, Freeze/Thaw, Thermal Cycling and Shock, and Instrumentation Tests, Sandia National Laboratories, SAND94-2525.

Radosevich, L.G. (1988) Final Report on the Power Production Phase of the 10 MWe Solar Thermal Central Receiver Pilot Plant, Sandia National Laboratories, SAND87-8082.

Smith, D. C., Chavez, J. M. (1992) A Final Report on the Phase I Testing of a Molten-Salt Cavity Receiver, Volume II - The Main Report, Sandia National Laboratories, SAND87-2290.

Smith, D. C., Rush, E. E., Mathews, C. W., Chavez, J. M., and Bator, P. A. (1992) Report on the Test of the Molten-Salt Pump and Valve Loops, Sandia National Laboratories, SAND91-1747.

Stoddard, M. C., et. al. (1987) SOLERGY - A Computer Code for Calculating the Annual Energy from Central Receiver Power Plants, Sandia National Laboratories, Livermore, CA, SAND868060 .

Stone, K., S.A. Jones (1999) "Analysis of Solar Two Heliostat Tracking Error Sources at Solar Two," SAND99-0092C, Proceedings of the Renewable and Advanced Energy Systems for the 21st Century, a joint ASME/JSME/JSES/KSME International Conference, April 11-15, 1999, Maui, Hawaii.

Vant-Hull, L. L., and Pitman, C. L. (1988) "Central Receiver System Optimization Under An Allowable Flux Constraint," Proceedings 4th International Symposium on Solar Thermal Technology-Research, Development and Applications, Santa Fe, NM, June, 1988, ed. Gupta, B. P. and Traugott, W. H., Hemisphere Publishing Corporation, New York, pp. 51-60.

Vant-Hull, L. L., Izygon, M. E. and Pitman, C. L. (1993) "Results of a Heliostat Field: Receiver Analysis for Solar Two," Solar Engineering 1993, A. Kirkpatrick and W. Worek eds., ASME Book No. H00785, pp. 413-419.

Vant-Hull, L. L., Izygon, M. E. and Pitman, C. L. (1996a) "Real Time Computation and Control of Solar Flux Density on a Central Receiver (Solar Two) (Protection Against Excess Flux Density)," Solar 96, Ed. by R. Campbell-Howe and B. Wilkins-Crowder, Proceedings of the 1996 Annual Conference, American Solar Energy Society, Asheville, North Carolina

Vant-Hull, L. L., Izygon, M. E. and Pitman, C. L. (1996b) "Real Time Computation and Control of Solar Flux Density on a Central Receiver (Solar Two - Preheat)," Solar Engineering 1996, Ed. by J. H. Davidson and J. Chavez, presented at 1996 ASME International Solar Energy Conference, San Antonio, TX. 
Walzel, M. D., Lipps, F. W., and Vant-Hull, L. L (1977) “A Solar Flux Density Calculation for a Solar Tower Concentrator Using a two-dimensional Hermite Function Expansion," Solar Energy 19, no. 3, pp. 239-253. 
Final Test and Evaluation Results from the Solar Two Project 


\section{Detailed Test and Evaluation Reports}

Appendix A. Evaluation of Heliostat Walk-On and Walk-Off at Solar Two (J. E.

Pacheco)

A.1 Objective

A.2 Approach

A.3 Walk On

A.4 Walk Off

A.5 Recommendations .................................................................................... 103

Appendix B. Receiver Efficiency Test (J. E. Pacheco) .................................................107

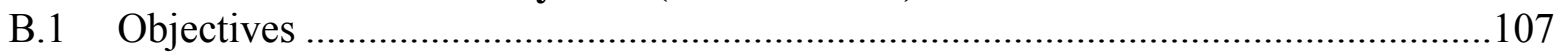

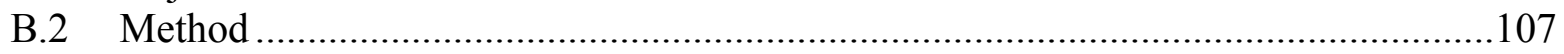

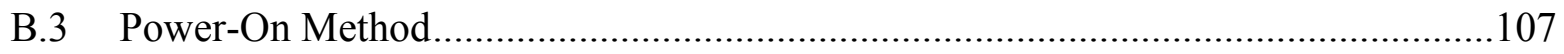

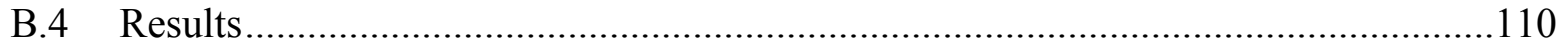

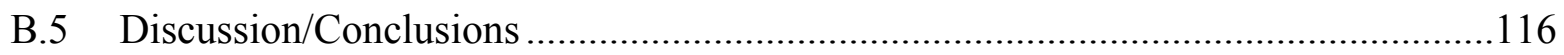

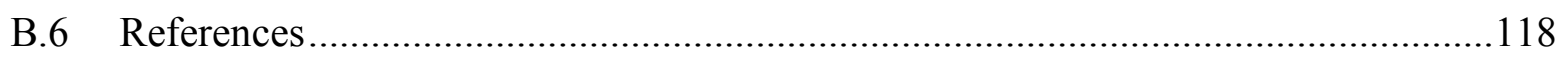

Appendix C. Solar Resource Measurement Quality Assessment at Solar Two (S. A.

Jones).........................................................................................................119

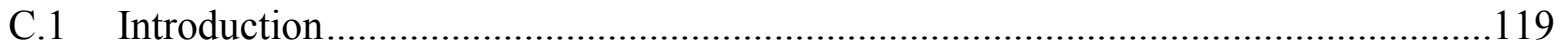

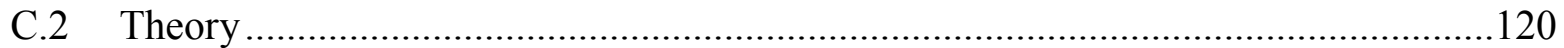

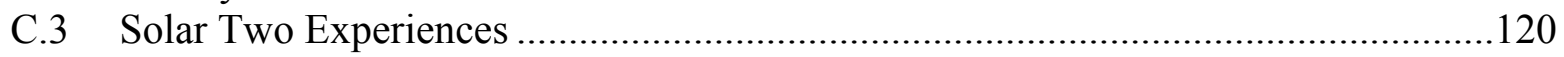

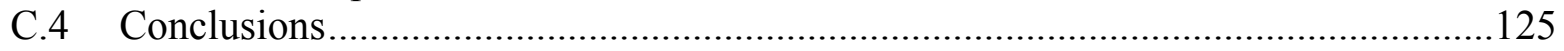

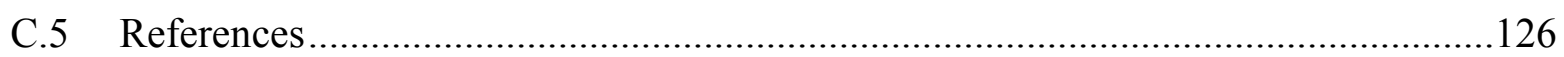

Appendix D. Development and Test of Solar Two Receiver Control Algorithm (G. J.

Kolb).

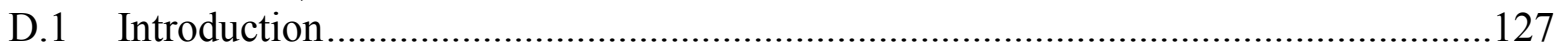

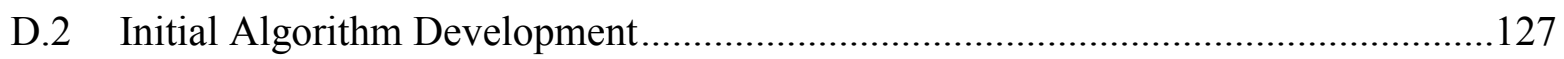

D.3 Implementation of Final Control Algorithm at Solar Two ......................................129

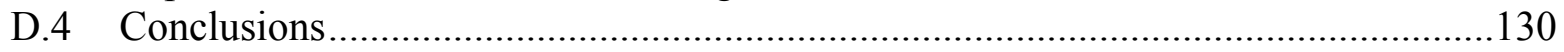

D.5 Receiver Control Algorithm References........................................................133

Appendix E. Nuclear Level Sensor (H. E. Reilly)..................................................135

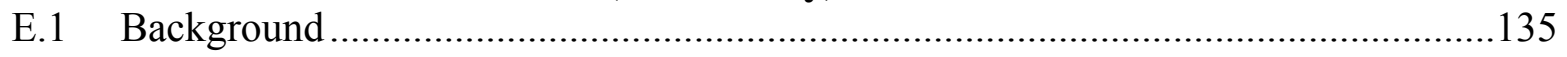

E.2 New Level Sensor .........................................................................................135

Appendix F. Procedure for Thawing Receiver Panels That Have Become Frozen

With Nitrate Salt (J. E. Pacheco) ...................................................................139

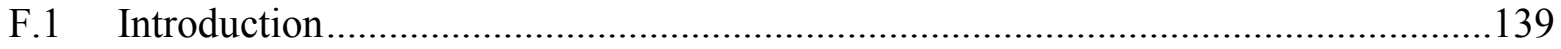

F.2 Thaw Procedure .............................................................................................. 139

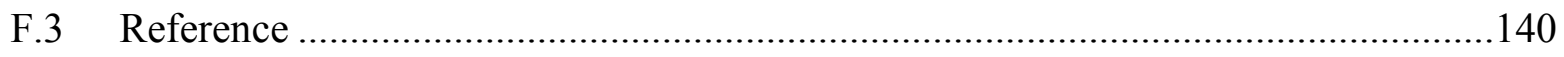

Appendix G. Analysis of Thawing Frozen Salt in the Solar Two Evaporator and

Damage Mitigation (J. E. Pacheco) ................................................................143

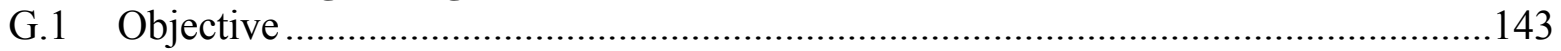

G.2 Stress and Thermal Analysis of Thawing Salt in Tubes .......................................143

G.3 Heat Trace Requirements to Thaw Salt in Channel Sections ..................................147

G.4 Suggested Safe Thawing Approach ................................................................... 150 
G.5 Hardware Requirements.......................................................................... 151

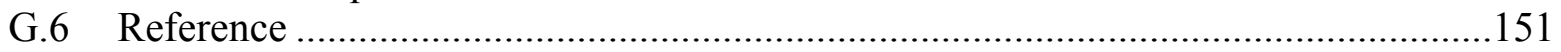

Appendix H. Coupon Corrosion Tests, Salt Chemistry and Post Mortem Analysis (D. Dawson, B. Bradshaw, S. Goods) .............................................................153

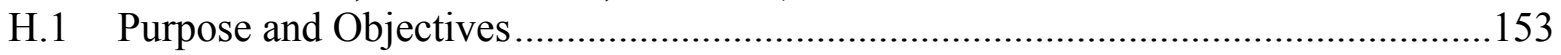

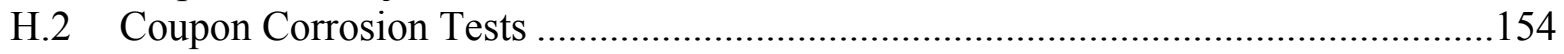

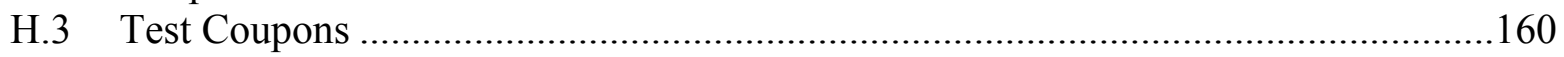

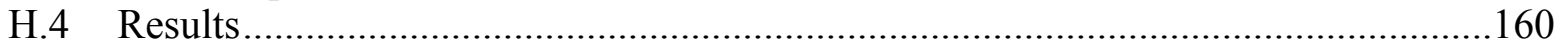

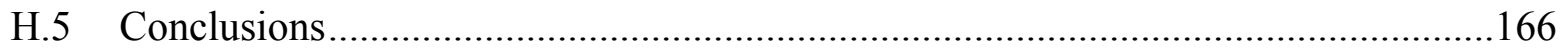

H.6 Salt Chemistry Tests .................................................................................... 166

H.7 Results............................................................................................... 168

H.8 Postmortem Analysis of Selected Portions of the Solar Two Salt System ................170

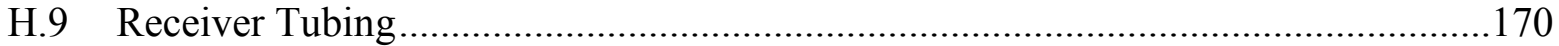

H.10 Storage Tank Alloys ............................................................................... 180

H.11 Conclusions............................................................................................. 189

H.12 References.............................................................................................189

Attachment 1 to Appendix H: Stress Corrosion Cracking Laboratory Tests Supplementary Test (B. Bradshaw, S. Goods, D. Dawson).................................191

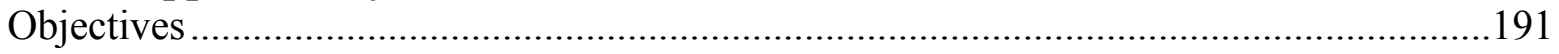

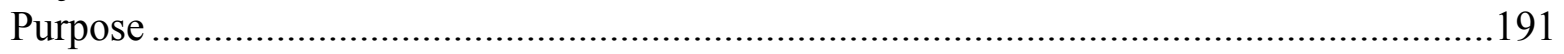

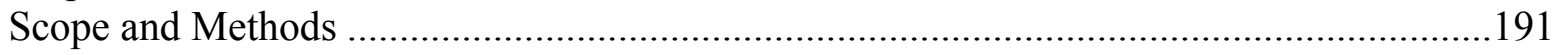

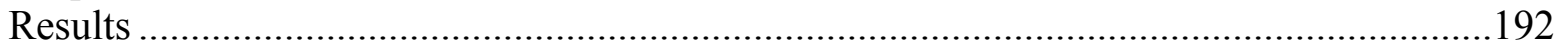

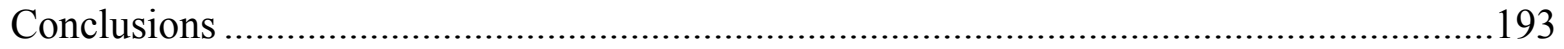

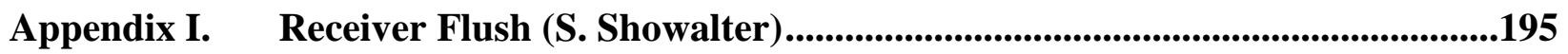

Appendix J. Storage Tank Thermal Stresses Test (J. E. Pacheco) ...................................197

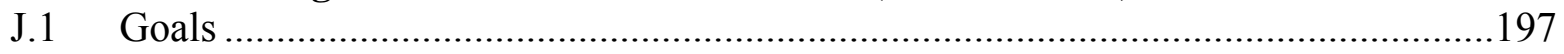

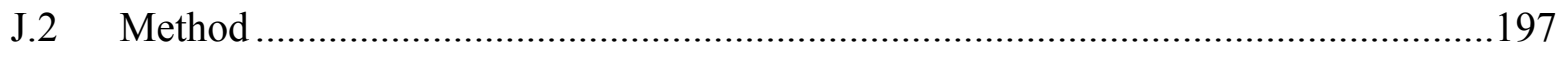

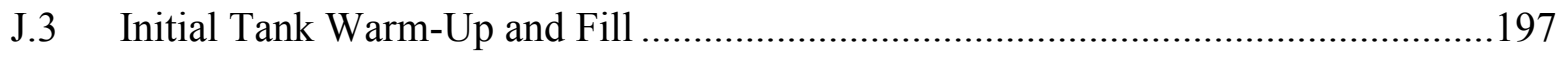

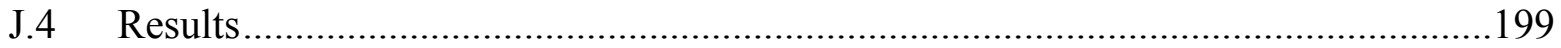

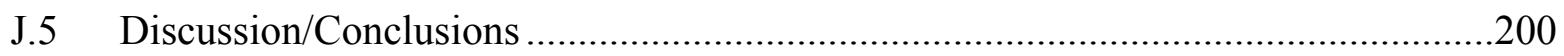

Appendix K. Thermal Losses Throughout the Plant (J. E. Pacheco and R. Gilbert) .....203

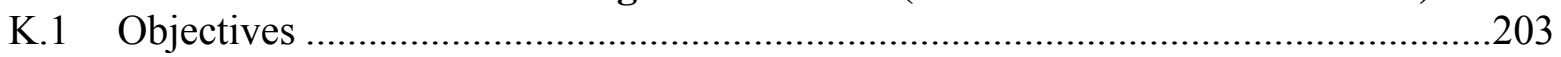

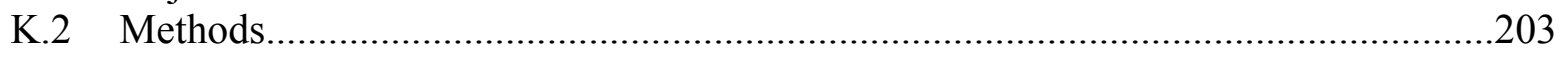

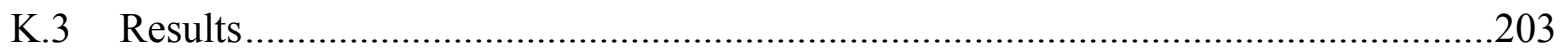

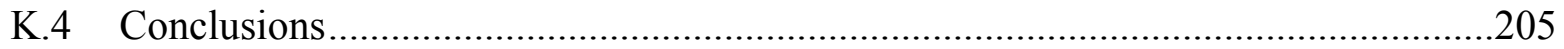

Appendix L. Solar Two Nitrate Salt - Lessons Learned (S. Showalter)...........................207

L.1 Specification and Composition As-Received ...............................................207

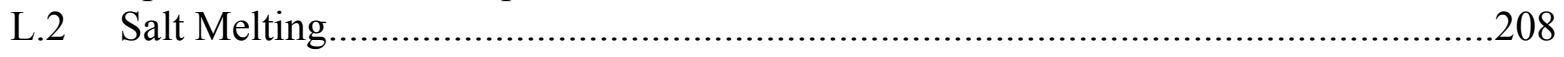

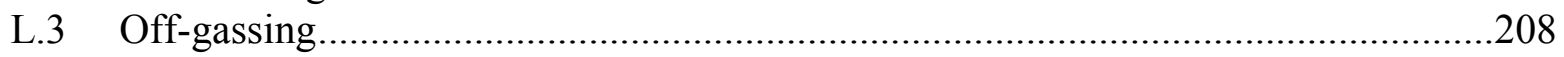

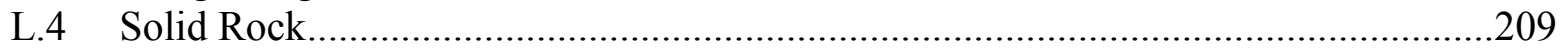

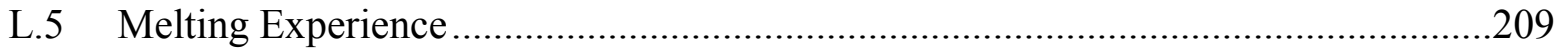

L.6 Changes with Use .....................................................................................209

L.7 Lessons Learned........................................................................................209

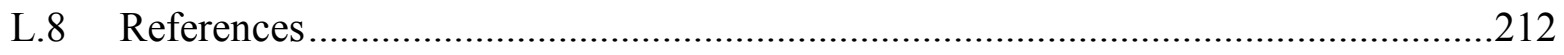




\section{Appendix M. Steam Generator/Electric Power Generation System Characterization}

Test (J. E. Pacheco) ....................................................................................................213

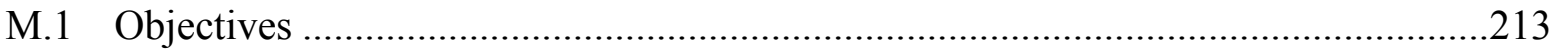

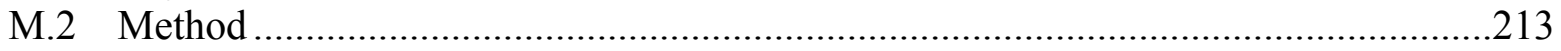

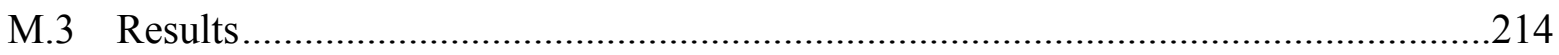

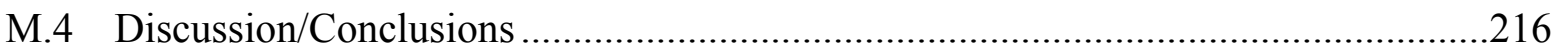

Appendix N. Inspection of Preheater After Using Phosphate Injection System (Wilfredo de la Rosa) ............................................................................................219

Appendix O. Solar Two Performance Evaluation (M. J. Hale) ..............................................221

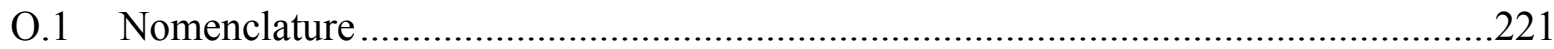

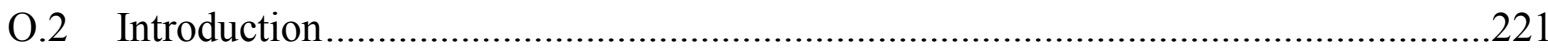

O.3 Method of Lost Electricity Analysis ........................................................................222

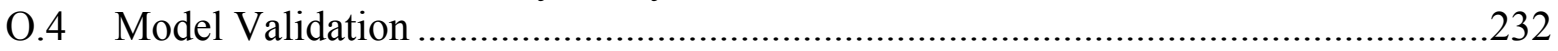

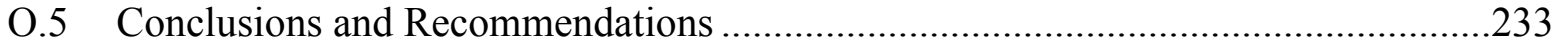

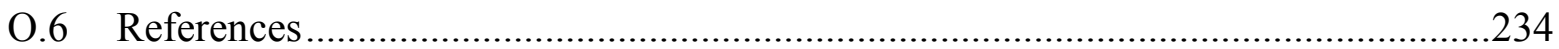

Appendix P. Evaluation of Plant Operations November 1, 1997 to April 8, 1999 (G.

Kolb).................................................................................................................235

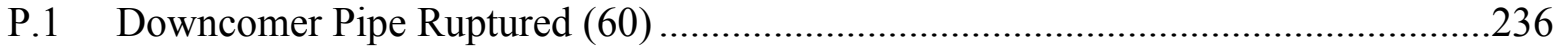

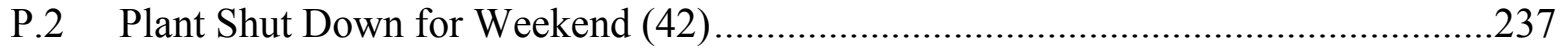

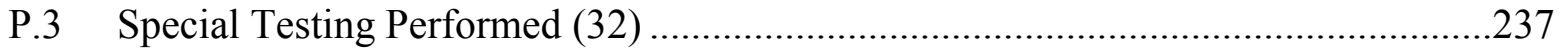

P.4 Receiver Tube Plugging Delays Startup (31) ………..........................................237

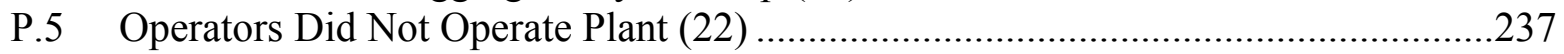

P.6 Warped Partition Plate in Steam Generator Superheater (21) ..................................238

P.7 High Winds Hampered Operation of Plant (20) ....................................................238

P.8 Heliostat Aiming Problems Cause Burning of Receiver Ovens (19) ........................239

P.9 Master Control System/Interlock Logic System Trips (18).....................................239

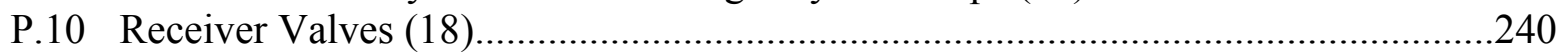

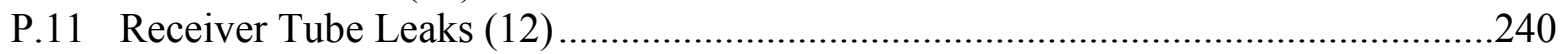

P.12 Receiver Panel Replacement (11) .....................................................................24

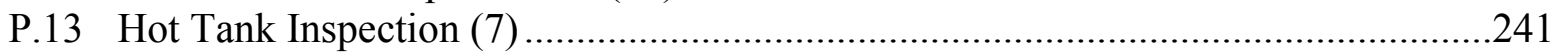

P.14 Interruptions in Power Supply to Heliostat Field (6) ...............................................24

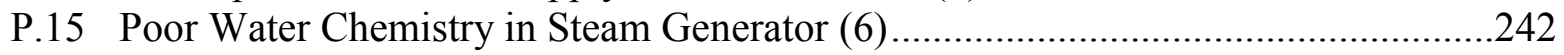

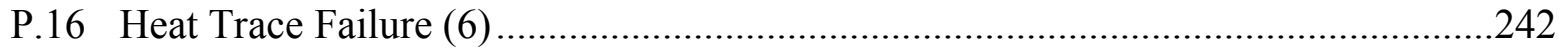

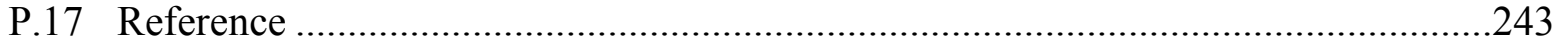

Appendix Q. Test and Evaluation of Solar Two Heat Trace System (G. J. Kolb) ...........245

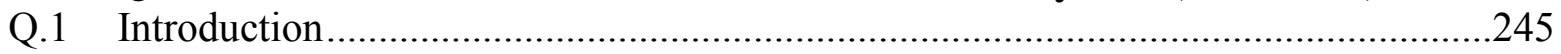

Q.2 Design, Operation, and Reliability of the Solar Two Heat Trace System .................245

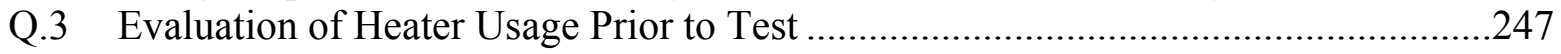

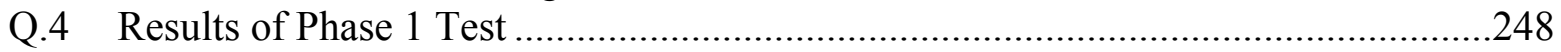

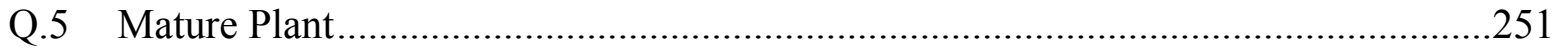

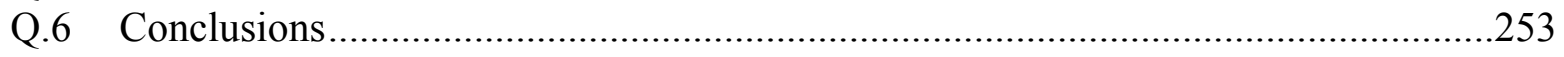

Q.7 References for Heat Trace System Test and Evaluation...........................................254

Appendix R. Energy Conservation at Solar Two (P. C. Jacobs)............................................255

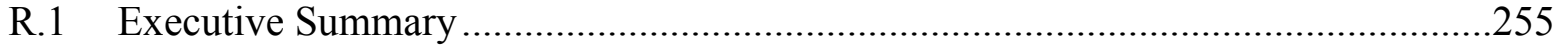

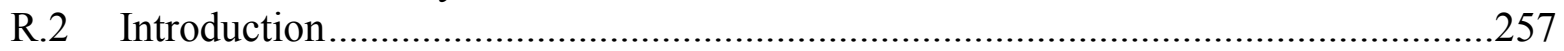




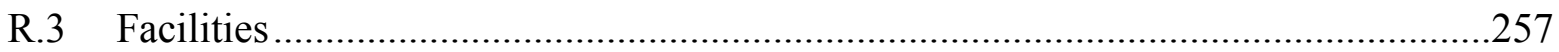

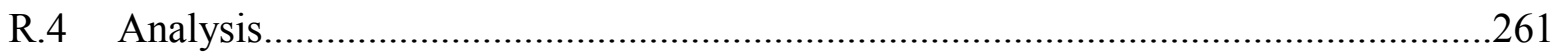

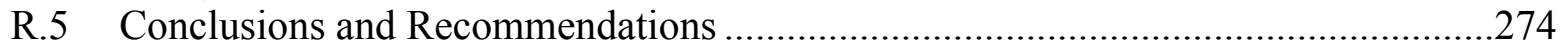

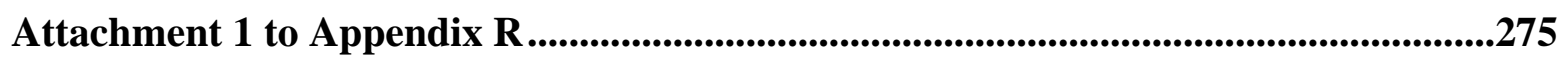

Appendix S. Dispatchability Test (H. E. Reilly and R. Gilbert) ...................................283

S.1 Goals and Objectives ..............................................................................283

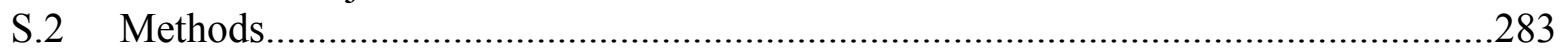

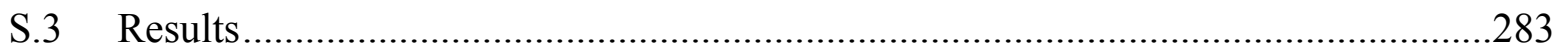

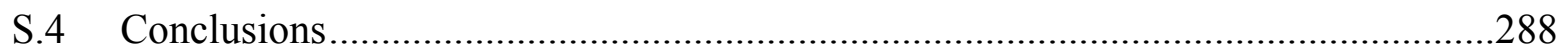




\section{Appendix A. Evaluation of Heliostat Walk-On and Walk-Off at Solar Two (J. E. Pacheco)}

\section{A.1 Objective}

This evaluation determined where the heliostats at Solar Two would drift during a power failure, assuming the heliostats freeze at their last position while the sun moves, and to determine what damage the drifting beams could do. It is likely that power failures could occur as often as three times a year.

Two cases were studied: 1) where the heliostats are at the standby aim points when power is lost (walk on) and 2) where the heliostats are on track, aimed at the receiver, when power is lost (walk off). The major concerns are where the heliostat beams drift and what structure (receiver, flashing above and below the receiver, Beam Characterization System (BCS) target, tower) they hit - in particular, if they hit the tower and cable trays - and how long it takes for all the heliostats to walk off the receiver.

\section{A.2 Approach}

Three days of the year (summer solstice, winter solstice, and spring equinox) and five times of day for each of these days (early morning, mid-morning, noon, mid-afternoon, and late afternoon) were examined for walk on and walk off. A Microsoft Excel spreadsheet with macros was used for all the computations. Sigma Plot was used to graph the results. For a particular time of day and day of year, the unit vector of the sun position was calculated. Unit target vectors were also calculated for each of the 1926 heliostats from its location to its aim point. Using each unit target vector and the sun-position unit-vector, each heliostat normal vector was calculated. Next, a new sun position and unit vector were calculated corresponding to a given amount of time since a power failure. Using the old heliostat normal vector and the new sun position, a new target vector was calculated. The time after power failure was incremented to determine where the beams go and what they hit.

The receiver, header ovens, flashing, BCS target, and tower were modeled as cylinders. To determine where the heliostat beam centroid hit, each target vector along with the heliostat location formed a line that will either intersect or miss each structure of interest. The number of hits was summed for each area of interest along with the total number of hits. Note that this analysis only looks where the centroid of each heliostat hit. In reality, each Solar One MM heliostat has a beam size nominally 7.0 meters in diameter. The recanted MM heliostats will have a smaller beam size and the Lugos will have larger beam sizes. This analysis shows trends for where the beams hit and from which direction. The analysis did not calculate flux levels. Other codes, such as DELSOL, could be used to estimate flux levels. 


\section{A.3 Walk On}

"Walk on" refers to heliostats at the standby aim point that drift onto the structure of interest during a power failure. There were four standby aim points used at any one time. Between February and October, one set of standby aim points was used, as illustrated in Figure A-1 and Figure A-2. Between November and January, another set was used. For beam safety for aviation, wire walks were defined (from Solar One) to eliminate beam hazard problems when moving heliostats from the stow position to the standby aim points.

When the site power fails, the positions of the heliostats become fixed, and the heliostat beams drift in the opposite direction as the sun moves. As the sun moves towards the west, the beams will drift to the east. The heliostats that are aimed at the west standby aim points are at risk for drifting onto the tower structure, BCS, receiver, etc.

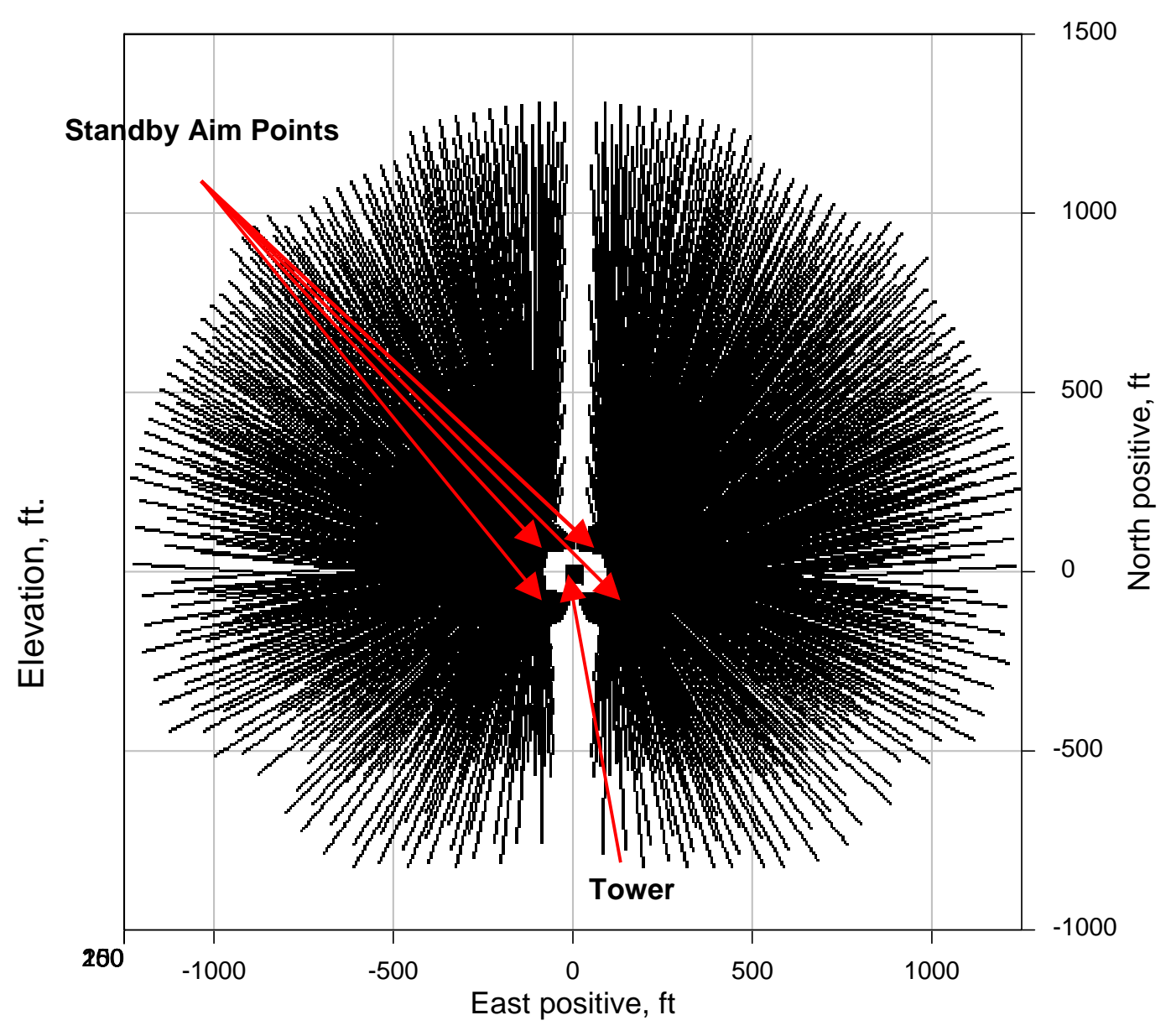

Figure A-1. Solar Two standby aimpoints viewed from above for February to October. Each line represents a ray going from the center of the heliostat through the aim point to an elevation of $85 \mathrm{~m}$ (280 ft) above the ground. 


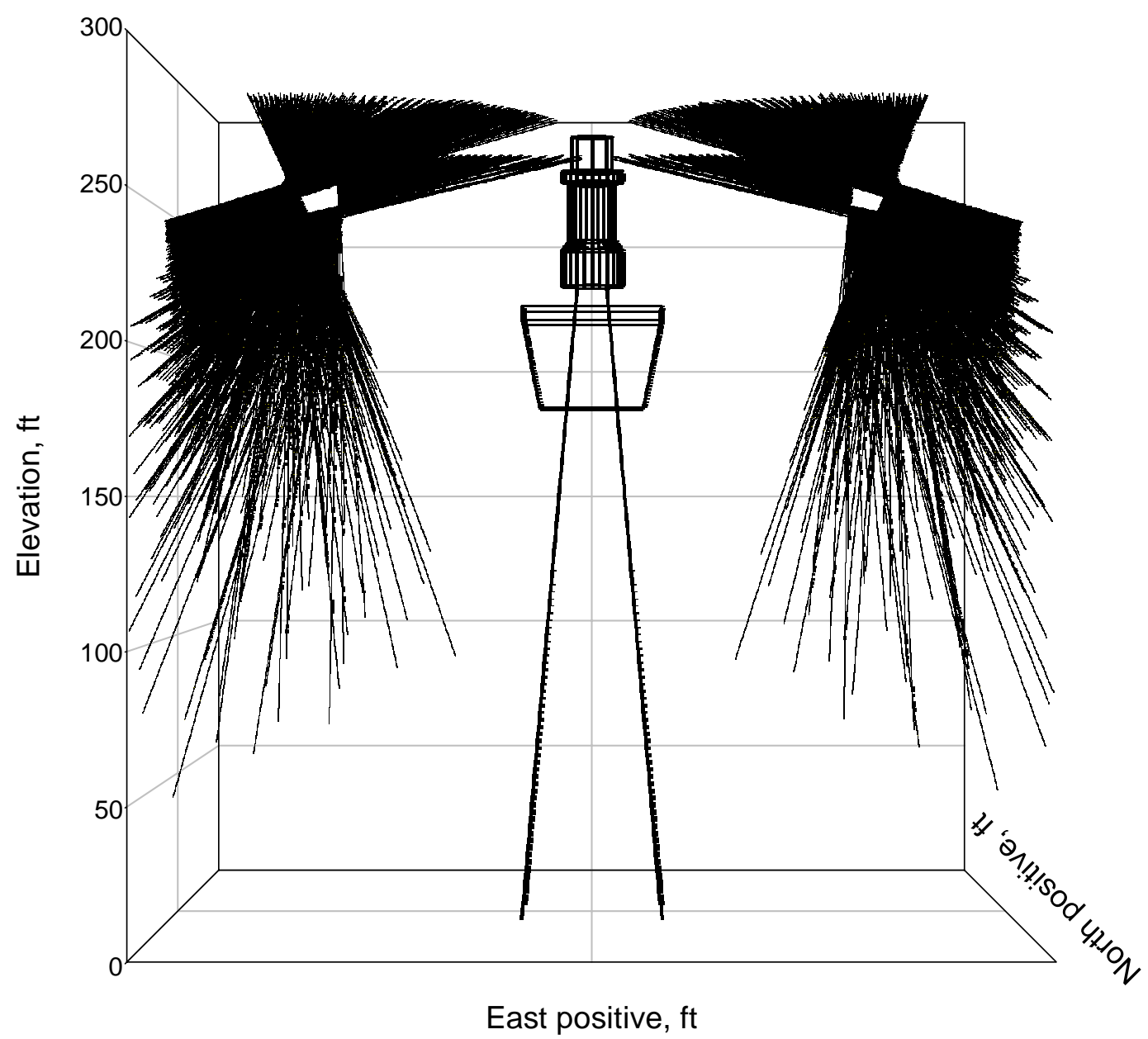

Figure A-2. Solar Two standby aimpoints viewed from the south looking north for February to October. Each line represents a ray going from the center of the heliostat through the aim point to an elevation of $85 \mathrm{~m}(280 \mathrm{ft})$ above the ground.

Table A-1 summarizes the walk-on analysis. For each of the three days, the total number of beams whose centroid intersects each region of interest is shown at various times of the day and times after a power failure. The total number of hits is broken down into various regions where the beams intersect the upper receiver flashing, upper receiver header oven, receiver, lower header oven, parapet on the BCS deck, BCS targets, and tower structure.

In most cases, the drifting beams miss the receiver. In the early morning (near sunrise) in the summer and at mid-morning on the equinox and winter solstice, the majority of the heliostats that hit something drift onto the BCS targets. In the early morning in March and December and at midday in June, the majority of the beams tend to drift onto the tower structure. In the worst case, the tower structure will see as many as 176 heliostats. This occurs on December 21, 40 minutes after a power failure that occurred at 7:30 AM. Most of the beams come from the northwest quadrant of the field. The intersection of the beam centroids with the tower structure is shown in Figure A-3, Figure A-4, and Figure A-5. For a period of 50 minutes, over 100 heliostat 
beams continually drift onto the tower. On December 21, at 9:30 AM (30 minutes after a power failure), 212 heliostats hit the BCS targets. Most of these beams come from the northwest quadrant.

Table A-1. Summary of the Solar Two walk-on analysis. For each of the three days, the number of beams whose centroid intersects the regions of interest is counted for at various times of the day and times after a power failure. The total number of intersections (hits) is broken down into various regions where the beams intersect the upper receiver flashing, upper receiver header oven, receiver, lower header oven, parapet on the BCS deck, BCS targets, and tower structure.

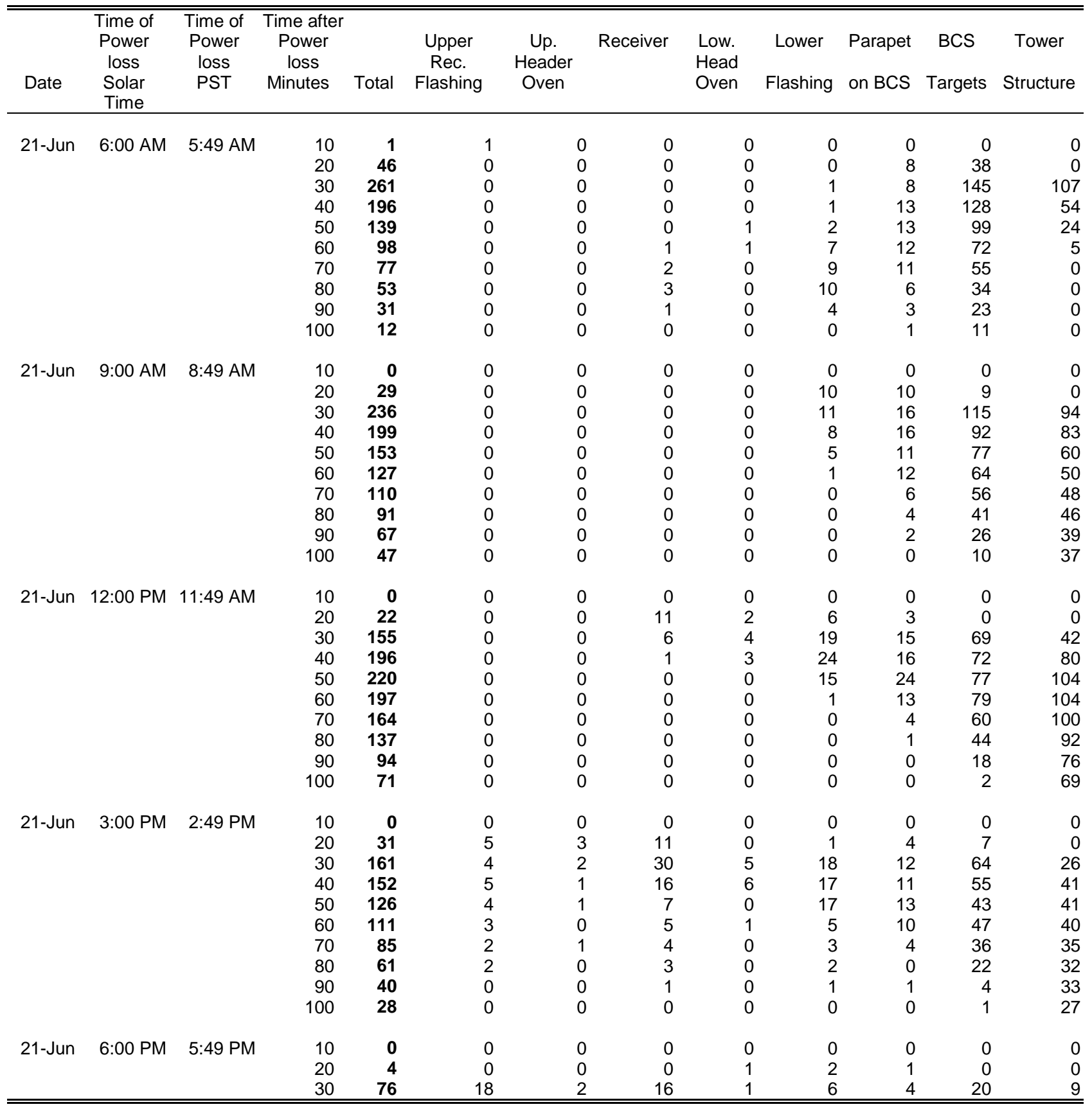


Table A-1. Summary of the Solar Two walk-on analysis. For each of the three days, the number of beams whose centroid intersects the regions of interest is counted for at various times of the day and times after a power failure. The total number of intersections (hits) is broken down into various regions where the beams intersect the upper receiver flashing, upper receiver header oven, receiver, lower header oven, parapet on the BCS deck, BCS targets, and tower structure. (continued)

\begin{tabular}{|c|c|c|c|c|c|c|c|c|c|c|c|c|}
\hline Date & $\begin{array}{l}\text { Time of } \\
\text { Power } \\
\text { loss } \\
\text { Solar } \\
\text { Time }\end{array}$ & $\begin{array}{c}\text { Time of } \\
\text { Power } \\
\text { loss } \\
\text { PST }\end{array}$ & $\begin{array}{c}\text { Time after } \\
\text { Power } \\
\text { loss } \\
\text { Minutes }\end{array}$ & Total & $\begin{array}{l}\text { Upper } \\
\text { Rec. } \\
\text { Flashing }\end{array}$ & $\begin{array}{l}\text { Up. } \\
\text { Header } \\
\text { Oven }\end{array}$ & Receiver & $\begin{array}{l}\text { Low. } \\
\text { Head } \\
\text { Oven }\end{array}$ & $\begin{array}{l}\text { Lower } \\
\text { Flashing }\end{array}$ & $\begin{array}{l}\text { Parapet } \\
\text { on BCS }\end{array}$ & $\begin{array}{c}\text { BCS } \\
\text { Targets }\end{array}$ & $\begin{array}{c}\text { Tower } \\
\text { Structure }\end{array}$ \\
\hline & & & 40 & 66 & 2 & 2 & 18 & 2 & 6 & 3 & 18 & 15 \\
\hline & & & 50 & 61 & 0 & 0 & 3 & 3 & 12 & 7 & 19 & 17 \\
\hline & & & 60 & 53 & 0 & 0 & 0 & 0 & 3 & 5 & 27 & 18 \\
\hline & & & 70 & 44 & 0 & 0 & 0 & 0 & 0 & 1 & 24 & 19 \\
\hline & & & 80 & 26 & 0 & 0 & 0 & 0 & 0 & 0 & 8 & 18 \\
\hline & & & 90 & 20 & 0 & 0 & 0 & 0 & 0 & 0 & 1 & 19 \\
\hline & & & 100 & 20 & 0 & 0 & 0 & 0 & 0 & 0 & 0 & 20 \\
\hline \multirow[t]{10}{*}{ 21-Mar } & 6:00 AM & 5:56 AM & 10 & 0 & 0 & 0 & 0 & 0 & 0 & 0 & 0 & 0 \\
\hline & & & 20 & 28 & 0 & 0 & 0 & 0 & 0 & 4 & 24 & 0 \\
\hline & & & 30 & 188 & 0 & 0 & 0 & 0 & 0 & 4 & 29 & 155 \\
\hline & & & 40 & 174 & 0 & 0 & 0 & 0 & 0 & 1 & 25 & 148 \\
\hline & & & 50 & 139 & 0 & 0 & 0 & 0 & 1 & 2 & 26 & 110 \\
\hline & & & 60 & 104 & 0 & 0 & 0 & 0 & 0 & 0 & 24 & 80 \\
\hline & & & 70 & 74 & 0 & 0 & 0 & 0 & 0 & 1 & 20 & 53 \\
\hline & & & 80 & 51 & 0 & 0 & 0 & 0 & 1 & 0 & 15 & 35 \\
\hline & & & 90 & 26 & 0 & 0 & 0 & 0 & 0 & 0 & 8 & 18 \\
\hline & & & 100 & 13 & 0 & 0 & 0 & 0 & 0 & 0 & 2 & 11 \\
\hline \multirow[t]{10}{*}{ 21-Mar } & $9: 00 \mathrm{AM}$ & 8:56 AM & 10 & 0 & 0 & 0 & 0 & 0 & 0 & 0 & 0 & 0 \\
\hline & & & 20 & 112 & 0 & 0 & 0 & 0 & 0 & 17 & 95 & 0 \\
\hline & & & 30 & 241 & 0 & 0 & 0 & 0 & 0 & 14 & 172 & 55 \\
\hline & & & 40 & 166 & 0 & 0 & 0 & 0 & 0 & 2 & 133 & 31 \\
\hline & & & 50 & 124 & 0 & 0 & 0 & 0 & 0 & 4 & 101 & 19 \\
\hline & & & 60 & 91 & 0 & 0 & 0 & 0 & 0 & 0 & 74 & 17 \\
\hline & & & 70 & 71 & 0 & 0 & 0 & 0 & 0 & 1 & 50 & 20 \\
\hline & & & 80 & 55 & 0 & 0 & 0 & 0 & 0 & 0 & 33 & 22 \\
\hline & & & 90 & 34 & 0 & 0 & 0 & 0 & 0 & 0 & 11 & 23 \\
\hline & & & 100 & 23 & 0 & 0 & 0 & 0 & 0 & 0 & 0 & 23 \\
\hline \multirow[t]{10}{*}{ 21-Mar } & 12:00 PM & $11: 56$ AM & 10 & 0 & 0 & 0 & 0 & 0 & 0 & 0 & 0 & 0 \\
\hline & & & 20 & 125 & 0 & 0 & 21 & 8 & 15 & 27 & 54 & 0 \\
\hline & & & 30 & 182 & 0 & 0 & 9 & 6 & 24 & 28 & 108 & 7 \\
\hline & & & 40 & 165 & 0 & 0 & 0 & 3 & 31 & 25 & 90 & 16 \\
\hline & & & 50 & 150 & 0 & 0 & 0 & 0 & 16 & 23 & 86 & 25 \\
\hline & & & 60 & 121 & 0 & 0 & 0 & 0 & 1 & 12 & 75 & 33 \\
\hline & & & 70 & 101 & 0 & 0 & 0 & 0 & 0 & 4 & 60 & 37 \\
\hline & & & 80 & 72 & 0 & 0 & 0 & 0 & 0 & 2 & 35 & 35 \\
\hline & & & 90 & 46 & 0 & 0 & 0 & 0 & 0 & 0 & 16 & 30 \\
\hline & & & 100 & 29 & 0 & 0 & 0 & 0 & 0 & 0 & 2 & 27 \\
\hline \multirow[t]{10}{*}{ 21-Mar } & 3:00 PM & $2: 56 \mathrm{PM}$ & 10 & 0 & 0 & 0 & 0 & 0 & 0 & 0 & 0 & 0 \\
\hline & & & 20 & 94 & 11 & 2 & 25 & 2 & 18 & 11 & 25 & 0 \\
\hline & & & 30 & 132 & 23 & 4 & 22 & 3 & 16 & 11 & 44 & 9 \\
\hline & & & 40 & 125 & 7 & 5 & 26 & 3 & 13 & 10 & 42 & 19 \\
\hline & & & 50 & 108 & 1 & 0 & 22 & 3 & 11 & 9 & 36 & 26 \\
\hline & & & 60 & 96 & 3 & 0 & 8 & 5 & 18 & 9 & 28 & 25 \\
\hline & & & 70 & 75 & 2 & 0 & 3 & 0 & 9 & 8 & 29 & 24 \\
\hline & & & 80 & 70 & 1 & 1 & 1 & 1 & 4 & 4 & 33 & 25 \\
\hline & & & 90 & 40 & 0 & 0 & 0 & 0 & 1 & 0 & 16 & 23 \\
\hline & & & 100 & 24 & 0 & 0 & 0 & 0 & 0 & 0 & 2 & 22 \\
\hline 21-Mar & 6:00 PM & 5:56 PM & 10 & 0 & 0 & 0 & 0 & 0 & 0 & 0 & 0 & 0 \\
\hline
\end{tabular}


Table A-1. Summary of the Solar Two walk-on analysis. For each of the three days, the number of beams whose centroid intersects the regions of interest is counted for at various times of the day and times after a power failure. The total number of intersections (hits) is broken down into various regions where the beams intersect the upper receiver flashing, upper receiver header oven, receiver, lower header oven, parapet on the BCS deck, BCS targets, and tower structure. (concluded)

\begin{tabular}{|c|c|c|c|c|c|c|c|c|c|c|c|c|}
\hline Date & $\begin{array}{l}\text { Time of } \\
\text { Power } \\
\text { loss } \\
\text { Solar } \\
\text { Time }\end{array}$ & $\begin{array}{l}\text { Time of } \\
\text { Power } \\
\text { loss } \\
\text { PST }\end{array}$ & $\begin{array}{l}\text { Time after } \\
\text { Power } \\
\text { loss } \\
\text { Minutes }\end{array}$ & Total & $\begin{array}{l}\text { Upper } \\
\text { Rec. } \\
\text { Flashing }\end{array}$ & $\begin{array}{l}\text { Up. } \\
\text { Header } \\
\text { Oven }\end{array}$ & Receiver & $\begin{array}{l}\text { Low. } \\
\text { Head } \\
\text { Oven }\end{array}$ & $\begin{array}{l}\text { Lower } \\
\text { Flashing }\end{array}$ & $\begin{array}{l}\text { Parapet } \\
\text { on BCS }\end{array}$ & $\begin{array}{c}\text { BCS } \\
\text { Targets }\end{array}$ & $\begin{array}{l}\text { Tower } \\
\text { Structure }\end{array}$ \\
\hline & & & 20 & 34 & 9 & 3 & 6 & 2 & 5 & 3 & 6 & 0 \\
\hline & & & 30 & 32 & 5 & 1 & 5 & 2 & 2 & 3 & 10 & 4 \\
\hline & & & 40 & 28 & 4 & 1 & 3 & 0 & 3 & 3 & 7 & 7 \\
\hline & & & 50 & 31 & 4 & 2 & 4 & 1 & 2 & 2 & 9 & 7 \\
\hline & & & 60 & 40 & 12 & 0 & 7 & 1 & 1 & 3 & 7 & 9 \\
\hline & & & 70 & 33 & 0 & 0 & 7 & 2 & 5 & 2 & 7 & 10 \\
\hline & & & 80 & 23 & 0 & 0 & 1 & 0 & 2 & 2 & 9 & 9 \\
\hline & & & 90 & 15 & 0 & 0 & 0 & 0 & 0 & 1 & 6 & 8 \\
\hline & & & 100 & 11 & 0 & 0 & 0 & 0 & 0 & 0 & 2 & 9 \\
\hline \multirow[t]{10}{*}{ 21-Dec } & 7:30 AM & 7:17 AM & 10 & 0 & 0 & 0 & 0 & 0 & 0 & 0 & 0 & 0 \\
\hline & & & 20 & 23 & 0 & 0 & 0 & 0 & 0 & 5 & 18 & 0 \\
\hline & & & 30 & 200 & 0 & 0 & 1 & 0 & 0 & 3 & 48 & 148 \\
\hline & & & 40 & 225 & 1 & 1 & 2 & 0 & 3 & 5 & 37 & 176 \\
\hline & & & 50 & 203 & 2 & 0 & 3 & 1 & 1 & 3 & 38 & 155 \\
\hline & & & 60 & 186 & 2 & 1 & 2 & 1 & 0 & 1 & 33 & 146 \\
\hline & & & 70 & 155 & 2 & 1 & 2 & 0 & 2 & 0 & 23 & 125 \\
\hline & & & 80 & 128 & 1 & 0 & 0 & 1 & 0 & 2 & 13 & 111 \\
\hline & & & 90 & 97 & 0 & 0 & 0 & 0 & 0 & 0 & 9 & 88 \\
\hline & & & 100 & 72 & 0 & 0 & 0 & 0 & 0 & 0 & 3 & 69 \\
\hline \multirow[t]{10}{*}{ 21-Dec } & 9:00 AM & 8:47 AM & 10 & 0 & 0 & 0 & 0 & 0 & 0 & 0 & 0 & 0 \\
\hline & & & 20 & 60 & 0 & 0 & 0 & 0 & 0 & 11 & 49 & 0 \\
\hline & & & 30 & 263 & 2 & 0 & 1 & 1 & 2 & 9 & 212 & 36 \\
\hline & & & 40 & 218 & 0 & 0 & 0 & 0 & 1 & 6 & 167 & 44 \\
\hline & & & 50 & 187 & 2 & 1 & 4 & 0 & 3 & 5 & 127 & 45 \\
\hline & & & 60 & 154 & 1 & 0 & 0 & 0 & 0 & 5 & 98 & 50 \\
\hline & & & 70 & 113 & 0 & 0 & 0 & 0 & 0 & 1 & 68 & 44 \\
\hline & & & 80 & 77 & 0 & 0 & 0 & 0 & 0 & 1 & 33 & 43 \\
\hline & & & 90 & 56 & 0 & 0 & 0 & 0 & 0 & 0 & 18 & 38 \\
\hline & & & 100 & 40 & 0 & 0 & 0 & 0 & 0 & 0 & 5 & 35 \\
\hline \multirow[t]{10}{*}{ 21-Dec } & 12:00 PM & $11: 47$ AM & 10 & 0 & 0 & 0 & 0 & 0 & 0 & 0 & 0 & 0 \\
\hline & & & 20 & 87 & 0 & 0 & 20 & 5 & 55 & 0 & 5 & 2 \\
\hline & & & 30 & 138 & 0 & 0 & 30 & 12 & 66 & 2 & 0 & 28 \\
\hline & & & 40 & 119 & 0 & 0 & 13 & 16 & 49 & 5 & 0 & 36 \\
\hline & & & 50 & 109 & 0 & 0 & 0 & 6 & 59 & 8 & 0 & 36 \\
\hline & & & 60 & 92 & 0 & 0 & 0 & 1 & 44 & 13 & 1 & 33 \\
\hline & & & 70 & 81 & 0 & 0 & 0 & 0 & 21 & 20 & 6 & 34 \\
\hline & & & 80 & 62 & 0 & 0 & 0 & 0 & 6 & 16 & 11 & 29 \\
\hline & & & 90 & 45 & 0 & 0 & 0 & 0 & 0 & 3 & 22 & 20 \\
\hline & & & 100 & 31 & 0 & 0 & 0 & 0 & 0 & 0 & 13 & 18 \\
\hline \multirow[t]{10}{*}{ 21-Dec } & 3:00 PM & 2:47 PM & 10 & 1 & 0 & 1 & 0 & 0 & 0 & 0 & 0 & 0 \\
\hline & & & 20 & 64 & 28 & 7 & 3 & 0 & 0 & 0 & 26 & 0 \\
\hline & & & 30 & 61 & 20 & 4 & 3 & 0 & 0 & 0 & 17 & 17 \\
\hline & & & 40 & 50 & 13 & 3 & 4 & 0 & 0 & 0 & 0 & 30 \\
\hline & & & 50 & 42 & 10 & 1 & 4 & 0 & 0 & 0 & 0 & 27 \\
\hline & & & 60 & 50 & 20 & 1 & 5 & 0 & 0 & 0 & 0 & 24 \\
\hline & & & 70 & 43 & 10 & 3 & 8 & 0 & 0 & 0 & 0 & 22 \\
\hline & & & 80 & 36 & 1 & 0 & 16 & 1 & 1 & 0 & 0 & 17 \\
\hline & & & 90 & 25 & 0 & 0 & 3 & 1 & 2 & 2 & 0 & 17 \\
\hline & & & 100 & 11 & 0 & 0 & 0 & 0 & 0 & 0 & 0 & 11 \\
\hline
\end{tabular}




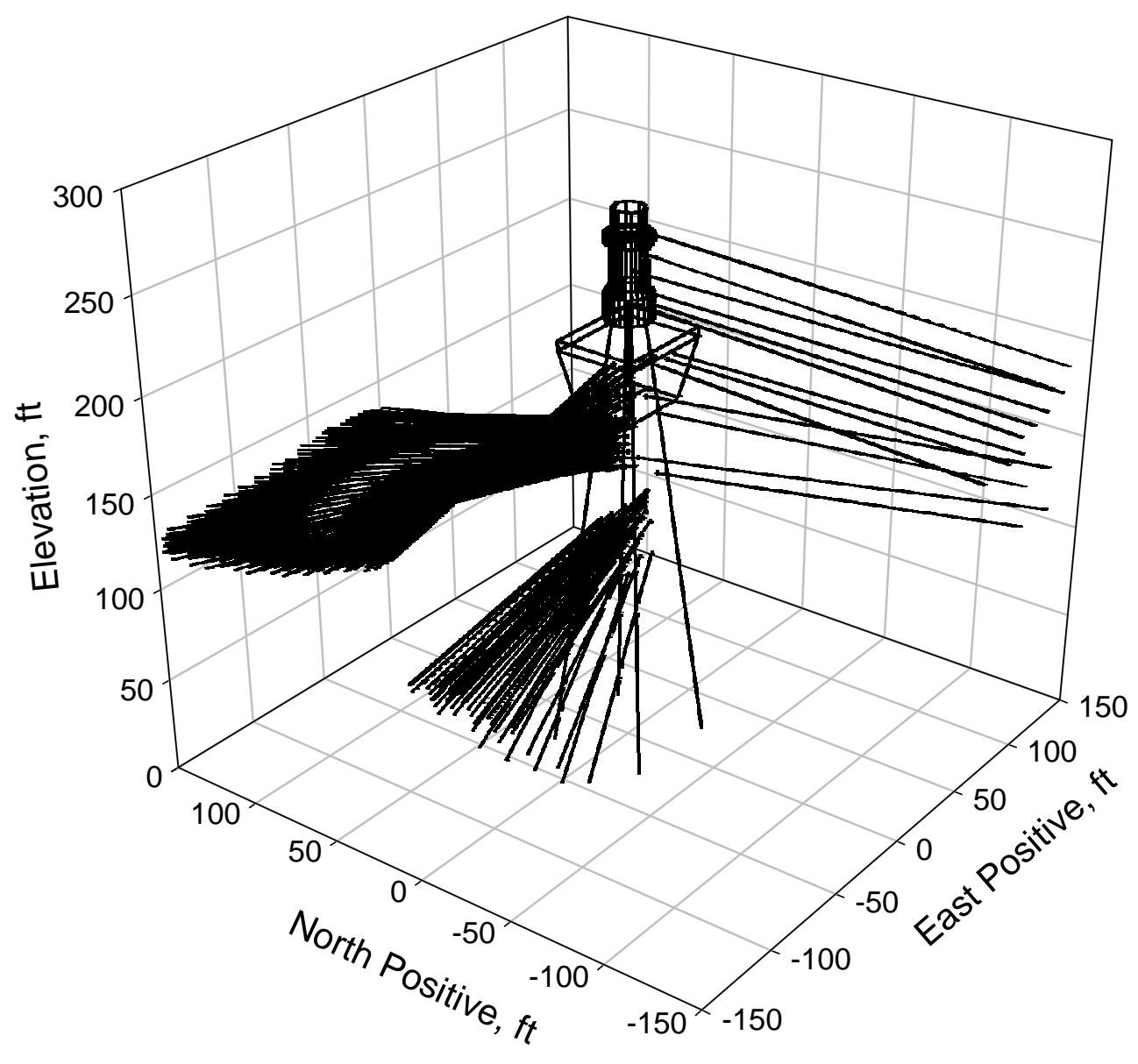

Figure A-3. Beams that walk on to the BCS targets and tower structure 40 minutes after a power failure that occurred at 7:30 AM on December 21 as viewed from the southwest. Each line represents a ray from the center of the heliostat to the point of intersection. The crosses mark the points of intersection. The tower is hit more than other components.

It is likely that any exposed cabling will be susceptible to melting. Since most of the beams are coming from the west, the cable tray on the east side of the tower needs to be protected on its west side. The tower framework will block some of those heliostat beams coming from the west. The cable tray on the south side of the tower needs to be protected on its north, south, and west sides.

\section{A.4 Walk Off}

Heliostat walk-off occurs when a power loss during receiver operation causes the heliostats freeze in their position and drift off the receiver. The two primary concerns are how long it takes for the heliostats to drift off the receiver and where the beams go when they drift off. If they hit the cable trays, control of the receiver will be lost. In addition, it could be costly to repair the 
wiring. They could cause considerable damage if they hit the oven covers for extended periods of time. It is also important to know the path the heliostats take to determine which areas may need protection.

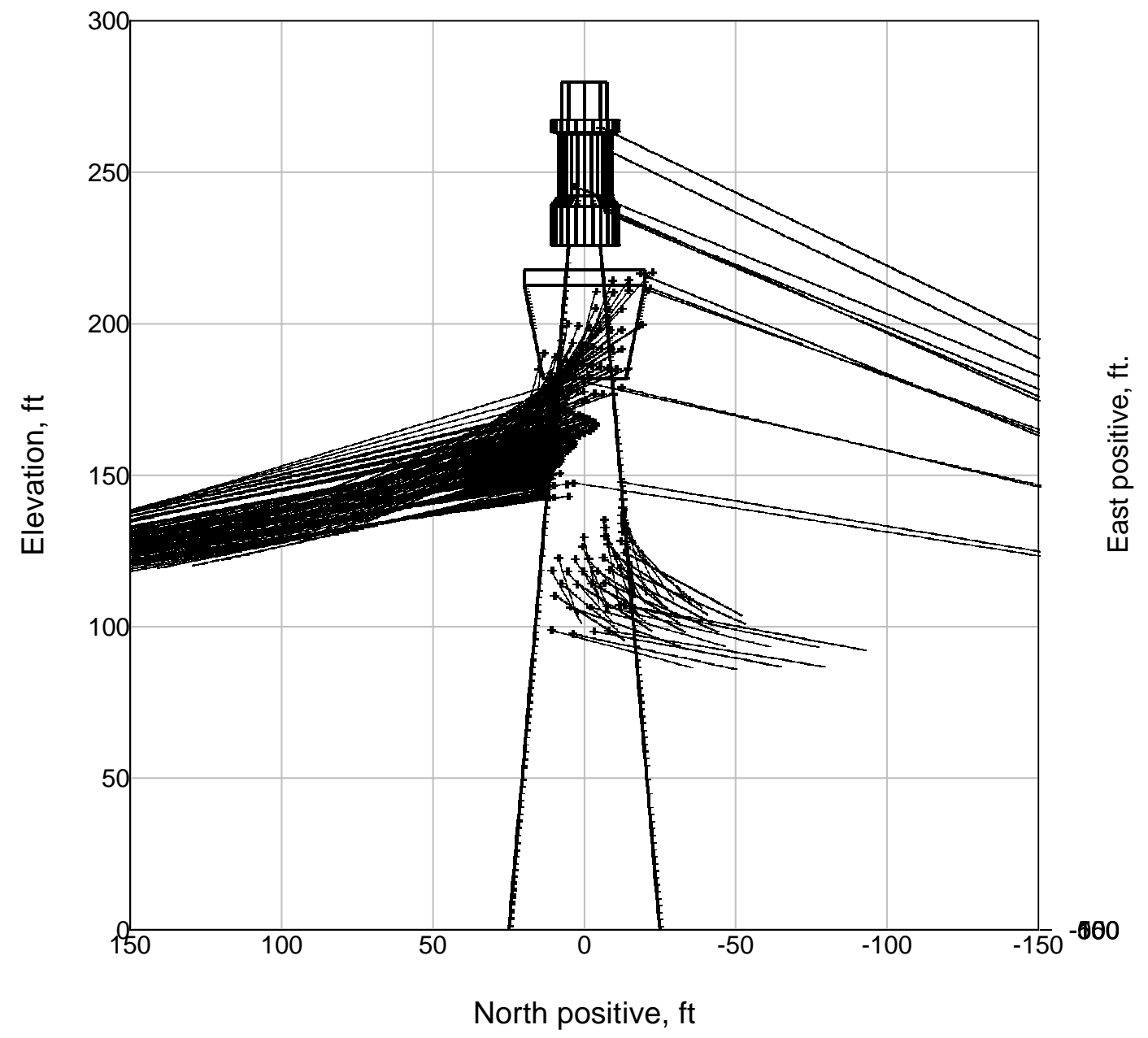

Figure A-4. Side view from the west looking east of walk-on beams that hit the BCS targets and tower structure 40 minutes after a power failure that occurred at 7:30 AM on December 21.

For the initial aiming strategy, it was assumed that the outermost heliostats (ring 5) are aimed at the elevation at the center of the receiver. Rings 3 and 4 were +0.5 meters and -0.5 meters from the centerline elevation, respectively, and rings 1 and 2 were +1 meter and -1 meter from the centerline elevation. It was further assumed that each wedge was aimed directly at the center of the panel in the middle of that wedge. 


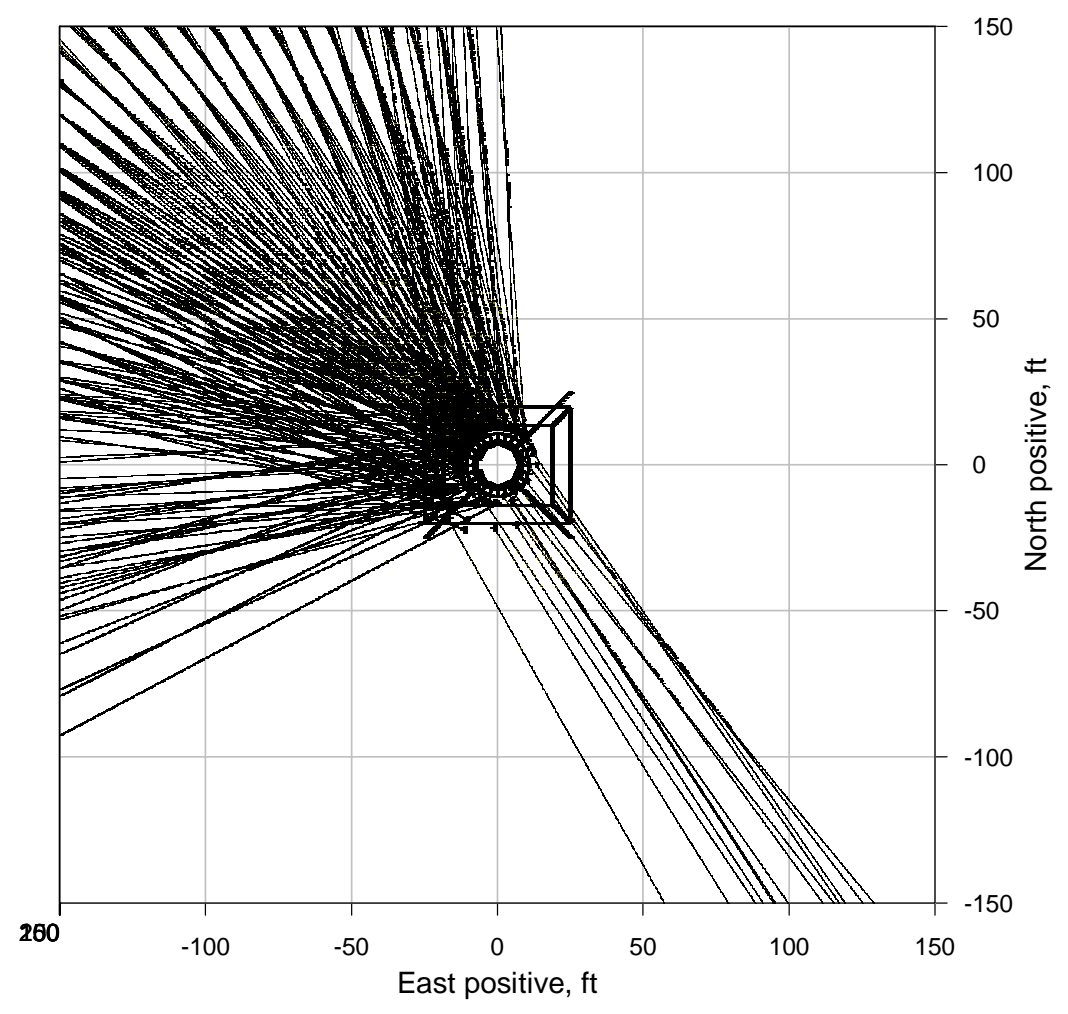

Figure A-5. Top view of beams that walk on the BCS targets and tower structure 40 minutes after a power failure that occurred at 7:30 AM on December 21. Most of the beams that hit the tower structures come from the northwest quadrant of the field.

Table A-2 summarizes the number of heliostats that intersect the major areas of interest during a walk-off event. In most cases, at least $98 \%$ of the heliostat centroids walk off the receiver in eight minutes or less. For three minutes after a power failure, approximately $50-60 \%$ of the heliostats are on the receiver. Note that even if the centroids of all the heliostats are hitting the receiver after a power failure, the total power on the receiver is dropping because the heliostat beams are only partially hitting the receiver-the rest of each beam misses, either hitting the header oven covers or going off into space.

Figure A-6 shows the paths that beams from ring 5 heliostats take on the east side of the receiver as they drift off the receiver during a power failure on June 21 at 12:00 PM. Since beams focused on the east side tend to drift upward and beams on the north and south sides tend to drift towards the east and upward, these beams will converge at the upper portion of the panels E6 and E7 and on the upper header oven covers of these panels. The lines represent the paths the beams drift. The figure shows where they drift upward starting from the center of the receiver; then one minute after power loss; then two minutes after power loss.

Figure A-7 shows the paths that beams on the west side of the receiver take when they drift during a power loss. The beams drift downward. 
Table A-2. Summary of the walk-off analysis. For each of the three days, the total number of heliostat beams whose centroid intersects the regions of interest is shown at various times of the day and times after a power failure. The total number of hits is broken down into various regions where the beams intersect.

\begin{tabular}{|c|c|c|c|c|c|c|c|c|c|c|c|c|}
\hline Date & $\begin{array}{c}\text { Time of } \\
\text { Power loss } \\
\text { Solar Time }\end{array}$ & $\begin{array}{c}\text { Time of } \\
\text { Power loss } \\
\text { PST }\end{array}$ & $\begin{array}{c}\text { Time after } \\
\text { Power loss } \\
\text { Minutes }\end{array}$ & Total & $\begin{array}{l}\text { Upper } \\
\text { Rec. } \\
\text { Flashing }\end{array}$ & $\begin{array}{l}\text { Up. } \\
\text { Header } \\
\text { Oven }\end{array}$ & Receiver & $\begin{array}{l}\text { Low. } \\
\text { Head } \\
\text { Oven }\end{array}$ & $\begin{array}{l}\text { Lower } \\
\text { Flashing }\end{array}$ & $\begin{array}{l}\text { Parapet } \\
\text { on BCS }\end{array}$ & $\begin{array}{c}\text { BCS } \\
\text { Targets }\end{array}$ & $\begin{array}{c}\text { Tower } \\
\text { Structure }\end{array}$ \\
\hline & & & & MAXIMUM & 299 & 213 & 1926 & 259 & 342 & 126 & 234 & 94 \\
\hline \multirow[t]{19}{*}{ 21-Mar } & $6: 00 \mathrm{AM}$ & $5: 56$ AM & 1 & 1926 & 0 & 0 & 1926 & 0 & 0 & 0 & 0 & 0 \\
\hline & & & 2 & 1757 & 0 & 0 & 1755 & 2 & 0 & 0 & 0 & 0 \\
\hline & & & 3 & 1260 & 11 & 20 & 942 & 259 & 28 & 0 & 0 & 0 \\
\hline & & & 4 & 1021 & 54 & 17 & 476 & 205 & 269 & 0 & 0 & 0 \\
\hline & & & 5 & 758 & 64 & 27 & 225 & 114 & 328 & 0 & 0 & 0 \\
\hline & & & 6 & 622 & 63 & 27 & 164 & 26 & 342 & 0 & 0 & 0 \\
\hline & & & 7 & 449 & 41 & 1 & 62 & 57 & 275 & 13 & 0 & 0 \\
\hline & & & 8 & 397 & 31 & 2 & 27 & 41 & 240 & 46 & 10 & 0 \\
\hline & & & 9 & 385 & 23 & 0 & 5 & 16 & 206 & 108 & 27 & 0 \\
\hline & & & 10 & 340 & 6 & 0 & 1 & 12 & 141 & 126 & 54 & 0 \\
\hline & & & 20 & 243| & 0 & 0 & 0 & 0 & 0 & 13 & 203 & 27 \\
\hline & & & 30 & 119 & 0 & 0 & 0 & 0 & 0 & 0 & 59 & 60 \\
\hline & & & 40 & 73 & 0 & 0 & 0 & 0 & 0 & 0 & 4 & 69 \\
\hline & & & 50 & 58 & 0 & 0 & 0 & 0 & 0 & 0 & 0 & 58 \\
\hline & & & 60 & 47 & 0 & 0 & 0 & 0 & 0 & 0 & 0 & 47 \\
\hline & & & 70 & 41 & 0 & 0 & 0 & 0 & 0 & 0 & 0 & 41 \\
\hline & & & 80 & 29 & 0 & 0 & 0 & 0 & 0 & 0 & 0 & 29 \\
\hline & & & 90 & 20 & 0 & 0 & 0 & 0 & 0 & 0 & 0 & 20 \\
\hline & & & 100 & 15 & 0 & 0 & 0 & 0 & 0 & 0 & 0 & 15 \\
\hline \multirow[t]{19}{*}{ 21-Mar } & $9: 00 \mathrm{AM}$ & $8: 56 \mathrm{AM}$ & 1 & 1926 & 0 & 0 & 1926 & 0 & 0 & 0 & 0 & 0 \\
\hline & & & 2 & 1634 & 0 & 0 & 1633 & 1 & 0 & 0 & 0 & 0 \\
\hline & & & 3 & 1199 & 41 & 60 & 886 & 171 & 41 & 0 & 0 & 0 \\
\hline & & & 4 & 900 & 115 & 31 & 421 & 151 & 182 & 0 & 0 & 0 \\
\hline & & & 5 & 722 & 141 & 63 & 197 & 49 & 272 & 0 & 0 & 0 \\
\hline & & & 6 & 543 & 130 & 34 & 104 & 34 & 241 & 0 & 0 & 0 \\
\hline & & & 7 & 414 & 83 & 3 & 33 & 62 & 216 & 17 & 0 & 0 \\
\hline & & & 8 & 383 & 62 & 2 & 16 & 32 & 205 & 62 & 4 & 0 \\
\hline & & & 9 & 306 & 43 & 1 & 10 & 7 & 139 & 71 & 35 & 0 \\
\hline & & & 10 & 309 & 13 & 0 & 2 & 5 & 105 & 113 & 71 & 0 \\
\hline & & & 20 & 232 & 0 & 0 & 0 & 0 & 0 & 16 & 189 & 27 \\
\hline & & & 30 & 131 & 0 & 0 & 0 & 0 & 0 & 0 & 63 & 68 \\
\hline & & & 40 & 76 & 0 & 0 & 0 & 0 & 0 & 0 & 2 & 74 \\
\hline & & & 50 & 64 & 0 & 0 & 0 & 0 & 0 & 0 & 0 & 64 \\
\hline & & & 60 & 52 & 0 & 0 & 0 & 0 & 0 & 0 & 0 & 52 \\
\hline & & & 70 & 43 & 0 & 0 & 0 & 0 & 0 & 0 & 0 & 43 \\
\hline & & & 80 & 35 & 0 & 0 & 0 & 0 & 0 & 0 & 0 & 35 \\
\hline & & & 90 & 30 & 0 & 0 & 0 & 0 & 0 & 0 & 0 & 30 \\
\hline & & & 100 & 20 & 0 & 0 & 0 & 0 & 0 & 0 & 0 & 20 \\
\hline \multirow[t]{13}{*}{ 21-Mar } & 12:00 PM & $11: 56 \mathrm{AM}$ & 1 & 1926 & 0 & 0 & 1926 & 0 & 0 & 0 & 0 & 0 \\
\hline & & & 2 & 1629 & 0 & 0 & 1619 & 10 & 0 & 0 & 0 & 0 \\
\hline & & & 3 & 1184 & 50 & 72 & 907 & 105 & 50 & 0 & 0 & 0 \\
\hline & & & 4 & 924 & 179 & 75 & 413 & 102 & 155 & 0 & 0 & 0 \\
\hline & & & 5 & 753 & 224 & 93 & 182 & 41 & 213 & 0 & 0 & 0 \\
\hline & & & 6 & 567 & 215 & 53 & 82 & 31 & 185 & 1 & 0 & 0 \\
\hline & & & 7 & 433 & 155 & 14 & 41 & 28 & 173 & 22 & 0 & 0 \\
\hline & & & 8 & 327 & 107 & 2 & 22 & 15 & 120 & 45 & 16 & 0 \\
\hline & & & 9 & 297 & 76 & 0 & 8 & 10 & 84 & 73 & 46 & 0 \\
\hline & & & 10 & 266 & 31 & 0 & 4 & 6 & 70 & 85 & 70 & 0 \\
\hline & & & 20 & 168 & 0 & 0 & 0 & 0 & 0 & 11 & 130 & 27 \\
\hline & & & 30 & 87 & 0 & 0 & 0 & 0 & 0 & 0 & 38 & 49 \\
\hline & & & 40 & 61 & 0 & 0 & 0 & 0 & 0 & 0 & 1 & 60 \\
\hline
\end{tabular}


Table A-2. Summary of the walk-off analysis. For each of the three days, the total number of heliostat beams whose centroid intersects the regions of interest is shown at various times of the day and times after a power failure. The total number of hits is broken down into various regions where the beams intersect. (continued)

\begin{tabular}{|c|c|c|c|c|c|c|c|c|c|c|c|c|}
\hline Date & $\begin{array}{c}\text { Time of } \\
\text { Power loss } \\
\text { Solar Time }\end{array}$ & $\begin{array}{c}\text { Time of } \\
\text { Power loss } \\
\text { PST }\end{array}$ & $\begin{array}{c}\text { Time after } \\
\text { Power loss } \\
\text { Minutes }\end{array}$ & Total & $\begin{array}{l}\text { Upper } \\
\text { Rec. } \\
\text { Flashing }\end{array}$ & $\begin{array}{l}\text { Up. } \\
\text { Header } \\
\text { Oven }\end{array}$ & Receiver & $\begin{array}{l}\text { Low. } \\
\text { Head } \\
\text { Oven }\end{array}$ & $\begin{array}{l}\text { Lower } \\
\text { Flashing }\end{array}$ & $\begin{array}{l}\text { Parapet } \\
\text { on BCS }\end{array}$ & $\begin{array}{c}\text { BCS } \\
\text { Targets }\end{array}$ & $\begin{array}{c}\text { Tower } \\
\text { Structure }\end{array}$ \\
\hline & & & 50 & 49 & 0 & 0 & 0 & 0 & 0 & 0 & 0 & 49 \\
\hline & & & 60 & 39 & 0 & 0 & 0 & 0 & 0 & 0 & 0 & 39 \\
\hline & & & 70 & 32 & 0 & 0 & 0 & 0 & 0 & 0 & 0 & 32 \\
\hline & & & 80 & 26 & 0 & 0 & 0 & 0 & 0 & 0 & 0 & 26 \\
\hline & & & 90 & 20 & 0 & 0 & 0 & 0 & 0 & 0 & 0 & 20 \\
\hline & & & 100 & 15 & 0 & 0 & 0 & 0 & 0 & 0 & 0 & 15 \\
\hline \multirow[t]{19}{*}{ 21-Mar } & 3:00 PM & $2: 56$ PM & 1 & 1926 & 0 & 0 & 1926 & 0 & 0 & 0 & 0 & 0 \\
\hline & & & 2 & 1640 & 0 & 0 & 1627 & 13 & 0 & 0 & 0 & 0 \\
\hline & & & 3 & 1126 & 38 & 85 & 900 & 63 & 40 & 0 & 0 & 0 \\
\hline & & & 4 & 843 & 206 & 94 & 384 & 53 & 106 & 0 & 0 & 0 \\
\hline & & & 5 & 679 & 256 & 117 & 164 & 16 & 126 & 0 & 0 & 0 \\
\hline & & & 6 & 515 & 264 & 69 & 69 & 14 & 96 & 3 & 0 & 0 \\
\hline & & & 7 & 391 & 213 & 14 & 29 & 25 & 85 & 23 & 2 & 0 \\
\hline & & & 8 & 286 & 148 & 1 & 11 & 23 & 64 & 21 & 18 & 0 \\
\hline & & & 9 & 259 & 109 & 0 & 3 & 15 & 52 & 46 & 34 & 0 \\
\hline & & & 10 & 210 & 61 & 0 & 1 & 6 & 49 & 48 & 45 & 0 \\
\hline & & & 20 & 103 & 0 & 0 & 0 & 0 & 0 & 9 & 70 & 24 \\
\hline & & & 30 & 62 & 0 & 0 & 0 & 0 & 0 & 0 & 27 & 35 \\
\hline & & & 40 & 34 & 0 & 0 & 0 & 0 & 0 & 0 & 1 & 33 \\
\hline & & & 50 & 28 & 0 & 0 & 0 & 0 & 0 & 0 & 0 & 28 \\
\hline & & & 60 & 19 & 0 & 0 & 0 & 0 & 0 & 0 & 0 & 19 \\
\hline & & & 70 & 14 & 0 & 0 & 0 & 0 & 0 & 0 & 0 & 14 \\
\hline & & & 80 & 8 & 0 & 0 & 0 & 0 & 0 & 0 & 0 & 8 \\
\hline & & & 90 & 6 & 0 & 0 & 0 & 0 & 0 & 0 & 0 & 6 \\
\hline & & & 100 & 4 & 0 & 0 & 0 & 0 & 0 & 0 & 0 & 4 \\
\hline \multirow[t]{19}{*}{ 21-Mar } & 6:00 PM & 5:56 PM & 1 & 1926 & 0 & 0 & 1926 & 0 & 0 & 0 & 0 & 0 \\
\hline & & & 2 & 1752 & 0 & 0 & 1747 & 5 & 0 & 0 & 0 & 0 \\
\hline & & & 3 & 1189 & 35 & 128 & 995 & 20 & 11 & 0 & 0 & 0 \\
\hline & & & 4 & 864 & 268 & 172 & 378 & 16 & 30 & 0 & 0 & 0 \\
\hline & & & 5 & 652 & 299 & 150 & 160 & 4 & 39 & 0 & 0 & 0 \\
\hline & & & 6 & 451 & 278 & 99 & 33 & 11 & 30 & 0 & 0 & 0 \\
\hline & & & 7 & 310 & 218 & 20 & 15 & 15 & 35 & 7 & 0 & 0 \\
\hline & & & 8 & 208 & 154 & 0 & 4 & 9 & 31 & 5 & 5 & 0 \\
\hline & & & 9 & 149 & 99 & 0 & 2 & 2 & 25 & 13 & 8 & 0 \\
\hline & & & 10 & 110 & 57 & 0 & 0 & 0 & 23 & 17 & 13 & 0 \\
\hline & & & 20 & 46 & 0 & 0 & 0 & 0 & 0 & 4 & 34 & 8 \\
\hline & & & 30 & 29 & 0 & 0 & 0 & 0 & 0 & 0 & 16 & 13 \\
\hline & & & 40 & 16 & 0 & 0 & 0 & 0 & 0 & 0 & 0 & 16 \\
\hline & & & 50 & 16 & 0 & 0 & 0 & 0 & 0 & 0 & 0 & 16 \\
\hline & & & 60 & 12 & 0 & 0 & 0 & 0 & 0 & 0 & 0 & 12 \\
\hline & & & 70 & 9 & 0 & 0 & 0 & 0 & 0 & 0 & 0 & 9 \\
\hline & & & 80 & 8 & 0 & 0 & 0 & 0 & 0 & 0 & 0 & 8 \\
\hline & & & 90 & 6 & 0 & 0 & 0 & 0 & 0 & 0 & 0 & 6 \\
\hline & & & 100 & 3 & 0 & 0 & 0 & 0 & 0 & 0 & 0 & 3 \\
\hline \multirow[t]{8}{*}{ 21-Jun } & $6: 00 \mathrm{AM}$ & 5:49 AM & 1 & 1926 & 0 & 0 & 1926 & 0 & 0 & 0 & 0 & 0 \\
\hline & & & 2 & 1759 & 0 & 0 & 1759 & 0 & 0 & 0 & 0 & 0 \\
\hline & & & 3 & 1337 & 28 & 30 & 1124 & 152 & 3 & 0 & 0 & 0 \\
\hline & & & 4 & 1029 & 80 & 24 & 576 & 187 & 162 & 0 & 0 & 0 \\
\hline & & & 5 & 849 & 120 & 46 & 262 & 152 & 269 & 0 & 0 & 0 \\
\hline & & & 6 & 706 & 120 & 45 & 162 & 54 & 325 & 0 & 0 & 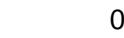 \\
\hline & & & 7 & 525 & 87 & 12 & 99 & 34 & 293 & 0 & 0 & 0 \\
\hline & & & 8 & 445 & 66 & 0 & 43 & 61 & 256 & 19 & 0 & 0 \\
\hline
\end{tabular}


Table A-2. Summary of the walk-off analysis. For each of the three days, the total number of heliostat beams whose centroid intersects the regions of interest is shown at various times of the day and times after a power failure. The total number of hits is broken down into various regions where the beams intersect. (continued)

\begin{tabular}{|c|c|c|c|c|c|c|c|c|c|c|c|c|}
\hline Date & $\begin{array}{c}\text { Time of } \\
\text { Power loss } \\
\text { Solar Time }\end{array}$ & $\begin{array}{c}\text { Time of } \\
\text { Power loss } \\
\text { PST }\end{array}$ & $\begin{array}{c}\text { Time after } \\
\text { Power loss } \\
\text { Minutes }\end{array}$ & Total & $\begin{array}{l}\text { Upper } \\
\text { Rec. } \\
\text { Flashing }\end{array}$ & $\begin{array}{l}\text { Up. } \\
\text { Header } \\
\text { Oven }\end{array}$ & Receiver & $\begin{array}{l}\text { Low. } \\
\text { Head } \\
\text { Oven }\end{array}$ & $\begin{array}{l}\text { Lower } \\
\text { Flashing }\end{array}$ & $\begin{array}{l}\text { Parapet } \\
\text { on BCS }\end{array}$ & $\begin{array}{c}\text { BCS } \\
\text { Targets }\end{array}$ & $\begin{array}{c}\text { Tower } \\
\text { Structure }\end{array}$ \\
\hline & & & 9 & \begin{tabular}{l|l}
433 \\
\end{tabular} & 59 & 0 & 12 & 35 & 243 & 76 & 8 & 0 \\
\hline & & & 10 & 384 & 37 & 0 & 5 & 11 & 196 & 109 & 26 & 0 \\
\hline & & & 20 & 286 & 0 & 0 & 0 & 0 & 0 & 37 & 234 & 15 \\
\hline & & & 30 & 133 & 0 & 0 & 0 & 0 & 0 & 0 & 86 & 47 \\
\hline & & & 40 & 76 & 0 & 0 & 0 & 0 & 0 & 0 & 16 & 60 \\
\hline & & & 50 & 54 & 0 & 0 & 0 & 0 & 0 & 0 & 0 & 54 \\
\hline & & & 60 & 44 & 0 & 0 & 0 & 0 & 0 & 0 & 0 & 44 \\
\hline & & & 70 & 36 & 0 & 0 & 0 & 0 & 0 & 0 & 0 & 36 \\
\hline & & & 80 & 23 & 0 & 0 & 0 & 0 & 0 & 0 & 0 & 23 \\
\hline & & & 90 & 20 & 0 & 0 & 0 & 0 & 0 & 0 & 0 & 20 \\
\hline & & & 100 & 19 & 0 & 0 & 0 & 0 & 0 & 0 & 0 & 19 \\
\hline \multirow[t]{19}{*}{ 21-Jun } & $9: 00 \mathrm{AM}$ & 8:49 AM & 1 & 1926 & 0 & 0 & 1926 & 0 & 0 & 0 & 0 & 0 \\
\hline & & & 2 & 1753 & 0 & 0 & 1753 & 0 & 0 & 0 & 0 & 0 \\
\hline & & & 3 & 1359 & 45 & 56 & 1034 & 203 & 21 & 0 & 0 & 0 \\
\hline & & & 4 & 1117 & 130 & 57 & 553 & 168 & 209 & 0 & 0 & 0 \\
\hline & & & 5 & 886 & 181 & 69 & 281 & 76 & 279 & 0 & 0 & 0 \\
\hline & & & 6 & 710 & 172 & 69 & 146 & 39 & 284 & 0 & 0 & 0 \\
\hline & & & 7 & 514 & 126 & 14 & 70 & 58 & 239 & 7 & 0 & 0 \\
\hline & & & 8 & 458 & 86 & 6 & 33 & 43 & 228 & 60 & 2 & 0 \\
\hline & & & 9 & 394 & 70 & 0 & 20 & 17 & 174 & 87 & 26 & 0 \\
\hline & & & 10 & 342 & 40 & 0 & 11 & 7 & 115 & 106 & 63 & 0 \\
\hline & & & 20 & 278| & 0 & 0 & 0 & 0 & 0 & 25 & 229 & 24 \\
\hline & & & 30 & 159 & 0 & 0 & 0 & 0 & 0 & 0 & 75 & 84 \\
\hline & & & 40 & 99 & 0 & 0 & 0 & 0 & 0 & 0 & 5 & 94 \\
\hline & & & 50 & 87 & 0 & 0 & 0 & 0 & 0 & 0 & 0 & 87 \\
\hline & & & 60 & 75 & 0 & 0 & 0 & 0 & 0 & 0 & 0 & 75 \\
\hline & & & 70 & 59 & 0 & 0 & 0 & 0 & 0 & 0 & 0 & 59 \\
\hline & & & 80 & 44 & 0 & 0 & 0 & 0 & 0 & 0 & 0 & 44 \\
\hline & & & 90 & 33 & 0 & 0 & 0 & 0 & 0 & 0 & 0 & 33 \\
\hline & & & 100 & 26 & 0 & 0 & 0 & 0 & 0 & 0 & 0 & 26 \\
\hline \multirow[t]{19}{*}{ 21-Jun } & 12:00 PM & $11: 49$ AM & 1 & 1926 & 0 & 0 & 1926 & 0 & 0 & 0 & 0 & 0 \\
\hline & & & 2 & 1769 & 0 & 0 & 1769 & 0 & 0 & 0 & 0 & 0 \\
\hline & & & 3 & 1401 & 46 & 68 & 1079 & 154 & 54 & 0 & 0 & 0 \\
\hline & & & 4 & 1139 & 182 & 68 & 568 & 132 & 189 & 0 & 0 & 0 \\
\hline & & & 5 & 929 & 250 & 90 & 282 & 42 & 265 & 0 & 0 & 0 \\
\hline & & & 6 & 716 & 253 & 89 & 128 & 23 & 223 & 0 & 0 & 0 \\
\hline & & & 7 & 534 & 201 & 27 & 65 & 40 & 179 & 22 & 0 & 0 \\
\hline & & & 8 & 441 & 127 & 10 & 23 & 43 & 164 & 64 & 10 & 0 \\
\hline & & & 9 & 359 & 110 & 0 & 5 & 27 & 107 & 60 & 50 & 0 \\
\hline & & & 10 & 343 & 64 & 0 & 1 & 9 & 82 & 109 & 78 & 0 \\
\hline & & & 20 & 210 & 0 & 0 & 0 & 0 & 1 & 19 & 157 & 33 \\
\hline & & & 30 & 113 & 0 & 0 & 0 & 0 & 0 & 0 & 55 & 58 \\
\hline & & & 40 & 70 & 0 & 0 & 0 & 0 & 0 & 0 & 9 & 61 \\
\hline & & & 50 & 51 & 0 & 0 & 0 & 0 & 0 & 0 & 0 & 51 \\
\hline & & & 60 & 42 & 0 & 0 & 0 & 0 & 0 & 0 & 0 & 42 \\
\hline & & & 70 & 26 & 0 & 0 & 0 & 0 & 0 & 0 & 0 & 26 \\
\hline & & & 80 & 18 & 0 & 0 & 0 & 0 & 0 & 0 & 0 & 18 \\
\hline & & & 90 & 11 & 0 & 0 & 0 & 0 & 0 & 0 & 0 & 11 \\
\hline & & & 100 & $7 \mid$ & 0 & 0 & 0 & 0 & 0 & 0 & 0 & 7 \\
\hline \multirow[t]{3}{*}{ 21-Jun } & 3:00 PM & $2: 49$ PM & 1 & 1926 & 0 & 0 & 1926 & 0 & 0 & 0 & 0 & 0 \\
\hline & & & 2 & 1762 & 0 & 0 & 1758 & 4 & 0 & 0 & 0 & 0 \\
\hline & & & 3 & 1312 & 32 & 67 & 1071 & 89 & 53 & 0 & 0 & 0 \\
\hline
\end{tabular}


Table A-2. Summary of the walk-off analysis. For each of the three days, the total number of heliostat beams whose centroid intersects the regions of interest is shown at various times of the day and times after a power failure. The total number of hits is broken down into various regions where the beams intersect. (continued)

\begin{tabular}{|c|c|c|c|c|c|c|c|c|c|c|c|c|}
\hline Date & $\begin{array}{c}\text { Time of } \\
\text { Power loss } \\
\text { Solar Time }\end{array}$ & $\begin{array}{c}\text { Time of } \\
\text { Power loss } \\
\text { PST }\end{array}$ & $\begin{array}{c}\text { Time after } \\
\text { Power loss } \\
\text { Minutes }\end{array}$ & Total & $\begin{array}{l}\text { Upper } \\
\text { Rec. } \\
\text { Flashing }\end{array}$ & $\begin{array}{l}\text { Up. } \\
\text { Header } \\
\text { Oven }\end{array}$ & Receiver & $\begin{array}{l}\text { Low. } \\
\text { Head } \\
\text { Oven }\end{array}$ & $\begin{array}{l}\text { Lower } \\
\text { Flashing }\end{array}$ & $\begin{array}{l}\text { Parapet } \\
\text { on BCS }\end{array}$ & $\begin{array}{c}\text { BCS } \\
\text { Targets }\end{array}$ & $\begin{array}{c}\text { Tower } \\
\text { Structure }\end{array}$ \\
\hline & & & 4 & 989 & 182 & 95 & 510 & 70 & 132 & 0 & 0 & 0 \\
\hline & & & 5 & 833 & 288 & 95 & 260 & 17 & 173 & 0 & 0 & 0 \\
\hline & & & 6 & 652 & 297 & 98 & 113 & 14 & 130 & 0 & 0 & 0 \\
\hline & & & 7 & 516 & 267 & 38 & 40 & 34 & 109 & 28 & 0 & 0 \\
\hline & & & 8 & 409 & 211 & 8 & 22 & 16 & 91 & 48 & 13 & 0 \\
\hline & & & 9 & 314 & 151 & 0 & 10 & 3 & 57 & 42 & 51 & 0 \\
\hline & & & 10 & 289 & 104 & 0 & 2 & 3 & 44 & 71 & 65 & 0 \\
\hline & & & 20 & 145 & 0 & 0 & 0 & 0 & 0 & 16 & 100 & 29 \\
\hline & & & 30 & 88 & 0 & 0 & 0 & 0 & 0 & 0 & 41 & 47 \\
\hline & & & 40 & 55 & 0 & 0 & 0 & 0 & 0 & 0 & 3 & 52 \\
\hline & & & 50 & 43 & 0 & 0 & 0 & 0 & 0 & 0 & 0 & 43 \\
\hline & & & 60 & 35 & 0 & 0 & 0 & 0 & 0 & 0 & 0 & 35 \\
\hline & & & 70 & 27 & 0 & 0 & 0 & 0 & 0 & 0 & 0 & 27 \\
\hline & & & 80 & 21 & 0 & 0 & 0 & 0 & 0 & 0 & 0 & 21 \\
\hline & & & 90 & 18 & 0 & 0 & 0 & 0 & 0 & 0 & 0 & 18 \\
\hline & & & 100 & 14 & 0 & 0 & 0 & 0 & 0 & 0 & 0 & 14 \\
\hline \multirow[t]{19}{*}{ 21-Jun } & 6:00 PM & 5:49 PM & 1 & 1926 & 0 & 0 & 1926 & 0 & 0 & 0 & 0 & 0 \\
\hline & & & 2 & 1773 & 0 & 0 & 1768 & 5 & 0 & 0 & 0 & 0 \\
\hline & & & 3 & 1326 & 18 & 69 & 1157 & 51 & 31 & 0 & 0 & 0 \\
\hline & & & 4 & 984 & 150 & 206 & 508 & 44 & 76 & 0 & 0 & 0 \\
\hline & & & 5 & 763 & 294 & 103 & 258 & 13 & 95 & 0 & 0 & 0 \\
\hline & & & 6 & 548 & 258 & 110 & 101 & 7 & 72 & 0 & 0 & 0 \\
\hline & & & 7 & 456 & 246 & 67 & 39 & 23 & 60 & 21 & 0 & 0 \\
\hline & & & 8 & 334 & 193 & 10 & 15 & 23 & 57 & 24 & 12 & 0 \\
\hline & & & 9 & 261 & 138 & 2 & 7 & 13 & 48 & 23 & 30 & 0 \\
\hline & & & 10 & 211 & 87 & 0 & 3 & 6 & 42 & 35 & 38 & 0 \\
\hline & & & 20 & $87 \mid$ & 0 & 0 & 0 & 0 & 0 & 9 & 63 & 15 \\
\hline & & & 30 & 54 & 0 & 0 & 0 & 0 & 0 & 1 & 32 & 21 \\
\hline & & & 40 & 32 & 0 & 0 & 0 & 0 & 0 & 0 & 5 & 27 \\
\hline & & & 50 & 25 & 0 & 0 & 0 & 0 & 0 & 0 & 0 & 25 \\
\hline & & & 60 & 17 & 0 & 0 & 0 & 0 & 0 & 0 & 0 & 17 \\
\hline & & & 70 & 14 & 0 & 0 & 0 & 0 & 0 & 0 & 0 & 14 \\
\hline & & & 80 & 13 & 0 & 0 & 0 & 0 & 0 & 0 & 0 & 13 \\
\hline & & & 90 & 11 & 0 & 0 & 0 & 0 & 0 & 0 & 0 & 11 \\
\hline & & & 100 & 9 & 0 & 0 & 0 & 0 & 0 & 0 & 0 & 9 \\
\hline \multirow[t]{18}{*}{ 21-Dec } & 7:00 AM & $6: 47 \mathrm{AM}$ & 1 & 1926 & 0 & 0 & 1926 & 0 & 0 & 0 & 0 & 0 \\
\hline & & & 2 & 1847 & 0 & 0 & 1847 & 0 & 0 & 0 & 0 & 0 \\
\hline & & & 3 & 1367 & 3 & 7 & 1183 & 174 & 0 & 0 & 0 & 0 \\
\hline & & & 4 & 1050 & 30 & 16 & 624 & 213 & 167 & 0 & 0 & 0 \\
\hline & & & 5 & 766 & 49 & 22 & 300 & 145 & 250 & 0 & 0 & 0 \\
\hline & & & 6 & 642 & 63 & 20 & 201 & 50 & 308 & 0 & 0 & 0 \\
\hline & & & 7 & 470 & 50 & 11 & 113 & 46 & 250 & 0 & 0 & 0 \\
\hline & & & 8 & 387 & 37 & 1 & 39 & 73 & 231 & 6 & 0 & 0 \\
\hline & & & 9 & 340 & 31 & 1 & 15 & 29 & 220 & 43 & 1 & 0 \\
\hline & & & 10 & 327 & 20 & 0 & 6 & 19 & 184 & 89 & 9 & 0 \\
\hline & & & 20 & 203 & 0 & 0 & 0 & 0 & 1 & 23 & 170 & 9 \\
\hline & & & 30 & 106 & 0 & 0 & 0 & 0 & 0 & 0 & 83 & 23 \\
\hline & & & 40 & 44 & 0 & 0 & 0 & 0 & 0 & 0 & 7 & 37 \\
\hline & & & 50 & 42 & 0 & 0 & 0 & 0 & 0 & 0 & 0 & 42 \\
\hline & & & 60 & 37 & 0 & 0 & 0 & 0 & 0 & 0 & 0 & 37 \\
\hline & & & 70 & 28 & 0 & 0 & 0 & 0 & 0 & 0 & 0 & 28 \\
\hline & & & 80 & 20 & 0 & 0 & 0 & 0 & 0 & 0 & 0 & 20 \\
\hline & & & 90 & 17 & 0 & 0 & 0 & 0 & 0 & 0 & 0 & 17 \\
\hline
\end{tabular}


Table A-2. Summary of the walk-off analysis. For each of the three days, the total number of heliostat beams whose centroid intersects the regions of interest is shown at various times of the day and times after a power failure. The total number of hits is broken down into various regions where the beams intersect. (continued)

\begin{tabular}{|c|c|c|c|c|c|c|c|c|c|c|c|c|}
\hline Date & $\begin{array}{c}\text { Time of } \\
\text { Power loss } \\
\text { Solar Time }\end{array}$ & $\begin{array}{c}\text { Time of } \\
\text { Power loss } \\
\text { PST }\end{array}$ & $\begin{array}{c}\text { Time after } \\
\text { Power loss } \\
\text { Minutes }\end{array}$ & Total & $\begin{array}{l}\text { Upper } \\
\text { Rec. } \\
\text { Flashing }\end{array}$ & $\begin{array}{l}\text { Up. } \\
\text { Header } \\
\text { Oven }\end{array}$ & Receiver & $\begin{array}{l}\text { Low. } \\
\text { Head } \\
\text { Oven }\end{array}$ & $\begin{array}{l}\text { Lower } \\
\text { Flashing }\end{array}$ & $\begin{array}{l}\text { Parapet } \\
\text { on BCS }\end{array}$ & $\begin{array}{c}\text { BCS } \\
\text { Targets }\end{array}$ & $\begin{array}{c}\text { Tower } \\
\text { Structure }\end{array}$ \\
\hline & & & 100 & $\mid 16$ & 0 & 0 & 0 & 0 & 0 & 0 & 0 & 16 \\
\hline \multirow[t]{19}{*}{ 21-Dec } & 9:00 AM & $8: 47$ AM & 1 & 1926 & 0 & 0 & 1926 & 0 & 0 & 0 & 0 & 0 \\
\hline & & & 2 & 1696 & 0 & 0 & 1696 & 0 & 0 & 0 & 0 & 0 \\
\hline & & & 3 & 1175 & 7 & 13 & 1042 & 113 & 0 & 0 & 0 & 0 \\
\hline & & & 4 & 908 & 57 & 43 & 574 & 119 & 115 & 0 & 0 & 0 \\
\hline & & & 5 & 644 & 111 & 27 & 261 & 83 & 162 & 0 & 0 & 0 \\
\hline & & & 6 & 542 & 120 & 54 & 157 & 11 & 200 & 0 & 0 & 0 \\
\hline & & & 7 & 411 & 104 & 10 & 77 & 39 & 180 & 1 & 0 & 0 \\
\hline & & & 8 & 351 & 82 & 4 & 21 & 65 & 175 & 4 & 0 & 0 \\
\hline & & & 9 & 323 & 58 & 4 & 11 & 34 & 173 & 42 & 1 & 0 \\
\hline & & & 10 & 270 & 39 & 0 & 7 & 15 & 136 & 62 & 11 & 0 \\
\hline & & & 20 & 184 & 0 & 0 & 0 & 0 & 0 & 12 & 168 & 4 \\
\hline & & & 30 & 105 & 0 & 0 & 0 & 0 & 0 & 0 & 71 & 34 \\
\hline & & & 40 & 56 & 0 & 0 & 0 & 0 & 0 & 0 & 13 & 43 \\
\hline & & & 50 & 50 & 0 & 0 & 0 & 0 & 0 & 0 & 0 & 50 \\
\hline & & & 60 & 38 & 0 & 0 & 0 & 0 & 0 & 0 & 0 & 38 \\
\hline & & & 70 & 36 & 0 & 0 & 0 & 0 & 0 & 0 & 0 & 36 \\
\hline & & & 80 & 27 & 0 & 0 & 0 & 0 & 0 & 0 & 0 & 27 \\
\hline & & & 90 & 21 & 0 & 0 & 0 & 0 & 0 & 0 & 0 & 21 \\
\hline & & & 100 & 22 & 0 & 0 & 0 & 0 & 0 & 0 & 0 & 22 \\
\hline \multirow[t]{19}{*}{ 21-Dec } & 12:00 PM & $11: 47$ AM & 1 & 1926 & 0 & 0 & 1926 & 0 & 0 & 0 & 0 & 0 \\
\hline & & & 2 & 1646 & 0 & 0 & 1646 & 0 & 0 & 0 & 0 & 0 \\
\hline & & & 3 & 1144 & 10 & 24 & 1026 & 84 & 0 & 0 & 0 & 0 \\
\hline & & & 4 & 875 & 96 & 80 & 529 & 89 & 81 & 0 & 0 & 0 \\
\hline & & & 5 & 691 & 179 & 64 & 255 & 53 & 140 & 0 & 0 & 0 \\
\hline & & & 6 & 552 & 192 & 79 & 117 & 8 & 156 & 0 & 0 & 0 \\
\hline & & & 7 & 404 & 174 & 30 & 44 & 31 & 125 & 0 & 0 & 0 \\
\hline & & & 8 & 337 & 133 & 7 & 9 & 48 & 125 & 15 & 0 & 0 \\
\hline & & & 9 & 275 & 82 & 0 & 5 & 22 & 123 & 39 & 4 & 0 \\
\hline & & & 10 & 210 & 63 & 0 & 2 & 8 & 81 & 38 & 18 & 0 \\
\hline & & & 20 & 149| & 0 & 0 & 0 & 0 & 0 & 11 & 128 & 10 \\
\hline & & & 30 & 91 & 0 & 0 & 0 & 0 & 0 & 0 & 48 & 43 \\
\hline & & & 40 & 51 & 0 & 0 & 0 & 0 & 0 & 0 & 8 & 43 \\
\hline & & & 50 & 41 & 0 & 0 & 0 & 0 & 0 & 0 & 0 & 41 \\
\hline & & & 60 & 35 & 0 & 0 & 0 & 0 & 0 & 0 & 0 & 35 \\
\hline & & & 70 & 30 & 0 & 0 & 0 & 0 & 0 & 0 & 0 & 30 \\
\hline & & & 80 & 23 & 0 & 0 & 0 & 0 & 0 & 0 & 0 & 23 \\
\hline & & & 90 & 20 & 0 & 0 & 0 & 0 & 0 & 0 & 0 & 20 \\
\hline & & & 100 & 16 & 0 & 0 & 0 & 0 & 0 & 0 & 0 & 16 \\
\hline \multirow[t]{13}{*}{ 21-Dec } & 3:00 PM & 2:47 PM & 1 & 1926 & 0 & 0 & 1926 & 0 & 0 & 0 & 0 & 0 \\
\hline & & & 2 & 1701 & 0 & 0 & 1701 & 0 & 0 & 0 & 0 & 0 \\
\hline & & & 3 & 1181 & 7 & 42 & 1085 & 44 & 3 & 0 & 0 & 0 \\
\hline & & & 4 & 845 & 106 & 135 & 503 & 55 & 46 & 0 & 0 & 0 \\
\hline & & & 5 & 665 & 222 & 96 & 229 & 34 & 84 & 0 & 0 & 0 \\
\hline & & & 6 & 508 & 214 & 103 & 87 & 11 & 93 & 0 & 0 & 0 \\
\hline & & & 7 & 381 & 203 & 39 & 33 & 25 & 81 & 0 & 0 & 0 \\
\hline & & & 8 & 299 & 168 & 3 & 14 & 26 & 77 & 11 & 0 & 0 \\
\hline & & & 9 & 235 & 124 & 0 & 4 & 13 & 69 & 21 & 4 & 0 \\
\hline & & & 10 & 188 & 90 & 0 & 0 & 7 & 51 & 26 & 14 & 0 \\
\hline & & & 20 & 91| & 0 & 0 & 0 & 0 & 0 & 9 & 76 & 6 \\
\hline & & & 30 & 55 & 0 & 0 & 0 & 0 & 0 & 0 & 35 & 20 \\
\hline & & & 40 & 30 & 0 & 0 & 0 & 0 & 0 & 0 & 5 & 25 \\
\hline
\end{tabular}


Table A-2. Summary of the walk-off analysis. For each of the three days, the total number of heliostat beams whose centroid intersects the regions of interest is shown at various times of the day and times after a power failure. The total number of hits is broken down into various regions where the beams intersect. (concluded)

\begin{tabular}{|c|c|c|c|c|c|c|c|c|c|c|c|c|}
\hline Date & $\begin{array}{c}\text { Time of } \\
\text { Power loss } \\
\text { Solar Time }\end{array}$ & $\begin{array}{c}\text { Time of } \\
\text { Power loss } \\
\text { PST }\end{array}$ & $\begin{array}{c}\text { Time after } \\
\text { Power loss } \\
\text { Minutes }\end{array}$ & Total & $\begin{array}{l}\text { Upper } \\
\text { Rec. } \\
\text { Flashing }\end{array}$ & $\begin{array}{l}\text { Up. } \\
\text { Header } \\
\text { Oven }\end{array}$ & Receiver & $\begin{array}{l}\text { Low. } \\
\text { Head } \\
\text { Oven }\end{array}$ & $\begin{array}{l}\text { Lower } \\
\text { Flashing }\end{array}$ & $\begin{array}{l}\text { Parapet } \\
\text { on BCS }\end{array}$ & $\begin{array}{c}\text { BCS } \\
\text { Targets }\end{array}$ & $\begin{array}{l}\text { Tower } \\
\text { Structure }\end{array}$ \\
\hline & & & 50 & \begin{tabular}{|l|}
27 \\
\end{tabular} & 0 & 0 & 0 & 0 & 0 & 0 & 0 & 27 \\
\hline & & & 60 & 23 & 0 & 0 & 0 & 0 & 0 & 0 & 0 & 23 \\
\hline & & & 70 & 20 & 0 & 0 & 0 & 0 & 0 & 0 & 0 & 20 \\
\hline & & & 80 & 14 & 0 & 0 & 0 & 0 & 0 & 0 & 0 & 14 \\
\hline & & & 90 & 11 & 0 & 0 & 0 & 0 & 0 & 0 & 0 & 11 \\
\hline & & & 100 & 10 & 0 & 0 & 0 & 0 & 0 & 0 & 0 & 10 \\
\hline \multirow[t]{19}{*}{ 21-Dec } & 5:00 PM & 4:47 PM & 1 & 1926 & 0 & 0 & 1926 & 0 & 0 & 0 & 0 & 0 \\
\hline & & & 2 & 1849 & 0 & 0 & 1849 & 0 & 0 & 0 & 0 & 0 \\
\hline & & & 3 & 1363 & 15 & 130 & 1196 & 19 & 3 & 0 & 0 & 0 \\
\hline & & & 4 & 912 & 138 & 213 & 511 & 28 & 22 & 0 & 0 & 0 \\
\hline & & & 5 & 702 & 281 & 142 & 234 & 6 & 39 & 0 & 0 & 0 \\
\hline & & & 6 & 499 & 251 & 133 & 71 & 6 & 38 & 0 & 0 & 0 \\
\hline & & & 7 & 363 & 225 & 61 & 22 & 17 & 37 & 1 & 0 & 0 \\
\hline & & & 8 & 258 & 174 & 8 & 6 & 19 & 45 & 6 & 0 & 0 \\
\hline & & & 9 & 191 & 130 & 1 & 2 & 9 & 39 & 8 & 2 & 0 \\
\hline & & & 10 & 144 & 92 & 0 & 0 & 3 & 29 & 15 & 5 & 0 \\
\hline & & & 20 & 50 & 0 & 0 & 0 & 0 & 0 & 6 & 42 & 2 \\
\hline & & & 30 & 32 & 0 & 0 & 0 & 0 & 0 & 1 & 24 & 7 \\
\hline & & & 40 & 15 & 0 & 0 & 0 & 0 & 0 & 0 & 2 & 13 \\
\hline & & & 50 & 15 & 0 & 0 & 0 & 0 & 0 & 0 & 0 & 15 \\
\hline & & & 60 & 11 & 0 & 0 & 0 & 0 & 0 & 0 & 0 & 11 \\
\hline & & & 70 & 10 & 0 & 0 & 0 & 0 & 0 & 0 & 0 & 10 \\
\hline & & & 80 & 8 & 0 & 0 & 0 & 0 & 0 & 0 & 0 & 8 \\
\hline & & & 90 & 7 & 0 & 0 & 0 & 0 & 0 & 0 & 0 & 7 \\
\hline & & & 100 & 6 & 0 & 0 & 0 & 0 & 0 & 0 & 0 & 6 \\
\hline
\end{tabular}

During a walk-off event, the greatest number of heliostats that hit the tower (for the three days and five times of day studied) occurs on June 21, 40 minutes after a 9:00 AM power failure. In this situation, 94 heliostats hit the tower structure. These heliostats come from the west side of the field.

\section{A.5 Recommendations}

1. The cable trays should be protected from damage caused by walk-on or walk-off heliostats. The exposed wiring on the tower should also be protected.

2. There should be at least eight minutes of salt flow provided by the salt pumps in the event of a power failure during receiver operation. The air that supplies valve actuation and control should also last for at least that amount of time.

3. During a walk-off event, the upper header oven covers of panels E6 and E7 and upper receiver flashing will be subjected to very high fluxes for several minutes. It is likely they will be damaged. A plan should be in place for replacing or repairing oven covers without putting the plant in a long-term outage while waiting for components to be fabricated. 


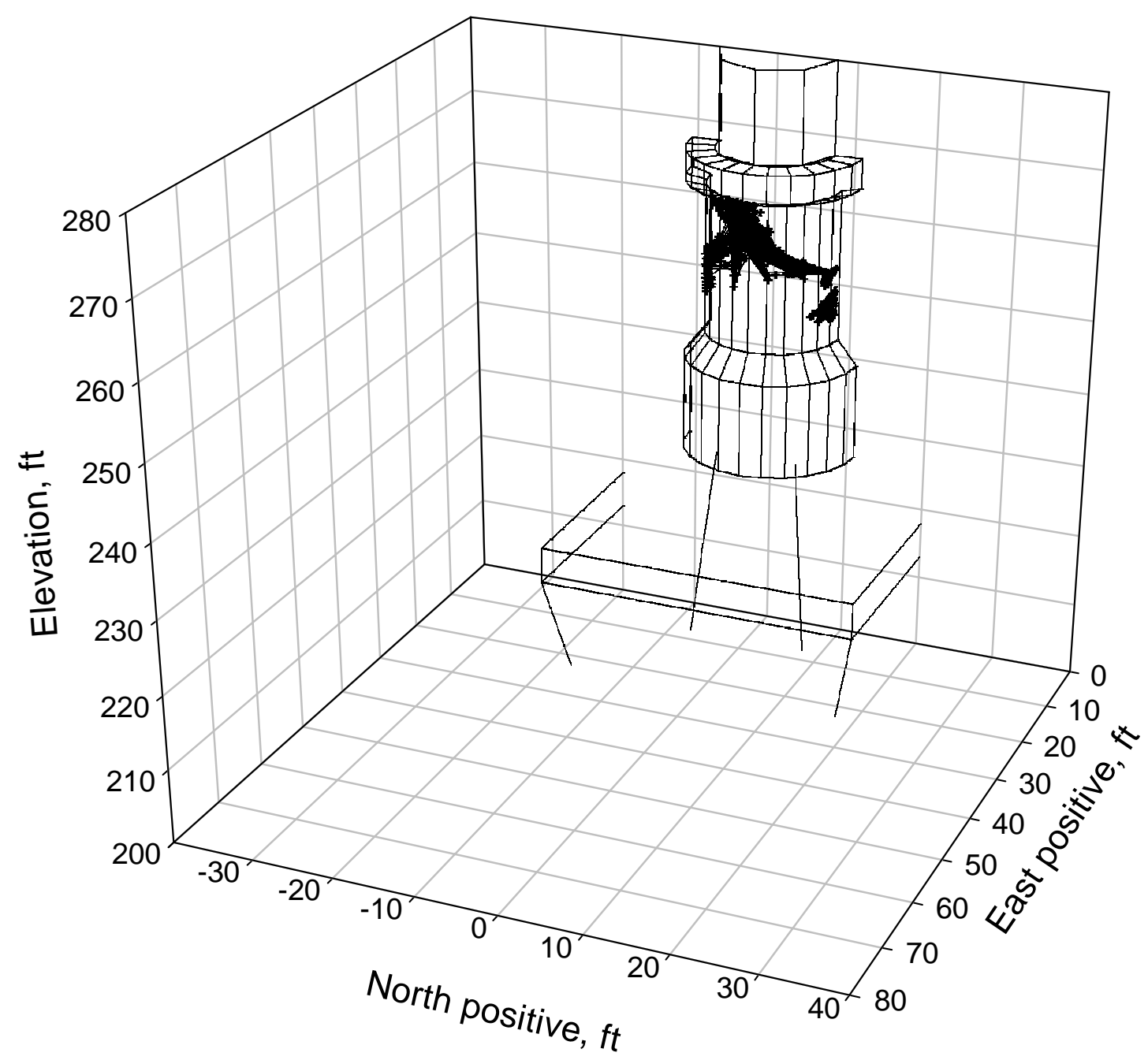

Figure A-6. This figure shows the path that beams from ring 5 heliostats on the east side of the receiver walk off during a power failure on June 21 at 12:00 PM. The lines represent the path the beams drift. They drift upward starting from the center of the receiver (as indicated by the cross marks at the center of the receiver). The next series of crosses represent the centroid location of the beams at one minute after power loss and then two minutes after power loss.

4. Do not change standby aim points to address walk on problems, provided the cable trays are protected. Changing these aim points would require defining or modifying the existing wire walks.

5. For new commercial power towers, new standby aim points should be investigated. Since the heliostat beams will always drift towards the east, the standby aim points for new plants should be on the east side of the tower.

6. The crane should be parked on the west side of the tower to minimize damage caused by drifting heliostats during walk on or walk off. 


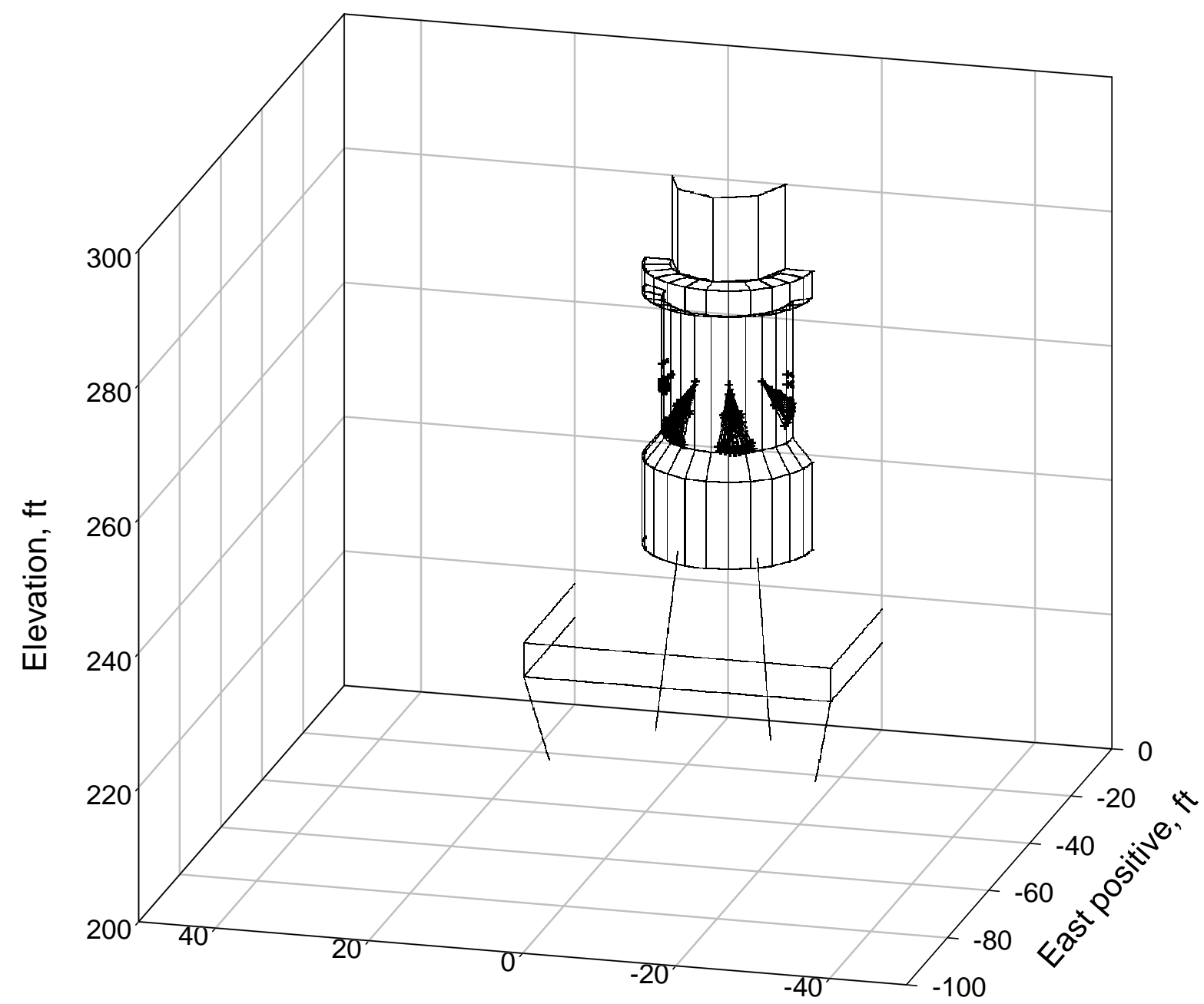

North positive, $\mathrm{ft}$

Figure A-7. This plot shows the path that ring 5 heliostat beams focused on the west side of the receiver walk off during a power loss. The beams drift downward starting from the center, as indicated by the cross at the center. The next series of crosses indicates the centroids of the heliostats after one minute and then two minutes. 
Final Test and Evaluation Results from the Solar Two Project 


\section{Appendix B. Receiver Efficiency Test (J. E. Pacheco)}

\section{B.1 Objectives}

The major goal of the receiver efficiency test was to map the receiver efficiency as a function of operating temperature and wind speed.

\section{B.2 Method}

The receiver efficiency, $\eta$, is defined as the ratio of the average power absorbed by the working fluid, $\mathrm{P}_{\mathrm{abs}}$, to the average power incident on the receiver, $\mathrm{P}_{\text {inc }}$, evaluated over a defined period under steady-state conditions.

$$
\eta=\frac{\bar{P} a b s}{\bar{P} i n c}
$$

Two methods were considered when evaluating the efficiency:

1. Complementary heliostat groups (power-on method), and

2. Receiver heat loss (power-off method).

Tests using the power-off method, where the heat loss across the receiver was measured directly without incident power on the receiver, were not implemented due to its inaccuracy. Only cold salt could be circulated through the receiver and the heat loss at that temperature was not representative of receiver operation.

\section{B.3 Power-On Method}

The incident power could not be measured directly on this size of receiver; therefore, the efficiency has to be obtained by eliminating incident power from the heat balance equation and by calculating the thermal losses from known measurements. The power-on method was designed for this type of measurement.

The plant conditions for this test were:

1. The heliostat field availability was greater than $80 \%$ with any heliostat outages randomly scattered throughout the field.

2. The heliostat field was biased within three months of the test.

3. The heliostat field cleanliness was measured within seven days of the test. 
4. Receiver system controls were able to tolerate a 50\% change in power and achieve steadystate conditions within five minutes.

5. The plant was able to support receiver operation for at least three hours at full power.

6. The receiver absorptivity was measured within 12 months of the test (either before or after).

The actual weather conditions experienced during these tests were:

1. Clear sunny days with peak insolation at $800 \mathrm{~W} / \mathrm{m}^{2}$ or more.

2. Mean wind speeds below $2.2 \mathrm{~m} / \mathrm{s}(5 \mathrm{mph})$ for of the low wind tests, and between 4.5 and 9 $\mathrm{m} / \mathrm{s}(10$ and $20 \mathrm{mph})$ for the high wind tests.

The procedure for conducting the power-on method was as follows. The heliostat field was divided into two groups with an equal numbers of heliostats symmetrically dispersed about the receiver. Group 1 contained every other heliostat. Group 2 contained the heliostats not in Group 1. See Figure B-1. The test was conducted symmetrically about solar noon between 11:00 AM and 1:00 PM solar time to minimize the changing cosine effects of the heliostat field.

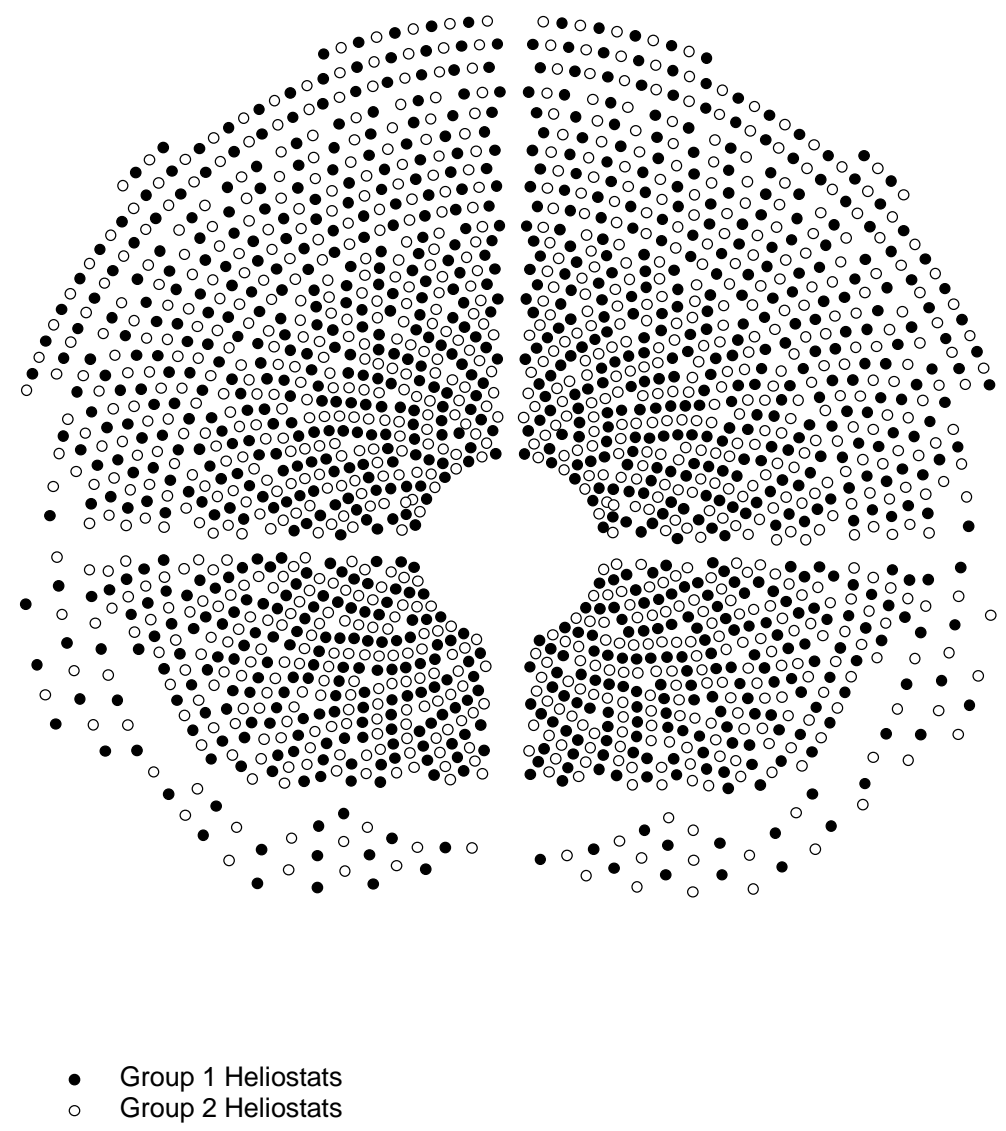

Figure B-1. Division of the Solar Two heliostats into Groups 1 and 2 for power-on test to measure receiver efficiency. 
The receiver was operated at full power (both groups) with the outlet temperature fixed (e.g., $565^{\circ} \mathrm{C} \pm 14^{\circ} \mathrm{C}$ ) during period $\mathrm{A}$, which ran between 11:00 AM and 11:30 AM (solar time). Then, for period B, Group 2 heliostats (half the field) were removed (put in standby) and the flow was adjusted so the same outlet temperature would be achieved. This period ran between 11:30 AM and 12:00 PM. At 12:00 PM, period C started. The flow was increased and the full field tracks the receiver again. The flow rate was again adjusted to maintain the same outlet temperature as for the previous periods. At 12:30 PM, period D began. Group 1 heliostats were removed. The flow rate was adjusted to maintain the desired salt outlet temperature. The test ended at 1:00 PM. Table B-1 illustrates this sequence.

Table B-1. Sequence of Heliostats Tracking the Receiver

\begin{tabular}{cccc}
\hline \hline Period & Solar Time & $\begin{array}{c}\text { Heliostat } \\
\text { Group(s) }\end{array}$ & Incident Power (Available) \\
\hline A & $11: 00$ AM to 11:30 AM & 1 and 2 & $100 \%$ \\
B & $11: 30$ AM to 12:00 PM & 1 & $50 \%$ \\
C & $12: 00$ PM to 12:30 PM & 1 and 2 & $100 \%$ \\
D & $12: 30$ PM to 1:00 PM & 2 & $50 \%$ \\
\hline \hline
\end{tabular}

By dividing the heliostat field into two symmetric groups, the power on the receiver can be halved independent of field cleanliness, mirror corrosion, and, to some extent, heliostat availability. Because of symmetry of the heliostat field output about solar noon, the average incident power during period $\mathrm{A}, \mathrm{P}_{\text {inc,A }}$ is twice the average incident power during period $\mathrm{D}, \mathrm{P}_{\text {inc, } \mathrm{D}}$. Likewise, for periods $\mathrm{C}$ and $\mathrm{B}$ :

$$
\begin{aligned}
& \bar{P}_{i n c, A}=2 \bar{P}_{i n c, D} \\
& \bar{P}_{i n c, C}=2 \bar{P}_{i n c, B} .
\end{aligned}
$$

From a heat balance on the receiver during steady-state conditions, the power incident on the receiver equals the sum of power reflected by the receiver $\left(\rho \mathrm{P}_{\text {inc }}\right)$, the power absorbed by the salt $\left(\mathrm{P}_{\mathrm{abs}}\right)$, and the thermal losses $\left(\mathrm{L}_{\text {thermal }}\right.$, radiation, convection, and conduction) from the receiver:

$$
\bar{P}_{i n c}=\rho \bar{P}_{i n c}+\bar{P}_{a b s}+\bar{L}_{t h e r m a l}
$$

where reflectivity $(\rho)$ is $1-$ absorptivity $(1-\alpha)$, yielding,

$$
\alpha \bar{P}_{i n c}=\bar{P}_{a b s}+\bar{L}_{\text {thermal }} .
$$

The absorbed power is the mass flow rate of salt times the change in enthalpy of the salt from the inlet to outlet of the receiver:

$$
\bar{P}_{a b s}=\overline{\dot{m}}\left(\bar{h}_{T_{\text {out }}}-\bar{h}_{T_{\text {in }}}\right) .
$$

An important assumption is made: 


\section{Under steady-state conditions with constant inlet and outlet salt temperatures and wind velocities, the temperature distributions on the receiver surface and throughout the receiver are independent of power level. Therefore, the thermal losses, $L_{\text {thermal, }}$ are independent of the incident power.}

Although this assumption is not entirely correct (mainly due to the slightly higher surface temperatures at the higher flux levels), inaccuracies related to it fall well within the uncertainty of the measurements. Consequently, thermal losses can be considered constant.

With constant thermal losses, equations B-2, B-3, and B-5 can be used to eliminate the incident power.

$$
\begin{aligned}
& \bar{P}_{a b s, A}+\bar{L}_{\text {thermal }}=2 \bar{P}_{a b s, D}+2 \bar{L}_{\text {thermal }} \\
& \bar{P}_{a b s, C}+\bar{L}_{\text {thermal }}=2 \bar{P}_{a b s, B}+2 \bar{L}_{\text {thermal }}
\end{aligned}
$$

The thermal loss can then be found. Adding equations B-7 and B-8 yields:

$$
\bar{L}_{\text {thermal }}=\frac{1}{2}\left(\bar{P}_{a b s, A}+\bar{P}_{a b s, C}-2 \bar{P}_{a b s, B}-2 \bar{P}_{a b s, D}\right) \text {. }
$$

The efficiency can be expressed in terms of the absorbed power, thermal losses, and absorptivity:

$$
\eta=\frac{\bar{P}_{a b s}}{\bar{P}_{i n c}}=\frac{\bar{P}_{a b s}}{\frac{\bar{P}_{a b s}+\bar{L}_{\text {thermal }}}{\alpha}}=\frac{\alpha}{1+\frac{\bar{L}_{\text {thermal }}}{\bar{P}_{a b s}}} .
$$

By employing this method, the receiver efficiency can be calculated subject to the uncertainties in the measurements associated with flow rate, inlet and outlet temperatures, and receiver absorptivity. The calculations are averaged over the steady-state portion of each test. Uncertainties of the incident power on the receiver due to the heliostat field performance (such as reflectivity, cosine effects, spillage, and alignment) are avoided.

\section{B.4 Results}

On September 29, 30, and October 1, 1997, the power-on method was used to measure receiver efficiency. For these tests, the outlet salt temperature was set to $552^{\circ} \mathrm{C}\left(1025^{\circ} \mathrm{F}\right)$ instead of $565^{\circ} \mathrm{C}\left(1050^{\circ} \mathrm{F}\right)$ because there was some concern that the outlet temperature would overshoot the set point when the receiver went through a severe transient. It turns out that the control system responded well and the temperature overshoot was within the operating limits of the receiver. Performing the test at the derated outlet temperature of $552^{\circ} \mathrm{C}\left(1025^{\circ} \mathrm{F}\right)$ resulted in measured efficiencies about $1 / 2$ a percentage point higher than what would be seen at $565^{\circ} \mathrm{C}\left(1050^{\circ} \mathrm{F}\right)$. Figure B-2 shows the number of heliostats tracking the receiver, receiver salt outlet temperature, salt flow rate, and direct normal insolation during the testing period for the test on October 1, 1997. For these tests, the heliostat availability was over $90 \%$. 


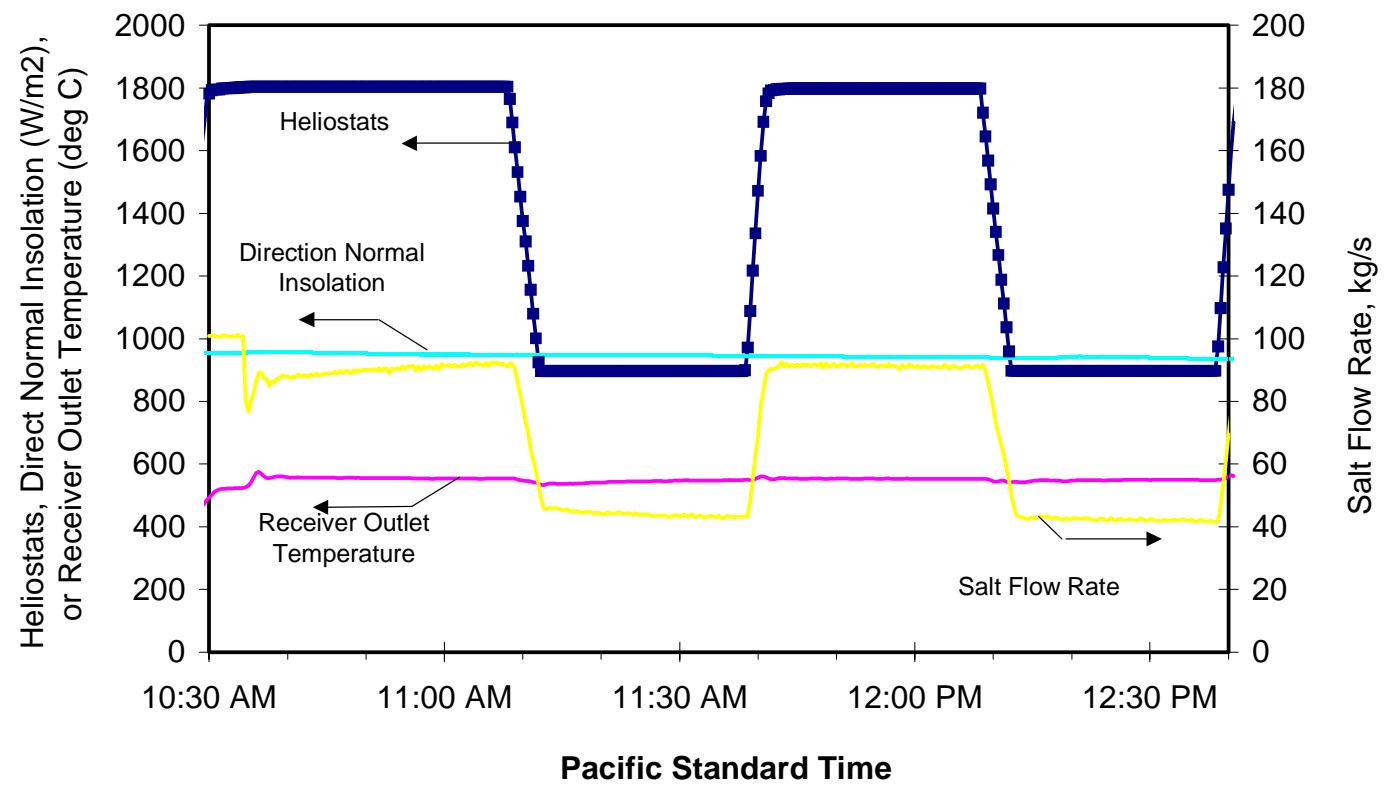

Figure B-2. Heliostats tracking the receiver, receiver outlet temperature, salt flow rate, and direct normal insolation for the receiver efficiency test on October 1, 1997. Solar noon occurred at 11:36 AM PST.

The power-on method was again used in March of 1999 to measure receiver efficiency. For these tests, the outlet salt temperature was set to the design value of $565^{\circ} \mathrm{C}\left(1050^{\circ} \mathrm{F}\right)$. The control system did not respond as well as during previous testing. Temperature overshoot during the increased power transient resulted in several high-temperature receiver trips. Temperature undershoot and sluggish response were exhibited during the reduced power transient. As a result of the degraded control system response, the March 1999 testing deviated from the original test plan. The individual test periods were increased from 30 minutes to 45 minutes to allow the control system time to stabilize the receiver outlet temperature. The degraded control system response was attributed to the replacement of several receiver photometers. The photometers were replaced by maintenance staff, but were not calibrated. For these tests, the heliostat availability was $86 \%$ to $90 \%$.

A summary of the key data taken over the steady-state portion of the tests is shown in Table B-2. Weather conditions over the steady-state portions of the tests are shown in Table B-3. Table B-4 shows average absorbed power, calculated thermal losses, and receiver efficiency. For the efficiency calculation, a receiver absorptivity of 0.95 was used. This was the measured average receiver absorptivity when the receiver was new. The steady-state portion of each period occurred in the timeframes shown in Table B-5. This table also shows when solar noon occurred. The heliostat field cleanliness data are summarized in Table B-6. The cleanliness of the heliostat field will not affect the receiver thermal efficiency since the receiver efficiency is based on the ratio of absorbed power to incident power on the receiver. The heliostat cleanliness is part of the heliostat field efficiency, not the receiver efficiency. 
Table B-2. Summary of Key Measurements for Receiver Efficiency Tests

\begin{tabular}{|c|c|c|c|c|c|c|c|c|c|}
\hline Test Date: & 29-Sep-97 & 30-Sep-97 & 1-Oct-97 & 5-Mar-99 & 12-Mar-99 & 17-Mar-99 & 22-Mar-99 & 23-Mar-99 & 24-Mar-99 \\
\hline \multicolumn{10}{|l|}{ Heliostats Tracking Receiver } \\
\hline A (full power) & 1767 & 1764 & 1804 & 1668 & 1685 & 1681 & 1699 & 1626 & 1725 \\
\hline B (half power) & 883 & 883 & 897 & 831 & 853 & 836 & 847 & 809 & 858 \\
\hline C (full power) & 1767 & 1758 & 1798 & 1664 & 1684 & 1676 & 1692 & 1625 & 1720 \\
\hline D (half power) & 884 & 876 & 898 & 833 & 830 & 840 & 847 & 805 & 848 \\
\hline Average Inlet Temperature, C & 295 & 301 & 305 & 308 & 303 & 302 & 301 & 302 & 299 \\
\hline A (full power) & 294 & 300 & 304 & 310 & 302 & 303 & 301 & 300 & 298 \\
\hline B (half power) & 295 & 301 & 305 & 311 & 302 & 301 & 300 & 301 & 297 \\
\hline C (full power) & 296 & 301 & 305 & 307 & 303 & 301 & 302 & 302 & 299 \\
\hline D (half power) & 296 & 302 & 306 & 306 & 304 & 301 & 303 & 303 & 300 \\
\hline Average Outlet Temperature, C & 551 & 550 & 550 & 564 & 563 & 564 & 563 & 561 & 564 \\
\hline A (full power) & 555 & 552 & 556 & 565 & 564 & 564 & 564 & 563 & 564 \\
\hline B (half power) & 547 & 548 & 544 & 562 & 561 & 562 & 560 & 558 & 562 \\
\hline C (full power) & 553 & 554 & 553 & 565 & 564 & 565 & 563 & 564 & 565 \\
\hline D (half power) & 549 & 547 & 549 & 564 & 564 & 564 & 564 & 557 & 564 \\
\hline Outlet Temperature Set Point, C & 552 & 552 & 552 & 566 & 566 & 566 & 566 & 566 & 566 \\
\hline \multicolumn{10}{|l|}{ Average Flow, kg/s } \\
\hline A (full power) & 80 & 90 & 90 & 81 & 67 & 78 & 69 & 61 & 70 \\
\hline$B$ (half power) & 39 & 43 & 44 & 36 & 32 & 37 & 32 & 28 & 33 \\
\hline C (full power) & 85 & 91 & 91 & 80 & 73 & 80 & 70 & 65 & 73 \\
\hline D (half power) & 39 & 43 & 42 & 38 & 33 & 36 & 32 & 30 & 32 \\
\hline
\end{tabular}


Table B-3. Weather Conditions During Receiver Efficiency Tests

\begin{tabular}{|c|c|c|c|c|c|c|c|c|c|}
\hline Test Date: & 29-Sep-97 & 30-Sep-97 & 1-Oct-97 & 5-Mar-99 & 12-Mar-99 & 17-Mar-99 & 22-Mar-99 & 23-Mar-99 & 24-Mar-99 \\
\hline $\begin{array}{l}\text { Average Wind Speed, Level } 7 \\
\text { (37.8 } \mathrm{m} \text { elevation), } \mathrm{m} / \mathrm{s}\end{array}$ & 0.6 & 1.0 & 0.6 & 3.0 & 1.8 & 1.4 & 0.9 & 7.9 & 1.3 \\
\hline A Speed & 0.6 & 1.2 & 1.0 & 2.8 & 2.0 & 3.2 & 0.9 & 9.0 & 2.5 \\
\hline B Speed & 0.5 & 1.4 & 0.7 & 2.7 & 1.8 & 1.4 & 0.6 & 8.6 & 1.0 \\
\hline C Speed & 0.6 & 0.7 & 0.4 & 4.0 & 2.2 & 0.5 & 1.0 & 6.9 & 1.0 \\
\hline D Speed & 0.7 & 0.8 & 0.5 & 2.5 & 1.1 & 0.6 & 1.2 & 7.0 & 0.9 \\
\hline $\begin{array}{l}\text { Average Wind Direction, Level 7, } \\
\text { deg (Clockwise from North) }\end{array}$ & 131 & 241 & 210 & 270 & 223 & 241 & 165 & 263 & 241 \\
\hline A Direction & 151 & 279 & 256 & 260 & 246 & 267 & 260 & 262 & 277 \\
\hline B Direction & 122 & 281 & 231 & 282 & 222 & 275 & 142 & 262 & 269 \\
\hline C Direction & 127 & 240 & 216 & 265 & 207 & 206 & 125 & 259 & 187 \\
\hline D Direction & 123 & 165 & 139 & 273 & 218 & 217 & 135 & 268 & 232 \\
\hline $\begin{array}{l}\text { Average Direct Normal Insolation, } \\
\mathrm{W} / \mathrm{m}^{\wedge} 2\end{array}$ & 913 & 975 & 942 & 989 & 898 & 960 & 871 & 874 & 894 \\
\hline A & 887 & 975 & 949 & 992 & 865 & 958 & 861 & 858 & 887 \\
\hline B & 913 & 977 & 945 & 963 & 879 & 969 & 872 & 869 & 902 \\
\hline C & 931 & 976 & 939 & 985 & 915 & 970 & 879 & 875 & 900 \\
\hline D & 922 & 971 & 934 & 1016 & 932 & 944 & 869 & 893 & 889 \\
\hline Average Ambient Temperature, C & 32 & 33 & 33 & 16 & 14 & 18 & 18 & 16 & 17 \\
\hline
\end{tabular}


Table B-4. Summary of Calculated Test Results. A receiver absorptivity of 0.95 was used for these calculations

\begin{tabular}{|c|c|c|c|c|c|c|c|c|c|}
\hline Test Date: & 29-Sep-97 & 30-Sep-97 & 1-Oct-97 & 5-Mar-99 & 12-Mar-99 & 17-Mar-99 & 22-Mar-99 & 23-Mar-99 & 24-Mar-99 \\
\hline \multicolumn{10}{|c|}{ Average Power Absorbed, MWt } \\
\hline A (full power) & 31.6 & 34.4 & 34.3 & 31.5 & 26.5 & 31.0 & 27.4 & 24.2 & 28.3 \\
\hline B (half power) & 15.0 & 15.9 & 15.9 & 13.7 & 12.5 & 14.5 & 12.5 & 10.8 & 13.3 \\
\hline C (full power) & 33.3 & 34.9 & 34.3 & 31.5 & 28.8 & 32.1 & 27.9 & 25.7 & 29.5 \\
\hline$D$ (half power) & 15.1 & 16.1 & 15.6 & 14.8 & 13.0 & 14.3 & 12.7 & 11.4 & 12.9 \\
\hline Thermal Loss, MWt & 2.27 & 2.57 & 2.75 & 3.04 & 2.18 & 2.76 & 2.55 & 2.75 & 2.63 \\
\hline \multicolumn{10}{|l|}{ Efficiency } \\
\hline Full Power & 0.888 & 0.884 & 0.880 & 0.866 & 0.881 & 0.874 & 0.870 & 0.856 & 0.871 \\
\hline Half Power & 0.827 & 0.819 & 0.809 & 0.783 & 0.811 & 0.797 & 0.790 & 0.761 & 0.792 \\
\hline
\end{tabular}

\begin{tabular}{|c|c|c|c|c|c|c|c|c|c|c|}
\hline Test Date: & & 9/29/97 & 9/30/97 & 10/1/97 & $3 / 5 / 99$ & $3 / 12 / 99$ & $3 / 17 / 99$ & $3 / 22 / 99$ & 3/23/99 & $3 / 24 / 99$ \\
\hline \multicolumn{11}{|c|}{ Average Absorbed Power, MWt } \\
\hline & A (full power) & 31.6 & 34.4 & 34.3 & 31.5 & 26.5 & 31.0 & 27.4 & 24.2 & 28.3 \\
\hline & B (half power) & 15.0 & 15.9 & 15.9 & 13.7 & 12.5 & 14.5 & 12.5 & 10.8 & 13.3 \\
\hline & $\mathrm{C}$ (full power) & 33.3 & 34.9 & 34.3 & 31.5 & 28.8 & 32.1 & 27.9 & 25.7 & 29.5 \\
\hline & $\mathrm{D}$ (half power) & 15.1 & 16.1 & 15.6 & 14.8 & 13.0 & 14.3 & 12.7 & 11.4 & 12.9 \\
\hline "Thermal Loss, MWt & & 2.27 & 2.57 & 2.75 & 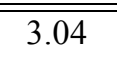 & 2.18 & 2.76 & 2.55 & 2.75 & 2.63 \\
\hline \multicolumn{11}{|l|}{ Efficiency } \\
\hline & Full Power & 0.888 & 0.884 & 0.880 & 0.866 & 0.881 & 0.874 & 0.870 & 0.856 & 0.871 \\
\hline & Half Power & 0.827 & 0.819 & 0.809 & 0.783 & 0.811 & 0.797 & 0.790 & 0.761 & 0.792 \\
\hline
\end{tabular}


Table B-5. Timeframes for Steady State Portions of Each Test (PST)

\begin{tabular}{|c|c|c|c|c|c|c|c|c|c|}
\hline Test Date: & 9/29/97 & 9/30/97 & 10/1/97 & $3 / 5 / 99$ & $3 / 12 / 99$ & 3/17/99 & 3/22/99 & $3 / 23 / 99$ & $3 / 24 / 99$ \\
\hline \multicolumn{10}{|c|}{$\begin{array}{l}\text { Steady State Measurement Times, } \\
\text { PST }\end{array}$} \\
\hline A Start & $10: 39: 40$ & 10:36:00 & 10:38:00 & 11:13:00 & 10:30:00 & $10: 40: 00$ & 11:00:00 & $10: 43: 20$ & $10: 53: 00$ \\
\hline A End & 11:06:00 & 11:06:00 & $11: 06: 00$ & $11: 30: 40$ & $11: 13: 20$ & $11: 15: 40$ & $11: 24: 40$ & $11: 10: 00$ & $11: 24: 00$ \\
\hline B Start & $11: 18: 00$ & $11: 17: 00$ & $11: 15: 00$ & $11: 37: 00$ & $11: 24: 00$ & $11: 25: 40$ & $11: 35: 20$ & $11: 23: 40$ & $11: 33: 40$ \\
\hline B End & $11: 36: 00$ & $11: 36: 00$ & $11: 36: 00$ & $11: 54: 00$ & $12: 00: 00$ & $11: 56: 00$ & $11: 52: 40$ & $11: 55: 20$ & $11: 53: 00$ \\
\hline C Start & $11: 51: 00$ & $11: 49: 40$ & $11: 45: 00$ & $12: 06: 00$ & $12: 05: 40$ & $12: 03: 00$ & 12:09:00 & $12: 03: 00$ & $12: 03: 00$ \\
\hline C End & $12: 06: 00$ & $12: 06: 00$ & $12: 06: 00$ & $12: 30: 00$ & $12: 44: 40$ & $12: 40: 40$ & $12: 24: 40$ & $12: 34: 00$ & $12: 21: 40$ \\
\hline D Start & $12: 27: 20$ & $12: 13: 20$ & $12: 14: 20$ & $12: 37: 00$ & $12: 55: 00$ & $12: 48: 40$ & $12: 31: 00$ & $12: 46: 20$ & $12: 34: 00$ \\
\hline D End & $12: 36: 00$ & $12: 36: 00$ & $12: 36: 00$ & 13:00:00 & $13: 36: 00$ & $13: 26: 40$ & $12: 54: 00$ & $13: 19: 20$ & $12: 53: 20$ \\
\hline Solar Noon & $11: 36$ & $11: 36$ & $11: 36$ & 11:59:58 & $11: 58: 14$ & $11: 56: 48$ & $11: 55: 16$ & $11: 54: 57$ & $11: 54: 38$ \\
\hline
\end{tabular}


Table B-6. Field Cleanliness Measurements

\begin{tabular}{|c|c|c|c|c|c|}
\hline Measurement Date & $9 / 30 / 97$ & $2 / 27 / 99$ & $3 / 8 / 99$ & $3 / 17 / 99$ & $3 / 26 / 99$ \\
\hline Martin Field & & & Cleanliness & & \\
\hline$\overline{N E}$ & $97.67 \%$ & $94.21 \%$ & $90.50 \%$ & $92.71 \%$ & $94.26 \%$ \\
\hline$\overline{N W}$ & $96.99 \%$ & $95.47 \%$ & $90.67 \%$ & $93.66 \%$ & $94.82 \%$ \\
\hline$\overline{S E}$ & $95.16 \%$ & $95.97 \%$ & $91.20 \%$ & $93.78 \%$ & $94.34 \%$ \\
\hline$S W$ & $96.90 \%$ & $96.26 \%$ & $92.55 \%$ & $94.06 \%$ & $92.31 \%$ \\
\hline \multicolumn{6}{|l|}{ Lugo Field } \\
\hline$\overline{L S E}$ & $92.43 \%$ & $84.61 \%$ & $68.39 \%$ & $87.76 \%$ & No Data \\
\hline$\overline{L S W}$ & $93.34 \%$ & $83.79 \%$ & $73.09 \%$ & $87.57 \%$ & $\overline{\text { No Data }}$ \\
\hline
\end{tabular}

\section{B.5 Discussion/Conclusions}

An uncertainty analysis was conducted of the receiver efficiency based on estimated measurement uncertainties of the instruments. The uncertainty for each measurement is summarized in Table B-7.

Uncertainty in the flow measurement is based on the random uncertainty (scatter at a constant flow rate), not slope or offset uncertainty. The reason is that the power-on test is a back-to-back comparison that depends on differences of parameters over a time period too short for significant calibration drift. This is confirmed in equations B-6, B-9, and B-10. In equation B-10, the efficiency is based on the ratio of the thermal loss (equation B-9) to the absorbed power (equation B-6). Even if the calibration curve slope of the mass flow rate is significantly off (say $10 \%$ ), the error will divide out. The errors that affect the measurement are offset and random scatter. The data show that the offset during no flow is very small (around $0.06 \mathrm{~kg} / \mathrm{s}(0.5 \mathrm{kpph})$ ). The random scatter under steady-state portions of the experiment is about $0.8 \mathrm{~kg} / \mathrm{s}(6.0 \mathrm{kpph})$. The sum of the these uncertainties is $0.82 \mathrm{~kg} / \mathrm{s}(6.5 \mathrm{kpph})$, which is $<1 \%$ at full flow.

Table B-7. Measurement uncertainties for receiver efficiency testing

\begin{tabular}{cc}
\hline \hline Measurement & Uncertainty \\
\hline Temperature & $\pm 2.8^{\circ} \mathrm{C}$, over $280^{\circ} \mathrm{C}\left( \pm 5^{\circ} \mathrm{F}\right.$, over $\left.500^{\circ} \mathrm{F}\right)$ span is $\pm 1 \%$ \\
Flow Rate & $\pm 1 \%$ (random uncertainty $)$ \\
Absorptivity $(\alpha)$ & $+0.00 /-0.02$, this corresponds to $+0.0 \% /-2.1 \% @$ \\
& $\alpha=0.95$ \\
Heliostat Tracking Repeatability & \pm 5 heliostats, or $5 / 1800=0.3 \%$ \\
\hline \hline
\end{tabular}

Using the values in Table B-7, the receiver efficiency uncertainty, based on the root-sum-square value (95\% confidence), is: 


$$
\begin{aligned}
& \epsilon_{\eta}=+\left(1^{2}+1^{2}+0^{2}+0.3^{2}\right)^{0.5}=+1.4 \% \\
& \epsilon_{\eta}=-\left(1^{2}+1^{2}+2.1^{2}+0.3^{2}\right)^{0.5}=-2.5 \% .
\end{aligned}
$$

For an efficiency of $\eta=0.884$, the true value of the receiver efficiency at $95 \%$ confidence is:

$$
\eta=0.884+0.012 /-0.022=0.862 \text { to } 0.896
$$

Prior to conducting the receiver efficiency test (on September 25, 1997), Boeing North American, Inc. (receiver manufacturer) verbally provided an estimate of the receiver efficiency as a function of wind speed. Their estimate, which is summarized in Table B-8, is based on the full power output of the heliostat field, which results in a receiver incident power of $48.6 \mathrm{MWt}$, receiver salt inlet and outlet temperatures of 288 and $565^{\circ} \mathrm{C}\left(550\right.$ and $\left.1050^{\circ} \mathrm{F}\right)$, respectively, and a receiver absorptivity of 0.95 . The efficiency calculation does not account for the additional loss from the gap between back of the receiver and the insulation due to convection. This amounts to approximately $300 \mathrm{~kW}$, or a drop in efficiency of 0.005 . The salt temperature measurements are based on the temperature of the salt entering the first panel and exiting the last panels. It does not include the effect of cold salt leaking past the receiver diversion valve to the downcomer.

Table B-8. $\quad$ Predicted Receiver Efficiency as a Function of Wind Speed Based on Boeing North American's Calculations for an Incident Power of 48.6 MWt

\begin{tabular}{cc}
\hline \hline $\begin{array}{c}\text { Wind Speed at 10 meters, } \\
\text { m/s (mph) }\end{array}$ & Receiver Thermal Efficiency \\
\hline $0(0)$ & 0.89 \\
$5.2(11.6)$ & 0.88 \\
$13.4(30)$ & 0.86 \\
\hline \hline
\end{tabular}

A model of the thermal performance of the receiver was used to estimate the efficiency at the test conditions (Lippke, 1995). This model does a heat balance on the receiver accounting for losses due to reflection, radiation, convection, and conduction. It employs the mixed convection correlation proposed by Stoddard (Stoddard, 1986).

The results of the model are within 1\% of the Boeing prediction for Boeing's conditions. Model results are compared to the test results in Table B-9. These predicted results fall within the uncertainty of the instruments for the measured results. A plot of the effect of wind speed and incident power on the receiver efficiency was generated using the model and is shown in Figure B-3. To calculate the wind speed at a different height, the wind velocity, $V$, is: $V=V_{10}$ meters $(h / 10)^{0.15}$, where $\mathrm{h}$ is the height in meters. At high incident powers, the effect of wind is relatively minor because the losses are dominated by reflection and radiation losses. 
Table B-9. Comparison of Predicted Efficiency (from Model) with Measured Efficiency

\begin{tabular}{cccccccccc}
\hline \hline Test Date: & $\mathbf{9 / 2 9 / 9 7}$ & $\mathbf{9 / 3 0 / 9 7}$ & $\mathbf{1 0 / 1 / 9 7}$ & $\mathbf{3 / 5 / 9 9}$ & $\mathbf{3 / 1 2 / 9 9}$ & $\mathbf{3 / 1 7 / 9 9}$ & $\mathbf{3 / 2 2 / 9 9}$ & $\mathbf{3 / 2 3 / 9 9}$ & $\mathbf{3 / 2 4 / 9 9}$ \\
\hline & & \multicolumn{7}{c}{ Efficiency } \\
$\begin{array}{c}\text { Predicted Full } \\
\quad \text { Power }\end{array}$ & 0.877 & 0.881 & 0.880 & 0.866 & 0.881 & 0.874 & 0.870 & 0.856 & 0.871 \\
$\begin{array}{c}\text { Measured Full } \\
\quad \text { Power }\end{array}$ & 0.888 & 0.884 & 0.880 & 0.872 & 0.865 & 0.874 & 0.866 & 0.839 & 0.869 \\
$\begin{array}{c}\text { Difference } \\
\quad\end{array}$ & $\mathbf{- 0 . 0 1 1}$ & $\mathbf{- 0 . 0 0 3}$ & $\mathbf{0 . 0 0 0}$ & $\mathbf{0 . 0 0 6}$ & $\mathbf{- 0 . 0 1 6}$ & $\mathbf{0 . 0 0 0}$ & $\mathbf{- 0 . 0 0 4}$ & $\mathbf{- 0 . 0 1 7}$ & $\mathbf{- 0 . 0 0 2}$ \\
$\begin{array}{c}\text { Predicted Half } \\
\quad \text { Power }\end{array}$ & 0.815 & 0.822 & 0.820 & 0.783 & 0.811 & 0.797 & 0.790 & 0.761 & 0.792 \\
$\begin{array}{c}\text { Measured Half } \\
\text { Power }\end{array}$ & 0.827 & 0.819 & 0.809 & 0.801 & 0.791 & 0.807 & 0.790 & 0.740 & 0.794 \\
Difference & $\mathbf{- 0 . 0 1 2}$ & $\mathbf{0 . 0 0 3}$ & $\mathbf{0 . 0 1 1}$ & $\mathbf{0 . 0 1 8}$ & $\mathbf{- 0 . 0 2 0}$ & $\mathbf{0 . 0 1 0}$ & $\mathbf{0 . 0 0 0}$ & $\mathbf{- 0 . 0 2 1}$ & $\mathbf{0 . 0 0 2}$ \\
\hline \hline
\end{tabular}

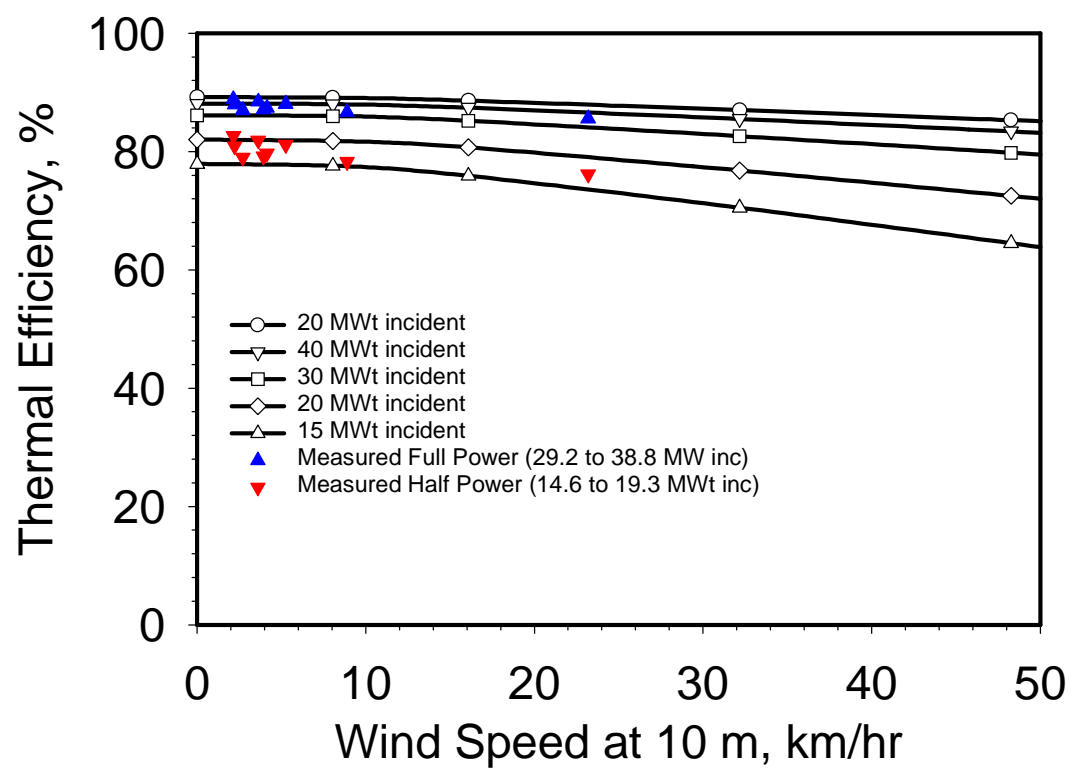

Figure B-3. Receiver efficiency as a function of wind speed (measured at 10m) at various incident powers along with measured receiver efficiency data.

\section{B.6 References}

Lippke, F. (1995) Solar Two Overall Efficiency at Reduced Receiver Outlet Temperatures, Sandia National Laboratories, Internal memo, April 1995.

Stoddard, M. C. (1986) Convective Loss Measurements at the $10 \mathrm{MWe}$ Solar Thermal Central Receiver Pilot Plant, Sandia National Laboratories, SAND85-8250. 


\section{Appendix C. Solar Resource Measurement Quality Assessment at Solar Two (S. A. Jones)}

\section{C.1 Introduction}

Accurate analysis of many Solar Two systems relies upon accurate solar resource data. In particular, the direct normal insolation (DNI) measurement is used to evaluate such things as solar collection efficiency and solar-to-electric conversion efficiency. DNI was measured at Solar Two with two redundant Normal Incidence Pyrheliometers (NIPs) manufactured by Epply, Inc. The instruments were carefully calibrated at Sandia before installation and then typically recalibrated yearly. Once calibrated, these instruments are accurate to $\pm 1-1.5 \%$ under normal operating conditions, but larger errors can occur when there are unplanned events such as tracking errors, reflections off objects, and shading from objects or due to soiled glass cover plates. To ensure the accuracy of the DNI measurements, a station measuring all three components of radiation was installed. Global horizontal radiation was measured with an Epply pyranometer and diffuse radiation was measured by shading an Epply pyranometer from direct sunlight with a tracking disc or stationary band. Figure C-1 shows a typical three-component station.

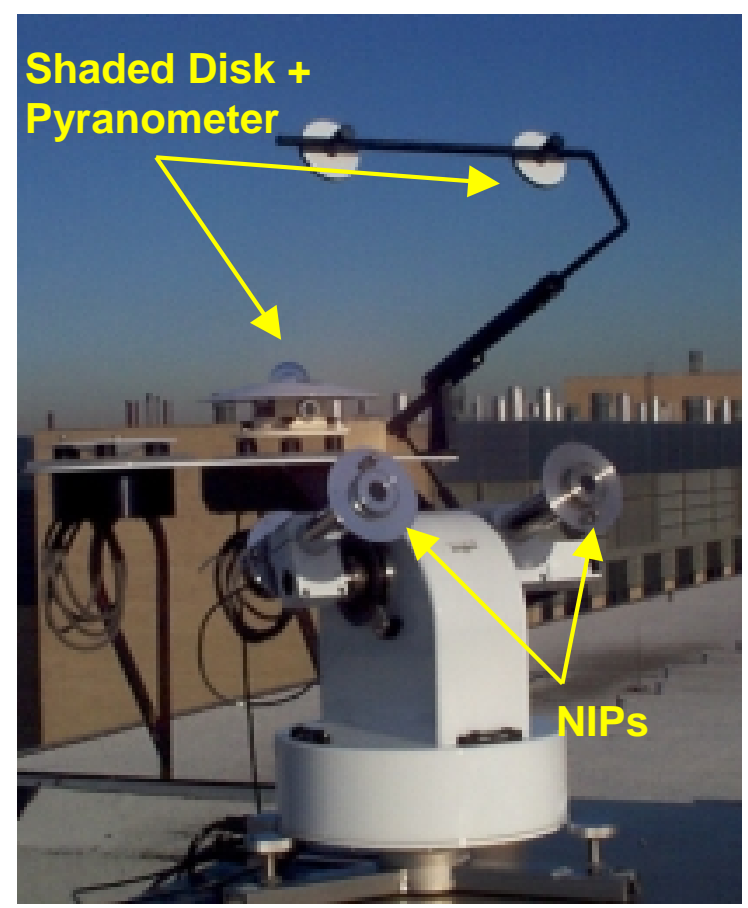

(a)

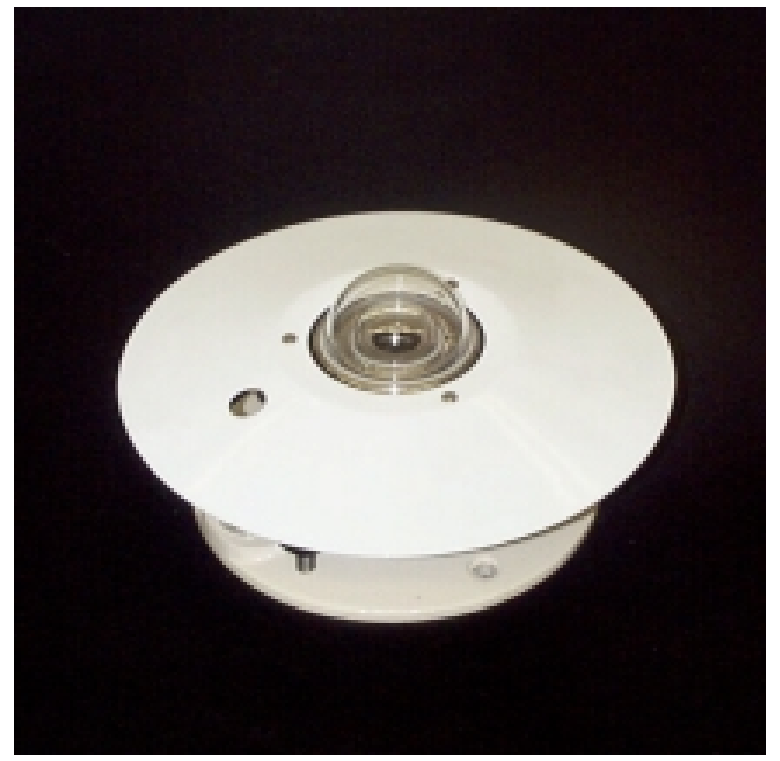

(b)

Figure C-1. (a) Three-component solar resource station with redundant tracking NIP devices measuring $\mathrm{DNI}$ and a shaded pyranometer measuring diffuse radiation. Missing from view is an unshaded pyranometer (b). 


\section{C.2 Theory}

A three-component station consists of sensors that independently measure direct, diffuse, and total (global) radiation. By having all three components, redundancy makes it possible to identify inconsistencies. Once radiation is corrected for view angle and normalized, the sum of the direct normal and diffuse components should equal the total radiation (NREL, 1993):

where,

$$
\mathrm{K}_{\mathrm{t}}=\mathrm{K}_{\mathrm{n}}+\mathrm{K}_{\mathrm{d}}
$$

and

$$
\begin{aligned}
& \mathrm{K}_{\mathrm{n}}=\mathrm{I}_{\mathrm{n}} / \mathrm{I}_{\mathrm{o}} \\
& \mathrm{K}_{\mathrm{t}}=\mathrm{I}_{\mathrm{t}} /\left(\mathrm{I}_{\mathrm{o}} \cos \mathrm{z}\right) \\
& \mathrm{K}_{\mathrm{d}}=\mathrm{I}_{\mathrm{d}} /\left(\mathrm{I}_{\mathrm{o}} \cos \mathrm{z}\right),
\end{aligned}
$$

$\mathrm{I}_{\mathrm{o}} \quad=$ extraterrestial direct normal radiation

$\mathrm{I}_{\mathrm{n}} \quad=$ direct normal radiation (insolation) at the earth's surface

$\mathrm{I}_{\mathrm{t}} \quad=$ total global horizontal radiation at the earth's surface

$\mathrm{I}_{\mathrm{d}} \quad=$ diffuse horizontal radiation at the earth's surface

$\mathrm{Z} \quad=$ solar zenith angle

$\mathrm{I}_{\mathrm{O}} \cos \mathrm{z}=$ extraterrestrial radiation on a surface parallel to the earth's surface

$\mathrm{K}_{\mathrm{n}} \quad=$ direct beam transmittance

$\mathrm{K}_{\mathrm{t}}=$ clearness index or effective global horizontal transmittance

$\mathrm{K}_{\mathrm{d}} \quad=$ effective diffuse horizontal transmittance.

Data quality was assessed with an error function (E)

$$
\mathrm{E}=\mathrm{K}_{\mathrm{t}}-\mathrm{K}_{\mathrm{n}}-\mathrm{K}_{\mathrm{d}}
$$

Small errors in K-space due to instrument and readout noise, temperature effects, and internal reflections on the glass domes of less than $3 \%$ are considered a sign of good data [1]. These boundaries were established:

$$
-0.03<\mathrm{E}<0.03
$$

While this test identifies data with potential errors, further analysis beyond this three-component redundancy test is required to establish the nature of those errors. The focus here will be on the three-component screening test.

\section{C.3 Solar Two Experiences}

Both proactive and reactive approaches were used to improve the accuracy of solar resource measurements at Solar Two. Operators were required to inspect the measurement station located on the roof of the control room twice per day. They checked cleanliness of instrument windows, 
alignment of the shade device for the diffuse measurement, and tracking accuracy of the NIP devices. They also checked the computer tracking system to ensure it had kept proper time. Solar resource data was also analyzed after the fact using the procedures described above to ensure data quality. This analysis was eventually incorporated into a daily report so that on-site personnel could monitor this information and quickly identify any problems. This feedback system was only moderately successful for a number of reasons. The daily reports were frequently run in batches, rather than every day, and sometimes problems with the solar resource measurements were not identified or corrected for a while. Also, on-site personnel may have thought the proactive measures sufficient, so less importance was placed on the three-component results. Data integrity is most important during times of high insolation. Poor quality readings during low-insolation periods like sunrise, sunset, and cloudy weather are not particularly detrimental to analysis of plant performance.

Figure C-2 is a plot of error from the three-component test for a typical clear-sky day. The lines with dots markers represent the three-component error values computed for each NIP. When these values fall between the lines at \pm 0.03 , the data is validated as accurate. When the error falls outside these bounds, this is a warning there may be a problem with the measurement of one or more radiation components. The lines at the bottom of the graph show the actual DNI measurement made by each NIP. This can be helpful in understanding cloud cover and in identifying problems. In the upper right is the legend that also lists the number of minutes outside the bounds based upon each NIP measurement, in this case 9 and 0 minutes.

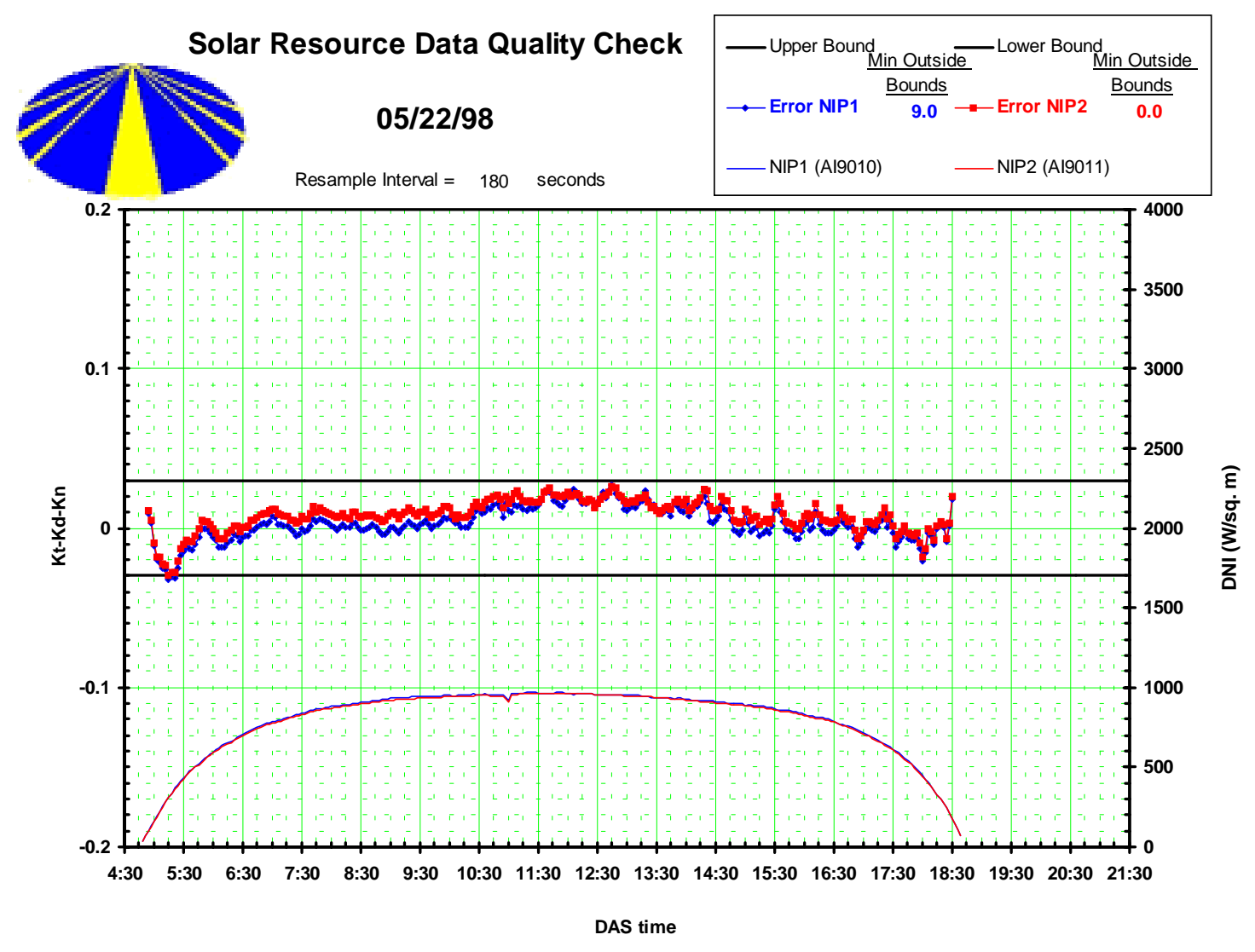

Figure C-2. Error from three-component test on a sunny day. 
On a cloudy day (Figure C-2), the three-component test frequently stays within the bounds, but sometimes clouds cause errors to exceed the bounds, as seen in the afternoon, in Figure C-3. Frequently, there were errors outside the bounds at the beginning and end of days, such as sunset, in Figure C-4. This may have been due to internal reflections on the dual-domed pyranometers or reflections off the salt tanks at the end of the day. The DNI at these times was very low, and accurate readings were not critical, so these errors were considered unimportant. However, there were times when errors were important.

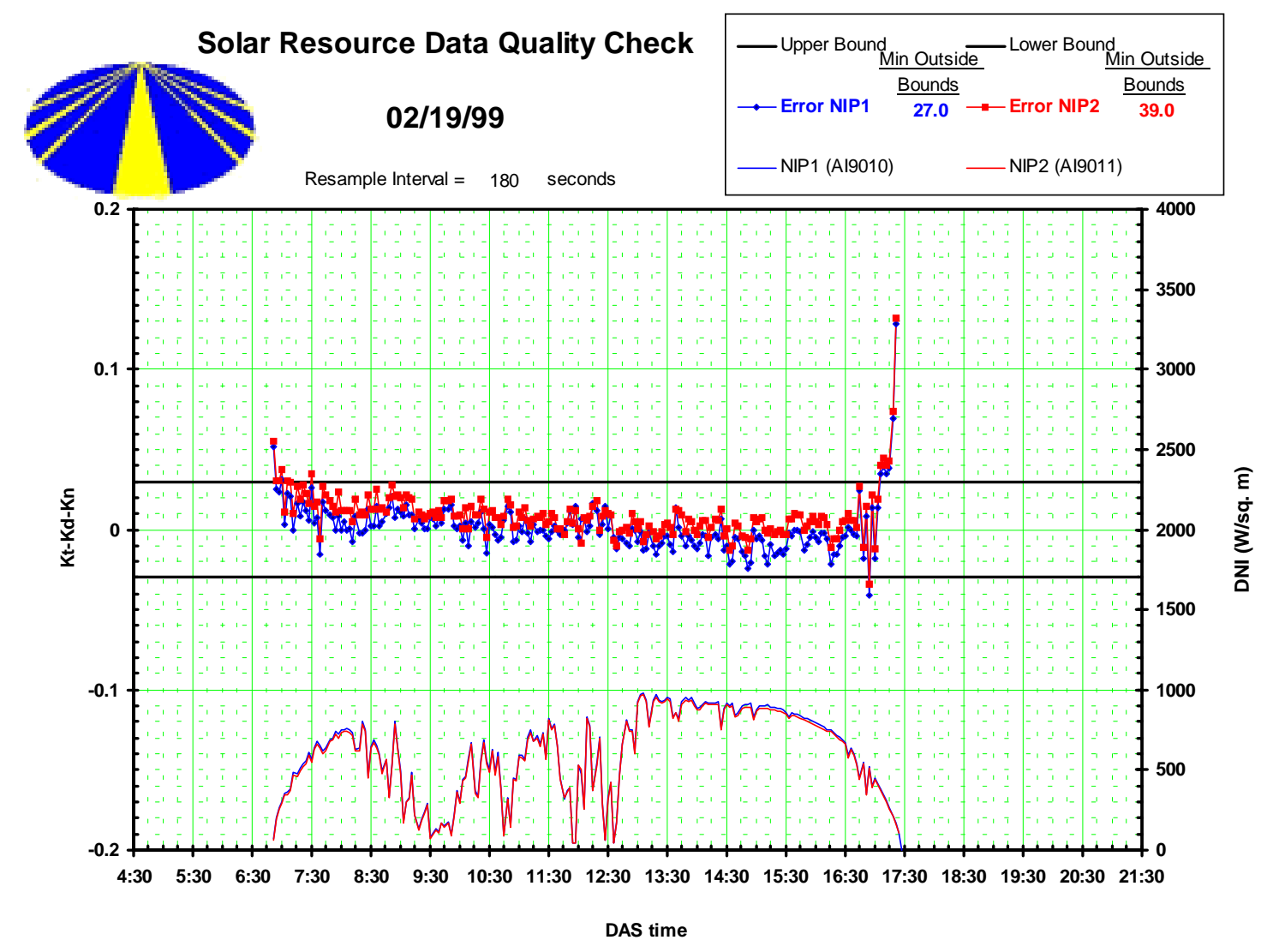

Figure C-3. Error from three-component test on a cloudy day.

Figure C-3 shows an example of important data integrity issues. Starting at about 8:30 in the morning, the errors climb above the upper bound. Just after 9:30, the errors drop to acceptable levels. The DNI measurements at the bottom of the graph start dropping off at 8:30, then rebound to higher levels just after 9:30. This was clearly an example of poor NIP tracking that led to low DNI measurements. The operators probably noticed the decreasing DNI readings when they expected increasing values on this clear morning and fixed the tracking problem. It is worth noting that the DNI values were about 30\% low when this problem was observed and corrected. Clearly, a three-component system like the one used here is needed to determine errors at lower magnitudes, as well as other error types that are harder for operators to notice. 


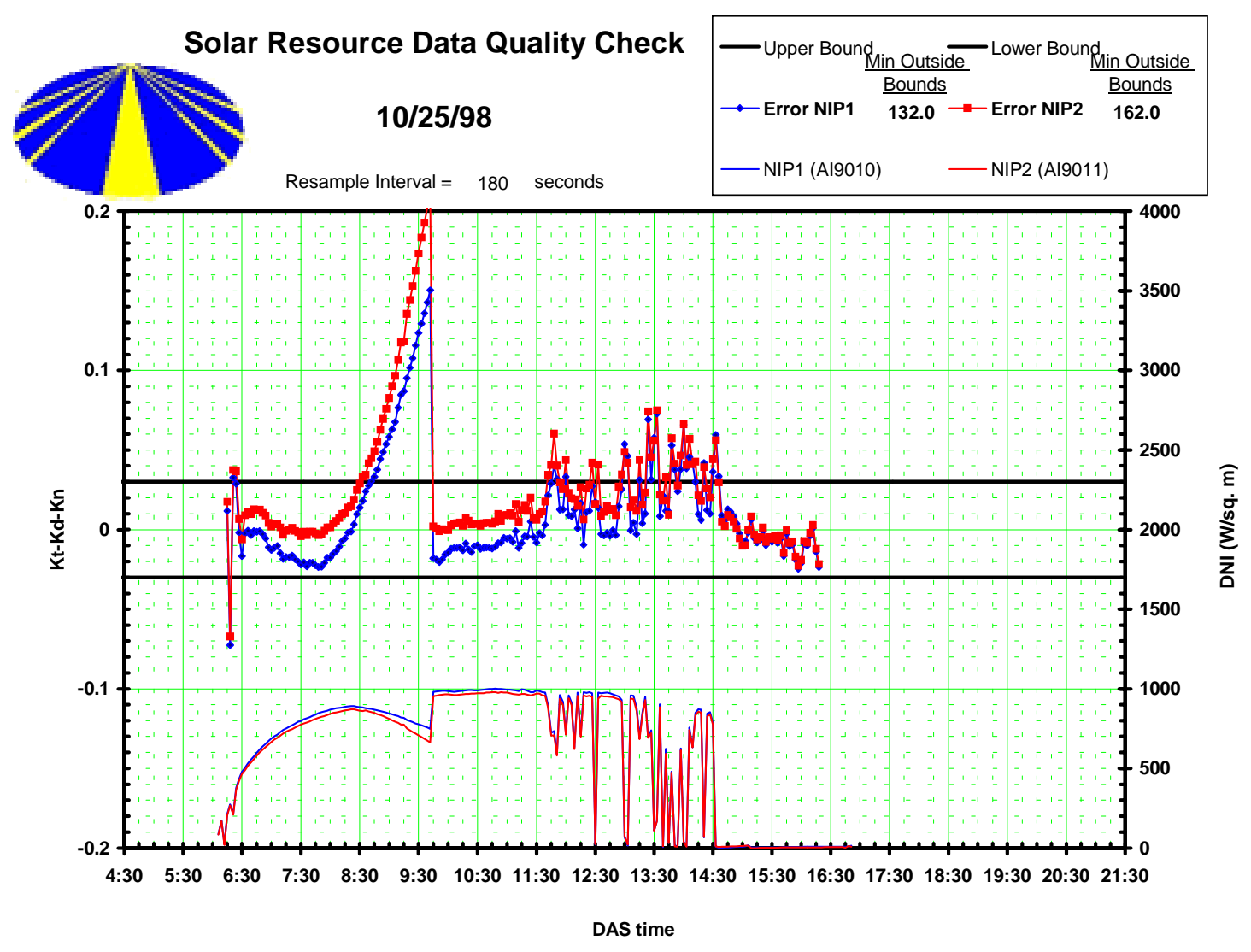

Figure C-4. Error from three-component test showing important errors in the morning due to poor NIP tracking and unimportant errors in the afternoon due to clouds.

If this data was used in a calculation (perhaps automated) of peak solar field efficiency or plant efficiency, a value 30\% higher than real would be found. For this reason, it is imperative that analysts check the quality of resource data used in the calculation of key performance metrics.

Figure C-5 and Figure C-6 provide an overview of the solar resource data errors from June, 1997 until the plant closed in April, 1999. Figure C-4 is provided because sometimes the percentage within bounds can be misleading. For example, sometimes data was collected only over a fraction of the day, so only a few minutes outside bounds can lead to a high percentage value outside bounds. This may occur when little data was logged because there were heavy clouds or due to an error with the sensor or data acquisition system that limited logged data. The system only logs data when the measured value changes by a fixed threshold amount.

These overview plots show that there were a number of days with a large time or percentage outside bounds. The mean percentage within bounds for NIP1 was $87 \%$ with a standard deviation of $11 \%$. The mean percentage within bounds for NIP2 was $85 \%$ with a standard deviation of $15 \%$. 


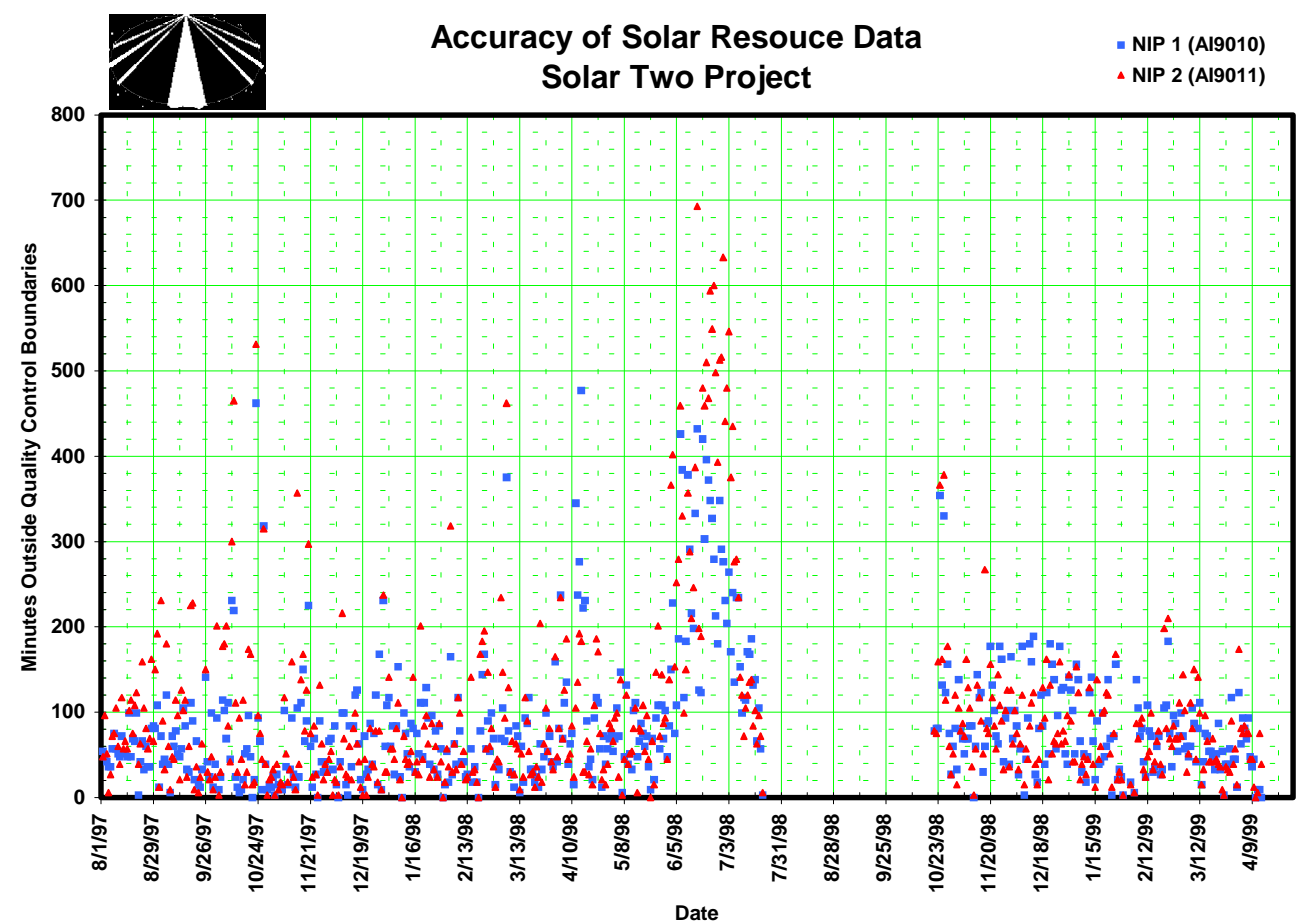

Figure C-5. Minutes per day that solar resource data test was outside bounds, indicating only that the data should be examined during the period of interest, not that they are definitely incorrect.

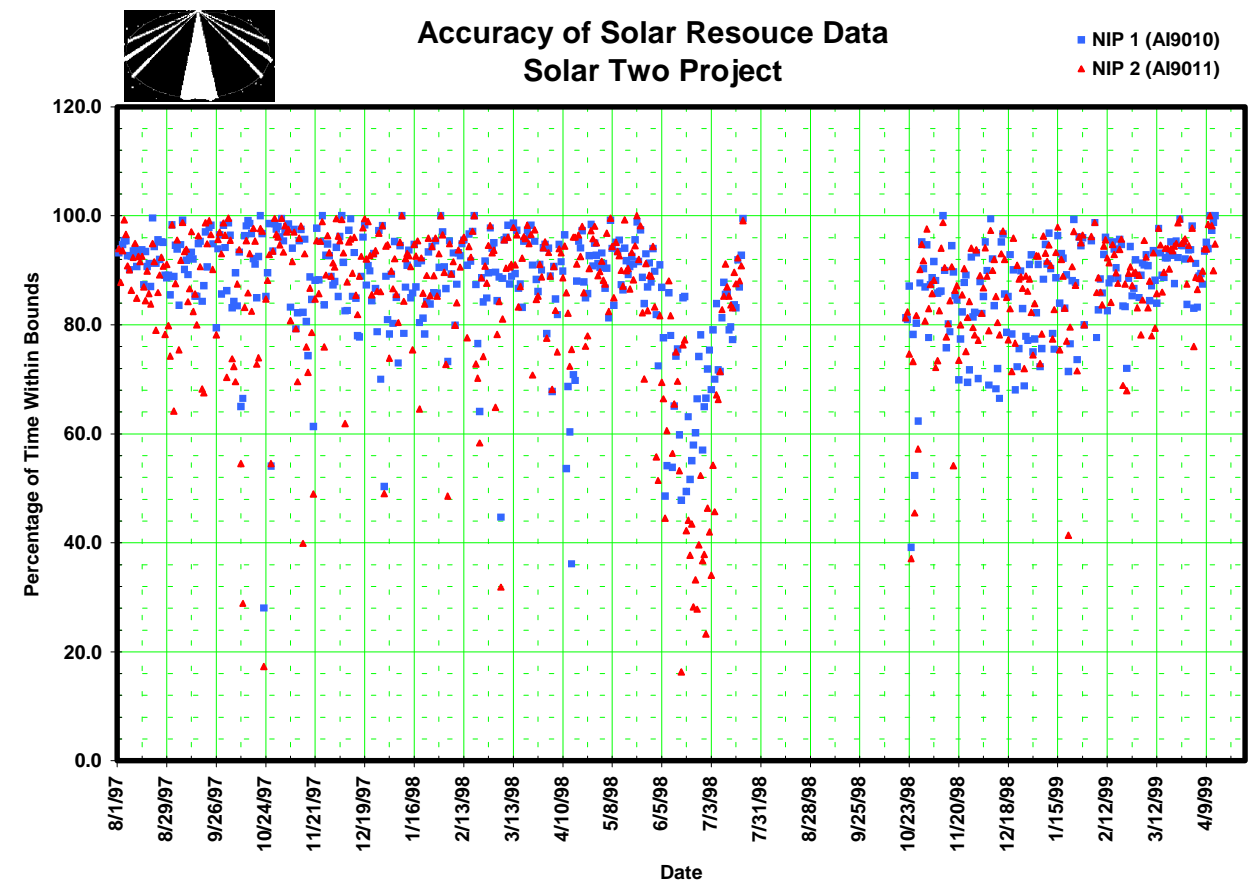

Figure C-6. Percentage of time each day that solar resource data was outside bounds, indicating only that the data should be examined during the period of interest, not that they are definitely incorrect. 
Actually, considering the many times that out-of-bounds values occurred at low sun angles or in cloudy weather, most of the data is accurate. At other times, the three-component errors were just beyond the acceptance boundaries, indicating the problem was just over 3\% and may not have been in the DNI measurement. Averaged solar resource values, such as daily and certainly annual DNI, should be sufficiently accurate. However, values over a short period, such as those used for calculating peak efficiencies, should be checked by analysts for accuracy.

Unfortunately, there were about three months (7/22/98 - 10/20/98) when diffuse data was not collected due to maintenance on the pyranometer, making three-component tests impossible. Nonetheless, inspection of the DNI measurements over this period indicated that on some days poor tracking caused erroneously low readings, a phenomenon illustrated in Figure C-3. While this problem can lead to large (e.g. 30\%) errors in the instantaneous DNI measurements, the impact on the daily total DNI is much smaller. A linear fit was used to estimate the error in the daily total DNI value on plant operational days during this period when poor tracking caused low DNI readings. Table $\mathrm{C}-1$ shows these results.

Table C-1. Estimated error in daily DNI during operating days due to poor tracking of NIPs in the three-month period without a three-instrument redundancy check

\begin{tabular}{cc}
\hline \hline Date & Daily Total DNI Error \\
\hline 17-Aug-98 & $-1 \%$ \\
31-Aug-98 & $-2 \%$ \\
10-Sep-98 & $-2 \%$ \\
13-Sep-98 & $-2 \%$ \\
$16-$ Sep-98 & $-1 \%$ \\
$17-$ Sep-98 & $-1 \%$ \\
9-Oct-98 & $-2 \%$ \\
10-Oct-98 & $-2 \%$ \\
13-Oct-98 & $-4 \%$ \\
$16-$ Oct-98 & $-3 \%$ \\
$17-O c t-98$ & $-1 \%$ \\
18-Oct-98 & $-6 \%$ \\
20-Oct-98 & $-4 \%$ \\
\hline \hline
\end{tabular}

\section{C.4 Conclusions}

The three-component station proved very valuable in providing a simple validity test of solar resource data. Overall, the solar resource data, and in particular the DNI, was found to be highly accurate. Daily plots of error from the three-component test were provided for analysts to verify the accuracy of measurements over a short period, such as those used in the computation of peak solar field or plant efficiency. While daily analysis of the test results and feedback to operations was planned, it turned out that the data was frequently examined much later than when it was collected. Understandably, the combination of many urgent issues, limited resources, and the implementation of a simple, twice-daily visual instrument inspection meant a low priority was 
assigned to these solar resource data quality control (QC) tests. The next plant would be best served by a three-component solar resource station and real-time QC analysis software that alerts the operators when the acceptable error bands are exceeded. The operator could then immediately view a plot of the error, such as those presented above, and consider current conditions, such as sun elevation angle and cloud cover. A decision could then be made if further analysis or adjustments to the instrument station were required.

\section{C.5 References}

Users Manual for SERI QC Software, Assessing the Quality of Solar Radiation Data, National Renewable Energy Laboratory, NREL/TP-463-5608, DE93018210, December, 1993. 


\section{Appendix D. Development and Test of Solar Two Receiver Control Algorithm (G. J. Kolb)}

\section{D.1 Introduction}

A control algorithm was developed to allow automatic operation of the Solar Two receiver. Given variations in solar heat input to the receiver, the algorithm was designed to (1) maintain the salt at $565^{\circ} \mathrm{C}$ at the exit of the receiver and (2) limit thermal fatigue damage to the receiver tubes to ensure a 20 - to 30 -year lifetime. The algorithm accomplished this by regulating the salt flow to match the solar heat impinging on the receiver. This section describes the design evolution of this algorithm and its implementation at Solar Two.

\section{D.2 Initial Algorithm Development}

An initial control algorithm was developed during the test of a small molten-salt cavity-type receiver at the National Solar Thermal Test Facility (NSTTF) (Smith, 1988). This algorithm was significantly modified to work with a cylindrical-type receiver (Kolb, 1992). A simulation model known as T-BRD (Transient Behavior Receiver Device), which was validated with NSTTF test data (Kolb, 1989), was used to model the dynamics of the Solar Two receiver system and to test initial design concepts. It consisted of a set of 127 ordinary differential equations (ODEs) that described the time-varying behavior of the plant components, i.e., receiver, pumps, valves, tanks, and controls. The model provided for the computation of temperatures, pressures, and flows when there were disturbances such as cloud passages over the heliostat field or component failures. The space dependence was handled by sectioning the system into several lumps (or nodes), yielding the following simplified vector description:

$$
\begin{aligned}
\frac{d \bar{x}}{d t} & =A \bar{x}+\bar{f}(\bar{x}, t)+B \bar{u}(t) ; \quad X(0)=X_{o} \\
\bar{x} & =\text { the state vector } \\
A & =\text { a matrix of constants for the linear terms } \\
\bar{f}(\bar{x}, t) & =\text { the vector of nonlinear and variable terms } \\
B & =\text { a matrix of constants } \\
\bar{u}(t) & =\text { forcing function vector } \\
X_{o} & =\text { vector of initial conditions }
\end{aligned}
$$

For example, the ODE that describes the conservation of energy for the salt within one of the receiver panels would be:

$$
\frac{d T_{o}}{d t}=\frac{1}{m c_{p}}\left[Q_{m s}+W c_{p} T_{i}-W c_{p} T_{o}\right]
$$

where the panel outlet salt temperature (state variable $T_{o}$ ) is a function of the mass of salt within the panel $(\mathrm{m})$, the specific heat of the salt $\left(\mathrm{c}_{\mathrm{p}}\right)$, the salt flow rate $(\mathrm{W})$, the salt inlet temperature 
$\left(\mathrm{T}_{\mathrm{i}}\right)$, and the solar heat transferred through the tube wall to the salt $\left(\mathrm{Q}_{\mathrm{ms}}\right)$. Because the coefficients $m$ and $c_{p}$ are a function of salt temperature, this is a nonlinear ODE.

Simulating of a variety of cloud transients with T-BRD yielded the initial control algorithm depicted in Figure D-1 for the Solar Two receiver.

Three independent control signals were used to regulate the salt flow:

1. A feedforward signal from the solar power on the receiver as measured by flux gauges.

2. A feedback signal from the average back-tube temperature thermocouples.

3. A feedback signal from the salt-outlet temperature thermocouple.

The three signals were summed to provide a total flow setpoint on the proportional-plus-integral (PI) controller that regulated the flow control valve to achieve the flow setpoint. The signals are listed above in order of their flow-control authority. The feedforward signal is the most authoritative, because it changes flowrate simultaneously with solar flux changes. The temperature signal from the back of the tubes is the next most authoritative, because of temperature changes along the entire flow path. The influence of the outlet-salt temperature signal is felt last because its knowledge is limited to only exit conditions, which occur after an extended residence time of the fluid.

\section{FEEDFORWARD FLOW SIGNAL}

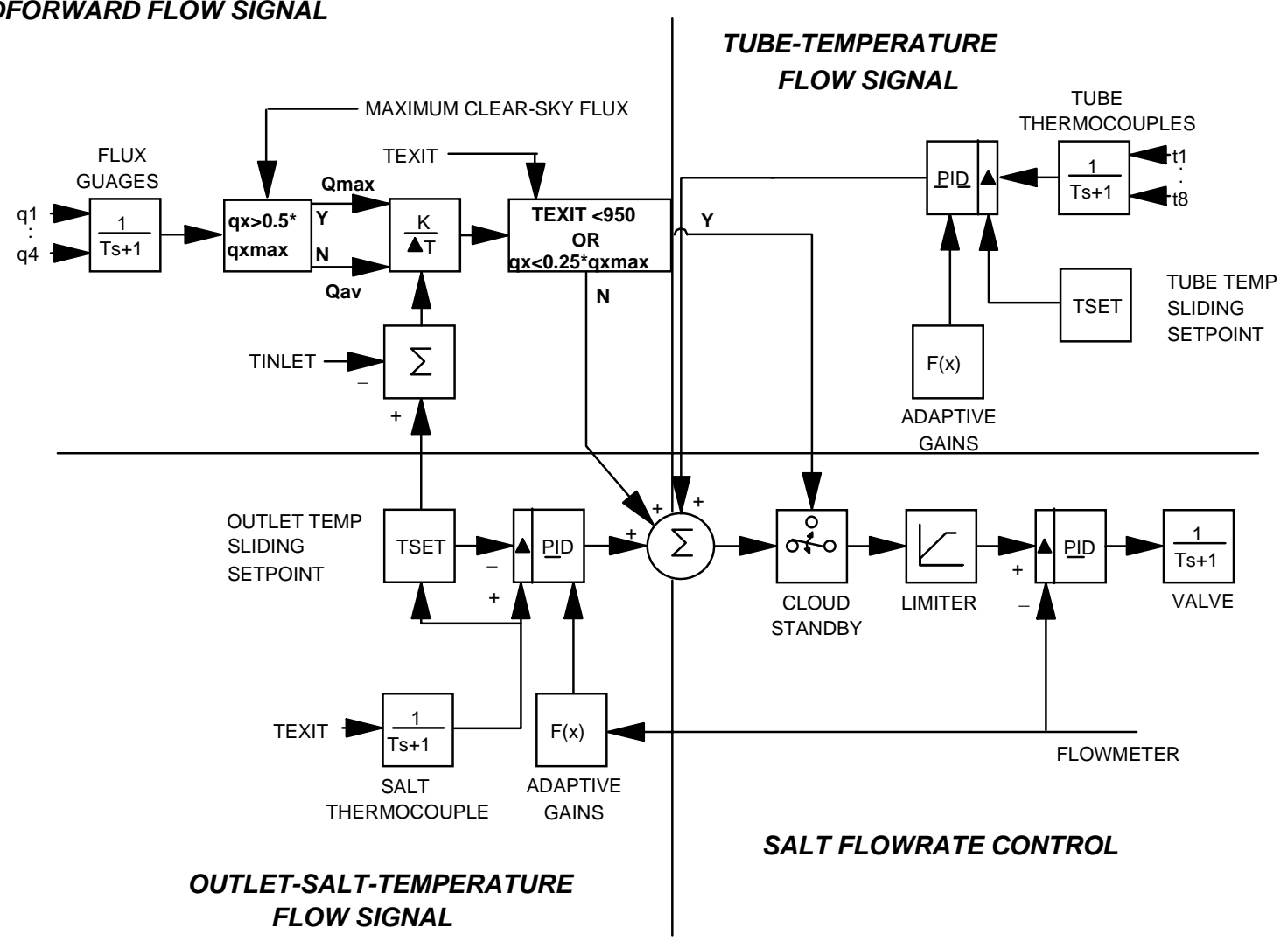

Figure D-1. Initial flow-control algorithm proposed for the Solar Two receiver. 
Adaptive gains are used to modify the PI gains as a function of flow rate in the salt-outlet temperature controller. The exit temperature setpoint is also ramped between $510^{\circ} \mathrm{C}$ and $565^{\circ} \mathrm{C}$. This "sliding setpoint mechanism" helps prevent high temperature trips of the receiver during cloud transients.

The T-BRD simulations indicated that translucent-type clouds (high and thin) can be easily controlled by the algorithm. However, if opaque-type clouds (cumulus) are passing over the plant, it is possible for a severely skewed solar-flux pattern to appear on the receiver. In this situation, some receiver panels may be nearly dark while others are seeing full sun from the heliostat field. Given this type of cloudy weather, it is not prudent to control flow based on average flux input to the receiver. Rather, to prevent excessive strains on the panels seeing full sun, flow should be controlled based on maximum flux input to the receiver. Therefore, the algorithm automatically checks for skewed flux patterns and increases flow to the maximum clear-sky value if a severely skewed pattern is present on the receiver. This control mode is called "cloud standby."

Cloud standby prevents the receiver tubes from experiencing excessive strains given skewed flux patterns. The axial strain is a function of the temperature gradient between the front and back of the tube and can be written as (Babcock \& Wilcox, 1984):

$$
\begin{aligned}
\varepsilon & =a\left[\frac{T_{c}+T_{c i}}{2}-\left(T_{s}+\left[\frac{T_{c}+T_{c i}}{2}-T_{s}\right] / \pi\right)+\frac{T_{c}-T_{c i}}{2(1-v)}\right] \\
& \text { where } \\
\varepsilon & =\text { total strain } \\
a & =\text { coef. of thermal expansion } \\
T_{c} & =\text { tube crown temp. } \\
T_{c i} & =\text { inside tube crown temp. } \\
T_{s} & =\text { bulk salt temp. }=\text { back tube temp. } \\
v & =\text { Poisson' s ratio }
\end{aligned}
$$

The strain is considered acceptable if the strains experienced by the receiver tubes during a transient are less than the allowable strain established for a 30-year lifetime. For tubes made of 316 stainless steel, the allowable strains as a function of temperature are published (Tyner, 1986).

\section{D.3 Implementation of Final Control Algorithm at Solar Two}

The initial flow control algorithm, described above, was proposed to the Solar Two design team. After that proposal, the two changes described below were recommended by the design team.

The first proposed change was to replace the flux gauges in the feedforward loop with photometers. Concurrently with the design of the rest of the plant, these devices were being demonstrated at Sandia's solar test facility (Pacheco, et al. 1994). This simple and inexpensive device is essentially a photovoltaic cell mounted in a collimating tube that senses reflected light from the receiver panels. Eight photometers (four per flow control loop) were thus installed at Solar Two rather than flux gauges within the feedforward loop of the control algorithm. Photometers have been shown to produce a much less noisy signal and have a much shorter time 
constant than flux gauges. In addition, they do not degrade with time and are much more reliable.

The second change was to modify the control strategy during a situation when the heliostat field was completely covered by clouds. In the initial control algorithm, the salt flow was to be throttled back to its minimum turndown value (see salt flowrate control "limiter" in Figure D-1). This control strategy was proposed for Solar Two because it was demonstrated during the earlier tests at the NSTTF (Smith, 1988). The advantage of the original approach is that salt-pump parasitic power is reduced during periods of total cloud cover. However, the Solar Two design team believed this small advantage was not worth the risk of damaging the receiver during the interval when the clouds clear the heliostat field and full sun is rapidly reestablished on the receiver. The logic within the feedforward loop of the initial algorithm was designed to rapidly ramp salt flow to full to prevent receiver damage. Rather than risk receiver damage, the more conservative (and perhaps more sensible) control approach adopted by the Solar Two design team was to maintain salt flow at its maximum clear-sky value during periods of total cloud cover. This way, when full sun returned, adequate salt cooling of the receiver would be guaranteed. Because of the two design changes described above, the on-site Solar Two startup team simplifying the control algorithm by eliminating the feedback signal from the back-tube thermocouples. T-BRD simulations also indicated that elimination of the back-tube control loop should adequately control outlet temperature and protect the receiver from thermal-fatigue damage. The final algorithm installed at Solar Two incorporated this design simplification and is depicted in Figure D-2.

The ability of the final flow-control algorithm to successfully meet its design objectives is demonstrated in Figure D-3 through D-7. This plant data was collected from 11a.m. to 3 p.m. on May 3, 1997, a period characterized by partly-cloudy weather conditions. The algorithm rapidly changed salt flow throughout the period to maintain receiver outlet temperature at the setpoint $\left(555^{\circ} \mathrm{C}\left[1030^{\circ} \mathrm{F}\right]\right.$ for this day). In addition, as shown in Figure D-7, tube strains calculated by the T-BRD software were acceptable.

\section{D.4 Conclusions}

Automatic control of the Solar Two receiver was successfully demonstrated. The control algorithm maintained molten-salt outlet at setpoint temperature and prevented overstrain of the tube materials during severe cloud transients. The algorithm was used on a daily basis. Additional improvements are possible that were not demonstrated during the test campaign. For example, a possible refinement would be to prohibit initiation of cloud standby when heliostats are removed from the receiver at the end of the day (see Figure D-5). 


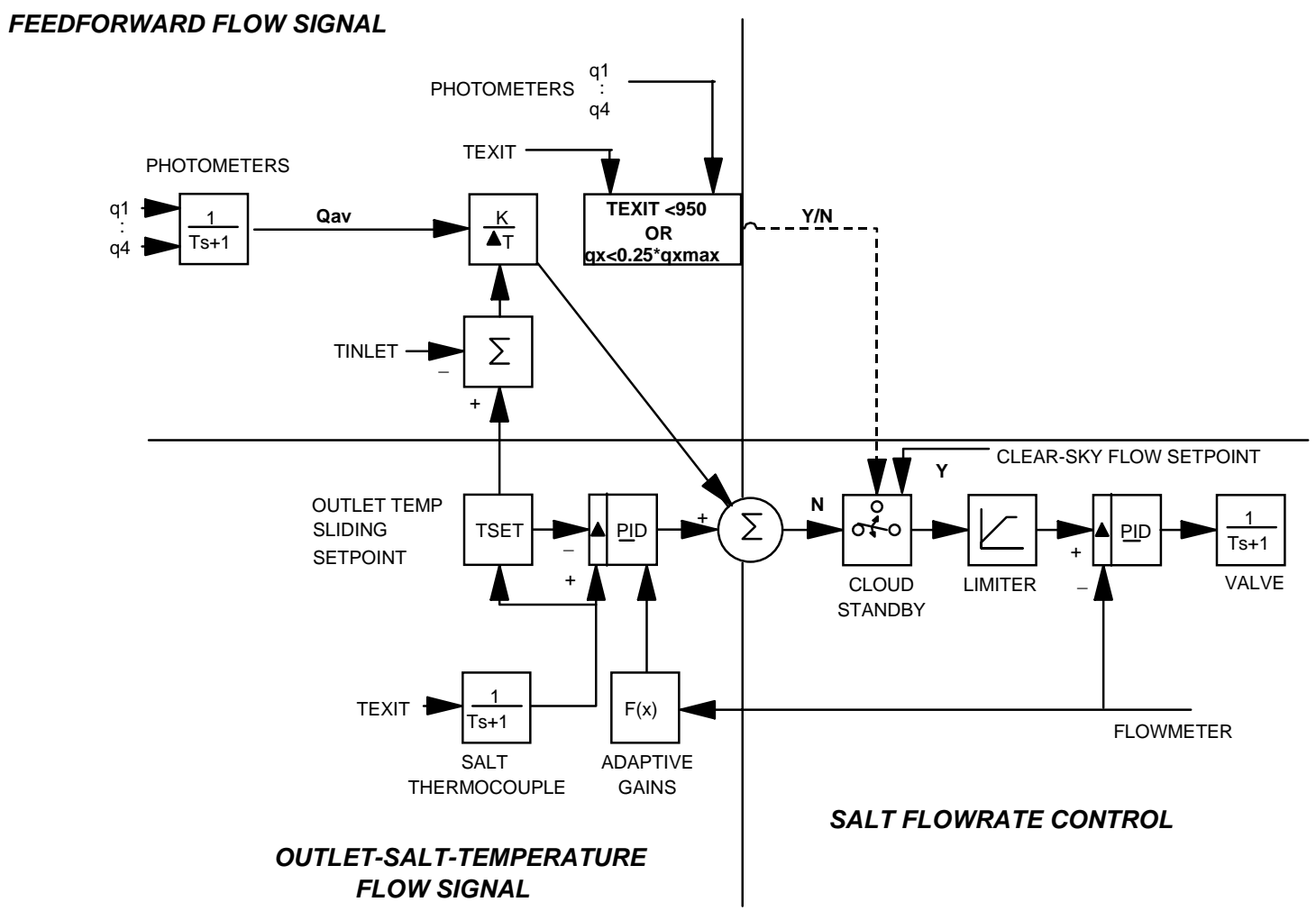

Figure D-2. Final flow-control algorithm implemented for the Solar Two receiver.

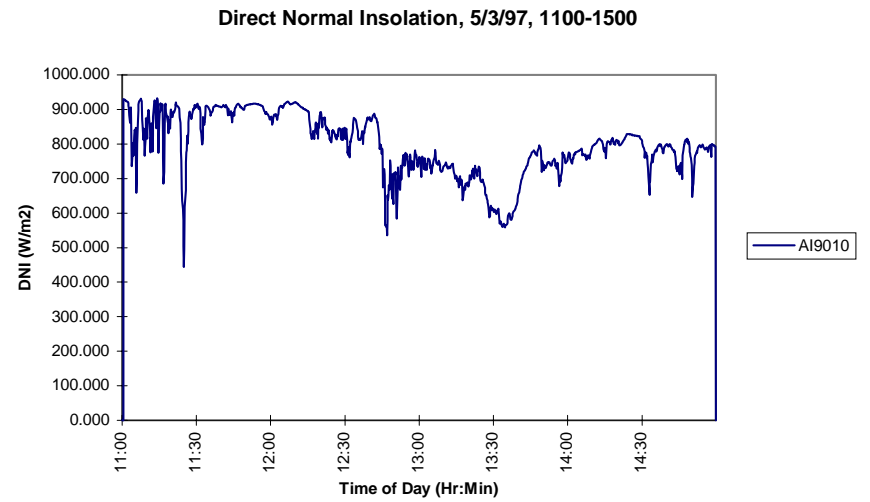

Figure D-3. Direct-normal insolation. 


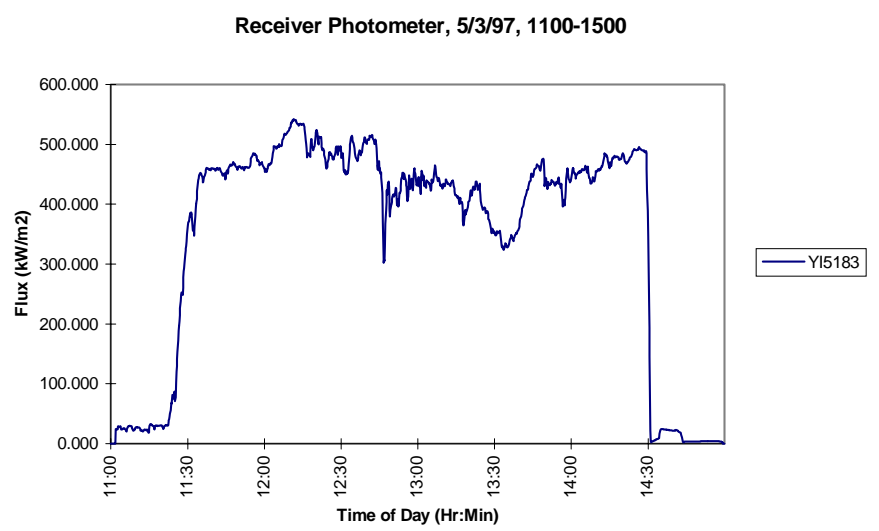

Figure D-4. Input control signal from 1 of 8 photometers installed at Solar Two. Note that heliostats were placed on the receiver at 11:30 and removed at 14:30. During that time, the photometer reading is directly proportional to the direct-normal insolation shown in Figure D-3.

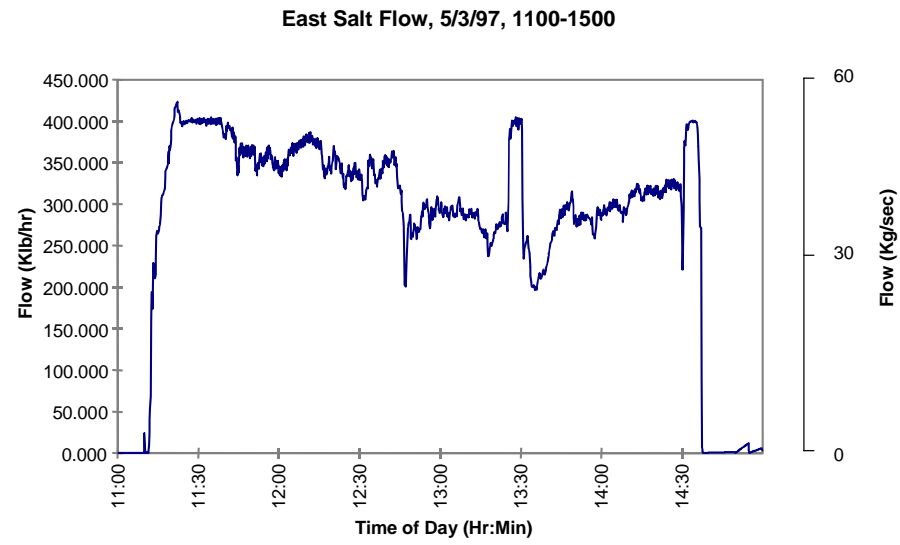

Figure D-5. Salt flow to east receiver panels. Cloud standby was initiated at 13:30 because of a skewed flux pattern and at 14:30 because the heliostats were removed from the receiver.

Receiver Outlet Temperature, 5/3/97, 1100-1500

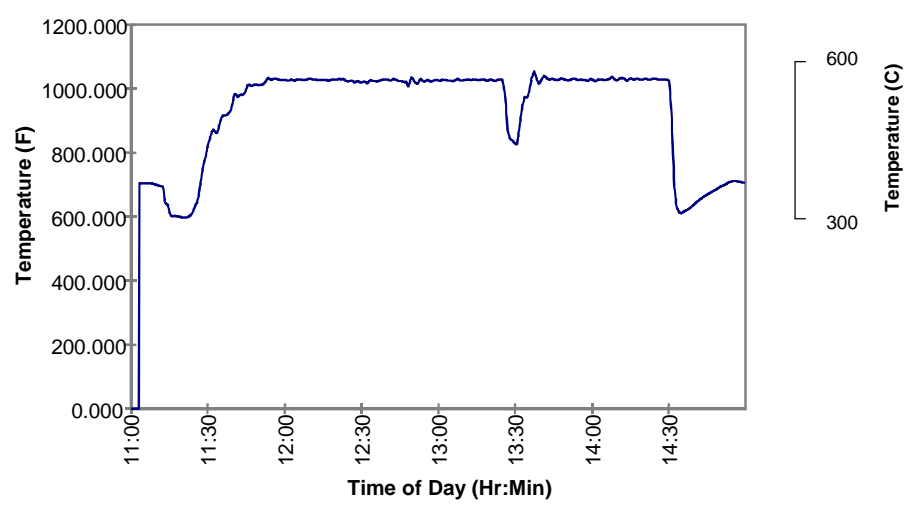

Figure D-6. Outlet salt temperature for east flow-control zone. Cloud standby initiated at 13:30. 


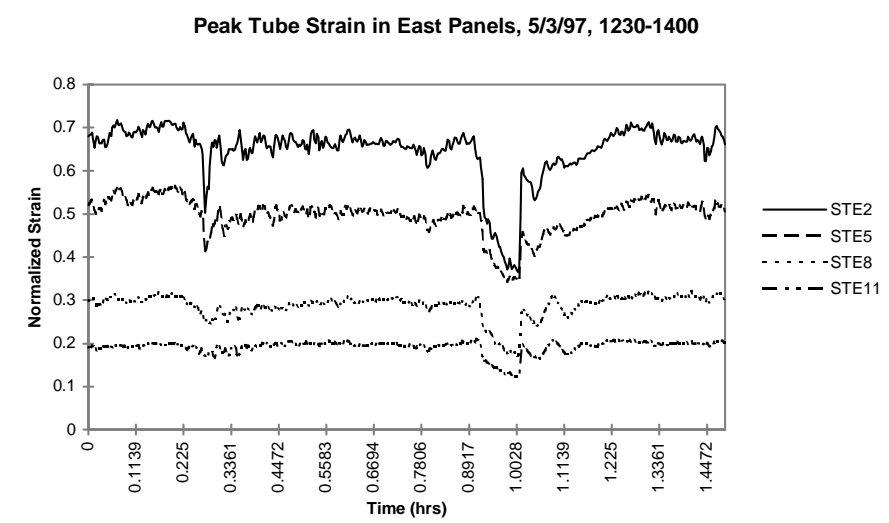

Figure D-7. Calculated normalized tube strains. Highest strains are in the north receiver panels and lowest strains are in the south panels. Strains should be kept less than unity to maintain design lifetime of receiver tubes.

\section{D.5 Receiver Control Algorithm References}

Babcock \& Wilcox Company, 1984, "Molten Salt Receiver Subsystem Research Experiment Phase 1 - Final Report, Volume 1 - Technical," SAND82-8178, Sandia National Laboratories, Albuquerque, NM.

Electric Power Research Institute and U.S. Department of Energy, 1997, "Renewable Energy Technology Characterizations," EPRI TR-109496, Palo Alto, CA.

Kolb, G. J., D. T. Neary, M. R. Ringham, and T. L. Greenlee, 1989, "Dynamic Simulation of a Molten-Salt Solar Receiver," SAND88-2895, Sandia National Laboratories, Albuquerque, NM.

Kolb, G. J., 1992, "Development of a Control Algorithm for a Molten-Salt Solar Central Receiver in a Cylindrical Configuration," Solar Engineering 1992, Proceedings of the 1992 ASME, JSES, KSES International Solar Energy Conference, April 5-9, 1992, Maui, HI.

Pacheco, J. E., R. M. Houser, and A. Neumann, 1994, "Concepts to Measure Flux and Temperature for External Central Receivers," Solar Engineering 1994, Proceedings of the 1994 ASME, JSME, JSES International Solar Energy Conference, March 27-30, 1994, San Francisco, CA.

Smith, D. C., and J. M. Chavez, 1988, "A Final Report on the Phase 1 Testing of a Molten-Salt Cavity Receiver," SAND87-2290, Sandia National Laboratories, Albuquerque, NM.

Tyner, C. E., 1986, "Summary of Workshop on Central Receiver Tube Life Considerations," Memorandum to distribution on December 17, 1986, Sandia National Laboratories, Albuquerque, NM. 
Final Test and Evaluation Results from the Solar Two Project 


\section{Appendix E. Nuclear Level Sensor (H. E. Reilly)}

\section{E.1 Background}

Using bubbler system to detect level proved to be problematic in a pressurized vessel. Bubblers worked well to record level in vessels that were vented to atmosphere; these included the receiver outlet vessel, salt storage tanks, and the pump sumps. However, the two bubblers on the receiver inlet vessel gave erroneous readings during vessel pressure transients. During normal receiver startup and operation, pressure in the inlet vessel increased from atmospheric to as high as $2.2 \mathrm{Mpa}$ (320 psig). Since a bubbler reports the difference in pressure between a reference leg and a leg at the bottom of the vessel, it does not provide a useful level indication during pressurization or any time the pressure above the liquid is changing rapidly.

At Solar Two, the speed of the receiver pumps (and therefore salt flow rate to the receiver) was controlled off the level in the inlet vessel. After the receiver was filled, the inlet vessel was pressurized in preparation for normal operation. As the inlet vessel was pressurized, the bubbler level indicators would typically report decreasing levels. This signal caused the pumps to speed up, providing more salt flow to the inlet vessel. Figure E-1 shows the interaction among inlet vessel bubbler A, inlet vessel pressure, and the speed of receiver pump P250A during pressurization of the inlet vessel.

During initial operating experience with the Solar Two receiver system, this control sequence led to difficulties in transitioning from receiver fill to normal operation. The system would become unstable and the receiver would trip. Bechtel developed a workaround wherein, for approximately 25 seconds while the inlet vessel was being pressurized, the level indication was ignored and pump speed was held constant. After the receiver inlet vessel reached operating pressure, pump speed was again controlled by level in the inlet vessel.

\section{E.2 New Level Sensor}

Both Sandia and Rockwell (now Boeing) were interested in demonstrating a new level sensor for use in pressurized vessels containing molten salt. As part of their effort under the SolMat program, Boeing provided a new level sensor for the Solar Two receiver inlet vessel. Boeing selected a level sensor that was based on the attenuation of the beam from a radiation source as it passed through the vessel. The source was a radioactive isotope of cesium (Cs-137). An ion chamber detected the attenuated beam and an electronics package (mounted in the receiver remote station) processed the signal and reported level to the plant control system.

The specific device, as originally specified and provided, was the following:

Supplier: TN Technologies, Round Rock, Texas

Model Number: 5205

Source: Two Cesium 137 sources at 50 millicuries each

Detectors: Two chambers 


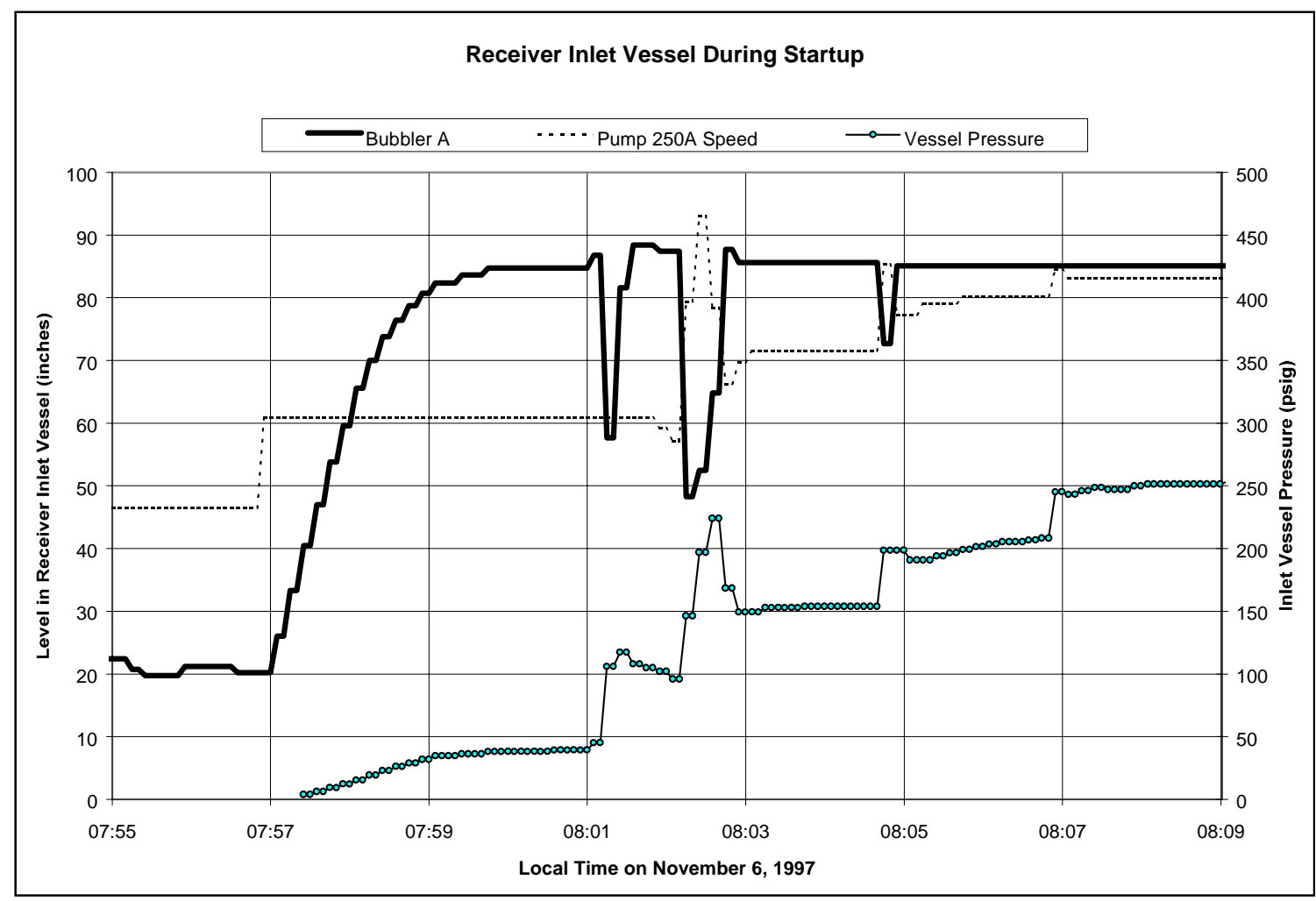

Figure E-1. Receiver pump speed and receiver inlet vessel level and pressure during transition from receiver fill to normal receiver operation.

The sensor was designed to cover the entire $0-2.5 \mathrm{~m}$ (0-100 inches) normal operating range of level in the inlet vessel. The sources were each contained in a shuttered enclosure. (The shutters were opened and closed manually.) The source enclosures were mounted immediately outside the metal cladding covering the inlet vessel insulation. The enclosures were mounted so that one source was vertically above the other. The ion chamber detectors were mounted diametrically opposite the sources, one to detect low levels, the other to detect higher levels.

The sensor was installed in December 1997, in conjunction with installation of the new W-2 receiver panel. When first installed, the output was erratic and the sensor did not provide meaningful or useful level indication. Initial attempts to correct the problem resulted in a more stable sensor output. However, on January 21, 1998, Bechtel and Sandia attempted to use the sensor's signal for receiver pump control. This experiment demonstrated that the sensor's combination of sample rate and signal accuracy were inadequate for pump control.

The sensor's reference manual states: "The system employs exponential filtering to minimize the statistical 'noise' associated with the random nature of radiation from the source. Exponential filtering provides the best noise reduction for the least decrease in responsiveness to process changes." Calculations by Boeing confirmed 50-millicurie sources were inadequate to provide a suitable combination of accuracy and response time. Boeing decided to replace the two 50millicurie sources with two 100-millicurie sources. These new sources were installed in June 1998. 
In late June, the Solar Two Control Room operator reported a drift in the sensor's signal. The sensor's output increased during stable receiver operation. Additional data analysis revealed that the sensor's output tended to increase during the course of receiver operation, even though the actual level in the receiver inlet vessel remained constant (with normal fluctuations around the set point.) Figure E-2 shows this behavior, where the sensor's output is plotted along with the output from the inlet vessel's two bubbler units.

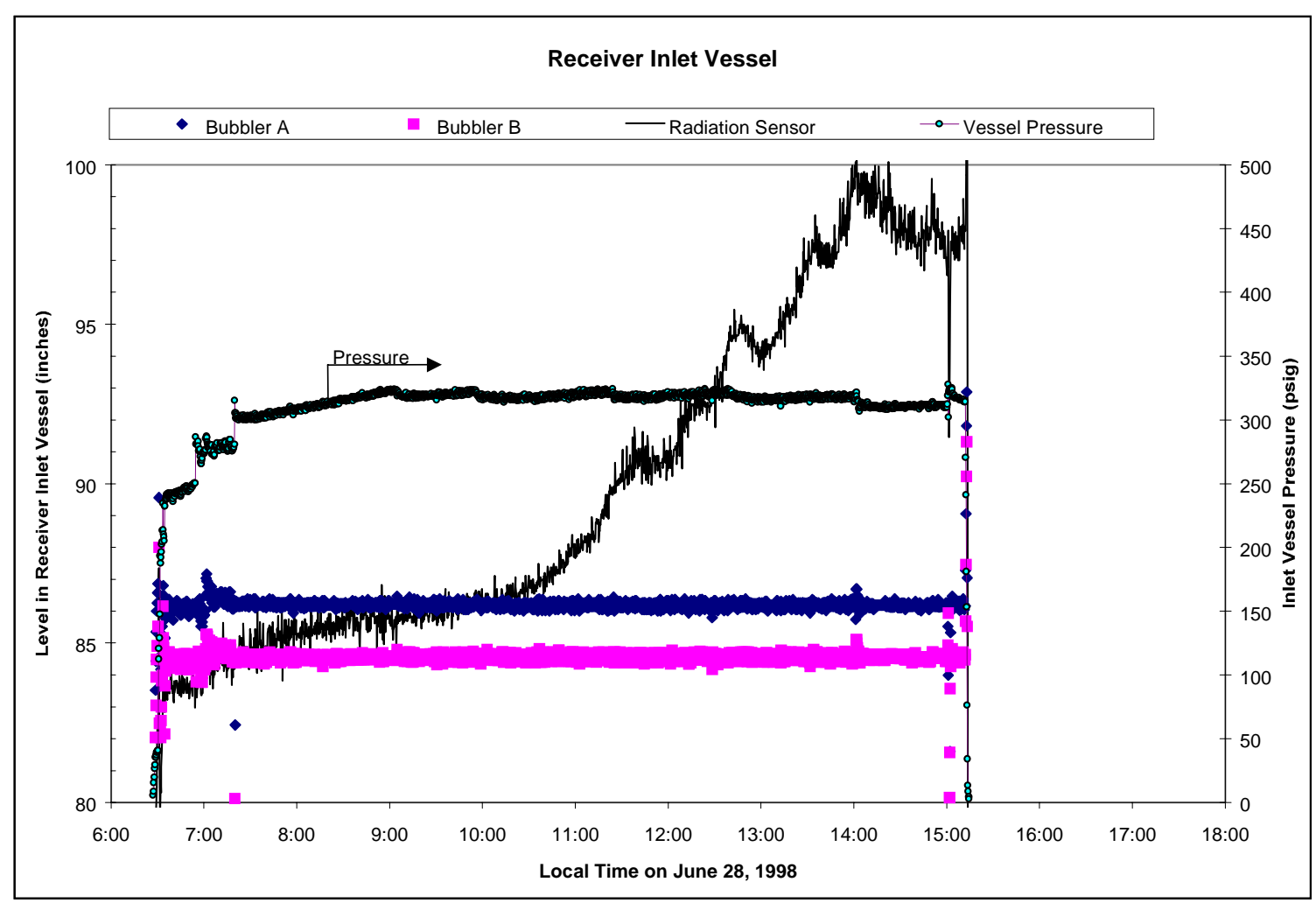

Figure E-2. Comparison of the receiver inlet vessel level indication from the two bubblers and the radiation sensor during normal receiver operation. Data is for June 28, 1998, prior to resolution of radiation sensor problems. Note the upward drift in the radiation sensor level indication.

Detector overheating was proposed as one possible explanation for the increasing sensor output. Per the sensor specifications, the detector's operating ambient temperature range is $-29^{\circ} \mathrm{C}$ to $60^{\circ} \mathrm{C}\left(-20^{\circ} \mathrm{F}\right.$ to $\left.140^{\circ} \mathrm{F}\right)$. Sandia attached three thermocouples to the detector housings and monitored the temperatures during a number of receiver operating periods. For the summer days monitored, the recorded temperatures approached, but did not exceed, $60^{\circ} \mathrm{C}\left(140^{\circ} \mathrm{F}\right)$. It also appeared that the highest housing temperatures occurred when normal sunlight shone directly on the housing in the afternoon.

In November 1998, TN Technologies returned to investigate and correct deficiencies in the electronics associated with the sensor. After these repairs, the sensor still did not provide meaningful level indication. A TN Technologies technician returned to the site on March 9, 1999, corrected the problems, and calibrated the electronics at a number of salt levels in the inlet 
vessel. One of the problems found and corrected was a pinched wire that cut off power to the heater element in the upper detector chamber. The internal heaters are designed to maintain the detectors at a constant temperature.

The sensor worked well after these problems were corrected. On March 11, 1999, operators began using the new sensor as the primary indicator of inlet vessel level and incorporated its output into the control system to control pump speed. Figure E-3 presents the level indications of the radiation sensor system and the two bubblers on March 29, 1999.

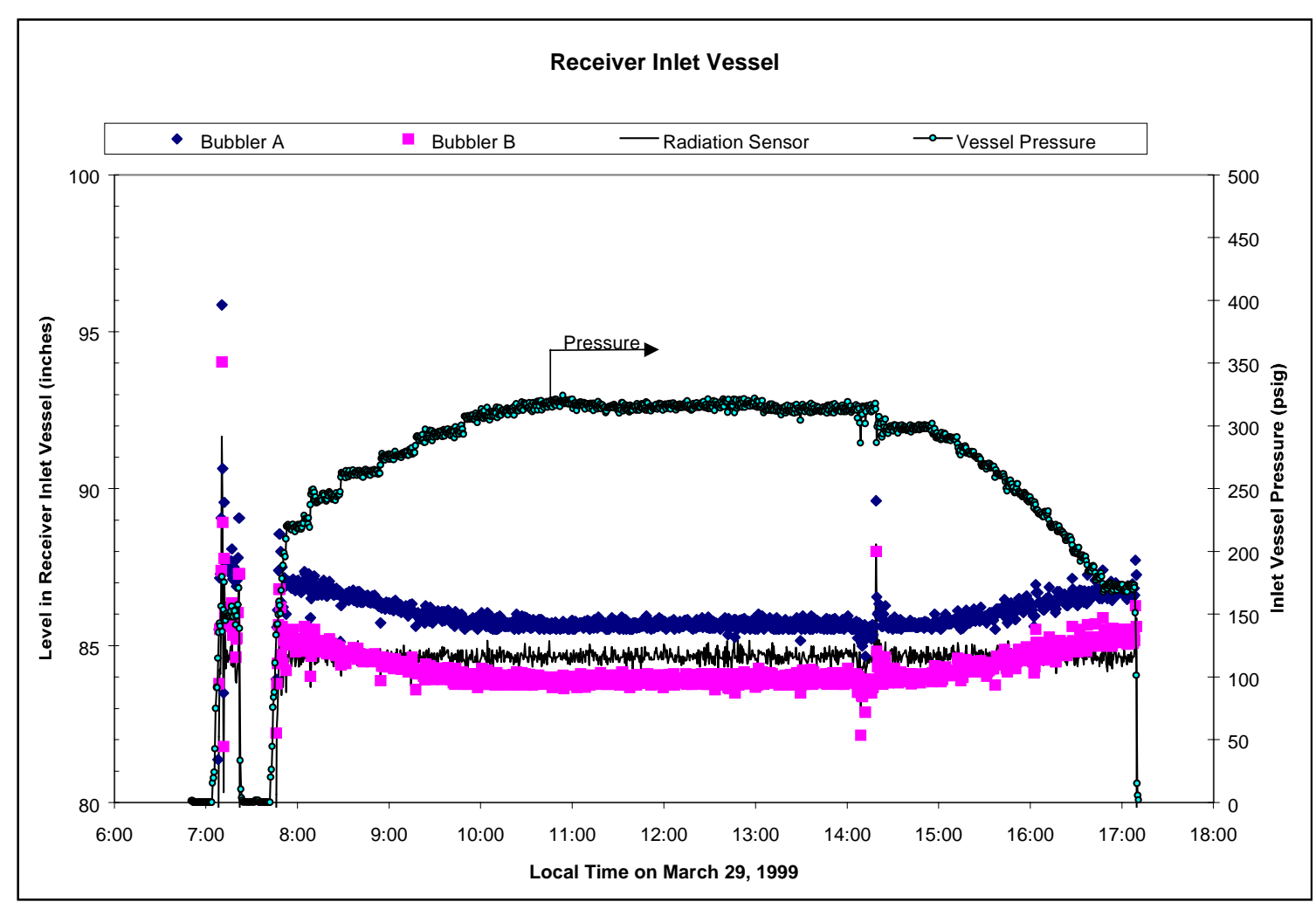

Figure E-3. Comparison of the receiver inlet vessel level indication from the two bubblers and the radiation sensor during normal receiver operation. Data is for March 29, 1999, after resolution of radiation sensor problems.

Control of the nuclear material and personnel training are important aspects of this type of sensor. If addressed properly, these issues should not pose an impediment to its use. Under terms of the purchase order, TN Technologies provided training to site personnel on the handling, use, custodial responsibilities, and safety aspects of nuclear sources. ESI designated the ESI Solar Two Operations Supervisor as the custodian of the sources. TN Technologies was obligated to accept receipt of the sources after termination of the project. When the 50millicurie sources were replaced with two 100-millicurie sources, TN Technologies arranged for delivery of the new sources and packaging of the returned sources; they also accepted receipt of the returned sources. 


\section{Appendix F. Procedure for Thawing Receiver Panels That Have Become Frozen With Nitrate Salt (J. E. Pacheco)}

\section{F.1 Introduction}

In a molten salt receiver, there are multiple drain valves. During the nightly shutdown of the receiver, the possibility exists that a drain valve will fail to actuate or that a vent line will become plugged. If this failure is not detected in time and corrective action (such as manually opening the valve) is not taken, the salt trapped in the associated panels could freeze. The procedure to recover from a freeze event is described here. Since the volume of salt increases for a fixed mass when it goes from the solid to the liquid state, damage can occur to the panel if the salt is thawed in a section of tubing or piping that is constrained at both ends. One or two freeze events in a panel may not be detrimental (causing permanent strains of up to $4 \%$ ), but several will surely rupture or cut short the life the receiver tubes. Experiments have shown that a receiver tube will rupture after 12 freeze/thaw cycles (Pacheco 1996).

It is strongly recommended that the thermocouples and valves associated with the receiver be monitored during shutdown and drain of the receiver. One method to detect if salt is trapped in a panel is to look at the temperature of the panel as a function of time. Empty panels will cool much faster than ones with salt trapped in them. Also, at approximately the salt freezing point $\left(221^{\circ} \mathrm{C}\left(430^{\circ} \mathrm{F}\right)\right)$, the panel temperature will stay nearly constant for 10 to 20 minutes while the salt undergoes a phase change. This phenomenon is best seen in a time plot of the panel temperatures. Alternately, a frozen panel will appear warmer than a drained panel when viewed through an infrared camera.

\section{F.2 Thaw Procedure}

This procedure describes how to thaw nitrate salt in a panel which has become frozen due to a mechanical or operational error. It may take several hours to completely thaw frozen salt in a panel. A critical zone is the area where the insulation from the lower header oven meets the panel. In this region, there is limited heating by conduction from the adjacent header oven and there is no direct illumination from solar. If a plug of salt exists, it could take several hours to thaw this region by conduction alone and it could damage the tubes in the process. A few temporary thermocouples should be placed in that region to monitor these temperatures. In addition, it might be necessary to install additional heaters or heat tracing to ensure this region is hot enough before heating the panel with heliostats. Using an infrared camera is highly recommended to easily determine where the cold spots are on the panel and where the salt is still frozen. The existing thermocouples will not provide enough resolution, and additional thermocouples might have to be added. The recommended procedure is as follows.

1. Verify that the heat traces to the header oven and to the vent and drain lines are on. After the valves are above $290^{\circ} \mathrm{C}\left(550^{\circ} \mathrm{F}\right)$, open (if they aren't already) the drain and vent valves to the frozen panel. This will allow any liquid salt to flow out of the header and jumper tubes. The only way for salt to leave the panel as it thaws is through the drain. 
2. Verify that the temperature of the lower header oven chamber is at least $290^{\circ} \mathrm{C}\left(550^{\circ} \mathrm{F}\right)$. Check the temperature readings from the thermocouples at the interface to verify that they are at least at the salt melting point $\left(221^{\circ} \mathrm{C}\right)$.

3. The panel should be thawed from the bottom upwards. Aim one heliostat from the middle to back rows (approximately $10 \mathrm{~kW} / \mathrm{m}^{2}$ peak intensity) on to the panel. Its centroid should be aimed at the region where the insulation meets the panel to begin heating from the bottom of the panel. Additional heliostats can be brought on adjacent to the other heliostat (in the horizontal direction) to provide additional horizontal heating of the panel. Care should be taken not to heat the panel in the vertical direction before there is a clear flow path in which the salt can expand.

4. When the salt has melted from the area illuminated by one or two heliostats, an additional one or two heliostat beams can be added above the previous ones (approximately $0.5 \mathrm{~m}(2 \mathrm{ft})$ above the others, depending on the flux distribution for the heliostat). See Figure F-1. The best way to verify that salt has melted is to check the temperature of the panel in that section. If it is above $290^{\circ} \mathrm{C}\left(550^{\circ} \mathrm{F}\right)$, it should be clear of salt.

5. Keep adding heliostat beams in the vertical direction after ensuring the salt has melted in each area. Be careful not to overheat some areas. If hot spots over $370^{\circ} \mathrm{C}\left(700^{\circ} \mathrm{F}\right)$ are detected, remove the associated heliostat beam or aim it at a cold spot.

6. Keep the panel above $290^{\circ} \mathrm{C}\left(550^{\circ} \mathrm{F}\right)$ for at least half an hour. Even though the exposed surface of the panel is above the melting point, there may still be plugs of frozen salt.

7. The next step is to flow salt through the receiver and verify the tubes are clear. Follow the normal operating procedure to initiate flow through the receiver. When flow has started, carefully monitor the thermocouples on the panel or the infrared camera to ensure there is flow through all the tubes. If the temperature of a region of the panel does not equilibrate to the salt temperature with 5 to 10 minutes after salt flow has been established, there is a strong likelihood that salt is frozen there or in a section downstream of the measurement.

8. If a plug still exists, continue to heat with heliostats while the salt is flowing and the plug will eventually melt or dissolve.

9. After the panel has been cleared of all frozen salt, the permanent strain can be measured to assess the damage. The strain is determined by simply measuring the percentage change in diameter of the receiver tubes using a micrometer.

\section{F.3 Reference}

Pacheco, J. E., S. R. Dunkin, “Assessment of Molten-Salt Solar Central Receiver Freeze-up and Recovery Events," Solar Engineering 1996, proceedings of the 1996 ASME International Solar Energy Society Conference, San Antonio, TX, April 1-3, 1996. 


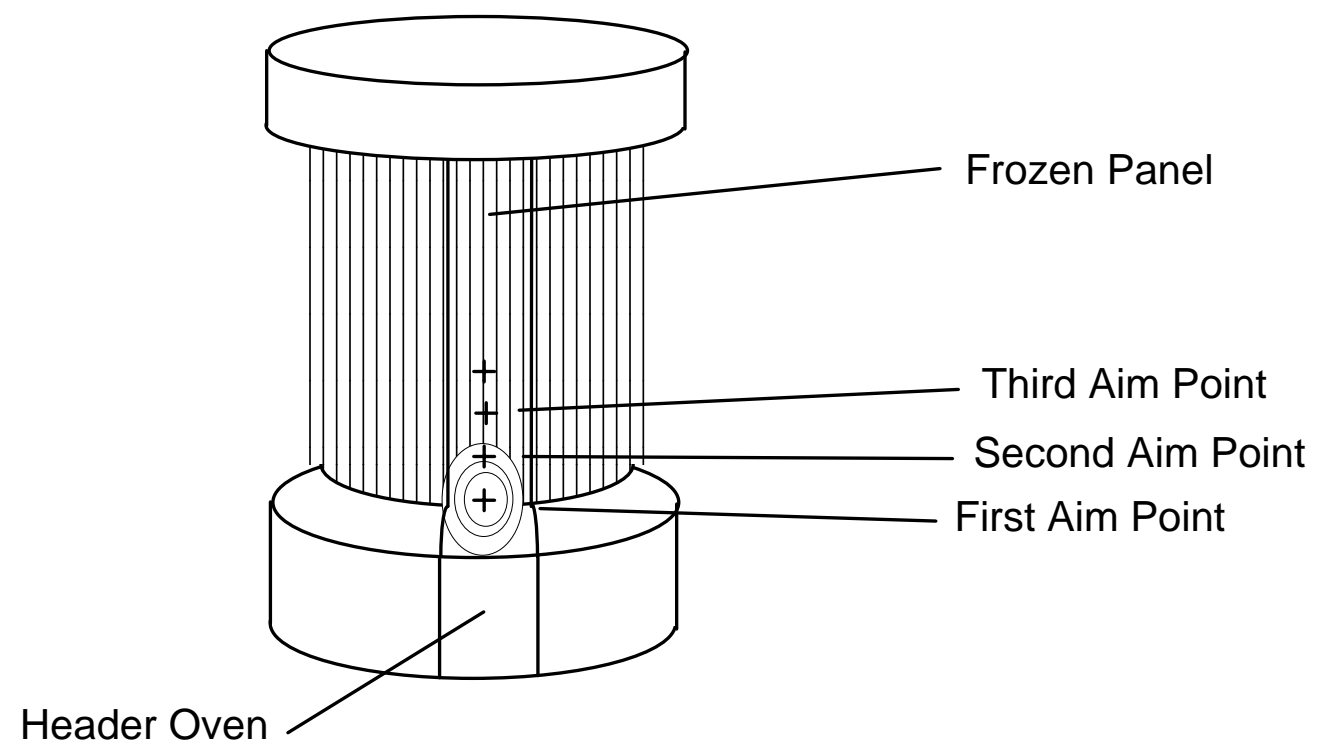

Figure F-1. Begin heating the panel from the bottom. 
Final Test and Evaluation Results from the Solar Two Project 


\section{Appendix G. Analysis of Thawing Frozen Salt in the Solar Two Evaporator and Damage Mitigation (J. E. Pacheco)}

\section{G.1 Objective}

The objectives of this analysis were: 1) to determine the conditions in which frozen salt in the Solar Two evaporator could be thawed safely without damaging the tubes, 2) to estimate the heat tracing required to thaw salt in the salt channel sections, and 3) to develop a safe procedure for thawing salt in the tubes and channel section of the evaporator.

In the Failure Modes Analysis, several events are identified that could lead to salt freezing in the evaporator. The biggest concern is how to recover when salt freezes in several or all the tubes. When the evaporator is drained, at worst a few tubes might remain partially full of salt due to unevenness in the tube bundle. If there is a sudden loss of water pressure in the evaporator, it is possible some or all of the tubes could freeze. If the rate of depressurization is fast enough, all the tubes will freeze within minutes and the upper chamber in the salt channel manifold will not be able to drain. Without heat trace on the channel, it will freeze, too, within hours.

When the salt in the tubes is thawed, the tubes will strain if the expanding salt is constrained. If the tubes strain enough times (as little as four cycles, as shown by freeze/thaw tests), they will rupture.

\section{G.2 Stress and Thermal Analysis of Thawing Salt in Tubes}

When salt freezes in a tube, it freezes on the tube wall first and continues to freeze from the outside in. As the salt freezes, it contracts. In the worst case, a liquid core of salt in the center of the tube flows and fills the volume left by the contracting freezing salt. When all the salt has solidified, the tube will be full of frozen salt and is assumed to be unstressed. As the tube and solid salt continue to cool, the solid salt and tube will continue to contract. The solid salt, though, will contract much more than the tube as it cools to room temperatures $(9 \%$ decrease in volume for the salt versus $1 \%$ decrease when the tube is cooled from 215 to $21^{\circ} \mathrm{C}\left(420^{\circ} \mathrm{F}\right.$ to $\left.70^{\circ} \mathrm{F}\right)$ ).

When the tube and solid salt are heated, they will expand. The tube will be unstressed up to the freezing point (when the salt is still solid). Once the salt starts to thaw, if the tube is plugged at the ends, stress will build in the tube. The tube will behave like a thick-walled cylinder under uniform internal pressure. Using formulas for thick-walled cylinders (Young, 1989) that describe the relation between the tube properties and dimensions and internal pressure, an estimate of the change in volume can be determined for certain stress criterion (based on a thickwalled cylinder). The allowable and yield stresses are $100 \mathrm{MPa}$ and $185 \mathrm{MPa}$ (15000 psi and $27000 \mathrm{psi})$, respectively, at $220^{\circ} \mathrm{C}\left(430^{\circ} \mathrm{F}\right)$ for ASME SA213, Grade T22 (2.25Cr $\left.1 \mathrm{Mo}\right)$ from the ASME Boiler and Pressure Vessel Code, Section 8, Division 1. The volume change is directly related to the fraction of salt that has melted. When salt melts, its volume increases by about 
4.6\%. At high pressures, the compressibility of the salt cannot be ignored. The compressibility is the fractional change in volume with pressure at constant temperature.

In order not to exceed the allowable stress, driven by the circumferential stress at the inner surface of the tube and accounting for compressibility, only about $18 \%$ of the salt by mass within a tube can be thawed. In this case, the pressure inside the tube from the expanding salt will be about $35 \mathrm{MPa}$ (5000 psi). If the requirement of allowable stress is relaxed, up to $32 \%$ of the salt can be melted with the ends constrained before the circumferential stress exceeds the yield (assumed to still be elastic). The pressure will be about $60 \mathrm{MPa}(8900 \mathrm{psi})$. See Table G-1. As more salt melts, the tube will begin to plastically deform, enlarging its diameter.

\section{Table G-1. Effect of Thawing on Stress in Tube}

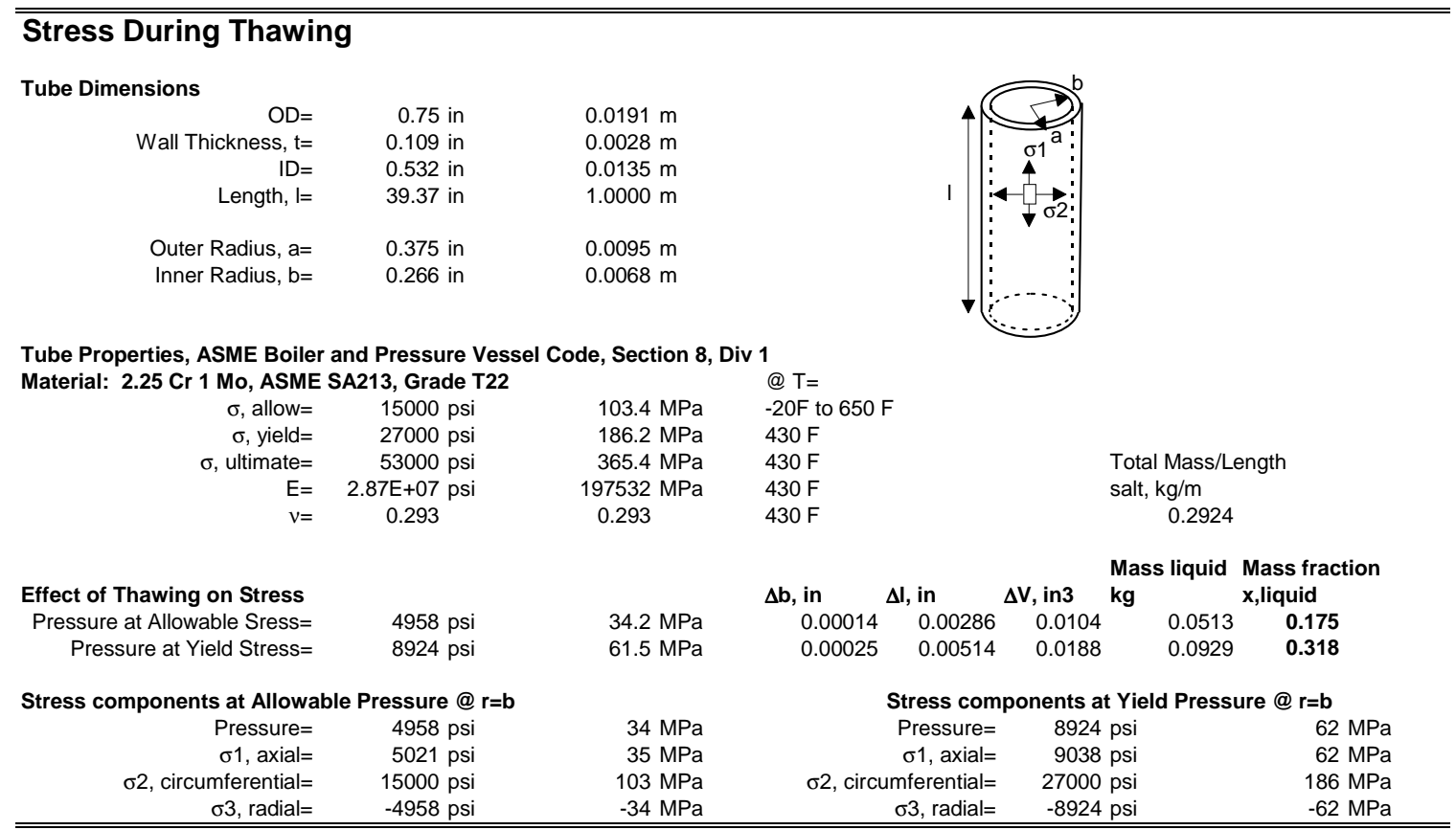

The next question is how long will it take to thaw a given percentage of salt and what kind of temperature variation of the water can be tolerated within the evaporator so that part of the salt tube does not melt more than a certain amount while the rest is still frozen. With the system modified by installing a canned recirculation pump (420 liters/min (111 gpm)) and with the current $200 \mathrm{~kW}$ electric heater, the water in the evaporator will reach the salt freezing point $\left(221^{\circ} \mathrm{C}\right)$ in approximately 9.6 hours. The outside tube temperature and the centerline temperature of the frozen salt will lag the water temperature by about $0.5^{\circ} \mathrm{C}\left(1^{\circ} \mathrm{F}\right)$ up until the melting point (assumed to be a constant $221^{\circ} \mathrm{C}, 430^{\circ} \mathrm{F}$ ) due to resistance from convection. At this point, the salt will start to melt from the tube wall inward. See Figure G-1 for a plot of the evaporator water temperature, tube outside wall temperature, and salt temperature at the centerline of the tube during this thaw process. The tabulated data of this plot is shown Table G-2. 


\section{Evaporator, Tube, and Salt Temperature}

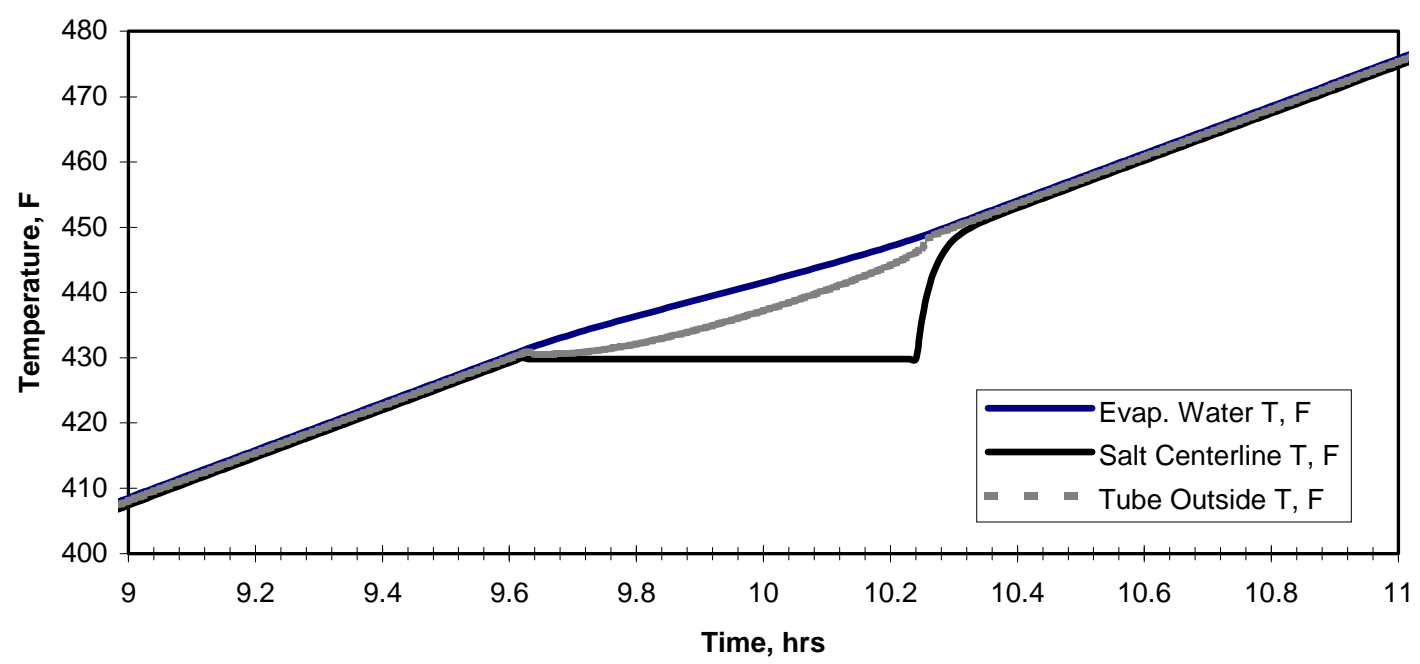

Figure G-1. Temperature of evaporator water, tube outside, and salt at centerline of the tube during thawing process.

Figure G-2 shows the amount of salt melted in a tube as a function of time. As the evaporator water continues to heat, $32 \%$ of the salt will have melted in about 13 minutes. If part of the tube has not reached the salt melting point, the tube will be plugged and it will start to permanently strain.

To prevent any damage, the temperature variation within the evaporator as it is heated through the salt melting point should not exceed $4.5^{\circ} \mathrm{C}\left(8^{\circ} \mathrm{F}\right)$ over its entire length; otherwise, the tube will be constrained. In other words, while the water is being heated, if part of the water is below the melting point of salt while another part is at $226^{\circ} \mathrm{C}\left(438^{\circ} \mathrm{F}\right)$, more than $32 \%$ of the salt in a tube could thaw. If heat is continuously added, after about 37 minutes, all the salt will have melted.

A few comments should be made about the $4^{\circ} \mathrm{C}\left(8^{\circ} \mathrm{F}\right)$ temperature variation limitation. The major difficulty with thawing salt in the evaporator tubes is preventing salt from melting in a portion of a tube while the rest of the tube is still frozen. If the evaporator was being heated after a long-term hold where the salt had been drained as much as possible, the residual salt would not completely fill the tube, assuming the evaporator was leveled properly. At worst, some tubes might be partially full of salt, but it is unlikely that the entire tube would be completely full of salt. The tubes would have to be out of alignment by more than $1.3 \mathrm{~cm}(1 / 2 \mathrm{inch})$ over this entire length to completely fill the inner tube diameter. If the tubes are reasonable aligned, the salt would not fill the inner diameter, would have space to expand, and, thus, the pressure in the tube would not build. 
Table G-2. Tabulated data from Figure G-1

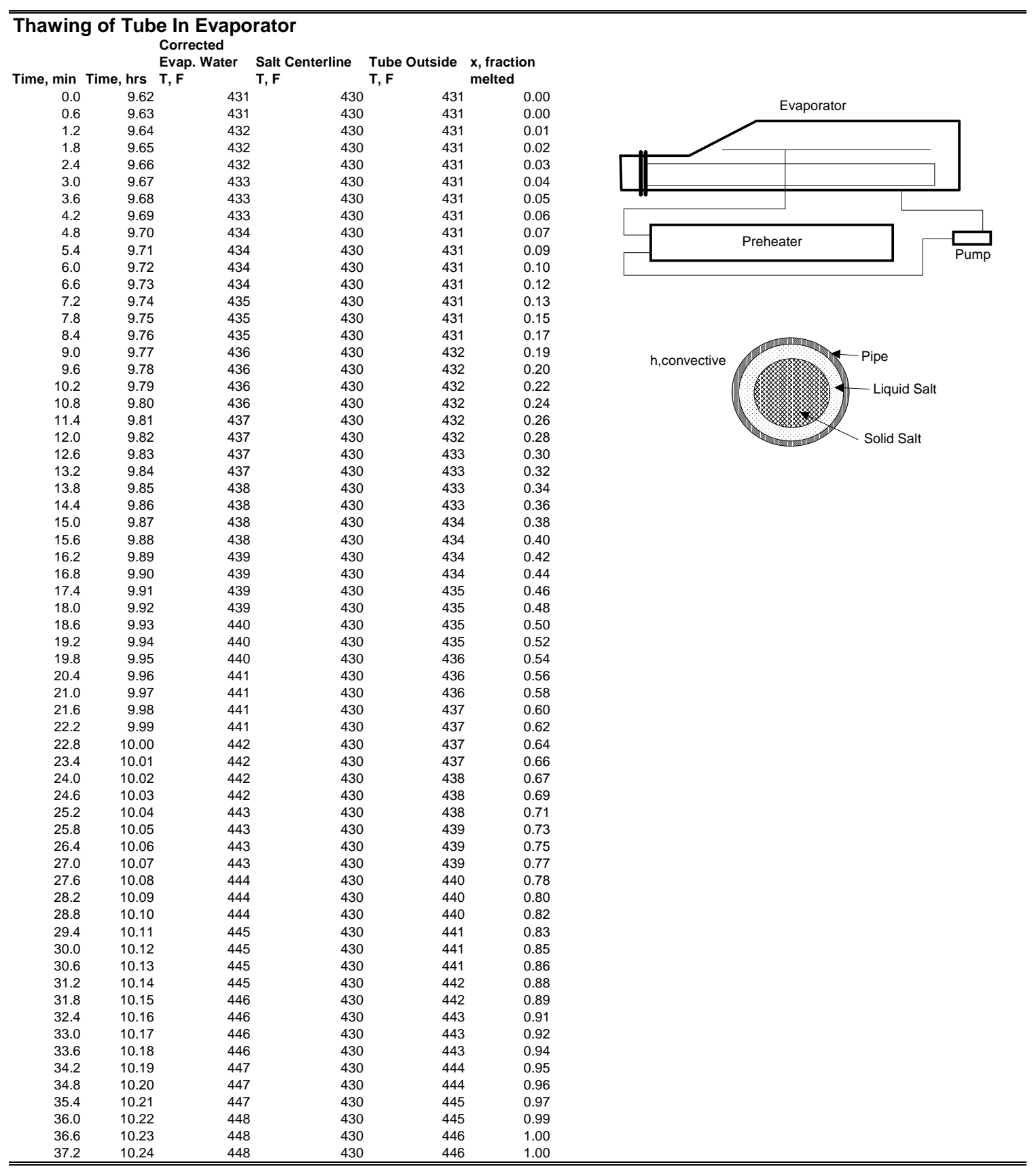

If the tubes were completely full of salt, such as from an upset condition, then the $4^{\circ} \mathrm{C}\left(8^{\circ} \mathrm{F}\right)$ temperature variation becomes much more important. To help the situation, the tube sheet should be hotter than rest of the evaporator, so salt will melt there first and create a free liquid salt interface into which the melting salt can expand. 


\section{Fraction Salt Melted vs Time}

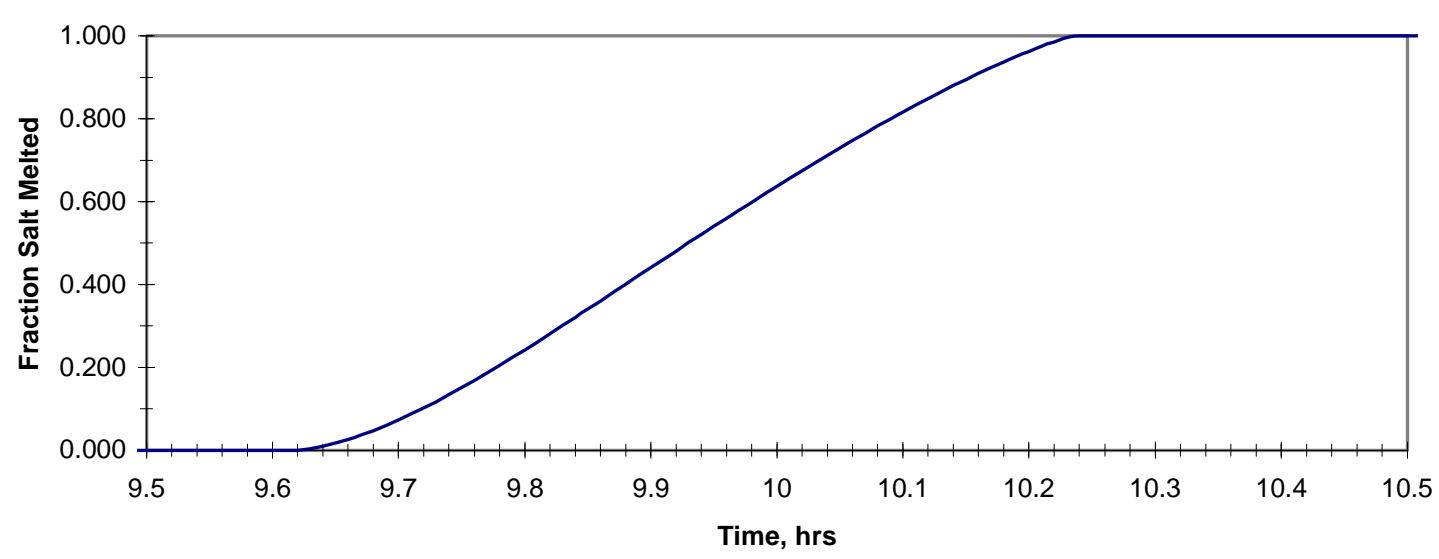

Figure G-2. Fraction of salt melted in evaporator tube as a function of time.

If the recirculation heater heated up the water and maintained it at $3^{\circ} \mathrm{C}\left(5^{\circ} \mathrm{F}\right)$ above the salt freezing point (e.g., $\left.224^{\circ} \mathrm{C}\left(435^{\circ} \mathrm{F}\right)\right)$, the rate of thawing could be slowed down slightly. See Figure G-3 for a plot of the evaporator water temperature, tube temperature, and salt temperature with water set point at $224^{\circ} \mathrm{C}\left(435^{\circ} \mathrm{F}\right)$. It would take 14 minutes to thaw $32 \%$ of the salt and 73 minutes to melt all the salt. The time to melt $32 \%$ and $100 \%$ of the salt as a function of the evaporator-water temperature set-point is shown in Table G-3, below. In reality, it would be very difficult to accurately control evaporator water temperature since the thermocouples and signal conditioners are not very accurate. Trying to hold the water temperature too close to the freezing point could be dangerous, because it could cause multiple freeze/thaws cycles. In addition, the temperature rise across the $200 \mathrm{~kW}$ heater (with the canned water pump) is about $7^{\circ} \mathrm{C}\left(13^{\circ} \mathrm{F}\right)$. If there are significant variations in evaporator water temperature (especially cold areas near the massive water-side flange and tube sheet), it would be better to soak the system well below the freezing point $\left(204^{\circ} \mathrm{C}\left(400^{\circ} \mathrm{F}\right)\right)$, then ramp the water temperature up so all areas come up well above the salt freezing point. During the soaking process, it is probably best to control the water temperature from the outlet of the preheater to assure no water above the salt freezing point is introduced.

\section{G.3 Heat Trace Requirements to Thaw Salt in Channel Sections}

The channel sections on the evaporator do not have heat trace. After coming out of a long-term shutdown or after an upset condition, the temperature in the channel should be hotter than the water side to thaw any residual salt in the channel and tube sheet or, in the worst case, to completely thaw salt in the channel full of frozen salt. This will ensure that the tubes will not be plugged with salt at the ends. 
Evaporator, Tube, and Salt Temperature with Water Set Point at $435 \mathrm{~F}$

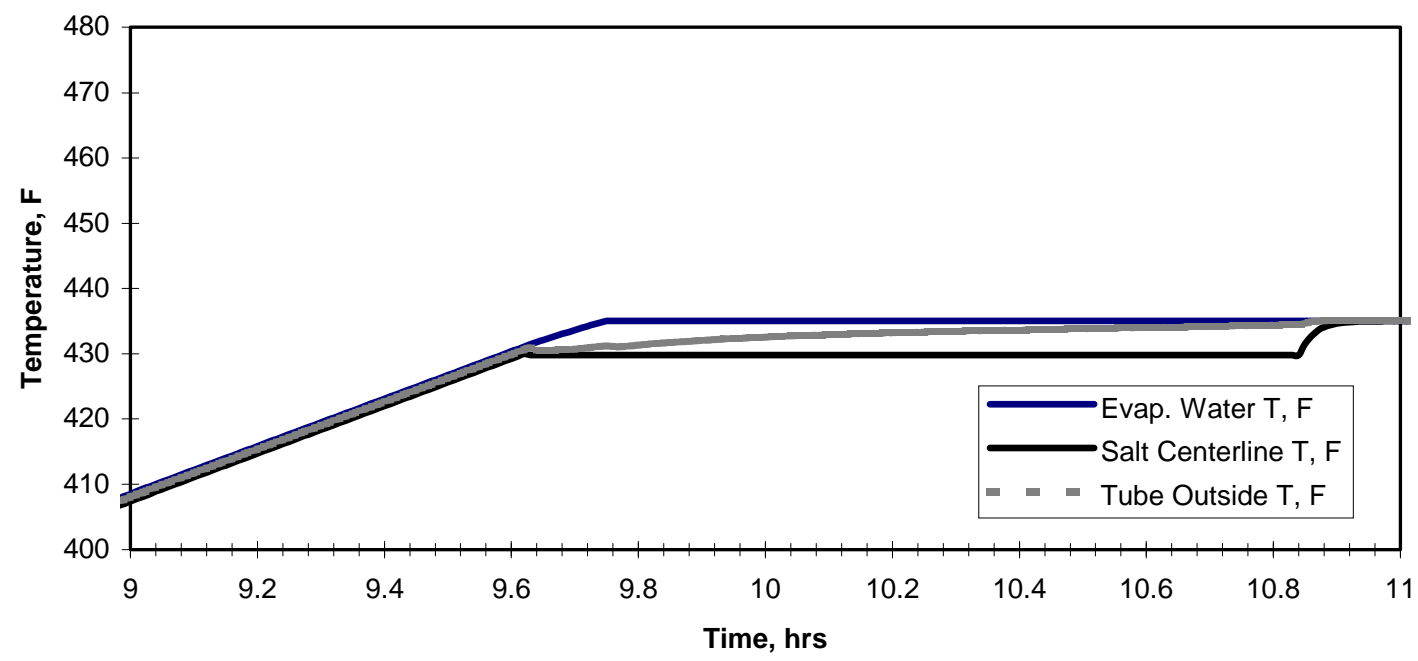

Figure G-3. Temperatures of the evaporator water, tube, and salt in the centerline of the tubes during the thawing process with the water set point at $224^{\circ} \mathrm{C}\left(435^{\circ} \mathrm{F}\right)$.

Table G-3. $\quad$ Time to melt $32 \%$ and $100 \%$ of salt in evaporator tubes as a function of evaporator-water set-point. The water is being heated as the salt is thawed. Salt freezing point is assumed to be $221^{\circ} \mathrm{C}\left(430^{\circ} \mathrm{F}\right)$.

\begin{tabular}{ccc}
\hline \hline $\begin{array}{c}\text { Evaporator Water } \\
\text { Set Point, }{ }^{\circ} \mathbf{F}\end{array}$ & $\begin{array}{c}\text { Time to Melt 32\% of } \\
\text { Salt, minutes }\end{array}$ & $\begin{array}{l}\text { Time to Melt 100\% of } \\
\text { Salt, minutes }\end{array}$ \\
\hline 432 & 26 & 167 \\
435 & 14 & 73 \\
440 & 13 & 43 \\
450 & 13 & 37 \\
600 & 13 & 37 \\
\hline \hline
\end{tabular}

If a flanged access port is included as part of the channel, the tube sheet and chamber can be inspected to see if there is frozen salt present. If there is frozen salt in the channel or tube sheet, it can be dissolved with water. It is important to dissolve salt out of the tube sheet to prevent frozen salt from plugging the tubes.

If there is not a flanged access port, a heat trace must be used to melt the salt. There are three cases for which a heat trace might be used: 1) no salt in either the upper or lower chamber, 2) salt in the upper chamber, and 3) salt in both the upper and lower chamber. See Figure G-4 for a diagram of the chamber sections. In each case, the temperature rise of the chamber and salt assuming a lumped system and accounting for the losses from each surface of the evaporator chamber (sides, elliptical end, and tube sheet) was estimated. With $10 \mathrm{~kW}$ of heat trace and the evaporator water heater turned on with a set point of $204^{\circ} \mathrm{C}\left(400^{\circ} \mathrm{F}\right)$, an empty channel will heat up faster than the water. The average temperature of the metal will peak out at about $277^{\circ} \mathrm{C}$ $\left(530^{\circ} \mathrm{F}\right)$. See Figure G-5 for a plot of the channel temperature rise as a function of time. With 
frozen salt in the upper chamber, it will take approximately 1.5 hours to thaw the salt. With salt in both the upper and lower chambers, it will take nearly three hours to thaw.

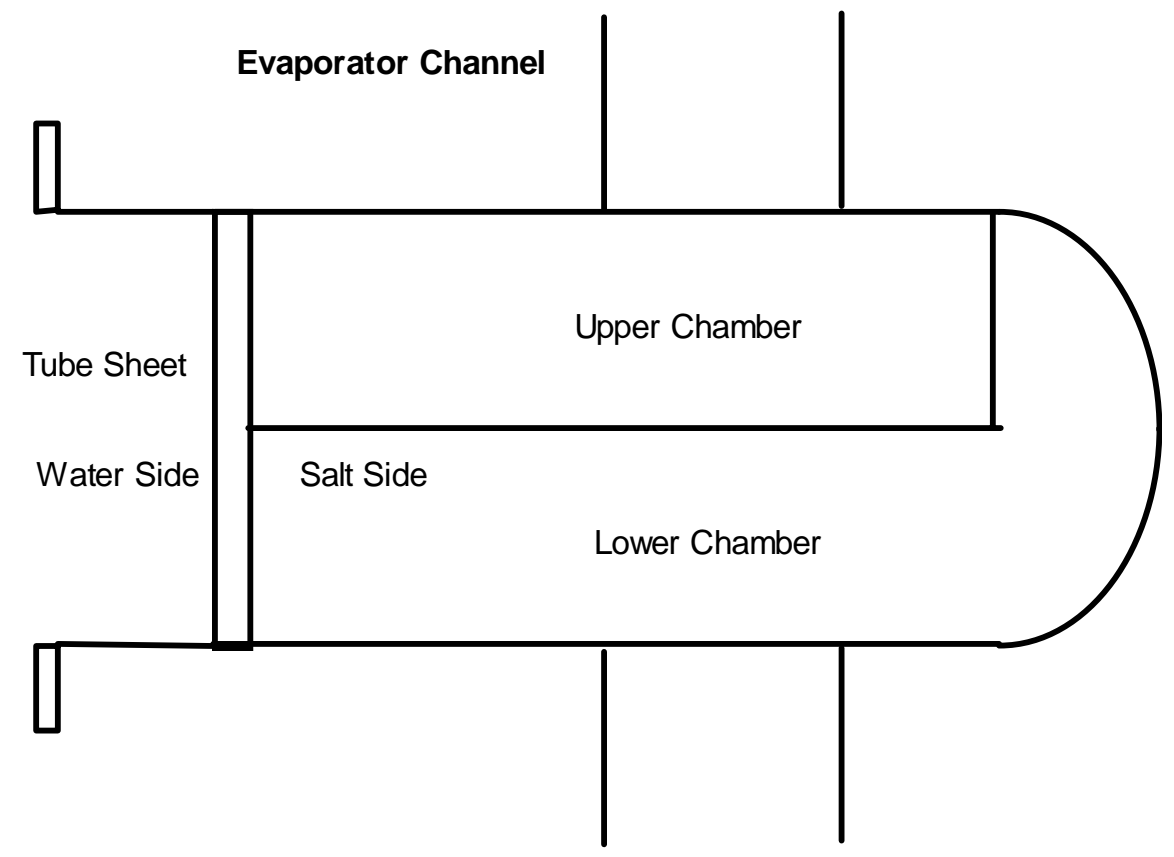

Figure G-4. Upper and lower chamber sections and tube sheet of evaporator channel.

The time estimates are not conservative. An empty channel with a massive tube sheet with water on one side will not truly behave like a lumped system. The surface of the chamber, where the heat trace is wrapped, will heat up quickly and transfer the heat to the tube sheet by radiation, convection, and conduction. As a conservative estimate, neglecting convection and conduction, radiation was assumed to be the dominant heat source for the tube sheet. By radiation equilibrium, the salt-side surface temperature of the tube sheet can be calculated by choosing the outside surface of the chamber using view factors. With the outside surface of the chamber held at $454^{\circ} \mathrm{C}\left(850^{\circ} \mathrm{F}\right)$ and the evaporator water temperature at $204^{\circ} \mathrm{C}\left(400^{\circ} \mathrm{F}\right)$, the salt side surface of the tube sheet will be approximately $241^{\circ} \mathrm{C}\left(466^{\circ} \mathrm{F}\right)$. This should be hot enough to at least partially melt plugs of salt in the tubes at the tube sheet. The only way to know the salt side temperature of the tube sheet, to verify that salt has thawed, is to install a thermocouple on the tube sheet in the upper chamber. The best location is about three rows up in the center of the tube sheet.

When the upper or lower chambers are full of salt, the surface of the channel will likely become hotter than the melting point of the salt, adding to the heat losses. Also, the cold tube sheet will conduct away a lot of heat. As a result, it will take longer to thaw the salt than what was estimated by a lumped system. 


\section{Channel Temperature Rise}

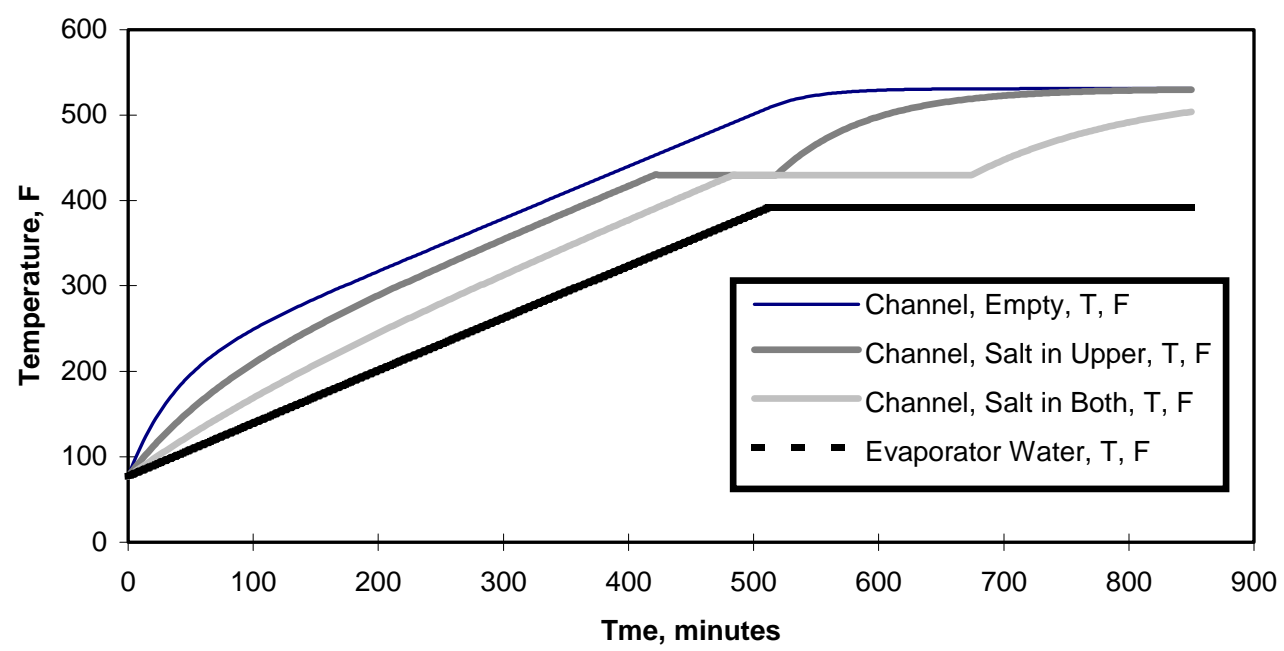

Figure G-5. Temperature rise of the evaporator channel during heating process.

\section{G.4 Suggested Safe Thawing Approach}

To assess the extent of the frozen salt, the lower chamber and tube sheet should be examined if a flanged access port is available. The salt could be dissolved with water from the chamber and tube sheet. If there is no access port, the salt must be melted with heat trace.

To heat up the evaporator if there is residual salt in the tubes or chamber (after a long term hold or after an upset condition), the channel must be heated first to ensure the tube sheet is hotter than the evaporator water. Any salt in the channel chambers must be melted before the salt in the tubes are thawed to prevent the tubes from being plugged at the ends.

The evaporator water should be heated to $204^{\circ} \mathrm{C}\left(400^{\circ} \mathrm{F}\right)$ and held there until all the salt in the channel section is melted. A thermocouple should be installed to measure the water temperature adjacent to the tube sheet. A thermocouple in the upper chamber on the tube sheet on the salt side would be invaluable if it was necessary to thaw the upper chamber in the channel. It would be prudent to let the heat soak for several hours at this point. Once all the salt is melted in the chamber and the tube sheet is hotter than the water temperature, the evaporator water temperature should be increased so all thermocouples are well above $227^{\circ} \mathrm{C}\left(440^{\circ} \mathrm{F}\right)$. (Do not stop heating until every part of the evaporator is well above the freezing point.) Hopefully, the water temperature variation throughout the evaporator will be $<4^{\circ} \mathrm{C}\left(<8^{\circ} \mathrm{F}\right)$ as it is heated through the freezing point. 


\section{G.5 Hardware Requirements}

The hardware that should be added is listed below.

- Add at least $10 \mathrm{~kW}$ of heat trace to the channel section (15-20 kW would allow a better margin).

- Add a flanged inspection port to access the lower chamber of the channel.

- Install a thermocouple to measure water temperature adjacent to the tube sheet between the tube sheet and the water-side flange.

- Install a thermocouple on the salt side of the tube sheet in the upper chamber of the channel at approximately three rows up from the centerline.

\section{G.6 Reference}

Young, W. C, Roark's Formulas for Stress and Strain, McGraw-Hill, sixth edition, 1989 
Final Test and Evaluation Results from the Solar Two Project 


\section{Appendix H. Coupon Corrosion Tests, Salt Chemistry and Post Mortem Analysis (D. Dawson, B. Bradshaw, S. Goods)}

The test and evaluation (T\&E) project originally consisted of two categories of tests to determine the long-term chemical behavior of molten salt and its effect on containment materials used in molten salt piping and components. During the course of the project, more questions and opportunities presented themselves. First, due to concerns about stress corrosion cracking (SCC) following the rinse of the receiver, a test was performed to determine the sensitivity of various structural materials to SCC. Second, at the end of the project (the plant shut down April 8, 1999), it was decided that portions of the facility could be removed for metallurgical tests to compare with the coupon corrosion tests. These tests results are included in Attachment 1. Lessons learned during the preparation and melting of the salt are included in Appendix L.

\section{H.1 Purpose and Objectives}

\section{H.1.1 Coupon Corrosion Tests}

Service temperature limits and corrosion rate allowances for molten nitrate salt exposures were established for a series of alloys using the results of laboratory corrosion experiments and experience from short-term solar tests. In this test, the corrosion behavior of containment materials in Solar Two service was quantitatively measured to determine whether corrosion rates were acceptable and whether significant differences existed when Solar Two corrosion data were compared to prior laboratory test data. Potential issues for Solar Two service included the effects of thermal cycling and periodic salt fill-and-drain in some components, and the exposure of materials to commercial-grade nitrate salt having a composition that evolves with time.

\section{H.1.2 Salt Chemistry Tests}

Laboratory tests have shown that the chemical composition of molten nitrate salt mixtures evolves over time as a result of exposure at elevated temperature, contact with the atmosphere, and contact with containment materials. Periodic salt samples were therefore obtained from Solar Two to determine how the composition of the commercial-grade salt used in this project evolved over the period that the plant was in operation.

\section{H.1.3 Post Mortem}

Following the shutdown of the plant, staff removed portions of the salt transfer system that were exposed repeatedly (or continuously) to molten salt throughout the life of the plant. These samples were examined for corrosion penetration, surface contamination, and oxide growth. 


\section{H.1.4 Stress Corrosion Cracking Supplemental Experiments}

A supplemental experiment was added to this test (see Attachment 1) to better understand the cracking of receiver tubes following a tube replacement operation. Debris in the receiver was dissolved with an aqueous flush, which may have contributed to SCC. In addition, overfluxing the receiver - caused by an error in the Dynamic Aim Processing System (DAPS), which locked the heliostat aimpoints for several months - may have contributed to SCC.

\section{H.1.5 Lessons Learned, Solar Two Salt Handling}

Appendix L discusses some of the problems associated with receiving and melting millions of pounds of nitrate salts and what might be performed differently in the future.

\section{H.2 Coupon Corrosion Tests}

Corrosion behavior of baseline and alternate salt-loop containment materials was measured under Solar Two service conditions. Corrosion coupons (specimens) were immersed in test chambers at selected locations in the salt loop and removed at intervals for metallographic and weight-loss analysis. Corrosion data were obtained for the duration of the Solar Two operation (except for chamber Y-251, which was removed in the fall of 1997). Where possible, Solar Two corrosion data were compared with existing laboratory corrosion data for identical materials and with the results of post-mortem examination from material samples removed from Solar Two components.

Equipment tag numbers, exposure locations, the nearest thermocouple (TC) for recording temperature, and nominal exposure conditions of the test chambers are given in Table H-1.

Table H-1. Information on test chambers and conditions

\begin{tabular}{cllll}
\hline \hline $\begin{array}{c}\text { Tag } \\
\text { ID \# }\end{array}$ & Chamber Location & Thermocouple & Nominal Temperature & Immersion \\
\hline Y-250 & $\begin{array}{l}\text { Receiver pump (cold) } \\
\text { sump }\end{array}$ & TE 5050 & $\begin{array}{l}\text { Isothermal }\left(290^{\circ} \mathrm{C}\left(550^{\circ}\right.\right. \\
\text { F }))\end{array}$ & Continuous \\
Y-850 & $\begin{array}{l}\text { Steam Generator System } \\
\text { (hot) pump sump }\end{array}$ & TE 5744 & $\begin{array}{l}\text { Isothermal }\left(565^{\circ} \mathrm{C}\right. \\
\left.\left(1050^{\circ} \mathrm{F}\right)\right)\end{array}$ & Continuous \\
Y-251 & $\begin{array}{l}\text { Receiver downcomer } \\
\text { piping }\end{array}$ & TE 5024 & $\begin{array}{l}\text { Thermal cycling }\left(565^{\circ} \mathrm{C}\right. \\
\left.\left(1050^{\circ} \mathrm{F}, \text { max }\right)\right)\end{array}$ & Fill-and-drain \\
Y-851 & $\begin{array}{l}\text { Evaporator salt inlet } \\
\text { piping }\end{array}$ & TE 5757 & $\begin{array}{l}\text { Thermal cycling }\left(480^{\circ} \mathrm{C}\right. \\
\left.\left(900^{\circ} \mathrm{F}\right), \max \right)\end{array}$ & Continuous* \\
\hline \hline
\end{tabular}

* Steam Generator System (SGS) piping and Chamber Y-851 drained during long-term holds. 


\section{H.2.1 Pump Sump Chambers}

Y-250 and Y-850 were bayonet-type chambers inserted vertically through spare 15-cm (6-inch) nozzle locations in the roof of the receiver pump sump (V-250) and SGS pump sump (V-850), respectively. The design of the chambers was similar, the primary differences being materials of construction (carbon steel for Y-250, 304 stainless steel for Y-850) and length of each chamber assembly. Each chamber assembly consisted of the 10-cm (4-inch) diameter chamber itself that was inserted through the sump nozzle, a mating extension adapter to bring the chamber access opening above the level of the sump maintenance platform, and a blind cover flange that was used to seal the opening at the top of the adapter. The flange joint between sump nozzle, chamber, and lower end of the extension adapter remained continuously bolted for the duration of Solar Two operation. Figure H-1 shows the arrangement for the Y-850 (SGS pump sump) chamber; Y-250 was similar.

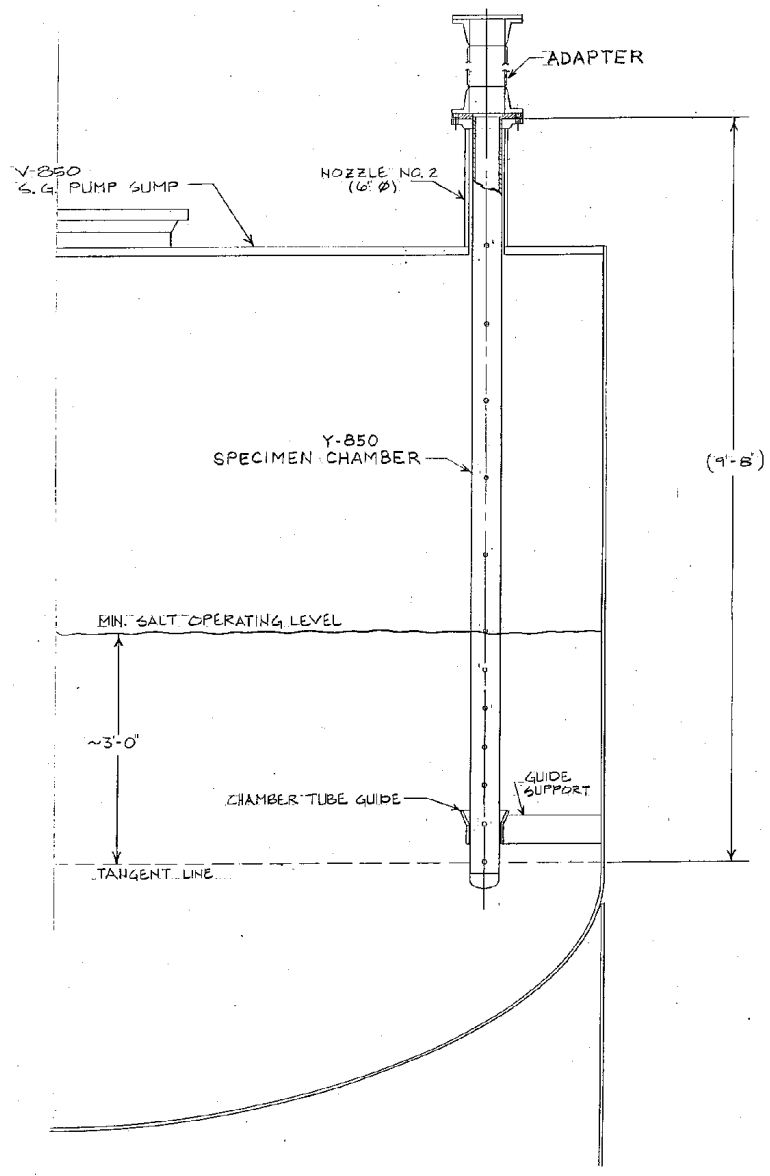

Figure H-1. Arrangement of Chamber Y-850 in the SGS pump sump. Sample mounting fixture was suspended in chamber below minimum salt level.

Access to the chamber for salt sampling and corrosion coupon insertion and removal was obtained through the blind flange at the top of the chamber extension adapter. The 10-cm (4- 
inch)-diameter chambers were capped at the bottom and perforated along their length to allow molten salt to circulate freely within them. Corrosion coupons were mounted on a "specimen tree" fixture that was contained within the chamber. Specimen fixtures for the bayonet chambers were similar in design to those used for the tee-type chambers (Y-251 and Y-851), shown in Figure H-2 and described below. Fixtures for the bayonet chambers were suspended from the cover flange by a chain, with chamber length and chain length sized to keep the specimens continuously immersed below the minimum salt operating level.

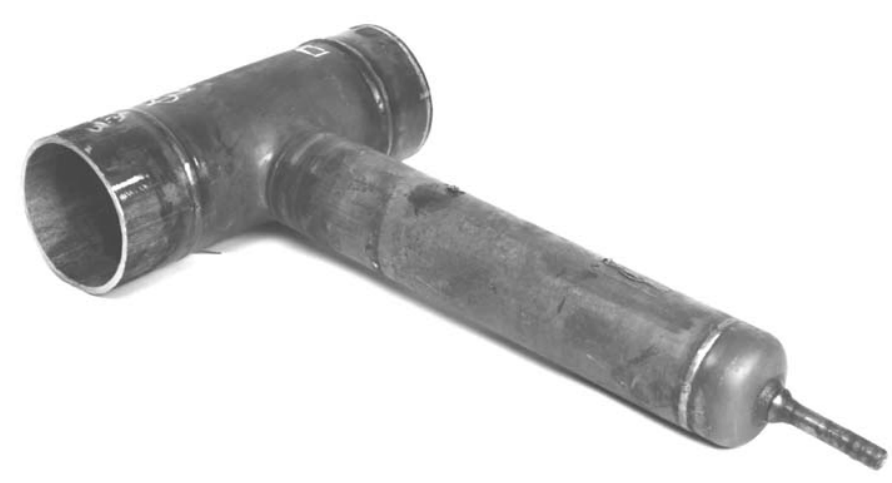

Figure H-2. Tee-type receiver downcomer chamber $Y$-251 after removal from service in October 1997.

\section{H.2.2 Salt Piping Chambers}

Y-251 and Y-851 were essentially identical tee-type chambers that were welded into salt piping lines. Y-251 is shown in Figure H-2. The principal elements of the 304SS tee-type chambers were a $15 \mathrm{~cm} \times 15 \mathrm{~cm} \times 10 \mathrm{~cm}(6 \mathrm{inch} \times 6 \mathrm{inch} \times 4 \mathrm{inch})$ reducing tee that was welded into the $15 \mathrm{~cm}$ (6-inch) salt piping line; a $51 \mathrm{~cm}$ (20-inch) length of 10-cm (4-inch) diameter pipe that comprised the chamber itself; and a $10-\mathrm{cm}$ (4-inch) cap to close the end of the chamber. A perforated baffle on the tee (downcomer) end allowed salt to fill and drain from the chamber. For operational reasons, it was decided that corrosion specimens should be kept in separate chambers, rather than exposing them to direct salt flow in the piping runs. Thus, flow velocity effects on corrosion behavior were not evaluated in this test. Tee chambers had no effect on flow through the $15-\mathrm{cm}$ (6-inch) salt lines.

Chamber Y-251 was located in a section of downcomer line NS012, between the receiver outlet tank (V-252) and the junction of NS012 with receiver bypass line NS188. Figure H-2 shows short sections of $15-\mathrm{cm}$ (6-inch) downcomer still attached to either end of the Y-251 tee. Chamber Y-851 was located in a section of steam generator interconnecting piping line NS037, between salt mixer MI-851 and the salt inlet to evaporator E-851. Tee-type chambers were 
located in vertical sections of salt piping runs, with the chambers themselves oriented horizontally to assist salt fill and drain.

Corrosion coupons for Y-251 and Y-851 were mounted on a specimen tree similar to the type used in the bayonet chambers. Steps in corrosion coupon removal included cutting the weld joining the end cap to the $10-\mathrm{cm}$ (4-inch) diameter pipe section; withdrawing the fixture and removing the required coupons for that sample interval; reinserting the fixture with remaining coupons into the chamber; and rewelding the end cap. A short length of $1.3-\mathrm{cm}(1 / 2$-inch) diameter pipe extending from the end cap purged gas during rewelding. The specimen fixture from Y-251 is shown in Figure H-3 after removal from the chamber, with the end cap and purge tube still attached.

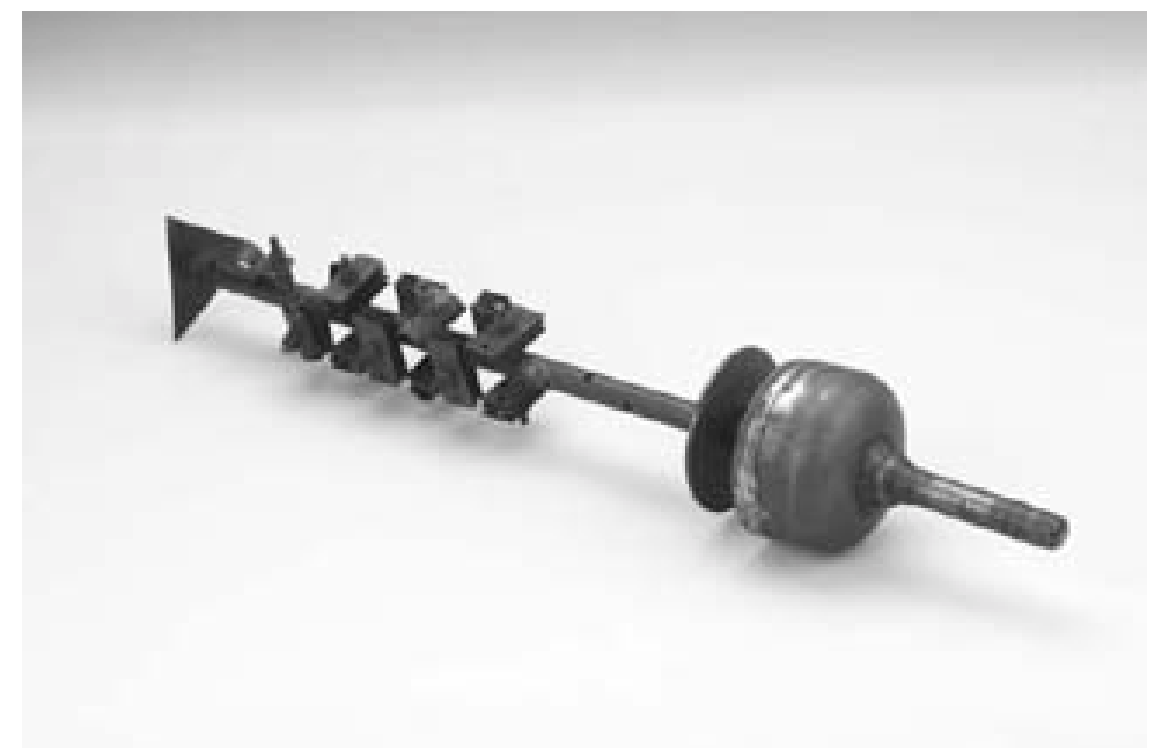

Figure H-3. Specimen mounting tree after removal from Chamber Y-251, with branches and specimens for first sampling interval already removed from the end of the tree nearest end cap.

Figure H-4 shows the typical specimen mounting arrangement used in all four chambers. Corrosion specimens shown in the figure include the more common, flat type used in laboratory tests, as well as curved coupons from tubing used in Solar Two construction. Coupons and other corrosion specimens were mounted on a series of "branches," consisting of threaded rods inserted through holes drilled in the "trunk" of the specimen tree. Nuts were used to fix specimens to the threaded rod and keep specimens separated from each other. Coupons were mounted on specimen trees in sets that corresponded to the original test plan for three sample removal intervals. For most materials, three coupons were included for each test interval: two for descaled weight change measurement and one for metallographic examination with the oxide scale intact. 


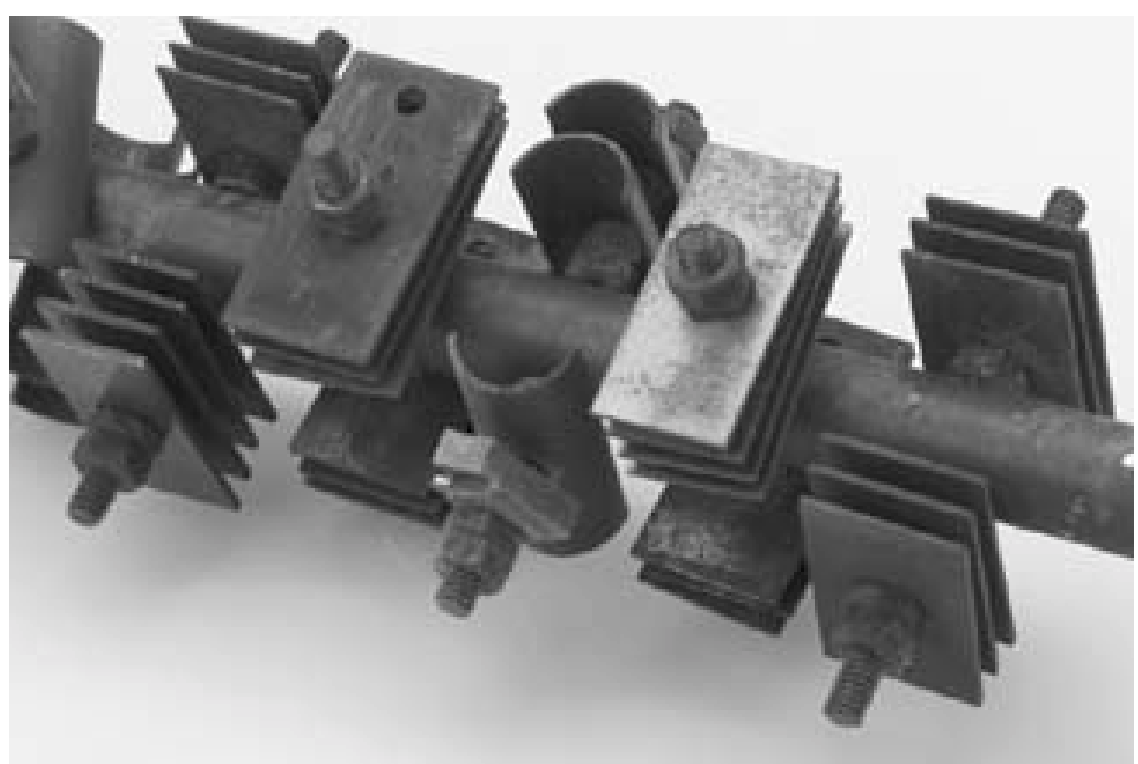

Figure H-4. Typical specimen mounting arrangement from the chamber Y-251 specimen tree. Flat coupons include 304SS and 316SS. Curved coupons are pieces of 316 SS Solar Two receiver tubing.

Chambers for specimen exposure were incorporated in salt loop construction. Coupons mounted on specimen fixtures were inserted in test chambers at different times, but in all cases, prior to plant start-up and checkout. Corrosion coupons were inserted in chambers Y-251 and Y-851 when the chambers were constructed; the chambers were welded into the salt loop piping in May 1995, and thus were present in the salt loop prior to salt loading and melting. For the pump sump chambers, Y-250 and Y-850, corrosion coupons were inserted on April 5, 1996, after salt melting was complete.

\section{H.2.3 Corrosion Tests}

Multiple sets of specimens were provided at each exposure location, and typically remained exposed to molten salt throughout plant operation. The original schedule for this test called for removing sets of specimens at approximately one-year intervals for a total of three exposure intervals. Alterations to the test schedule for Solar Two reduced this to an initial removal from Y-250, Y-850, and Y-851 on May 13, 1998, and a second and final removal a year later, on April 19, 1999. In addition, specimens in chamber Y-251 had only a short exposure time. After intergranular SCC was detected in a section of hot salt piping in September 1997, it was decided to completely remove chamber Y-251 from service so the chamber piping could likewise be checked for evidence of intergranular attack. Y-251 was removed October 8, 1997 and sectioned for examination (shallow intergranular attack was in fact found near welds), and its specimens received no further salt exposure. It was felt that adequate information could be obtained from (isothermal) chamber Y-850, which contained the same materials.

The detailed procedures for conducting the corrosion tests involving inserted coupons are described in the previous section. The locations of inserted coupons and nominal exposure conditions of the test chambers are listed in Table H-1. 
The materials exposed to the molten salt at each location are noted in Table H-2. The table also indicates the dates at which samples were removed from a particular location. The set of corrosion specimens included coupons made from standard materials of construction for Solar Two; samples of receiver tubing, evaporator tubing, and plate from the cold salt storage tank; and additional materials contemplated for use in next-generation commercial plants. Receiver materials evaluated included 316 stainless-steel (SS) coupons and 316 SS receiver tubing samples. Carbon steels for cold salt applications included AISI A36 coupons and samples of AISI A516 plate material from the cold salt storage tank. Hot salt piping candidates included 304 SS and 347 SS (the latter added partway through the test). SGS materials for evaporator applications included ferritic 9Cr-1Mo steel coupons and evaporator tubing samples and $2.25 \mathrm{Cr}$ 1 Mo coupons. There were two intentional overtests of materials, based on results from prior laboratory corrosion experiments: $9 \mathrm{Cr}-1 \mathrm{Mo}$ coupons were included in 1050F exposures for Y251 and Y-850, and A36 carbon steel was included in 900F exposures for Y-851. Exposure of 2.25Cr-1Mo ferritic steel in the $900 \mathrm{~F}$ Y-851 chamber might also be considered to be a marginal overtest for long-term molten salt service at that temperature.

Table H-2. Locations of corrosion coupons for all materials installed in the Solar Two test chambers. The sampling schedule for each location and material is given by the corresponding footnote number.

\begin{tabular}{lcccc}
\hline \hline \multicolumn{1}{c}{ Material } & $\begin{array}{c}\text { Cold } \\
\text { Sump } \\
(\text { Y-250) }\end{array}$ & $\begin{array}{c}\text { Hot } \\
\text { Sump } \\
(\text { Y-850) }\end{array}$ & $\begin{array}{c}\text { Receiver } \\
\text { Outlet } \\
(\text { Y-251) }\end{array}$ & $\begin{array}{c}\text { Evaporator } \\
\text { Inlet } \\
(\text { Y-851) }\end{array}$ \\
\hline Coupon samples & & 2,3 & 1 & \\
304 SS & & 2,3 & 1 & 3 \\
316 SS & & 3 & & 2,3 \\
347 SS (4) & & 2,3 & 1 & 2,3 \\
9Cr-1Mo (F9 steel) & 2,3 & & & \\
2.25Cr-1Mo (F22 steel) & & & & 2,3 \\
A36 Carbon steel & & 2,3 & 1 & \\
Component samples & & & & \\
316SS receiver tube & & & & \\
9Cr-1Mo evaporator tube & & 3 & 1 & \\
A516 Carbon steel plate & 3 & & & \\
Receiver tube/header & & &
\end{tabular}

1. Samples removed October 8, 1997.

2. Samples removed May 13, 1998.

3. Samples removed April 19, 1999.

4. 347 SS coupons were not installed until May 13, 1998.

Multiple sets of coupons were provided at each exposure location and remained exposed to molten salt throughout plant operation. Specimen fixtures were retrieved approximately yearly during normal plant shut-down. At this time, one coupon set from each location was removed from its fixture for analysis, and the fixtures with remaining coupons were returned to their exposure locations. Coupons removed for analysis were not returned to the salt for additional exposure. 


\section{H.3 Test Coupons}

The elemental composition of the materials used to prepare corrosion coupons is given in Table H-3. Rectangular coupons measuring approximately $20 \mathrm{~mm} \times 50 \mathrm{~mm} \times 2 \mathrm{~mm}$ in thickness were fabricated by Metal Samples Co., Inc., Munford, AL. The coupons were ground with 180 grit carborundum paper to produce uniform surface finishes.

Table H-3. Elemental compositions of alloys tested. (wt. \% by analysis, balance Fe)

\begin{tabular}{clrrrrrr}
\hline \hline Alloy & $\mathrm{C}$ & $\mathrm{Cr}$ & $\mathrm{Ni}$ & $\mathrm{Mo}$ & $\mathrm{Si}$ & $\mathrm{Mn}$ & Other \\
\hline 316 SS & 0.06 & 16.93 & 10.10 & 2.20 & 0.49 & 1.51 & \\
304 SS & 0.06 & 18.30 & 8.07 & & 0.42 & 1.85 & \\
347 SS & 0.05 & 18.03 & 8.72 & 0.19 & & & $0.76 \mathrm{Nb}$ \\
9Cr-1Mo & 0.13 & 8.90 & & 1.03 & 0.86 & 0.47 & \\
2.25Cr-1Mo & 0.13 & 2.12 & & 0.99 & 0.25 & 0.39 & \\
A36 steel & 0.29 & & & & $0.15-0.3$ & & \\
\hline \hline
\end{tabular}

Weight change measurements and metallographic examinations were performed on removed coupons to evaluate the corrosion behavior under plant operating conditions. Weight changes were determined by the descaled metal loss of the coupons, the weight after stripping the oxide scale minus the initial weight of the coupon. These data were normalized according to the surface area of the particular specimen and subsequently converted to the equivalent metal thickness lost. The same descaling procedures were used as those for laboratory testing. Stainless steel samples were descaled using a two-step process that involved boiling in an alkaline permanganate solution followed by boiling in a citrate-EDTA solution. Carbon steel and Cr-Mo steels were descaled in hydrochloric acid containing a corrosion inhibitor to suppress attack on the underlying metal. In almost all cases, duplicate or triplicate samples were descaled and the values reported below are averages of the group of related samples. Metallographic examination was performed on a few samples that exhibited relatively large weight losses, as well as key materials (such as $316 \mathrm{SS}$ ), regardless of the measured weight losses.

\section{H.4 Results}

\section{H.4.1 Corrosion Tests}

The data concerning metal losses measured by descaling coupons are shown in Table H-4. The table indicates the type of material, the location of the chamber, and the date that samples were removed from molten salt. Metal losses are reported as the thickness of metal consumed by corrosion and imply that corrosion was uniform. Units of microns $(1$ micron $=0.0001 \mathrm{~cm})$ are used to report the metal losses. The last column in Table H-4 provides notes regarding the appearance of the coupons after removal according to the adherence, color, and superficial uniformity of the surface scale. The tabulated data are average values. 
Table H-4. Descaled metal loss data for Solar Two corrosion samples. Unless noted otherwise, the materials were in the form of flat coupons.

\begin{tabular}{|c|c|c|c|c|}
\hline Alloy & Location & $\begin{array}{l}\text { Date of } \\
\text { Removal }\end{array}$ & $\begin{array}{c}\text { Metal } \\
\text { Loss } \\
\text { (microns) }\end{array}$ & Comments \\
\hline \multirow[t]{4}{*}{ A36 } & Cold Sump & $5-13-98$ & 0.2 & adherent black tarnish film \\
\hline & " " 6 & 4-19-99 & 0.9 & " $\quad$ " $\quad$ " \\
\hline & Evaporator inlet & $5-13-98$ & 36.3 & thick, adherent red scale \\
\hline & " 6 & 4-19-99 & 43.9 & “ $\quad$ “ $\quad$ “ \\
\hline A516 & Cold Sump & 4-19-99 & 2.1 & adherent black scale \\
\hline \multirow[t]{2}{*}{ F22 steel } & Evaporator inlet & $5-13-98$ & 9.8 & blistered, spalling red scale \\
\hline & " c 6 & 4-19-99 & 41.4 & 666 \\
\hline \multirow[t]{5}{*}{ F9 steel } & Evaporator inlet & $5-13-98$ & 0.7 & adherent black scale \\
\hline & "6 6 & $4-19-99$ & 1.8 & ، 66 \\
\hline & Hot Sump & $5-13-98$ & 18.0 & black scale, some flaking \\
\hline & & $4-19-99$ & 31.9 & " " " " \\
\hline & Receiver outlet & $10-8-97$ & 7.6 & spalling red scale \\
\hline F9 steel & Evaporator inlet & $5-13-98$ & 5.4 & spalling red scale \\
\hline (tubing) & “ & $4-19-99$ & 9.1 & ، 6 \\
\hline \multirow[t]{3}{*}{$316 \mathrm{SS}$} & Hot Sump & $5-13-98$ & 2.4 & adherent oxide scale \\
\hline & " 6 & 4-19-99 & 3.1 & " $\quad$ " $\quad$ " \\
\hline & Receiver outlet & $10-8-97$ & 1.6 & “ \\
\hline $316 \mathrm{SS}$ & Receiver outlet & $10-8-97$ & 0.9 & black tarnish film, red oxide \\
\hline \multirow[t]{2}{*}{ (tubing) } & Hot Sump & $5-13-98$ & 1.2 & “ \\
\hline & " 6 & $4-19-99$ & 2.1 & ، 646 \\
\hline \multirow[t]{3}{*}{$304 \mathrm{SS}$} & Hot Sump & $5-13-98$ & 2.9 & adherent oxide scale \\
\hline & " " & 4-19-99 & 3.8 & " " " \\
\hline & Receiver outlet & $10-8-97$ & 3.1 & patches of red and black oxide \\
\hline $347 \mathrm{SS}$ & Hot Sump & 4-19-99 & 3.0 & adherent oxide scale \\
\hline
\end{tabular}

All of the stainless-steel types displayed only a few microns of metal loss during the entire testing period. The differences between 316 SS, 304 SS, and 347 SS were minimal. Similarly, the type of surface finish did not appear to affect corrosion, as the 316 SS coupons, which had a surface ground by 180-grit carborundum paper, corroded about the same as the 316 SS receiver tubing sections that were used in as-received condition and had a surface produced by rolling.

The Cr-Mo steels experienced more corrosion than expected based on previous laboratory corrosion tests. The 2-1/4Cr-1Mo (F22 steel) coupons at the evaporator inlet (Y851) experienced almost 10 microns of average metal loss after the first sampling on May 13, 1998, and more than 40 microns of metal loss was measured at the final sampling time, April 19, 1999. In addition, numerous pits were formed, meaning that local penetration depths were somewhat greater. Coupons of $9 \mathrm{Cr}-1 \mathrm{Mo}$ (F9 steel) behaved quite well when exposed in the Evaporator Inlet at $480^{\circ} \mathrm{C}\left(900^{\circ} \mathrm{F}\right)$, but not at the higher temperature of the hot-salt sump (Y-850). Coupons of $9 \mathrm{Cr}-1 \mathrm{Mo}$ from the latter location were covered with a weakly adherent black oxide and lost 32 microns of metal during the complete exposure period. This degree of metal loss is well in excess of that observed during earlier laboratory experiments; see Bradshaw and Goods (1994). 
Although carbon steel corroded a great deal in the evaporator inlet (Y-851), such behavior was expected due to the high temperature $\left(480^{\circ} \mathrm{C}\right.$ vs. $\left.290^{\circ} \mathrm{C}\right)$ relative to the conditions recommended for this material. Indeed, the carbon steel samples were placed in the evaporator inlet port to provide an indication that the time/temperature history of that location was sufficient to induce corrosion in a susceptible material. At least in this instance, it was verified that the expected corrosive conditions existed for a prolonged period of time.

A number of coupons were prepared metallographically and inspected using optical microscopy to examine the degree of corrosion scale growth and to confirm the absence of intergranular corrosion. Figure H-5 shows a cross-sectioned coupon of 316 SS that was removed from the hot-salt sump (Y-850) at the end of the Solar Two test. The coupon displayed only a few microns of oxide scale growth, which is consistent with the relatively small weight losses reported in Table H-4. The lower micrograph in Figure H-5 shows a cross-sectioned coupon of a 316 SS tube-to-header weld that was removed from the hot-salt sump (Y-850) at the end of the test. This region corresponds to the fusion zone of the weld and displayed about 15 microns of oxide scale growth. The oxide scales on these two coupons appeared similar to that observed in previous laboratory tests. The composition of these oxide scales is comprised of spinel-type oxides of iron and an iron-chromium mixture. Figure H-6 shows a cross-sectioned coupon of $347 \mathrm{SS}$ that was removed from the hot-salt sump (Y-850) at the end of the test. This coupon was placed in the chamber later than the coupon of 316 SS shown in the preceding figure. The 347 SS displayed little oxide scale growth, insufficient to form a fully-covered surface, which is consistent with the small weight loss reported in Table H-4. Neither of these stainless steels showed any evidence of intergranular corrosion after prolonged exposure to the Solar Two molten salt environment, a result expected based upon previous long-term laboratory tests.

Cross-sectioned samples of F9 steel $(9 \mathrm{Cr}-1 \mathrm{Mo})$ that were removed from the Evaporator Inlet chamber (Y-851) at the end of the test are shown in Figure H-7. The upper micrograph corresponds to a section of F9 steel tubing; the lower photo corresponds to a coupon of sheet stock. The tubing section experienced about 10-15 microns of oxide scaling, while the coupon displayed only a few microns of oxide scale growth. The tubing section was likely cut from material that had a somewhat lower silicon content than that of the coupon material, although both variations were within the composition specifications for this type of steel. However, previous laboratory tests confirmed that minor differences in silicon content, of only a few tenths of a weight percent, are sufficient to cause rather large differences in corrosion resistance in the molten salt environment. Higher silicon content increases the corrosion resistance and the benefit was found to be particularly evident in molten nitrate salts that contained chloride impurities (Goods, et. al, 1997). The oxide scales on these two coupons appear similar to that observed in previous laboratory tests. The composition of these oxide scales was comprised of spinel oxides of iron and an iron-chromium spinel. 

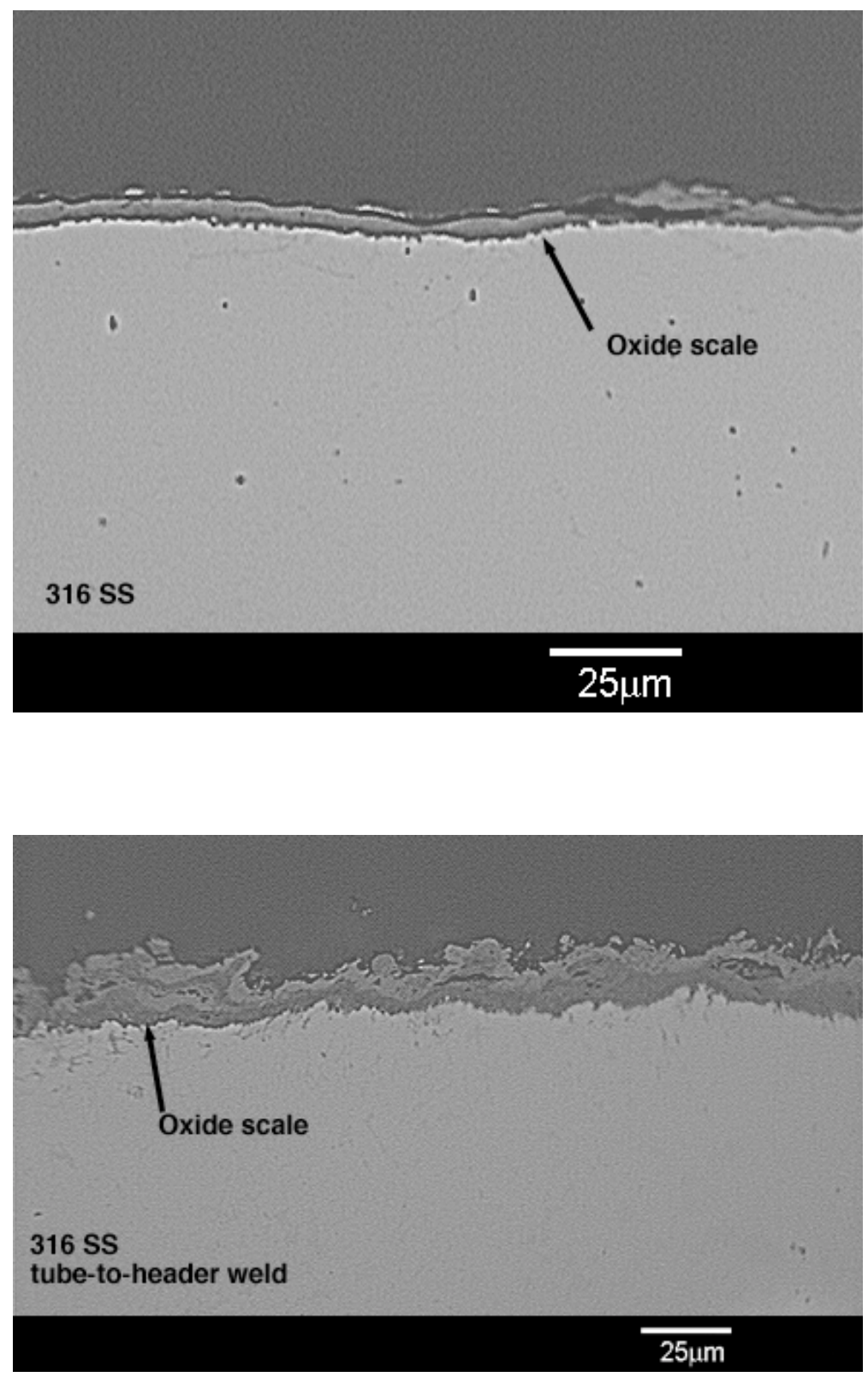

Figure H-5. (upper) Optical micrograph of oxide scale formed on 316 SS, removed from test chamber Y-850 (hot-salt sump) on April 19, 1999. (lower) Optical micrograph of oxide scale formed on a welded 316 SS sample after removal from test chamber Y-850 (hot-salt sump) on April 19, 1999. 


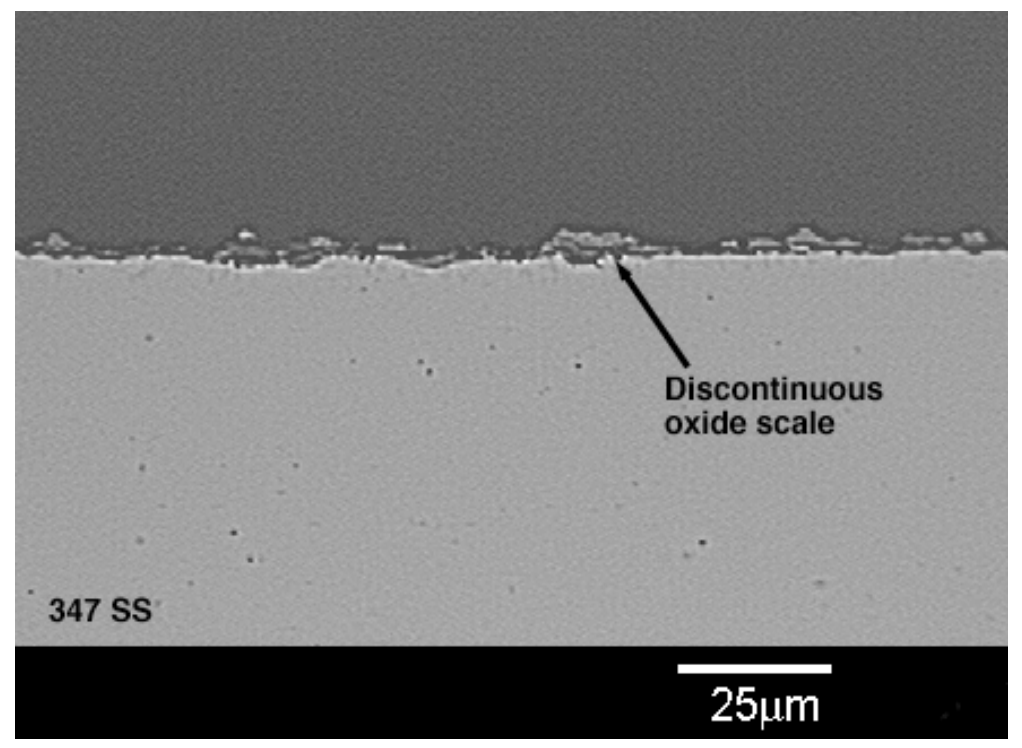

Figure H-6. Optical micrograph of oxide scale formed on 347 SS, removed from test chamber Y-850 (hot-salt sump) on April 19, 1999. 

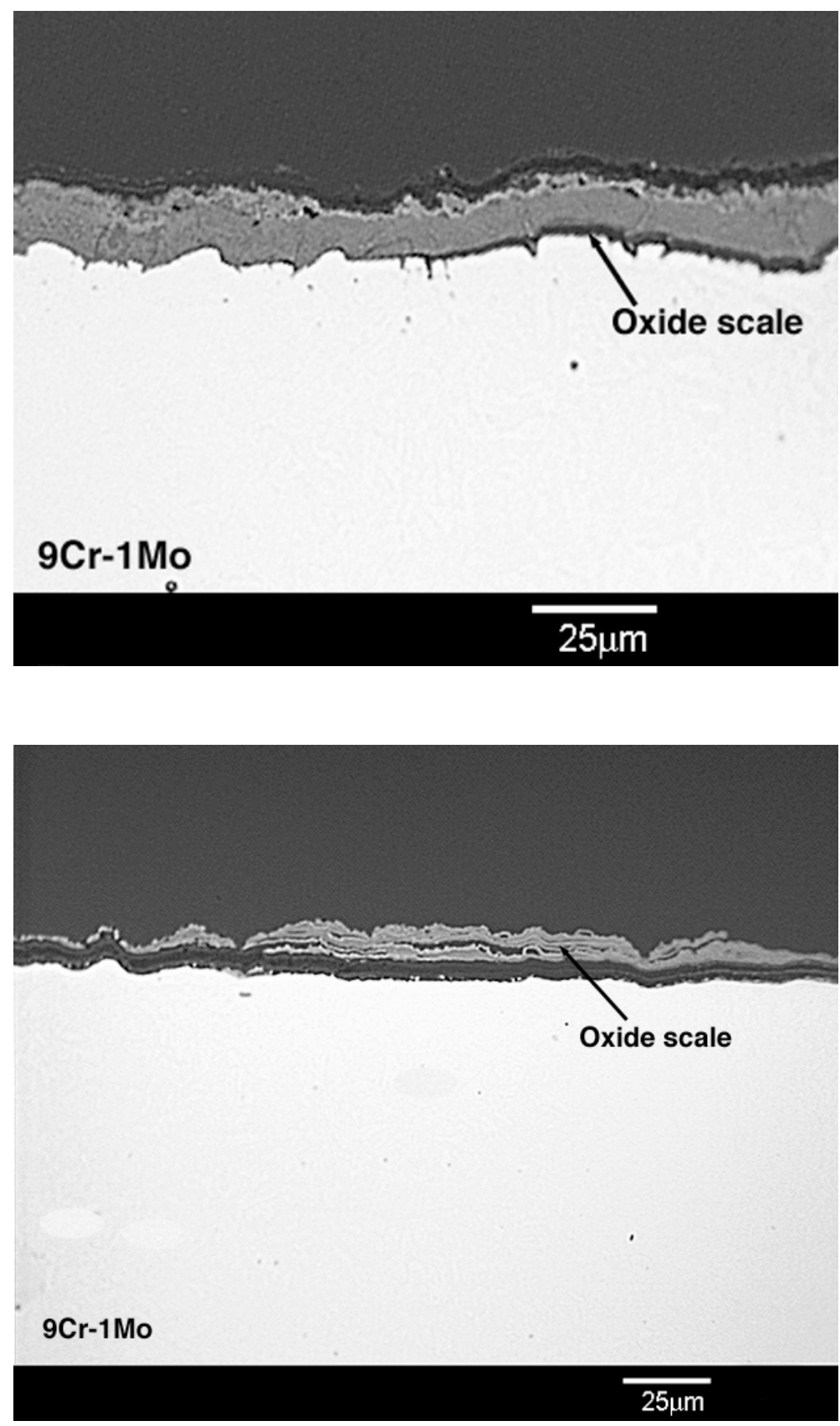

Figure H-7. (upper) Optical micrograph of oxide scale formed on F9 alloy steel (9Cr-1Mo) tubing section after removal from test chamber $Y-851$ (evaporator inlet) from the Solar Two plant on April 19, 1999. (lower) Optical micrograph of oxide scale formed on F9 alloy steel (9Cr-1Mo) coupon after removal on same date. 
More severe scaling behavior of the chromium-molybdenum steels was observed in samples of F22 steel (2-1/4Cr-1Mo) that were exposed in the evaporator inlet chamber (Y-851), as shown in Figure H-8 (upper). This coupon experienced more than 200 microns of oxide scaling, and formed a fragile scale that contained many delaminations within the oxide layer. As noted in the comments in Table H-4, the oxide layer on this chromium-lean steel was prone to cracking and spalling. The corrosion behavior observed in this test is entirely consistent with previous laboratory corrosion studies involving this alloy (Goods, et. al., 1997). The lower micrograph in Figure H-8 shows a sample of F9 steel that was exposed to the molten salt at high temperature in the hot salt sump (Y-850). This coupon experienced up to 80 microns of oxide scaling and formed a scale that contained a large amount of internal porosity and delaminations. However, this alloy was exposed to temperatures exceeding those used in any of the previous laboratory tests and indicates that sustained use of such an alloy at temperature of $550^{\circ} \mathrm{C}$ and higher must be avoided to avoid excessive corrosion.

\section{H.5 Conclusions}

\section{H.5.1 Corrosion}

The choice of stainless steels and carbon steel for molten salt containment, in their respective temperature regimes, presents no problems with regard to corrosion resistance. Carbon steel corrodes very slowly at the cold-salt temperature $\left(290^{\circ} \mathrm{C}\right)$, and, as the mechanical design requirements of components fabricated with this material ordinarily result in specifying thick walls, corrosion allowances are not a design consideration. The molten salt corrosion resistance of stainless steels, e.g., $316 \mathrm{SS}$ and $304 \mathrm{SS}$, is more than adequate for prolonged service at $565^{\circ} \mathrm{C}$ in either receiver tubes or piping. However, these two alloys form microstructures after a short period of thermal exposure that are sensitized to aqueous SCC resulting from incidental contact with water. If an alternative to these stainless steels were needed, $347 \mathrm{SS}$ appears to have similarly good molten salt corrosion resistance, but is less susceptible to aqueous cracking. The need for a non-austenitic alloy to construct the evaporator (to avoid aqueous SCC) requires that a Cr-Mo steel having 9\% chromium be specified to provide good corrosion behavior in the molten salt. The steel containing only $2.25 \%$ chromium does not have adequate corrosion resistance in the molten salt. These conclusions agreed, in general, with those reached on the basis of laboratory corrosion testing of the same materials.

\section{H.6 Salt Chemistry Tests}

Chemical composition of the salt inventory in Solar Two was determined as a function of time for a specific set of chemical species known to have important effects on the physical and chemical properties of the molten salt mixture. Salt sampling commenced upon completion of salt melting and continued for the duration of Solar Two operation. Periodic salt samples were obtained from the two pump sumps. These samples were representative of the salt composition circulating through the system. 


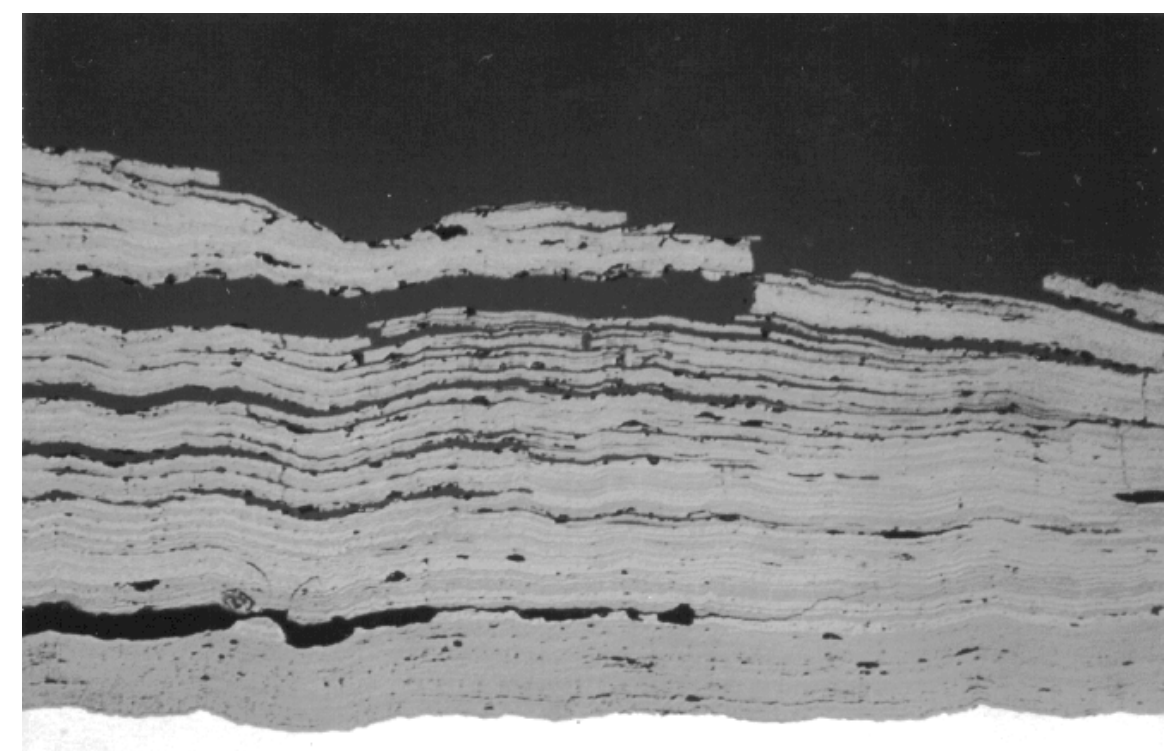

\section{0 microns}

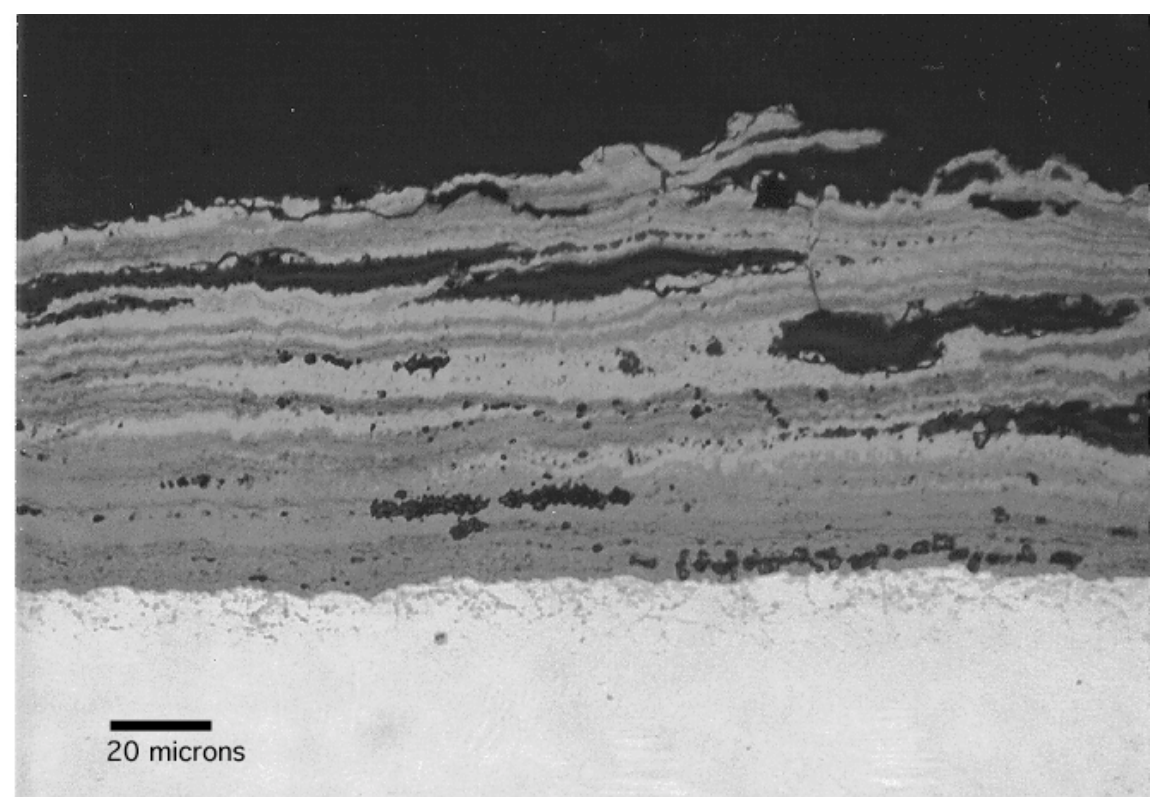

Figure $\mathrm{H}-8 . \quad$ (upper) Optical micrograph of oxide scale formed on F22 steel removed from test chamber Y-851 (evaporator inlet) on April 19, 1999. (lower) Optical micrograph of oxide scale formed on F9 steel, removed from test chamber Y-850 (hot salt sump) on April 19, 1999. 
Salt samples were removed from the pump sumps during plant shutdown or standby operation. Access for salt sampling was obtained by removing the blind flanges that covered the openings to the sump corrosion chambers, Y-250 and Y-850. A ladle was lowered inside of the chamber to obtain a minimum 20-gram salt sample. The molten salt sample was poured on a stainless-steel sheet to solidify and cool, and the solidified flakes were then collected in an inert sample container and sent for chemical analysis.

An initial zero-time salt sample was removed from both the receiver pump sump (V-250) and the steam generator system pump (V-850) upon completion of salt melting on April 5, 1996, the same time that corrosion specimens were loaded in the pump sump corrosion chambers (Y-250 and Y-850, respectively). Salt samples were subsequently removed from both sumps at intervals dictated by the level of plant operation and observed trends in salt chemistry.

\section{H.7 Results}

\section{H.7.1 Salt Chemistry}

Table H-5 summarizes salt composition data for samples removed from Solar Two. All values fall within their expected ranges based on the initial concentration of the various contaminants. Nitrite levels rose (with the exception of a few points) throughout the life of the project, but this was lower than expected (Nissan, 1981). Magnesium and perchlorate dropped substantially from the as-received salt. The magnesium nitrate decomposes to gaseous NOx and salt insoluble $\mathrm{MgO}$ (see Appendix L). The disposition of the perchlorate is unknown, although it does not appear to have decomposed to chloride based on the concentrations of chloride measured. It is doubtful that chloride would be reduced to chlorine in a nitrate salt environment; however, it could be removed from the solution as an unidentified precipitate. The calcium levels peaked after one month of operation and then decreased. Calcium was found in the receiver tubing (Section I.8) as well as on the corrosion coupons (see Section H.2). The carbonate levels were starting to rise in the last four to five months of operation, most likely due to increased air contact and lack of calcium to form an insoluble carbonate. Chromium levels were lower than previous experiments would suggest (Goods, et. al., 1994); however, a lower salt surface-area-toair ratio could be responsible. As the carbonate levels begin to rise, so does (initially) the chromium level in the salt. The weight ratio of $\mathrm{Na} / \mathrm{K}$ should be ideally $60 / 40$ (by wt \%) or 1.038; the as-received material was actually 1.056, but the shipment was accepted since this would lower the starting melt point. The reported weight ratio numbers cover a broad range, but may be due more to sampling/measurement error than actual stratification within the salt.

The melting temperature range of the nitrate salt mixture at Solar Two decreased over time, as shown in Figure H-9. This was expected, as the concentration of nitrite in the molten salt generally increased with time. The melting point data were obtained by applying differential scanning calorimetry to salt samples removed from various points around the plant. In reality, the data in Figure H-9 represent the melting temperature range for the salt mixture, rather than an actual melting point. This is illustrated in Figure H-10, showing data from a typical calorimetry run. Melting is detected in calorimetry as an endotherm, a downward trend from the baseline. For the as-received salt sample used to generate Figure H-10, ramping temperature up from 
$182^{\circ} \mathrm{C}\left(360^{\circ} \mathrm{F}\right)$ results in the onset of melting at $207^{\circ} \mathrm{C}\left(404^{\circ} \mathrm{F}\right)$. Two additional endotherms occur, as indicated by the two descending sections of the trace, and melting is complete at $240^{\circ} \mathrm{C}$ $\left(464^{\circ} \mathrm{F}\right)$. Melting and freezing occur over a range of temperatures in this multicomponent molten salt mixture.

Table H-5. Salt chemistry contaminant results. All values are ppm, wt, except as noted.

\begin{tabular}{|c|c|c|c|c|c|c|c|c|c|c|c|c|c|c|c|}
\hline \multirow[t]{2}{*}{ Date } & \multirow{2}{*}{$\begin{array}{c}07 / 26 / 1995 \\
\text { As } \\
\text { received }\end{array}$} & \multicolumn{2}{|c|}{$04 / 05 / 1996$} & \multicolumn{2}{|c|}{$05 / 21 / 1996$} & \multicolumn{2}{|c|}{$05 / 07 / 1997$} & \multicolumn{2}{|c|}{$02 / 25 / 1998$} & \multicolumn{2}{|c|}{$05 / 13 / 1998$} & \multicolumn{2}{|c|}{$12 / 23 / 1998$} & \multicolumn{2}{|c|}{ 04/09/1999 } \\
\hline & & $\begin{array}{l}\text { Cold } \\
\text { Sump }\end{array}$ & $\begin{array}{l}\text { Hot } \\
\text { Sump }\end{array}$ & $\begin{array}{l}\text { Cold } \\
\text { Sump }\end{array}$ & $\begin{array}{l}\text { Hot } \\
\text { Sump }\end{array}$ & $\begin{array}{l}\text { Cold } \\
\text { Sump }\end{array}$ & $\begin{array}{l}\text { Hot } \\
\text { Sump }\end{array}$ & $\begin{array}{c}\text { Cold } \\
\text { Sump }\end{array}$ & $\begin{array}{c}\text { Hot } \\
\text { Sump }\end{array}$ & $\begin{array}{l}\text { Cold } \\
\text { Sump }\end{array}$ & $\begin{array}{c}\text { Hot } \\
\text { Sump }\end{array}$ & $\begin{array}{l}\text { Cold } \\
\text { Sump }\end{array}$ & $\begin{array}{c}\text { Hot } \\
\text { Sump }\end{array}$ & $\begin{array}{l}\text { Cold } \\
\text { Sump }\end{array}$ & $\begin{array}{c}\text { Hot } \\
\text { Sump }\end{array}$ \\
\hline$\overline{M g}$ & 453 & 2 & 2 & 51 & 4 & 3.7 & 3.3 & 15 & 2 & 20.43 & 0.95 & 3.2 & 2.1 & 0.72 & 0.25 \\
\hline $\mathrm{Ca}$ & 77 & & & 268 & 83 & & & & & 10.3 & 12 & 1 & 4 & 6.83 & 2.42 \\
\hline $\mathrm{Cl}$ & 3640 & 4120 & 4090 & 4050 & 3930 & 3940 & 4000 & 3970 & 3960 & 4070 & 4040 & 4210 & 4100 & 4160 & 4060 \\
\hline $\mathrm{ClO}_{2}$ & 2640 & $<10$ & $<10$ & $<10$ & $<10$ & $<10$ & $<10$ & & & $<10$ & $<10$ & $<10$ & $<10$ & 10 & $<10$ \\
\hline 03 & 23.4 & $<10$ & $<10$ & $<10$ & $<10$ & $<10$ & $<10$ & $<10$ & 13.3 & $<10$ & $<10$ & 130 & 87 & 40.9 & 43.4 \\
\hline H & & $<3$ & $<3$ & $<3$ & $<3$ & $<3$ & $<3$ & $<3$ & $<3$ & $<3$ & $<3$ & $<3$ & $<3$ & $<3$ & $<3$ \\
\hline SO4 & 1240 & & & 1010 & 600 & & & 1160 & 1400 & 1580 & 1500 & & & 1380 & 1450 \\
\hline NO2 & 2050 & 5880 & 6350 & 233 & 3210 & 6420 & 2000 & 18500 & 17800 & 11400 & 11300 & 21900 & 16800 & 16300 & 13000 \\
\hline $\mathrm{Cr}$ & & 5 & 6 & 3 & 3 & 3 & 3 & 2.6 & 2.9 & 0.94 & 2.05 & 4.6 & 4.8 & 1.55 & 3.3 \\
\hline $\mathrm{Na}: \mathrm{K}$ & 1.056 & & & 1.28 & 1.15 & & & & & 1.37 & 1.41 & & & & \\
\hline In & & & & & & & & $<1$ & $<1$ & $<0.25$ & $<0.25$ & & & $<0.25$ & $<0.25$ \\
\hline
\end{tabular}

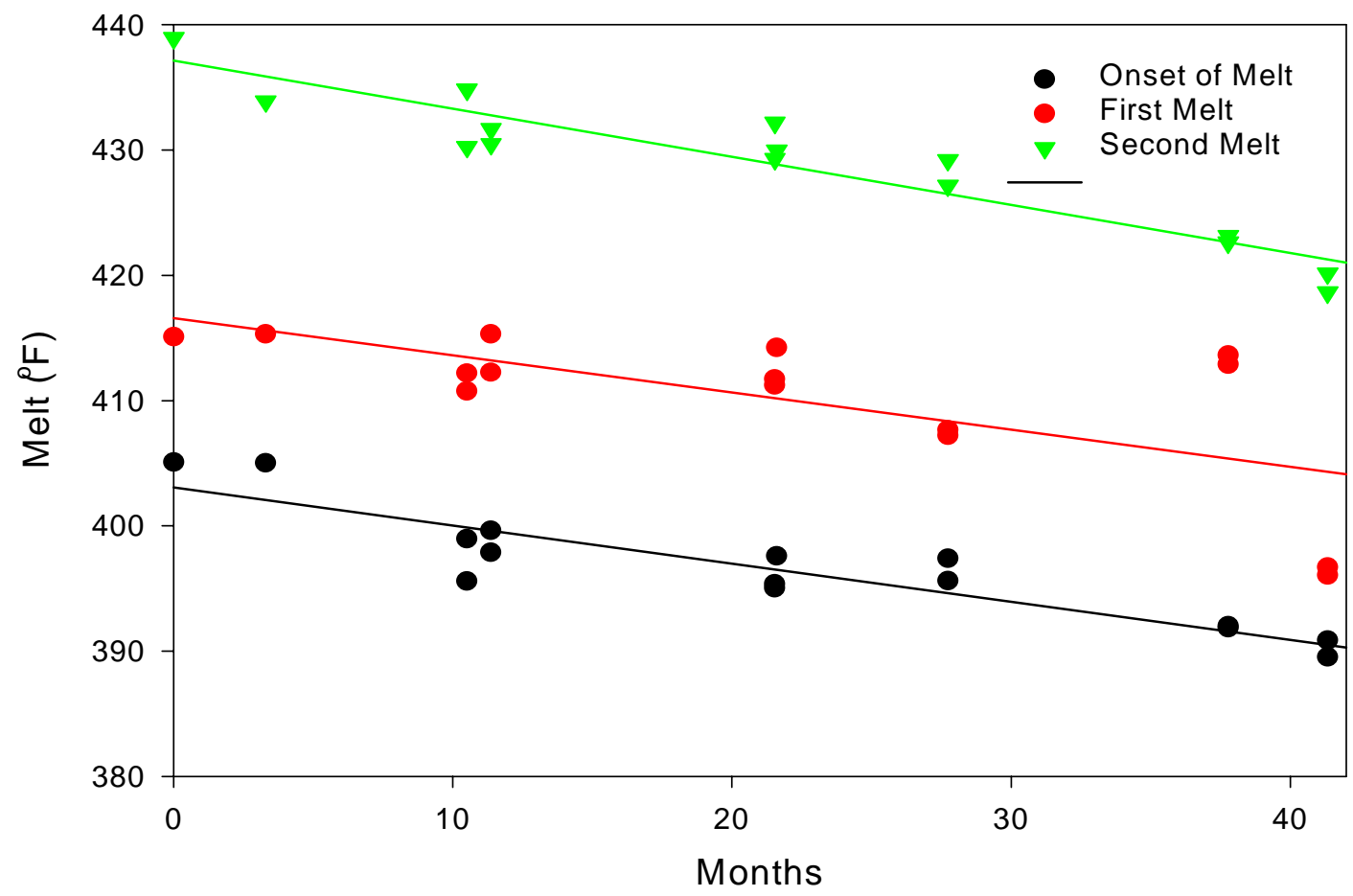

Figure H-9. Melting temperature range of Solar Two salt samples over the life of the plant. Data were measured by differential scanning calorimetry (see Figure $\mathrm{H}-10$ ). 


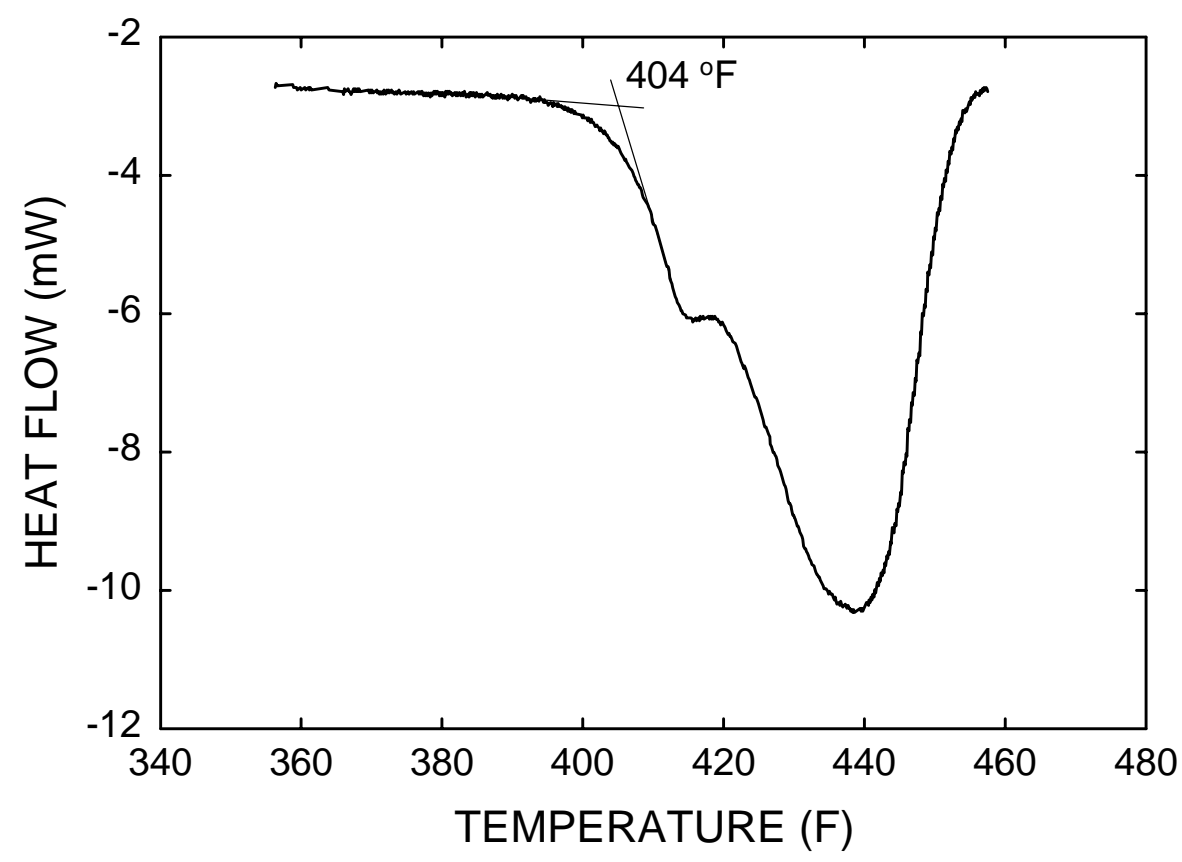

Figure H-10. Diffential scanning calorimetry of Solar Two as-received salt. Melting onset was at $207^{\circ} \mathrm{C}\left(404^{\circ} \mathrm{F}\right)$.

\section{H.8 Postmortem Analysis of Selected Portions of the Solar Two Salt System}

The coupon corrosion tests were envisioned as a simple way to introduce surrogate material into the molten salt environment without making major changes to draw samples throughout the life of Solar Two. The removal of these sacrificial samples did not affect the working integrity of the salt transport system. Once the project was completed and the plant was shut down, it was decided to grab some "real" samples at various points within the salt transport system. Tube samples were removed from the receiver, as well as two wall samples each from the cold and hot salt tanks above and below the permanent salt lines. Sections of receiver tubing and storage tank alloys were returned to Livermore for microstructural characterization. Particular attention was given to the development and structure of oxide products on the salt-exposed identification (ID) of these sections. Some evidence of stress corrosion cracking was observed earlier in the project in sections removed from the receiver.

\section{H.9 Receiver Tubing}

The Solar Two receiver utilized 24 panels in two flow circuits. Each panel was comprised of 32 tubes that were approximately $6 \mathrm{~m}(20 \mathrm{ft})$ long (Figure H-11). A representation of the flow panels and the salt flow are indicated in Figure H-12. Sections of the stainless-steel tubing were removed from four panels: W1, W3, W12, and E3. Specimens were extracted from tubes located at or near the edge of these four panels. Sections were then designated as "E" for edge. Furthermore, these sections were taken from either the mid-region of a tube, where the incident 
flux would be greatest, or from the top of the tube, where they were shielded from direct insolation. A second designation was then assigned as " $\mathrm{T}$ " or " $\mathrm{M}$ " for top or middle. Table H-6 identifies the tube sections examined and nominal salt exposure temperatures for typical operating conditions. Total time on sun was approximately 1500 hours over the course of the demonstration (December 1995 to April 1999).

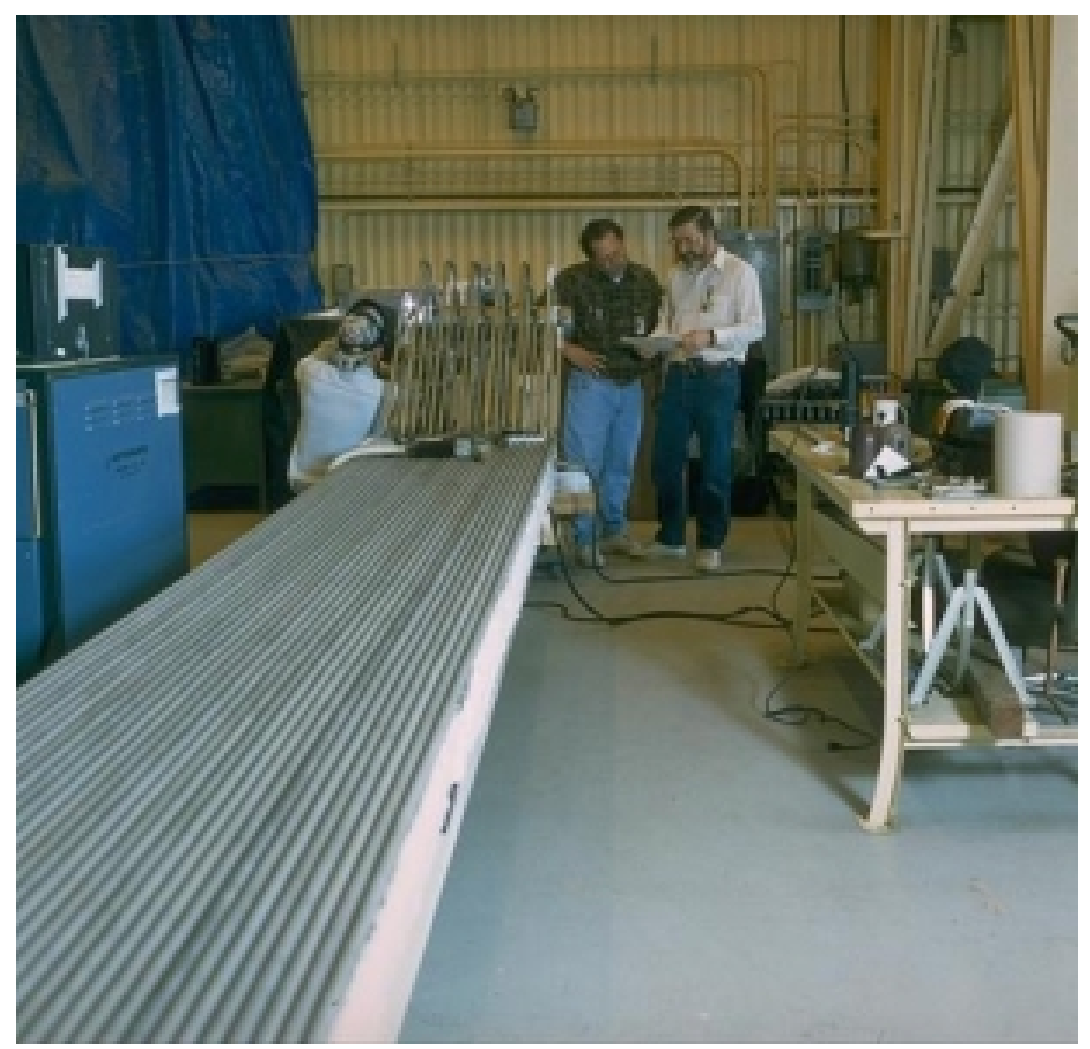

Figure H-11. Single panel from Solar Two receiver. Individual tubes can be seen in the foreground and the headers are in the background. This is before installation vertically into the receiver.

\section{H.9.1 Panel W12}

Two sections from Panel W12 were examined, as indicated in Table H-6. As a south-facing panel, it experienced the lowest incident solar flux. However, this panel experienced the highest salt temperatures during the duration of the demonstration experiment. The salt film temperature was also the highest for this panel. As a result of the high bulk salt and film temperatures, these specimens exhibited the most well-developed oxide structures of all of the specimens examined. Generally, the oxide film was found to be quite uniform in thickness (approximately 5-10 $\mu \mathrm{m}$ ) and generally adherent to the alloy substrate. Figure H-13a is a scanning electron micrograph and shows an example of the oxide structure on the ID of specimen W12-EM. In this particular location, the oxide structure exhibited a striated appearance that was somewhat different than prior studies have shown to be the most common morphology (Goods, 1983a, Goods, 1985). In these previous studies, nitrate-salt induced oxide films on austenitic stainless steels were usually duplex in nature and consisted of a salt-contacting surface scale that was predominantly iron oxide and a subsurface oxide that was an iron-chromium spinel. Figure H-13b shows the 
Pyromark coating on the tube ID. Generally, the Pyromark was found to be intact and adherent. The residual thickness of the coating is approximately $10 \mu \mathrm{m}$.

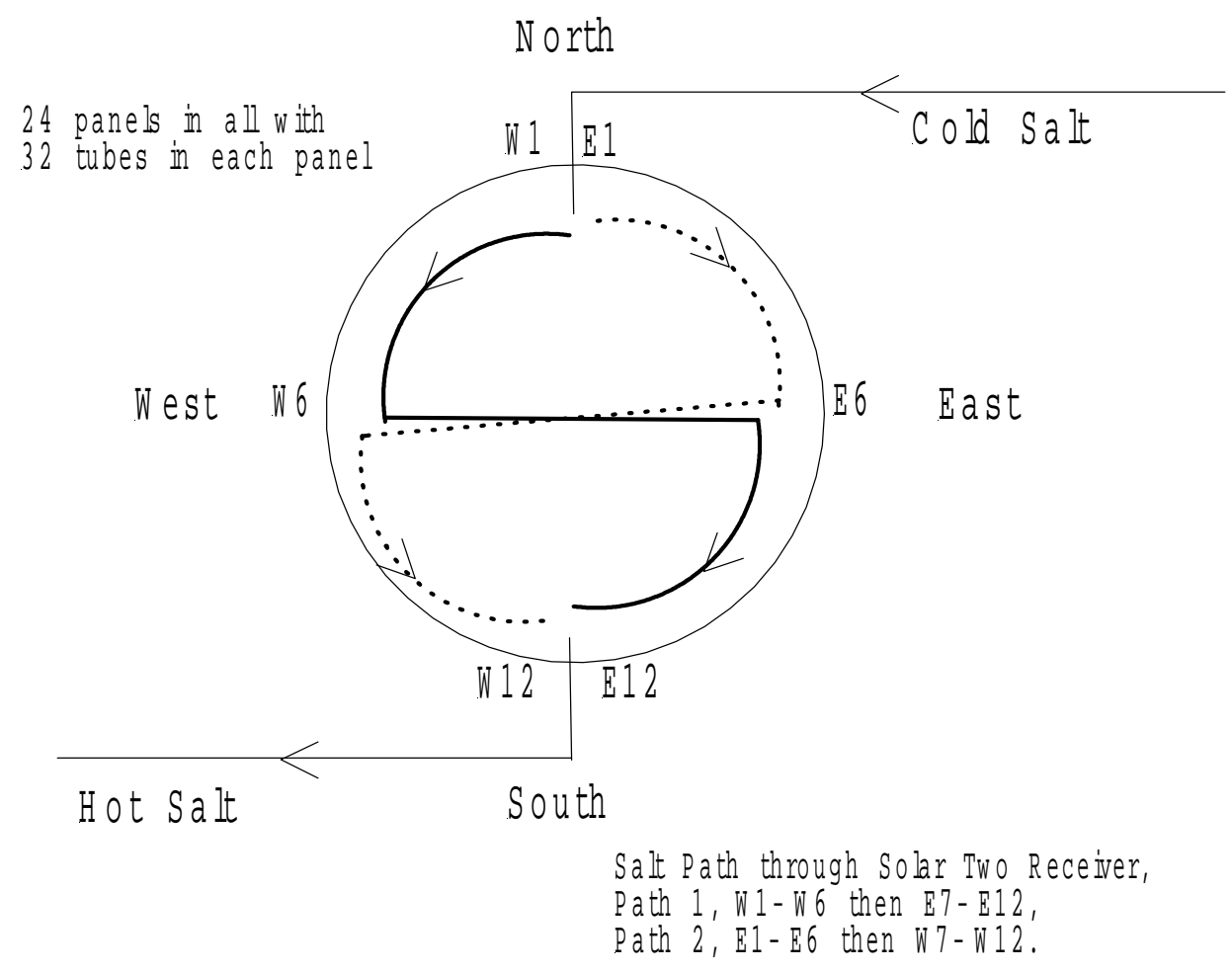

Figure $\mathrm{H}$-12. Overhead schematic of Solar Two receiver salt flow paths.

Table H-6. Specimen identification, location, and operating characteristics

\begin{tabular}{lllccc}
\hline \hline \multirow{2}{*}{$\begin{array}{l}\text { Specimen } \\
\text { Designation }\end{array}$} & \multirow{2}{*}{ Panel } & Specimen & \multicolumn{3}{c}{ Tube Exposure Conditions $\left({ }^{\circ} \mathrm{C}\right)$} \\
\cline { 4 - 6 } & & Location & Salt Inlet Temp & Salt Outlet Temp & Film Temp \\
\hline W12-EM & W12 & Middle & 559 & 566 & 593 \\
W12-ET & W12 & Top & 559 & 566 & 593 \\
W1-EM & W1 & Middle & 288 & 323 & 443 \\
W1-ET & W1 & Top & 288 & 323 & 443 \\
W3-EM & W3 & Middle & 356 & 390 & 496 \\
W3-ET & W3 & Top & 356 & 390 & 496 \\
E3-EM & E3 & Middle & 356 & 390 & 496 \\
E3-ET & E3 & Top & 356 & 390 & 496 \\
\hline \hline
\end{tabular}

Energy dispersive spectroscopy (EDS) was performed on the oxide shown in Figure H-13a at the locations indicated and revealed that the oxide structure was comprised of alternating layers of iron oxide and the spinel-like phase. The EDS spectra from these four locations are shown in Figure H-14. The areas of darker contrast (i.e., locations 2 and 4) correspond to the Cr-rich 
spinel structure, while the lighter contrast layers (locations 1 and 3) are depleted in chromium and only significant iron and oxygen peaks are seen.
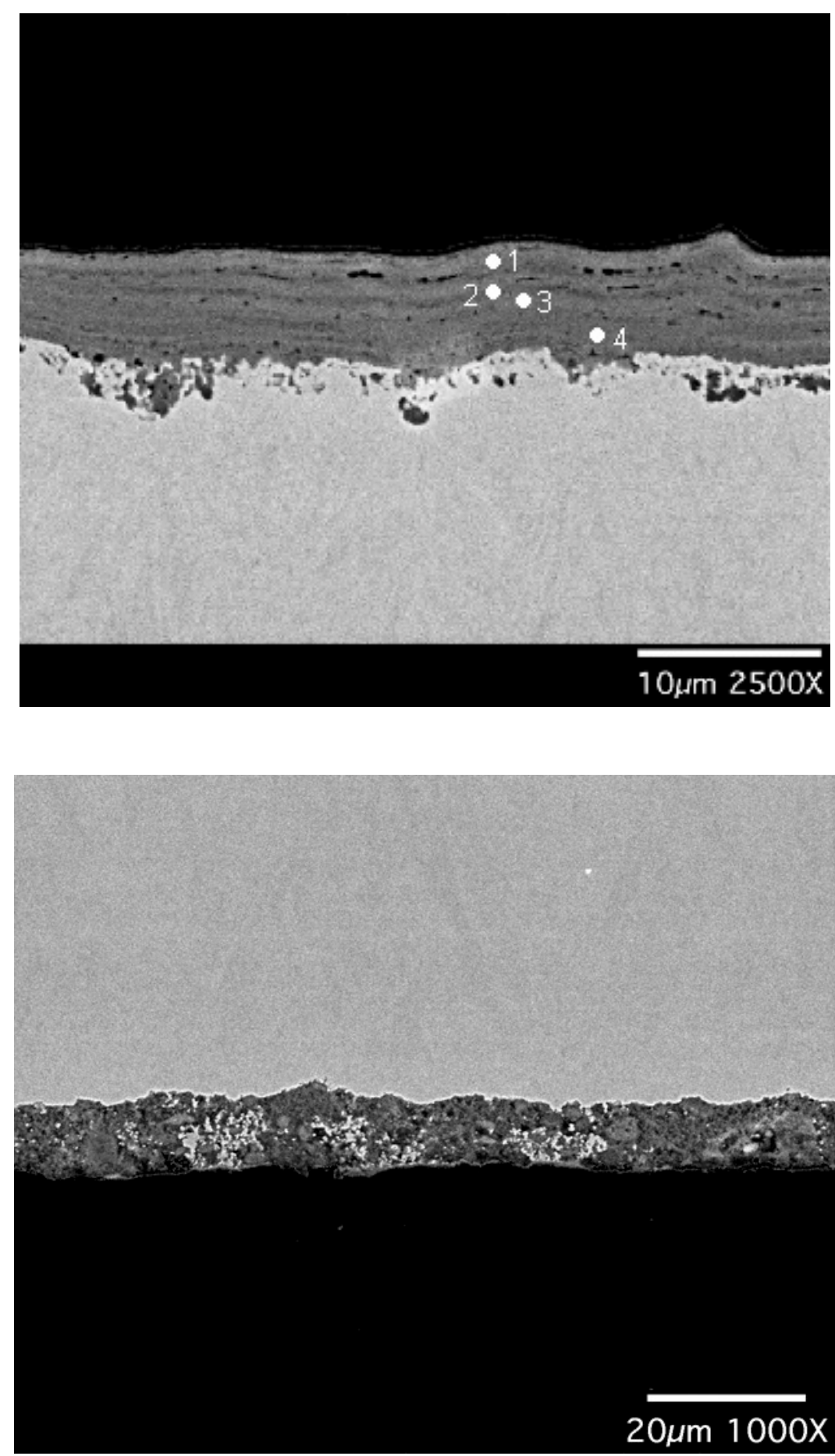

Figure $\mathrm{H}$-13. a) Oxide structure formed on sample W12-EM inner diameter. b) Pyromark on sample W12-EM outside diameter. 

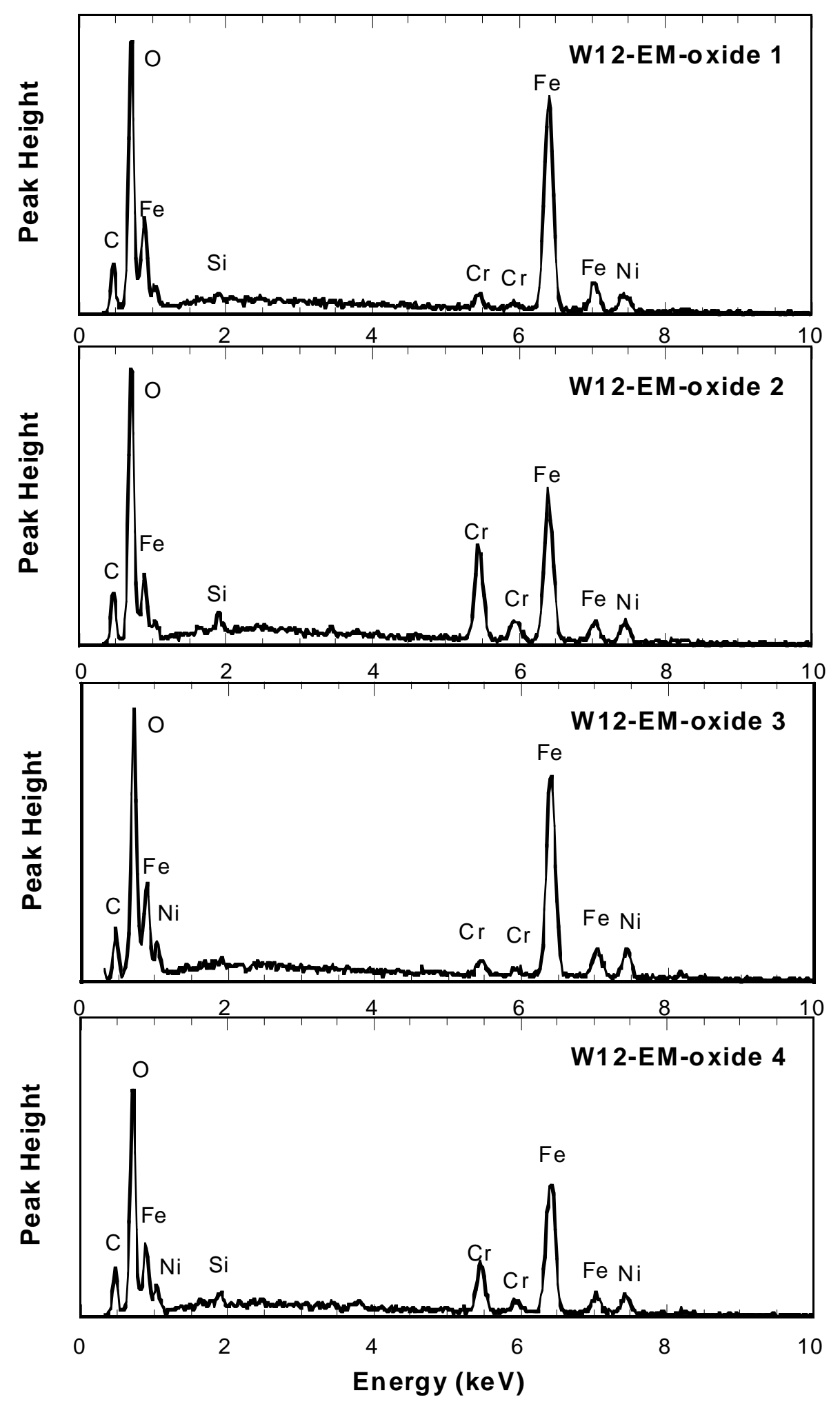

Figure $\mathrm{H}-14$. EDS spectra from the locations indicated in Figure $\mathrm{H}$-13a reveal that oxide is composed of alternating layers of iron oxide and iron-chromium spinel. 
An example of the more usual duplex structure is shown in Figure H-15 (also for W12-EM). Here, the oxide is approximately $5 \mu \mathrm{m}$ in thickness. While the contrast on the micrograph is not pronounced, the associated EDS spectra shown Figure H-16 reveals the more typical structure consisting of an outer iron oxide (location 5) and an inner Fe-Cr spinel (location 6). This duplex structure occurs because $\mathrm{Cr}$ is soluble in the salt mixture. Thus, as $\mathrm{Cr}$ dissolves into the salt, the outer oxide contains only iron. The peak associated with aluminum is probably an artifact resulting from the polishing compounds used during sample preparation.

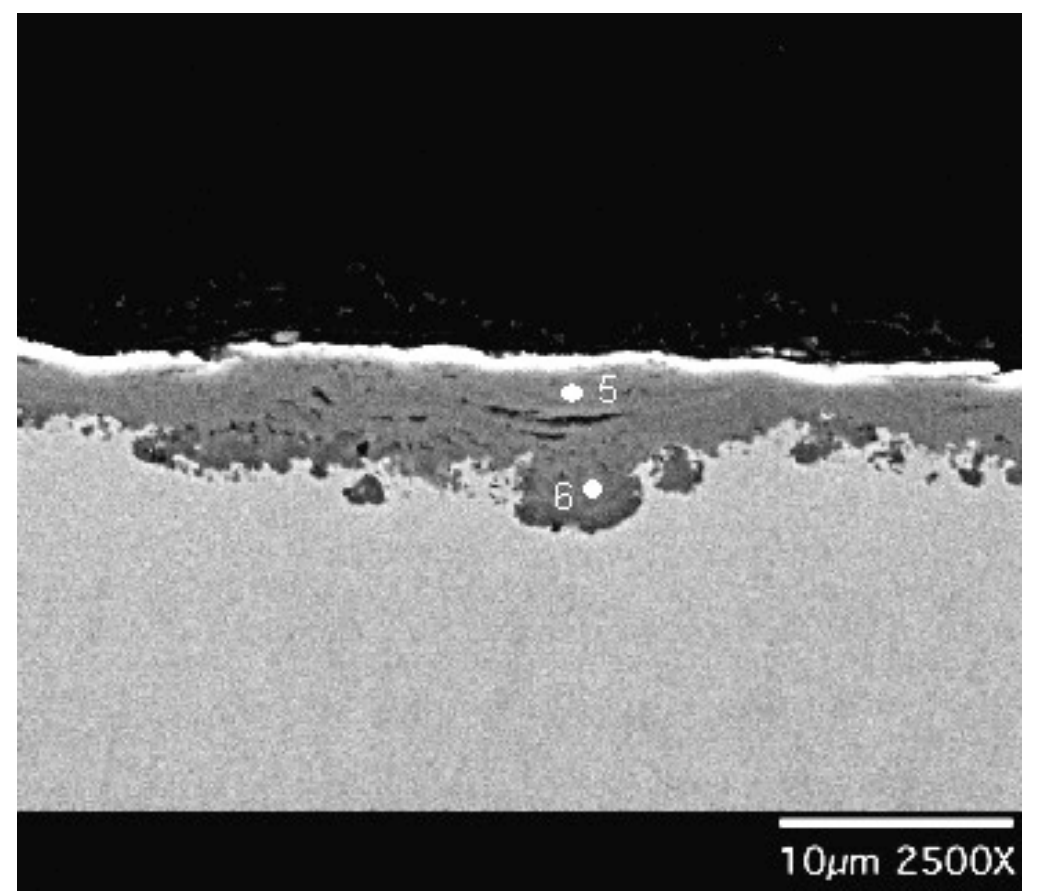

Figure $\mathrm{H}$-15. Oxide structure from different region of W12-EM.

The micrographs and EDS analyses presented above were from the ID of that portion of the tube facing "outward," that is, exposed to the solar flux (except Figure H-13a). The entire 360 degrees of the tube ID was examined and there was no appreciable difference in either the structure or composition of the oxide relative to its location with respect to the incident flux.

The oxide structure from a specimen extracted from the top of this tube is shown in Figure H-17 (specimen W12-ET). Here, too, the oxide has the more typical duplex structure commonly observed for $316 \mathrm{SS}$ after extended exposure to nitrate salt. Once again, the EDS spectra shown in the following figure (Figure H-18) reveals that the outer, salt-exposed oxide is iron-based, while the inner oxide is a Fe-Cr spinel.

\section{H.9.2 Panel W1}

The salt exposure temperature for Panel W1 was low, as indicated in Figure H-17. Bulk salt temperature varied between $288^{\circ} \mathrm{C}$ at the inlet to $323^{\circ} \mathrm{C}$ at the outlet. The salt film temperature was also quite low, at $443^{\circ} \mathrm{C}$. As a result, there was very little oxide observed on any of the tube 
sections from this panel. As an example, Figure H-19a shows the ID of specimen W1-EM. Only very thin, discrete islands of oxide were observed. The oxide film was never more than about $0.5 \mu \mathrm{m}$ in thickness and, as a result, EDS analysis for the purpose of determining oxide composition was impractical. Figure H-19b shows the residual Pyromark coating on the tube ID to be intact and adherent. In this instance, the coating was about $20 \mu \mathrm{m}$, approximately twice the thickness found on specimen W12-EM. As for the panel W12 specimen, the entire 360 degrees of the tube ID was examined and, there was no appreciable difference in the appearance of the oxide relative to its location with respect to the incident solar flux. Figure H-20 shows a similarly thin oxide film for the inner diameter of specimen W1-ET. At the very high magnification, an interface along the midline of the oxide film suggests that it may have the characteristic duplex structure. However, as for the previous specimen, the oxide structure was too thin to characterize using conventional EDS techniques.
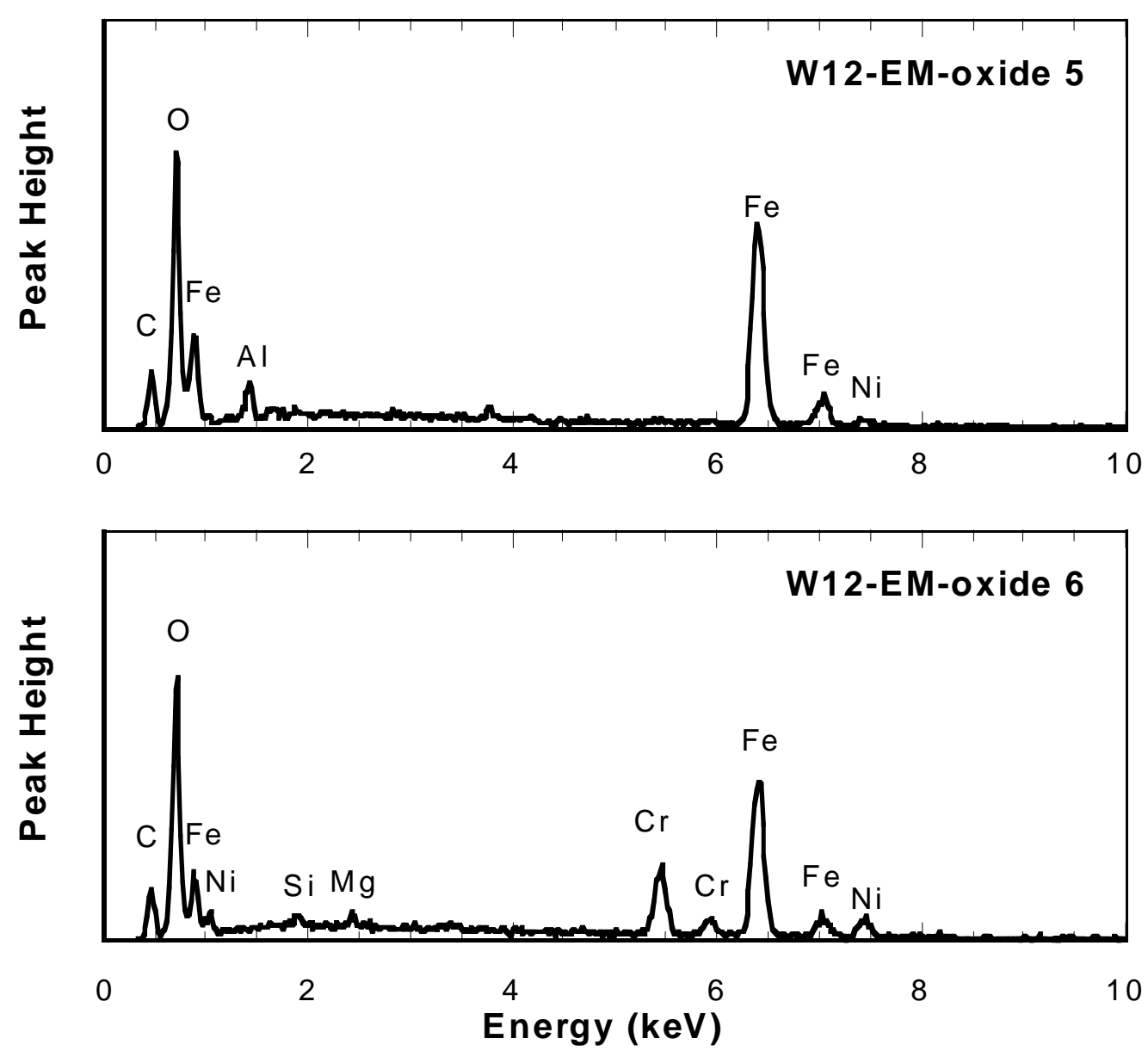

Figure $\mathrm{H}$-16. EDS spectra for oxide structure shown in Figure $\mathrm{H}-15$ reveal duplex oxide structures typical of long-term exposure of 316 SS in nitrate salts. 


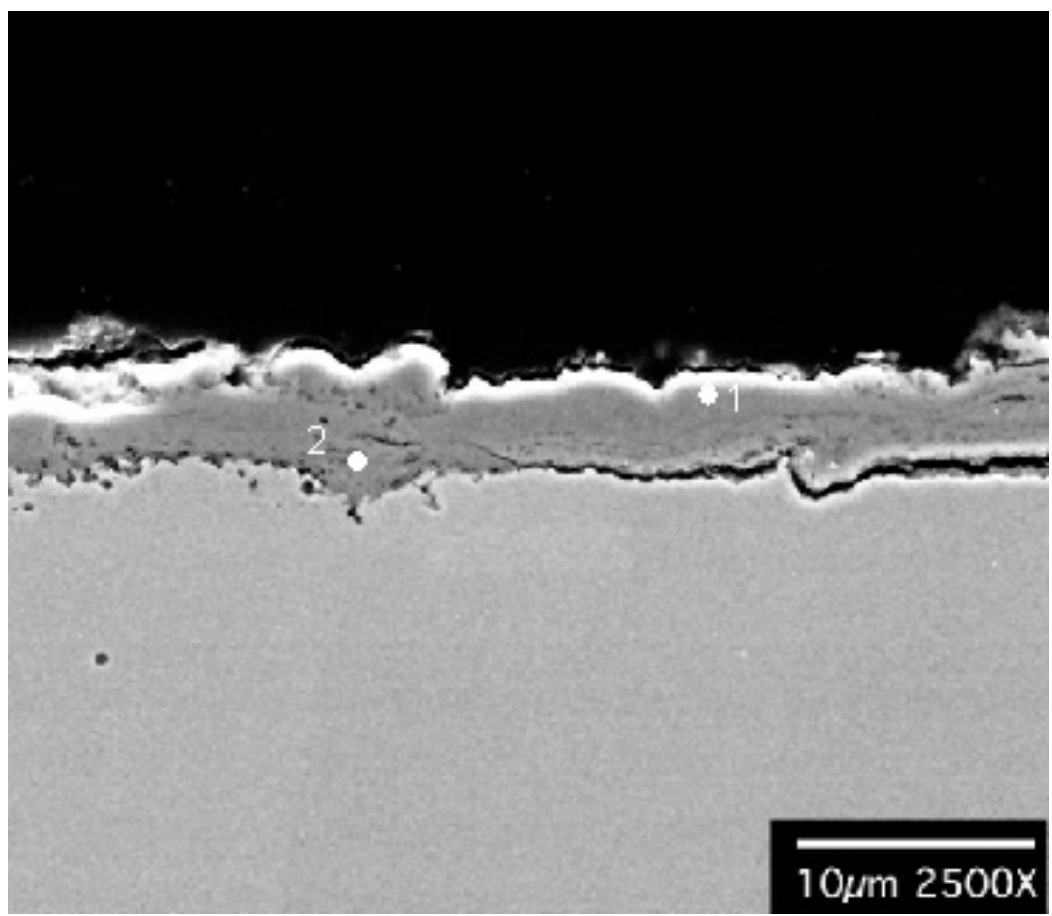

Figure H-17. Oxide structure from W12-ET.

\section{H.9.3 Panel W3}

Tube sections extracted from Panel W3 experienced bulk salt and film temperatures that were between those of Panels W12 and W1. Scanning electron microscopy of these tube sections revealed very little oxide formation. The oxide film shown in Figure H-21a for W3-EM is typical of that found on the ID of the tube section examined. As before, the oxide was only a few tenths of a micron in thickness and could not be elementally characterized by EDS techniques. Figure H-21b shows the Pyromark coating on the tubing ID to be intact, but relatively thin; only about 2-4 $\mu \mathrm{m}$. Specimen W3-ET was examined as well. In this instance, any oxide observed was less than $0.2 \mu \mathrm{m}$ in thickness. As such, no micrograph is shown.

\section{H.9.4 Panel E3}

Although the bulk salt inlet, outlet, and salt film temperatures were the same as that for Panel W3, there was a much more well-developed oxide present on the ID of the tube section E3-EM. Figure H-22a shows the characteristic oxide scale to be approximately $2-3 \mu \mathrm{m}$ in thickness. As with all of the previous tube sections, there was no appreciable difference in the appearance of the oxide relative to its location with respect to the incident solar flux. The Pyromark coating (Figure H-22b) was quite thick for this tube section, at $30-40 \mu \mathrm{m}$. As before, EDS analysis shown in Figure H-23 reveals the oxide to have the characteristic duplex structure described earlier with the salt-exposed, outer layer consisting of iron oxide and an inner layer that is a iron- 
chromium spinel. Note the presence of calcium in the scale. Calcium was present in the bulk salt as an impurity and, in this instance, has been incorporated in the structure of the oxide.
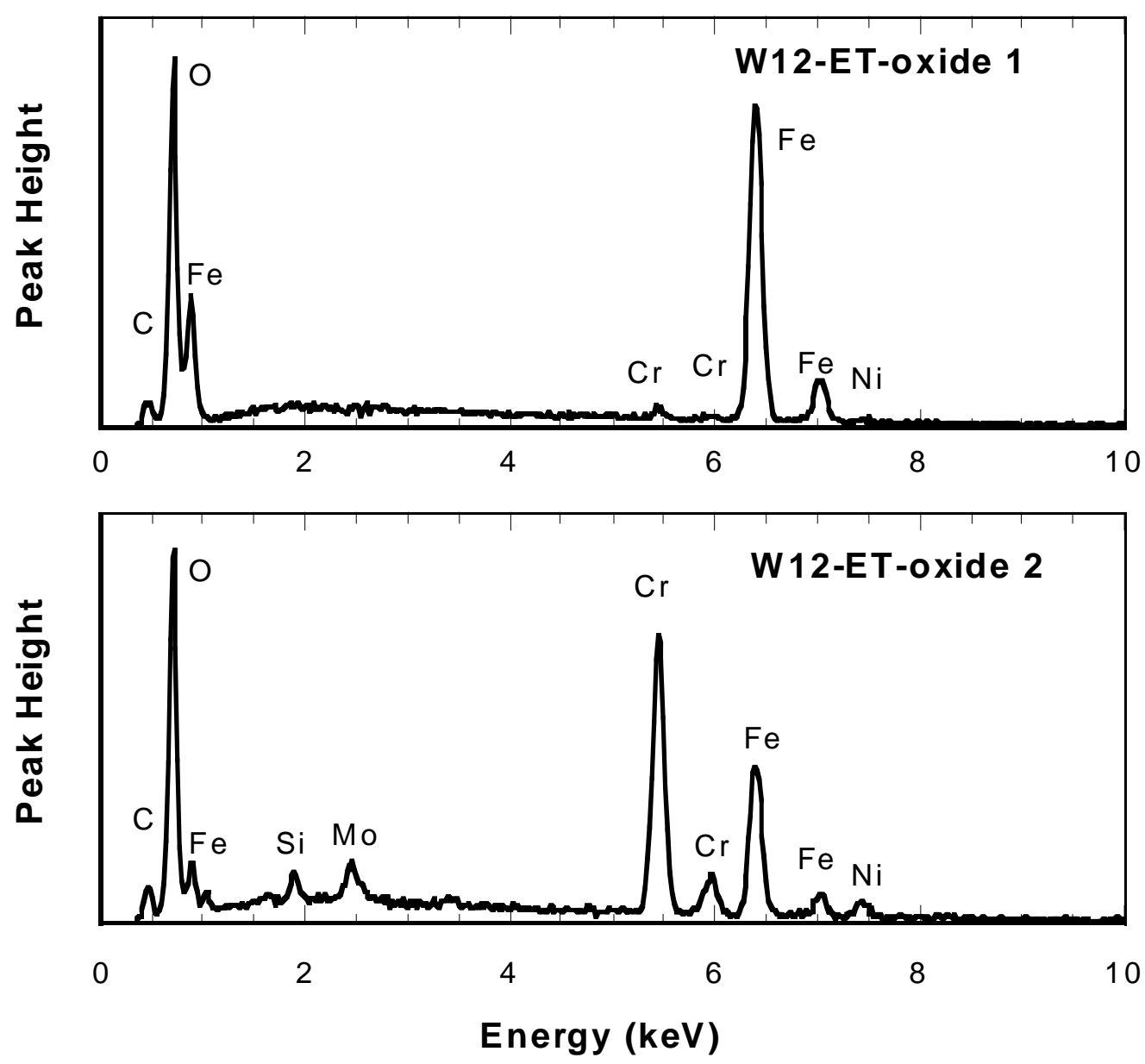

Figure $\mathrm{H}$-18. EDS spectra for oxide structure shown in Figure $\mathrm{H}-17$ reveal a duplex oxide structure typical of long-term exposure of 316 SS in nitrate salts.

Significant amounts of SCC were observed in this specimen as well. This cracking was not initiated by salt exposure. Rather, it initiated from the combination of the sensitized alloy at service temperature, chloride impurities in the nitrate salt mixture, and an aqueous flush of the receiver early in the operation of Solar Two. Figure H-24 shows a cross-section from a SCC region of this specimen. Since the grain boundary cracks were open to the ID of the tube, salt was able to freely penetrate to the crack roots. As a result, the cracks were "filled" with oxide. It is interesting to note that the crack tips are sharp, as is typical for SCC. It does not appear that salt exposure has resulted in much, if any, further extension of the SCC cracks. Previous work that examined fatigue crack growth of stainless steels in salt revealed that under cyclic loading sufficient to advance a fatigue crack, oxidation due to salt-exposure tended to blunt the crack tip (Goods, 1983b). Thus, the sharpness of the cracks shown in Figure H-24 suggests that the thermomechanical fatigue environment experienced by the receiver generated stress amplitudes 
sufficient to propagate these SCC cracks. More importantly, the sharpness of the crack tips suggests that salt-induced oxidation did not extend the cracks beyond their initial depth.

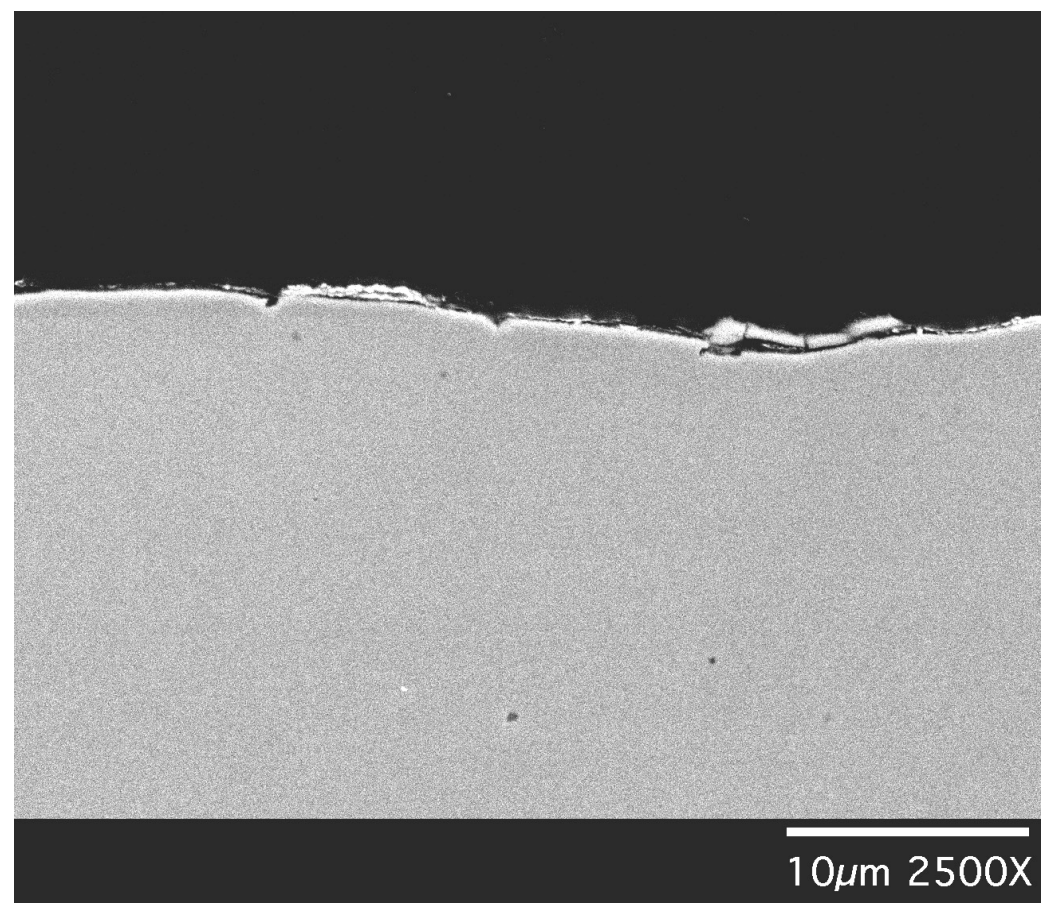

a)

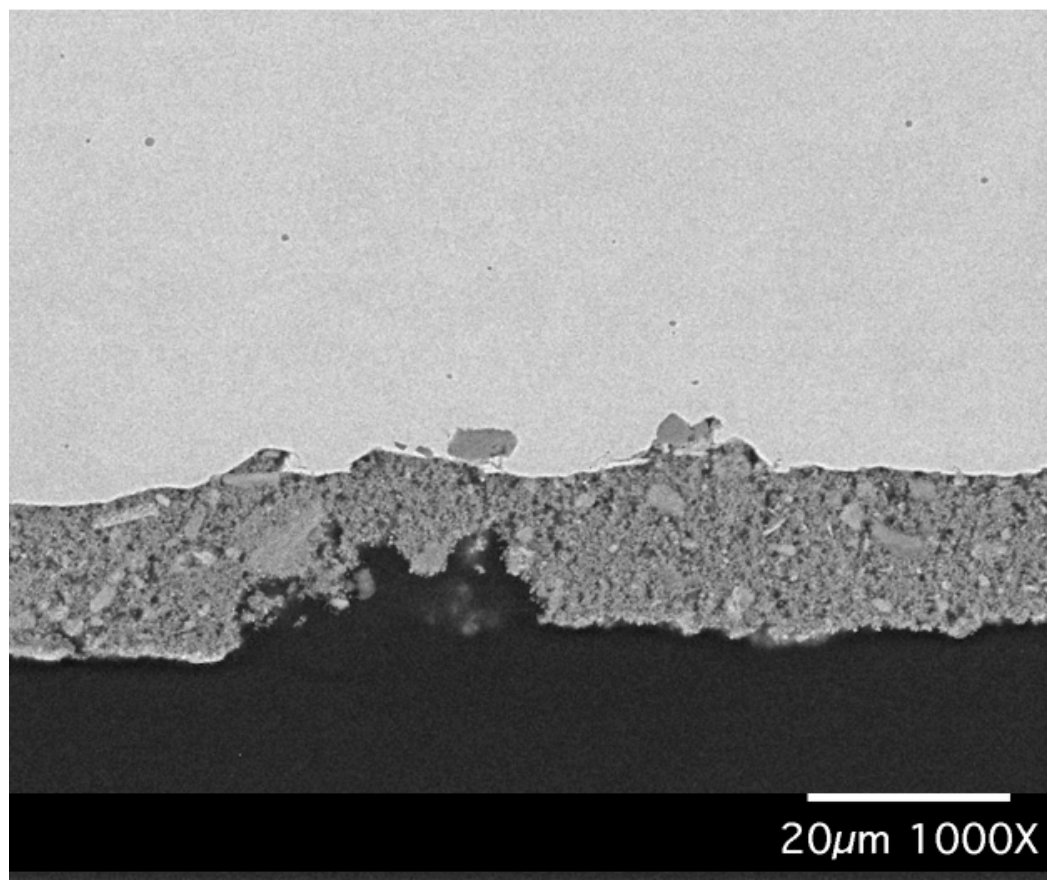

b)

Figure H-19. a) Minimal oxide is on the salt-exposed ID of specimen W1-EM. b) Pyromark on sample W1-EM. 


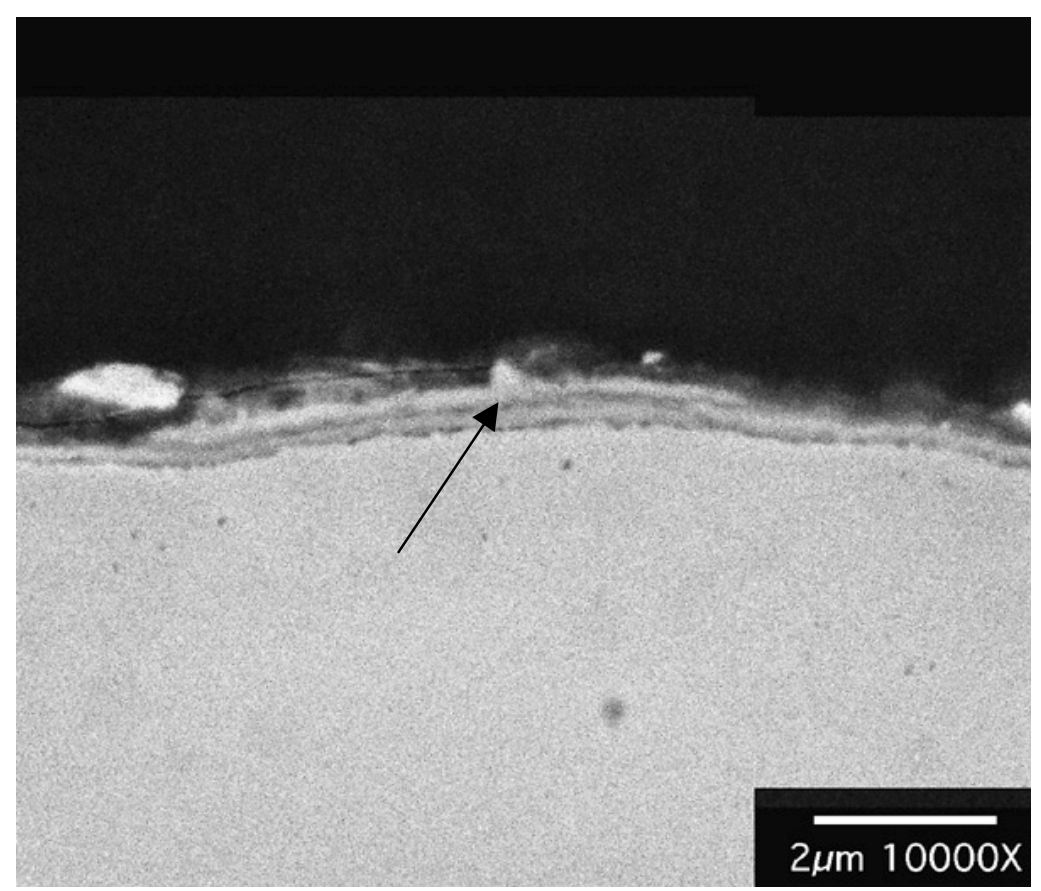

Figure $\mathrm{H}$-20. Very thin oxide film is typical for specimen W1-ET. The arrow indicates the location of interface within the oxide.

Surprisingly, the companion section, extracted from the top of the tube, E3-ET, exhibits only trace evidence of corrosion. In fact, the morphology of the oxide scale looks entirely like that for W3-EM and W3-ET. This suggests that the local temperature in the high flux region of this tube (i.e., E3-EM) was considerably higher than that where the flux was low (E3-ET). This region (E3-EM) happened to have been exposed to severe fluxes, perhaps over twice the design limit for several months due to a failure of the DAPS. See Section 3 for a discussion of the heliostat field operating experience.

\section{H.10 Storage Tank Alloys}

\section{H.10.1 Cold Tank}

The cold storage tank was fabricated from ASTM A516-70, a carbon steel, and the nominal salt storage temperature was $290^{\circ} \mathrm{C}$. Two sections were removed from the cold tank that had accumulated $>30,000$ hours of total contact time with salt. One section was from the lower portion of the tank and was therefore fully immersed in the low temperature salt for the duration of the demonstration. The second section was removed from a region nearer the top of the tank and was therefore not immersed in the salt during the operation of the plant. These sections are referred to as "CT(1), cold tank (lower)" and "CT(u), cold tank (upper)," respectively. The intent of removing these two sections was to identify potential issues associated with cyclic exposure and thermal cycling of the mild steel tank material. 


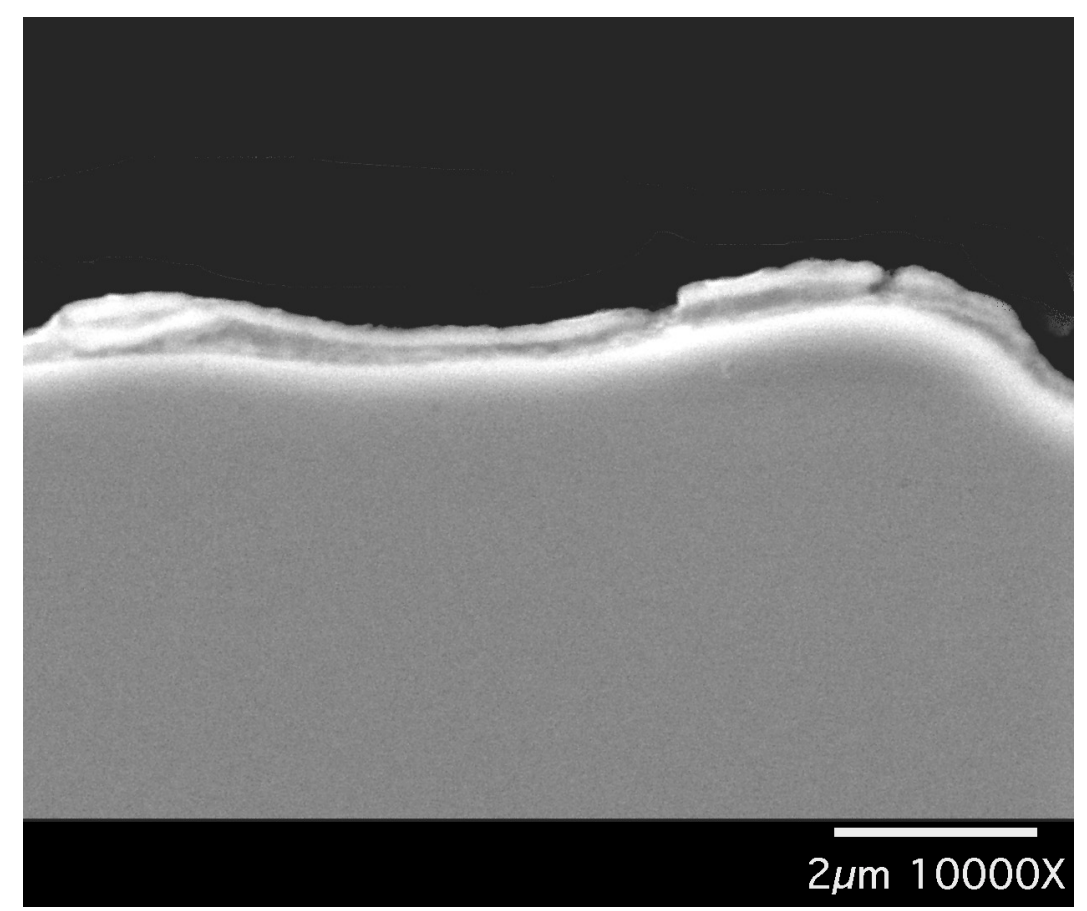

a)

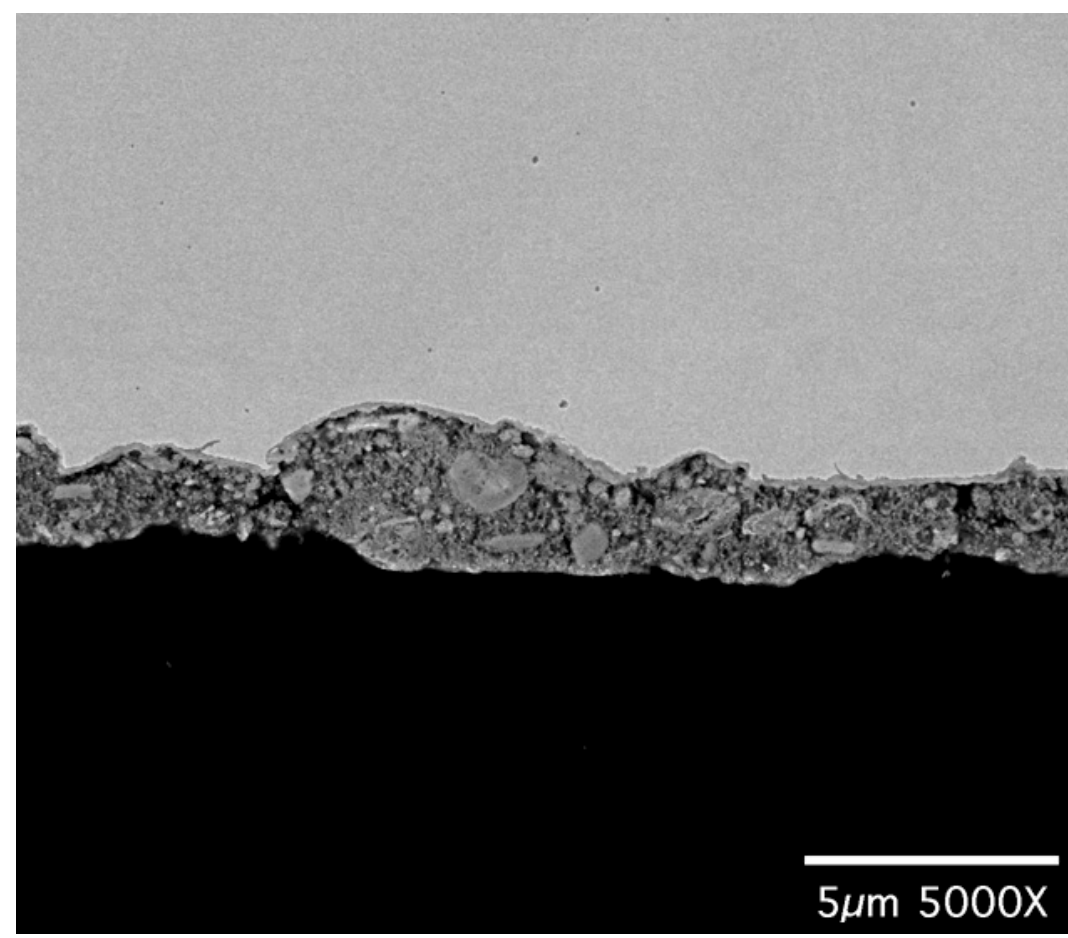

b)

Figure H-21. a) Very thin oxide film is typical for specimen W3-EM. b) Pyromark coating on tube ID remains intact for specimen W3-EM. 


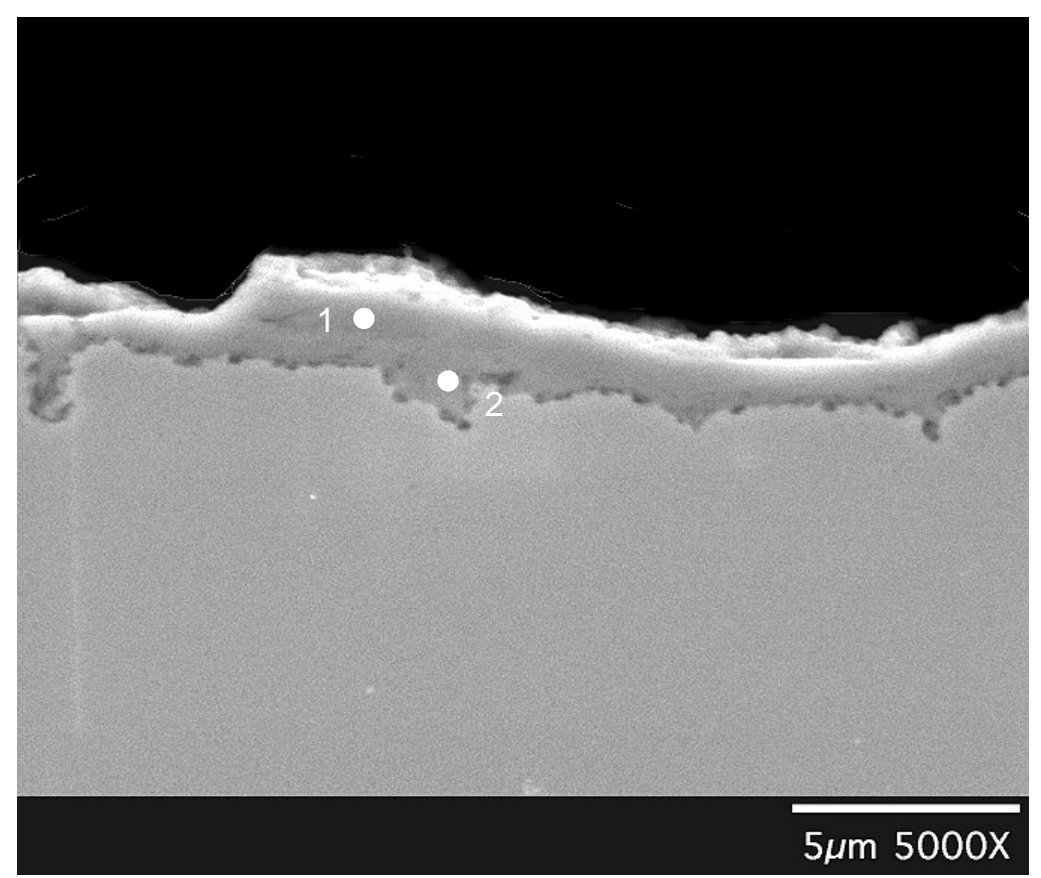

a)

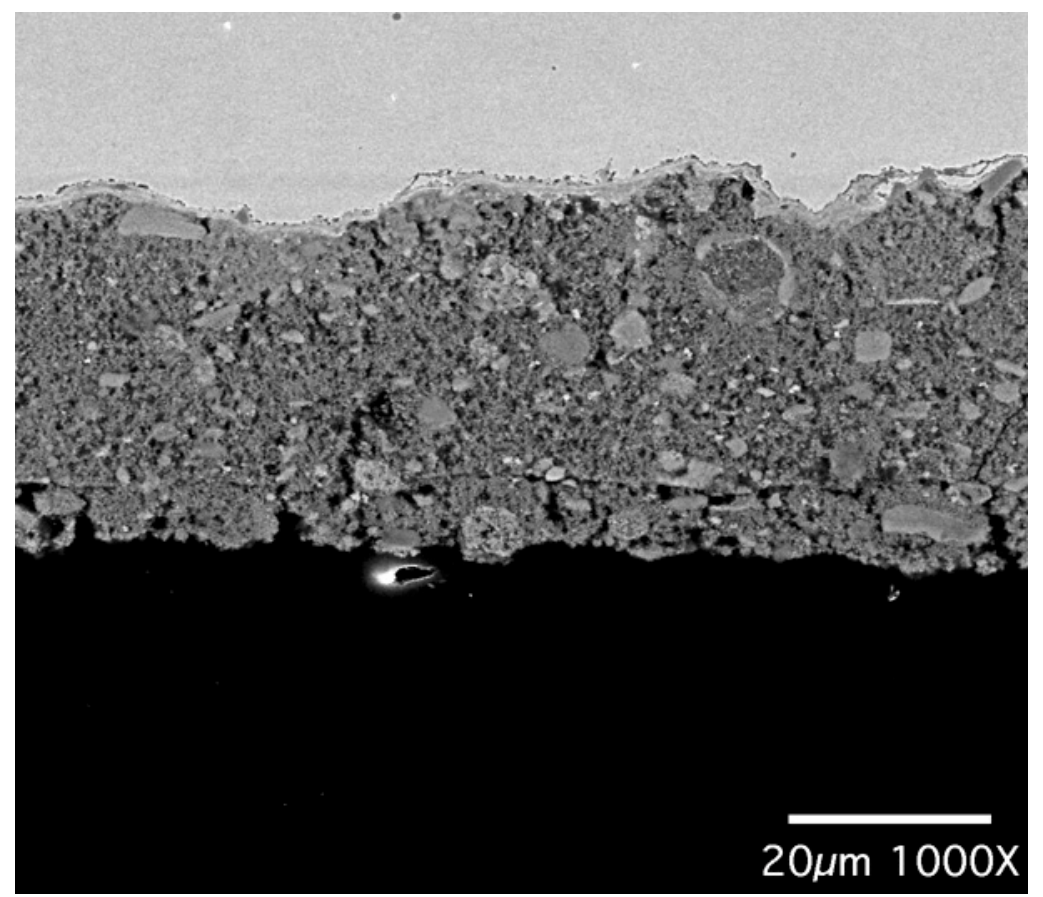

b)

Figure H-22. a) Oxide structure from E3-EM. Locations of EDS analysis are indicated. b) Pyromark coating. 

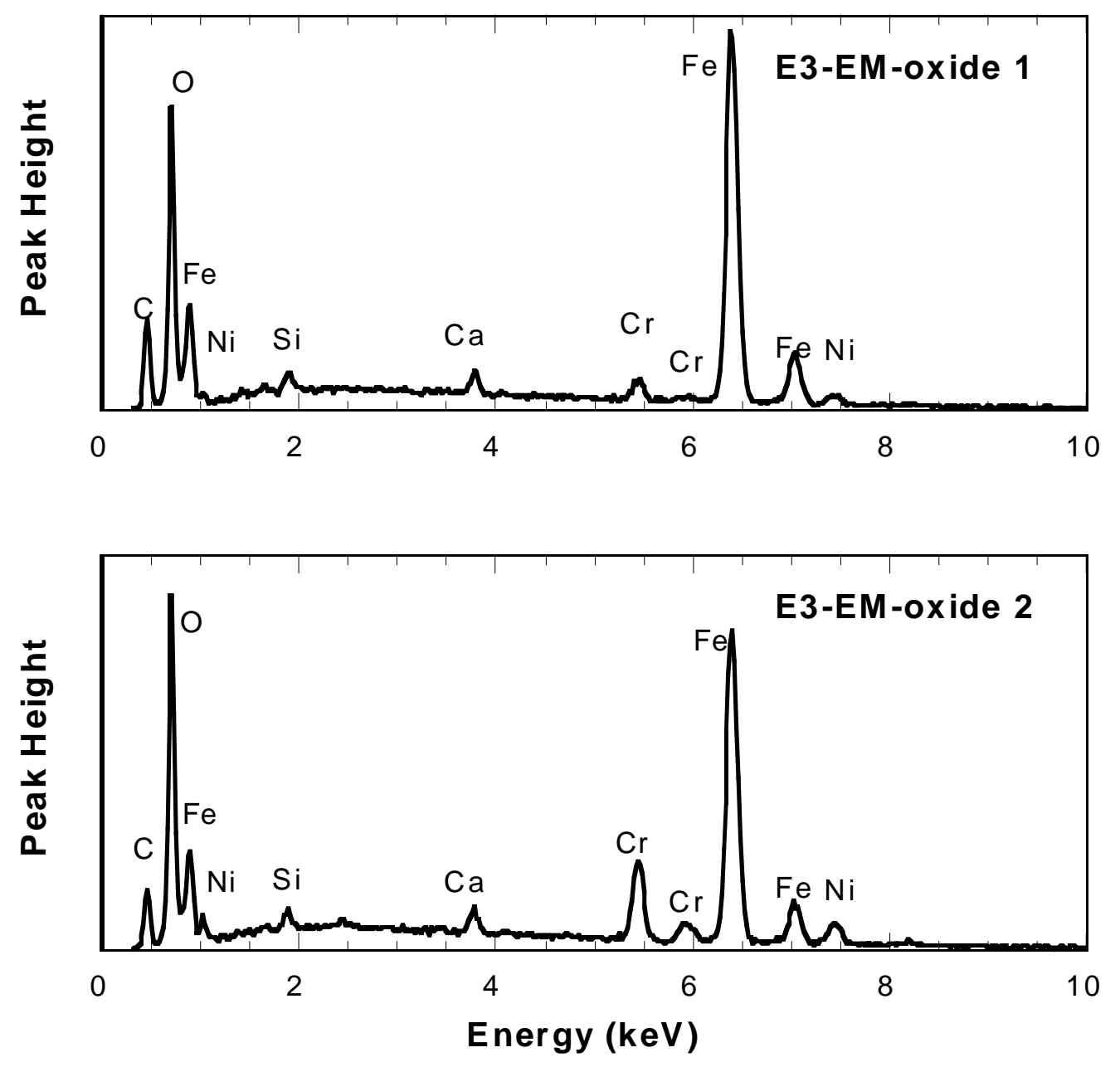

Figure H-23. EDS characterization of oxide film for specimen E3-EM reveals typical duplex structure. 


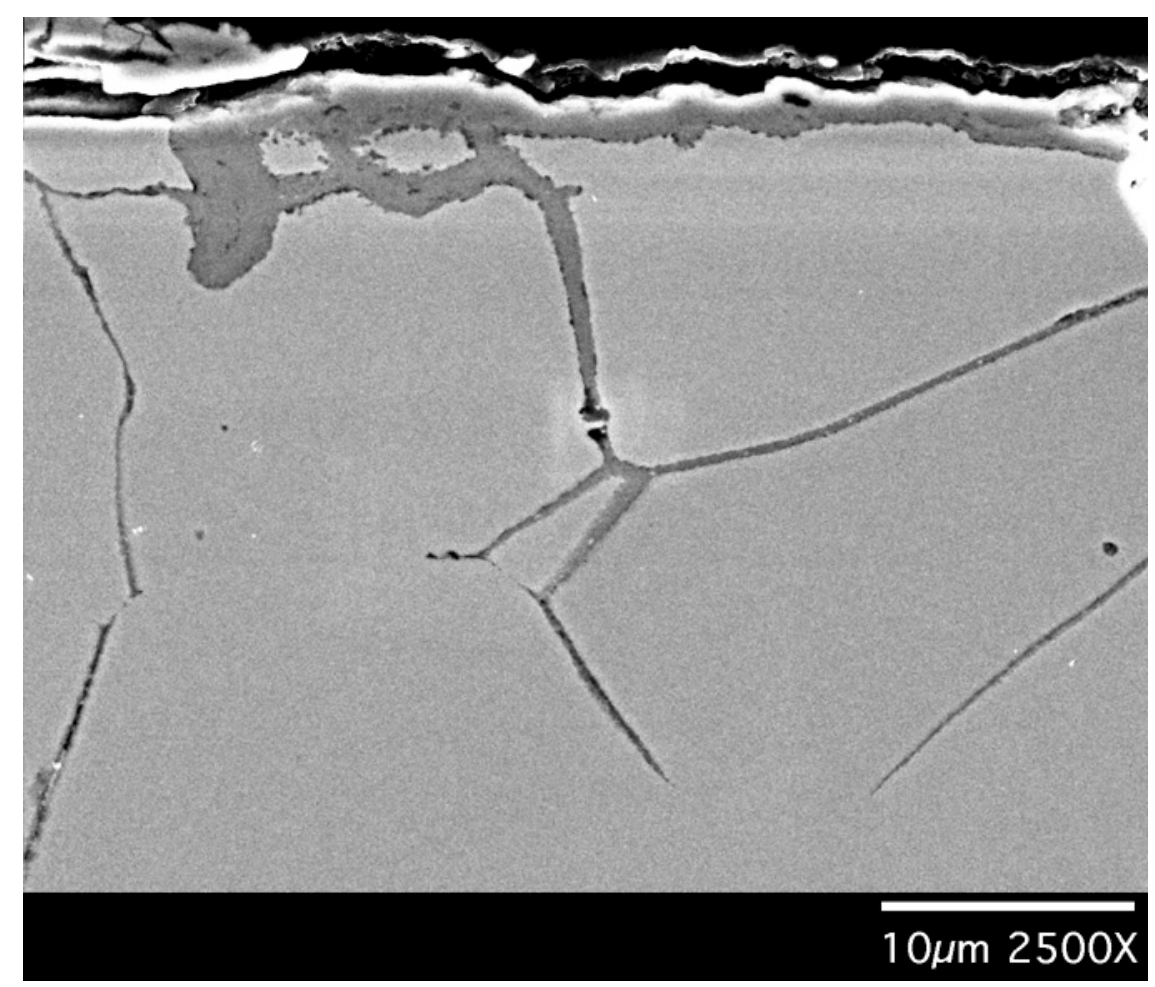

Figure H-24. Stress corrosion cracking is evident, having initiated at the tube ID for specimen E3-EM.

Figure H-25a shows a low-magnification image of a salt-exposed surface from the CT(1) section. The oxide was found to be continuous across the exposed surface and surprisingly uniform in thickness. On average, the oxide film was approximately $50 \mu \mathrm{m}$ in thickness. Prior experience has shown that oxides on mild or low alloy steels resulting from nitrate salt exposure can be prone to blistering and spallation down to the base alloy surface (Goods et.al., 1997). This blistering may be exacerbated at higher exposure temperatures and by high levels of chloride impurities. In the present case, no such blistering is apparent. Although the chloride level for the Solar Two salt mixture was relatively high $(\approx 0.5 \mathrm{wt} . \%)$, the low exposure temperature may have helped suppress the kinds of blistering previously observed.

While not blistered, the oxide film in the present instance is not adherent. In fact, much of the residual oxide film flaked off the surface before the section could be cut into small samples suitable for metallographic preparation. What remains, therefore, (and what is shown in Figure $\mathrm{H}-25)$ is only representative of a residual oxide that is partially adhered to the base metal. EDS analysis indicated that the oxide was comprised solely of iron and oxygen, which is expected for carbon steels. At higher magnification, Figure H-25b, the oxide is seen to be poorly bonded to the base metal. In certain areas, as much as $60 \%$ of the oxide-metal interface was cracked or decorated with voids. Notwithstanding this, there is every indication that the A516 steel is acceptable for extended salt containment. There was no evidence of any aggressive localized attack or anomalously high metal loss. 
The oxide film formed on the CT(u) section was identical in every respect to that discussed above for the continuously immersed CT(1) section, except that it was not as thick. At most, the residual oxide was only about $10 \mu \mathrm{m}$ in thickness.

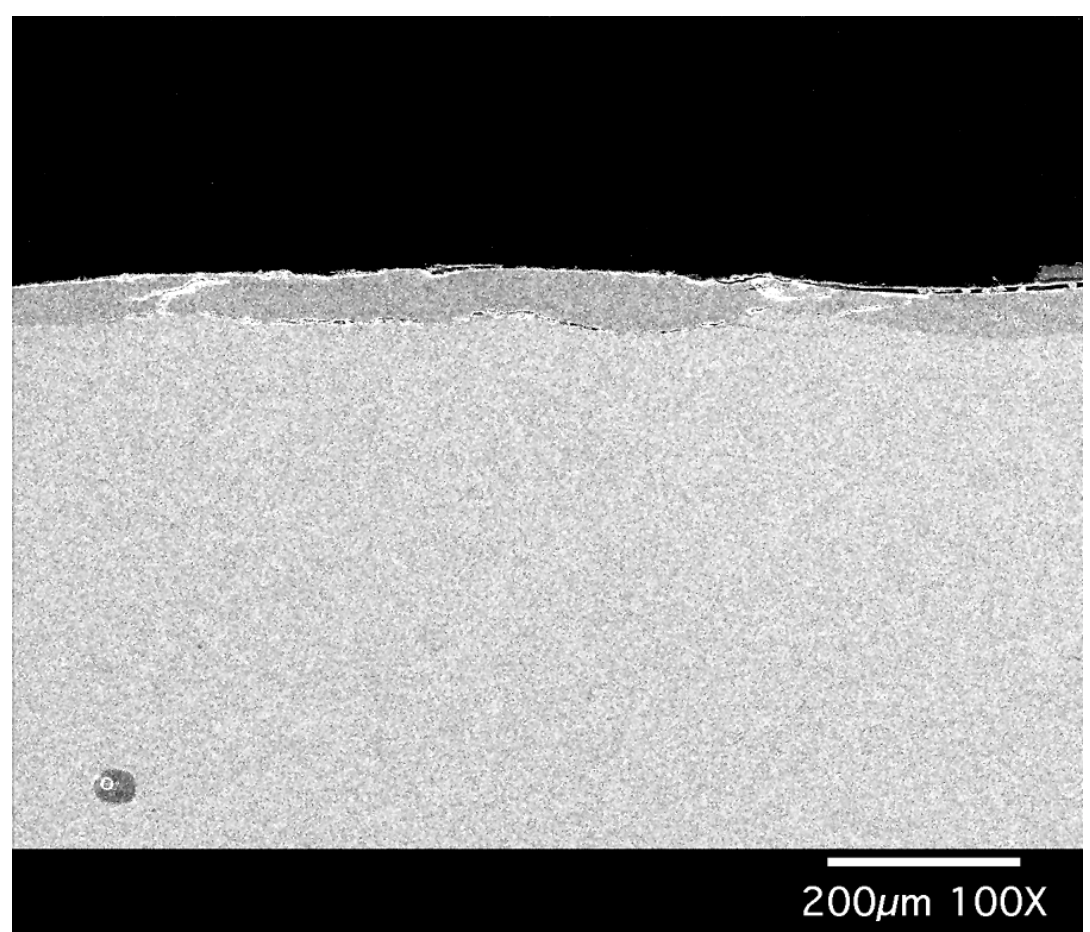

a)

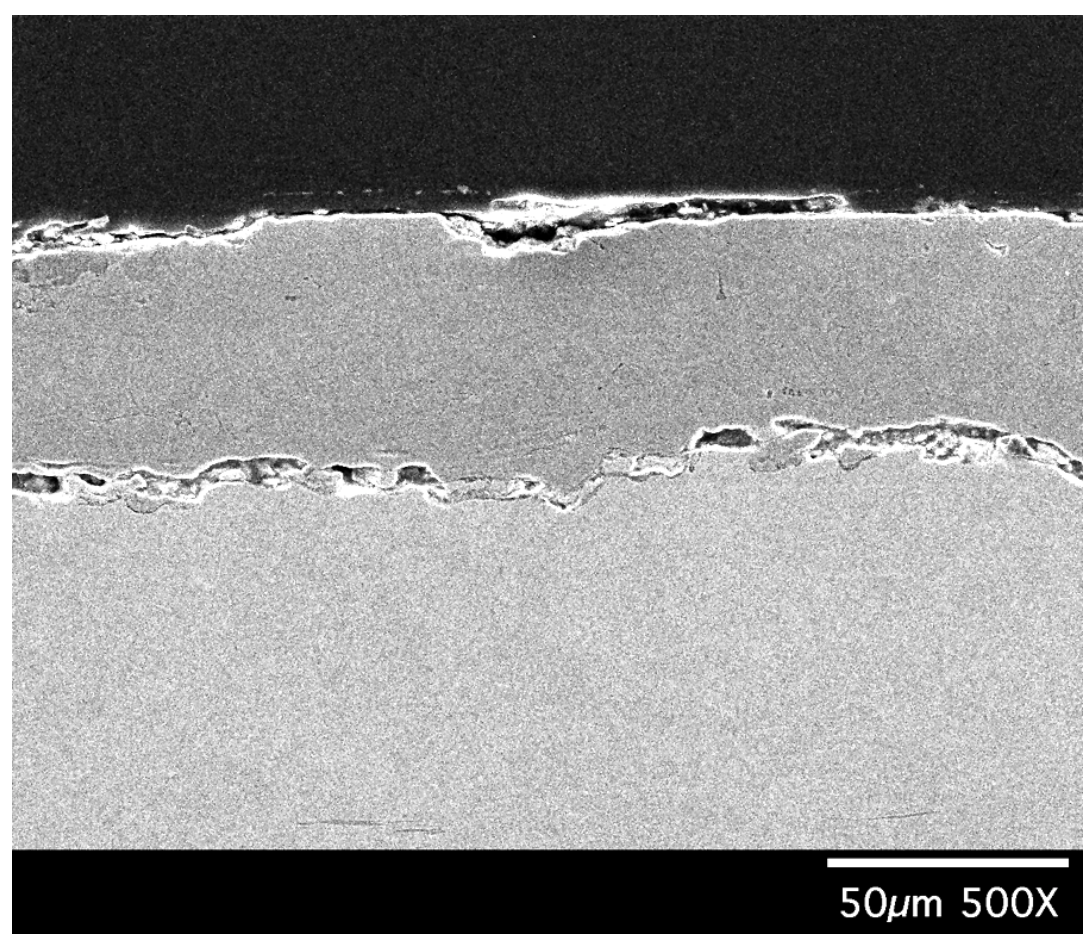

b)

Figure $\mathrm{H}-25$. a) Oxide film formation on cold tank (lower) specimen. b) Oxide metal interface shows cracks and porosity. 


\section{H.10.2 Hot Tank}

The nominal salt storage temperature in the hot tank was $565^{\circ} \mathrm{C}$ and the tank was fabricated from 304 SS. Here as well, two sections were removed for post-mortem analysis. As before, one was from the lower portion of the tank and was therefore continuously immersed in the high temperature salt, while the second was removed from a region near the top of the tank and not immersed in salt. These sections are referred to as "HT[1]" (for hot tank [lower]) and "HT[u]" (for hot tank [upper]), respectively.

As a general observation, the ID of the hot tank specimens from both regions had a scalloped appearance that was quite uncharacteristic of rolled steel sheet or a steel-plate surface. This appearance likely had its origins in the forming process used to shape the steel plate to the tank diameter. The scalloped features were on the order of $100-200 \mu \mathrm{m}$ in length. At high magnification, the ID also had a worked appearance, in that there were many shallow surface cracks that appeared to have been "hammered" or mechanically lapped closed.

The continuously immersed surface from the HT[1] section is shown in Figure H-26. The scalloped surface morphology described above is evident in the lower magnification micrograph, Figure H-26a. With regard to corrosion, only discrete islands of the characteristic salt-induced oxide were present on the ID of this specimen. This is especially surprising given the extended exposure time experienced by the containment alloy. All prior experience (Goods, 1983a, $1983 \mathrm{~b}, 1985)$ suggests that there should have been $20-50 \mu \mathrm{m}$ of a well-formed and adherent duplex oxide consisting of iron oxide and the spinel phase on the salt exposed surface. In the area shown in Figure H-26b, one of these discrete islands of oxide filled a shallow surface crack.

Figure H-27a shows the salt-exposed inner surface of a specimen from the HT[u] section of the hot tank. The feature in the upper right corner is part of the metallographic mount and not part of the specimen surface. This micrograph illustrates the scalloped surface morphology described above and also reveals the presence of a continuous, blocky, crystalline film on the salt-exposed surface. This deposit is more clearly seen in Figure H-27b. EDS analysis revealed this deposit to be composed solely of magnesium (an impurity in the salt) and oxygen. It is surprisingly tenacious, remaining intact throughout the sample preparation process. The presence of an $\mathrm{MgO}$ film on this surface and not on the continuously immersed surface suggests a mechanism that may account for its formation. Mixtures of sodium and potassium nitrate salt tend to creep over, and therefore wet, hot surfaces. So, although this upper portion of the hot tank was not immersed in salt, it was almost certainly wetted by it. A small amount of $\mathrm{Mg}\left(\mathrm{NO}_{3}\right)_{2}$ is present as an impurity in the salt and can decompose at elevated temperatures. The magnesium is then free to redeposition as $\mathrm{MgO}$ on the tank ID in the ullage space above the salt. As with the HT[1] section, the absence of a continuous oxide comprised of the nickel, iron, and chromium is noteworthy. Only discrete islands of the characteristic salt-induced oxide are present on the ID of this specimen and are, once again, typically associated with the partially-closed surface cracks. 


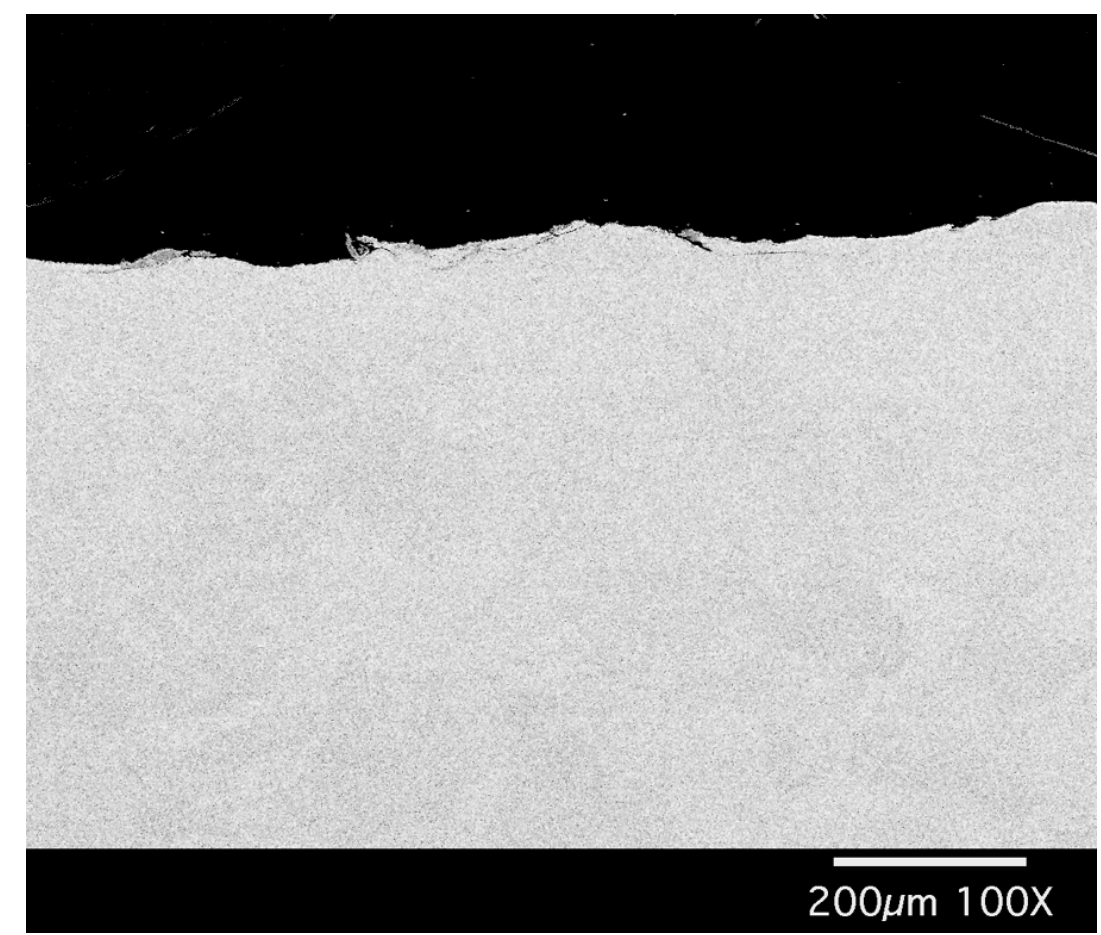

a)

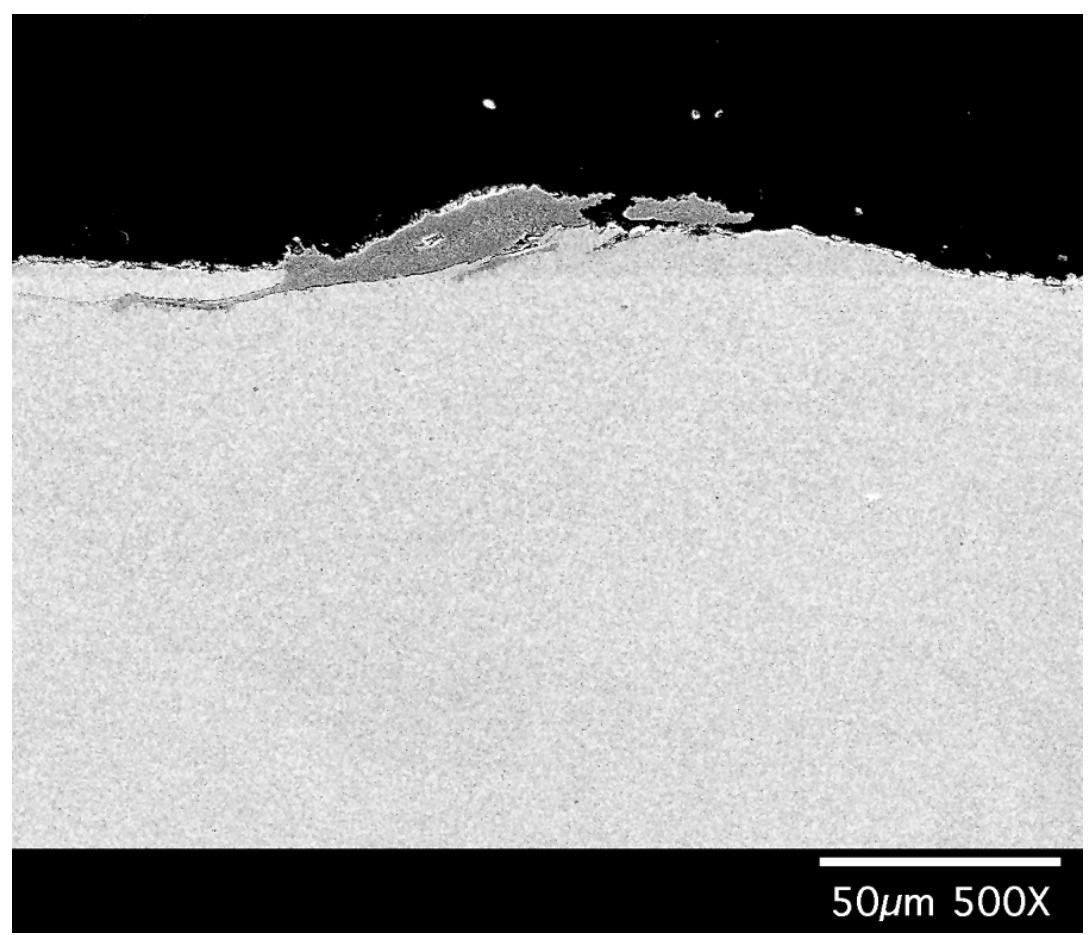

b)

Figure H-26. a) Oxide film formation on hot tank [lower] specimen. b) At higher magnification, only discrete islands of oxides were found. 


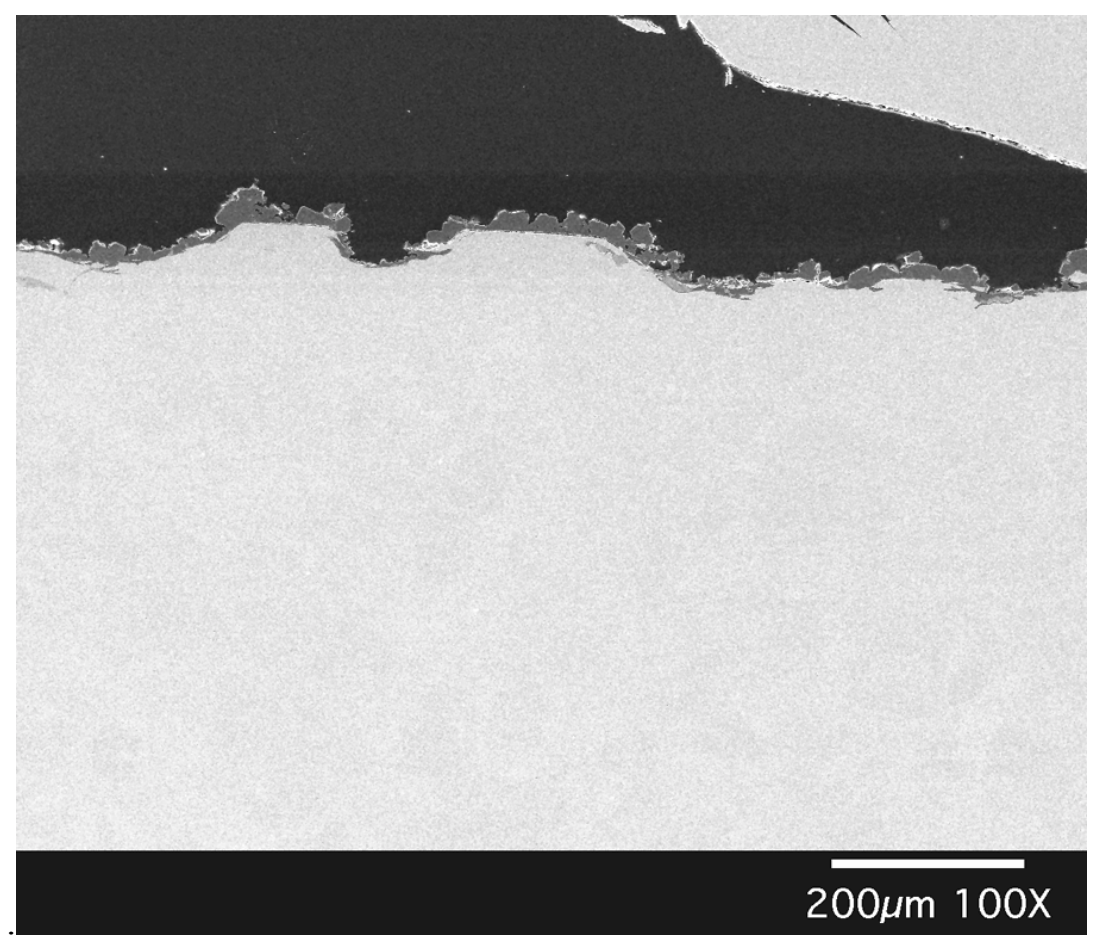

a)

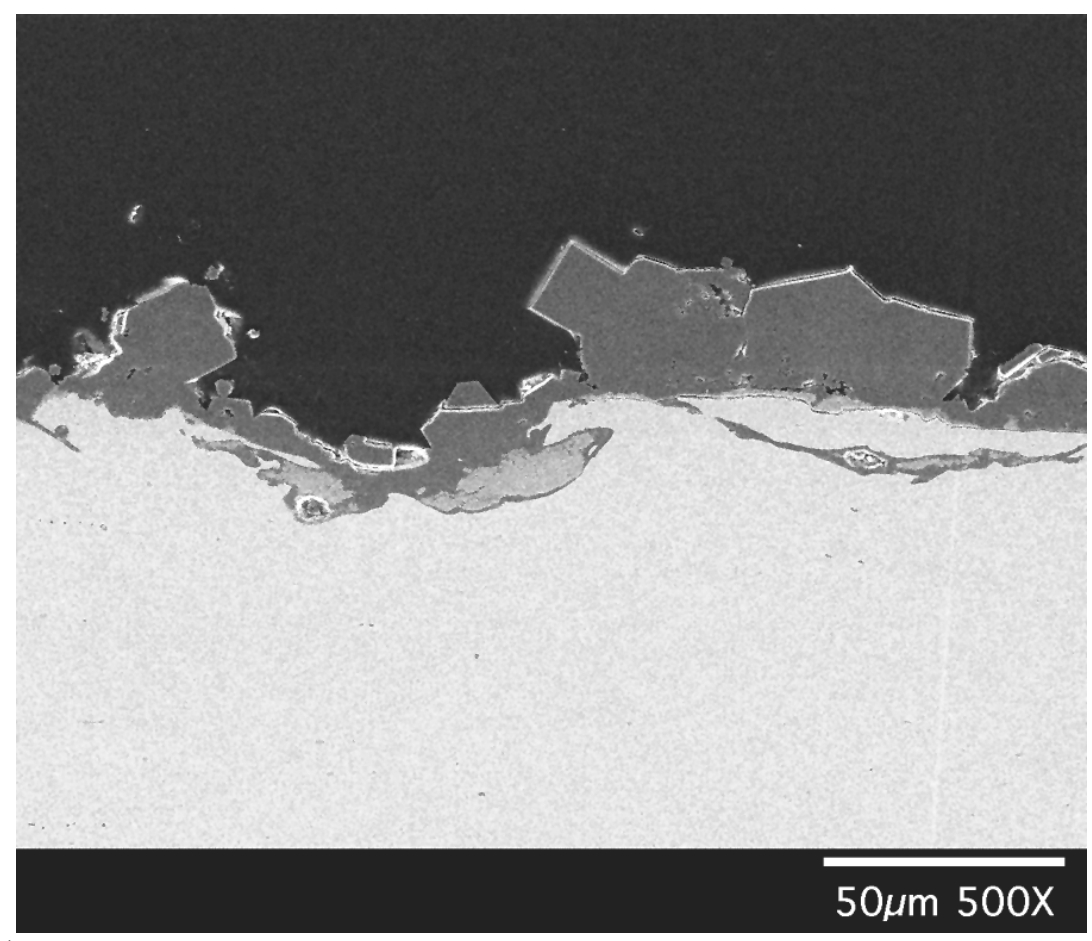

b)

Figure $\mathrm{H}-27$. a) Oxide film formation on hot tank [upper] specimen. b) High magnification reveals presence of $\mathrm{MgO}$ surface deposit. 


\section{H.11 Conclusions}

Salt-induced corrosion of the 316 SS receiver tubing formed of only very thin oxide films over the $\approx 1500$ hours of operation of the receiver. Even in the case of the highest bulk salt and salt film temperatures, oxide scales were never greater than approximately $10 \mu \mathrm{m}$. For tubes experiencing intermediate and lower temperatures, the oxide structures on the tube IDs were typically less than $3 \mu \mathrm{m}$. Corrosion occurred via a process of uniform surface oxidation, as is well-documented for austenitic stainless steels. The thermomechanical environment of the receiver structure did not affect this mode of oxidation or the rate of oxide film formation.

With regard to the alloys used to fabricate the storage tanks, here, too, corrosion occurred at an acceptably low rate. Not withstanding the $>30,000$ hour exposure time of the storage tanks, corrosion was minimal. No unusual features were noted with respect to oxide structure or oxidation products on the carbon steel used for the cold tank. For the hot tank, the singularly noteworthy observation was the presence of oxide films of only minimal thickness.

Salt-induced corrosion of the receiver and salt storage tank alloys poses no practical limitation on the useful life of these structures.

\section{H.12 References}

Goods, S. H. (1983a) J. Mater. Energy Sys, 5, 28. Goods, S. H. (1985) in High Temperature Corrosion in Energy Systems, p. 643, M. F. Rothman, Editor, The Metallurgical Society, Warrendale, PA. Goods, S. H. (1983b) Trans Metall, 14A, 314.

Goods, S. H., R. W. Bradshaw, M. R. Prairie and J. M. Chavez (1994) Corrosion of Stainless and Carbon Steels in Molten Mixtures of Industrial Nitrates, SAND94-8211, March 1994.

Goods, S. H., R. W. Bradshaw, M. Clift, and D. R. Boehme, (1997) The Effect of Silicon on the Corrosion Characteristics of 2 1/4 Cr-1 Mo Steel in Molten Nitrate Salt, SAND97-8269.

R. W. Bradshaw and S. H. Goods to G. J. Kolb, Sandia National Laboratories memo dated Dec. $5,1994$.

Nissan, D. A. (1981) The Chemistry of the Binary $\mathrm{NaNO}_{3}-\mathrm{KNO}_{3}$ System, Sandia National Laboratories, SAND94-8211, June 1981. 
Final Test and Evaluation Results from the Solar Two Project 


\section{Attachment 1 to Appendix H: Stre ss Corrosion Cracking Laboratory Tests - Supplementary Test (B. Bradshaw, S. Goods, D. Dawson)}

\section{Objectives}

A supplemental experiment was added to the coupon corrosion test to better understand the cracking of receiver tubes following a tube replacement operation. The tube replacement process involved an aqueous flush of the receiver. This operation resulted in contact between the thermally-sensitized stainless-steel tubing and an aqueous solution that contained dissolved chloride impurities derived from the molten salt residue in the tubes. These unexpected circumstances created an environment conducive to intergranular stress corrosion cracking (IGSCC) of these materials. These tests also compared the IG-SCC resistance of the stabilized stainless steel $347 \mathrm{SS}$, which could be used as an alternative in these components.

\section{Purpose}

The susceptibility of 300-series stainless steels (e.g., 316 SS and 304 SS) to SCC in aqueous environments that contain chloride ion impurities is well-documented in the corrosion literature. IG SCC is similarly well recognized, particularly for stainless steels that contain appreciable amounts of carbon. When such steels are heated into the temperature range characteristic of the upper operating temperature of the Solar Two system, grain-boundary carbide precipitation (sensitization) occurs. Sensitization of stainless steels severely degrades the resistance of these alloys to SCC, although the effect on molten salt corrosion is minimal (see Appendix H). The induction time before cracks in sensitized alloys appear depends on many variables, such as the composition of the alloy, prior heat treatment, operating thermal history, stress imposed, cycling variation of stress, etc., in addition to the environmental variables.

\section{Scope and Methods}

Corrosion and cracking behavior of several stainless steels were evaluated using ASTM G-1 and G-30 procedures. Samples were exposed in a salt-fog chamber at $35^{\circ} \mathrm{C}\left(95^{\circ} \mathrm{F}\right)$ for several hundred hours, as necessary, to cause cracking in susceptible material. The chamber was operated according to ASTM B-117, except that the concentration of $\mathrm{NaCl}$ in the aqueous feedwater was $0.5 \mathrm{wt} . \%$. This level of chloride exceeds the amount estimated to have been present when tubes or piping in Solar Two cracked. The specimens were exposed in several batches, as the chamber could not accommodate all of the samples simultaneously. Samples were removed periodically for inspection, after which all were returned for further exposure, except for the cracked samples. Inspection was performed using a $40 \mathrm{X}$ stereo microscope to examine the crown of the samples where the maximum stress was imposed.

Three types of samples were used; U-bends and C-rings for the stressed samples, and flat stock. Flat stock of all materials except 316 SS was used to provide a baseline for observing the corrosion response of the various heat treatments. Initially, these specimens were to be bent 
around a mandrel after exposure to the salt fog atmosphere, as a further evaluation of susceptibility to cracking. However, the post-chamber bending tests were not deemed necessary and were not performed. The elemental compositions of the sheets of $316 \mathrm{SS}, 304 \mathrm{SS}, 304 \mathrm{~L} \mathrm{SS}$, and 347 SS used to prepare SCC samples are specified in Table 1. U-bend samples of all types (except 316 SS) were fabricated by Metal Samples Co., Inc., Munford, AL, according to specifications in ASTM G-30 and ASTM G-58 (welded specimens). Considerable difficulty was encountered in obtaining 316 SS material suitable for making SCC samples that had a high carbon content (at least $0.05 \mathrm{wt} . \%$ ) similar to that of the tubing used in the Solar Two receiver. Sheet stock proved to be unavailable from any U.S. supplier. Thus, U-bend specimens could not be fabricated. However, a few short lengths of 3.8-cm (1.5-in.) diameter tubing were located and the composition verified by chemical analysis at a commercial laboratory. C-ring samples of this $316 \mathrm{SS}$, conforming to the ASTM specifications above, were prepared by Metaspec Co., San Antonio, TX. Samples of all of the stainless steels were fabricated from both wrought (parent) material and material that had an autogenous weld bead formed across the sample. U-bend and C-ring samples were stressed according to ASTM G-30 to produce maximum stresses that exceeded the yield value.

Table 1. Elemental Compositions of Alloys used to Fabricate Stress Corrosion Cracking Specimens (Wt. \% by analysis, balance Fe)

\begin{tabular}{lllllllc}
\hline \hline \multicolumn{1}{c}{ Alloy } & $\mathrm{C}$ & $\mathrm{Cr}$ & $\mathrm{Ni}$ & $\mathrm{Mo}$ & $\mathrm{Si}$ & $\mathrm{Mn}$ & Other \\
\hline 316 SS & 0.062 & 17.18 & 11.17 & 2.05 & 0.42 & 1.82 & -- \\
304 SS & 0.07 & 18.26 & 8.16 & 0.15 & 0.49 & 1.83 & -- \\
304L SS & 0.017 & 18.34 & 8.31 & 0.28 & 0.39 & 1.85 & -- \\
347 SS & 0.05 & 18.03 & 9.72 & 0.19 & 0.69 & 1.45 & $0.76 \mathrm{Nb}$ \\
\hline
\end{tabular}

The samples were heat-treated to ensure that controlled sensitized microstructures would develop and that these microstructures would overlap those expected to develop in the receiver tubes and hot-salt piping of the Solar Two plant. Types $316 \mathrm{SS}, 304 \mathrm{SS}$, and 304L SS were heated, in vacuum, for 20 hours at temperatures of $540^{\circ} \mathrm{C}\left(1000^{\circ} \mathrm{F}\right), 620^{\circ} \mathrm{C}\left(1150^{\circ} \mathrm{F}\right)$, and $705^{\circ} \mathrm{C}\left(1300^{\circ} \mathrm{F}\right)$. The intermediate temperature was intended to produce fully-sensitized material, while the other treatments only partially sensitized the material. In addition to the heating schedule applied to the other three steels, some samples of Type $347 \mathrm{SS}$ were heated to $1315^{\circ} \mathrm{C}\left(2400^{\circ} \mathrm{F}\right)$ to simulate a welding treatment in an attempt to produce a material susceptible to "knife-line attack," a particular form of corrosion that is possible in $347 \mathrm{SS}$.

\section{Results}

\section{SS C-rings}

The results of the SCC tests are summarized in Table 2. Cracking was only observed in a few cases, indicated by the shaded boxes in the table. Only welded samples of $316 \mathrm{SS}$ cracked. Of four samples sensitized at $620^{\circ} \mathrm{C}\left(1150^{\circ} \mathrm{F}\right)$, only one cracked after 144 hours in the salt-fog. A second sample cracked after 379 hours of exposure, and the remaining two samples showed no evidence of any cracking when the test was stopped after 763 hours. One of the four samples of 
welded $316 \mathrm{SS}$ sensitized at $705^{\circ} \mathrm{C}\left(1300^{\circ} \mathrm{F}\right)$ cracked after 763 hours in the salt-fog. Cracking was first observed after 144 hours for the welded $316 \mathrm{SS}$ specimens heat-treated at $620^{\circ} \mathrm{C}$ $\left(1150^{\circ} \mathrm{F}\right)$. A second sample cracked at the next sampling interval, 379 hours. No further cracking was observed in the remaining samples at long exposure times. No cracks were found in the $316 \mathrm{SS}$ welded samples sensitized at $540^{\circ} \mathrm{C}\left(1000^{\circ} \mathrm{F}\right)$. Cracking of $316 \mathrm{SS}$ welded samples was observed in the heat-affected zone and not in the fusion zone.

\section{SS, 304L SS, and 347 SS U-bends}

Cracking of $304 \mathrm{SS}$ occurred primarily in the welded samples. $304 \mathrm{SS}$ heat-treated at $620^{\circ} \mathrm{C}$ cracked in a relatively short exposure to the salt-fog. Two of two U-bends in this condition were cracked when first removed for inspection after 144 hours. Similarly, both samples of the unwelded alloy were also cracked at that time. Cracking was also experienced by 304 SS weldments that were sensitized at $540^{\circ} \mathrm{C}$, but not at $705^{\circ} \mathrm{C}$. As mentioned above, SCC behavior can be very sensitive to the microstructure. All of the cracked samples displayed obvious corrosion products, e.g., rust, but other corroded samples did not crack regardless of the exposure time. Welded samples of $304 \mathrm{SS}$ displayed cracks in the heat-affected zone rather than the fusion zone.

No cracking was observed in either parent or welded samples of 304L SS or 347 SS, regardless of heat treatment. The low-carbon grade of $304 \mathrm{SS}$ is specifically formulated to avoid significant depletion of chromium at grain boundaries and, accordingly, no corrosion or cracking was observed. $347 \mathrm{SS}$ has a small addition of niobium (see Table 1, Nb entry) that forms a more stable carbide than chromium and thereby avoids depletion at grain boundaries. No corrosion or cracking of either parent or welded 347 SS U-bends was observed during the test period that exceeded 600 hours. Both of these results were expected.

\section{Conclusions}

These tests confirm that 316 SS and 304 SS are susceptible to intergranular SCC because the thermal operating conditions of the Solar Two plant sensitize the microstructure of these alloys in a short time. Intergranular SCC of receiver tubes or hot-salt piping could then occur due to off-normal conditions that result in contact of stressed and sensitized material with aqueous solutions containing even minor amounts of dissolved chloride. These tests indicate that 347 SS is much less susceptible to cracking in these environmental conditions due to its stabilized microstructure. 347 SS should be considered as an alternative to high-carbon 316 SS or 304 SS in the current use of those alloys for the receiver and hot salt piping. 
Table 2. Summary of results for SCC tests. The entries indicate when cracks, if any, were observed for each type of stainless steel, welded samples, and the corresponding heat treatment used to sensitize the material. The occurrence of cracking is emphasized by the shaded boxes.

\begin{tabular}{|c|c|c|c|c|c|c|}
\hline \multirow{3}{*}{$\begin{array}{c}\text { Stainless } \\
\text { Steel } \\
316 \mathrm{SS}\end{array}$} & \multirow{3}{*}{\begin{tabular}{l}
\multicolumn{1}{c}{ Heat } \\
Treatment \\
$540^{\circ} \mathrm{C}$ \\
$\left(1000^{\circ} \mathrm{F}\right)$
\end{tabular}} & \multicolumn{5}{|c|}{$\begin{array}{l}\text { Test time } \\
\text { (hours) }\end{array}$} \\
\hline & & 140 & 450 & 677 & 890 & 1090 \\
\hline & & $\begin{array}{l}\text { No cracks } \\
\text { (92 hrs) }\end{array}$ & No cracks & $\begin{array}{l}\text { No cracks } \\
\text { (763 hrs) }\end{array}$ & & \\
\hline \multirow{6}{*}{$\begin{array}{l}316 \mathrm{SS} \\
\text { welded }\end{array}$} & $\begin{array}{l}620^{\circ} \mathrm{C} \\
\left(1150^{\circ} \mathrm{F}\right)\end{array}$ & $\begin{array}{l}\text { No cracks } \\
\text { (92 hrs) }\end{array}$ & No cracks & $\begin{array}{l}\text { No cracks } \\
(763 \mathrm{hrs})\end{array}$ & & \\
\hline & $\begin{array}{l}705^{\circ} \mathrm{C} \\
\left(1300^{\circ} \mathrm{F}\right)\end{array}$ & $\begin{array}{l}\text { No cracks } \\
\text { (92 hrs) }\end{array}$ & No cracks & $\begin{array}{l}\text { No cracks } \\
\text { (763 hrs) }\end{array}$ & & \\
\hline & $\begin{array}{l}540^{\circ} \mathrm{C} \\
\left(1000^{\circ} \mathrm{F}\right)\end{array}$ & $\begin{array}{l}\text { No cracks } \\
\text { (92 hrs) }\end{array}$ & No cracks & $\begin{array}{l}\text { No cracks } \\
\text { (763 hrs) }\end{array}$ & & \\
\hline & $620^{\circ} \mathrm{C}$ & $\begin{array}{l}\text { No cracks } \\
\text { (92 hrs) }\end{array}$ & $\begin{array}{l}\text { 2nd of } 4 \\
\text { cracked }\end{array}$ & $\begin{array}{l}\text { No cracks } \\
\text { (763 hrs) }\end{array}$ & & \\
\hline & $\left(1150^{\circ} \mathrm{F}\right)$ & $\begin{array}{l}\text { 1st of } 4 \\
\text { cracked } \\
\text { (144 hrs) }\end{array}$ & (379 hrs) & & & \\
\hline & $\begin{array}{l}705^{\circ} \mathrm{C} \\
\left(1300^{\circ} \mathrm{F}\right)\end{array}$ & $\begin{array}{l}\text { No cracks } \\
\text { ( } 92 \mathrm{hrs})\end{array}$ & No cracks & $\begin{array}{l}1 \text { of } 4 \\
\text { cracked } \\
(763 \mathrm{hrs})\end{array}$ & & \\
\hline \multirow[t]{3}{*}{$304 \mathrm{SS}$} & $\begin{array}{l}540^{\circ} \mathrm{C} \\
\left(1000^{\circ} \mathrm{F}\right)\end{array}$ & & $\begin{array}{l}\text { No cracks } \\
(465 \mathrm{hrs})\end{array}$ & & & \\
\hline & $\begin{array}{l}620^{\circ} \mathrm{C} \\
\left(1150^{\circ} \mathrm{F}\right)\end{array}$ & $\begin{array}{l}2 \text { of } 2 \\
\text { cracked }\end{array}$ & & & & \\
\hline & $\begin{array}{l}705^{\circ} \mathrm{C} \\
\left(1300^{\circ} \mathrm{F}\right)\end{array}$ & & $\begin{array}{l}\text { No cracks } \\
(465 \mathrm{hrs})\end{array}$ & & & \\
\hline \multirow[t]{3}{*}{$\begin{array}{l}304 \mathrm{SS} \\
\text { welded }\end{array}$} & $\begin{array}{l}540^{\circ} \mathrm{C} \\
\left(1000^{\circ} \mathrm{F}\right)\end{array}$ & & $\begin{array}{l}\text { No cracks } \\
\text { ( } 465 \mathrm{hrs})\end{array}$ & $\begin{array}{l}1 \text { st of } 2 \\
\text { cracked }\end{array}$ & $\begin{array}{l}\text { No } \\
\text { cracks }\end{array}$ & $\begin{array}{l}\text { 2nd of } 2 \\
\text { cracked }\end{array}$ \\
\hline & $\begin{array}{l}620^{\circ} \mathrm{C} \\
\left(1150^{\circ} \mathrm{F}\right)\end{array}$ & $\begin{array}{l}2 \text { of } 2 \\
\text { cracked }\end{array}$ & & & & \\
\hline & $\begin{array}{l}705^{\circ} \mathrm{C} \\
\left(1300^{\circ} \mathrm{F}\right)\end{array}$ & & $\begin{array}{l}\text { No cracks } \\
(465 \text { hrs })\end{array}$ & No cracks & $\begin{array}{l}\text { No } \\
\text { cracks }\end{array}$ & \\
\hline 304L SS & All & & $\begin{array}{l}\text { No cracks } \\
(444 \mathrm{hrs})\end{array}$ & & & \\
\hline $\begin{array}{l}\text { 304L SS } \\
\text { welded }\end{array}$ & All & & $\begin{array}{l}\text { No cracks } \\
(444 \mathrm{hrs})\end{array}$ & & & \\
\hline $347 \mathrm{SS}$ & All & & $\begin{array}{l}\text { No cracks } \\
(426 \mathrm{hrs})\end{array}$ & $\begin{array}{l}\text { No cracks } \\
(625 \mathrm{hrs})\end{array}$ & & \\
\hline $\begin{array}{l}347 \mathrm{SS} \\
\text { welded }\end{array}$ & All & & $\begin{array}{l}\text { No cracks } \\
(426 \mathrm{hrs})\end{array}$ & $\begin{array}{l}\text { No cracks } \\
(625 \mathrm{hrs})\end{array}$ & & \\
\hline
\end{tabular}

Note 1. C-ring samples were used for $316 \mathrm{SS}$.

Note 2. U-bend samples were used for 304SS, 304L SS, and 347SS. 


\section{Appendix I. Receiver Flush (S. Showalter)}

A discovery of $\mathrm{Ca}_{3}(\mathrm{PO} 4)_{2}$ within the Solar Two receiver tubes during a post-mortem metallurgical analysis raised questions about the chemicals used in the flush of the receiver in 1996. The following is a short synopsis of what happened from July 10-14, 1996. HydroChem Industrial Services (HCIS) was contracted to do a flush and chemical cleaning of the receiver tubes.

1. The piping/tubing was flushed in three separate stages. The first step was simply with hot demineralized water, provided by HCIS, to wash out residual salt. The $\mathrm{pH}$ during this step was typically 9-11. This was continued until the nitrate level stabilized (no more salt available to go into solution).

2. The tubes were then flushed with a chemical solution of (NH4) $)_{2}$ EDTA (trade name Vertan 665 Chelant with a $\mathrm{pH}$ of about 5). A 35\% solution of Hydrazine was also used (as a reducing agent), and $\mathrm{pH}$ regulated with $\mathrm{NH}_{4} \mathrm{OH}$. Measured $\mathrm{pH}$ during this step was 7.9. This was continued until $\mathrm{Fe}, \mathrm{pH}$, and chelate levels stabilized. Finally, sections of the receiver were X-rayed to look for scale/corrosion products.

3. The tubing was then passivated using a proprietary solution (trade name Corrosion Inhibitor A251) of isopropanol, thiourea, ethylene glycol butyl ether, and an unnamed generic inorganic halogen (assumed to not be a chloride), organic nitrogen, and organic sulfur compounds. The $\mathrm{pH}$ was reported to be about 9 during this step.

4. Finally, the system was rinsed again with demineralized water to remove cleaning chemicals from the receiver.

It appears that the receiver flush procedure did not introduce the calcium or phosphate. The most likely source is impurities in the as-received salt. Why the calcium chose this area to precipitate out of the bulk salt is unknown, but might have a basis in the large thermal transients affecting the material's solubility in the molten salt. The material could be in solution during on-sun operation and then precipitate out during either fill or drain operations of the receiver. If this were the case, the phosphate would be present throughout the bulk salt and would have a tendency to precipitate at any cold point, such as the cold storage tank. 
Final Test and Evaluation Results from the Solar Two Project 


\section{Appendix J. Storage Tank Thermal Stresses Test (J. E. Pacheco)}

\section{J.1 Goals}

The storage tank thermal stresses test measured the thermal stresses and initial growth in the hot nitrate-salt storage tank as a function of initial heat up and fill and compared these results to predicted values.

\section{J.2 Method}

Both hot and cold molten-salt storage tanks were externally insulated, atmospheric pressure tanks built to American Petroleum Institute Standard 650. During the initial tank warm-up and fill operation, staff monitored movement and expansion of the tank wall with respect to independent reference points. In addition, the surface strains were measured as the tank was initially heated and charged.

The first part of this test (initial tank warm-up and fill) was conducted when the salt was melted during the start-up phase of the project (October-December 1995). Because of minor salt decomposition that occurs the first time it is heated to $480^{\circ} \mathrm{C}\left(900^{\circ} \mathrm{F}\right)$, the salt was first melted directly into the hot tank and then heated above $480^{\circ} \mathrm{C}\left(900^{\circ} \mathrm{F}\right)$ to thermally condition the salt.

\section{J.3 Initial Tank Warm-Up and Fill}

The test equipment used to measure tank growth consisted of four plumb bobs suspended from all-thread rods screwed into the heater flanges (spaced at 90 degree intervals) and four metal rulers mounted to steel plates that were staked into the ground and welded to the cooling pipes. As the tank heated up, the diameter of the tank changed. This growth was measured by reading the position of the plumb bob relative to the ruler. Figure J-1 shows the location of the tank growth measurements (heater flanges and plumb bobs) and a schematic of the plumb bob mounting. The plumb bobs were suspended by rods at the following azimuth locations: 45,135 , 225, and 315 degrees. Note: 0 degrees is due north, 90 degrees is due east, etc. The elevations of the all thread rods were two feet from the tank bottom. A laser and targets were mounted on the all-thread to measure distance from fixed locations on the brick wall surrounding the hot tank to the target.

The strains were measured using four high-temperature, capacitive, strain gages (type HTC-DC100-06) made by Hitec Products, Inc. There were three zones where the strain gages were located. The first zone had two strain gages: one horizontal and one vertical, with five type K thermocouples (center, upper, lower, left, and right) supplied by the tank manufacturer. The first zone was centered at an elevation of $0.53 \mathrm{~m}$ ( 1 feet 9 inches) and an azimuth of 200 degrees. The second and third zones each had one vertical strain gage and five thermocouples. Their elevations were $0.91 \mathrm{~m}$ ( 3 feet 0 inches) and $3.35 \mathrm{~m}$ (11 feet 0 inches), respectively. Their azimuths were 200 degrees and 160 degrees. 

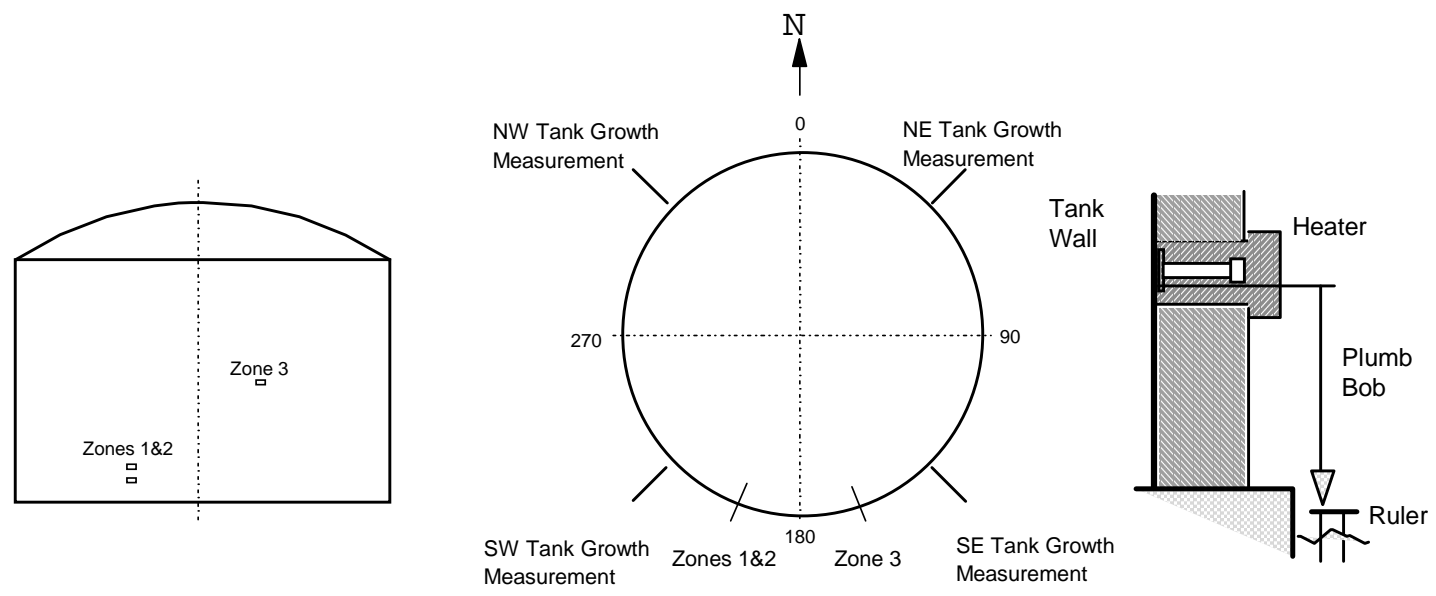

Figure J-1. Location of tank growth measuring system and strain gages on hot tank.

The strain gages were connected via high-temperature cables to signal conditioning hardware (mode cards and power supplies) located in a junction box on the south side of the tank. The signal conditioning hardware converted the signal into a $\pm 5 \mathrm{Vdc}$ analog signal for the data acquisition system. Wiring connected the strain-gage junction-box terminals to the portable data acquisition system (PDAS).

The PDAS was located on the north side of the building housing the jockey-pump fire-protection system, south of the hot tank. The PDAS consisted of three data acquisition modules (model DS-16-8-TC-AO, manufactured by Strawberry Tree, Inc.) and a personal computer (PC). The modules were connected with 25 pin cables that communicated with the PC through the parallel port. The PDAS used Windows ${ }^{\mathrm{TM}}$-based software (WorkBench PC for Windows ${ }^{\mathrm{TM}}$, version 2.0.4) to configure the channels and record the data.

The following data were recorded at a rate of approximately one sample per minute along with 15 minute averages.

The special instrumentation used was:

TE 11 to TE 15 - thermocouples in zone 1.

TE 21 to TE 25 - thermocouples in zone 2.

TE 31 to TE 35 - thermocouples in zone 3.

WE 11 and WE 12 - strain gages in zone 1 .

WE 21 - strain gage in zone 2.

WE 31 - strain gage in zone 3 .

Other plant instrumentation was:

LI-5609, salt level in hot tank.

TI-5671 to TI-5674, hot tank wall temperatures. 


\section{J.4 Results}

The start-up team began heating the hot tank with a propane-fired convective heater on October 9, 1995. The tank was preheated to approximately $315^{\circ} \mathrm{C}\left(600^{\circ} \mathrm{F}\right)$ and allowed to soak at this temperature for about 9.5 days before introducing the molten salt. The molten salt was then pumped into the hot tank as it was melted. The melting procedure lasted until November 6, 1995 (about 16 days). The entire salt inventory was then thermally conditioned above $540^{\circ} \mathrm{C}$ $\left(1000^{\circ} \mathrm{F}\right)$. This procedure started on October 31, 1995 and lasted until November 30, 1995 using an external salt recirculation loop containing a propane-fired heater. During this time, the strains, tank temperatures, tank growth, and salt level were monitored. Figure J-2 shows the temperatures of the tank wall (mean of five thermocouples for each zone) during preheat, soak, salt melting, and thermal conditioning.

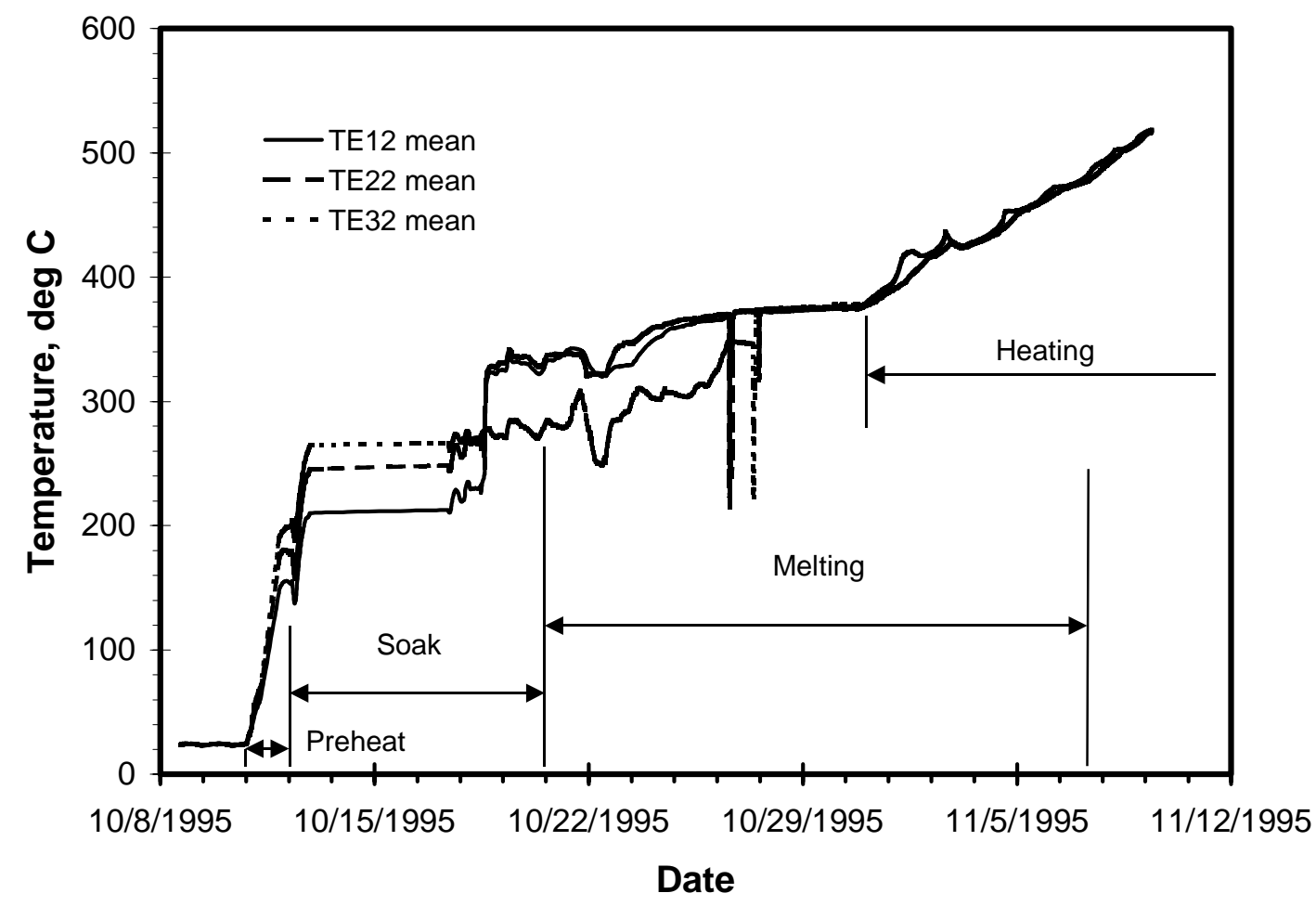

Figure J-2. Tank wall temperatures during preheat, soak, salt melting, and heating procedures.

The tank growth was measured with the plumb-bobs and laser methods during this time. These results are plotted in Figure J-3. Also shown is the predicted expansion based on the tank material's thermal expansion coefficient and change in temperature. 


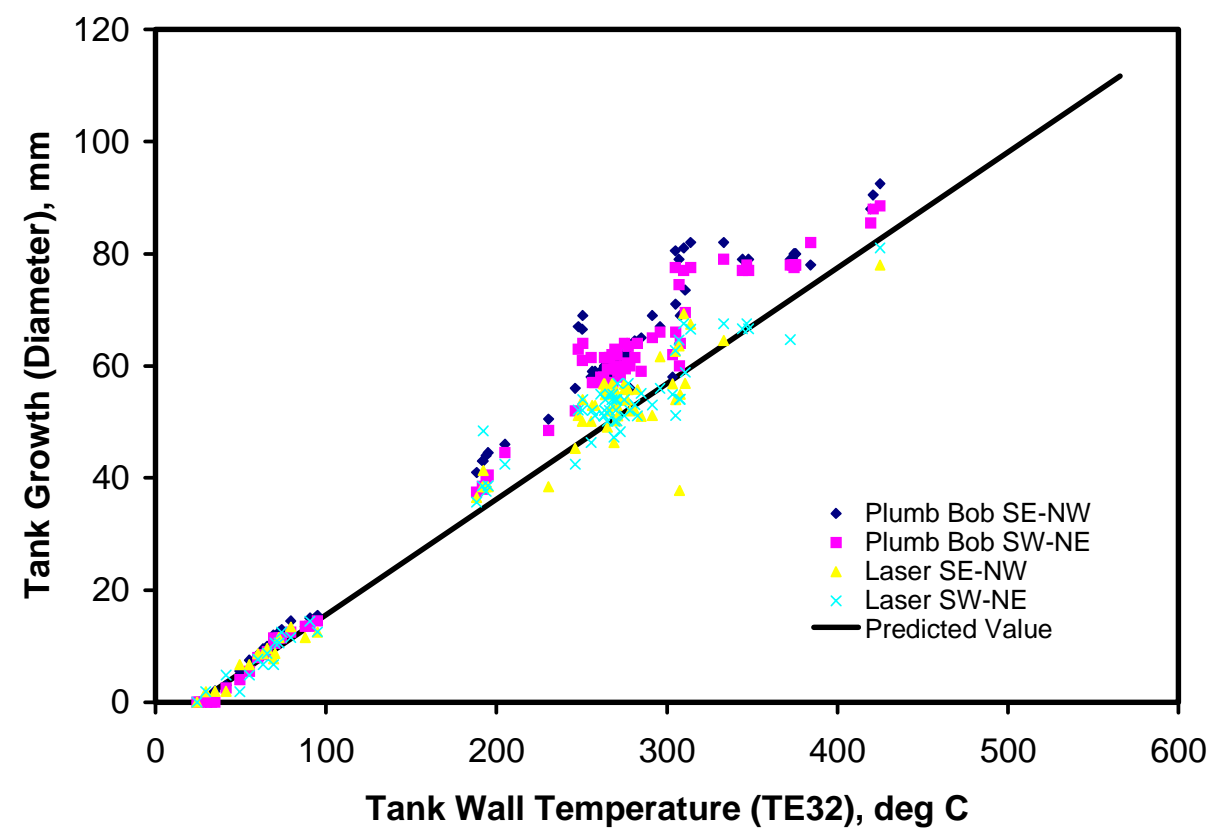

Figure J-3. Growth of hot tank diameter was a function of temperature as measured by the plumb bob and laser method. The predicted growth is shown as a solid line.

Attempts to measure the strains in the tank wall as it was heated up were unsuccessful. The strain gauge signal conditioning electronics were strongly influenced by temperature. In an attempt to reduce the temperature variation in the box (which was located on the south side of the hot tank), a heat lamp was installed and controlled its temperature to $43^{\circ} \mathrm{C} \pm 0.8^{\circ} \mathrm{C}\left(110^{\circ} \mathrm{F}\right.$ $\pm 1.5^{\circ} \mathrm{F}$ ). Unfortunately, the noise in the signal was greater than the strains being measured.

\section{J.5 Discussion/Conclusions}

The tank grew as predicted when the temperature increased and no problems were encountered related to thermal expansion. Both hot and cold tanks had a leak detection system consisting of small tubes placed under the base of the tank that allowed liquid salt to flow towards the outside. No leaks were ever seen from these tanks.

An important lesson learned while conducting this test was that it is critical to eliminate error sources in the instrumentation prior to conducting any testing. For example, even though five identical thermocouples were welded onto the tank surface, all located within an area of $0.15 \mathrm{~m} \times$ $0.15 \mathrm{~m}(6$ inches $\times 6$ inches $)$, temperature variations were measured of over $\pm 55^{\circ} \mathrm{C}\left( \pm 100^{\circ} \mathrm{F}\right)$. At first, it was thought this variability was due to miswiring or problems in the data acquisition system. However, upon inserting a thermocouple through the $0.46 \mathrm{~m}$ (18 inches) of insulation to the tank wall, significant temperature variations were again measured. This was due to natural convection, because there was a $0.03-\mathrm{m}$ (1-inch) gap between the tank wall and the insulation. This gap allowed air to enter the bottom and chimney up the tank wall, providing various degrees 
of cooling to the tank surface. To eliminate this problem, welded metal foil was tacked around each thermocouple, resulting in a maximum variation of $1.7^{\circ} \mathrm{C}\left(3^{\circ} \mathrm{F}\right)$. 
Final Test and Evaluation Results from the Solar Two Project 


\section{Appendix K. Thermal Losses Throughout the Plant (J. E. Pacheco and R. Gilbert)}

\section{K.1 Objectives}

The objectives of this test were to measure the thermal losses of the major Solar Two components due to convection, conduction, and radiation. The information obtained was used to develop a detailed heat balance for the plant and acquire the data required to design a thermally efficient commercial plant.

\section{K.2 Methods}

Two methods were employed to acquire the data necessary to determine the component and system heat losses at Solar Two:

1. Isothermal Testing

During a plant shutdown, the heat tracing and immersion heater power consumption were monitored as they maintained the vessels and components at a constant temperature.

\section{Cool-Down Testing}

During a plant shutdown, all heat tracing and immersion heaters were shut off. The installed temperature sensors were monitored to determine the mean temperature of the components. Using measured temperature data, the component and system heat losses were calculated.

\section{K.3 Results}

On April 2 and 3, 1997, a precursor test was performed by Bechtel with participation of the Test and Evaluation (T\&E) Team. In this test, the receiver system was drained and all heat trace associated with receiver equipment provided by Rocketdyne (equipment near top of tower) was turned off for a period of 18 hours. During the 18-hour period, pipes, vessels, and valves were allowed to cool. Most equipment was near ambient temperature at the end of the period (except for the surge vessels, which cooled to $\left.\sim 150^{\circ} \mathrm{C}\left(300^{\circ} \mathrm{F}\right)\right)$. The heat trace was then turned on and the equipment was returned to operating temperature. The times required to return the equipment to $260^{\circ} \mathrm{C}\left(500^{\circ} \mathrm{F}\right)$ are provided in Table $\mathrm{K}-1$.

A cursory evaluation of the results was performed. The review showed that a vast majority of the components, but not all, satisfied the acceptance criteria. Similar tests were performed on the remainder of the plant during the test period. 
Table K-1. Acceptance Criteria for Receiver Heat Trace Test

\begin{tabular}{ll}
\hline \hline Valves & $\leq 4 \mathrm{hrs}$ \\
Insulated Pipes & $\leq 2 \mathrm{hrs}$ \\
Inlet and Outlet Surge Vessels & $\leq 1 \mathrm{hr}$ \\
Upper Headers Heated by Oven & $\leq 2 \mathrm{hr}$ \\
Lower Headers Heated by Oven & $\leq 2 \mathrm{hrs}$ \\
\hline \hline
\end{tabular}

The actual thermal capacity of the thermal storage system was estimated to be $107 \mathrm{MWh}$ based on the delivered amount of salt in the storage system, accounting for the mass of salt in the heels of the tanks and in the pump sumps and the actual attainable salt temperatures delivered to and returning from the steam generator system (SGS). The thermal storage system was designed to deliver thermal energy at full-rated duty of the steam generator for three hours at the rated hot and cold salt temperatures of $565^{\circ} \mathrm{C}$ and $288^{\circ} \mathrm{C}$, respectively. The amount of salt in the system was estimated to be 1380 tonnes, which was somewhat less than design-specified 1490 tonnes because approximately 90 tonnes of salt were not delivered to the site. In addition, the maximum attainable hot salt temperature from thermal storage delivered to the SGS (before attemperation) was typically $554^{\circ} \mathrm{C}$ (due to leaks from the valves). Despite the slightly lower-than-specified salt inventory and decreased hot-salt temperature, the storage system still had the capacity to deliver the full-rated steam generator duty for three hours $(35.5 \mathrm{MW} \times 3 \mathrm{~h}=106.5 \mathrm{MWh})$. The results are presented in Table K-2. All of the losses are essentially as predicted except for the steam generator system. The higher than expected steam generator system losses are believed due to damaged insulation. During the startup phase, a salt leak saturated the sump's insulation and reduced its effectiveness.

Table K-2. Measured and Calculated Thermal Losses Tanks and Sumps

\begin{tabular}{lcc}
\hline Major Equipment & $\begin{array}{c}\text { Calculated Thermal } \\
\text { Loss, kW }\end{array}$ & $\begin{array}{c}\text { Measured Thermal } \\
\text { Loss, }_{\mathbf{t}}\end{array}$ \\
\hline Hot Salt Tank @ 565 ${ }^{\circ} \mathrm{C}\left(1050^{\circ} \circ \mathrm{F}\right)$ & 98 & 102 \\
Cold Salt Tank @ $290^{\circ} \mathrm{C}\left(550^{\circ} \mathrm{F}\right)$ & 45 & 44 \\
Steam generator system @ $1050^{\circ} \mathrm{F}$ & 14 & 29 \\
Receiver Sump@ 550年 & 13 & 9.5 \\
\hline \hline
\end{tabular}

A summary of the measured and design thermal losses is shown in Table K-2. The thermal losses for the tanks and sumps are similar to the design values, except for the steam generator system. The losses for the steam generator system were higher than predicted, possibly because the insulation degraded over the course of the project. Salt had leaked out of the sump and into the insulation on the sump, which significantly affected its insulating properties.

The fractional amount of the energy sent to thermal storage that is later discharged to the steam generator to make electricity is nearly 1 , but is a function of the availability. The thermal losses are basically a fixed loss to the environment. The higher the plant availability, the more energy that is collected, and the losses are a smaller fraction of the total energy sent to storage. For 
example, on Dec. 2, 1997, a sunny winter day, the receiver collected $217 \mathrm{MWh}$, which was sent to the SGS to make electricity. Based on a constant thermal loss of $185 \mathrm{~kW}$ from the hot and cold tanks and the receiver and steam generator systems, the total energy lost to the environment that day was $185 \mathrm{~kW} \times 24 \mathrm{~h}=4.43 \mathrm{MWh}$, or $2.0 \%$ of the collected energy. On a sunny summer day-for example, June 18, 1998 - the receiver collected 334 MWht and the thermal losses were $1.3 \%$ of the collected energy. Some days (actually many days for Solar Two), the plant did not run. Even with the very prototypical nature of Solar Two (e.g. poor availability, frequent outages, first year operation, etc.), over several months, the fractional amount lost to the environment was only $6 \%$ of collected. If the plant ran with higher availability, as is typical for a mature operation, the factional amount lost to the environment would only be about $2 \%$ of collected.

\section{K.4 Conclusions}

The heat loss associated with the Solar Two thermal storage system was very low, as predicted. This allows for efficient storage of thermal energy. Based on these results, it is expected the annual efficiency of the thermal storage system in a commercial plant should be $>99 \%$. 
Final Test and Evaluation Results from the Solar Two Project 


\section{Appendix L. Solar Two Nitrate Salt - Lessons Learned (S. Showalter)}

\section{L.1 Specification and Composition As-Received}

The original specification for the heat transfer and thermal energy storage medium at Solar Two called for 3.37 million pounds of nitrate salt prills with the following characteristics:

1. $60 \mathrm{wt} \% \mathrm{NaNO}_{3}$ and $40 \mathrm{wt} \% \mathrm{KNO}_{3}$ delivered in $1000 \mathrm{~kg}(2000 \mathrm{lb})$ bags.

2. Minimum nitrate salt concentration of $98 \mathrm{wt} \%$.

3. Maximum $0.6 \mathrm{wt} \%$ chloride ion from all sources (corrosion control).

4. Maximum contamination from other (non-chloride) sources

Nitrite $-1.00 \mathrm{wt} \%$

Carbonate $-0.10 \mathrm{wt} \%$

Sulfate $-0.75 \mathrm{wt} \%$

Hydroxyl alkalinity - $0.20 \mathrm{wt} \%$

5. Notification to buyer if concentration of any unnamed species exceeded $0.10 \mathrm{wt} \%$.

This specification was arrived at through years of research and development at Sandia and elsewhere. Areas of attention included energy storage properties, viscous/flow properties, melting point tradeoffs, cost tradeoffs, and corrosivity. Chloride was identified as the primary factor, among minor salt constituents, determining the rates at which mild and stainless steels corrode when exposed to molten nitrate salt in the temperature range of interest (Bradshaw and Goods, 2001a, Bradshaw and Goods, 2001b, Goods, et. al, 1994). The salt came in the form of $1000 \mathrm{~kg}$ bags of $\mathrm{NaNO}_{3}-\mathrm{KNO}_{3}$ prills. As received, it contained the impurities shown in Table L-1.

Table L-1.

\begin{tabular}{lc}
\hline \hline \multicolumn{1}{c}{ Impurity } & Concentration \\
\hline Magnesium & $0.045 \%$ \\
Chloride & $0.36 \%$ \\
Perchlorate & $0.26 \%$ \\
Carbonate & $23.4 \mathrm{ppm}$ \\
Hydroxide & 0 \\
Sulfate & $0.12 \%$ \\
Nitrite & $0.00 \%$ \\
Calcium & $45 \mathrm{ppm}$ \\
Chromium & 0 \\
\hline \hline
\end{tabular}


Only 2.8 million lbs of salt were actually received on site. The Na:K weight for the salt as received was slightly off specification at $\mathrm{Na}: \mathrm{K}=1.056$ (theoretical ratio 1.038). The project elected to accept the salt at this weight ratio since the only implication was a slightly lower melting range. On-set of melting for the salt occurred at $207^{\circ} \mathrm{C}\left(404^{\circ} \mathrm{F}\right)$. On-set of freezing occurred at a somewhat higher temperature, below $238^{\circ} \mathrm{C}\left(460^{\circ} \mathrm{F}\right)$ and above $207^{\circ} \mathrm{C}\left(404^{\circ} \mathrm{F}\right)$. Between the melting and freezing onset points, solid and liquid phases coexist in equilibrium.

\section{L.2 Salt Melting}

The original project plan called for the prilled salt to be melted and loaded into the cold salt storage tank. Several unforeseen obstacles affected this plan.

\section{L.3 Off-gassing}

Upon receiving the Solar Two salt on site, Sandia researchers collected a sample that was shipped to Albuquerque to use in some corrosion tests. Upon melting the sample and heating it to around $538^{\circ} \mathrm{C}\left(1000^{\circ} \mathrm{F}\right)$, vigorous boiling and the emission of brown gas was observed that was uncharacteristic of previous experiments with molten nitrate salts. A detailed analysis revealed that the off-gassing occurred due to a decomposition reaction that takes place above $482^{\circ} \mathrm{C}\left(900^{\circ} \mathrm{F}\right)$ :

$$
\mathrm{Mg}\left(\mathrm{NO}_{3}\right)_{2} \rightarrow \mathrm{MgO}_{(\mathrm{s})}+2 \mathrm{NO}_{2,(\mathrm{~g})}+1 / 2 \mathrm{O}_{2,(\mathrm{~g})}
$$

It turns out that the Solar Two salt contained approximately $0.05 \mathrm{wt} \%$ (500 ppm) $\mathrm{Mg}$ in the form of magnesium nitrate, as can be seen in Table L-1. The original specification provided no specific limit for magnesium because this decomposition reaction had never been experienced in previous tests and experiments. $\mathrm{NO}_{2}$ is responsible for the brown gas and $\mathrm{MgO}$ precipitates to the bottom of the melt as a white flocculated solid. As the salt decomposes, it loses weight as gas evolves.

Experiments revealed that below $482^{\circ} \mathrm{C}\left(900^{\circ} \mathrm{F}\right)$, the rate of weight loss is negligible. At $565^{\circ} \mathrm{C}$ $\left(1050^{\circ} \mathrm{F}\right)$ in a steel vessel containing about $9 \mathrm{~kg}(20 \mathrm{lb})$ of salt, off-gassing resulted in a weight loss rate of $0.002 \mathrm{lb} / \mathrm{lb} / \mathrm{min}$ initially, tapering to zero once the reaction was complete. Once complete, the reaction was essentially irreversible.

The nominal inventory of Solar Two salt of 1.5 million $\mathrm{kg}$ (3.3 million pounds) was therefore expected to generate about $4500 \mathrm{~kg}(9,900 \mathrm{lbs})$ of gas $\left(85 \% \mathrm{NO}_{2}\right.$ and $\left.15 \% \mathrm{O}_{2}\right)$ once heated to temperatures in excess of $482^{\circ} \mathrm{C}\left(900^{\circ} \mathrm{F}\right)$. Since the original plan for salt melting at Solar Two called for a low-temperature melt and loading into the cold tank, with the first high-temperature exposure of the salt to occur in the receiver, staff and management became concerned that offgassing in the receiver could cause major problems. Vapor locking and corrosion in the receiver, along with uncontrolled release of toxic $\mathrm{NO}_{\mathrm{x}}$, were the biggest concerns. A plan was 
implemented to thermally condition the salt to remove $\mathrm{Mg}$ by precipitation prior to first exposure to high temperatures in the receiver.

\section{L.4 Solid Rock}

Because of startup delays, the bags of nitrate salt sat exposed to the elements at Solar Two for about 4 months. As a result, much of the salt in many of the bags consolidated to form large, hard blocks, which required special rock-hammer-like equipment to convert the salt into particle sizes that could be handled and fed to the salt melter.

\section{L.5 Melting Experience}

Figure L-1 and Figure L-2 show pictures of the salt in bags awaiting melting.

The supersacks were loaded into a hammer-mill and crushed into small pieces that were then sent along a conveyor belt to a feed hopper. The feed hopper had a screw auger to push the salt into the melting chest (Figure L-3 and Figure L-4). Air was blown through a stack over the melting chest to dissipate the NOx generated during the initial melt. This melted salt was then fed directly into the hot tank. The hot tank salt was continuously circulated through a $2.9 \mathrm{MW}$ (10 Million BTU) propane heater to bring the salt up to the temperature of $370^{\circ} \mathrm{C}\left(700^{\circ} \mathrm{F}\right)$ (Figure L-5). It took 16 days to add the complete inventory of salt to the hot tank. Once the inventory of salt was in the hot tank, it was slowly heated to $540^{\circ} \mathrm{C}\left(1000^{\circ} \mathrm{F}\right)$ over 10 days and then heat-soaked at that temperature for 20 days.

After 20 days at temperatures around $1025^{\circ} \mathrm{F}$, the concentration of magnesium dissolved in the salt reached a level, around $0.001 \mathrm{wt} \%$, such that weight loss was complete, as verified by thermogravimetric analyses performed at Sandia. The salt was henceforth used in the system with no problem related to its composition or melting point.

\section{L.6 Changes with Use}

The composition of the salt changed as expected throughout the project. Perchlorate decreased, magnesium stayed low, nitrite formed within the bounds of equilibrium expectations, and no problems were observed. For an unknown reason, the salt melting point gradually lowered throughout the project from $404^{\circ} \mathrm{F}$ to something near $395^{\circ} \mathrm{F}$ when the plant was shut down. Although unexplained, this change appeared to have no effect, positive or negative, on the performance of Solar Two.

\section{L.7 Lessons Learned}

The following points summarize lessons learned with respect to the nitrate salt:

- The salt specification for Solar Two was adequate, with the exception of the magnesium. 


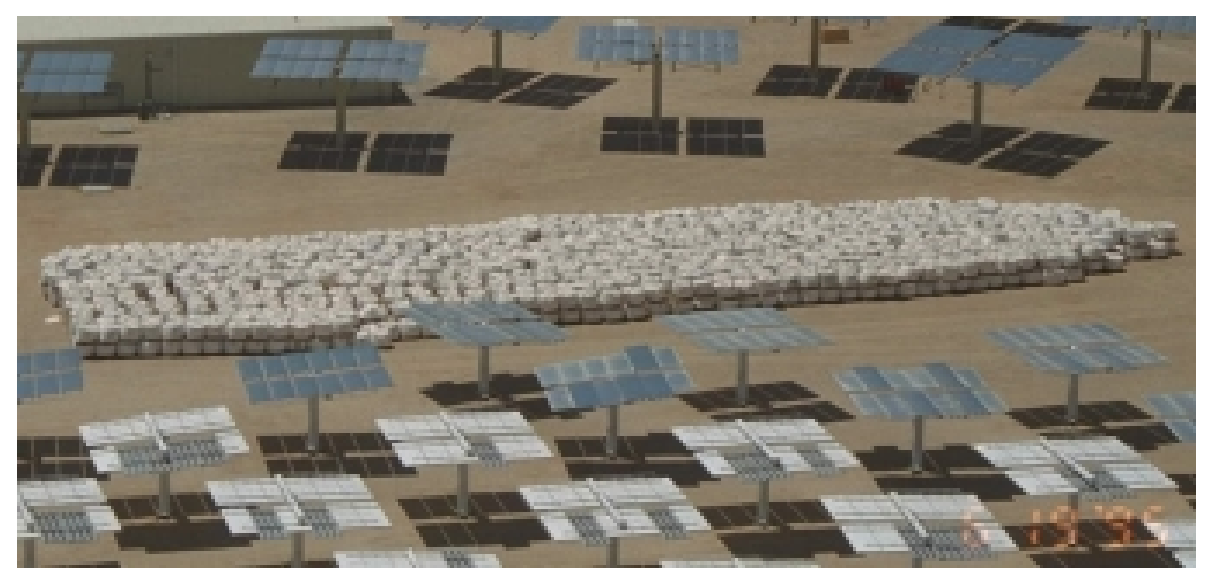

Figure L-1. 1.3 million $\mathrm{kg}$ (2.8 million pounds) of nitrate salt awaiting melting at Solar Two.

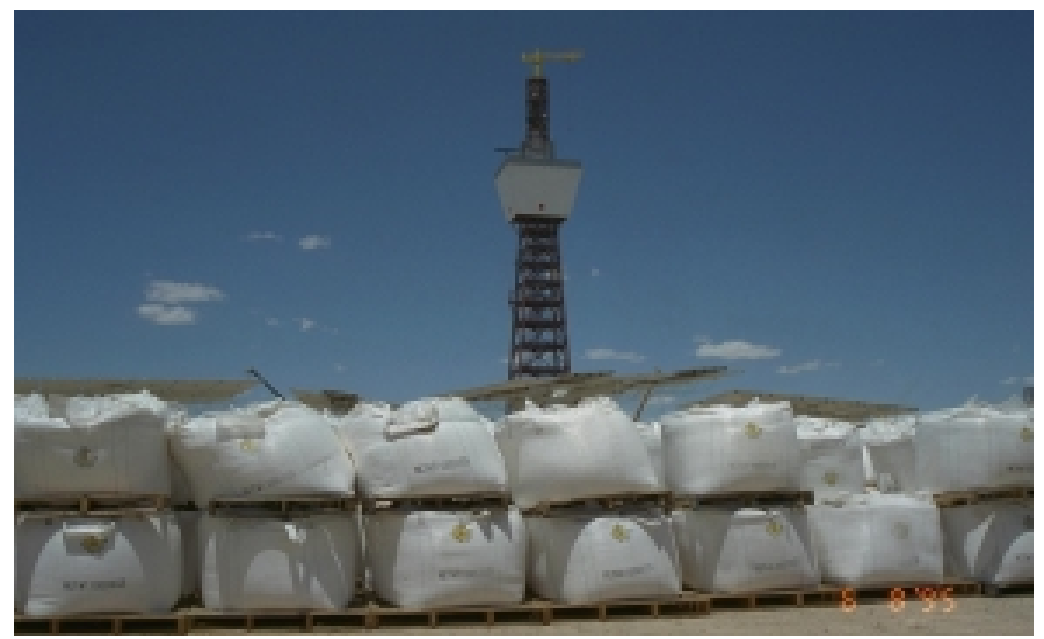

Figure L-2. $1000 \mathrm{~kg}$ bags of nitrate salt awaiting melting at Solar Two. The Solar One tower in the background is being prepared for installation of the new molten salt receiver.

- Magnesium results in off-gassing that should be accounted for in the plant design and startup plan. Care must be taken because $\mathrm{NO}_{2}$ is extremely toxic and forms corrosive nitric acid when combined with water.

- Thermal conditioning was adequate for removing the magnesium. $\mathrm{MgO}$ solid fines that accumulated in the tanks and elsewhere presented no problem.

- Since salt prices increase with salt purity, it may be economical to accept lower purity salt if pretreatment is designed into the system/plan.

- Other impurities not yet experienced may result in a problem similar to the $\mathrm{Mg}$. The likelihood for such problems is low, however, since work at Sandia with a wide range of 
grades of salt from Chilean Nitrate and other sources showed no problem like the off-gassing problem encountered for Solar Two.

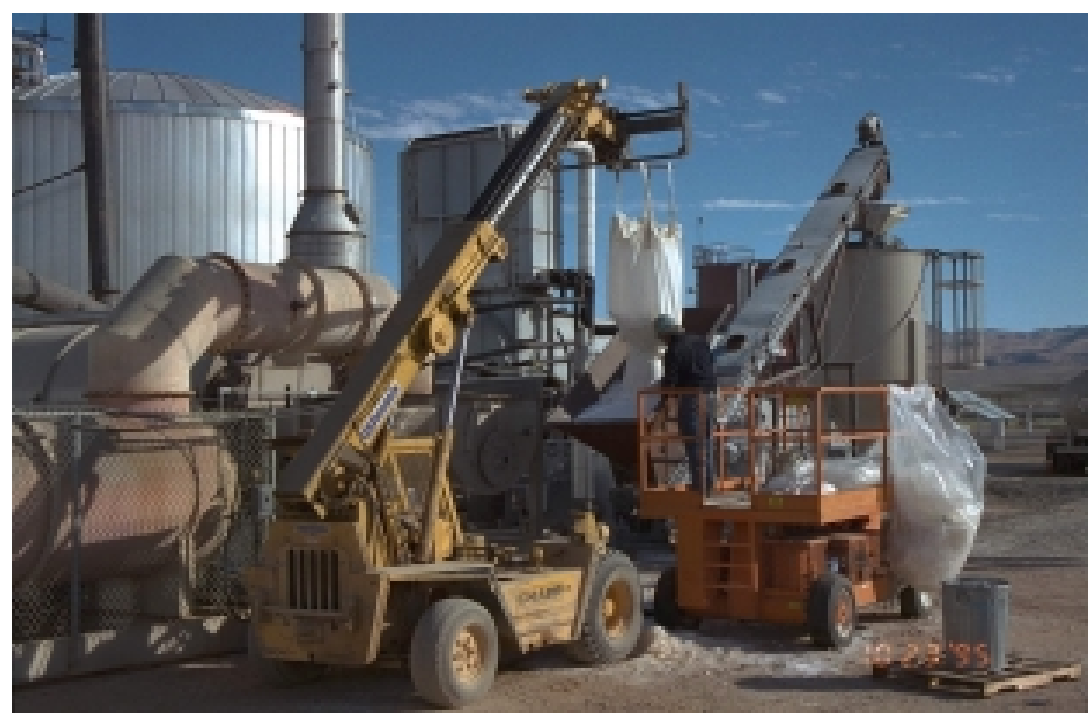

Figure L-3. The salt handling system crushed the salt and transported it to the melter.

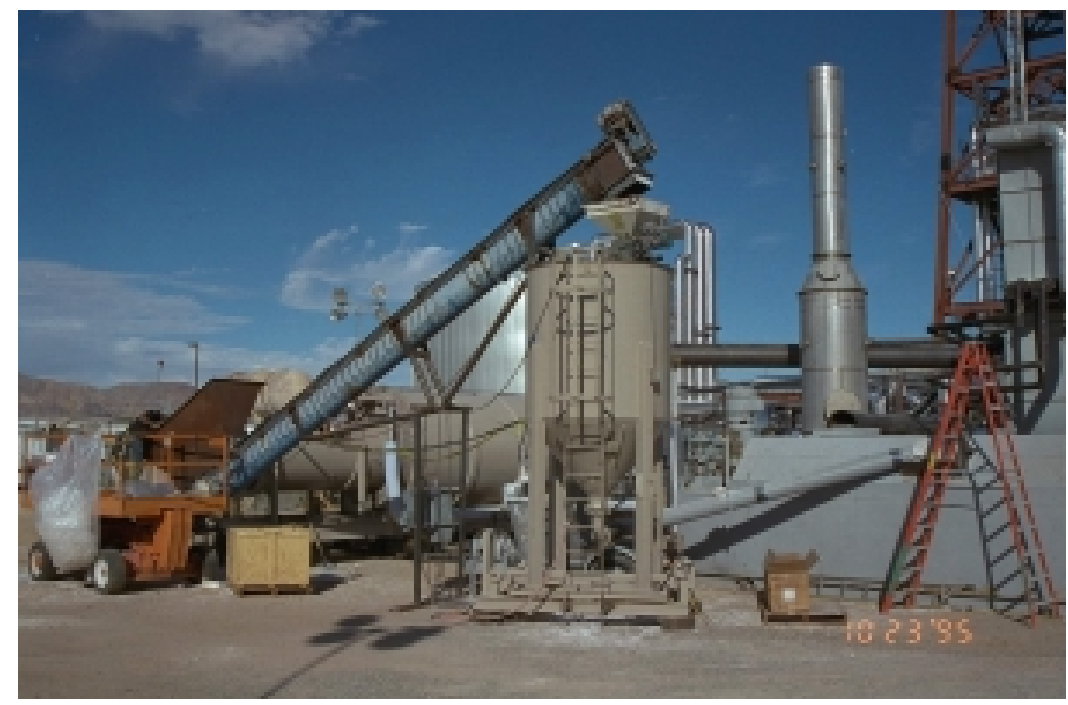

Figure L-4. Conveyor belt feeding crushed salt from the hammer mill into the salt hopper. The screw auger can be seen as the pipe feeding into the wall next to the ladder. The vent stack to dilute the NOx can be seen in the background.

- Thermogravimetric and differential scanning calorimetry experiments should be performed to characterize salt stability and melting point, respectively, over the temperature range of interest prior to procuring the entire plant inventory.

- If chloride concentration is kept within the Solar Two specification, additional corrosion tests are not needed. Corrosion was not a problem with the exception of SCC, which is related 
more to salt chemistry than to moisture intrusion. It would not make sense to specify chloride-free salt and there is not enough information to provide a new chloride specification related to SCC.

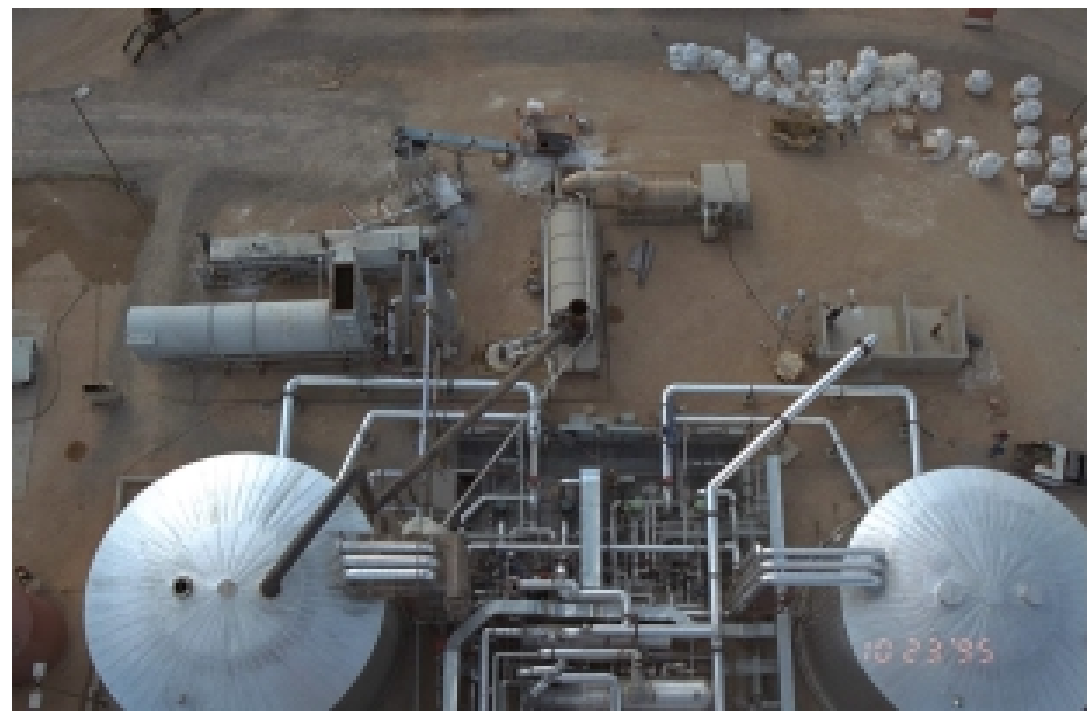

Figure L-5. Overhead view of the salt fill operation; the hot tank is on the left and the cold tank is on the right.

- Salt prills form blocks if they sit around too long. This should be included in the startup plan.

- Salt composition changed as expected.

\section{L.8 References}

Bradshaw, R. W. and S. H. Goods, Corrosion of Alloys and Metals by Molten Nitrates, Sandia National Laboratories, SAND2000-8727, August 2001.

Bradshaw, R. W. and S. H. Goods, Corrosion Resistance of Stainless Steels during Thermal Cycling in Alkali Nitrate Molten Salts, Sandia National Laboratories, SAND2001-8518, September 2001.

Goods, S. H., R. W. Bradshaw, M. R. Prairie, and J. M. Chavez, Corrosion of Stainless and Carbon Steels in Molten Mixtures of Industrial Nitrates, Sandia National Laboratories, SAND94-8211, March 1994. 


\section{Appendix M. Steam Generator/Electric Power Generation System Characterization Test (J. E. Pacheco)}

\section{M.1 Objectives}

The objectives of the Steam Generator/Electric Power Generation System (EPGS) Characterization Test were to develop a performance map for the steam generator and the turbine/generator systems and determine the reason(s) for any departures from the predicted performance values.

\section{M.2 Method}

The test was intended to measure the steam generator system (SGS) and EPGS performance over a range of power loads and two inlet salt temperature, as described in Table M-1. All the subtests, except the first, deviated from normal plant operation. Testing was performed under steady-state conditions where the unit was held at that state for a minimum of two hours, but typically three to eight hours. Additionally, the steam generator and turbine/generator startup and overnight hold operating modes were characterized so the energy usage in these states could ultimately be optimized.

For the steady-state operations test, the SGS and the EPGS were operated together to measure the gross thermal conversion efficiency at the various loading conditions.

Table M-1. Desired and Actual Steady-State Operating Load Conditions

\begin{tabular}{|c|c|c|c|c|c|c|}
\hline \multirow{2}{*}{$\begin{array}{l}\text { Test } \\
\text { No. }\end{array}$} & \multirow{2}{*}{$\begin{array}{c}\text { Hot Salt } \\
\text { Temperature } \\
{ }^{\circ} \mathrm{C}\left({ }^{\circ} \mathrm{F}\right) \\
\text { (Desired/Actual) }\end{array}$} & \multicolumn{2}{|c|}{ Salt Outlet Flow } & \multirow{2}{*}{$\begin{array}{l}\text { Pressure } \\
\text { MPa } \\
\text { (Psia) }\end{array}$} & \multirow{2}{*}{$\begin{array}{c}\text { Steam } \\
\text { Temperature } \\
{ }^{\circ} \mathrm{C}\left({ }^{\circ} \mathrm{F}\right) \\
\text { (Desired/Actual) }\end{array}$} & \multirow{2}{*}{$\begin{array}{c}\text { Actual } \\
\text { Gross } \\
\text { Electrical } \\
\text { Output } \\
\text { kWe }\end{array}$} \\
\hline & & $\stackrel{\%}{\%}$ Full Flow & $\begin{array}{c}\mathrm{kg} / \mathrm{s} \\
\left.\text { (lbm } \times 10^{-3} / \mathrm{hr}\right) \\
\text { (Desired/Actual) }\end{array}$ & & & \\
\hline 1 & $\begin{array}{c}565 / 543 \\
(1050 / 1010)\end{array}$ & $100 \%$ & $\begin{array}{l}82.5 / 86.4 \\
(655 / 686)\end{array}$ & $\begin{array}{c}10.1 \\
(1465)\end{array}$ & $\begin{array}{c}538 / 532 \\
(1000 / 990)\end{array}$ & 10570 \\
\hline 2 & $\begin{array}{c}565 / 543 \\
(1050 / 1010)\end{array}$ & $80 \%$ & $\begin{array}{l}66.0 / 69.8 \\
(524 / 554)\end{array}$ & $\begin{array}{c}10.1 \\
(1465)\end{array}$ & $\begin{array}{c}538 / 534 \\
(1000 / 993)\end{array}$ & 8880 \\
\hline 3 & $\begin{array}{c}565 / 542 \\
(1050 / 1008)\end{array}$ & $60 \%$ & $\begin{array}{l}49.5 / 54.8 \\
(393 / 435)\end{array}$ & $\begin{array}{c}10.1 \\
(1465)\end{array}$ & $\begin{array}{c}538 / 536 \\
(1000 / 997)\end{array}$ & 5900 \\
\hline 4 & $\begin{array}{c}565 / 516 \\
(1050 / 960)\end{array}$ & $40 \%$ & $\begin{array}{l}33.0 / 18.0 \\
(262 / 143)\end{array}$ & $\begin{array}{c}10.1 \\
(1465)\end{array}$ & $\begin{array}{c}538 / 513 \\
(1000 / 955)\end{array}$ & 1310 \\
\hline 5 & $\begin{array}{c}574 / 557 \\
(1065 / 1035)\end{array}$ & $100 \%$ & $\begin{array}{l}82.5 / 82.5 \\
(655 / 655)\end{array}$ & $\begin{array}{c}10.1 \\
(1465)\end{array}$ & $\begin{array}{c}546 / 542 \\
(1015 / 1008)\end{array}$ & 10930 \\
\hline 6 & $\begin{array}{c}574 / 553 \\
(1065 / 1028)\end{array}$ & $80 \%$ & $\begin{array}{l}66.0 / 69.0 \\
(524 / 548)\end{array}$ & $\begin{array}{c}10.1 \\
(1465)\end{array}$ & $\begin{array}{c}546 / 542 \\
(1015 / 1008)\end{array}$ & 9170 \\
\hline 7 & $\begin{array}{c}574 / 551 \\
(1065 / 1024)\end{array}$ & $60 \%$ & $\begin{array}{l}49.5 / 46.7 \\
(393 / 371)\end{array}$ & $\begin{array}{c}10.1 \\
(1465)\end{array}$ & $\begin{array}{c}546 / 543 \\
(1015 / 1009)\end{array}$ & 5830 \\
\hline 8 & $\begin{array}{c}574 / 526 \\
(1065 / 978)\end{array}$ & $40 \%$ & $\begin{array}{l}33.0 / 18.0 \\
(262 / 143)\end{array}$ & $\begin{array}{c}10.1 \\
(1465)\end{array}$ & $\begin{array}{c}546 / 522 \\
(1015 / 972)\end{array}$ & 1300 \\
\hline
\end{tabular}


The desired steam generator salt inlet temperature of $565^{\circ} \mathrm{C}\left(1050^{\circ} \mathrm{F}\right)$ was not achieved. Although the receiver outlet temperature set point was $565^{\circ} \mathrm{C}\left(1050^{\circ} \mathrm{F}\right)$ in the first four tests and $574^{\circ} \mathrm{C}\left(1065^{\circ} \mathrm{F}\right)$ in the last four tests, the salt entering the steam generator was typically about $21^{\circ} \mathrm{C}\left(38^{\circ} \mathrm{F}\right)$ cooler due to attemperation from leaky valves between the riser and downcomer and thermal losses in piping and the hot storage tank. At low salt flow rates, the operating procedure dictated that the cold mixer pump be in operation. This further decreased the inlet salt temperature by $27^{\circ} \mathrm{C}\left(48^{\circ} \mathrm{F}\right)$. The project purchased new gate valves to eliminate the valve problem; however, they were not installed due to financial constraints.

The energy required to start the SGS/EPGS was measured on a daily basis and compared to the results obtained by the SOLERGY computer code.

\section{M.3 Results}

The measured gross turbine electrical output is plotted as a function of the heat input to the steam generator in Figure M-1. The heat balance values calculated by Bechtel during the design phase of the project are also shown. The measurements agree well with design estimates. The gross cycle efficiency (gross electrical power output divided by thermal power input to the SGS) is plotted against salt flow rate in Figure M-2. Also shown is the design calculated gross cycle efficiency. Again, the measurements agree well with the design calculations. The inlet salt temperature had only a slight effect on both the efficiency and gross power output.

The heat exchanger effectivenesses for the preheater, evaporator, and superheater were calculated. The effectiveness is defined as the ratio of the actual heat transferred to the maximum possible heat transfer based on actual flows and inlet and outlet temperatures of the salt and water. The results are shown in Figure M-3. It is apparent from this data that the preheater effectiveness was low. In August 1998, after these tests, the flange on the preheater was removed and the tubes were found to have fouling and plugging. The inspection also found that the partition plate gasket was eroded away. This allowed feedwater flow to bypass the tube portion of the exchanger and contributed significantly to the reduced effectiveness. It was determined that the original gasket supplied by the heat exchanger manufacturer was inappropriate for the design water temperature and pressure. The gasket was replaced with a high temperature and pressure gasket. 


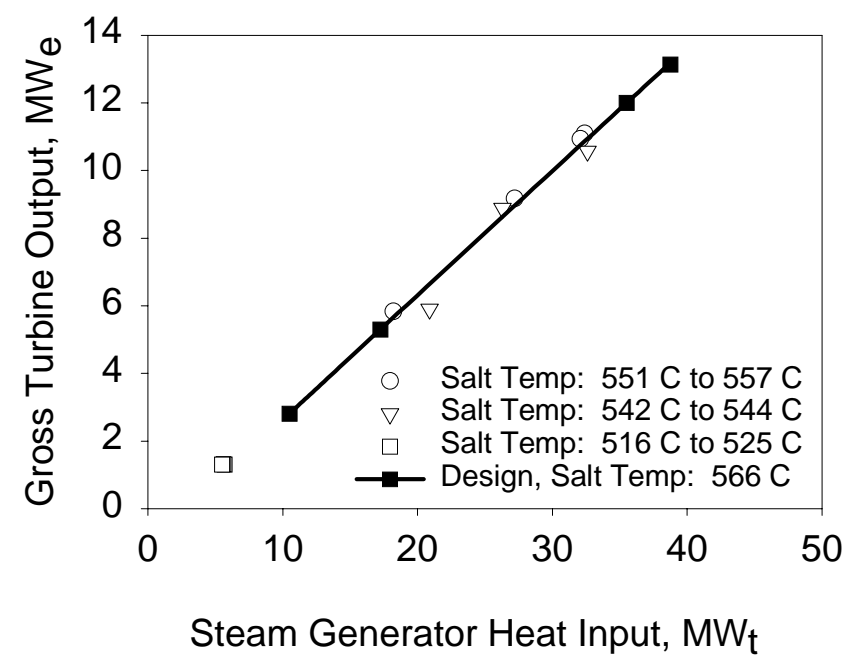

Figure M-1. Gross Turbine Electrical Output as a Function of Heat Input to the Steam Generator.

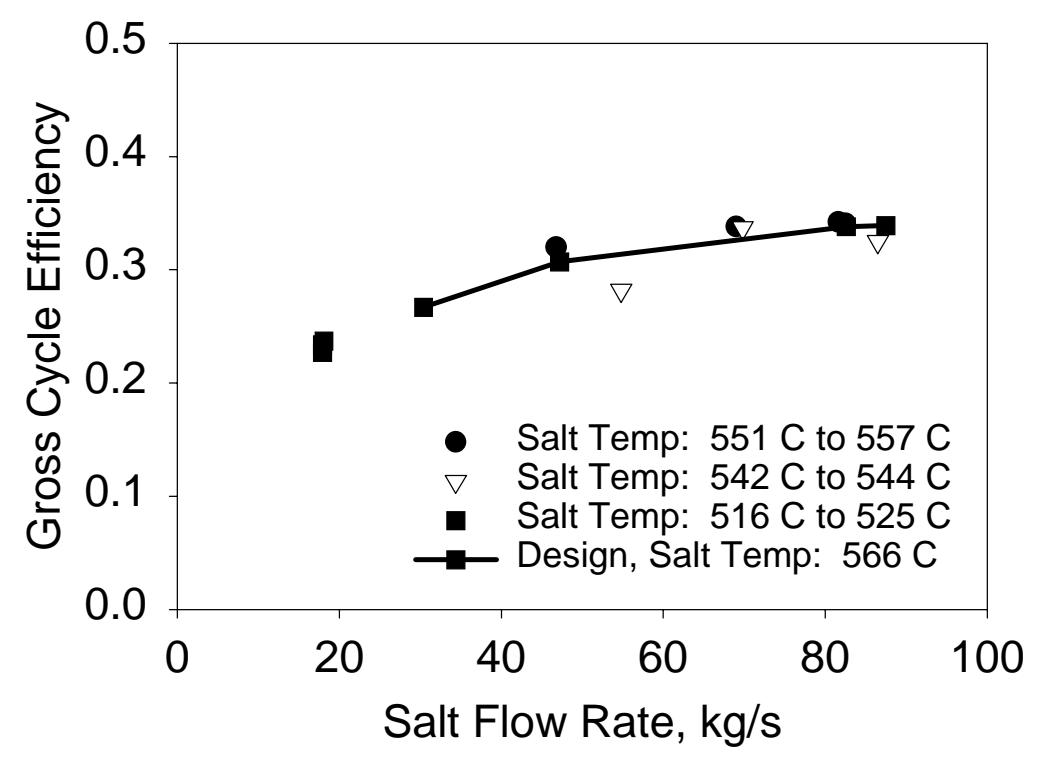

Figure M-2. Gross Cycle Efficiency as a Function of Salt Flow Rate.

Table M-2. Steam Generator Heat Exchanger Effectiveness

\begin{tabular}{ccccc}
\hline $\begin{array}{c}\text { Salt Flow, } \\
\mathrm{kg} / \mathrm{s}(\mathrm{Kpph})\end{array}$ & $\begin{array}{c}\text { Salt Temp, } \\
{ }^{\circ} \mathrm{C}\left({ }^{\circ} \mathrm{F}\right)\end{array}$ & $\begin{array}{c}\text { Preheater } \\
\text { Effectiveness }\end{array}$ & $\begin{array}{c}\text { Evaporator } \\
\text { Effectiveness }\end{array}$ & $\begin{array}{c}\text { Superheater } \\
\text { Effectiveness }\end{array}$ \\
\hline $47.0(373)$ & $551(1024)$ & 0.42 & 0.75 & 0.98 \\
$55.1(437)$ & $542(1008)$ & 0.45 & 0.75 & 0.98 \\
$69.0(548)$ & $553(1027)$ & 0.47 & 0.74 & 0.96 \\
$70.1(556)$ & $544(1011)$ & 0.48 & 0.74 & 0.97 \\
$82.0(651)$ & $557(1035)$ & 0.46 & 0.73 & 0.96 \\
$83.0(659)$ & $557(1035)$ & 0.40 & 0.74 & 0.95 \\
$87.1(691)$ & $544(1011)$ & 0.47 & 0.74 & 0.96 \\
\hline \hline
\end{tabular}


After replacing the gasket and cleaning the tubes, the performance improved dramatically, yielding a record gross turbine output of 11.6 MWe.

The steam generator was also evaluated from a total operational system perspective. Actual operating data was compared to predictions from a Solar Two model. SOLERGY, a computer program used to simulate the operation and power output of a solar central receiver power plant, was the code used to model Solar Two performance. To gain a more detailed understanding of how the performance of the steam generator compared with the SOLERGY goals, the "inputoutput" plot shown in Figure M-3 was used. Each point on the plot is the performance of the plant on a particular day, and the line is the SOLERGY goal. By studying the plot, it can be seen that plant optimizations frequently met the energy conversion goal during October and November. There are two reasons why the energy conversion goal, depicted in Figure M-3, was routinely met. First, the operators were running the turbine at full output power much more frequently. Operating the turbine in this way is more thermodynamically efficient than running it at partial load. Second, operators developed techniques to significantly reduce the energy required to start up the steam generator/turbine. The SOLERGY computer code assumed 10 MWhrt would be required for startup. Operations developed the new startup procedure in October of 1998 and implemented it in November 1998. This reduced the required startup energy to as low as 6.6 MWhrt. This was a major reason the SOLERGY goal was often exceeded in November.

Solar Two Gross Generation vs. Energy to Steam Generator vs. SOLERGY Goal

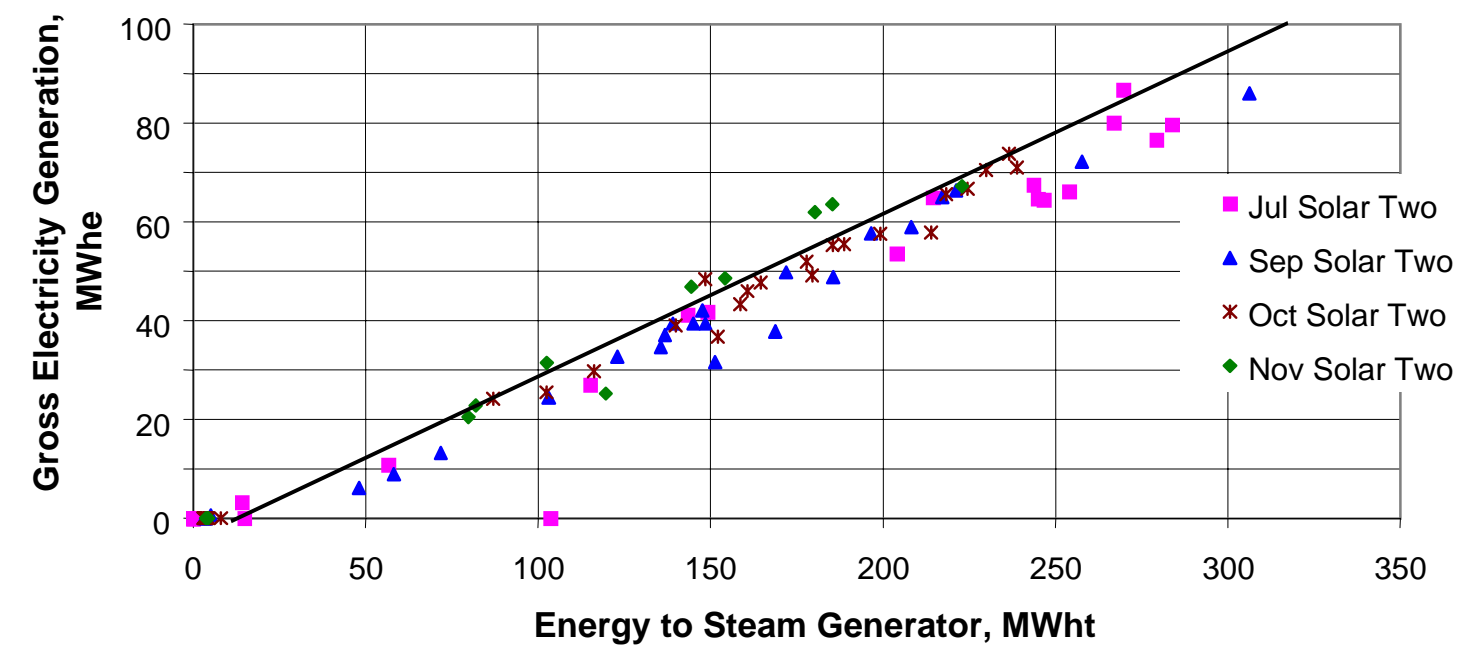

Figure M-3. Daily Conversion of Thermal Energy to Electric Energy vs. SOLERGY Goal.

\section{M.4 Discussion/Conclusions}

At design conditions of $82.5 \mathrm{~kg} / \mathrm{s}$ (655 kpph (thousand pounds per hour)) salt flow rate, inlet salt temperature of $565^{\circ} \mathrm{C}\left(1050^{\circ} \mathrm{F}\right)$, and outlet salt temperature of $288^{\circ} \mathrm{C}\left(550^{\circ} \mathrm{F}\right)$, the steam generator was designed to transfer $35.5 \mathrm{MWt}$ for a gross turbine output of $12 \mathrm{MWe}$. The design gross turbine output was not reached for several reasons. 
First, some cold salt bypassed the receiver and leaked past isolation valves in the SGS. As a result, the inlet salt temperature to the steam generator was degraded. The highest salt temperature going into the steam generator was approximately $557^{\circ} \mathrm{C}\left(1035^{\circ} \mathrm{F}\right)$. Modification of the receiver bypass loop piping and/or isolation valve and replacement of the leaking SGS valves were included in the plans for the Power Production/Test and Evaluation (T\&E) Phase of the project. These plans were not implemented due to budget restraints and the abbreviated duration of the project.

Second, the steam generator was modified to recirculate saturated water from bottom of the evaporator to the inlet of the preheater. This assured feedwater below the salt freezing point would never enter the preheater or evaporator during startup or normal operation. The recirculation limits the amount of heat the preheater transfers from the salt to the feedwater.

The preheater fouling problem was apparently the result of a deficiency in the feedwater chemistry control program. This topic is discussed in a subsequent report on the inspection of the preheater after using phosphate.

The bolted partition plate design for the preheater was reviewed. In a commercial plant design, a welded partition plate is recommended. This would eliminate the need for a gasket.

Notwithstanding the known system deficiencies, a number of the overall performance goals of the system were demonstrated, specifically:

1. The daily conversion of thermal energy to electrical energy essentially met design goals.

2. The steady-state gross cycle efficiency matched design.

3. The startup of the SGS and turbine routinely surpassed the SOLERGY goal. Startup energy usage as low as 6.6 MWht was achieved.

The evaluation of the SGS and EPGS also resulted in recommendations to optimize the design and operation of these systems. They will be presented in a subsequent report. 
Final Test and Evaluation Results from the Solar Two Project 


\section{Appendix N. Inspection of Preheater After Using Phosphate Injection System (Wilfredo de la Rosa)}

Water Technology Resources was asked to evaluate the effectiveness of the new phosphate treatment by inspecting the tubes and tube sheet of the preheater to determine the extent of scaling and deposition present. Trisodium and disodium phosphate were injected into the feedwater initially on March 1, 1999 as an additional chemical treatment to the preheaterevaporator system. The head of the preheater was opened on April 21, 1999 for this inspection.

It was previously reported that the preheater was scaled-up prior to the start of the phosphate treatment. The objective of the phosphate addition was to stop further scaling and possibly reduce the amount of scale already deposited on the interior of the tubes. In addition, the phosphate treatment was expected to provide passivation of the surfaces.

Wil de la Rosa performed the inspection during this trip, resulting in the following observations:

- The interior of the preheater had a dark red to purplish shade and appeared passivated (It was reported that the tubes and tube sheets were red prior to the treatment).

- The tubes and the tube sheet appeared much cleaner compared to its condition before the preheater was hydrocleaned in November 1998.

- The tubes in the top half (return pass) of the preheater were free of scale.

- Scaling inside some of the tubes of the lower half (first pass from feedwater inlet) was noted. The scale varied from several mils thick to $1 / 16$ inch at the 0600 position of the tubes. About $33 \%$ of the tubes in the lower section had scale. This was probably original scale, but appeared to have been diminished by the chemical treatment.

Based on these observations, it is felt that the new phosphate treatment, in the short time that it was applied to the system, already manifested its beneficial effects and indicated meeting the treatment objectives. 
Final Test and Evaluation Results from the Solar Two Project 


\title{
Appendix O. Solar Two Performance Evaluation (M. J. Hale)
}

\author{
0.1 Nomenclature \\ $\mathrm{E}_{\mathrm{INC}} \quad$ Daily incident thermal energy, $\mathrm{kWhr}$. This is the daily integrated direct \\ normal solar radiation multiplied by the total heliostat field reflective area. \\ E ENAVAIL Daily incident thermal energy during times that salt is not flowing through \\ the receiver and SOLERGY indicates that the receiver should be in \\ operation, kWhr. \\ $\mathrm{E}_{\mathrm{AVAIL}} \quad$ Daily incident thermal energy during times that salt is flowing through the \\ receiver, kWhr. \\ \%Area Tracking Daily fraction of field area that tracked the receiver, integrated over the \\ time that salt flowed through the receiver. \\ Clean Cleanliness of the field, as measured throughout the month by the plant \\ maintenance crew. \\ $\eta_{\text {field }} \quad$ General field efficiency. Includes reflectivity, cosine loss, spillage, etc. \\ $\eta_{\text {REC }} \quad$ Receiver efficiency.

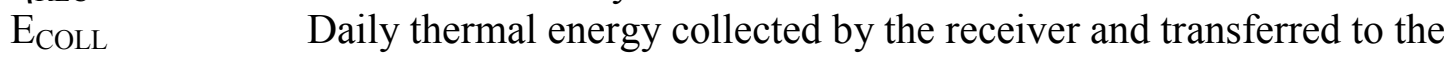 \\ working fluid, kWhr. \\ $\eta_{\mathrm{TS}} \quad$ Loss factor for energy passed through thermal storage and the heat \\ transport piping. Defined as the ratio of the thermal energy collected on \\ the salt side of the steam generator system (SGS) to the thermal energy \\ collected by the receiver throughout the month. Includes the effect of \\ thermal energy consumed during short-term hold by the SGS. \\ E $\mathrm{E}_{\mathrm{TOSGS}} \quad$ Daily thermal energy sent to the steam generator for warm up and power \\ production, kWhr. \\ $\eta_{\mathrm{SGS} / \mathrm{EPGS}} \quad$ Combined thermal efficiencies of the SGS and the electric power \\ generation system (EPGS). \\ $\mathrm{E}_{\mathrm{GROSS}} \quad$ Daily gross electric energy generated, $\mathrm{kWhr}$. \\ EPARA Daily electric parasitic energy, kWhr \\ $\mathrm{E}_{\mathrm{NET}} \quad$ Daily net electrical energy generated, $\mathrm{kWhr}$.
}

\subsection{Introduction}

The objective of Solar Two's performance evaluation and prediction activity was to determine and understand the plant's performance (on an instantaneous, daily, and annual basis) and to use the evaluation information to:

- Optimize plant performance,

- Extrapolate Solar Two's performance to general performance of molten salt central receiver technology, and 
- Recommend revisions to predictive models and engineering design methods for Solar Two and future-generation molten salt central receiver technology.

The overall approach of the performance evaluation as it applied to understanding and optimizing Solar Two performance was to compute the actual performance values (e.g., collection, production, consumption, availabilities), compare them with predicted values, and attempt to understand the agreement or disagreement between them. The first step of this process was to reduce the actual Solar Two plant data to calculate the pertinent performance parameters listed above. The performance parameters were then compared to performance predictions from a Solar Two model. The model used was SOLERGY, a computer program developed at Sandia National Laboratories that simulates the operation and power output of a solar central receiver power plant (Stoddard, 1987). The SOLERGY predictions provided a design-point performance baseline for the plant that made it possible to understand the details of why the plant was or was not performing as designed.

One way Solar Two data will assist in developing future-generation molten salt central receiver technology is by helping to develop accurate modeling techniques for the technology. However, significant uncertainties still exist in the performance modeling of the plant. An important aspect of the performance analysis is that disagreement between predicted and actual plant performance may not be due to inadequacies on the part of Solar Two, but rather inaccuracies on the part of the SOLERGY model. The primary causes of these inaccuracies are due to uncertainties associated with the following:

- Wind losses from the receiver (e.g. receiver efficiency tests under high-wind conditions),

- Calibration of instrumentation (e.g. flow meters),

- Degradation of the heliostat field,

- Modeling of plant parasitics, and

- Realistic operating patterns resulting from the plant's "human element."

As Solar Two operating experience accumulates and the performance evaluation progresses, Solar Two data also will become useful for future-generation central receiver technology designs. A significant portion of the evaluation will examine which Solar Two operating procedures and equipment types best accommodate optimized performance. These procedures and equipment types will become part of future molten salt central receiver designs. Operating procedures and equipment not conducive to optimizing plant performance should be reviewed for exclusion from potential plant designs.

\subsection{Method of Lost Electricity Analysis}

The primary aspect of the performance analysis was the lost electricity analysis, which was summarized on a monthly basis. The analysis treated the gross electricity generation predicted by the model as the design performance level for the plant. Any difference between the design performance (modeled values) and the actual performance (measured values) was translated into lost electricity. 
The results were useful in determining which operating procedures were best for plant performance and where to get the best return - in terms of power generation - on plant operation and maintenance resources.

Because the SOLERGY prediction was based on an ideal, design-level performance for the Solar Two plant's configuration and because the Solar Two design was still being debugged and operation was not yet fully optimized, Solar Two's actual performance was generally (but not always) lower than SOLERGY's prediction. In this documentation, if Solar Two underperforms relative to the model, the calculated losses are positive. If Solar Two outperforms the model, all equations here are still valid but losses become negative.

The final product of the analysis was the calculated difference between the actual and predicted gross generation. The difference (i.e., the lost electricity) was broken down into the different efficiency and availability categories responsible for the loss. The steps that led up to this final product were as follows.

\section{O.3.1 Step 1. Calculate and Process Actual Plant Performance}

The plant data used in the lost electricity analysis were:

- Insolation (Direct Normal Insolation)

- wind speed

- heliostat field cleanliness

- heliostat field availability

- energy to the working fluid in the receiver

- energy to the SGS

- gross electricity from the turbine.

The weather data and the gross electricity were metered directly at Solar Two. The energy to the working fluid and the energy to the SGS were calculated from plant data. The actual Solar Two weather data was used as input to the SOLERGY model. The energy to the working fluid was used to determine whether or not the actual solar plant thermal delivery matched the design. The energy to the steam generator and the gross electricity were used together for power plant efficiency calculations. All plant performance data were processed over five-minute intervals with the exception of the weather data, which was processed in 15-minute intervals for SOLERGY.

\section{O.3.2 Step 2. Calculate SOLERGY Predicted Performance}

Using a given month's actual weather data, a SOLERGY model of Solar Two was run to calculate the design performance of the plant in terms of energy to the working fluid, energy to the steam generator, and the gross electricity from the turbine. 
Important SOLERGY assumptions for the analysis were:

- $98 \%$ heliostat field availability.

- $\quad 95 \%$ field cleanliness, corresponding to heliostat field washing on a two-week cycle.

- Heliostats were canted and tracking properly.

- Heliostat field efficiency included what is known about existing corrosion.

Using these assumptions in the model did not necessarily mean these values agreed with actual plant conditions. Rather, their use resulted in a metric that described what the collector system should have been able to achieve. By design, $98 \%$ of the heliostats should have been available for tracking the receiver. If the heliostat field availability was below 98\%, the actual thermal collection would be lower than the predicted value. To bring the performance up to the design level, the heliostat field availability would need to be improved. All of the SOLERGY input values are based on values thought to be achievable after optimization was complete, given the plant's design configuration. However, the plant was closed down before optimization efforts were completed.

SOLERGY data inputs and outputs were on a 15-minute time interval. When finer time intervals were required for comparing the SOLERGY output with the actual data, the analysis used linear interpolation between the SOLERGY points. The SOLERGY run spanned the entire month, but each day's performance was examined separately.

\section{O.3.3 Step 3. Determine When Plant Was and Was Not Available for Operation}

This was the first step in distinguishing between availability losses and efficiency losses. The analysis began by examining the actual and modeled energy to the working fluid on a fiveminute basis. It determined at which times the Solar Two receiver was operating and the SOLERGY model determined it should have been, and at which times the Solar Two receiver was not operating but the model determined it should have been operating. If both the actual and the modeled energy to the working fluid were nonzero for a five-minute time span, the plant was classified as available during that time span. If, on the other hand, the actual energy to the working fluid was zero and the modeled was nonzero, the plant was classified as unavailable during that time span.

For isolating times when the plant was unavailable, the assumption was that all Solar Two plant availability problems would either immediately or eventually force the receiver to become unavailable. For example, an SGS unavailability significant enough to cause a loss in gross generation (as opposed to just a slight shift in the generation profile) would result in a loss of receiver availability once the hot storage tank was full and there was no more cold salt to run through the receiver. This example illustrates why it was necessary to examine the energy to the working fluid as part of the lost electricity analysis. Without looking at the energy to the working fluid, it could not be determined if the SGS unavailability resulted in a generation loss due to availability (i.e., it shut down receiver operation) or just caused a slight delay in electricity generation. 
The methodology for this portion of the analysis is illustrated in Figure O-1. Figure O-1 is a plot of the actual and predicted power to the working fluid for one day in March 1998. The total area under the curve represents the predicted energy collection for the day. The area labeled EunAVAIL represents the predicted energy to the working fluid when the actual plant was not operating. The area labeled $E_{\text {AVAIL }}$ represents the actual energy to the working fluid, which in this example was collected during a time of predicted energy collection. Thus, the plant was available during the time span encompassed by this area.

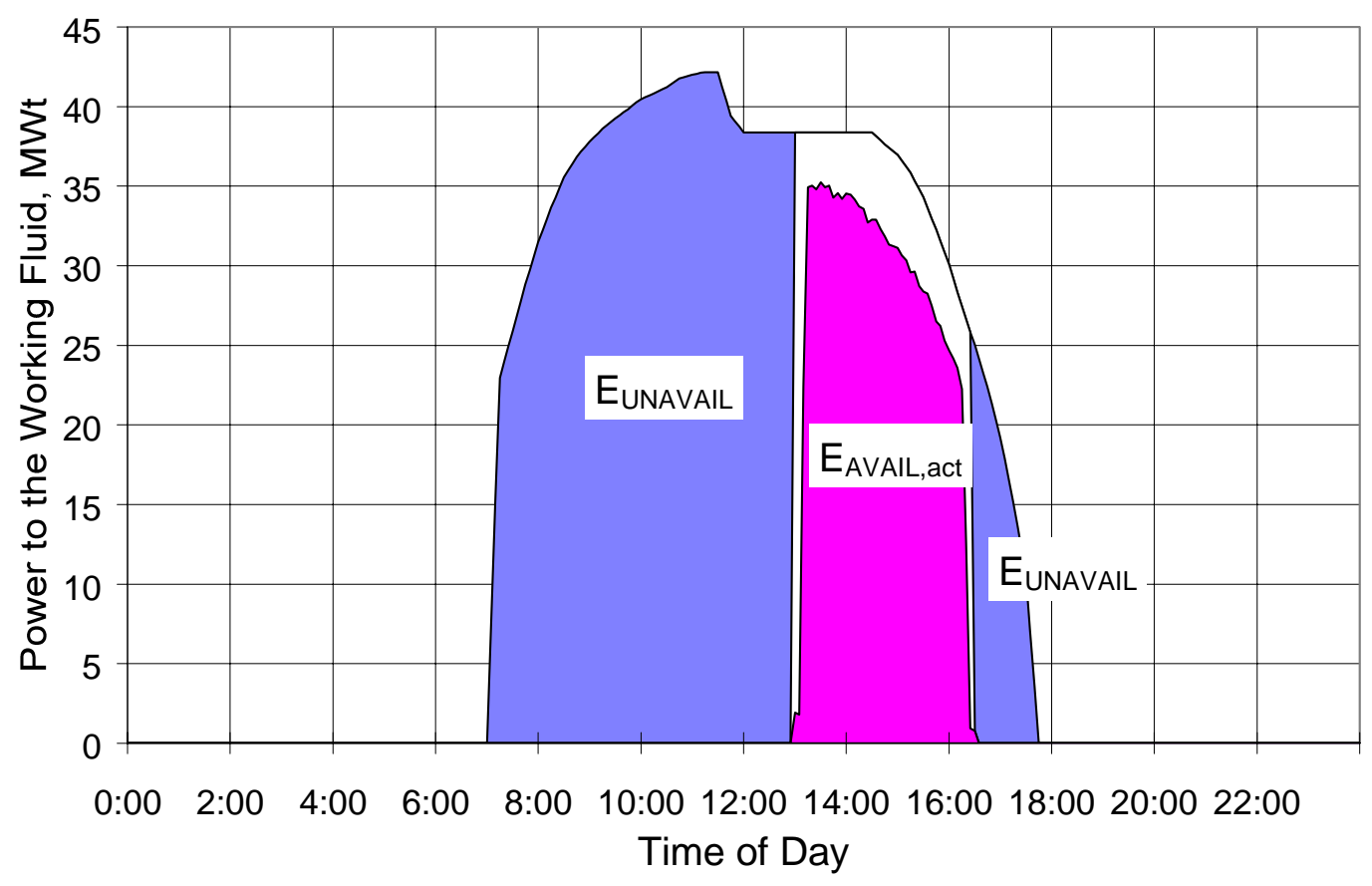

Figure O-1. Actual and predicted power to the working fluid for one day in March 1998.

It should be noted that times when the receiver was operating and SOLERGY predicted it should not have been were classified as times when the plant's performance beat the design-level performance. These times were tracked and reported in a category separate from the available and unavailable categories.

\section{O.3.4 Step 4. Attribute Losses}

The last step in the analysis broke down the plant/system losses into different categories. The loss analysis began with the energy incident on the heliostat field and tracked that energy through the plant to generated electricity. This analysis path is illustrated in Figure O-2. 


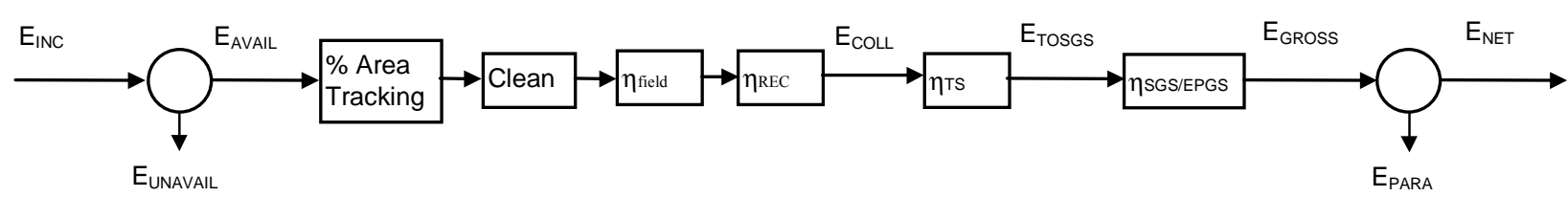

Figure O-2. Energy flow diagram for Solar Two lost electricity analysis.

The mathematical relationship for the energy flow shown in Figure O-2 is as follows:

$$
\mathrm{E}_{\text {GROSS }}=\left[\left(\mathrm{E}_{\text {AVAIL }}\right)(\% \text { AreaTracking })(\text { Clean })\left(\eta_{\text {field }}\right)\left(\eta_{\text {REC }}\right)\left(\eta_{\text {TS }}\right)\left(\eta_{\text {SGS / EPGS }}\right)\right]
$$

All of the terms in Figure O-2 could be calculated from plant data except for EUNAVAIL and $\mathrm{E}_{\text {AVAIL, }}$ which required SOLERGY results. The receiver efficiency, $\eta_{\text {REC }}$, was calculated based on testing (for low-wind conditions) and documented in Appendix B. The sensitivity to a change in each term on the right-hand side of Equation O-1 on the gross electrical production, $\mathrm{E}_{\mathrm{GROSS}}$, can be estimated by taking the partial differential of $E_{\text {GROSS }}$ with respect to that term. For example:

Sensitivity to change in available energy $=$

$$
\frac{\partial E_{\text {GROSS }}}{\partial E_{\text {AVAIL }}}=(\% \text { AreaTracking })(\text { Clean })\left(\eta_{\text {field }}\right)\left(\eta_{R E C}\right)\left(\eta_{T S}\right)\left(\eta_{S G S / E P G S}\right) .
$$

The energy lost due to a difference in the factor relative to the SOLERGY model can be estimated by multiplying the sensitivity by the magnitude of the change in the factor:

energy lost due to fewer heliostats tracking than predicted $=$

$$
\mathrm{E}_{\text {LOSS }, \% \text { TRACK }}=\left(\mathrm{E}_{\text {AVAIL }}\right)(\text { Clean })\left(\eta_{\text {field }}\right)\left(\eta_{\text {REC }}\right)\left(\eta_{\text {TS }}\right)\left(\eta_{\text {SGS / EPGS }}\right) \Delta \% \text { AreaTracking, }
$$

energy lost due to soiled heliostats $=$

$$
\mathrm{E}_{\text {LOSS }, \text { CLEAN }}=\left(\mathrm{E}_{\text {AVAIL }}\right)(\% \text { AreaTracking })\left(\eta_{\text {field }}\right)\left(\eta_{\text {REC }}\right)\left(\eta_{\text {TS }}\right)\left(\eta_{\text {SGS } / \text { EPGS }}\right) \Delta \text { Clean, }
$$

energy lost due to lower field efficiency than predicted $=$

$$
\mathrm{E}_{\text {LOSS,FIELD }}=\left(\mathrm{E}_{\text {AVAIL }}\right)(\% \text { AreaTracking })(\text { Clean })\left(\eta_{\text {REC }}\right)\left(\eta_{\text {TS }}\right)\left(\eta_{\text {SGS / EPGS }}\right) \Delta \eta_{\text {field }} \text {, }
$$

energy lost due to lower receiver efficiency than predicted $=$

$$
\mathrm{E}_{\mathrm{LOSS}, \mathrm{REC}}=\left(\mathrm{E}_{\mathrm{AVAIL}}\right)(\% \text { AreaTracking })(\text { Clean })\left(\eta_{\text {field }}\right)\left(\eta_{\mathrm{TS}}\right)\left(\eta_{\mathrm{SGS} / \mathrm{EPGS}}\right) \Delta \eta_{\mathrm{REC}},
$$

energy lost due to greater heat losses from the storage tanks and thermal transport system than predicted $=$ 


$$
\mathrm{E}_{\text {LOSS,TS }}=\left(\mathrm{E}_{\text {AVAIL }}\right)(\% \text { AreaTracking })(\text { Clean })\left(\eta_{\text {field }}\right)\left(\eta_{\text {REC }}\right)\left(\eta_{\mathrm{SGS} / \mathrm{EPGS}}\right) \Delta \eta_{\mathrm{TS}}
$$

energy lost due to lower SGS and EPGS thermal efficiency than predicted $=$

$$
\mathrm{E}_{\mathrm{LOSS}, \mathrm{SGS} / \mathrm{EPGS}}=\left(\mathrm{E}_{\text {AVAIL }}\right)(\% \text { AreaTracking })(\text { Clean })\left(\eta_{\text {field }}\right)\left(\eta_{\mathrm{REC}}\right) \Delta \eta_{\mathrm{SGS} / \mathrm{EPGS}},
$$

The form of the delta is determined by the predicted values chosen as the reference case. For example, Equation O-8 would be computed as:

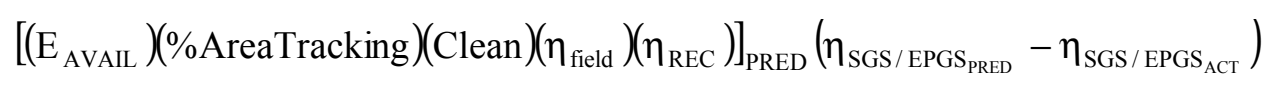

where the subscripts PRED and ACT indicate predicted and actual (i.e. SOLERGY and Solar Two) terms, respectively.

The sum of the loss estimates in Equations O-3-O-8 is not equal to the total lost electricity. This is because the loss expressions assume that all factors are independent, when in actuality they are not. Because the same reference (predicted) is used in Equations O-3-O-8, they do give the relative contribution of each loss factor, so the actual losses can be quantified. To apportion that part of the lost electricity not accounted in the partial differential equations, all loss factors are multiplied by the following correction factor:

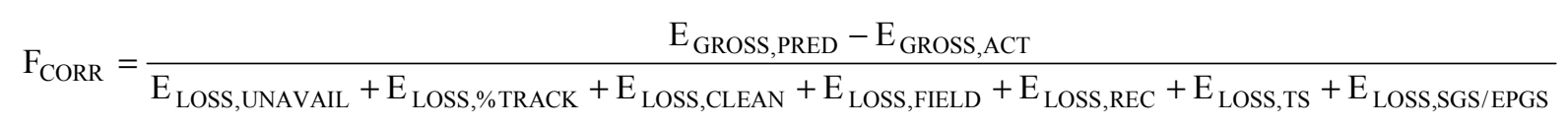

The equations and energy flow diagram in this section were originally documented in a July 15 , 1998 memo by S. Faas (Faas, 1998).

It is important to note that EUNAVAIL in Figure O-2 goes through a similar loss analysis that $\mathrm{E}_{\mathrm{AVAIL}}$ does. This method of loss attribution was used rather than attributing all generation losses during these times to plant availability losses because it more accurately categorized losses. The lost electricity analysis served as a tool for plant optimization, and this method of dealing with E UNAVAIL provided a more accurate picture of the electricity that would be gained if a specific problem were corrected. Using this method, the electricity loss attributed to plant availability is the actual amount that would be gained if the plant availability were at the design level. Correcting the availability problems would not, however, influence the plant's performance in the fraction of the field area tracking, receiver efficiency, etc.

The results of the lost electricity analysis were summarized in monthly plots. Examples of these plots for January 1998, March 1998, June 1998, July 1998, and September 1998 are shown in Figure O-3 through Figure O-7. Other months had too much outage time to complete monthly reports. The pie chart in each monthly statement quantifies the gross electricity lost due to various causes. The advantage of this plot is that it quantifies the performance in terms of electricity. The whole pie represents the difference between the total SOLERGY predicted gross generation and the actual Solar Two generation. The individual pie wedges quantify the fraction 
of loss attributed to each factor. Another advantage of this plot is that it explicitly calls out the availability losses; all of the wedges from Miscellaneous Availabilities through Operator Discretion are availability losses.

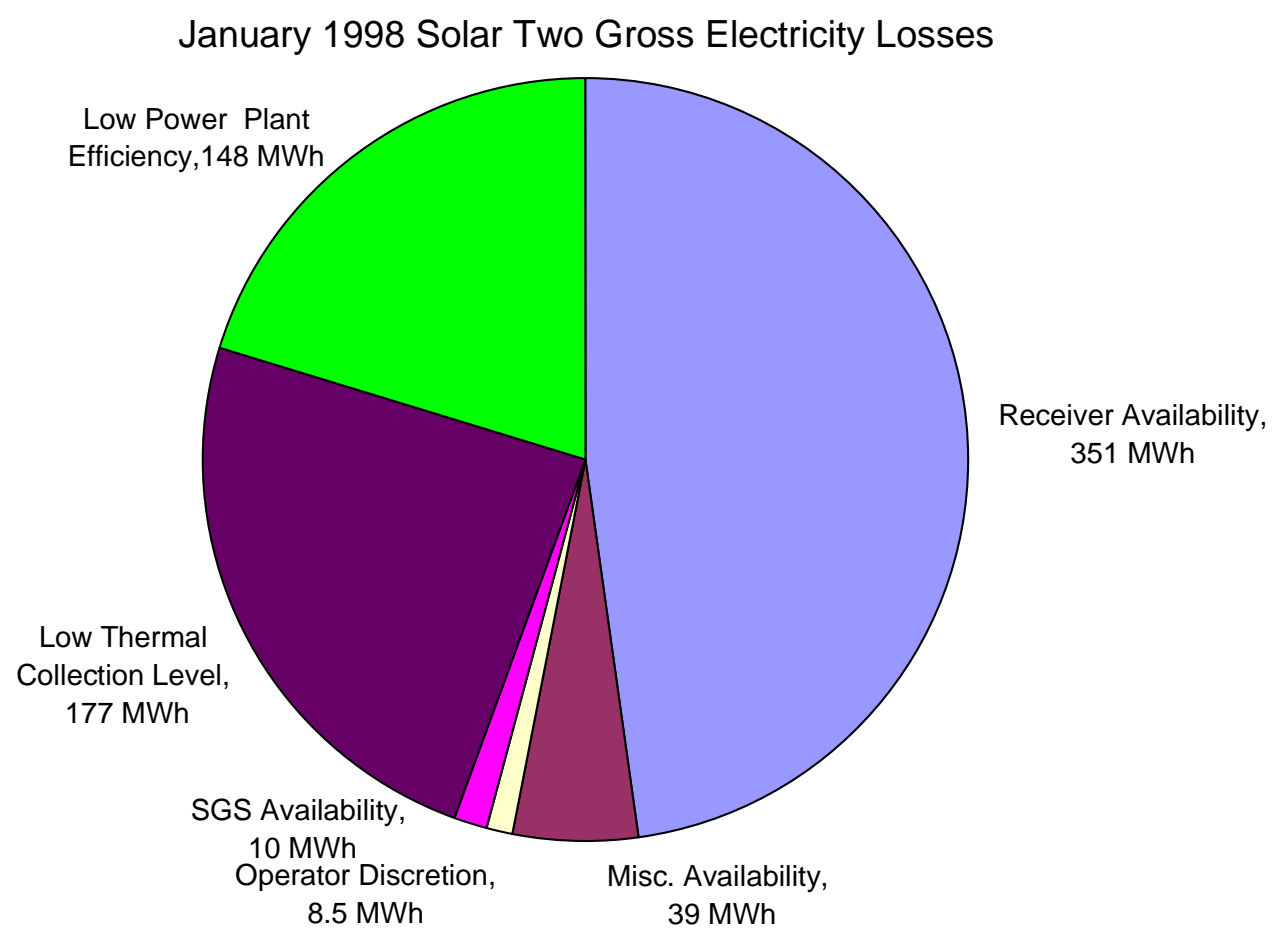

Figure O-3. Gross electricity losses for January 1998.

\section{March 1998 Solar Two Gross Electricity Generation \& Losses \\ SOLERGY Predicted Generation: 2027 Mwhe; Solar Two Generation: 490 MWhe}

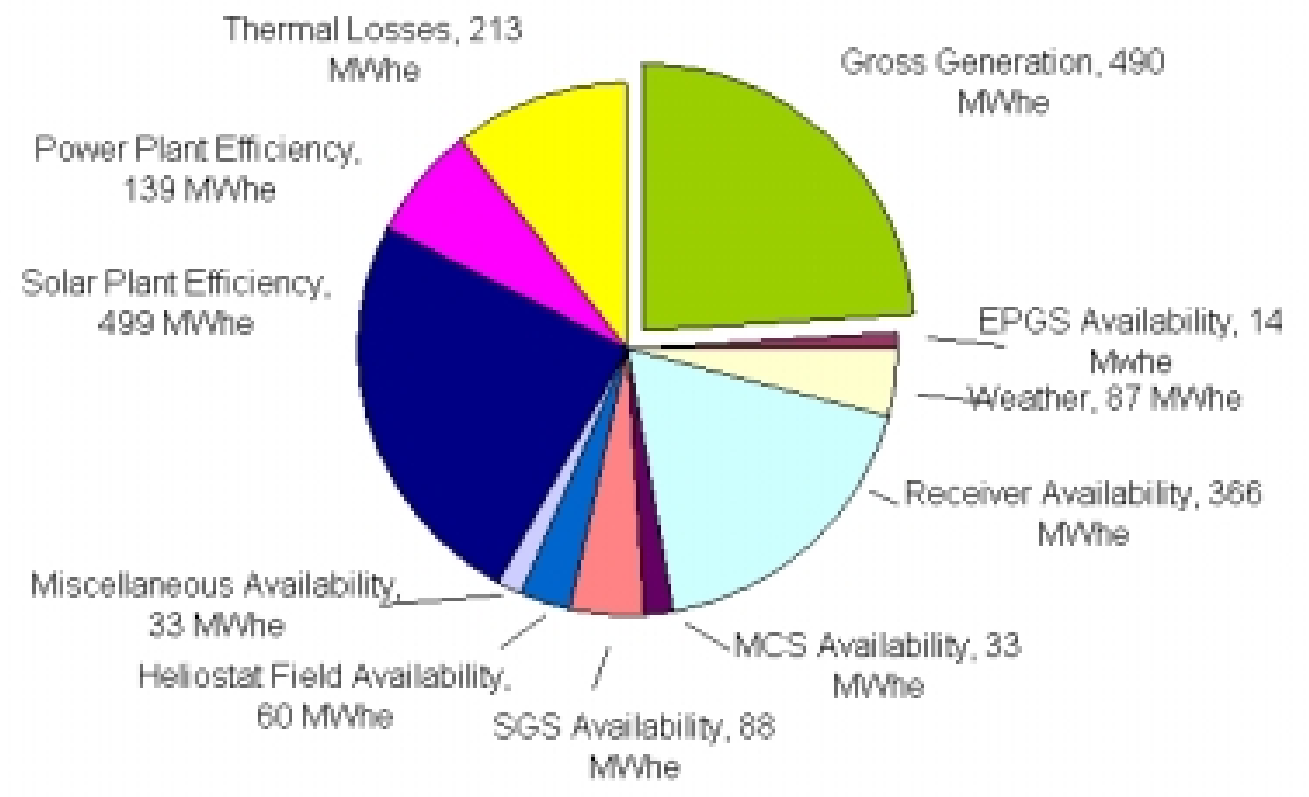

Figure O-4. Gross electricity generation and losses for March 1998. 


\section{June 1998 Solar Two Gross Electricity Generation \& Losses SOLERGY Predicted Generation: 2729 MWhe}

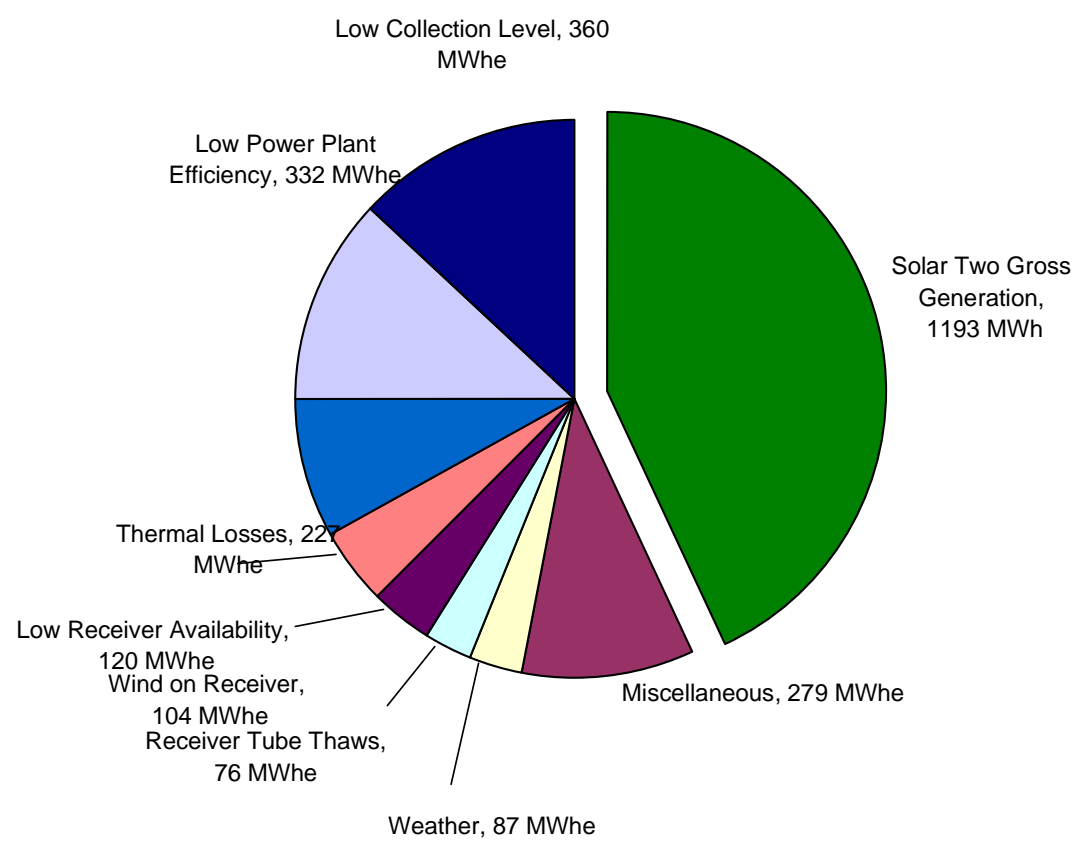

June 1998 Solar Two Plant System Effectivenesses (Actual System Efficiency/SOLERGY System Efficiency)

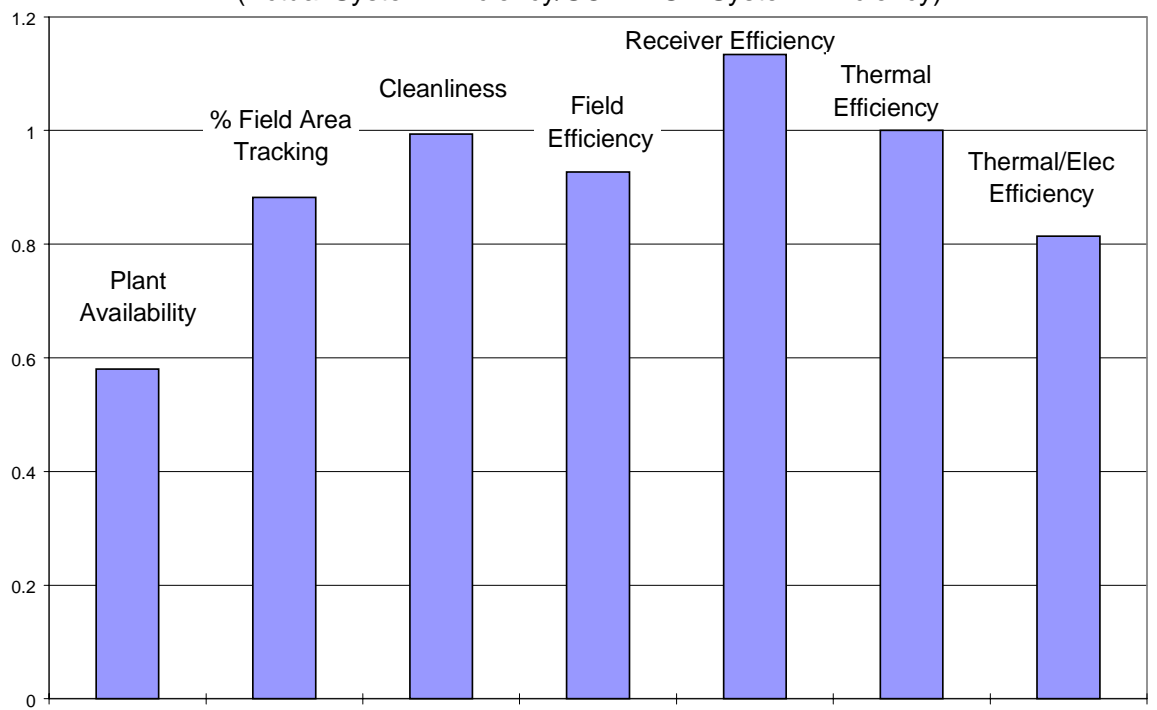

Figure 0-5. Gross electricity generation and loss and system effectivenesses for June 1998. 
July 1998 Solar Two Gross Electricity Generation \& Losses

SOLERGY Predicted Generation: 3030 MWhe; Solar Two Generation: 898 MWhe

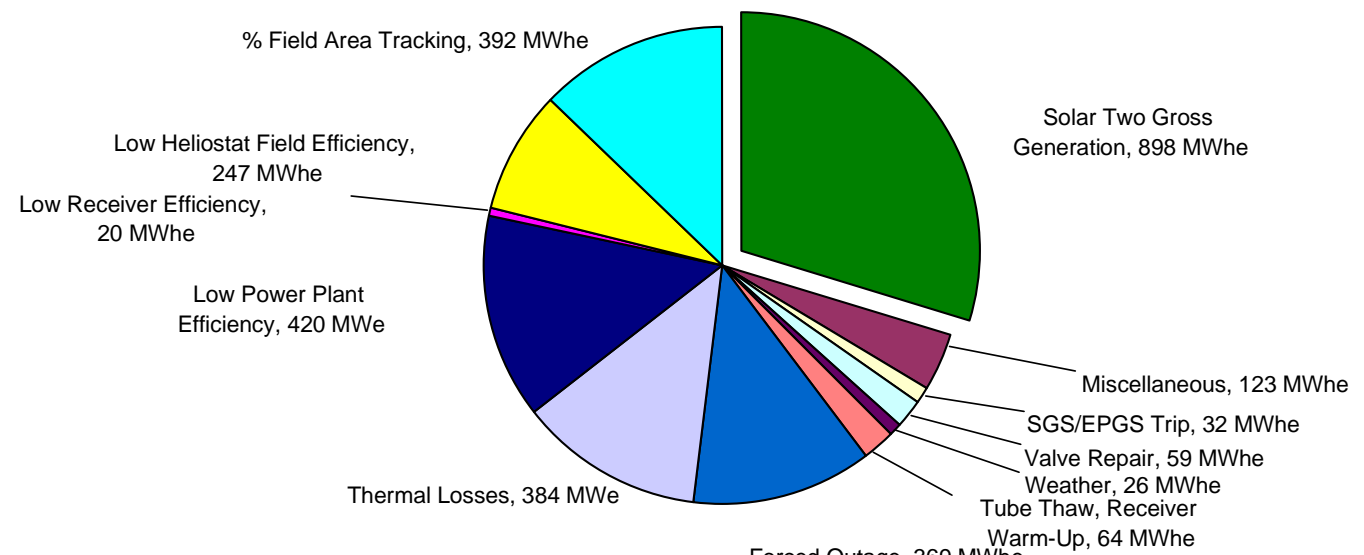

Forced Outage, 369 MWhe

July 1998 Solar Two Plant System Effectivenesses

(Actual System Efficiency/SOLERGY System Efficiency)

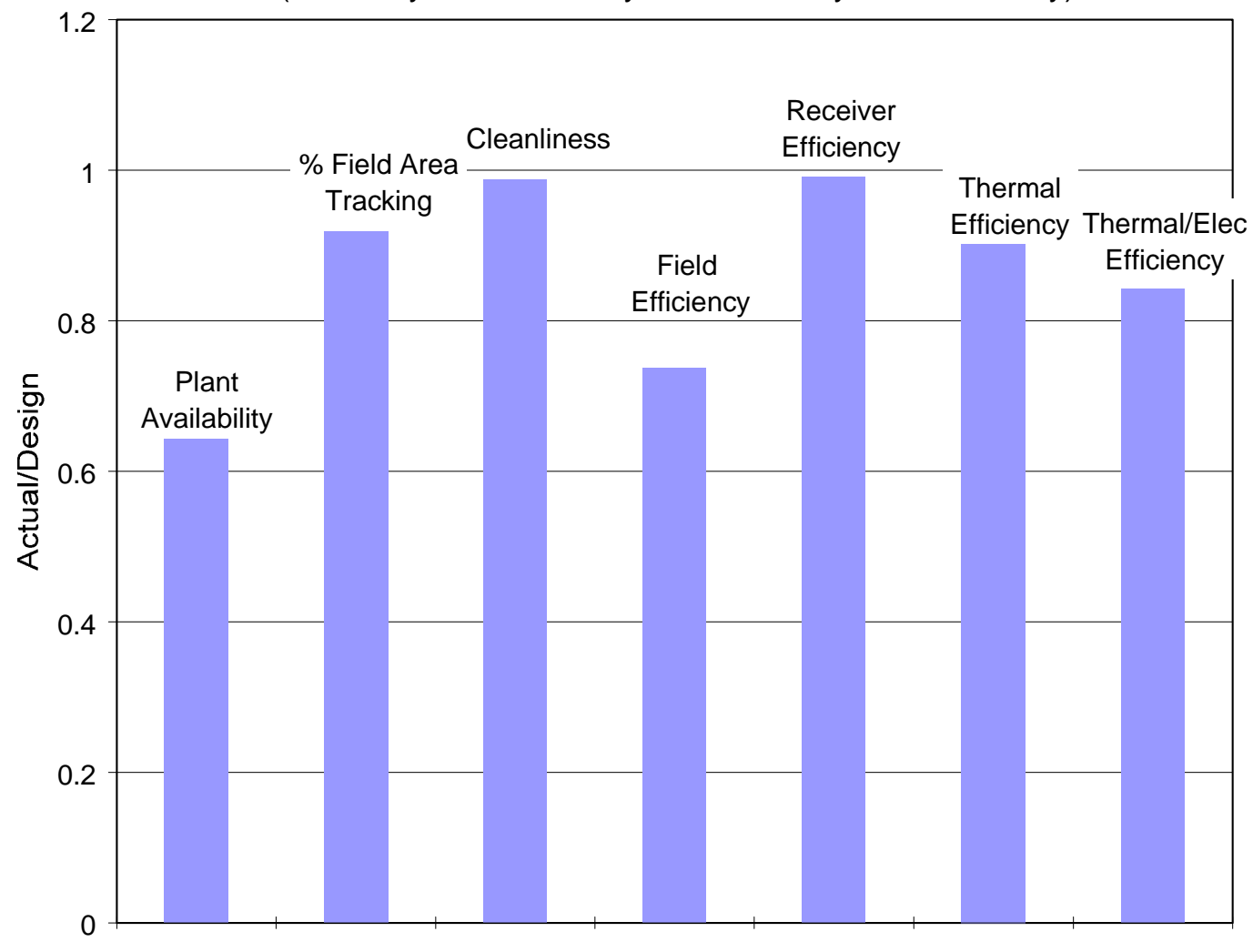

Figure 0-6. Gross electricity generation and loss and system effectivenesses for July 1998. 
September 1998 Solar Two Gross Electricity Generation \& Losses SOLERGY Predicted Generation: 2131 MWhe; Solar Two Generation:

892 MWhe
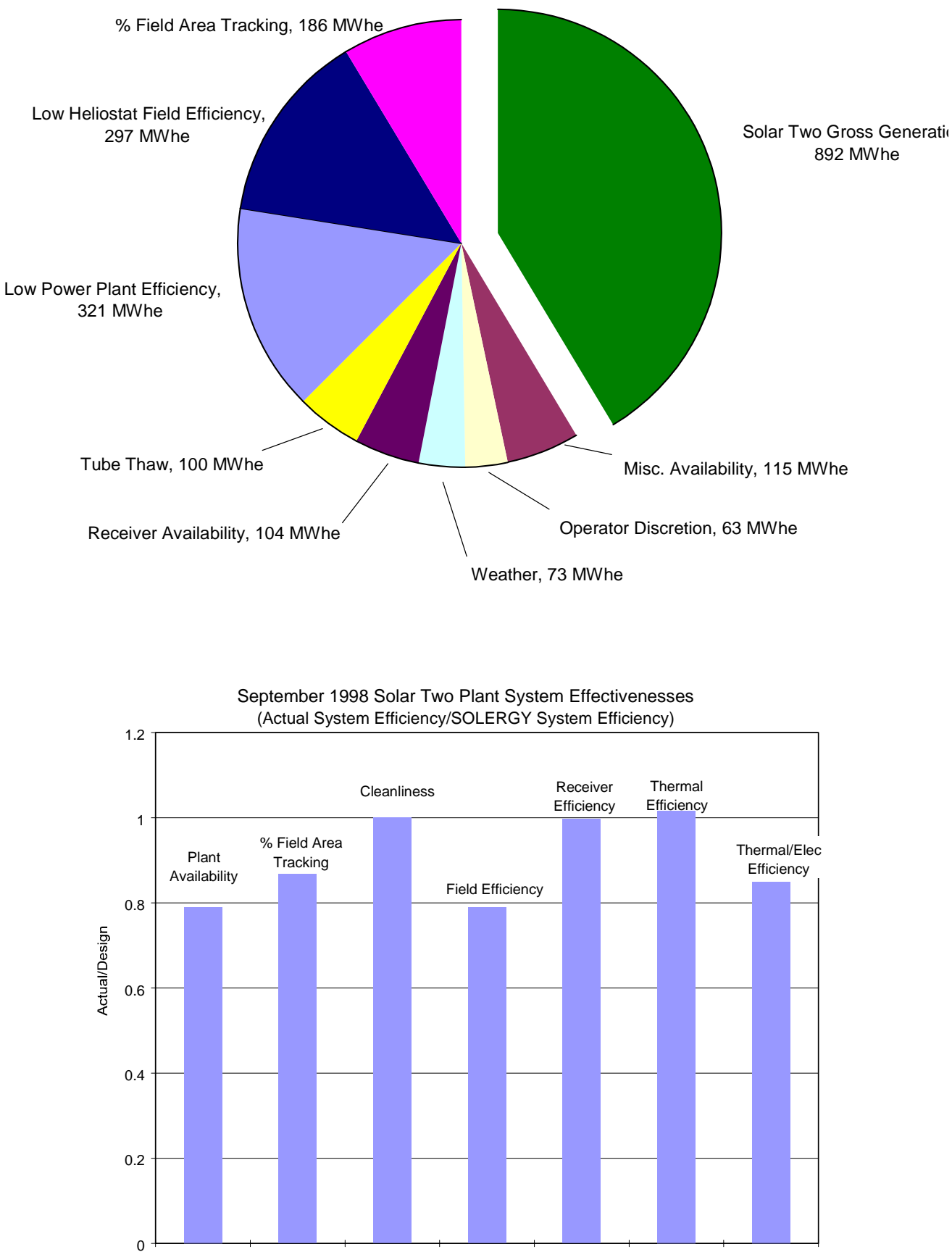

Figure 0-7. Gross electricity generation and loss and system effectivenesses for September 1998. 
Each bar of the "effectiveness" chart in the monthly statement is a ratio of the Solar Two system efficiency to the SOLERGY system efficiency. A bar with a value of one represents a Solar Two system that met predicted performance; any value less than one represents performance below the predicted level. The September 1998 plant availability was approximately $80 \%$ of design availability, which was $90 \%$. It also shows that the field cleanliness, the receiver efficiency, and thermal efficiency were at design level, whereas the percentage of the field tracking the receiver (field availability) and field efficiency were below design. It should be noted that the thermal-toelectric conversion efficiency losses were more significant than typical in September because the EPGS was run continuously for characterization tests.

As pointed out earlier, there is still uncertainty in several areas of the data and modeling. The two potentially most significant uncertainties are the SGS flow meter and the receiver efficiency during windy conditions. The SGS flow meter readings are likely higher than the actual flow rate and the actual receiver efficiency is at times lower than that calculated under non-windy test conditions.

\subsection{Model Validation}

In validating the SOLERGY model for Solar Two, to the extent possible, actual plant conditions were incorporated into the model as opposed to design plant conditions. At a minimum, this included actual heliostat availability (daily average) and cleanliness.

The areas chosen for model validation were:

- energy to the working fluid,

- thermal losses between the receiver and the SGS,

- operating efficiency of the SGS/EPGS, and

- electric parasitic consumption.

Preliminary results show that during ideal weather conditions (i.e., no wind or high, thin clouds), SOLERGY did a fairly good job of predicting energy collected by the working fluid. The plot of power to the working fluid for September 30, 1998 in Figure O-8 shows an example. This day had morning clouds that cleared abruptly followed by ideal weather. During the time SOLERGY determined the receiver should be collecting energy for this day, the results show $6.5 \%$ error between the measured and predicted data. (Notice that Solar Two actually "beat" SOLERGY at the end of the day. This is because the operators tracked the sun into the ground.) This margin of error is indicative of days with no equipment or weather problems.

On windy days, however, this analysis pointed out discrepancies that need further investigation. An example of this is shown in the September 29, 1998 power to the working fluid plot, shown in Figure O-9. (It should be noted that the Solar Two plant was shut down early on September $29^{\text {th }}$ for reasons unrelated to the weather.) This plot includes two SOLERGY curves; each used a different receiver radiation/convection loss model. The first SOLERGY radiation and convection losses from the receiver surface are based on a calculation from a study conducted by Seibers and Kraabel (Seibers and Kraabel, 1984). The calculations show the losses to be 30.5 $\mathrm{kW} / \mathrm{m}^{2}$ for an average wind speed of $5 \mathrm{~m} / \mathrm{s}$. Because the total area of the Solar Two receiver was 
$100 \mathrm{~m}^{2}$, the total loss was 3.1 $\mathrm{MW}_{\mathrm{t}}$. The second loss model, which was also based on the Seiber and Kraabel derivation, takes variation in wind speed into account. The difference between both the modeled collections and the actual is greater than $20 \%$.

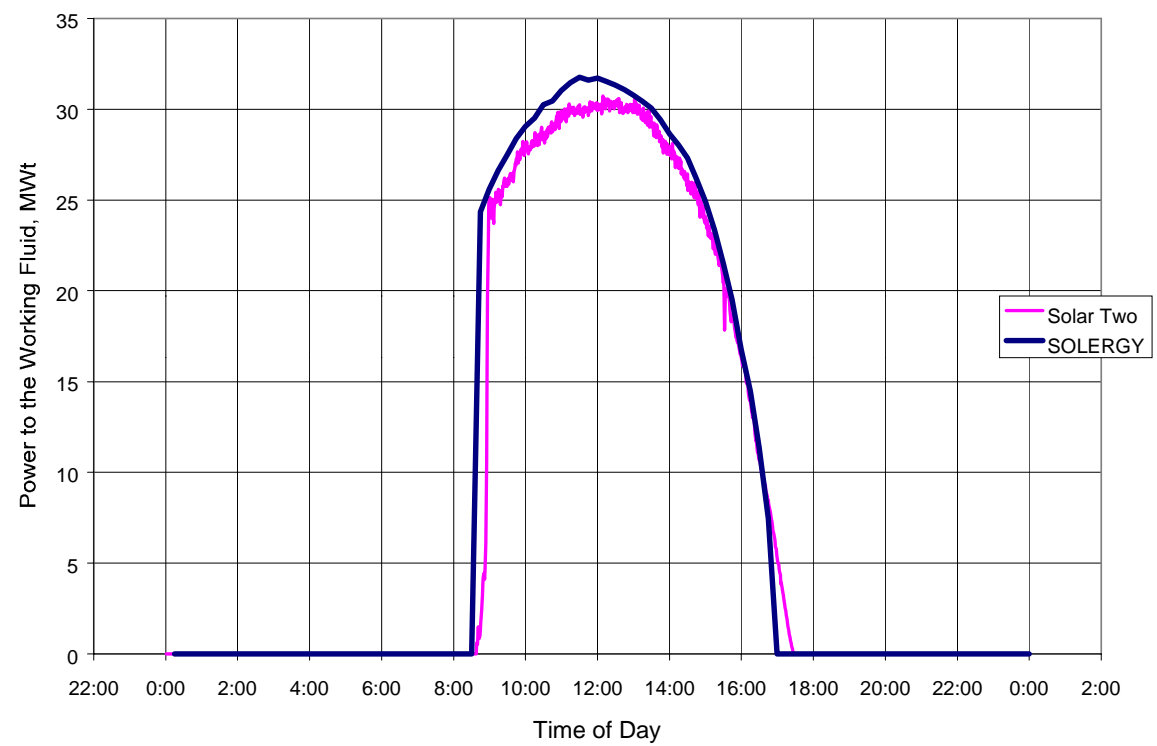

Figure O-8. Actual and predicted power to the working fluid, September 30, 1998.

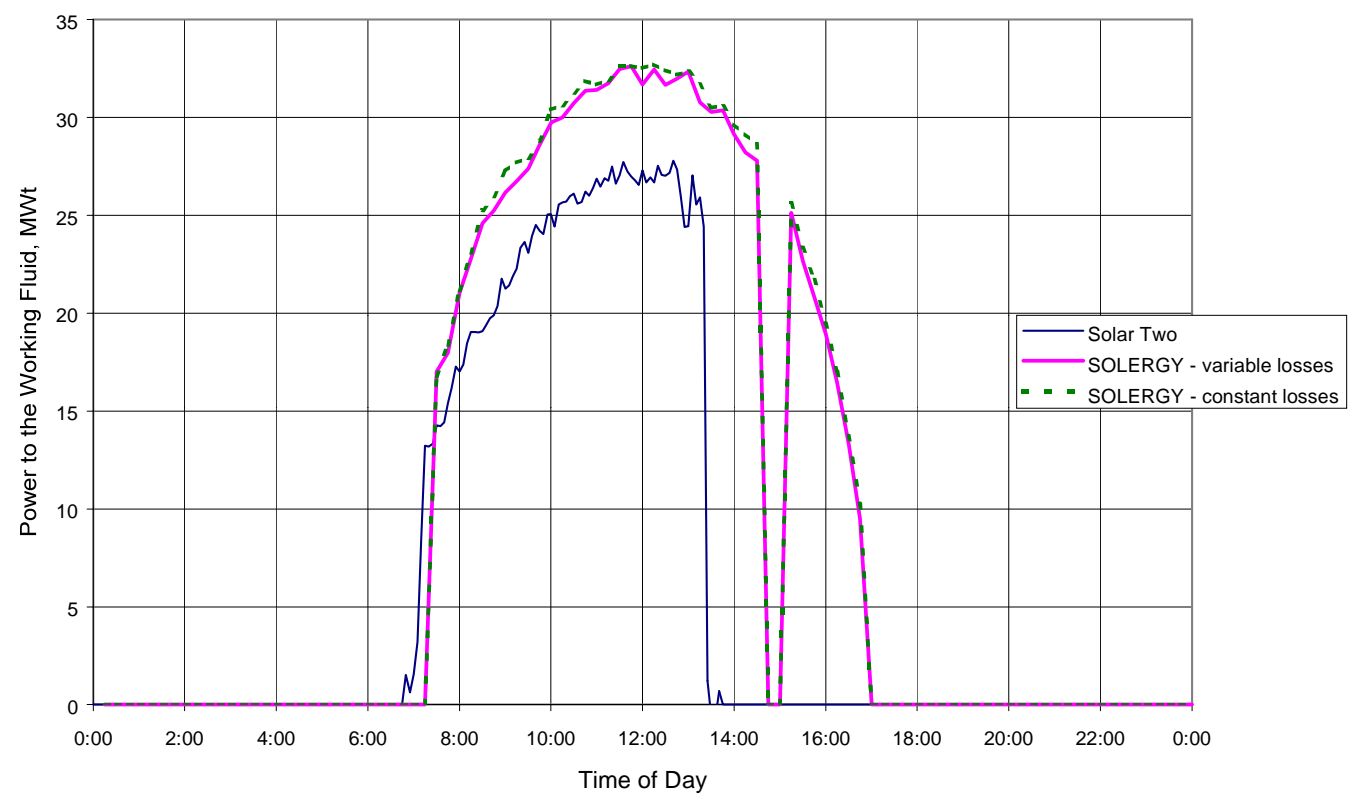

Figure O-9. Actual and predicted power to the working fluid, September 29, 1998.

\subsection{Conclusions and Recommendations}

The Solar Two performance evaluation activity was able to help with the plant optimization objectives. Using the relatively general results of the lost electricity analysis, abnormally large 
system losses were tracked down and the process of examining the details of these losses was ready to begin. However, this process needed to continue and expand to be useful in improving the plant performance.

To better understand the sources of the losses and to optimize the performance process, the model validation must be completed. The biggest challenge in model validation is better characterizing the heliostat field conditions and the receiver losses. The analysis should also be extended to include electric parasitic consumption.

\subsection{References}

1. Stoddard, D. L., SOLERGY - A Computer Code for Calculating the Annual Energy from Central Receiver Power Plants, Sandia National Laboratories Report SAND 86-8060, May 1987

2. Memo from S. Faas to M.J. Hale, subject: Review of Lost Solar Electricity Analysis Methodology Handout, July 15, 1998.

4. Stoddard, D. L. and J. S. Kraabel, Estimating Convective Energy Losses from Solar Central Receivers, Sandia National Laboratories Report SAND84-8717, April 1984 


\section{Appendix P. Evaluation of Plant Operations November 1, 1997 to April 8, 1999 (G. Kolb)}

After several construction-related problems were solved at Solar Two, the plant operated on a regular basis between November 1, 1997 and November 13, 1998. On the latter date, another major construction-related failure occurred that led to a three-month outage of the plant. After correcting the problem, the plant was restarted in mid-February to collect final critical test and evaluation (T\&E) data for the receiver. In addition, operation of the complete plant was demonstrated to potential developers of the first commercial power tower (Solar Tres, to be built in Spain). The final day of operation was April 8, 1999.

In this appendix, the operation of the plant during the final 1.5 years of the Solar Two project is evaluated. The evaluation focuses on problems that occurred and associated solutions. A detailed discussion of the problems (and successes) that occurred during the design and operations phase of Solar Two are documented in detail within the Bechtel/ESI document entitled Topical Report on the Lessons Learned, Project History, and Operating Experience, Solar Two Project. The analysis conducted here compliments the Lesson Learned report by emphasizing those problems that had the biggest impact on lost energy production.

A problem was defined to occur anytime the daily solar energy collection was greater than 10\% below the SOLERGY computer code prediction for that day ${ }^{1}$. SOLERGY predicts that Solar Two should have operated anytime daily Direct Normal Insolation (DNI) exceeded $\sim 2.5$ $\mathrm{kWh} / \mathrm{m}^{2}$. However, during the evaluation period, the plant usually did not operate unless DNI exceeded $4 \mathrm{kWh} / \mathrm{m}^{2}$ because the operating crews were learning to operate the plant and they did not want to attempt startup during very cloudy weather, i.e., typical for days with DNI between 2.5 and 4. Consequently, in the analysis conducted here, problems were not identified if the plant did not operate when daily insolation dropped by 4 , and all such days were attributed to a "weather outage."

Listed in Table P-1 is a grouping of the problems that led to outages at Solar Two. To gauge the severity of the problems, they are ordered in terms of the number of days they affected the plant. Some problems led to multiple day outages, while others were of short duration (e.g., a partial to a full day) but occurred several times ${ }^{2}$ this difference can be seen by comparing columns 1 and 2.

In the paragraphs that follow, problems that accounted for $90 \%$ of the days listed in Table P-1 are described, along with solutions that were either implemented at Solar Two or are proposed for the first commercial plant. Descriptions of the problems are based on information from several sources. This includes the Solar Two daily report generated by the plant operators and the expert opinion/analyses by the engineering staff. For more detailed information concerning most of the problems listed, the Lessons Learned report should be consulted.

1 The SOLERGY prediction was corrected for the actual state of the heliostat field on a given day.

2 A more quantitative breakdown of the energy losses at Solar Two can be found within Appendix O. 


\begin{tabular}{|c|c|c|}
\hline $\begin{array}{l}\text { Number of } \\
\text { Days } \\
\text { Problem } \\
\text { Affected } \\
\text { Plant }\end{array}$ & $\begin{array}{l}\text { Number of } \\
\text { Events }\end{array}$ & Problem Description \\
\hline 60 & 1 & Downcomer pipe ruptured \\
\hline 42 & -- & Plant shut down for weekend \\
\hline 32 & -- & Special testing performed \\
\hline 31 & 31 & Receiver tube plugging delayed startup \\
\hline 24 & 24 & Operators did not operate plant \\
\hline 21 & 1 & Warped partition plate in steam generator superheater \\
\hline 20 & 20 & High winds hampered operation of plant \\
\hline 19 & 7 & Heliostat aiming problems caused burning of receiver ovens \\
\hline 18 & 18 & Master control system/Interlock logic system trips \\
\hline 17 & 17 & Receiver valve malfunctions \\
\hline 12 & 4 & Receiver tube leaks \\
\hline 11 & 1 & Receiver panel replacement \\
\hline 7 & 1 & Hot Tank inspection \\
\hline 6 & 6 & Interruptions in power supply to heliostat field \\
\hline 6 & 1 & Poor water chemistry in steam generator \\
\hline 6 & 5 & Heat trace failure \\
\hline 5 & 4 & Heatup of steam generator after plant outage \\
\hline 4 & 4 & Malfunction of steam dump to condenser \\
\hline 4 & 4 & Operator error during startup of steam generator \\
\hline 3 & 1 & Electronics failures due to rain intrusion \\
\hline 3 & 3 & Malfunction of heliostat dynamic aim point system (DAPS) \\
\hline 3 & 3 & Steam-turbine generator trip \\
\hline 3 & 3 & Steam-generator trip \\
\hline 3 & 2 & Heliostat bias problems \\
\hline 3 & 3 & Receiver flow control cycled during cloudy weather \\
\hline 2 & 2 & Salt-flow meter failure \\
\hline 2 & 2 & Air conditioner failure in remote control buildings \\
\hline 2 & 2 & Maintenance error \\
\hline 2 & 2 & Condenser vacuum problem \\
\hline 2 & 2 & External grid restriction limited power production \\
\hline
\end{tabular}

\section{P.1 Downcomer Pipe Ruptured (60)}

Problem: The plant experienced a lengthy outage from mid-November 1998 to late February 1999 due to a buckling failure of the salt-downcomer pipe. The root cause was the binding of the pipe thermal-expansion mechanism. The outage was longer than necessary because project 
money wasn't immediately available to fix the pipe. The piping expansion system was faulty due to an ill-defined design interface between the receiver supplier, who provided the piping on top of the tower, and the architect engineer, who provided the piping within the tower itself. The amount of piping thermal expansion across the interface was not properly accounted for during the design phase.

Solution: Thermal expansion calculations across the interface were reworked and the piping system was modified to accept the anticipated amount of expansion.

\section{P.2 Plant Shut Down for Weekend (42)}

This was not a technology problem. From early November 1998 to the end of the project in April 1999, Solar Two did not operate on the weekends due to budget constraints.

\section{P.3 Special Testing Performed (32)}

This was not a technology problem. Throughout the evaluation period, the plant was often derated or brought offline to perform T\&E activities.

\section{P.4 Receiver Tube Plugging Delays Startup (31)}

Problem: During fill of the receiver in the morning, the salt within one or more tubes on the windward side of the receiver would sometimes freeze. This delayed startup for up to several hours until the tube thawed. The problem was especially tenacious when ground wind speeds approached $32 \mathrm{~km} / \mathrm{h}(20 \mathrm{mph})$. This occurred because of the inability of the receiver header ovens to exceed the salt freezing point during windy conditions. In addition, there was an $20-\mathrm{cm}$ (8-inch) tube section at the interface between the receiver surface and the oven that was difficult to heat with solar heat or oven heat, especially when the wind was blowing hard. When the preheat heliostats were placed on the receiver in the morning, the residual salt film, attached to inside tube wall from the previous day's run, melted and flowed downward towards the lower oven interface. If the interface or the tubes within the oven were too cold, the salt would freeze and form a plug. The ovens did not reach design point temperature because of air leaks.

Solution: The oven heatup problem could be solved by installing several tightly-sealed baffles within the interior of the receiver oven assembly and improving the seal at the interface between the oven and receiver panel. Late in the project, a few new prototype baffles and seals were installed that seemed to significantly improve the areas in which they were tried. However, the prototypes were not fully evaluated due to time and budget constraints.

\section{P.5 Operators Did Not Operate Plant (22)}

Problem: There were several days when the operating crew did not operate the plant for part of a day; startup was delayed until well after sunrise or the receiver was shut down a significant time before sunset. Not much is stated in the operator logs regarding why startups were delayed, 
but it is often stated that early shutdown of the plant was caused by clouds. However, examination of the insolation data for these days often show that the full sun returned after the shutdown, suggesting that the receiver could have been restarted and additional energy collected for several more hours. Discussions with plant staff indicated there were several reasons why restart was not attempted: 1) during mostly cloudy weather, the receiver control system went into "cloud standby" mode several times, which was a difficult situation for the operators learning to operate the plant, 2) a conservative operating policy was in force because the stress put on the plant components due to multiple restarts of the receiver was considered to be risky, and 3) there was not a major push to collect maximum energy at Solar Two during this initial phase of plant operation in which T\&E activities were the main thrust. In addition, the power produced by Solar Two was not sold to the utility grid. Thus, there was no direct economic incentive to produce maximum power.

Solution: A more aggressive operating policy should be employed in the first commercial plant. This may occur naturally, because the power will be sold to the grid and maximum energy collection will be the primary motive. The heliostat field should track the sun "out of the ground" in the morning, and "into the ground" at night. Such a policy was standard practice during the latter years of operation at Solar One. Salt circulation should be used to keep the receiver warm during cloudy weather in anticipation of a quick restart when the sun returns. If operators are certain the sun will not return for the rest of the day, the receiver should be drained, but contingency plans should be developed for refill and restart later if the weather forecast is incorrect and the sun returns. To achieve the SOLERGY energy collection goal during partly cloudy weather, the operators should operate the receiver anytime the sky over the plant is less than $50 \%$ covered with clouds.

\section{P.6 Warped Partition Plate in Steam Generator Superheater (21)}

Problem: A scheduled outage occurred from mid-December 1997 to January 5, 1998 to rectify a noticeable degradation in steam generator performance. The superheater was opened and an examination of pass partition cover showed several of 22 mounting bolts to be loose and most of the gasket material to be missing. The absence of a gasket allowed a portion of the saturated steam at the inlet to the superheater to bypass the superheater tubes, thus degrading performance.

Solution: The gasket failed because it only had a maximum service temperature of $315^{\circ} \mathrm{C}$ $\left(600^{\circ} \mathrm{F}\right)$. The manufacturer provided a replacement gasket with a higher service temperature.

\section{P.7 High Winds Hampered Operation of Plant (20)}

Problem: Wind outages could prevent plant startup, as well as cause the plant to be shutdown after successful startup. Winds prevented plant startup because receiver panels could not warm up above salt flow temperature, since DAPS was designed to operate with wind speed $<8 \mathrm{~km} / \mathrm{h}$ ( $<5 \mathrm{mph})$. Also, receiver ovens were leaky on windward side and had trouble raising temperature above salt flow temperature. Winds shut down the plant after startup because heliostats were generally stowed when winds approached $50 \mathrm{~km} / \mathrm{h}(30 \mathrm{mph})$. 
Solutions: The panel heatup problem could be fixed by modifying DAPS to work with higher wind speeds. For example, more heliostats could preheat the receiver panels on a windy day. Oven seals should be improved so winds do not infiltrate the oven and lower the temperature. The frequency of winds that shutdown the plant after startup could be reduced by increasing the wind speed at which heliostats are stowed. The heliostats were conservatively stowed at Solar Two when wind approached $50 \mathrm{~km} / \mathrm{h}(30 \mathrm{mph})$, even though the design stow speed for the Martins was $65 \mathrm{~km} / \mathrm{h}$ (40 $\mathrm{mph}$ ). Since the field was old and degraded, the conservative philosophy was adopted. At Solar One during its final years, high winds did not cause significant outage time because the heliostat field was sturdier and the operators grew comfortable with operation in higher wind conditions. High winds also did not hamper startup of Solar One because salt freezing was not an issue.

\section{P.8 Heliostat Aiming Problems Cause Burning of Receiver Ovens (19)}

Problem: Excessive burning of the exterior surface of the upper ovens on the NE side of the receiver was a nagging problem in April 1998. Ovens were damaged when temperatures exceeded $1100^{\circ} \mathrm{C}\left(2000^{\circ} \mathrm{F}\right)$. Heliostat pointing errors led to the high oven temperatures.

Solution: A considerable effort was devoted to finding the source of the aiming problem. As described in the Lessons Learned report, problems were found in 1) the surveyed location of the receiver, 2) out-of-date correction factors in the sun position algorithm, 3) errors in the surveyed locations of the 32 relocated Martin Marietta (MM) heliostats, 4) poor canting of the mirrors, and 5) reverse rotation (on the order of one revolution) in the drive motors of the Lugo heliostats after an instruction to move. Several of these problems were corrected, but aiming problems continued to plague the project. Aim points were progressively brought closer to the belt of the receiver to help alleviate the spillage loss. The ultimate solution for the commercial plant is to use a new heliostat field that is pre-canted prior to installation and is governed by an algorithm that corrects for pointing errors, like that developed by Ken Stone of Boeing (Stone and Jones, 1999).

\section{P.9 Master Control System/Interlock Logic System Trips (18)}

Problems: Several problems are described in detail in the Lessons Learned report. They are related to slow computer speed, communication failure between subsystem components, software inadequacies, and reuse of old/unreliable Solar One control hardware. An additional complication was the numerous vendors used to provide software and hardware in an attempt to save money.

Solution: The Solar Two control system structure should not be used as the model for the first commercial power tower. Commercial distributed control systems are available from a number of manufacturers that combine the control, logic, and communication functions in one package of hardware and software. The first commercial power tower should take advantage of commercial control software and assign responsibility to one vendor. 


\section{P.10 Receiver Valves (18)}

Problems: One-half of the valve problems were within the air supply and discharge circuits to the receiver inlet tank. Failures were due to control signal problems, diaphragm failures, or unknown malfunctions. On at least one occasion, an air valve was plugged with salt, suggesting a tank overfill may have occurred.

The remaining nine problems were with valves designed to pass salt. Three outages were attributed to the receiver vent valves (valves seized) and two were caused by the safety valve at the discharge of the cold salt pump (valve opened too soon). Valve packing leaks and local valve control problems led to the remaining four outages.

Solutions: The air supply and discharge system to the inlet tank was unnecessarily complex. The system actively fed and bled air to the tank throughout the day in an attempt to improve control of the salt flow to the receiver during normal operation and during emergency shutdown following a station blackout. Engineering analysis and experiments at Solar Two have shown that active feed and bleed of air is not necessary. Rather, the inlet tank only needs to be charged with compressed air once per day during receiver startup. A simple, reliable system should be implemented in the commercial plant to perform this function, as demonstrated in small receiver experiments at Sandia prior to Solar Two.

Replacing the original ball-type valve with a gate-type valve eliminated receiver vent valve problems. Ball valves should not be used in molten-salt service, as documented in depth in the Lessons Learned report. Installing a stiffer spring that could operate at the elevated temperature associated with molten salt service eliminated the safety valve problem.

Valve packing and control problems will likely continue to occur on occasion at the commercial plant. The Lessons Learned report describes options for reducing the frequency of their occurrence, including the development of advanced salt-circuit design that requires far fewer salt valves than were used at Solar Two.

\section{P.11 Receiver Tube Leaks (12)}

Problem: Two tube ruptures and two pinhole leaks caused outages at Solar Two. All tube problems were in Panel \#5 on the western side of the receiver. Each tube rupture took approximately four days to repair because high winds hampered the repair process. When the first pinhole leak occurred, the plant was shut down and the tube was repaired over a two-day period. A week later, another pinhole leak occurred that only shut down the plant for part of a day to allow an inspection. The receiver was restarted and continued to operate with the leak.

Solution: Problems with the tubes in panel W5 were related to the panel being more susceptible to tube plugging during startup. This problem was discussed above. When a tube plugged, it would become very hot and subject to high thermal stress. The stress could result in a complete rupture of a tube or a pinhole leak. Solving the tube-plugging problem during receiver startup should therefore reduce the frequency of tube leaks. 
The receiver design allowed a bad tube to be replaced within 16 hours. While in theory this could be done, it was not demonstrated at Solar Two because the repair operation was not optimized during the relatively short operational period of the plant and because poor lighting at night and/or high winds often hampered welding. The receiver design and/or maintenance procedures in the commercial plant should allow the replacement of an individual tube to be performed at night in high $(50 \mathrm{~km} / \mathrm{h}(30 \mathrm{mph}))$ winds.

\section{P.12 Receiver Panel Replacement (11)}

Problem: Because of the several tube leaks in panel W5 described above, it was decided to replace this panel with the available spare in mid-May, 1998. Eleven days of energy collection during a prime solar month was lost due to this outage. High winds delayed weld up of the new panel for four days during this period. The frequency of windy days during May is relatively high in the Mojave Desert.

Solution: The receiver design allowed a panel to be replaced within 16 hours. For this to be accomplished, winds must remain calm and much preplanning and staging of maintenance equipment must be performed before work begins. Another panel (W2) was replaced for a special experiment in late 1997 within 16 hours, subtracting lost time needed to repair the panellifting crane. Alternatively, one might delay panel replacement until the annual two-week outage that would normally occur during the low-insolation and low-wind winter months. Several tube repairs may be required during the delay interval, but individual tube repairs could be performed relatively quickly, as discussed above.

\section{P.13 Hot Tank Inspection (7)}

Problem: During switchover of the salt supply from the cold storage tank to the hot storage tank in late August 1998, the wall of the hot tank flexed several inches for a short period of time. To be safe, it was decided to shut down the plant, drain and inspect the hot tank, and to determine the cause of the flexure.

Solution: The inspection did not reveal any damage to the hot tank. Analyzing the tank pressure relief system design and the salt switchover procedure indicated that a 7-to-14 kPa (1-to-2 psi) pressure transient was possible. To fix the problem, the tank pressure relief system was replaced with a simple vent and the timing for valve switching between the cold and hot tank was altered.

\section{P.14 Interruptions in Power Supply to Heliostat Field (6)}

Problem: Voltage droop and loss of power supply to the heliostat field caused several hundred heliostats to lose communication with the main heliostat computer. During some severe voltage surges, heliostat controller boards were damaged. The power supply problems were caused by lightning and, on one occasion, failure of an electricity supply pole due to high winds. To restore communication, the operations crew had to walk through the field and cycle the individual power supplies to the affected heliostats. This proved to be tedious and time-consuming. Next, operators attempted to anticipate lightning problems and began to shut down the plant and 
depower the field anytime lightning was reported in the area. This did not help because communication to hundreds of heliostats was still lost due to the manual depowering.

Solution: The heliostat control technology at Solar Two is vintage 1980. In the commercial plant, state-of-the-art control electronics should be used that are protected against lightinginduced voltage surges. In addition, the control architecture should allow the power supply to the entire field to be turned off and rebooted within a few minutes without requiring the local toggling of the power supplies at the individual heliostats.

\section{P.15 Poor Water Chemistry in Steam Generator (6)}

Problem: The performance of the steam generator degraded over time due to an expected fouling on the waterside of the heat exchangers. The plant was shut down and the preheater was found to be clogged with iron oxides. The evaporator also showed signs of fouling. Poor attention to water chemistry was determined to be the root cause of the problem. The outage time was lengthened because it took a few days for the evaporator to cool enough to allow inspection and cleaning; the thick evaporator shell has considerable thermal mass. After outage work was completed, it took two additional days to reheat the evaporator to operating temperature. (The latter two days are included in the more general outage category in Table P-1, "Heatup of Steam Generator after Plant Outage.")

Solution: Good water chemistry is important at any Rankine cycle power plant and there was no excuse for the poor conditions found at Solar Two. Standard industry practice must be followed religiously. The time required to cool down and heat up the steam generator was excessive at Solar Two and needs to be reexamined in the commercial plant. The potential revenue lost could justify the development of a clever method for rapidly heating and cooling the system. For example, the Kramer Junction solar plants recently demonstrated a 16-hour cooldown of the evaporator to allow entry by personnel when air temperature drops to between 60 and $71^{\circ} \mathrm{C}(140$ and $160^{\circ} \mathrm{F}$ ). Several fills and drains with cold water are initially used to remove residual heat. Next, the manway to the evaporator shell is opened and fans are used to blow cool air into the evaporator air space. If necessary, personnel could wear ice jackets and other heat-protective clothing typically worn by firemen.

\section{P.16 Heat Trace Failure (6)}

Problem: The heat trace at Solar Two proved to be reliable after the total rework of the construction flaws in 1996. In general, each circuit contains primary and backup cabling, both of which must fail to cause a problem. This redundancy was a good design feature that significantly reduced the number of heat-trace related outages. The problems reported here were isolated to a few valves and an occasional tripped breaker that required resetting to correct.

Failure of the redundant heat trace cables on the receiver bypass valve occurred due to a salt leak from a valve seal and the resulting corrosion on the heating elements. Three weeks later, the same event happened again, and it was attributed to use of an incorrect gasket material or incorrect torque (or a combination of the two) that was applied the first time. 
Failure of the redundant heat trace cables on the receiver vent valves also occurred. This was attributed to the damaged heater cables from replacing ball-type valves with gate-type valves. (Replacement of these valves is described above.)

Solution: Heat trace failures were usually discovered during plant startup when the operators reviewed data on the heat trace computer. The format for information display on this computer was very poor and there were no audible alarms to notify the operators when a circuit was bad. In the commercial plant, an improved format with alarms should be able to identify problems with a particular heater circuit well in advance of a plant startup. Given this advance warning, there is a good chance the heater circuit could be repaired during the nightly shutdown, thus avoiding a plant outage.

\section{P.17 Reference}

Stone, K. W. and S. A. Jones (1999) "Analysis of Solar Two Tracking Error Sources," Proceedings of the ASME Renewable and Advanced Energy Systems for the $21^{\text {st }}$ Century Conference, April 11-15, 1999, Lahaina, Maui, HI. 
Final Test and Evaluation Results from the Solar Two Project 


\section{Appendix Q. Test and Evaluation of Solar Two Heat Trace System (G. J. Kolb)}

\section{Q.1 Introduction}

Tests were performed at Solar Two to evaluate the design and operation of the plant heat trace subsystem. Because of the relatively high freezing point $\left(205^{\circ} \mathrm{C}\right)$ of the molten salt heat-transfer fluid, electric heating circuits should be applied to the piping, valves, and other components within the salt pumping loops to ensure that it remains in a liquid state. To maximize net electricity production from the power plant, electricity consumption by the heat trace (i.e., parasitics) should be minimized during the online and offline periods. A detailed test program was implemented at Solar Two in the fall of 1998 to identify preferred design features and operating procedures to reduce heat trace parasitics. The results of the test program are described below.

\section{Q.2 Design, Operation, and Reliability of the Solar Two Heat Trace System}

The heat trace subsystem was designed by Raychem, Bechtel, and Boeing Corporations. Approximately 360 thermocouples or resistive temperature detectors (RTDs) actuated $\sim 212$ separate electric heater circuits. The general locations of the circuits are depicted in Figure Q-1.

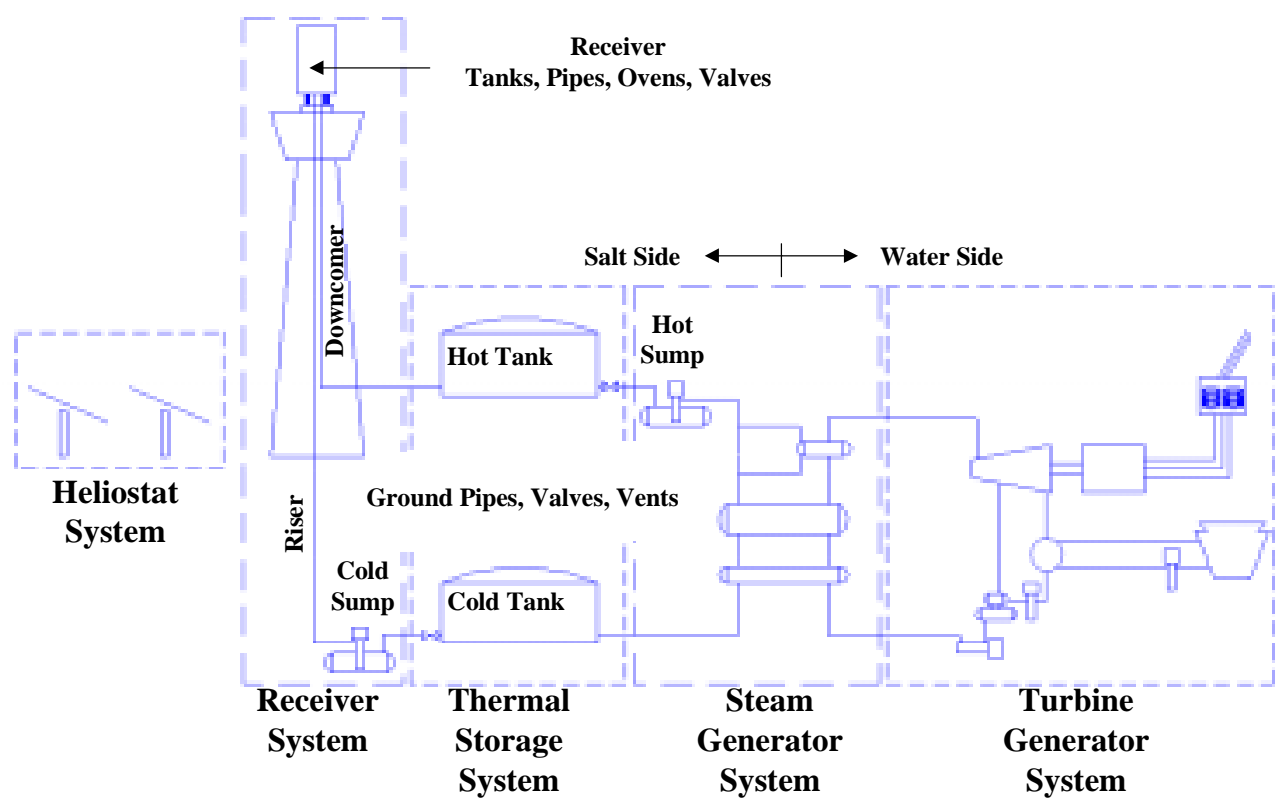

Figure Q-1. Electric heater circuits were located on the "salt side" at Solar Two. 
Immersion heaters were located below the level of salt in the hot tank, cold tank, hot sump, and cold sump. External heaters were applied to the piping/valves/instruments that transport the salt up and down the tower (riser/downcomer), as well as the piping at ground level that connected the storage tanks to the steam generator system (SGS).

On top of the tower, heat trace was applied to all receiver components that could not be heated by the heliostat field. These components included the two internal control tanks, internal piping/valves, and the upper/lower receiver ovens. The ovens heated the unexposed sections of the receiver tubes just above and below the section heated by the heliostat field and the receiver headers. The ovens are box structures that contain heating elements. The elements heated the air space in the box that surrounded the unexposed tubes; the design was similar to ovens used to cook food in the home. In order for the ovens to work efficiently, a good seal must be maintained at the interface between the exposed and unexposed receiver tubes (see Figure Q-2).
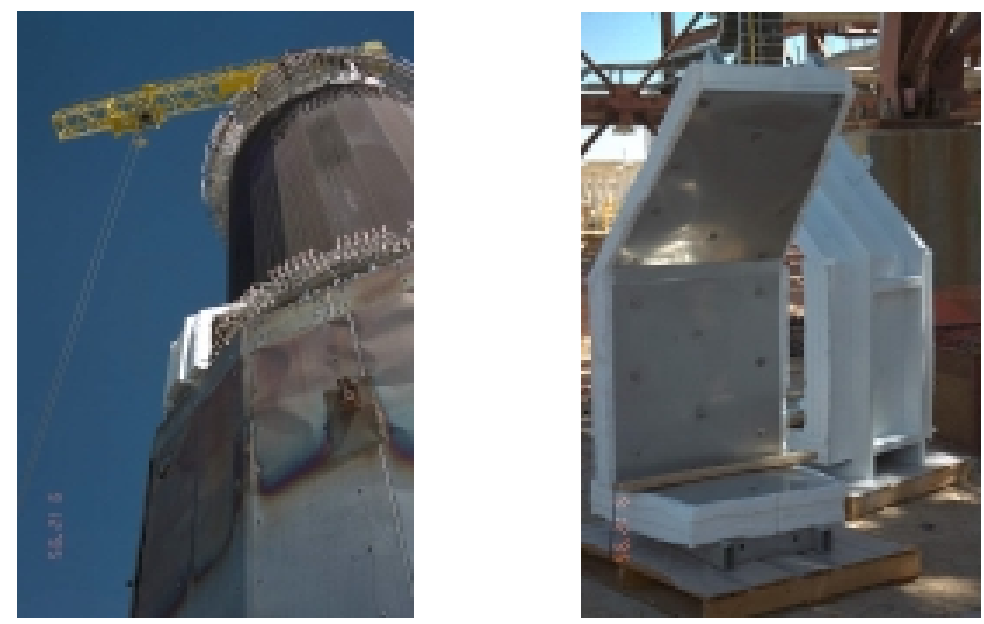

Figure Q-2. Ovens structures surround the receiver header pipes. Seals must be good for ovens to be effective. Sealing problems often made it difficult to heat up the ovens on the windward side of the receiver.

At the end of the operating day, salt was drained from the receiver, riser, and downcomer back to the thermal storage system at ground level. The thermal storage and SGS remained filled with salt at all times. After power operations were completed for the day, a small auxiliary salt pump circulated salt from the thermal storage system to the steam generator and back to storage. Salt equipment at ground level was kept warm through a combination of salt circulation and heat trace.

The total connected load of the 212 heat trace circuits was $\sim 850 \mathrm{~kW}$. If all circuits were actuated all the time, the heat trace parasitics would exceed $20 \mathrm{MWh} /$ day, whereas the goal set during the design phase was less than $2 \mathrm{MWh}$. To achieve the goal, the Solar Two designers recognized that parasitics would be high if heat trace was not turned off within the receiver system during overnight shutdown. Design features were therefore included to allow for nightly draining of the receiver system, followed by heatup in the morning; thin-walled piping and generous amounts of heat tracing were installed to allow for rapid heatup from ambient to operating temperature in $\sim 2$ hours (see Figure Q-3). 


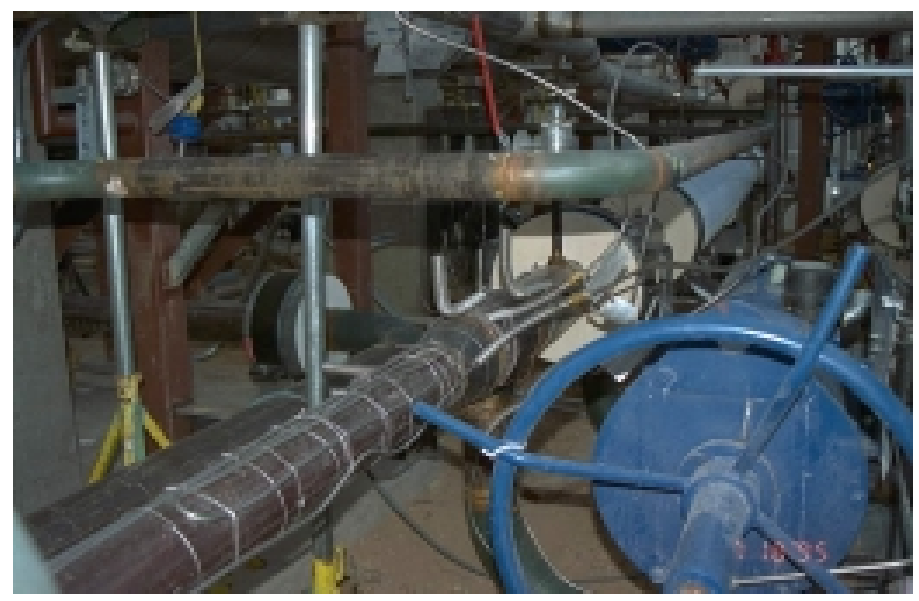

Figure Q-3. Multiple heat trace cables were applied to pipes that drained nightly to allow a two-hour heatup time the next morning. One or two spare cables were installed as well. A lesson learned was that heat trace must be installed uniformly (i.e. constant value of $\mathrm{W} / \mathrm{ft}$ ); otherwise, hot spots can occur that lead to pipe corrosion. A nonuniform section of heat trace is seen in this photo (see loop back). During the rework of the heat trace system in 1996, nonuniformities were eliminated.

The designers also recognized that parasitics could be significantly reduced in all salt systems by lowering the heater actuation setpoints to a level below the normal operating temperature of the salt loops. For example, if the normal operating temperature of salt flowing through a pipe is $290^{\circ} \mathrm{C}$, the setpoint for the circuit on that pipe should be set below $290^{\circ} \mathrm{C}$ to prevent heat trace actuation, but above $205^{\circ} \mathrm{C}$ to prevent salt freezing.

A comment is warranted regarding the reliability of this fairly complex system. Soon after plant dedication, in June 1996, it was discovered that most heat trace circuits were not installed properly, largely due to a lack of quality control inspections and also due to cable lengths being too long for the combined pipe lengths and valve bodies. This led to unacceptable thermal stresses and corrosion in certain areas of the salt-piping system (see Figure Q-3). The plant was shut down for $\sim 4$ months to correct the problems. After proper reinstallation of the heat trace, the system was reliable until final plant shutdown in April 1999, and only a few plant outages occurred due to heat trace problems (see Appendix P).

\section{Q.3 Evaluation of Heater Usage Prior to Test}

Heater consumption was calculated by analyzing data contained in the Solar Two data acquisition system and engineering drawings of the heat trace circuits. Data entries were logged each time a heat trace circuit is actuated. By integrating the data with EXCEL-based software, ${ }^{1}$ the equivalent number of full-power hours each circuit operated each day was determined. The full-power hours were multiplied by the connected load for the circuit, listed on engineering drawings, to estimate daily electric energy consumption. To check the validity of the estimates,

1 Visual-basic software was developed by Scott Faas and Scott Jones of Sandia National Laboratories. 
the energy consumption for all circuits was summed and the total was compared to the total heater energy consumption measured by a watt-meter at Solar Two.

From the time of plant dedication (June 1996) until the initiation of the test described here (test interval was September 23, to November 15, 1998), no significant effort was made at Solar Two to reduce heat trace parasitics. Heater setpoints were set conservatively high in all circuits (often equal to or above the normal operating temperature of the salt within a pipe) and the heater circuits in the receiver system were not turned off during the overnight period. Consequently, the plant was not operated in the optimized mode intended by the plant designers and parasitic usage was very high. During this period, parasitics on a typical online and offline day were similar to those labeled as "Pre-Test" in Table Q-1 (September 1 to 22, 1998). Offline days were especially bad; comparing the energy used $(9.7 \mathrm{MWh})$ to the maximum possible in a day (20 $\mathrm{MWh})$, it can be seen that the average duty cycle for the entire plant was $\sim 50 \%$.

Besides determining that parasitics were unacceptably high, analysis of the pre-test data in Table Q-1 provided some insights that helped improve the parasitic reduction test. One insight was that valve parasitics were a small fraction of the total. Thus, to ensure a high degree of valve reliability, it was decided to avoid daily thermal cycles and to use the heaters to maintain all valves in a warm state during overnight shutdown (see Figure Q-4).

Another insight was that heater parasitics could be significantly reduced by using the thermal heat from flowing salt to keep lines warm as long the heater set points were lowered below the salt temperature. This can be seen by comparing the heat trace usage during online days (flowing salt) vs. offline days for categories "Rcvr Inlet Tank," "Rcvr Exit Tank," "Riser," "Downcomer," "Rcvr Flow," and "Piping on Ground."

\section{Q.4 Results of Phase 1 Test}

The heat-trace parasitic reduction test was divided into two phases. In Phase 1, parasitic reduction was accomplished with the following methods.

- Salt in receiver, riser, and downcomer was drained after shutting down the receiver for the day, and these heater setpoints were reduced to $100^{\circ} \mathrm{F}^{1}$ (except for valves, which were kept warm overnight). A few hours before flowing salt through the receiver the next operating day, heater setpoints were raised the salt operating temperature. After establishing salt flow, heater setpoints were reduced to below operating temperature.

- Setpoints in components that always contained salt (ground level) were reduced to significantly below normal operating temperature.

- Heat trace on air receiver tank was deactivated because it was not required.

\footnotetext{
${ }^{1}$ Heater setpoints in the receiver were reduced to $100^{\circ} \mathrm{F}$ during shutdown and not completely turned off, because experience at other experimental installations operated by Boeing suggested that the reliability of heat trace and piping is improved if moisture formation can be avoided by keeping temperatures above the dew point.
} 
Table Q-1. Test results

\begin{tabular}{|c|c|c|c|c|c|c|c|c|c|c|}
\hline $\begin{array}{l}\text { Component } \\
\text { Group }\end{array}$ & $\begin{array}{c}\text { Connected } \\
\text { Heater } \\
\text { Load } \\
(\mathbf{k W})\end{array}$ & $\begin{array}{l}\text { Parasitic } \\
\text { Reduction } \\
\text { Method }\end{array}$ & $\begin{array}{c}\text { Pre-Test } \\
\text { Online } \\
\text { Days } \\
\text { (kWh) }\end{array}$ & $\begin{array}{c}\text { All } \\
\text { Online } \\
\text { Test } \\
\text { Days } \\
\text { (kWh) }\end{array}$ & $\begin{array}{l}\text { Semi- } \\
\text { Mature } \\
\text { Online } \\
\text { Test Days } \\
\text { (kWh) }\end{array}$ & $\begin{array}{c}\text { Mature } \\
\text { Online } \\
\text { Day } \\
(\mathbf{k W h})\end{array}$ & $\begin{array}{l}\text { Pre-Test } \\
\text { Offline } \\
\text { Days } \\
\text { (kWh) }\end{array}$ & $\begin{array}{c}\text { All } \\
\text { Offline } \\
\text { Test } \\
\text { Days } \\
\text { (kWh) }\end{array}$ & $\begin{array}{c}\text { Semi- } \\
\text { Mature } \\
\text { Offline } \\
\text { Test Days } \\
(\mathbf{k W h})\end{array}$ & $\begin{array}{c}\text { Mature } \\
\text { Offline } \\
\text { Day } \\
(\mathbf{k W h})\end{array}$ \\
\hline & & & 16 days & 41 days & 20 days & Prediction & 6 days & 13 days & 9 days & Prediction \\
\hline Rcvr Inlet Tank & 44 & T3am & 137 & 106 & $95(2.7 \%)$ & 95 & 326 & 37 & $7.3(0.3 \%)$ & 7 \\
\hline Rcvr Exit Tank & 32 & T3am & 11 & 9.8 & $8.0(0.2 \%)$ & 8 & 270 & 5.8 & $0.6(0 \%)$ & 1 \\
\hline Downcomer & 44 & T3am & 221 & 130 & $110(3.2 \%)$ & 110 & 458 & 82.5 & $16(0.6 \%)$ & 16 \\
\hline Riser & 19 & T3am & 184 & 96 & $80(2.3 \%)$ & 80 & 282 & 59.4 & $12(0.43)$ & 12 \\
\hline Rcvr Drain Pipes & 13 & T1am & 203 & 166 & $164(4.7 \%)$ & 160 & 236 & 42.3 & $12(0.5 \%)$ & 12 \\
\hline $\begin{array}{l}\text { Revr Flow \& Vent } \\
\text { Pipes }\end{array}$ & 97 & T3am & 775 & 410 & $391(11 \%)$ & 390 & 1320 & 154 & $36(1.3 \%)$ & 36 \\
\hline Rcvr Valves (20) & 8 & S525 & 87 & 95 & $95(2.7 \%)$ & 95 & 117 & 130 & $134(4.9 \%)$ & 130 \\
\hline $\begin{array}{l}\text { Valves (38) and } \\
\text { Instruments (13) } \\
\text { on Ground }\end{array}$ & 28 & S525 & 272 & 248 & $238(6.8 \%)$ & 240 & 373 & 345 & $346(13 \%)$ & 350 \\
\hline SG Relief Piping & 25 & S525 & 377 & 357 & $361(10 \%)$ & 360 & 360 & 350 & $348(13 \%)$ & 350 \\
\hline Air Receiver Tank & 8 & Deactivate & 175 & 12 & $14.5(0.4 \%)$ & 0 & 161 & 0 & $0(0 \%)$ & 0 \\
\hline Upper Rcvr Oven & 104 & T5am & 721 & 306 & $261(7.4 \%)$ & 160 & 839 & 165 & $0(0 \%)$ & 0 \\
\hline Lower Rcvr Oven & 104 & T3am & 860 & 550 & $485(14 \%)$ & 160 & 976 & 283 & $21(0.8 \%)$ & 0 \\
\hline Tank/Sump Vents & 18 & S525 & 193 & 180 & $176(5 \%)$ & 0 & 248 & 206 & $203(7.4 \%)$ & 0 \\
\hline Piping on Ground & 110 & S525 & 1316 & 973 & $936(27 \%)$ & 380 & 1817 & 1424 & $1400(51 \%)$ & 560 \\
\hline Cold Storage Tank & 50 & S500 & 368 & 0 & $0(0 \%)$ & 0 & 977 & 0 & $0(0 \%)$ & 0 \\
\hline Hot Storage Tank & 75 & S700 & 400 & 109 & $60.9(1.7 \%)$ & 0 & 0 & 121 & $135(4.9 \%)$ & 0 \\
\hline Cold Sump & 31 & S500 & 69 & 2 & $2(0 \%)$ & 0 & 202 & 0 & $0(0 \%)$ & 0 \\
\hline Hot Sump & 33 & S500 & 464 & 26 & $22(0.6 \%)$ & 0 & 790 & 64 & $76(2.8 \%)$ & 0 \\
\hline Total (kWh/day) & & & 6830 & 3780 & $\begin{array}{c}3500 \\
(100 \%)\end{array}$ & $2200^{*}$ & 9700 & 3470 & $\begin{array}{c}2740 \\
(100 \%)\end{array}$ & $1500^{*}$ \\
\hline
\end{tabular}

Note:

Parasitic Reduction Methods

T"X"am - Drain salt after shutdown and reduce heater setpoint to $100^{\circ} \mathrm{F}$. At "X"am on a receiver operating day, raise heater setpoint to salt operating temperature.

$S$ "XXX" - Reduce heater setpoints from conservative pre-test value to value "XXX" $\mathrm{F}$.

During the design phase of Solar Two, the original predictions for electric heater energy consumption were 1700 and $1300 \mathrm{kWhrs}$ for online and offline days, respectively (Kolb, 1995). 


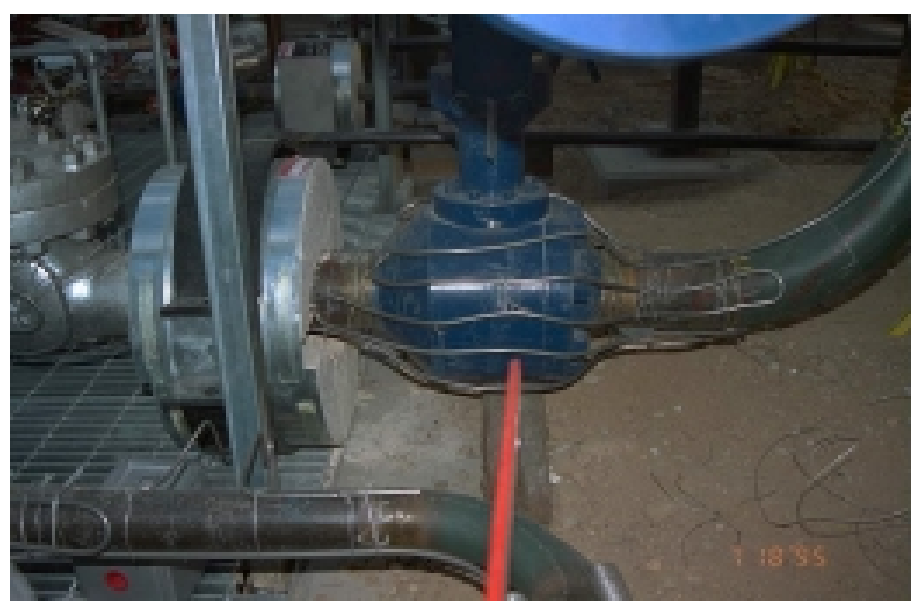

Figure Q-4. Valves can be kept warm overnight, independently of the surrounding pipe, if a separate heat trace circuit is applied to the valve. This reduces parasitics because the pipe heaters can be turned off at night. In this photo, the same heat trace circuit was applied to the valve and surrounding pipe. During the rework of the heat trace system in 1996, separate valve circuits were installed on valves 4 inches in diameter and bigger.

In the first phase of the test, changes made to the operating procedures of the plant were conservative relative to the ultimate goals to be achieved during Phase 2. For example, in Phase 1 , many of the components in the receiver system were reheated earlier than the ultimate goal. These times were one to two hours sooner than the ideal times suggested by piping heat-up tests conducted earlier in the Solar Two project. In addition, the heater setpoints were typically only reduced 25 to $50^{\circ} \mathrm{F}$ below normal operating temperature, but still nearly $100^{\circ} \mathrm{F}$ above the salt freezing point.

Despite the conservative approach taken in Phase 1, the data presented in Table Q-1 indicates that heater parasitics were dramatically reduced relative to the pretest consumption. Online days were cut by almost half and offline days by $2 / 3$. Examination of the individual component groups indicates some dropped over $90 \%$, while others did not change significantly.

In the table, a portion of the test days are classified as "semi-mature." On these days, heater consumption was lower because the plant was being operated according to plan. On online days, daily energy collection by the receiver was close to the analytically derived goal for that day; during offline days, the parasitic reduction methods were strictly followed by the plant operators. On non-mature days, problems occurred that led to higher parasitic consumption than normal. For example, it can seen that the average consumption by the receiver upper and lower ovens on offline days was $165 \mathrm{kWh}$ and $283 \mathrm{kWh}$, respectively. Since these ovens are only needed on online days, a mature value should be close to zero. The reason the ovens were mistakenly actuated on some offline days was due to a receiver/heliostat design problem that prevented morning startup of the plant. The receiver/heliostat design was still being debugged during the interval of the test. In a mature plant design, these aborted startups would be eliminated.

The results presented in Table Q-1 are daily averages. The day-to-day variability of the data set can be seen in Figure Q-5. Total heat-trace parasitics are plotted as a function of receiver daily 
energy collected, both before and after initiation of the test. Points on the y-axis are offline days and the ones clustered near 2.5 MWhrs are classified semi-mature. Parasitic consumption for the online "after test initiation" days is somewhat lower for high receiver energy days than lower energy days, but is relatively independent of receiver energy level.

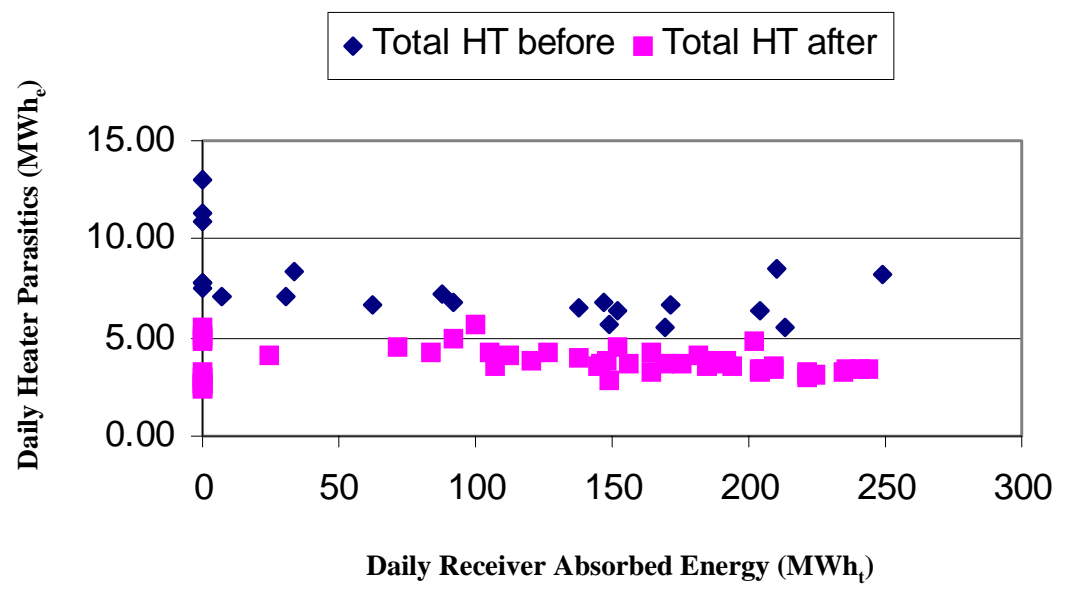

Figure Q-5. Daily heater parasitics as a function of daily thermal energy absorbed by the receiver.

Though reduced significantly after initiation of the test, hot storage tank and hot sump parasitics were not totally eliminated. Since these are large thermal masses that cool off very slowly, they would not reach their immersion heater/heat trace actuation setpoints during the entire test period. However, examination of the temperatures of these devices indicated that heat trace was actuated prior to the setpoints listed in Table Q-1. The cause for the hot tank heater actuation was attributed to a bad thermocouple. The cause for the sump heater actuation was due to the failure of the operators to actually reduce the setpoint to the intended value of $500^{\circ} \mathrm{F}$; rather, for an unknown reason, they only reduced it to $800^{\circ} \mathrm{F}$, possibly to maintain the temperature of the salt in the sump to ease startup of the SGS.

The percentage contribution, by heat trace group, for the semi-mature days is also listed in Table Q-1. "Piping on ground" is the largest contributor for both online $(27 \%)$ and offline $(51 \%)$ days. Methods to further reduce the parasitics for this group and other significant contributors is the subject of the next section.

\section{Q.5 Mature Plant}

The Solar Two engineers intended Phase 2 of the testing program to serve as the final optimization of heater parasitics. Unfortunately, Solar Two was shut down before Phase 2 could be implemented. Thus, the engineers resorted to a "dry lab" type analysis of what should have been the likely result of these more aggressive tests. Based on the analysis of the Solar Two data collected during Phase 1 and expert judgment, the mature plant would likely have achieved the parasitics listed in the final columns of Table Q-1. Online and offline heater parasitics in the mature plant would be approximately $37 \%$ and $45 \%$ lower, respectively, relative to the semi- 
mature test data. The mature values for each entry in the Table Q-1 are discussed below, starting with the top of the table.

For purposes of this analysis, the first 10 categories listed, "receiver inlet tank" through "air receiver tank," were not changed (except to round off). While some gains would be expected in a Phase 2 test (e.g., by delaying morning reheat of receiver components and reducing heater setpoints further), parasitics for these groups would only be reduced by perhaps 10 to $20 \%$. However, while not possible at Solar Two, a future plant should closely examine the parasitics consumed by the steam generator relief piping. These pipes protect the salt side of the steam generator from overpressure. Normally filled with air, in an overpressure situation, relief valves open and momentarily direct salt to the pump sumps. By shortening the lengths of these pipes, a future design could realize significant parasitic savings.

The receiver ovens are only needed on online days. Thus, the mature parasitic value for offline days is nearly zero. For the online days, a Phase 2 test would have demonstrated a significant reduction in oven parasitics. The first improvement would be to improve the thermal performance of the lower ovens to match the upper ovens. The lower ovens were more prone to thermal losses through the seal between the exposed and unexposed receiver tubes; thus, the heater parasitics were higher in the lower ovens. An improved seal was installed on a portion of the lower ovens shortly before plant shutdown, significantly reducing the thermal losses. Besides the improved seal, data from Phase 1 suggested that the upper ovens could be actuated only 1.5 hours prior to salt flow through the receiver, rather than the 3.2-hour average achieved on semi-mature days. Combining these two improvements yields the mature oven parasitic estimates presented in Table Q-1.

The air space within the thermal storage tanks and pump sumps were connected with an extensive amount of piping to allow the transfer of hot air between these devices caused by rising and falling salt levels. By shuttling the air back and forth, rather than expelling the hot air to the atmosphere, the plant designers hoped to reduce heat loss. Heat tracing was added to the pipe (called "tank/sump vents" in Table Q-1) to prevent salt dew from forming and eventually clogging the pipes. At the initiation of the Phase 1 test, a new calculation was performed that showed if air was expelled to the atmosphere, the thermal losses would be insignificant and the savings were certainly not worth the complexity and cost of the existing piping arrangement. Consequently, in Phase 2, the heat trace would have been deactiviated, vent piping cut open, and the tanks/sumps vented directly to the atmosphere. Thus, the mature values listed in Table Q-1 are zero.

Piping on the ground was the largest parasitic contributor during the Phase 1 tests. To reduce these parasitics, the plan for Phase 2 was to keep pipes warm by circulating salt (with the auxiliary salt pump) through many of the pipes that were closed to salt flow during Phase 1 . This would occur by opening several normally closed valves after power operations were completed for the day. In addition, reducing the setpoints on all piping to less conservative values was a goal. Figure Q-6 is an illustrative example of the significant effect these methods can have on reducing heat trace usage. Plotted in the figure are the daily number of hours that heat trace was actuated on the piping at the discharge of the auxiliary pump during the pretest period and during the entire Phase 1 test. In the pretest period, the piping was primarily kept warm with heat trace because the heater setpoint was equal to the normal operating temperature of the salt flowing in 
the pipe. On September 23, 1998, the Phase 1 test was initiated and the heater setpoint was reduced $25^{\circ} \mathrm{F}$ below the normal salt temperature. During Phase 1, the piping was primarily kept warm with the salt that was flowing through the pipe. Average time of heat trace use was reduced from 20 hours/day before the test to 3.5 hours/day after the test, an $82 \%$ reduction. The "mature" parasitic estimates listed in Table Q-1 for ground piping are rough estimates of what might have been achieved in a Phase 2 test; a $60 \%$ reduction was assumed.

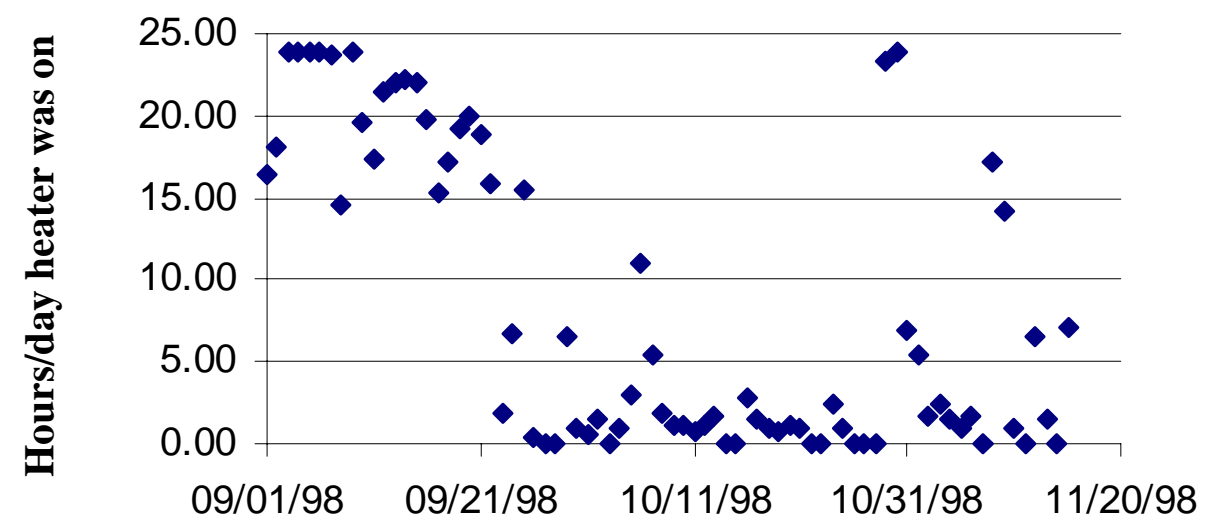

Figure Q-6. Daily heater actuation times for piping at discharge of auxiliary salt pump.

As discussed in the previous section, the storage tank and sumps are large thermal masses that cool off very slowly, and it is reasonable to expect that actuation of the heat trace in these devices could be virtually eliminated in a mature plant. Zeros thus appear in Table Q-1.

\section{Q.6 Conclusions}

Heat trace electricity consumption at Solar Two was high prior to the initiation of the parasiticreduction test. Implementation of the relatively conservative Phase 1 test cut heat trace parasitics by almost $1 / 2$ on online days, and by $2 / 3$ on offline days. Further improvements were expected to be demonstrated in a more aggressive Phase 2 test, meant to simulate mature plant operation. Due to time and budget constraints, the mature plant test was not performed. However, sufficient plant data was available to analyze what should be achieved during the mature test. This analysis indicated that the heat trace parasitic goals established during the design of the Solar Two project could nearly be met (Kolb, 1995). Future molten-salt power towers, such as the Spanish Solar Tres project, will benefit from the lessons learned at Solar Two. It is reasonable to expect that heat trace parasitic energy consumption at Solar Tres should be less than $1.5 \%$ of the total gross electricity produced based on the higher capacity factor of Solar Tres relative to Solar Two. 


\section{Q.7 References for Heat Trace System Test and Evaluation}

Kolb, G. J., Sandia National Laboratories memo to Scott Faas (Sandia), subject: Documentation of initial SOLERGY parameters for Solar Two, April 7, 1995.

Pacheco, J. E., H. E. Reilly, G. J. Kolb, and C. E. Tyner, "Summary of the Solar Two Tests and Evaluations," Proceedings of the Renewable Energy for the New Millennium, Solar Thermal 2000 International Conference, March 8-10, 2000, Sydney, Australia. 


\section{Appendix R. Energy Conservation at Solar Two (P. C. Jacobs)}

\section{R.1 Executive Summary}

To increase net plant efficiency, an energy conservation study of the auxiliary loads at Solar Two was commissioned by National Renewable Energy Laboratory (NREL). For the purpose of this study, auxiliary loads are defined as lighting and space conditioning loads at support facilities, including the control building, remote stations, load centers, and the warehouse. Plant site outdoor lighting was also considered. Equipment used in the electricity generation process (e.g. pumps, fans, heat tracing, heliostats, controls) and the data acquisition system was not considered part of the auxiliary load. The Edison administration building at the entrance of the plant was also not included because it is atypical of a commercial power plant.

There are many opportunities to improve the energy efficiency of the support buildings at Solar Two. The buildings were designed and constructed in the early 1980s, and many of the building systems are old, inefficient, and reaching the end of their design life. A number of energy conservation opportunities were evaluated, which are described below.

1. Reduce tower lighting. Nighttime lighting of the tower represents about one third of the total exterior lighting load of the plant. Since the tower is generally not occupied during evening hours, it may be possible to turn off most of the tower lighting without sacrificing the health and safety of plant employees. This option considers retaining nighttime lighting of the receiver, while eliminating walkway lighting on levels 1 through 14.

2. Install occupancy sensors and lighting timers. Energy can be saved by turning off lights in areas that are unoccupied, especially electrical rooms and mechanical spaces. This option includes installing "twist" timers on the lighting circuits in normally unoccupied spaces, such as electrical rooms and remote stations, and occupancy sensors in control building spaces that are unoccupied for extended portions of the day.

3. Retrofit lighting system. The lighting systems at Solar Two were inefficient by modern standards. This option evaluates replacing existing fluorescent lamps and ballasts with energy-saving lamps and electronic ballasts.

4. Install evaporative cooling in remote stations and load centers. The load centers and remote stations located in the field and up in the tower were cooled by mechanical air conditioning systems. Due to the dry climate at the site, these spaces can be cooled effectively and much more efficiently with evaporative cooling. This options considers replacing the existing mechanical air conditioners with industrial-grade evaporative cooling systems.

5. Replace air conditioners in control building. The air conditioning systems at the control building were old and inefficient by modern standards. This option considers replacing the existing systems with new high-efficiency units. 
6. Replace computer room coolers. The computer room coolers serving the underfloor air distribution system in level two of the control building were also old and inefficient by modern standards. This option considers replacing the existing computer room coolers with new high-efficiency units.

The estimated energy savings and first costs of each of these options is summarized in Table R-1-Table R-3, below.

Table R-1. No cost-low cost

\begin{tabular}{lcc}
\hline \hline Option & $\begin{array}{c}\text { Energy savings } \\
(\mathrm{kWh})\end{array}$ & First Cost \\
\hline Reduce tower lighting & 29469 & $\$ 0$ \\
Control Building occupancy sensors and timers & 18324 & $\$ 417$ \\
Load center A timer & 15951 & $\$ 48$ \\
RS 1 timer & 6728 & $\$ 48$ \\
RS 2 timer & 9533 & $\$ 48$ \\
RS 3 timer & 9533 & $\$ 48$ \\
Level 13 electrical room timer & 5046 & $\$ 48$ \\
Total & 94583 & $\$ 657$ \\
\hline \hline
\end{tabular}

Table R-2. Medium cost

\begin{tabular}{lcc}
\hline \hline Option & $\begin{array}{c}\text { Energy savings } \\
(\mathrm{kWh})\end{array}$ & First Cost \\
\hline Retrofit lamps and ballasts - Control building & 22904 & $\$ 4,830$ \\
Retrofit lamps and ballasts - Warehouse & 6396 & $\$ 1,260$ \\
Evaporative cooling - Load Center A & 32389 & $\$ 4,626$ \\
Evaporative cooling - RS-1 & 8400 & $\$ 2,520$ \\
Evaporative cooling - RS-2 & 7159 & $\$ 2,100$ \\
Evaporative cooling - RS-3 & 7159 & $\$ 2,100$ \\
Total & 84407 & $\$ 17,436$ \\
\hline \hline
\end{tabular}

Table R-3. Higher cost

\begin{tabular}{lcc}
\hline Option & $\begin{array}{c}\text { Energy savings } \\
(\mathrm{kWh})\end{array}$ & First Cost \\
\hline Upgrade HVAC - control building & 13459 & $\$ 41,602$ \\
Upgrade Computer coolers & 11532 & $\$ 30,901$ \\
Total & 24991 & $\$ 72,504$ \\
\hline \hline
\end{tabular}

It is recommended that the project team implement the options outlined in the low- and mediumcost categories above. The low-cost options have the potential to save 94.6 MWh, roughly equivalent to a full-day of plant output, at little or no cost. The medium-cost options have the potential to save another $84 \mathrm{MWh}$, with a simple payback of about two years. ${ }^{1}$ Replacement of

1 The simple payback assumed a retail levelized cost for electricity of $\$ 0.10$ per kWh. 
the existing air conditioning systems and computer room coolers is hard to justify based on energy savings alone, but the option of installing high-efficiency models should be considered when the existing equipment either fails or is scheduled for replacement.

\section{R.2 Introduction}

The Solar 2 central receiver power station located in Barstow, California is a 10 MWe solar demonstration power plant. The plant generates electricity, some of which is consumed on-site, the rest of which is introduced into the southern California electrical grid. In order to improve the net operating efficiency of the plant, the Solar Two Operations Team - Sandia, NREL, and Southern California Edison (SCE) - would like to reduce the auxiliary electrical loads of support facilities served by the plant. For the purpose of this study, auxiliary loads are defined as lighting and space conditioning loads at support facilities, including the control building, remote stations, load centers, and the warehouse. Plant site outdoor lighting was also considered. Equipment used in the electricity generation process (e.g. pumps, fans, heat tracing, heliostats, controls) and the data acquisition system was not considered part of the auxiliary load. The Edison administration building at the entrance of the plant was also not included because it is atypical of a commercial power plant.

\section{R.3 Facilities}

A preliminary walk-through survey of the site was done July 27, 1998, and an inventory of buildings and major HVAC equipment was taken. Based on the walk-through survey, a preliminary estimate of the total energy consumption for each building was calculated, as shown in Figure R-1.

Since it was not feasible to study all buildings on the site, a sample of buildings representing the majority of the energy consumption was selected. Each of the selected facilities was surveyed in greater detail during a subsequent site visit on August 4-5, 1998. A description of the buildings covered in the study is given below.

\section{R.3.1 Control Building}

The control building is a 1000-square-meter (11,000-square-foot), two-story structure housing most of the technical support activities for the plant. The first floor contains electrical switchgear and other electrical equipment, workshops, a water quality lab, and lunch room. The second floor contains the control room, data acquisition equipment room, and staff offices. The lighting system consists primarily of 40 watt T-12 fluorescent lamps with magnetic ballasts. Recessed and suspended fixtures are used in two-, three-, and four-lamp configurations. Air conditioning is supplied by a 9-ton and a 15-ton single-package heat pump, one serving each floor. Additional cooling to computer intensive spaces on the second floor is supplied by an underfloor distribution systems served by three computer room coolers, totaling 13 tons of cooling capacity. 


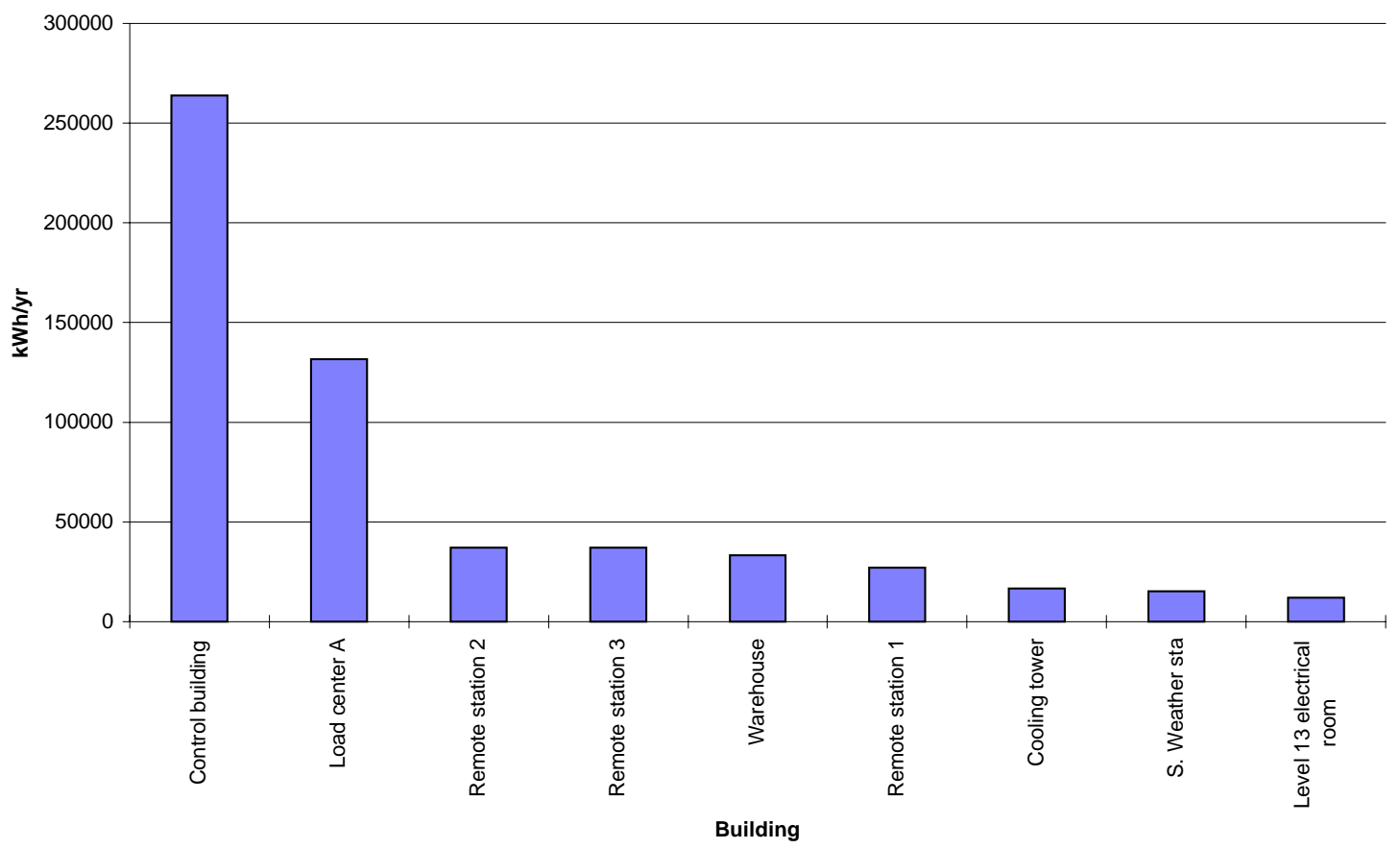

Figure R-1. Estimated kWh by Building.

\section{R.3.2 Load Center A}

Load center A is one of several support buildings located in the heliostat field. The 650-squarefoot building contains variable speed drives, transformers, and other electronic equipment. The building is normally unoccupied. Lighting to the space is provided by two lamp-suspended fluorescent fixtures using 40 Watt T-12 lamps and magnetic ballasts. In order to maintain a cool environment for the electronics, the building is cooled by a 20 -ton packaged split air conditioning system. Heating is provided by electric resistance unit heaters, which keeps the building from freezing.

\section{R.3.3 Remote Station 1}

Remote station 1 is one of several support buildings housing control panels, data acquisition equipment, and other electronics. Remote station 1 is a small, insulated metal building located on level 14 of the tower, which is normally unoccupied. Lighting to the space is provided by four lamp-suspended fluorescent fixtures using 40 Watt T-12 lamps and magnetic ballasts. In order to maintain a cool environment for the electronics, the building is cooled by a 6-ton packaged split air conditioning system. Heating is provided by an electric resistance unit heater, which keeps the building from freezing. 


\section{R.3.4 Remote Station 2}

Remote station 2 is another support buildings housing control panels, data acquisition equipment, and other electronics. Remote station 1 is a 28 -square-meter (300-square-foot) insulated metal building located in the heliostat field, and is normally unoccupied. Lighting to the space is provided by two lamp-suspended fluorescent fixtures using 40 Watt T-12 lamps and magnetic ballasts. In order to maintain a cool environment for the electronics, the building is cooled by a 5-ton packaged split air conditioning system. Heating is provided by an electric resistance unit heater, which keeps the building from freezing.

\section{R.3.5 Remote Station 3}

Remote station 3 is virtually identical to remote station 2, but is located in a different part of the heliostat field.

\section{R.3.6 Level 13 Electrical Room}

This building is a small electrical room located on level 13 of the tower, which is normally unoccupied. Lighting is provided by four lamp-suspended fluorescent fixtures using $40 \mathrm{Watt} \mathrm{T}$ 12 lamps and magnetic ballasts. In order to maintain a cool environment for the electronics, the building is cooled by two small, through-the-wall air conditioners. Heating is provided by an electric resistance unit heater, which keeps the building from freezing.

\section{R.3.7 Warehouse}

The warehouse is a 590-square-meter (6300-square-foot) insulated pre-fab metal building housing general stores, shipping and receiving offices, and a workshop. Lighting is provided by four lamp-suspended fluorescent fixtures using 40 Watt T-12 lamps and magnetic ballasts. The main floor area is cooled by two roof-mounted evaporative coolers. Through-the-wall air conditioners are also used to provide additional comfort to two small enclosed offices located on the shop floor.

\section{R.3.8 Exterior Lighting}

Nighttime lighting of the site is provided by high-pressure sodium lamps. A series of groundmounted pendant fixtures is used to provide lighting on each of four access roads located in the heliostat field. Numerous fixtures are provided on the tower walkways, receiver, and upper tower levels. Additional lighting is provided on the steam turbine deck, piping racks, and salt storage tanks. Pole-mounted street lights illuminate the parking and service area adjacent to the control building. 


\section{R.3.9 Short-Term Monitoring}

In order to establish the baseline energy consumption of the systems under study, short-term monitoring of selected lighting and HVAC systems was done. It was not possible, under the budget constraints, to measure all HVAC and lighting loads. Thus, staff attempted to capture the majority of the lighting and HVAC energy consumption by installing monitoring equipment on selected circuits in the control building, load center A, and remote station 2. Portable, batterypowered data loggers were utilized to make the measurements. The loggers were configured to sample at 5 minute intervals and log data for about a week. Short-term monitoring started at midnight on August 6 and finished at midnight on August 13. The measurements taken at each building are summarized below. See Attachment 1 for a detailed monitoring plan.

\section{R.3.9.1 Control Building}

All HVAC equipment in the building shares a common subpanel. A watt transducer was installed at this location, and time-series energy consumption measurements were made on the HVAC system. The HVAC energy consumption data were compared to ambient temperature collected at the site. A baseline energy consumption curve for the control building was developed by plotting the average daily temperature to the daily HVAC energy consumption, as shown in Figure R-2.

Control Building HVAC

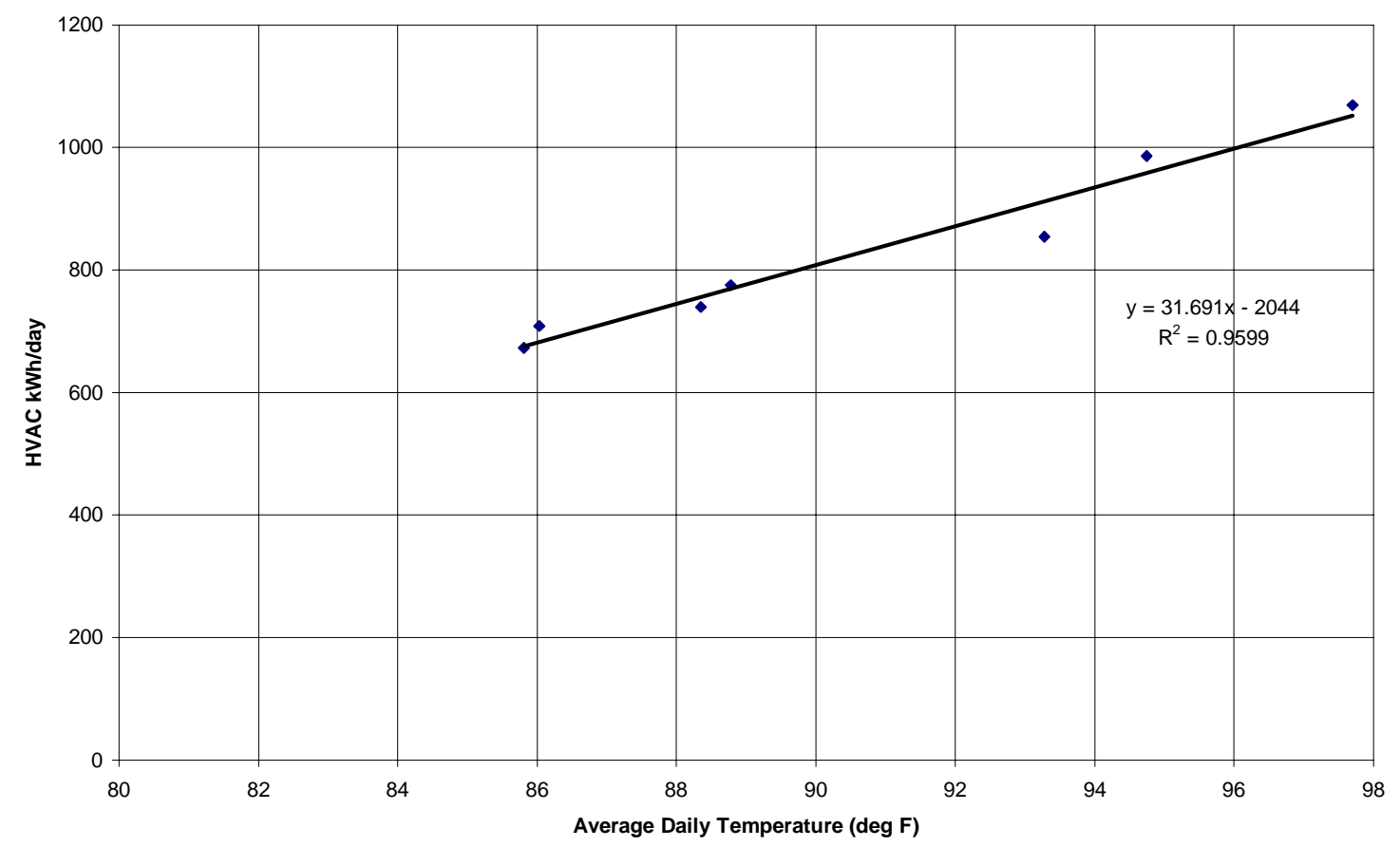

Figure R-2. Daily HVAC energy consumption for the control building as a function of the average daily temperature. 
Current measurements were made on individual lighting circuits serving the first and second floors. A plot of the daily average lighting consumption is shown in Figure R-3.

Note that there is very little variation on an hourly basis, indicative of a facility that operates 24 hours per day.

Load Center A. Spot kW measurements were made on air-handler fans and condensing unit compressors. Time-series current measurements were made on the air conditioning compressors and fan circuits. The spot $\mathrm{kW}$ measurements were combined with the time-series current measurements to calculate hourly energy consumption. Room temperature and relative humidity were also monitored.

Note that the system was set to maintain a cooling setpoint of $19^{\circ} \mathrm{C}\left(67^{\circ} \mathrm{F}\right)$. Excursions in room temperature to $24^{\circ} \mathrm{C}\left(76^{\circ} \mathrm{F}\right)$ were observed during the day. Note that the compressor operated full-time, but could not hold the temperature set point.

Remote Station 2. The same suite of measurements made in load center A was repeated in remote station 2. Spot $\mathrm{kW}$ measurements were made on air-handler fans and condensing unit compressors. Time-series current measurements were made on the air conditioning compressors and fan circuits. The spot $\mathrm{kW}$ measurements were combined with the time-series current measurements to calculate hourly energy consumption. Room temperature and relative humidity were also monitored.

Based on these data, the nominal temperature setpoint appears to be $22^{\circ} \mathrm{C}\left(72^{\circ} \mathrm{F}\right)$. Note temperature excursions to $29^{\circ} \mathrm{C}\left(85^{\circ} \mathrm{F}\right)$ during the day, indicating insufficient cooling capacity.

Note that the system maintains a temperature between 21 and $23^{\circ} \mathrm{C}\left(70\right.$ and $\left.74^{\circ} \mathrm{F}\right)$. The compressor cycles frequently, indicating sufficient capacity to meet the setpoint.

Remote station 1. Temperature and relative humidity measurements were made in remote station 1. These data are shown in Figure R-7.

\section{R.4 Analysis}

\section{R.4.1 Model generation}

On-site survey data collected from the control building, load center A, and remote station 2 were entered into an electronic database. A DOE-2.1E simulation model was automatically created for each of these buildings from the on-site survey data using automated model generation software. These DOE-2 models were then calibrated to the measured data, and the calibrated models were used to estimate the performance of the energy-conservation measures. 
First Floor Baseline Lighting Load

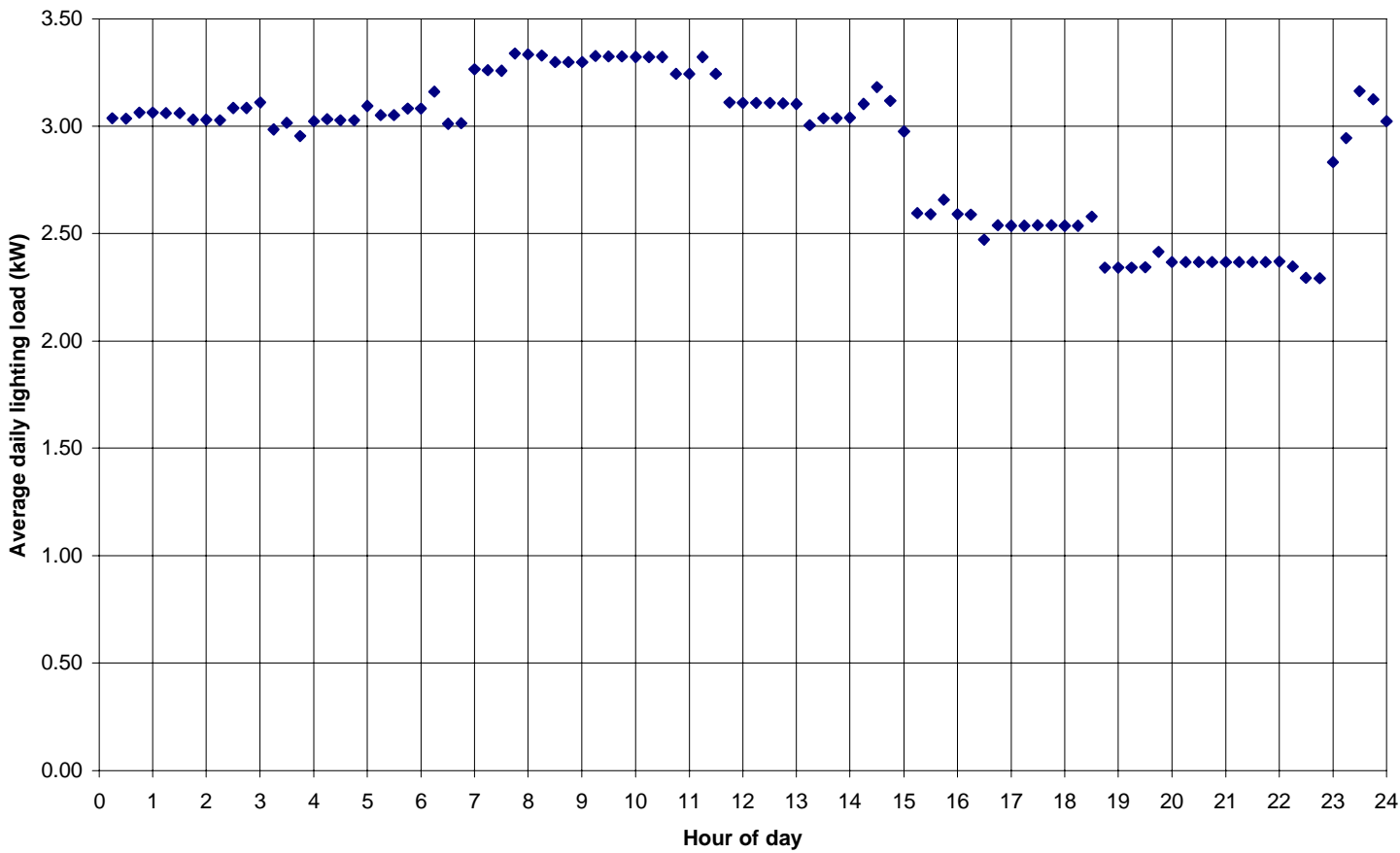

Second Floor Baseline Lighting Load

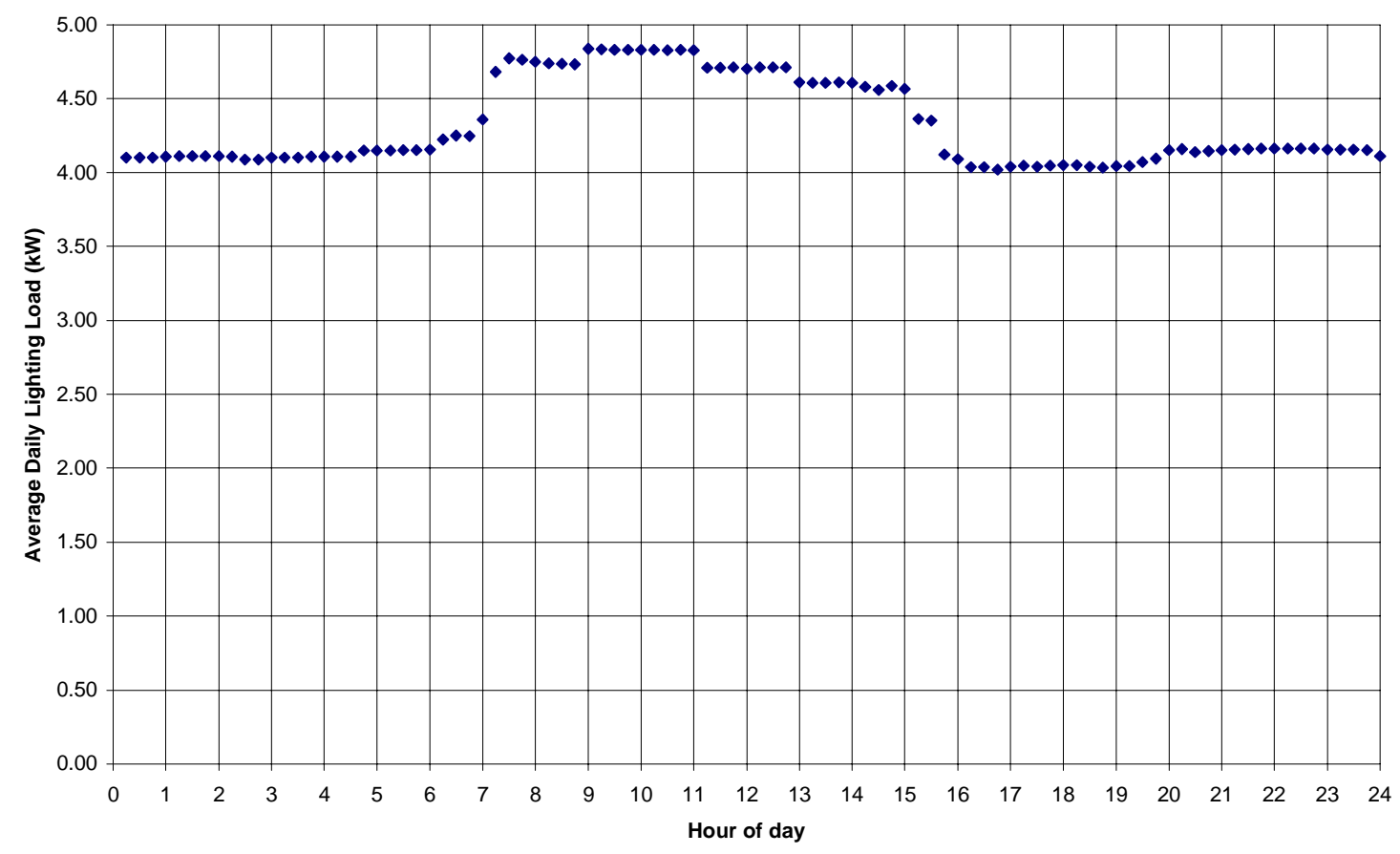

Figure R-3. Daily average lighting consumption. 
Load Center A Baseline HVAC Consumption
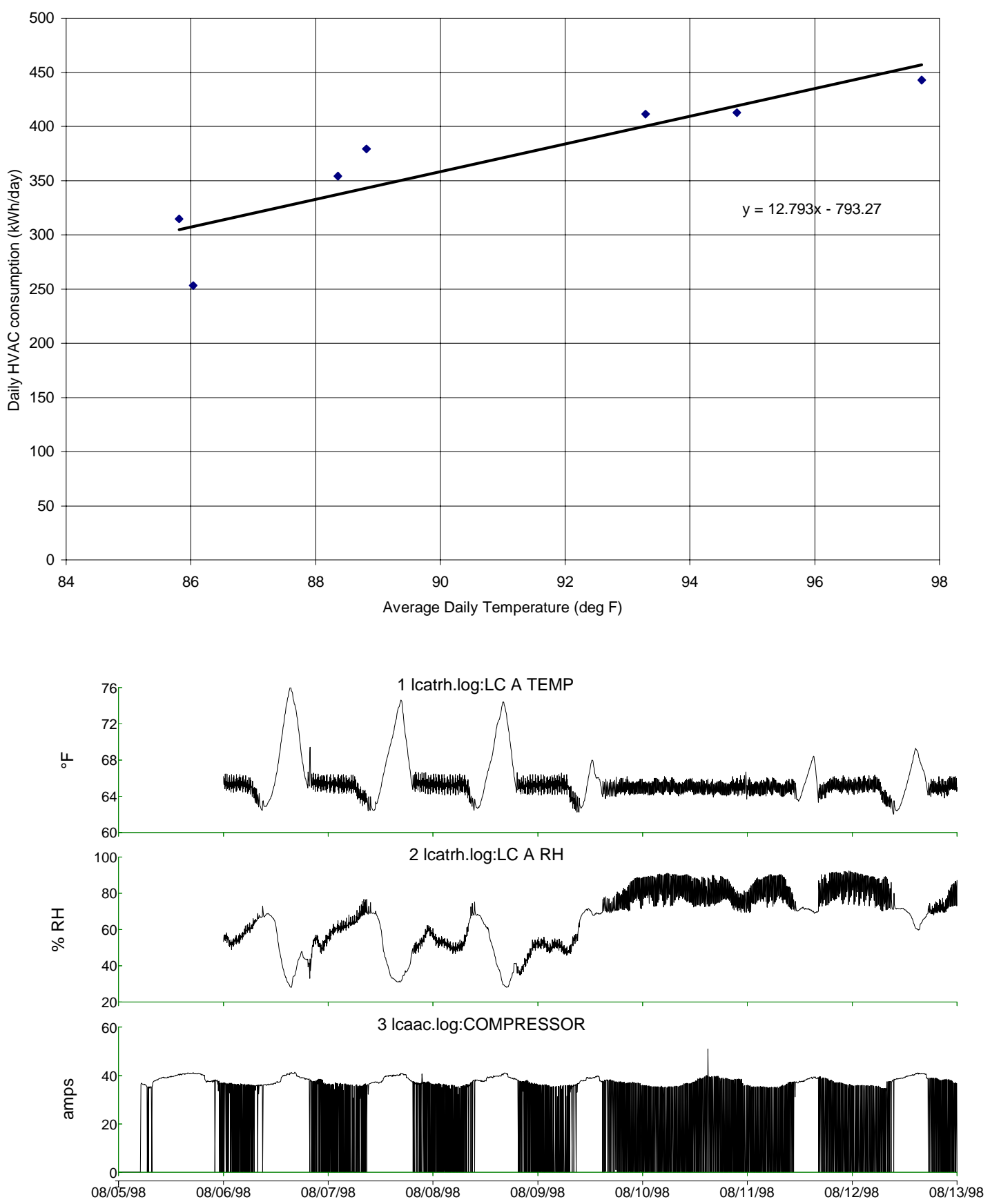

Figure $R-4$. 
Remote Station 2 HVAC Baseline
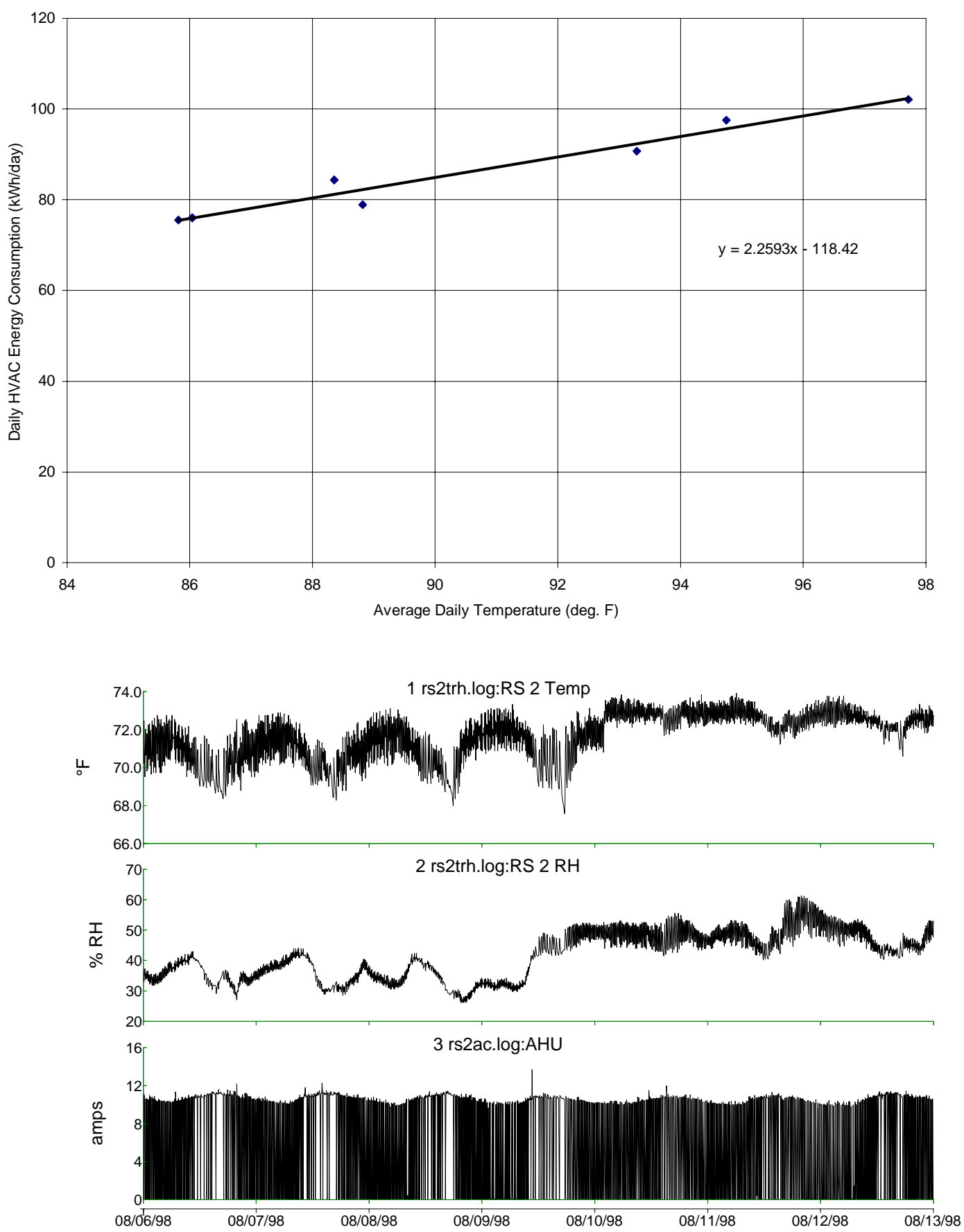

Figure $R-5$. 


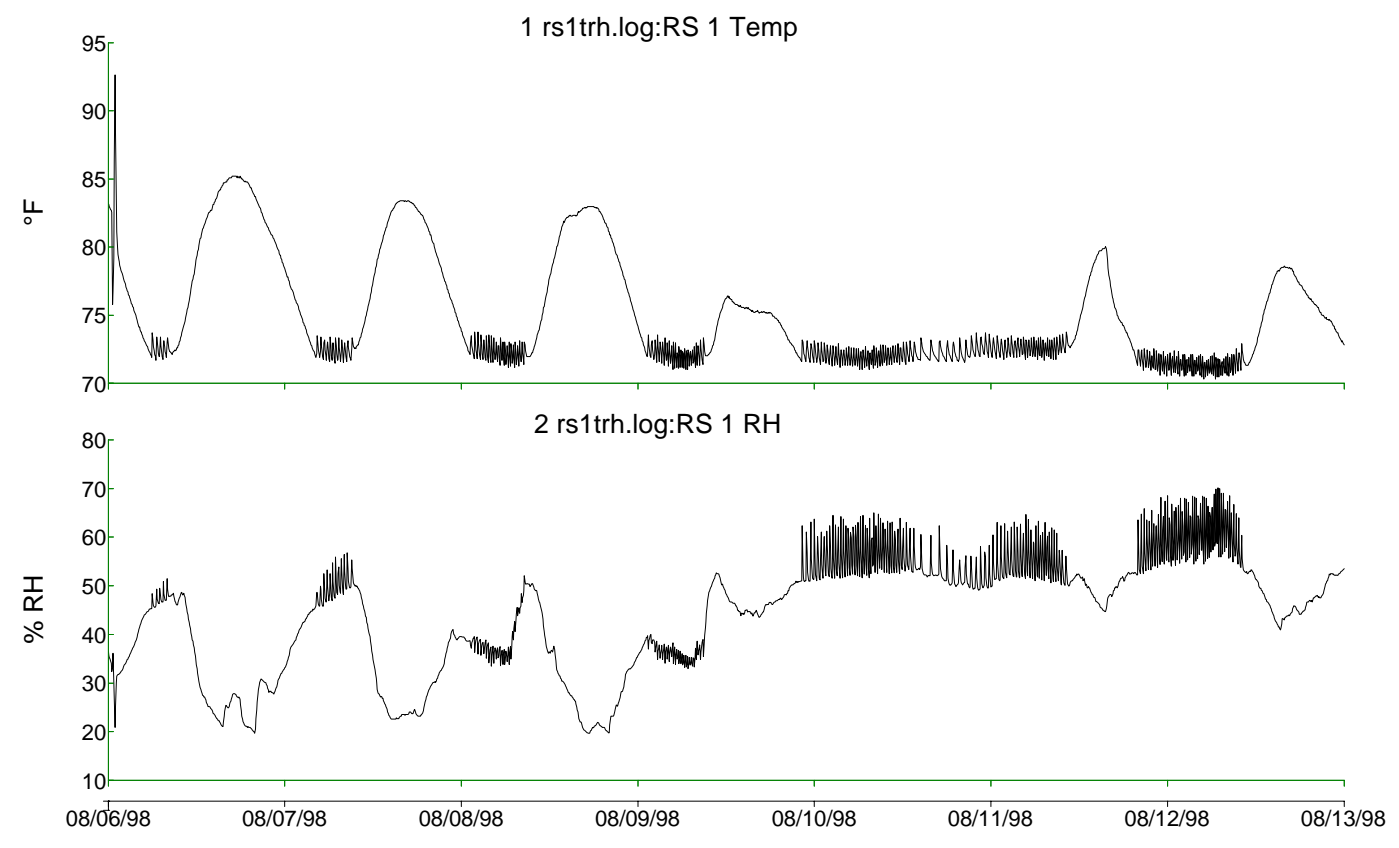

Figure R-6. Remote Station 1 temperature and relative humidity.

\section{R.4.1.1 Model Calibration}

Short-term baseline data collected on each of the buildings were used to calibrate the DOE-2 models. Lighting load data were used to establish the lighting use profiles. HVAC data were used to check the response of the model of the HVAC system. A comparison of the simulations and monitored data is shown in Figure R-7-Figure R-9.

\section{R.4.2 Energy conservation measures}

There are many opportunities to improve the energy efficiency of the support buildings at Solar 2. The buildings were designed and constructed in the early 1980s and many of the building systems are old, inefficient, and reaching the end of their design life. A number of energy conservation opportunities were evaluated and are described below.

\section{R.4.2.1 Reduce Tower Lighting}

Nighttime lighting of the tower represents about $1 / 3$ of the total exterior lighting load of the plant. Since the tower is generally unoccupied during evening hours, it may be possible to turn off most of the tower lighting without sacrificing the health and safety of plant employees. This option considers retaining nighttime lighting of the receiver while eliminating walkway lighting on levels 1 through 14. A summary of the installed exterior lighting and the energy savings from reducing tower lighting is shown in Figure R-4. 
Final Test and Evaluation Results from the Solar Two Project

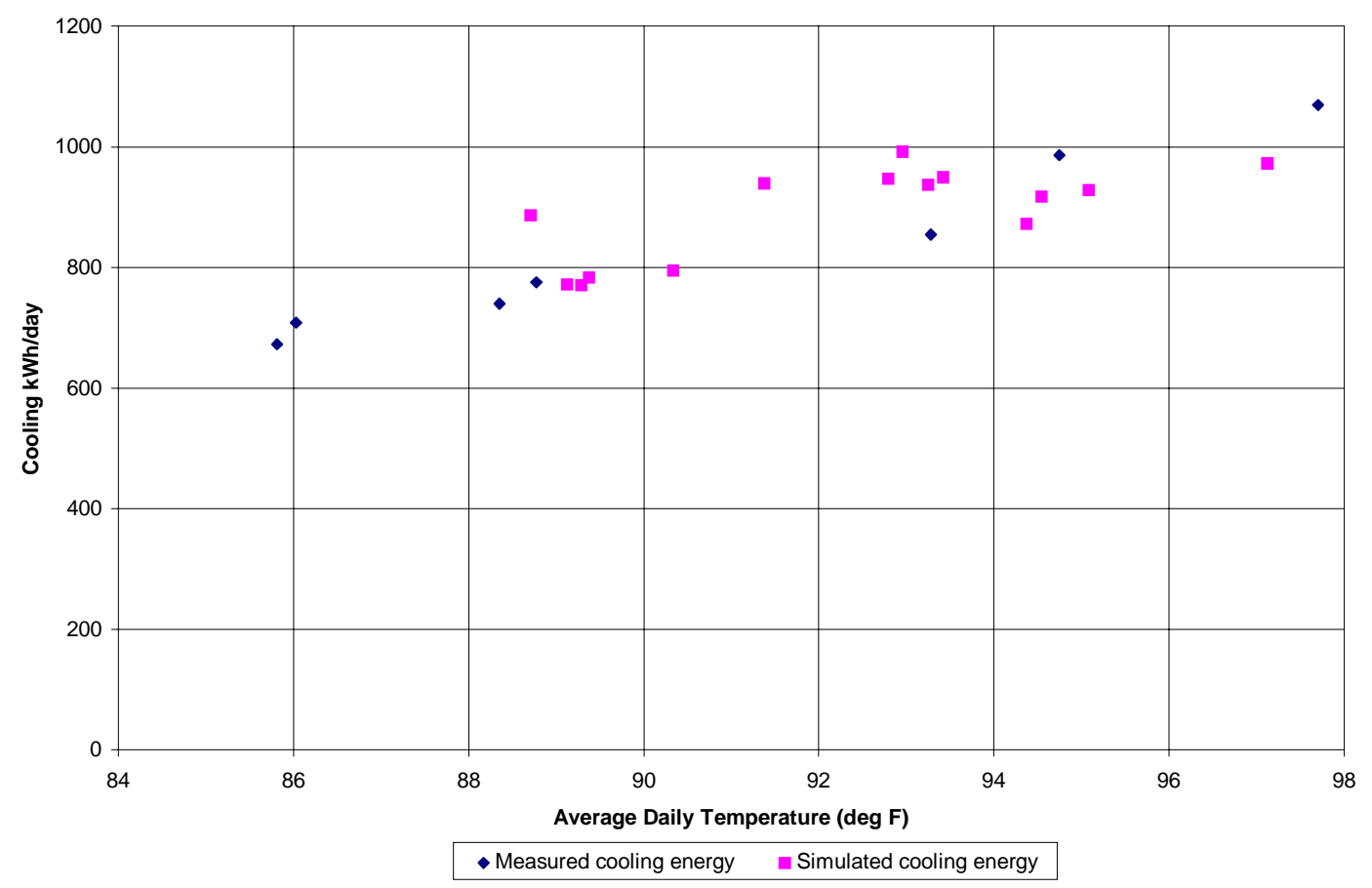

Figure R-7. Control building cooling calibration.

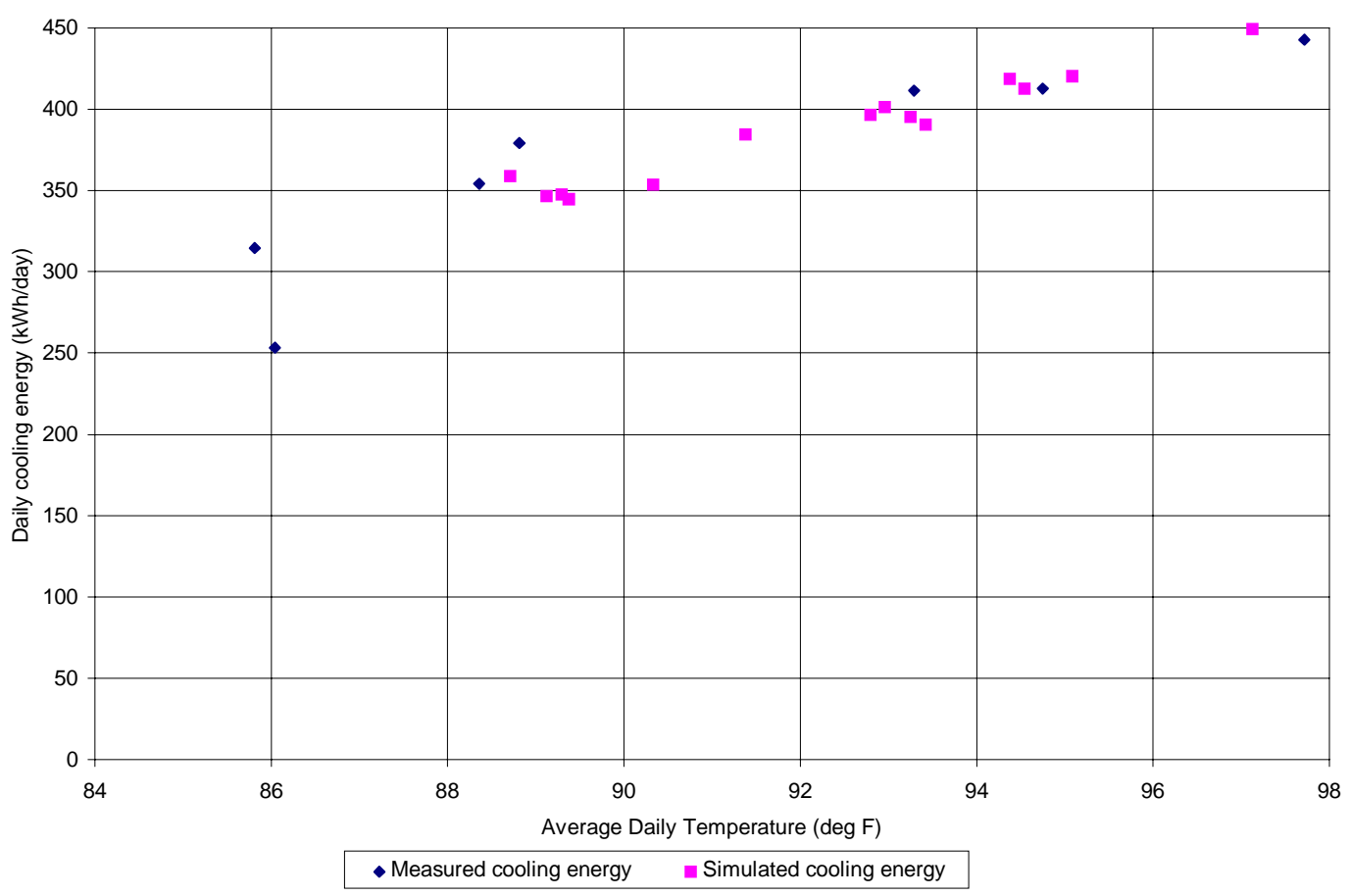

Figure R-8. Load center A cooling calibration. 


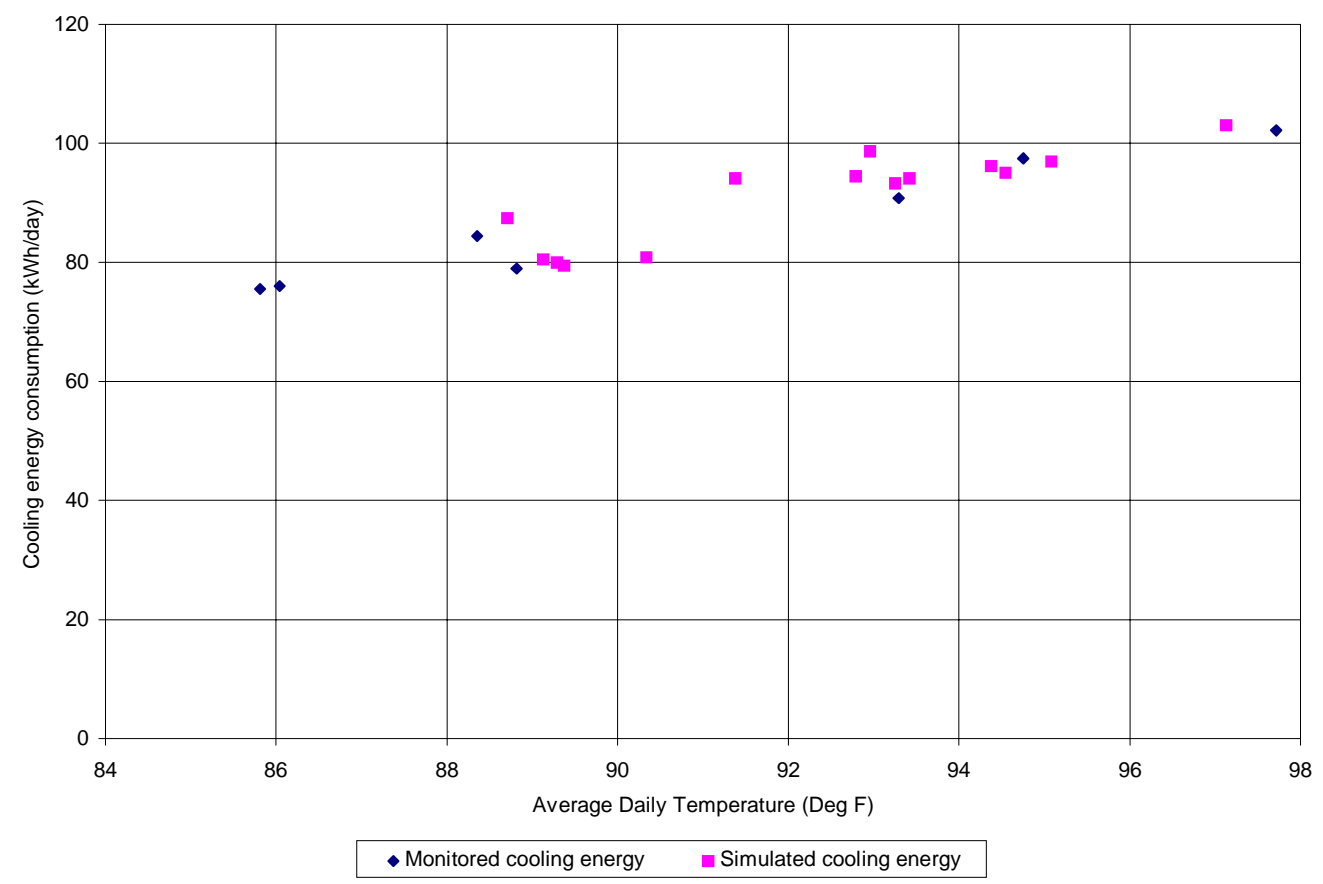

Figure R-9. Remote station 2 cooling calibration.

Table R-4.

\begin{tabular}{lcccccc}
\hline \hline Area & \multicolumn{5}{c}{ Existing condition } & \multicolumn{3}{c}{ De-lamping option } \\
\cline { 2 - 7 } & 13 & 100 & 116 & 1.51 & & 0.00 \\
\hline \# fixtures & lamp W & Fixture W & kW & \# fixtures & kW \\
Turbine deck & 8 & 100 & 116 & 0.93 & 8 & 0.93 \\
Tower level 2 & 6 & 100 & 116 & 0.70 & & 0.00 \\
Tower level 3 & 7 & 100 & 116 & 0.81 & & 0.00 \\
Tower level 4-11 & 24 & 100 & 116 & 2.78 & & 0.00 \\
Tower level 12 & 4 & 100 & 116 & 0.46 & & 0.00 \\
Tower level 13 & 4 & 100 & 116 & 0.46 & & 0.00 \\
Tower level 14 & 4 & 100 & 116 & 0.46 & 4 & 0.46 \\
Catwalk & 19 & 100 & 116 & 2.20 & 19 & 2.20 \\
Equipment room (under & 30 & 100 & 116 & 3.48 & 30 & 3.48 \\
turbine deck) & & & & & & \\
Streetlights & 6 & 400 & 469 & 2.81 & 6 & 2.81 \\
Salt tank & 6 & 100 & 116 & 0.70 & 6 & 0.70 \\
Pump station & 2 & 100 & 116 & 0.23 & 2 & 0.23 \\
Remote station 3 & 1 & 100 & 116 & 0.12 & 1 & 0.12 \\
Field - W Access road & 10 & 100 & 116 & 1.16 & 10 & 1.16 \\
Field - N Access road & 3 & 100 & 116 & 0.35 & 3 & 0.35 \\
Field - E Access road & 10 & 100 & 116 & 1.16 & 10 & 1.16 \\
Field - S Access road & 10 & 100 & 116 & 1.16 & 10 & 1.16 \\
Total kW & & & & 21.49 & & 14.76 \\
kWh (assuming 12 hr/day avg operation) & & & 94126 & & 64658 \\
Savings (kWh) & & & & & & \\
\hline \hline
\end{tabular}




\section{R.4.2.2 Install Occupancy Sensors and Lighting Timers}

Energy can be saved by turning off lights in areas that are unoccupied, especially electrical rooms and mechanical spaces. This options includes installing "twist-timers" on the lighting circuits in normally unoccupied spaces, including the switch gear, battery charging, and electrical rooms on level 1 of the control building; in load center A and remote stations 2-3 located in the field; and in remote station 1 and the electrical room on levels 13 and 14 of the tower. During the on-site survey, it was observed that the lights were generally left on in these spaces, even when unoccupied. Twist-timers are preferable to occupancy sensors in these spaces because the arrangement of equipment and switchgear cabinets makes it difficult for an occupancy sensor to "see" an occupant working in a remote part of the building. The timers provide enough time to complete whatever maintenance work is required, then shut off the lights until the next repair or maintenance task is required. Occupancy sensors were evaluated in the lunch room, instrumentation shop, and water quality lab on level 1 of the control building and in all spaces on level 2 except the control room. These spaces have intermittent occupancy during the day, and could benefit from occupancy controls. An estimate of the lighting loads in the control building with and without lighting controls is shown in Figure R-10 and Figure R-11.

The cost for the occupancy sensors and twist timers is shown in Table R-5.

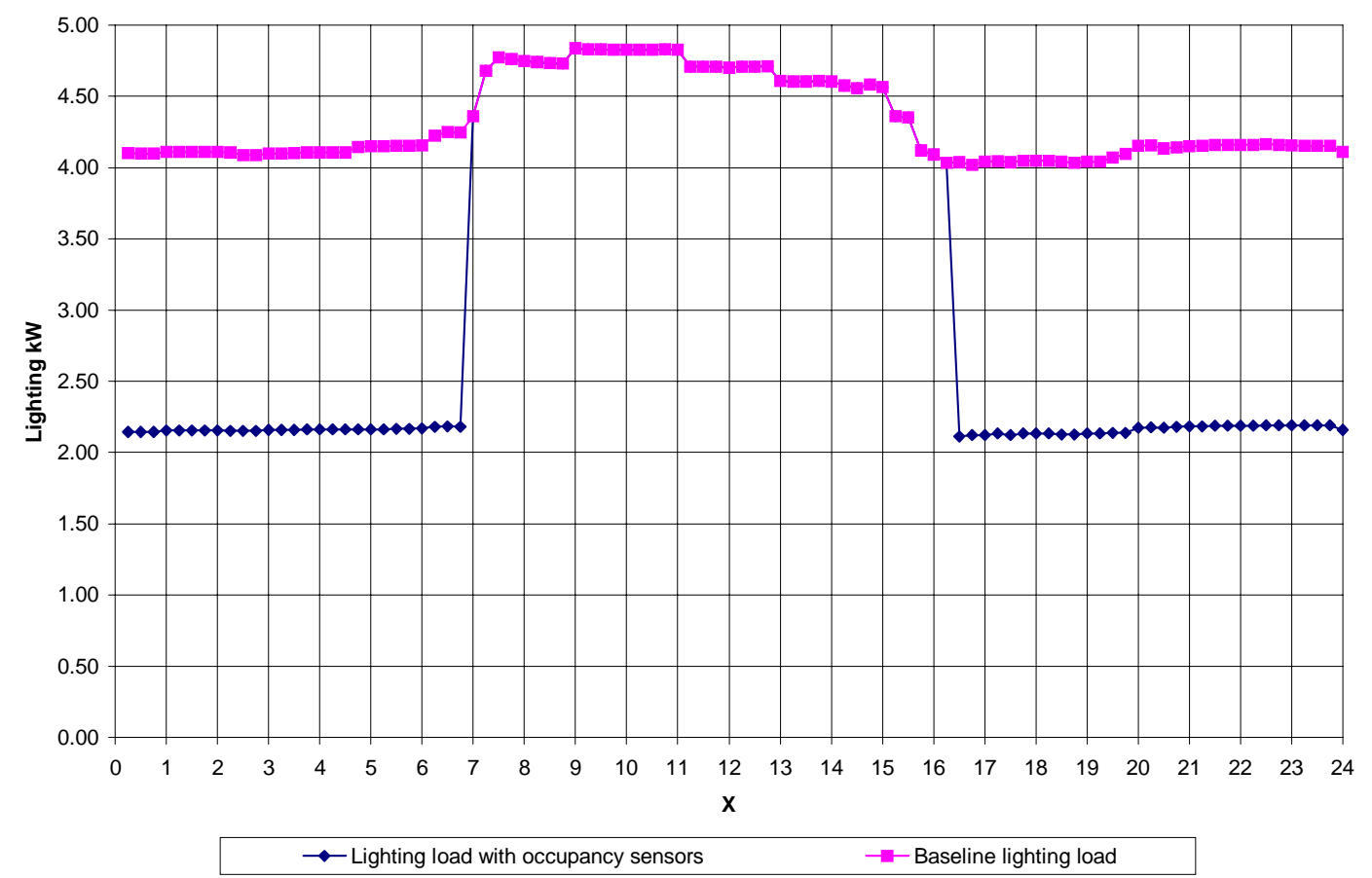

Figure R-10. Control building, second floor lighting load with and without occupancy sensors and timers. 


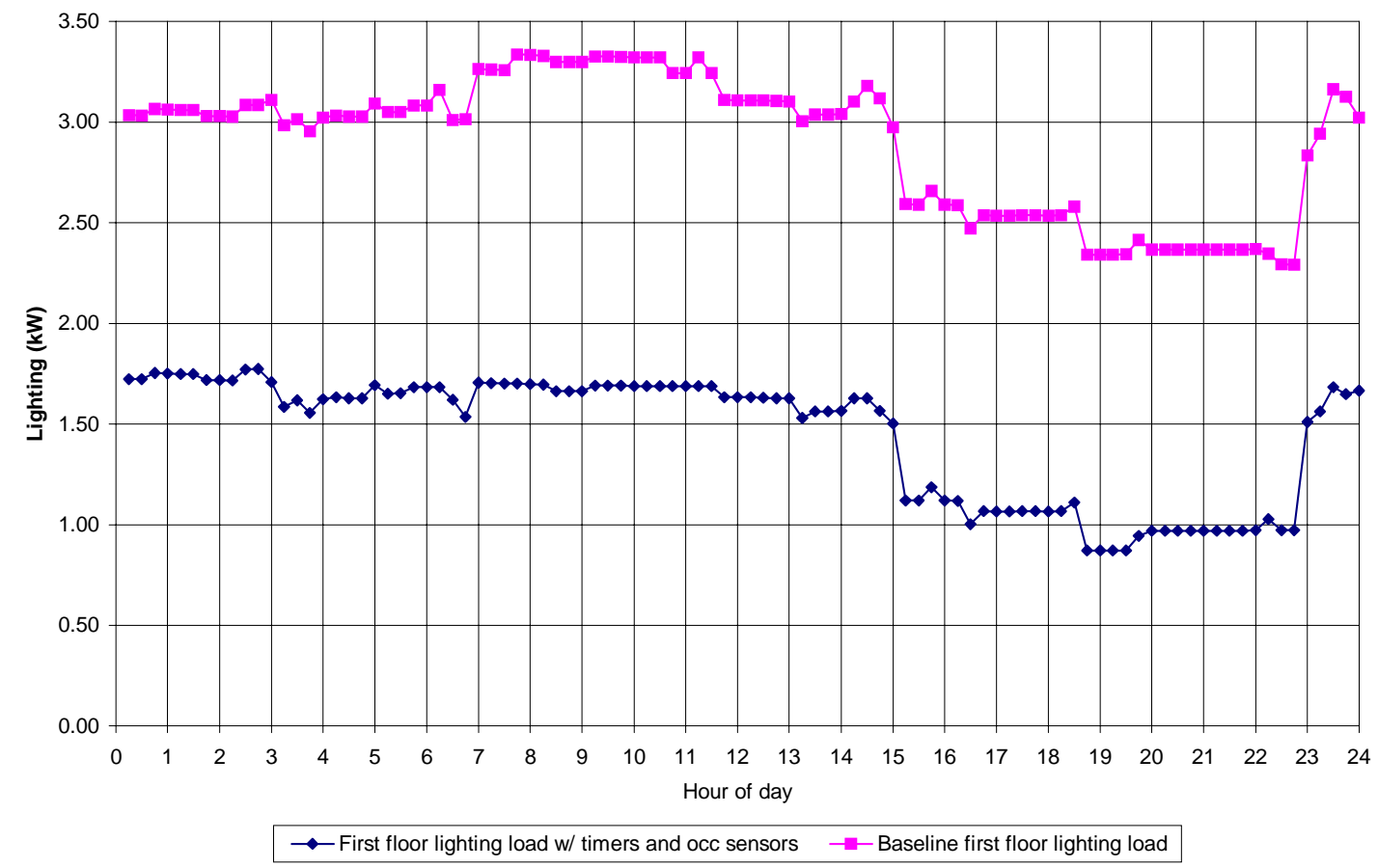

Figure R-11. Control building, first floor lighting load with and without occupancy sensors and timers.

Table R-5.

\begin{tabular}{lccccc}
\hline Measure & Unit & Material & Labor & Total & $\begin{array}{c}\text { Total including } \\
\text { overhead and profit }\end{array}$ \\
\hline $\begin{array}{l}\text { Occupancy sensor } \\
\text { Twist-timer }\end{array}$ & ea & $\$ 25$ & $\$ 20$ & $\$ 45$ & $\$ 54$ \\
\hline \hline
\end{tabular}

\section{R.4.2.3 Retrofit Lighting System}

The fluorescent lighting systems at Solar Two are inefficient by modern standards. This option evaluates replacing existing fluorescent lamps and ballasts with energy-saving T-8 lamps and electronic ballasts. The T-8 lamps provide better color rendition than the existing cool-white fluorescent lamps, and the high-frequency electronic ballasts reduce flicker relative to the existing $60 \mathrm{~Hz}$ magnetic ballasts. Light level measurements made in the space indicated that lighting levels can be reduced without sacrificing visual comfort, thus three- and four-lamp fixtures will be retrofitted with two T-8 lamps. Energy savings per fixture range from $35 \%$ for a two-lamp fixture conversion to $68 \%$ for a four-lamp fixture conversion.

Lighting fixture retrofit is proposed for the control building and warehouse. Other buildings, once occupancy controls and timers have been installed, will not benefit from improved lighting due to greatly reduced operating hours. A summary of the lighting fixture changes proposed for the control building is shown in Table R-6. 
Table R-6.

\begin{tabular}{|c|c|c|c|c|c|c|c|c|c|c|}
\hline \multirow[t]{2}{*}{ Space } & \multirow{2}{*}{$\begin{array}{c}\text { Fixture } \\
\text { count }\end{array}$} & \multirow{2}{*}{$\begin{array}{c}\text { Lamp } \\
\text { Length (ft) }\end{array}$} & \multicolumn{4}{|c|}{ Existing lamps and ballasts } & \multicolumn{4}{|c|}{ Proposed lamps and ballasts } \\
\hline & & & $\begin{array}{c}\text { No } \\
\text { lamps }\end{array}$ & $\begin{array}{l}\text { Lamp } \\
\text { type }\end{array}$ & Ballast type & Watts & $\begin{array}{c}\text { No } \\
\text { lamps }\end{array}$ & $\begin{array}{c}\text { Lamp } \\
\text { type }\end{array}$ & Ballast type & Watts \\
\hline 101-Lobby & 1 & 2 & 2 & $\mathrm{~T}-12$ & Magnetic & 50 & 1 & $\mathrm{~T}-8$ & Electronic & 23 \\
\hline 101-Lobby & 3 & 4 & 2 & $\mathrm{~T}-12$ & Magnetic & 96 & 2 & $\mathrm{~T}-8$ & Electronic & 71 \\
\hline 204-205 restroom & 1 & 2 & 2 & $\mathrm{~T}-12$ & Magnetic & 50 & 1 & $\mathrm{~T}-8$ & Electronic & 23 \\
\hline 209-Control rm & 1 & 2 & 2 & $\mathrm{~T}-12$ & Magnetic & 50 & 1 & $\mathrm{~T}-8$ & Electronic & 23 \\
\hline 209-Control rm & 2 & 2 & 2 & $\mathrm{~T}-12$ & Magnetic & 50 & 1 & $\mathrm{~T}-8$ & Electronic & 23 \\
\hline 102-Service ent & 3 & 4 & 2 & $\mathrm{~T}-12$ & Magnetic & 96 & 2 & $\mathrm{~T}-8$ & Electronic & 71 \\
\hline 104-Chem lab & 4 & 4 & 2 & $\mathrm{~T}-12$ & Magnetic & 96 & 2 & $\mathrm{~T}-8$ & Electronic & 71 \\
\hline 107-Lunch room & 3 & 4 & 2 & $\mathrm{~T}-12$ & Magnetic & 96 & 2 & $\mathrm{~T}-8$ & Electronic & 71 \\
\hline 108-Shop & 8 & 4 & 2 & $\mathrm{~T}-12$ & Magnetic & 96 & 2 & $\mathrm{~T}-8$ & Electronic & 71 \\
\hline 109-Battery rm & 6 & 4 & 2 & $\mathrm{~T}-12$ & Magnetic & 96 & 2 & $\mathrm{~T}-8$ & Electronic & 71 \\
\hline 110-Switchgear & 9 & 4 & 2 & $\mathrm{~T}-12$ & Magnetic & 96 & 2 & $\mathrm{~T}-8$ & Electronic & 71 \\
\hline 201-Lobby & 4 & 4 & 2 & $\mathrm{~T}-12$ & Magnetic & 96 & 2 & $\mathrm{~T}-8$ & Electronic & 71 \\
\hline 202-Hall & 3 & 4 & 2 & $\mathrm{~T}-12$ & Magnetic & 96 & 2 & $\mathrm{~T}-8$ & Electronic & 71 \\
\hline 203-Locker & 2 & 4 & 2 & $\mathrm{~T}-12$ & Magnetic & 96 & 2 & $\mathrm{~T}-8$ & Electronic & 71 \\
\hline 208-Watch engr & 2 & 4 & 2 & $\mathrm{~T}-12$ & Magnetic & 96 & 2 & $\mathrm{~T}-8$ & Electronic & 71 \\
\hline 106-Inst shop & 4 & 4 & 3 & $\mathrm{~T}-12$ & Magnetic & 153 & 2 & $\mathrm{~T}-8$ & Electronic & 71 \\
\hline 206-Equipment & 10 & 4 & 3 & $\mathrm{~T}-12$ & Magnetic & 153 & 2 & $\mathrm{~T}-8$ & Electronic & 71 \\
\hline 206-Equipment & 9 & 4 & 3 & $\mathrm{~T}-12$ & Magnetic & 153 & 2 & $\mathrm{~T}-8$ & Electronic & 71 \\
\hline 209-Control rm & 12 & 4 & 3 & $\mathrm{~T}-12$ & Magnetic & 153 & 2 & $\mathrm{~T}-8$ & Electronic & 71 \\
\hline 210-Conference & 2 & 4 & 3 & $\mathrm{~T}-12$ & Magnetic & 153 & 2 & $\mathrm{~T}-8$ & Electronic & 71 \\
\hline 105-Elec room & 4 & 4 & 4 & $\mathrm{~T}-12$ & Magnetic & 192 & 2 & $\mathrm{~T}-8$ & Electronic & 71 \\
\hline 207-DAS & 6 & 4 & 4 & $\mathrm{~T}-12$ & Magnetic & 192 & 2 & T-8 & Electronic & 71 \\
\hline
\end{tabular}

A summary of the lighting improvements proposed for the warehouse is shown in Table R-7.

Table R-7.

\begin{tabular}{|c|c|c|c|c|c|c|c|c|c|c|}
\hline \multirow{2}{*}{ Space } & \multirow{2}{*}{$\begin{array}{c}\text { Fixture } \\
\text { count }\end{array}$} & \multirow{2}{*}{$\begin{array}{c}\text { Lamp } \\
\text { Length (ft) }\end{array}$} & \multicolumn{4}{|c|}{ Existing lamps and ballasts } & \multicolumn{4}{|c|}{ Proposed lamps and ballasts } \\
\hline & & & $\begin{array}{c}\text { No } \\
\text { lamps }\end{array}$ & $\begin{array}{c}\text { Lamp } \\
\text { type }\end{array}$ & Ballast type & Watts & $\begin{array}{c}\text { No } \\
\text { lamps }\end{array}$ & $\begin{array}{l}\text { Lamp } \\
\text { type }\end{array}$ & Ballast type & Watts \\
\hline Warehouse & 26 & 4 & 4 & $\mathrm{~T}-12$ & Magnetic & 192 & 4 & $\mathrm{~T}-8$ & Electronic & 110 \\
\hline
\end{tabular}

An estimate of lighting fixture retrofit costs is shown in Table R-8.

Table R-8.

\begin{tabular}{lccccc}
\hline Measure & unit & Material & Labor & Total & $\begin{array}{c}\text { Total including } \\
\text { overhead and profit }\end{array}$ \\
\hline $\begin{array}{l}\text { Two-lamp retrofit }- \text { T-8 w/ } \\
\text { electronic ballast }\end{array}$ & fixture & $\$ 26$ & $\$ 15$ & $\$ 41$ & $\$ 49$ \\
$\begin{array}{l}\text { Four-lamp retrofit }- \text { T-8 w/ } \\
\text { electronic ballast }\end{array}$ & fixture & $\$ 32$ & $\$ 15$ & $\$ 47$ & $\$ 56$ \\
\hline \hline
\end{tabular}




\section{R.4.2.4 Install Evaporative Cooling in Remote Stations and Load Centers}

The load centers and remote stations located in the field and the tower are currently cooled by mechanical air-conditioning systems. Due to the dry climate at the site, these spaces can be cooled effectively and much more efficiently with evaporative cooling. This option considers replacing the existing mechanical air conditioners with industrial-grade evaporative-cooling systems. The systems proposed for each building are summarized in Table R-9.

Table R-9.

\begin{tabular}{lll}
\hline \hline Site & Existing & Proposed \\
\hline Remote station 1 & Trane SARCC B754-A, 6 ton, & Direct evaporative cooler, \\
& 2700 CFM, 8 EER & 2700 CFM, 0.85 effectiveness \\
Remote station 2 & Trane RAUC 504 B, 5 Ton, & Direct evaporative cooler, \\
& 3000 CFM, 8 EER & 3000 CFM, 0.85 effectiveness \\
Remote station 3 & Trane RAUC 504 B, 5 Ton, & Direct evaporative cooler, \\
& 3000 CFM, 8 EER & 3000 CFM, 0.85 effectiveness \\
Load center A & Trane RAUA2004-ND, 19.25 & Direct evaporative cooler, \\
& Ton, 8260 CFM, 8 EER & 8260 CFM, 0.85 effectiveness \\
\hline \hline
\end{tabular}

One of the project team's concerns was the ability of the evaporative coolers to maintain reasonable space temperatures on hot days. To investigate this issue, a space temperature histogram was produced by the DOE-2 program. Maximum space temperatures of $80^{\circ} \mathrm{F}$ or less were maintained throughout the year. The histogram is shown in Table R-10.

Cost estimates for industrial-grade evaporative coolers are shown in Table R-11.

\section{R.4.2.5 Replace Air Conditioners in Control Building}

The packaged heat pump systems at the control building are old and inefficient by modern standards. This option considers replacing the existing systems with new high-efficiency units. The units installed, and the proposed replacements, are shown in Table R-12.

The estimated costs of a high-efficiency unit, in the size range required, is shown in Table R-13.

\section{R.4.2.6 Replace Computer Room Coolers}

The computer room coolers serving the underfloor air distribution system in level 2 of the control building are also old and inefficient by modern standards. This option considers replacing the existing computer room coolers with new high-efficiency units. The units installed, and the proposed replacements, are shown in Table R-14.

The estimated costs of high-efficiency units, in the size range required, is listed in Table R-15.

The estimated energy savings and first costs of each of these options is summarized in Table R-16-Table R-18. 


\section{Table $R-10$.}

TOTAL HOURS AT TEMPERATURE LEVEL AND TIME OF DAY

\begin{tabular}{|c|c|c|c|c|c|c|c|c|c|c|c|c|c|c|c|c|c|c|c|c|c|c|c|c|c|c|c|}
\hline & HOUR & $\begin{array}{c}1 \mathrm{AM} \\
---\end{array}$ & $\begin{array}{l}12 \\
---\end{array}$ & $\begin{array}{c}3 \\
---\end{array}$ & $\begin{array}{c}4 \\
---\end{array}$ & $\begin{array}{c}5 \\
---\end{array}$ & $\begin{array}{c}6 \\
---\end{array}$ & $\begin{array}{c}7 \\
---\end{array}$ & $\begin{array}{c}8 \\
---\end{array}$ & $\begin{array}{c}9 \\
---\end{array}$ & $\begin{array}{l}10 \\
---\end{array}$ & $\begin{array}{l}11 \\
---\end{array}$ & $\begin{array}{l}12 \\
---\end{array}$ & $\begin{array}{c}1 \mathrm{PN} \\
---\end{array}$ & $\begin{array}{l}\text { M } 2 \\
---\end{array}$ & $\begin{array}{c}3 \\
---\end{array}$ & $\begin{array}{c}4 \\
---\end{array}$ & $\begin{array}{c}5 \\
---\end{array}$ & $\begin{array}{c}6 \\
---\end{array}$ & $\begin{array}{c}7 \\
---\end{array}$ & 8 & $\begin{array}{r}9 \\
---\end{array}$ & & $\begin{array}{l}10 \\
---\end{array}$ & 11 & $\begin{array}{l}12 \\
----\end{array}$ & TOTAL \\
\hline ABOVE & $85^{\circ} \mathrm{F}$ & 0 & 0 & 0 & 0 & 0 & 0 & 0 & 0 & 0 & 0 & 0 & 0 & 0 & 0 & 0 & 0 & 0 & 0 & 0 & 0 & 0 & & 0 & 0 & 0 & 0 \\
\hline $80-85$ & & 0 & 0 & 0 & 0 & 0 & 0 & 0 & 0 & 0 & 0 & 0 & 0 & 0 & 0 & 0 & 0 & 0 & 0 & 0 & 0 & 0 & & 0 & 0 & 0 & 0 \\
\hline $75-80$ & & 0 & 0 & 0 & 0 & 0 & 0 & 0 & 0 & 0 & 0 & 0 & 0 & 9 & 8 & 9 & 10 & 2 & 2 & 0 & 0 & ) & & 0 & 0 & 0 & 40 \\
\hline $70-75$ & & 267 & 256 & 239 & 227 & 219 & 206 & 200 & 222 & 251 & 279 & 324 & 345 & 348 & 355 & 354 & 353 & 361 & 359 & 354 & 343 & $3 \quad 327$ & & 315 & 296 & 5280 & 7080 \\
\hline $65-70$ & & 72 & 68 & 78 & 80 & 71 & 69 & 69 & 46 & 38 & 51 & 29 & 19 & 8 & 2 & 2 & 2 & 2 & 4 & 11 & 21 & 35 & & 41 & 57 & 67 & 942 \\
\hline $60-65$ & & 24 & 36 & 38 & 44 & 56 & 66 & 65 & 61 & 51 & 24 & 12 & 1 & 0 & 0 & 0 & 0 & 0 & 0 & 0 & 1 & 3 & & 9 & 12 & 18 & 521 \\
\hline BELOW & 60 & 2 & 5 & 10 & 14 & 19 & 24 & 31 & 36 & 25 & 11 & 0 & 0 & 0 & 0 & 0 & 0 & 0 & 0 & 0 & 0 & 0 & & 0 & 0 & 0 & 177 \\
\hline
\end{tabular}

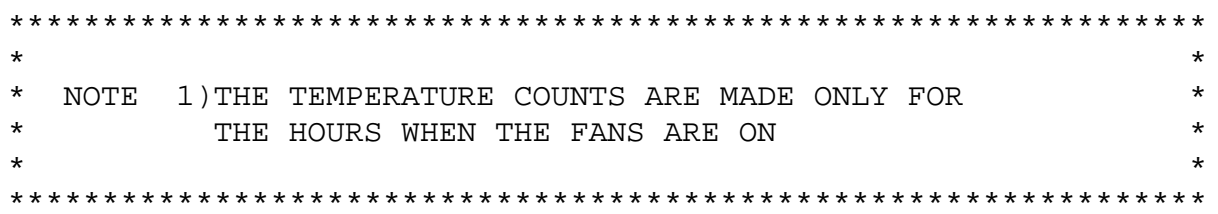


Table R-11.

\begin{tabular}{lccccc}
\hline \hline Measure & Material & Labor & Total & $\begin{array}{c}\text { Total including } \\
\text { overhead and profit }\end{array}$ & Unit cost Unit \\
\hline Evap cooler - 3000 CFM & $\$ 1,234$ & $\$ 528$ & $\$ 1,762$ & $\$ 2,097$ & $\$ 0.70$ per CFM \\
Evap cooler - 5500 CFM & $\$ 1,519$ & $\$ 528$ & $\$ 2,047$ & $\$ 2,436$ & $\$ 0.44$ per CFM \\
Evap cooler - 8500 CFM & $\$ 3,500$ & $\$ 528$ & $\$ 4,028$ & $\$ 4,793$ & $\$ 0.56$ per CFM \\
\hline \hline
\end{tabular}

Table $R-12$.

\begin{tabular}{lll}
\hline \hline Site & Existing & Proposed \\
\hline Control building - first floor & Carrier 50PQ016600 DA, 15 & High efficiency unit, 11 EER, \\
& Ton, 6000 CFM, 7.5 EER, 2.0 & 3.2 COP \\
& COP & \\
Control building - second floor & Carrier 50RQ010600 DA, 9 & High efficiency unit, 11 EER, \\
& Ton, 3600 CFM, 7.7, EER, 2.0 & 3.2 COP \\
& COP & \\
\hline \hline
\end{tabular}

Table R-13.

\begin{tabular}{lccccc}
\hline \hline Measure & Material & Labor & Total & $\begin{array}{c}\text { Total including } \\
\text { overhead and profit }\end{array}$ & Unit cost Unit \\
\hline Single package HP-15 Ton & $\$ 19,125^{*}$ & $\$ 2,725$ & $\$ 21,850$ & $\$ 26,002$ & $\$ 1,733$ per ton \\
\hline \hline
\end{tabular}

*Material cost includes a $25 \%$ premium for an energy-efficient unit

Table R-14.

\begin{tabular}{lll}
\hline \hline Space & Existing & Proposed \\
\hline Room 206 - equipment room & Liskey Aire Model DA18, & High efficiency unit, 10 EER \\
& Ton, 6 EER, 3600 CFM & \\
Control building - second floor & 2 ea., Liskey Aire Model DA-3, & High efficiency unit, 10 EER \\
& 1.5 Ton, 6 EER, 800 CFM & \\
\hline \hline
\end{tabular}

Table R-15.

\begin{tabular}{|c|c|c|c|c|c|}
\hline Measure & Material & Labor & Total & $\begin{array}{c}\text { Total including } \\
\text { overhead and profit }\end{array}$ & Unit cost Unit \\
\hline Computer cooler - 3 Ton & $\$ 6,175$ & $\$ 1,050$ & $\$ 7,225$ & $\$ 8,598$ & $\$ 2,866$ Ton \\
\hline Computer cooler - 10 Ton & $\$ 17,900$ & $\$ 2,075$ & $\$ 19,975$ & $\$ 23,770$ & \$2,377 Ton \\
\hline
\end{tabular}


Table R-16. No cost - low cost

\begin{tabular}{lcc}
\hline \hline Option & $\begin{array}{c}\text { Energy savings } \\
(\mathrm{kWh})\end{array}$ & First Cost \\
\hline Reduce tower lighting & 29469 & $\$ 0$ \\
Control building occupancy sensors and timers & 18324 & $\$ 417$ \\
Load center A timer & 15951 & $\$ 48$ \\
RS 1 timer & 6728 & $\$ 48$ \\
RS 2 timer & 9533 & $\$ 48$ \\
RS 3 timer & 9533 & $\$ 48$ \\
Level 13 electrical room timer & 5046 & $\$ 48$ \\
Total & 94583 & $\$ 657$ \\
\hline \hline
\end{tabular}

Table R-17. Medium cost

\begin{tabular}{lcc}
\hline Option & $\begin{array}{c}\text { Energy savings } \\
(\mathrm{kWh})\end{array}$ & First Cost \\
\hline Retrofit lamps and ballasts - control building & 22904 & $\$ 4,830$ \\
Retrofit lamps and ballasts - warehouse & 6396 & $\$ 1,260$ \\
Evaporative cooling - load center A & 32389 & $\$ 4,626$ \\
Evaporative cooling - RS-1 & 8400 & $\$ 2,520$ \\
Evaporative cooling - RS-2 & 7159 & $\$ 2,100$ \\
Evaporative cooling - RS-3 & 7159 & $\$ 2,100$ \\
Total & 84407 & $\$ 17,436$ \\
\hline \hline
\end{tabular}

Table R-18. Higher cost

\begin{tabular}{lcc}
\hline \hline Option & $\begin{array}{c}\text { Energy savings } \\
(\mathrm{kWh})\end{array}$ & First Cost \\
\hline Upgrade HVAC - control building & 13459 & $\$ 41,602$ \\
Upgrade computer coolers & 11532 & $\$ 30,901$ \\
Total & 24991 & $\$ 72,504$ \\
\hline \hline
\end{tabular}

\section{R.5 Conclusions and Recommendations}

It is recommended that the project team implement the options outlined in the low- and mediumcost categories above. The low-cost options have the potential to save 94.6 MWh, roughly equivalent to a full-day of plant output, at little or no cost. The medium-cost options have the potential to save another $84 \mathrm{MWh}$, with a simple payback of about two years. ${ }^{1}$ Replacement of the existing air-conditioning systems and computer room coolers is hard to justify based on energy savings alone, but the option of installing high-efficiency models should be considered when the existing equipment either fails or is scheduled for replacement.

\footnotetext{
1 Simple payback was evaluated assuming a retail levelized cost for electricity of $\$ 0.10$ per kWh.
} 


\section{Attachment 1 to Appendix R}

\section{Solar Two Baseline Study}

\section{Monitoring Plan}

\section{General Information}

\begin{tabular}{ll} 
Building Name & \multicolumn{1}{c}{ Solar Two Power Plant } \\
\cline { 2 - 2 } Address & Santa Fe Road \\
\cline { 2 - 2 } Contact Name & Barstow, CA \\
\cline { 2 - 2 } Phone & Rocky Gilbert \\
\cline { 2 - 2 } & $760-254-3035$
\end{tabular}

Goal

1. Estimate baseline energy consumption for lighting and HVAC systems in auxiliary buildings at Solar Two.

2. Measure environmental conditions in control building.

\section{Scope}

The scope of the project is limited to "auxiliary loads," which are defined as lighting and space conditioning loads at support facilities. Equipment used in the electricity generation process (e.g. pumps, fans, heat tracing, heliostats, controls) and the data acquisition equipment are not in the scope of this project. The SCE administration building at the entrance of the plant is also not within the scope this project.

\section{Experimental Design}

1. One-time (spot) measurements on constant load equipment, such as HVAC fans and 24 hour lighting

2. Short term ( 1 week) time series monitoring on variable load equipment, such as intermittent use lighting and HVAC compressors. 
3. Short-term (1 week) time-series monitoring on interior space temperatures and $\mathrm{RH}$ in selected spaces.

\section{Data Products}

Cooling Systems

- Linear model of compressor energy consumption as a function of ambient temperature

- Extrapolation of annual energy consumption from monitored data.

Air Handling Systems

- Fan power, annual energy consumption

Lighting Systems

- Connected loads

- Operating hours and schedules

Environmental Conditions

- Room temperature profile

- Room temperature fluctuations as a function of ambient temperature

- Room RH profile

\section{Monitoring Points}

Table 1. One-time tests

\begin{tabular}{ll}
\hline \hline Equipment/Circuits Tested & Equipment/Circuits Tested \\
\hline AHU-1 fan $\mathrm{kW}$ & ACCU-1 kW \\
AHU-3 fan $\mathrm{kW}$ & ACCU-3 kW \\
Lighting circuit kW & Panel PA kW \\
\hline \hline
\end{tabular}


Table 2. Short-term tests

\begin{tabular}{|c|c|c|c|c|c|c|}
\hline Data & Equipment/ & \multicolumn{4}{|c|}{ Measurements Taken } & Comments \\
\hline 1 & $\begin{array}{l}\text { Switch gear room 110, } \\
\text { panel PA }\end{array}$ & $\begin{array}{l}\text { Total } \\
\text { panel } \mathrm{kW}\end{array}$ & & & & $\begin{array}{l}\text { All control building HVAC } \\
\text { loads, plus elevator }\end{array}$ \\
\hline 2 & $\begin{array}{l}\text { Service entrance 101, } \\
\text { panel 1LB }\end{array}$ & $\mathrm{C} 1 \mathrm{amps}$ & $\mathrm{C} 2$ amps & C4 amps & & First floor lighting circuits \\
\hline 3 & Hall - 201, panel 2LC & $\mathrm{C} 1 \mathrm{amps}$ & $\mathrm{C} 2$ amps & C3 amps & C4 amps & $\begin{array}{l}\text { A sample of second floor } \\
\text { lighting circuits }\end{array}$ \\
\hline 4 & Remote station 1 & Zone temp & Zone RH & & & $\begin{array}{l}\text { Remote station } \\
\text { environmental conditions }\end{array}$ \\
\hline 5 & Load Control A & $\begin{array}{l}\text { ACCU-3 } \\
\text { amps }\end{array}$ & $\begin{array}{l}\text { AHU-3 } \\
\text { amps }\end{array}$ & & & Largest remote station load \\
\hline 6 & Load Control A & Zone temp & Zone RH & & & $\begin{array}{l}\text { Remote station } \\
\text { environmental conditions }\end{array}$ \\
\hline 7 & Remote station 2 & $\begin{array}{l}\text { ACCU-1 } \\
\text { amps }\end{array}$ & $\begin{array}{l}\text { AHU-1 } \\
\text { amps }\end{array}$ & & & $\begin{array}{l}\text { One of two identical remote } \\
\text { stations }\end{array}$ \\
\hline 8 & Remote station 2 & Zone temp & Zone RH & & & $\begin{array}{l}\text { Remote station } \\
\text { environmental conditions }\end{array}$ \\
\hline
\end{tabular}

Notes

1. Ambient temperature data to be obtained from the Solar Two site data acquisition system.

2. Data loggers to be removed by Solar Two site personnel at the conclusion of the monitoring period. 
Final Test and Evaluation Results from the Solar Two Project

\section{Monitored data}

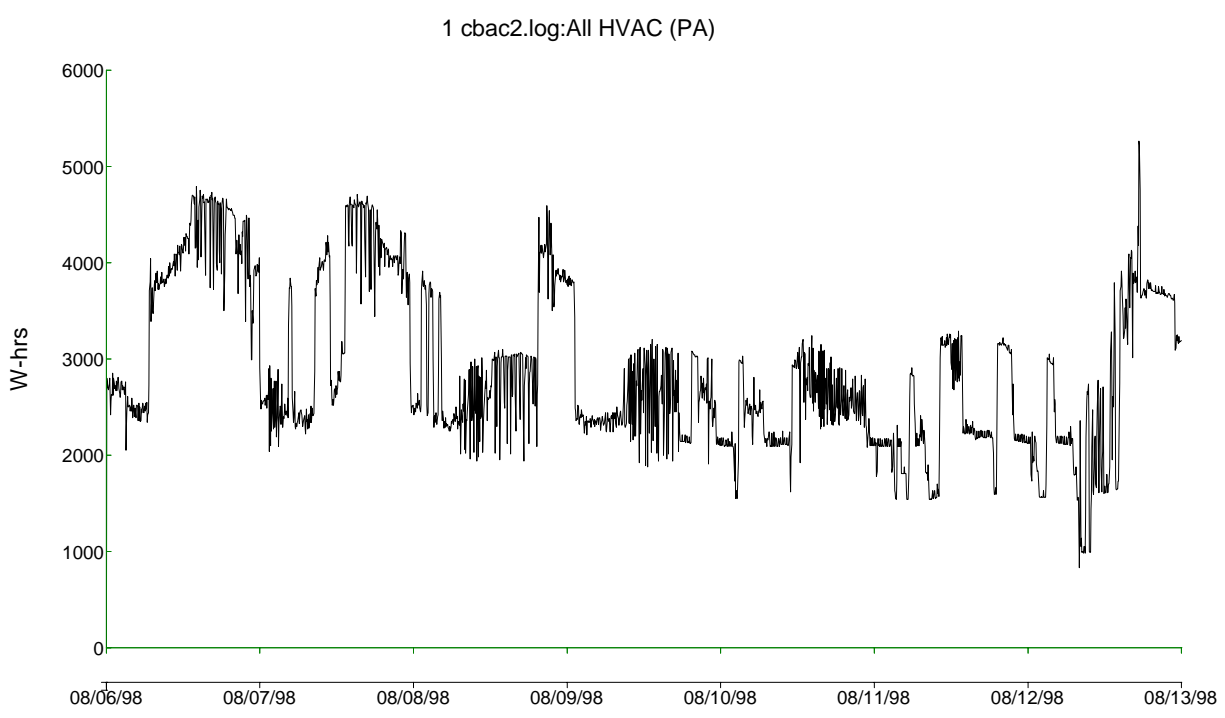

Figure 1. Control building HVAC.

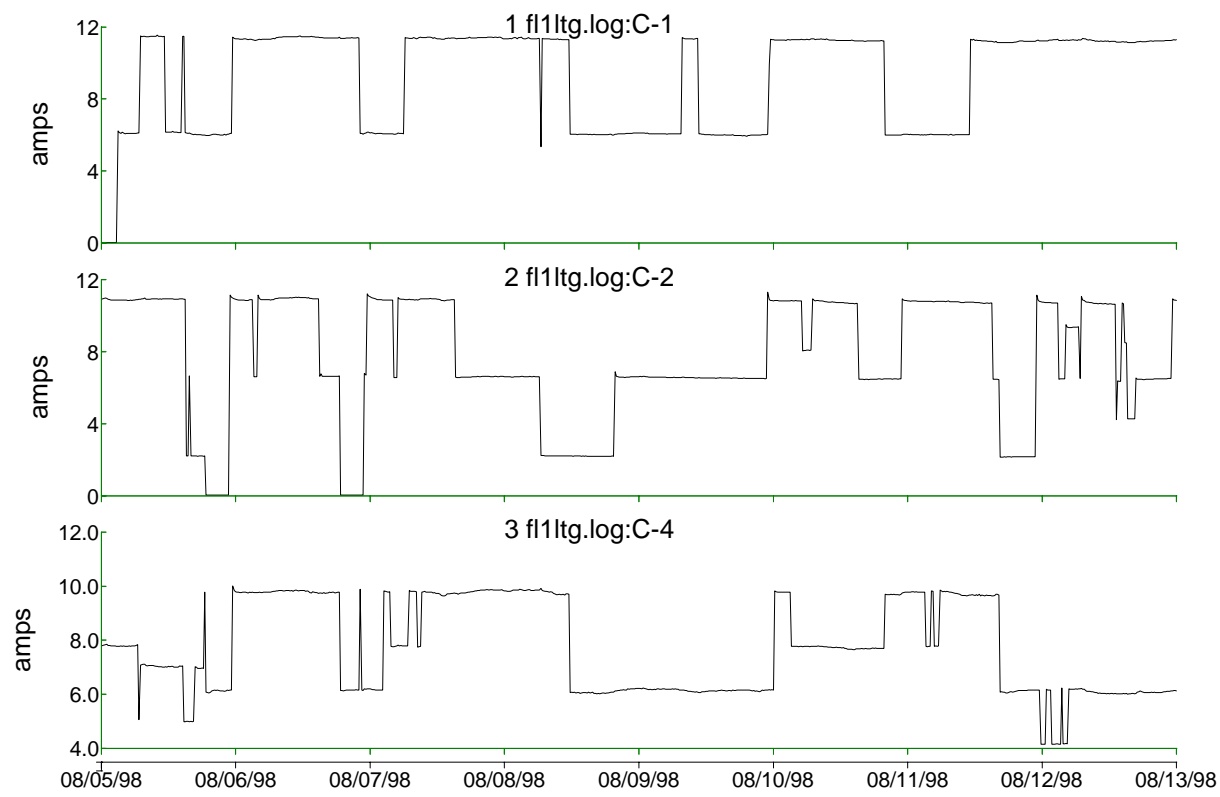

Figure 2. Control building lighting - floor 1 . 


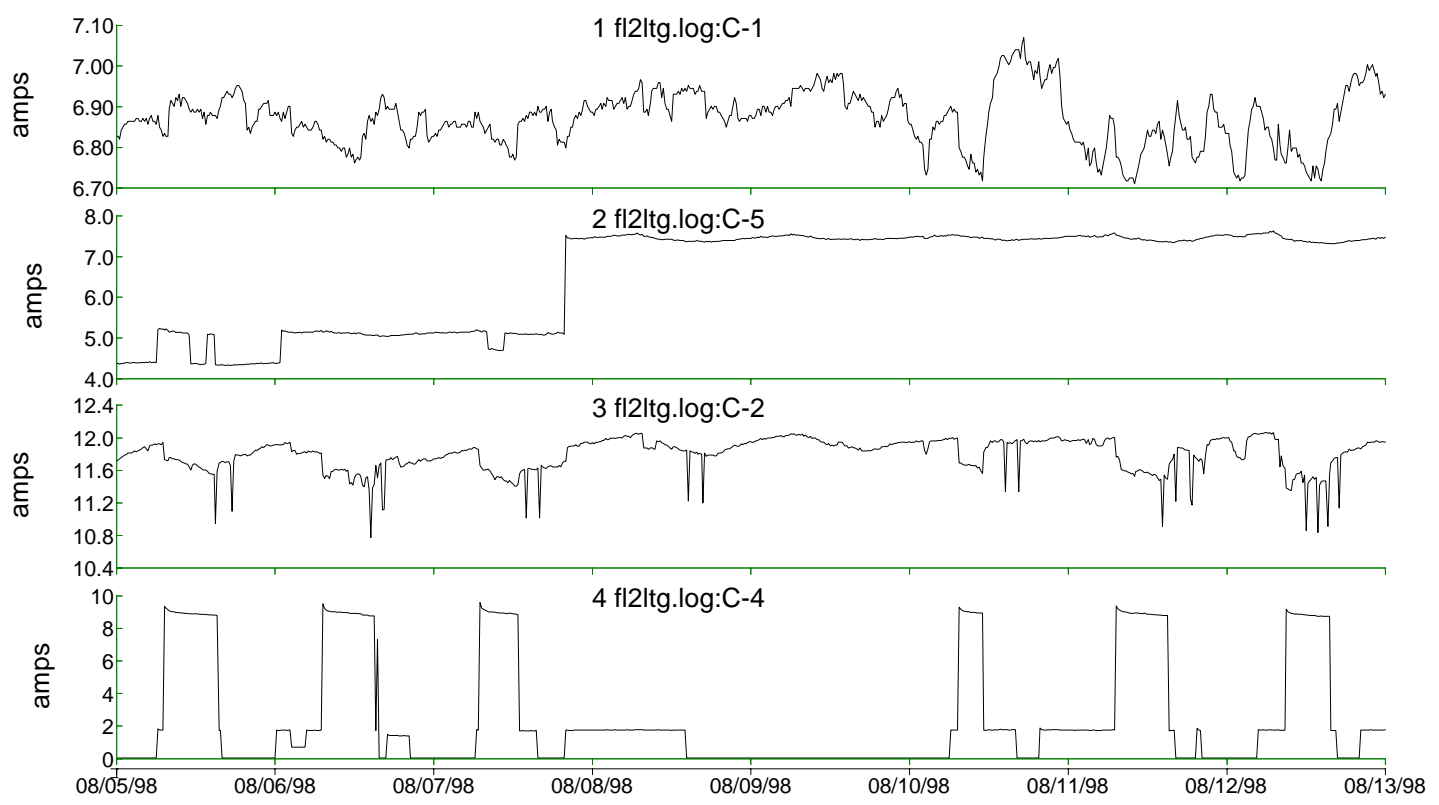

Figure 3. Control building second floor lighting.
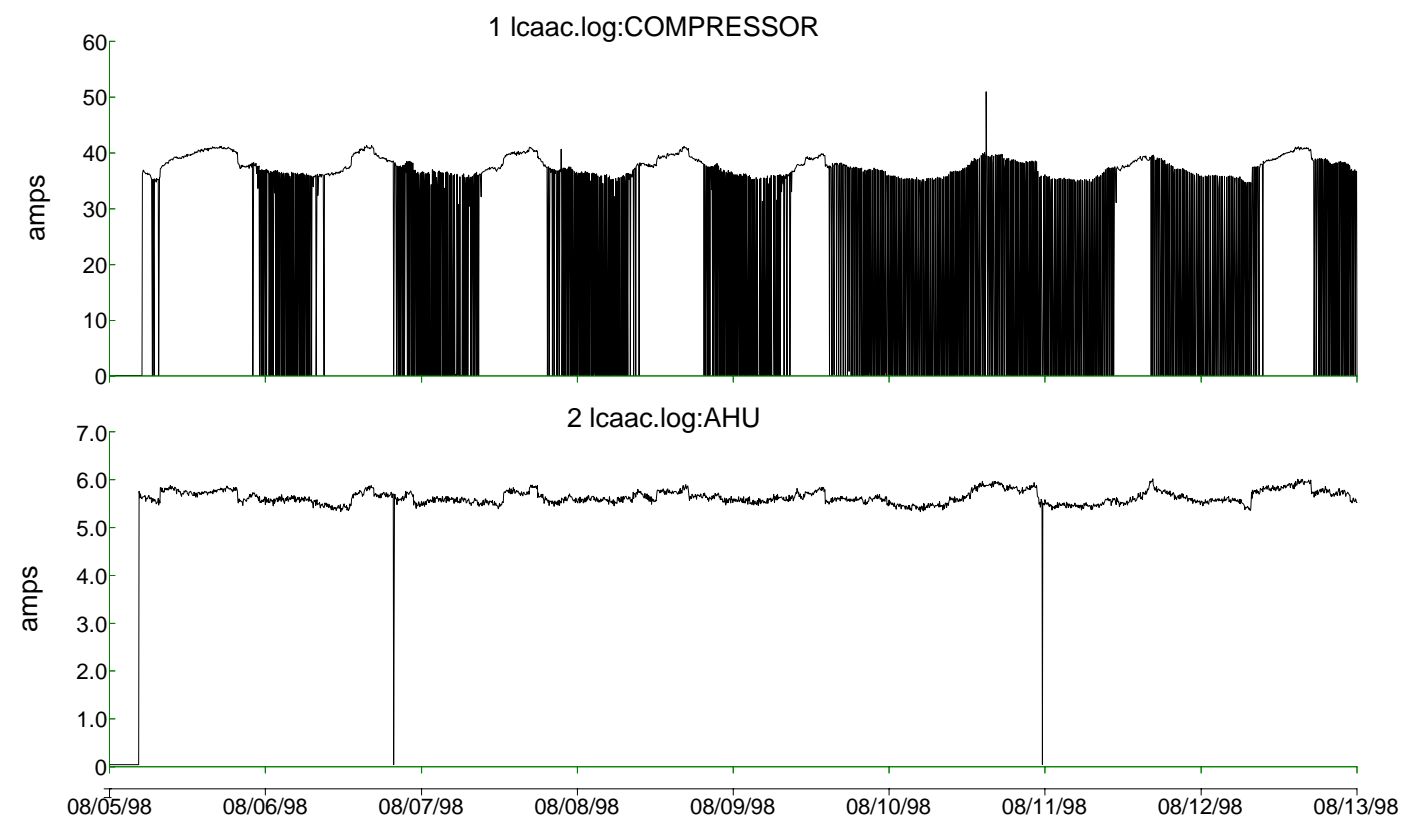

Figure 4. Load center A HVAC. 
Final Test and Evaluation Results from the Solar Two Project

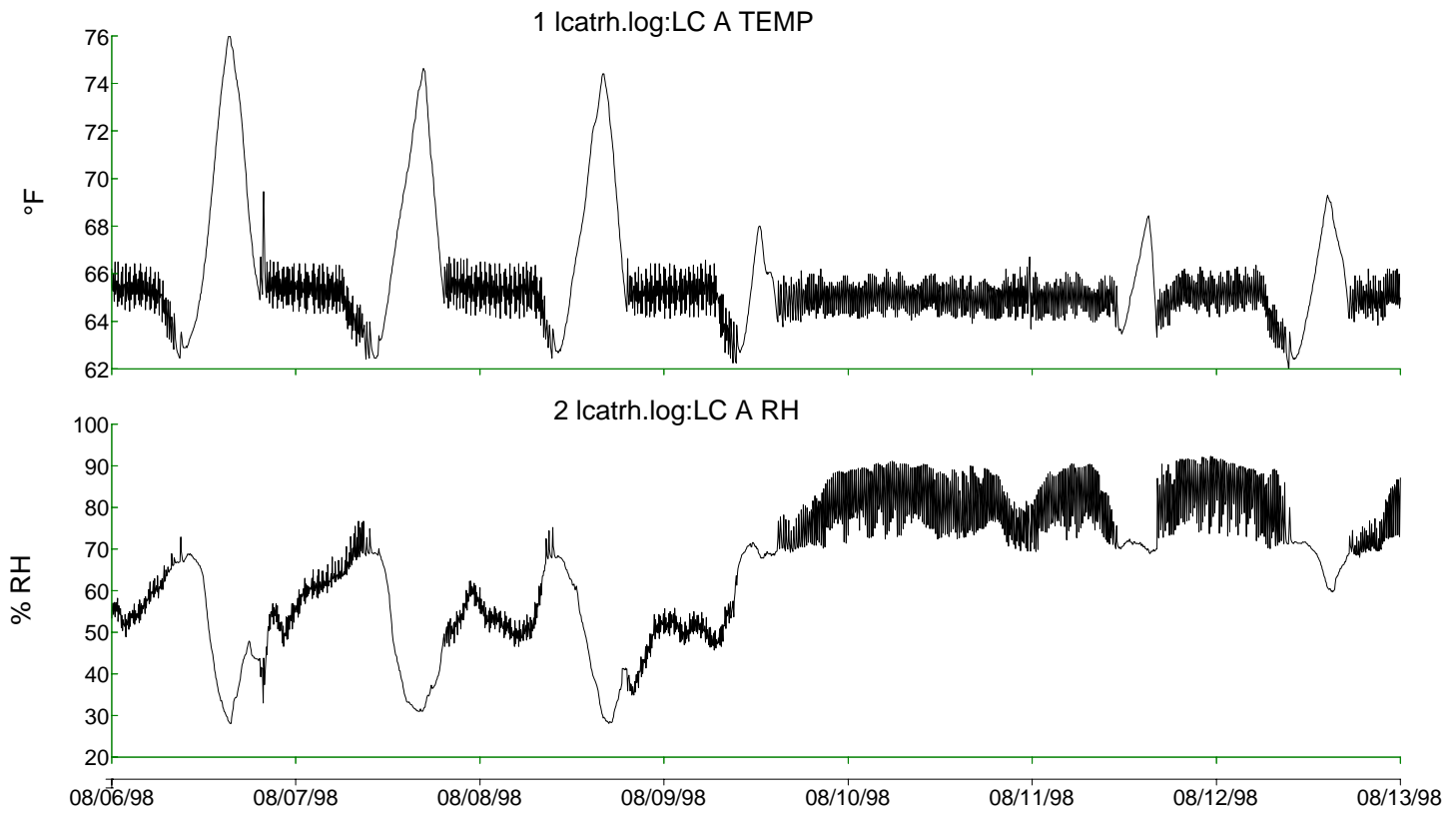

Figure 5. Load center A temperature and RH.

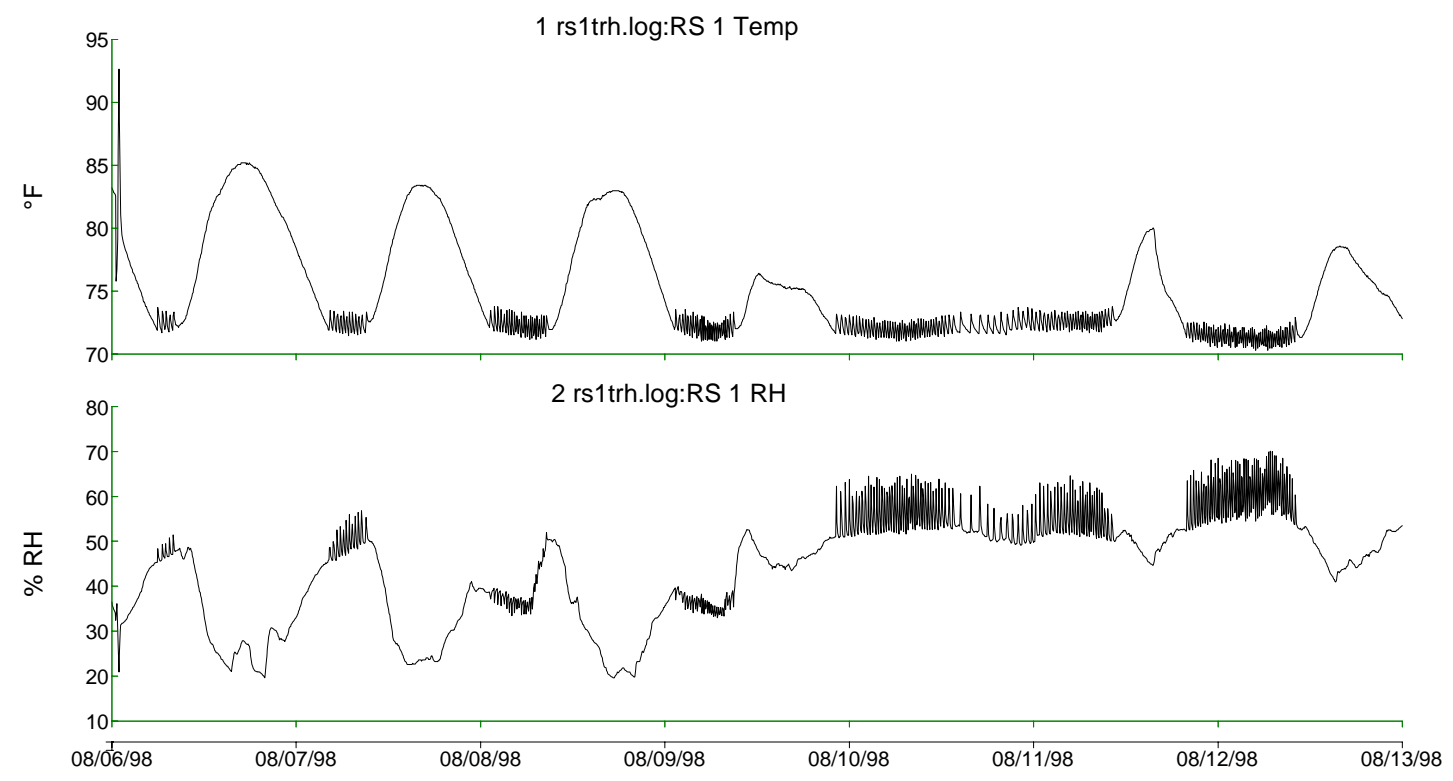

Figure 6. Remote station 1 temperature and $\mathrm{RH}$. 

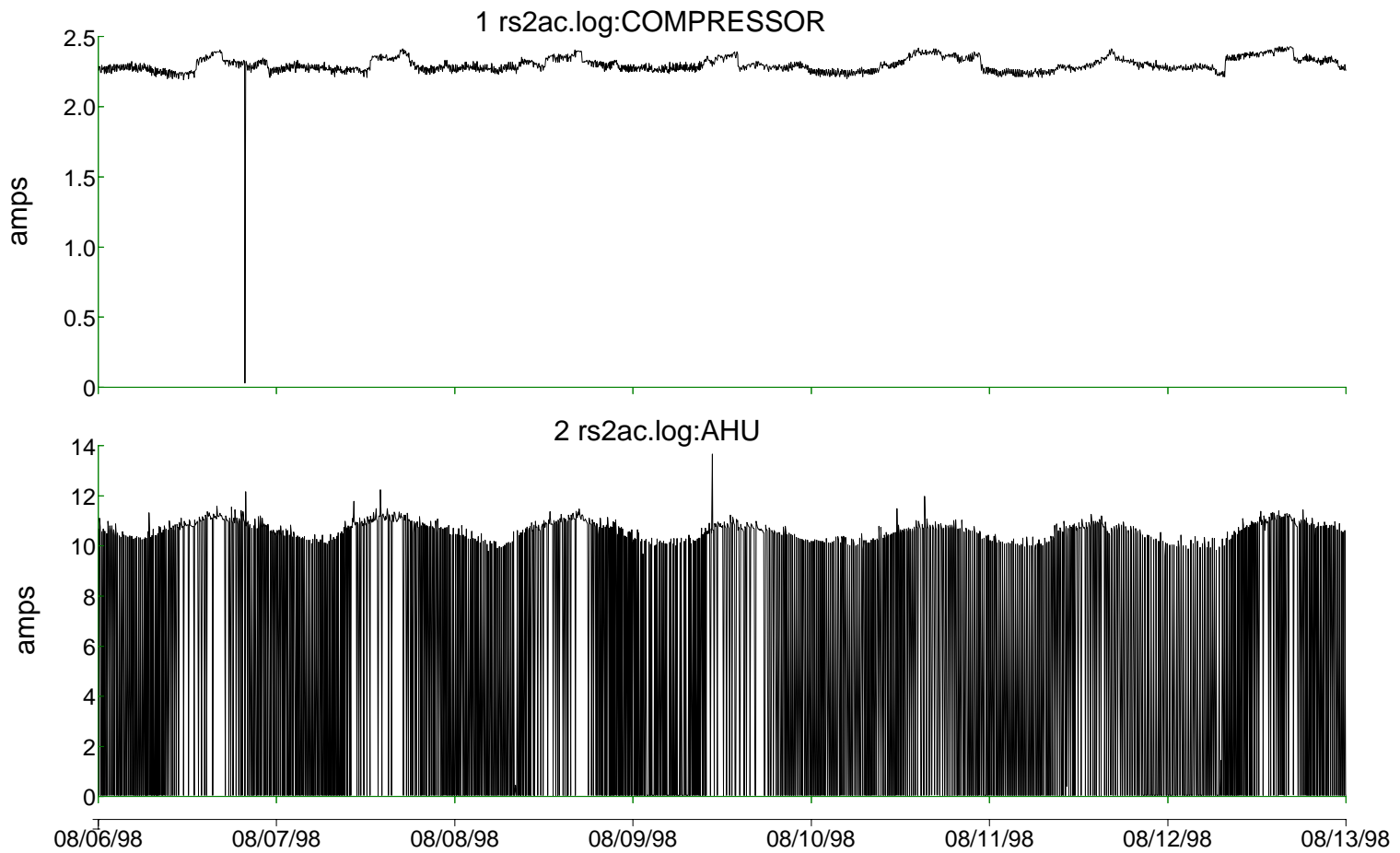

Figure 7. Remote station 2 HVAC (note channel labels reversed).
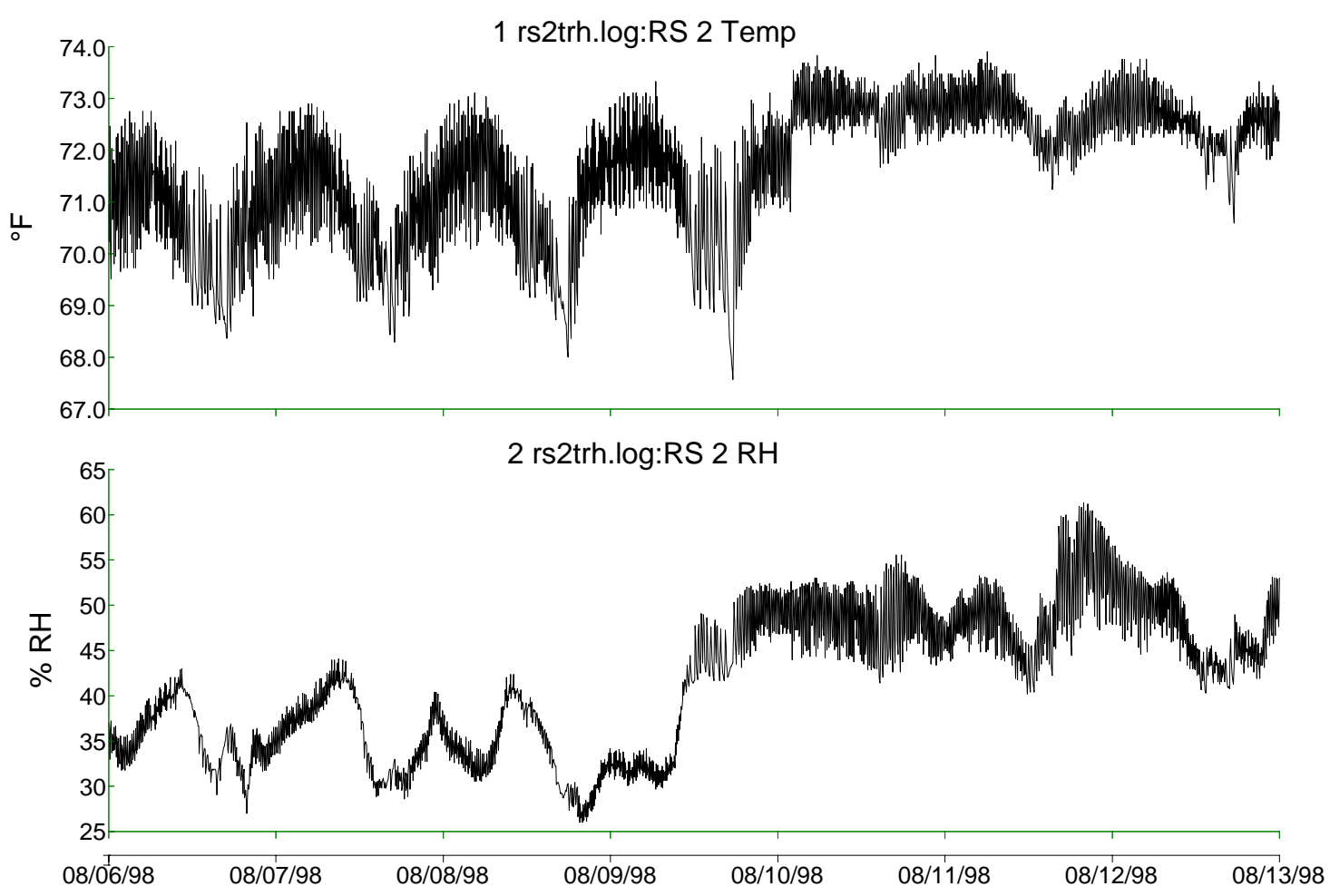

Figure 8. Remote station 2 temperature and $\mathrm{RH}$. 
Final Test and Evaluation Results from the Solar Two Project 


\section{Appendix S. Dispatchability Test (H. E. Reilly and R. Gilbert)}

\section{S.1 Goals and Objectives}

One of the distinct advantages of a molten-salt power tower plant is its ability to effectively store solar energy to later produce electricity. The dispatchability test demonstrated Solar Two's ability to generate dispatchable (i.e., on-demand) electricity from solar energy stored in the molten salt.

The specific goals and objectives of the dispatchability test were to:

- Determine the capability of the plant to dispatch electricity for different periods of time and at different rates,

- Determine the capability of the plant to dispatch electricity around the clock,

- Dispatch electric power produced from stored heat at different times of the day and night to identify effects on operating procedures and changes in plant efficiency, and

- Document the lessons learned and recommend changes for plant design and operation, if applicable.

\section{S.2 Methods}

The dispatchability test demonstrated the flexibility of meeting a wide range of load-shifting requirements. Starting in March 1998, the plant operating guideline was to operate in a power production mode, while still meeting test and evaluation objectives. That is, the plant was to run as often as possible and produce power whenever possible. Under this scheme, power production was rather unscheduled and electricity was produced at whatever rate made sense for the combination of weather and thermal storage conditions. For the dispatchability test, a series of tests was run in June 1998 wherein electricity was produced at a specified rate, with each test starting with a full tank of hot salt. By operating at reduced turbine output, the tests demonstrated extended electricity production from stored energy. For example, by operating the electric power generation system (EPGS) at 25\% load, Solar Two's three-hour, full-load storage capacity was used to demonstrate the equivalent of a 12-hour storage system. This flexibility was expanded in June and July of 1998 to demonstrate continuous power production for extended periods of time, including round-the-clock electricity production.

\section{S.3 Results}

Several operational periods were selected to demonstrate Solar Two's dispatchability. These were:

1. November 1, 1996-Dispatch of electricity after dark. 
2. November 5, 1996-Dispatch of electricity during periods of heavy clouds.

3. November 6, 1997-Dispatch of electricity throughout the day.

4. June 24, 1998-Dispatch of electricity at $100 \%$ turbine load.

5. June 13-16, 1998-Round-the-clock electricity generation.

6. July 1-7, 1998-Round-the-clock electricity generation.

The following paragraphs describe each of these operating periods and the dispatchability results obtained.

\section{S.3.1 November 1, 1996}

This test sequence occurred prior to the evaporator tube rupture on November 7, 1996, and the subsequent repairs, modifications, and improvements to the steam generator system (SGS). Figure S-1 provides a plot of the day's solar insolation, receiver power, energy storage, and gross electric power. Solar energy was collected for approximately 2.5 hours during the middle of a nearly flawless solar day. The electric power generation systems (EPGSs) was heated and brought to operating conditions so that, as the sun set, the turbine was synchronized and delivered power to the grid for approximately 1 hour and 45 minutes. The data reflect the early state of operations in the fall of 1996, as evidenced by the short receiver operating day; the EPGS dropout for an hour after approximately 15 minutes of power production and the low EPGS output levels (approximately 5MWe gross) resulting from the unavailability of the extraction steam/feedwater heater system.

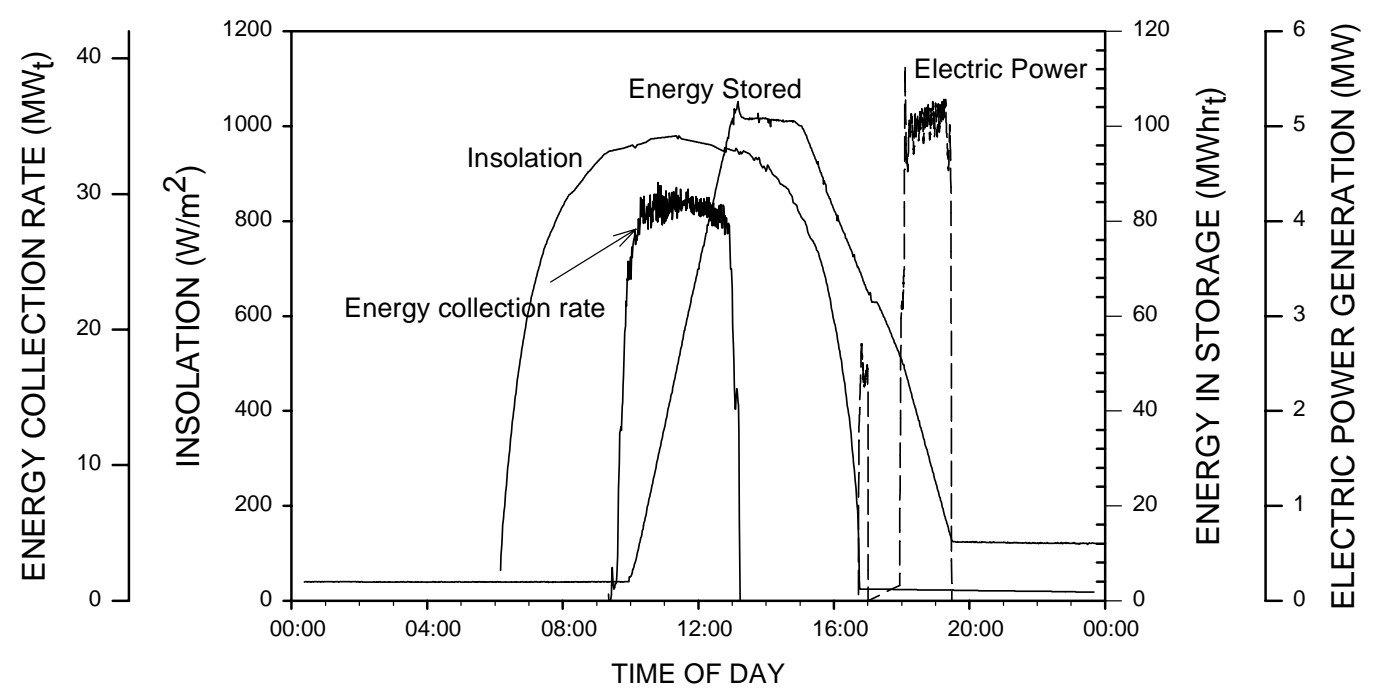

Figure S-1. Electric energy dispatch at Solar Two on November 1, 1996, demonstrating electricity generation after dark. 


\section{S.3.2 November 5, 1996}

The data for this day, shown in Figure S-2, were also recorded just prior to the evaporator tube rupture. The receiver was brought to operating power levels at approximately the same time as November 1, 1996, and was still operating when the insolation dropped off in the early afternoon due to heavy cloud cover. The generator was synchronized and delivered power to the grid as the receiver energy collection ended. The EPGS gross power output was approximately 5.5MWe.

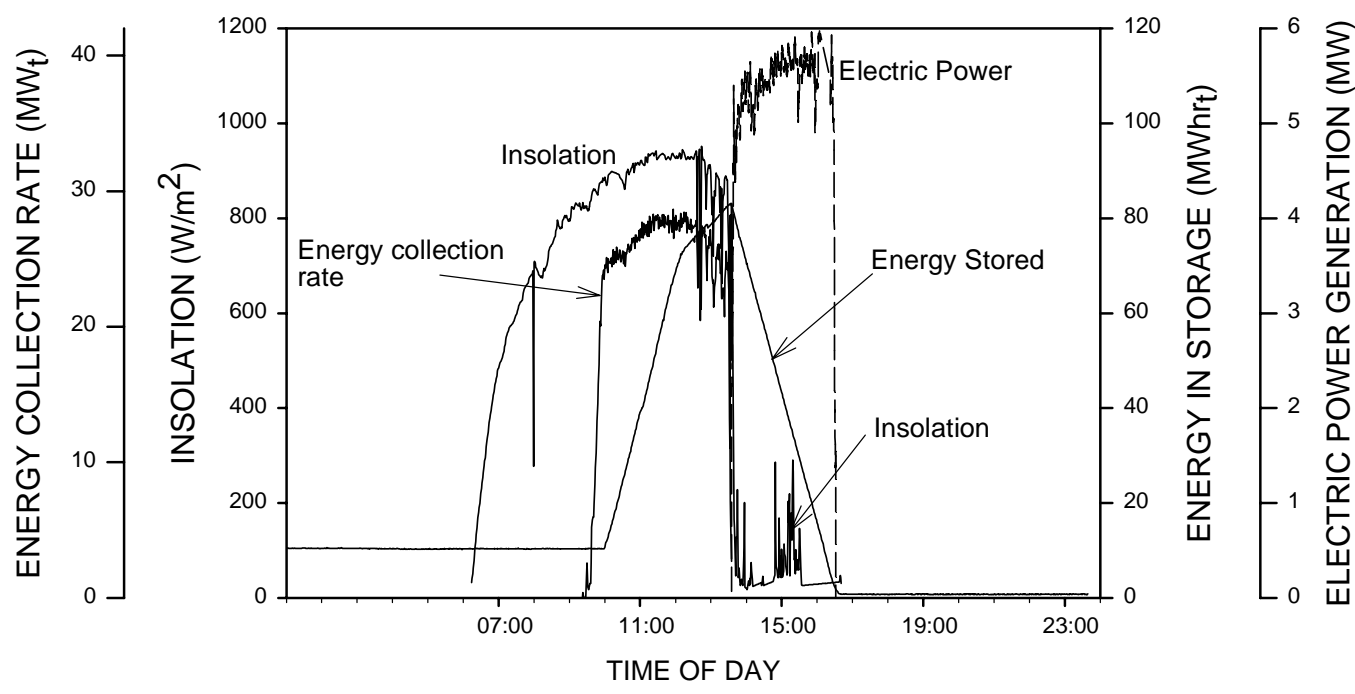

Figure S-2. Electric energy dispatch at Solar Two on November 5, 1996, demonstrating electricity generation after heavy clouds rolled in.

\section{S.3.3 November 6, 1997}

The next period selected for discussion of dispatch occurred one year later, on November 6, 1997, after the SGS had been redesigned, repaired, and returned to service. The data for November 6, 1997 are shown in Figure S-3. A successful run of the receiver system the previous day had filled the hot salt tank with salt at approximately $543^{\circ} \mathrm{C}\left(1010^{\circ} \mathrm{F}\right)$. This stored energy allowed operators to start turbine operations early in the morning. Then, as the sun rose and solar insolation climbed, the operators brought the receiver on-line and started recharging the hot salt tank with hot salt. The turbine/generator was synchronized to the grid at 8:23 a.m. and produced power until it was taken offline at approximately 4:15 p.m. In parallel, the receiver was brought to operations mode at 8:00 a.m. and produced hot salt until heliostats were removed at 3:45 p.m. Although power was not produced after dark, these data indicate the ability to uncouple (within the limits of the plant's storage capacity) the energy collection and power production functions.

Comparing Figure S-3 to the previous two figures reveals the improvements in plant performance and operation. For example, the receiver was started an hour earlier and the generator output peaked at $11 \mathrm{MWe}$ gross, compared to less than $6 \mathrm{MWe}$ gross a year earlier. 
Improvements were due to modifications to the EPGS; placing the feedwater heaters in full service; and overall improvements in plant operations due to operating experience.

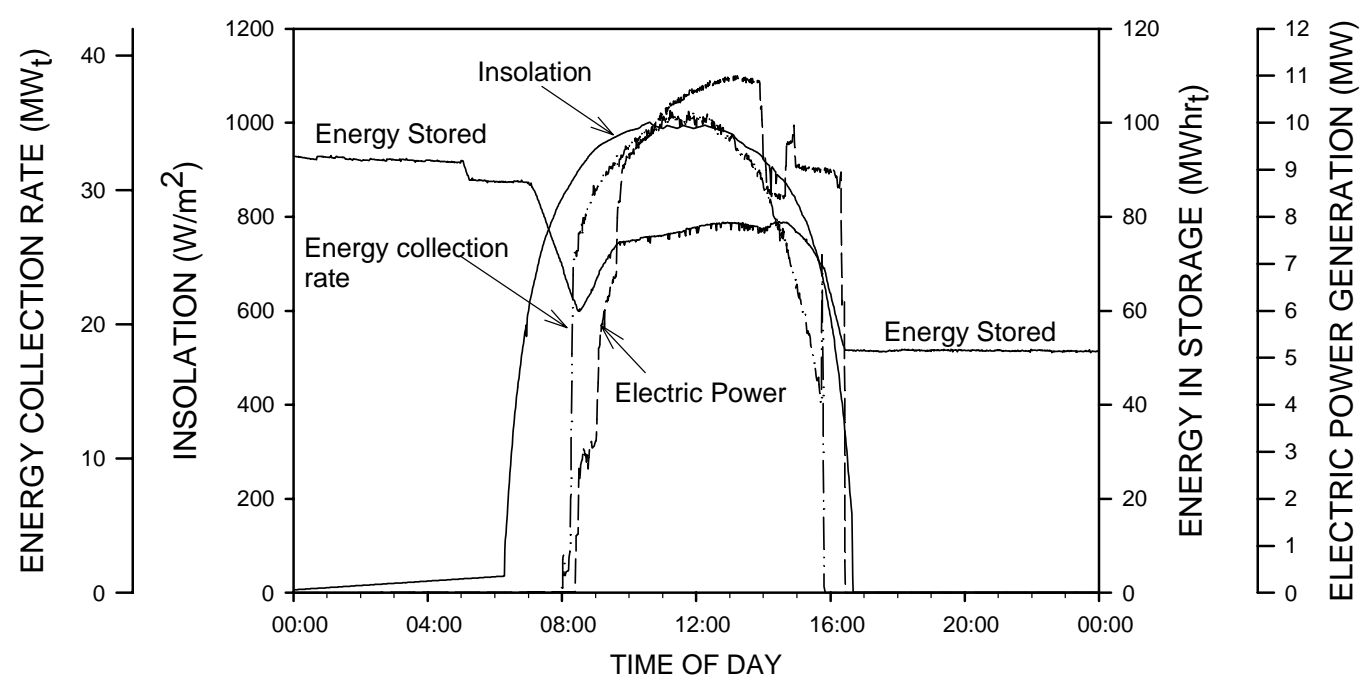

Figure S-3. Electric energy dispatch at Solar Two on November 6, 1997, demonstrating electricity generation throughout the day.

\section{S.3.4 June 24, 1998}

In late June of 1998, several dispatch scenarios were run to demonstrate the ability to generate electricity for extended periods from stored energy. A series of four tests was run in June as follows:

1. June 24, 1998: Dispatch electricity from storage with 100\% turbine load.

2. June 27, 1998: Dispatch electricity from storage with $75 \%$ turbine load.

3. June 28, 1998: Dispatch electricity from storage with 50\% turbine load.

4. June 29, 1998: Dispatch electricity from storage with $25 \%$ turbine load.

Each test in this series started with a full tank of hot salt and the turbine already in operation. The tests were run at a specified generator output that was maintained for the duration of the test. The test on June 24, 1998 illustrates the approach for this series of tests. Figure S-4 presents the data for this test. (Note that Figure S-4 uses standard, not daylight, time.) The receiver was started and began collecting solar energy early in the morning. The steam generator was started at 9:30 a.m. PDT (8:30 a.m. PST) and the EPGS began sending electricity to the grid at approximately 11:00 a.m. PDT. The plant produced electricity at 100\% capacity (which, in June 1998, was approximately 10.4 MWe) until midafternoon, at which time the operator reduced the hot salt flow to the SGS to start filling the hot salt tank. At approximately 3:30 p.m. PDT, the cold salt tank reached its minimum level of 3.1 feet and the hot tank reached 19.8 feet. 
Operators shut down the receiver system and returned the SGS and EPGS to full power. This marked the start of the $100 \%$ load test. Using energy stored in the salt in the hot salt storage tank, the electric generator produced electricity at full load (approximately 10.4 MWe gross) from 4:05 p.m. to 6:52 p.m. PDT.

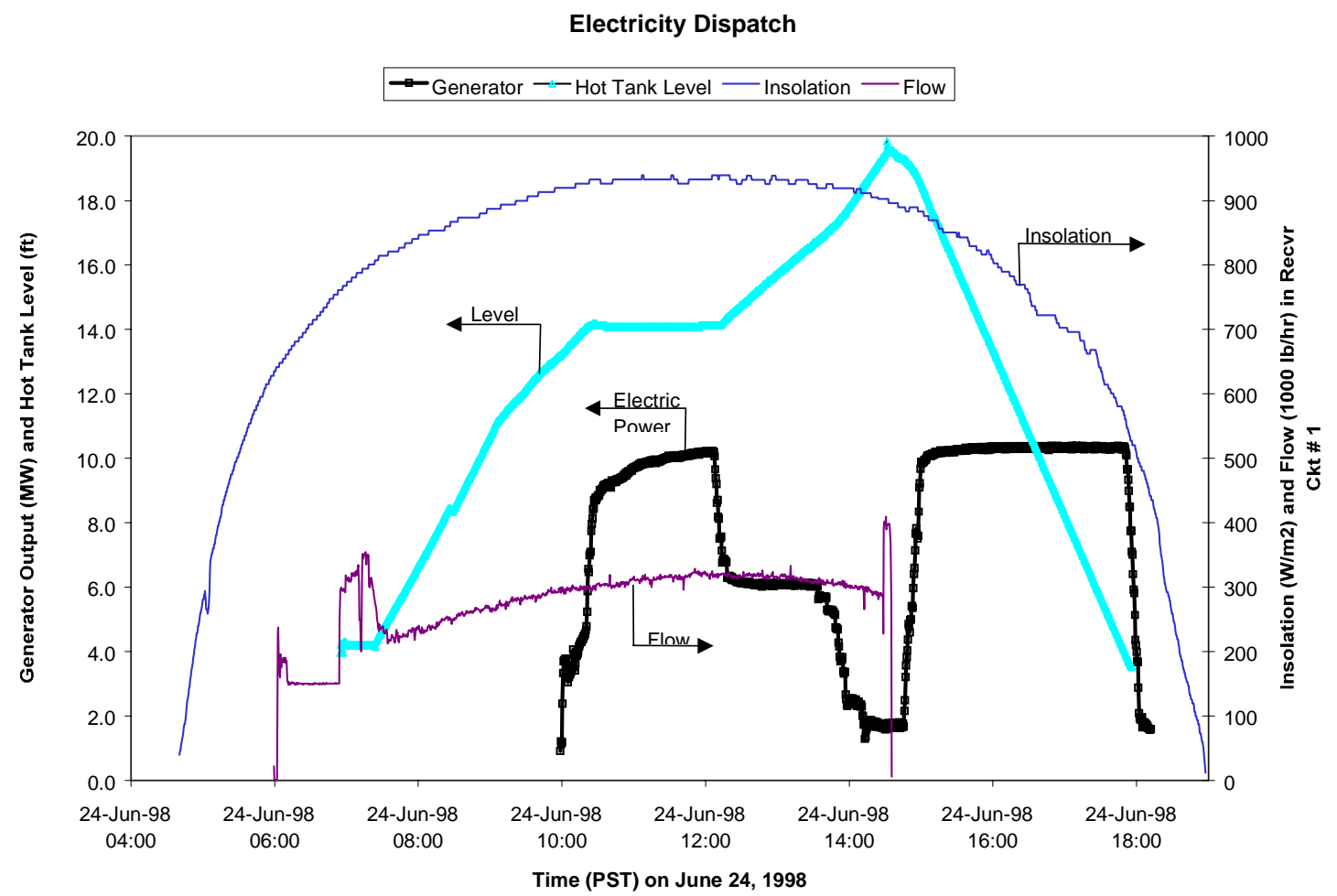

Figure S-4. Electric energy dispatch at Solar Two on June 24, 1998, demonstrating 100\% load dispatch from a full hot salt tank.

\section{S.3.5 June 13-16, 1998}

Solar Two continuously delivered power to the electric grid for 69 hours and 45 minutes between June 13 and 16, 1998. Evidently, this established a new record for solar-only grid power from a solar thermal plant. (For comparison, at its best, Solar One delivered power to the grid continuously for 33 hours and 36 minutes.) The turbine was synchronized to the grid at 12:41 p.m. PDT on Saturday, June 13 and continuously delivered power to the grid until 10:26 a.m. PDT on Tuesday, June 16. Winds in excess of $65 \mathrm{~km} / \mathrm{hr}(40 \mathrm{mph})$ on the morning of June 16 prevented startup of the receiver, causing the streak to end later that morning when the supply of hot salt was exhausted.

For this and subsequent continuous operational periods, the operator would select an overnight generator output level (approximately $1.1 \mathrm{MWe}$ ) that would comfortably allow operation to continue until the receiver could start recharging the hot tank the following morning. 


\section{S.3.6 July 1-7, 1998}

Solar Two surpassed June's online record by continuously delivering power to the electric grid for 153 hours between July 1 and 7, 1998. The turbine was synchronized to the grid at 10:15 a.m. PDT on Wednesday, July 1, and continuously delivered power to the grid until after 7 p.m. on Tuesday, July 7. During the afternoon of July $7^{\text {th }}$, persistent clouds prevented production of sufficient hot salt to allow the steam generator to run through the night. The nearly week-long run therefore ended that evening when the supply of hot salt was exhausted. (Turbine operation was resumed the following morning.) The new record more than doubled the June record.

\section{S.4 Conclusions}

The dispatchability tests demonstrated the capability of Solar Two to satisfy a wide range of load-shifting requirements. The tests were run at various power levels and during periods when solar energy collection was not possible.

The progression of dispatch tests from November 1996 to July 1998 illustrates the improvements in both plant design and operating experience during this relatively short period of time. Producing electricity continuously for nearly one week underscored both the power-dispatch flexibility of a molten salt power tower plant, as well as the continuous improvements in the operation of Solar Two. The July record was particularly encouraging, since it was accomplished with a skeleton crew over a holiday weekend.

Demonstrating the ability to operate continuously affords some interesting options for plant design, operation, and maintenance. Continuous operation avoided the energy penalties associated with daily startup of the SGS and EPGS. Continuous operation almost certainly improved plant water chemistry. In addition, continuous operation quickly established maintenance priorities, both in terms of overnight maintenance (for example, on the receiver system) and for the next non-operational period for the steam generation and EPGSs. These considerations will become increasingly important as plants are built with higher capacity factors, larger storage systems, and longer operating days. 


\section{UNLIMITED RELEASE:}

Donald Aitken

Union of Concerned Scientists

2625 Alcatraz Ave., \#505

Berkeley, CA 94705-2702

Daniel J. Alpert

Senator Bingaman's Office

SH 703, 2nd \& Constitution

Washington, DC 20510

Ian Andrews

PacifiCorp

Utah Power Generation Engineering

1407 West North Temple

Salt Lake City, UT 84140-0001

Robert M. Balzar

Nevada Power \& Sierra Pacific

Power

P.O. Box 10100

Reno, Nevada

Daniel L. Barth

Nagle Pumps, Inc.

1249 Center Avenue

Chicago Heights, IL 60411

Bud Beebe

Sacramento Municipal Utility

District

6201 'S' St.

P.O. Box 15830

Sacramento, CA 95852-1830

Jose Benevente Sierra

Avda. del Puerto N 1-6

11006 Cadiz

Spain

Jerry Berquist

Southern California Edison Co.

300 N. Lone Hill Avenue

San Dimas, CA 91773
Manuel J.Blanco Muriel

CIEMAT - PSA

Apartado 22

E-04200 Tabernas (Almeria)

Spain

Dan Brake, P.E.

FPL Energy, Inc.

6952 Preston Avenue

Livermore, CA 94550

Robert A. Briffett

Los Angeles Dept. of Water and

Power

P.O. Box 111, Room 1129

Los Angeles, CA 90051-0100

Gary D. Burch

U. S. Department of Energy EE-16 1000 Independence Avenue SW

Washington, DC 20585-0121

Barry L. Butler

Science Applications International

Corp.

Room 2043, M/S C2J

10260 Campus Point Dr.

San Diego, CA 92121

John Carstensen

Idaho Power

$1221 \mathrm{~W}$. Idaho

MS CHQ-4

Boise, ID 83702

Gilbert E. Cohen

Duke Solar

2101 - 115 Westinghouse Blvd.

Raleigh, NC 27604

Walter E. Collier

Boeing Company

499 Boeing Blvd., MC JW-63

P.O. Box 240002

Huntsville, AL 35824-6402 
David L. Dean

Boeing Company

499 Boeing Blvd.

PO Box 240002

Huntsville, AL 35824-6402

John C. Dewey

Pitt-Des Moines, Inc.

9719 Lincoln Village Drive, Suite

301

Sacramento, CA 95827

David Engberg

PacifiCorp

825 NE Multnomah

Portland, OR 97232

E. A. Fletcher

University of Minnesota

1111 Church Street, SE

Dept. of Mech. Engr.

Minneapolis, MN 55455

Scott D. Frier

KJC Operating Company

41100 Highway 395

Boron, CA 93516-2109

Bobi Garrett

National Renewable Energy

Laboratory

1617 Cole Blvd.

Golden, CO 80401-3393

Ranji George

South Coast AQMD

21865 Copley Drive

Diamond Bar, CA 91765

Dave Gorman

Advanced Thermal Systems, Inc.

5031 W. Red Rock Drive

Larkspur, CO 80118
William R. Gould, Jr.

Nexant

44 Montgomery St., Suite 4100

San Francisco, CA 94104-4814

Tom M. Griffin

Boeing Company

P.O. Box 582808

Tulsa, OK 74158

Ignacio Grimaldi Pastoril

Ghersa

Avda. del Puerto N 1-6

11006 Cadiz

Spain

Pedro Grimaldi Pedrosa

Avda. del Puerto N 1-6

11006 Cadiz

Spain

Jose Gutierrez

Los Angeles Dept. of Water and Power

111 North Hope Street, Room 648

Los Angeles, CA 90012

Mary Jane Hale

National Renewable Energy

Laboratory

1617 Cole Blvd.

Golden, CO 80401-3393

Larry Hamlin

Southern California Edison Co.

300 N. Lone Hill Avenue

San Dimas, CA 91773

Herb Hayden

Pinnacle West Capital Corporation

(APS)

400 N. Fifth Street, MS 8931

Phoenix, AZ 85004 
Mats E. Hellstrom

Queue Systems, Inc.

1800 St. Julian Place, Suite 2000

Columbia, SC 29204

Arlon Hunt

Lawrence Berkeley Laboratory

University of California

MS 90-2024

One Cyclotron Road

Berkeley, CA 94720

Gus Hutchison

Solar Kinetics, Inc.

10635 King William Drive

P.O. Box 540636

Dallas, TX 75354-0636

Micel E. Izygon

I-Net

NASA/Johnson Space Center

Software Technology Branch - MC

BT2

NASA Rd. 1

Houston, TX 77058

Paul Jaster

3M - Solar Optics Program

3M Center, Bldg. 225-2N-06

St. Paul, MN 55144-1000

Alexander Jenkins

California Energy Commission

Energy Technology Development

Div. R\&D Office

1516 9th Street, MS-43

Sacramento, CA 95814-5512

Peter Johnston

Arizona Public Service

400 N. 5th Street

Phoenix, AZ 85072
Ron Judkoff

National Renewable Energy

Laboratory

1617 Cole Boulevard

Golden, CO 80401-3393

David W. Kearney

Kearney \& Associates

PO Box 2568

Vashon WA 98070

Bruce Kelly

Nexant

44 Montgomery St., Suite 4100

San Francisco, CA 94104-4814

Jim Kern

U. S. Department of Energy EE-11

1000 Independence Ave., SW

Washington, DC 20585

Michael J. Kiley

Boeing Company

6633 Canoga Ave. MC FA-66

P.O. Box 7922

Canoga Park, CA 91309-7922

3 Judd Kilimnik

Business Support Services, Power

Production Department

Room 229, Bushnell Building

300 N. Lone Hill Ave.

San Dimas, CA 91773

Kurt Klunder

Klunder Consulting

4498 Larchmont Ct.

Dumfries, VA 22026

R. LeChevalier

Boeing Company

Energy Technology Engineering

Center

P.O. Box 1449

Canoga Park, CA 91304 
Mark Lichtwardt

U.S. Bureau of Reclamation

Code D-8230

P.O. Box 205007

Denver, CO 80225

Bob Litwin

Boeing Company

6633 Canoga Avenue

PO Box 7922 - Mail Code LA38

Canoga Park, CA 91309-7922

W. Marlatt

Boeing Company

Rocketdyne Division

6633 Canoga Avenue

P.O. Box 7922

Canoga Park, CA 91309-7922

Larry Matthews

New Mexico State University

Box 30001, Dept. 3449

Las Cruces, NM 88003-0001

Michael W. McDowell

Boeing Company

6633 Canoga Ave. MC T038

P.O. Box 7922

Canoga Park, CA 91309-7922

Mark Mehos

National Renewable Energy

Laboratory

1617 Cole Boulevard

Golden, CO 80401-3393

M. Merrigan

Los Alamos National Laboratory

P.O. Box 1663, MS J576

Los Alamos, NM 87545

Jan Miller

Salt River Project

1600 N. Priest St.

Tempe, AZ 85281
Doug Morris

Electric Power Research Institute

P.O. Box 10412

3412 Hillview Avenue

Palo Alto, CA 94303

Peter G. Mueller

U.S. Department of Energy

Nevada Operations Office

P.O. Box 98518

Las Vegas, NV 89193-8518

Jay Mulki

Hawaiian Electric Company

P.O. Box 2750

Honolulu, HI 96840-0001

James Nagle

Nagle Pumps, Inc.

1249 Center Avenue

Chicago Heights, IL 60411

Don Osborne

Sacramento Municipal Utility

District

6201 'S' St., P.O. Box 15830

Sacramento, CA 95852-1830

Ernie Palomino

Salt River Project

P. O. Box 52025

Mail Station ISB664

Phoenix, AZ 85072-2025

Terry Peterson

EPRI

3412 Hillview Avenue

Palo Alto, CA 94304

Lizana K. Pierce

Dept. of Energy/GFO

1617 Cole Blvd.

Golden, CO 80401-3393 
Faith Puffer

Tech Reps

5000 Marble NE

Suite 222

Albuquerque, NM 87110

James E. Rannels

U. S. Department of Energy EE-11

1000 Independence Avenue SW

Washington, DC 20585

Dale Rogers

Boeing Company

6633 Canoga Avenue

PO Box 7922 - Mail Code LA38

Canoga Park, CA 91309-7922

Manuel Romero Alvarez

CIEMAT - Madrid

Institudo de Energias Renovables

Avda. Complutense, 22

E-28040 Madrid

Spain

Tommy Rueckert

U. S. Department of Energy EE-11 1000 Independence Avenue SW

Washington DC 20585

D. A. Sanchez

U.S. Department of Energy/AL

P.O. Box 5400

Albuquerque, NM 87115

Scott Sklar

Stella Group, Ltd.

733 15th Street, NW Suite 700

Washington, D.C. 20005

Glenn Strahs

U. S. Department of Energy EE-11

1000 Independence Avenue, SW

Washington, DC 20585
Steven E. Taylor

Southern California Edison Co.

2131 Walnut Grove Ave.

Rosemead, CA 91770

Robert Thomas

Advanced Thermal Systems, Inc. 5031 W. Red Rock Drive

Larkspur CO 80118-9053

Tom Tracey

6922 S. Adams Way

Littleton, CO 80122

Lorin Vant-Hull

University of Houston

Physics Department 5506

4800 Calhoun Road

Houston, TX 77204-5506

Byron J. Washom

Spencer Management Associates

P.O. Box 724

Diablo, CA 94528-0724

Tim Wendelin

National Renewable Energy

Laboratory

1617 Cole Blvd.

Golden, CO 80401-3393

David White

Solar Kinetics, Inc.

10635 King William Drive

P.O. Box 540636

Dallas, TX 75354-0636

John White

Queue Systems, Inc.

1800 St. Julian Place, Suite 2000

Columbia, SC 29204 
Bob Wichert

Sacramento Municipal Utility

District

6201 'S' St., P.O. Box 15830

Sacramento, CA 95852-1830

Curtt N. Wilkins

U.S. Department of Energy

1309 Barnes Drive

Arlington, TX 76013

Frank (Tex) Wilkins

U. S. Department of Energy EE-11

1000 Independence Avenue, SW

Washington, DC 20585

Alex Zavoico

Nexant

44 Montgomery St., Suite 4100

San Francisco, CA 94104-4814
MS 1127 Cordeiro, Patricia 6215

MS $1127 \quad$ Edgar, Mike 6215

MS 1127 Kelton, John 6215

MS 1127 Kolb, Bill 6215

MS 1127 Mahoney, Rod 6215

MS 1127 Rawlinson, Scott

6215

MS 1127 Reynolds, Tim 6215

5 MS 1127 Solar Tower Library

MS 1373 Kolb, Greg 5324

MS 1425 Bradshaw, Bob 8722

MS 9004 Dawson, Dan 8746

MS 9014 Faas, Scott 2271

MS 9404 Goods, Steve 8725

MS 9018 Central Technical

Files, 8945-1

2 MS 0899 Technical Library,

9616

2 MS 0612 Review and Approval Desk, 9612

Sandia National Laboratories:

$5 \quad$ MS $0783 \quad$ Pacheco, James 5832

MS 0131 Chavez, James 12121

MS $0703 \quad$ Jones, Scott 6216

MS 0703 Tyner, Craig 6216

5 MS 0703 Reilly, Hugh 6216

MS $0703 \quad$ Andraka, Chuck 6216

MS 0703 Diver, Rick 6216

MS $0703 \quad$ Kobos, Peter, 6216

MS $0703 \quad$ Lowrey, Gray, 6216

MS 0703 Mancini, Tom, 6216

MS 0703 Moreno, Jim, 6216

MS 0703 Modesto-Beato,

Marcos A., 6216

MS 0703 Moss, Tim, 6216

MS 0704 Tatro, Marjorie 6200

MS 0752 Rush, Earl 6218

MS $0783 \quad$ Scott, Steve 5832

MS $0834 \quad$ Prairie, Mike 9112

MS $0892 \quad$ Showalter, Steve

1764

MS 1127 Cameron, Chris 6215 